Evaluation of the Transient Hydrologic Source Term for the Cambric Underground Nuclear Test at Frenchman Flat, Nevada test Site

S. F. Carle, R. M. Maxwell, G. A. Pawloski, D. E. Shumaker, A. F. B. Tompson, M. Zavarin

December 19, 2006 
This document was prepared as an account of work sponsored by an agency of the United States Government. Neither the United States Government nor the University of California nor any of their employees, makes any warranty, express or implied, or assumes any legal liability or responsibility for the accuracy, completeness, or usefulness of any information, apparatus, product, or process disclosed, or represents that its use would not infringe privately owned rights. Reference herein to any specific commercial product, process, or service by trade name, trademark, manufacturer, or otherwise, does not necessarily constitute or imply its endorsement, recommendation, or favoring by the United States Government or the University of California. The views and opinions of authors expressed herein do not necessarily state or reflect those of the United States Government or the University of California, and shall not be used for advertising or product endorsement purposes.

This work was performed under the auspices of the U.S. Department of Energy by University of California, Lawrence Livermore National Laboratory under Contract W-7405-Eng-48. 


\section{Evaluation of the Transient}

LAWRENCE LIVERMORE NATIONAL LABORATORY

\section{Hydrologic Source Term for the Cambric Underground Nuclear Test at Frenchman Flat, Nevada Test Site}

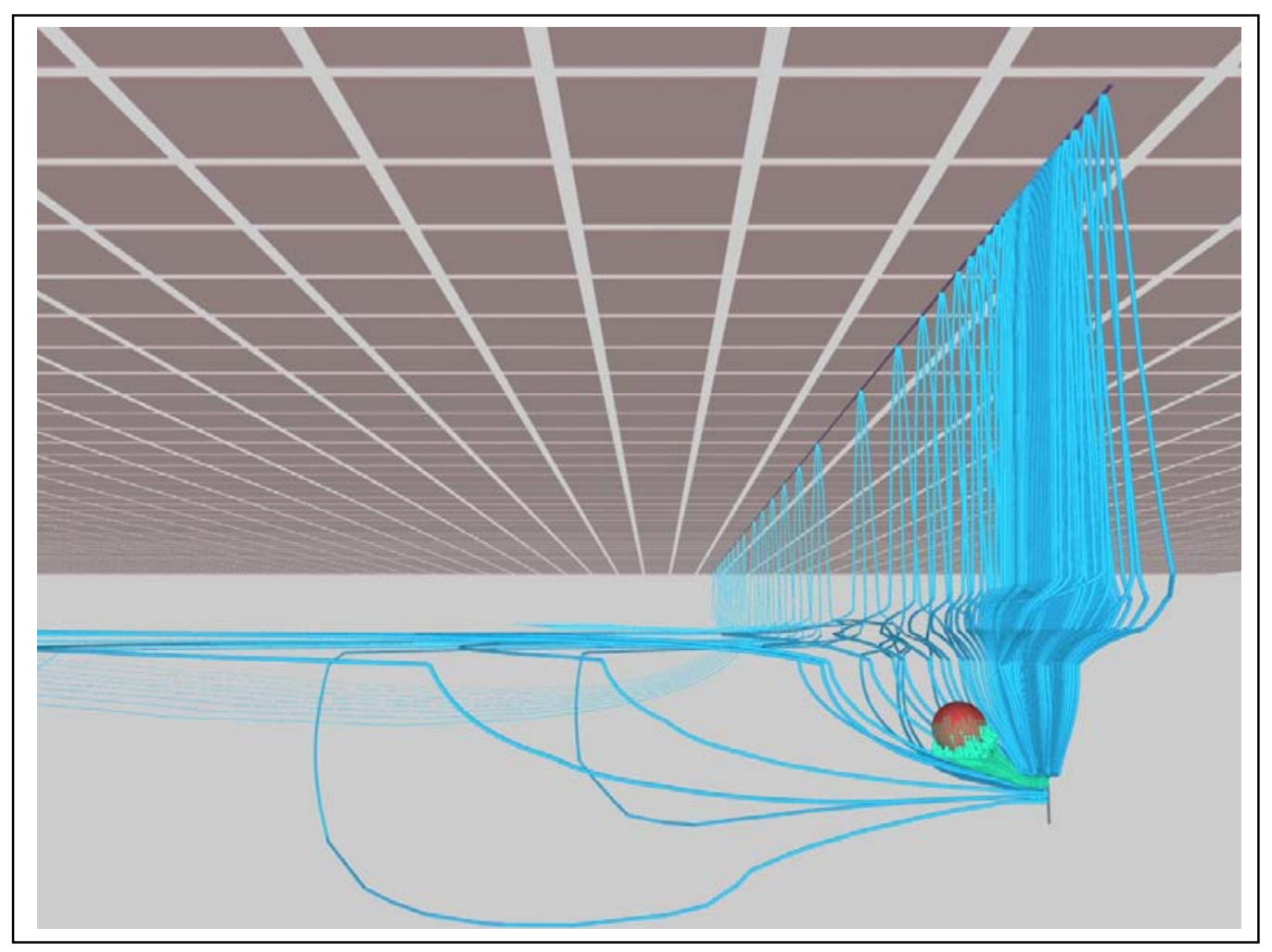

Steven F. Carle, Reed M. Maxwell, Gayle A. Pawloski, Dana E. Shumaker, Andrew F. B. Tompson, and Mavrik Zavarin

March 2007 
This document was prepared as an account of work sponsored by an agency of the United States Government. Neither the United States Government nor the University of California nor any of their employees, makes any warranty, express or implied, or assumes any legal liability or responsibility for the accuracy, completeness, or usefulness of any information, apparatus, product, or process disclosed, or represents that its use would not infringe privately owned rights. Reference herein to any specific commercial product, process, or service by trade name, trademark, manufacturer, or otherwise, does not necessarily constitute or imply its endorsement, recommendation, or favoring by the United States Government or the University of California. The views and opinions of authors expressed herein do not necessarily state or reflect those of the United States Government or the University of California, and shall not be used for advertising or product endorsement purposes.

This work was performed under the auspices of the U.S. Department of Energy by University of California, Lawrence Livermore National Laboratory under Contract W7405-Eng-48.

This work was performed in support of the U.S. Department of Energy National Nuclear Security Administration Las Vegas Office Underground Test Area Project. 


\title{
Evaluation of the Transient Hydrologic Source Term for the Cambric Underground Nuclear Test at Frenchman Flat, Nevada Test Site
}

\author{
Steven F. Carle \\ Reed M. Maxwell \\ Gayle A. Pawloski \\ Dana E. Shumaker \\ Andrew F. B. Tompson \\ Mavrik Zavarin
}

March 2007

Lawrence Livermore National Laboratory

Livermore, California 94551 


\section{Table of Contents}

\section{Chapter 1}

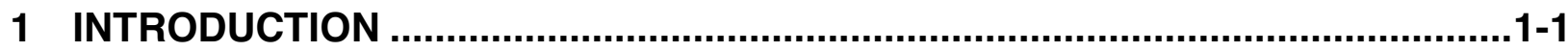

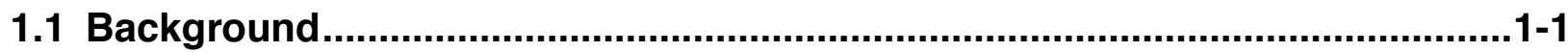

1.2 Objectives of the Current Work .......................................................................

1.3 History of Activities and Studies Related to CAMBRIC.....................................1-3

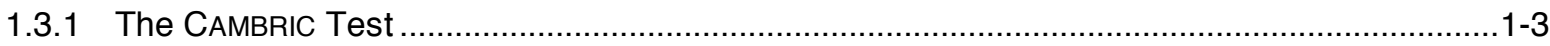

1.3.2 The Radionuclide Migration Experiment ……................................................................ 1-5

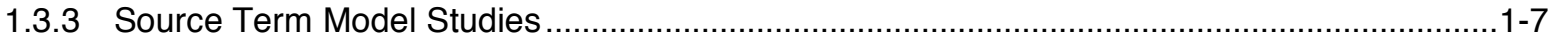

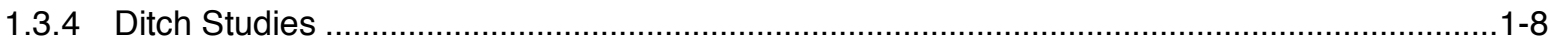

1.3.5 ER-5-4 Wells and the RNM-2S Multiple Well Aquifer Test ..............................................1-9

1.4 Modeling Approach in the Current Work......................................................1-10

1.4.1 Revised Conceptual Models....................................................................................... 1-10

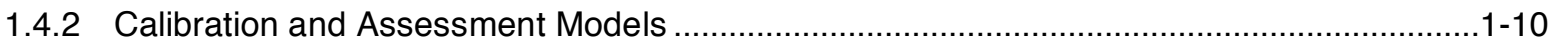

1.4.3 Hydrologic Source Term Models...................................................................................

1.4.4 Considerations for Applying HST Results in the CAU Model ............................................1-12

\section{Chapter 2}

2 NATURAL PHYSICAL AND CHEMICAL SETTING..............................................2-1

2.1 Hydrogeologic Setting of Frenchman Flat ....................................................2-1

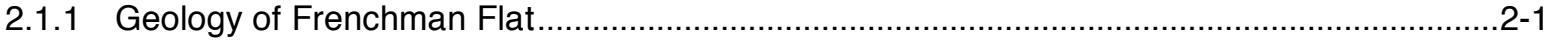

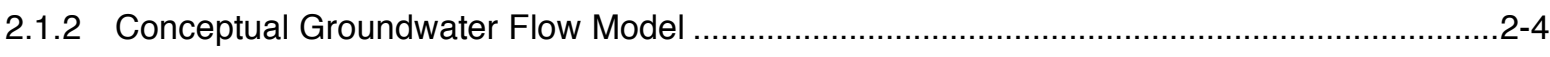

2.1.3 Hydrostratigraphic Framework Model..................................................................... $2-4$

2.2 The Near-Field Environment at CAmBric ..........................................................

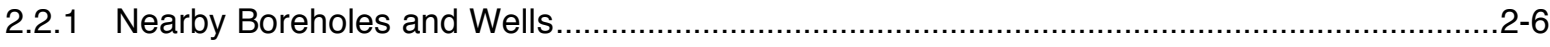

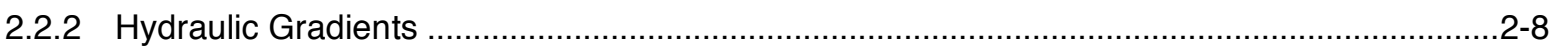

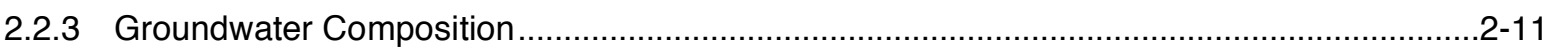

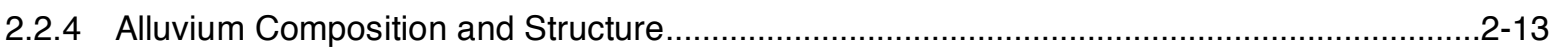




\section{Chapter 3}

3 ALTERED PHYSICAL AND CHEMICAL SETTING ..............................................

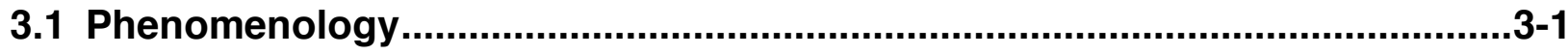

3.2 Cavity, Chimney, and Compressed Zones ........................................................

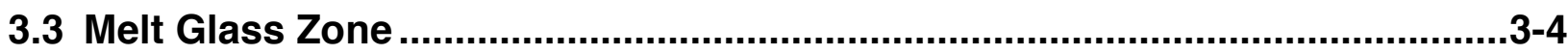

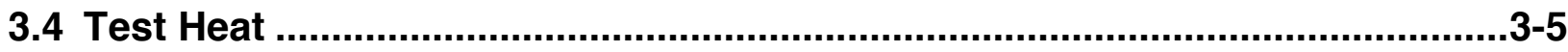

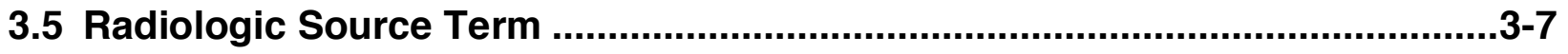

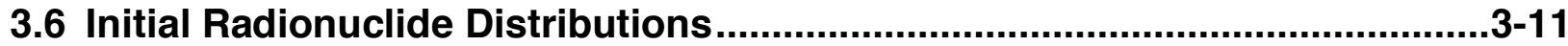

3.6.1 Predicted Partitioning of Radionuclides..................................................................................

3.6.2 Measured Partitioning of Radionuclides ........................................................................ $3-13$

3.7 Radionuclide Transport Behavior During the Pumping Experiment .............3-25

\section{Chapter 4}

4 CALIBRATION AND ASSESSMENT MODELS....................................................

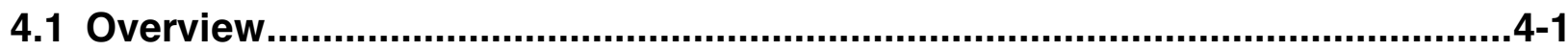

4.2 Hydrogeologic Model Conceptualization ........................................................ 4-3

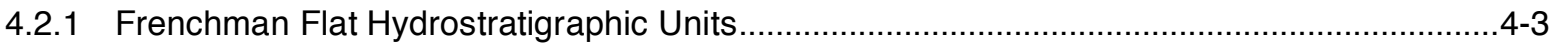

4.2.2 Layered Conceptual Model and Hydrofacies ...........................................................................4-4

4.2.3 Advantages and Disadvantages of a Layered Conceptual Model.........................................4-7

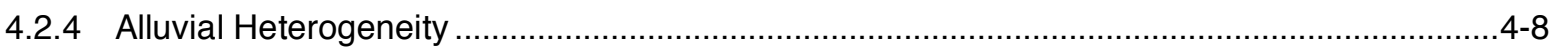

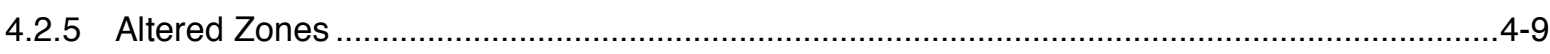

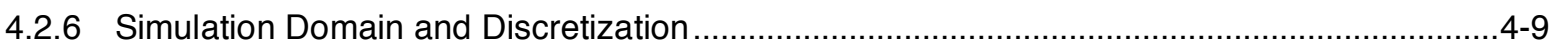

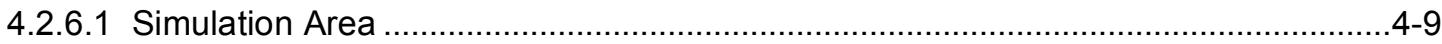

4.2.6.2 NUFT Simulation Domain and Grid ...............................................................4-10

4.2.6.3 ParFlow Simulation Domain and Grid ................................................................ $4-11$

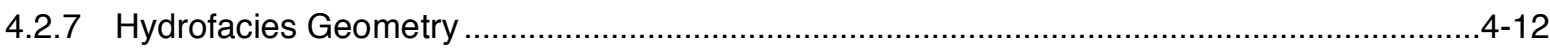

4.2.7.1 Alluvial Aquifer and Background Alluvium .......................................................... $4-15$

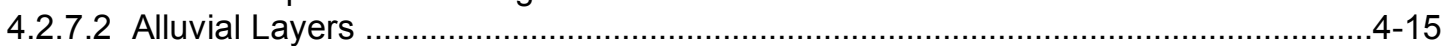

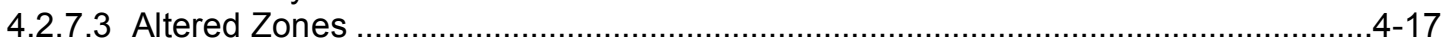

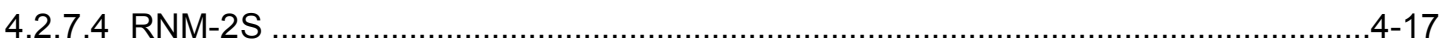

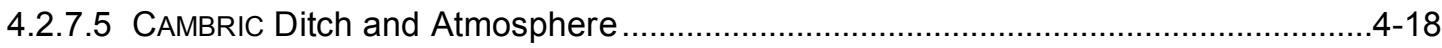


4.3 Hydraulic Properties

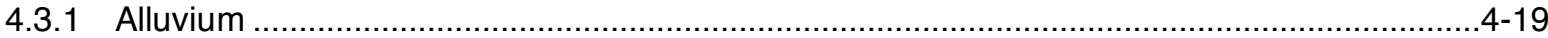

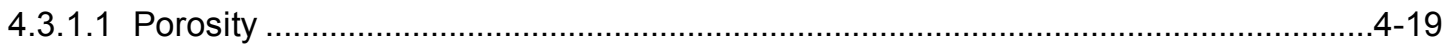

4.3.1.2 UE-5n Grain-Size Distribution and Alluvial Layers ............................................4-20

4.3.1.3 Hydraulic Conductivity and Specific Yield ......................................................4-22

4.3.1.4 Comparison to Previous Hydraulic Conductivity Estimates near CAMBRIC ..............4-25

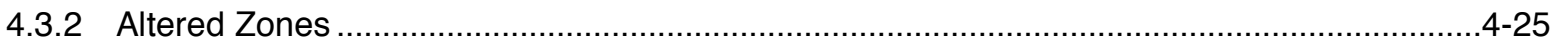

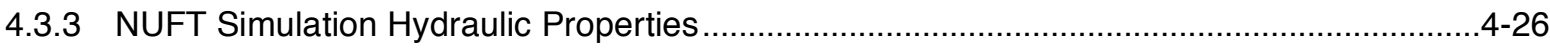

4.3.4 Intra-Hydrofacies Heterogeneity ................................................................................. 40

4.4 Groundwater Flow Conditions...................................................................... 4-30

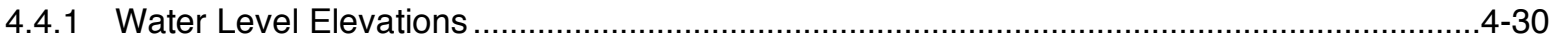

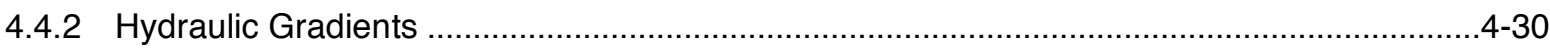

4.4.3 Geothermal Gradient and Residual Test Heat ..................................................................

4.4.4 Model Boundary Conditions .........................................................................................

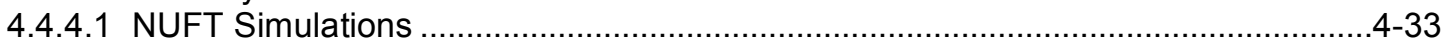

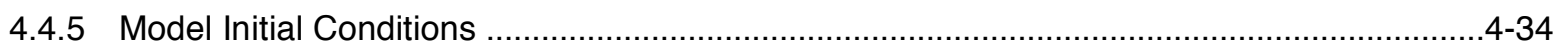

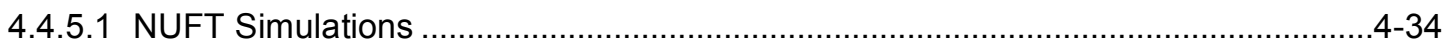

4.5 Flow Model Calibration ....................................................................................34

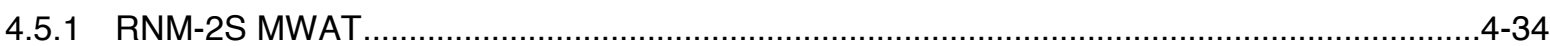

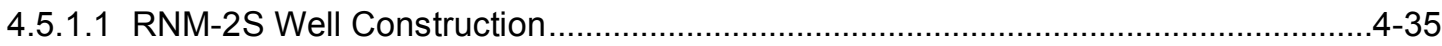

4.5.1.2 NUFT Flow Simulation Calibration and Sensitivity Studies ..................................4-36

4.5.1.3 Comparison to Previous MWAT Interpretations...................................................4-39

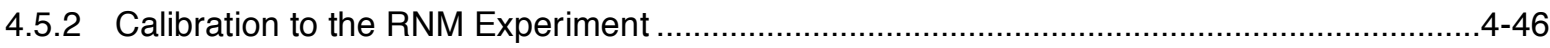

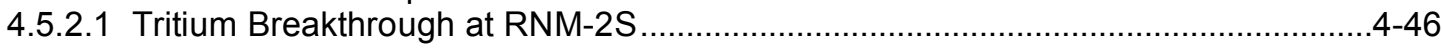

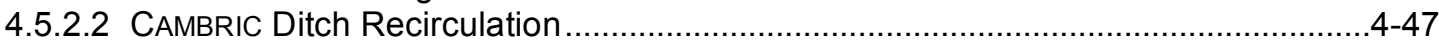

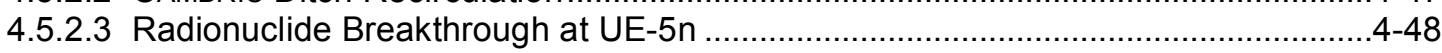

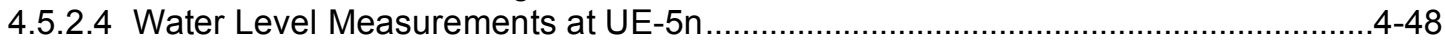

4.6 NUFT Transient Flow Simulation Results....................................................4-49

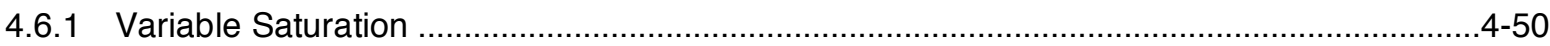

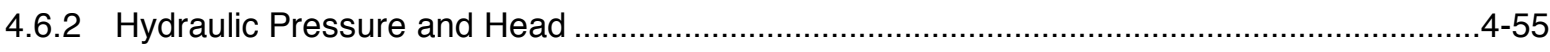

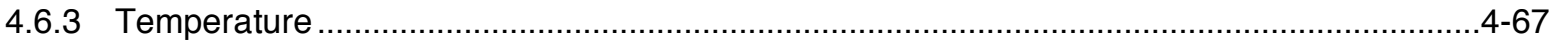

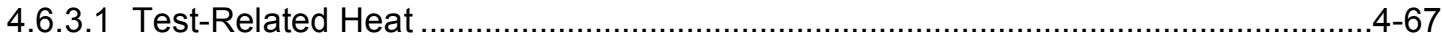

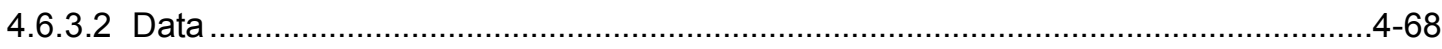

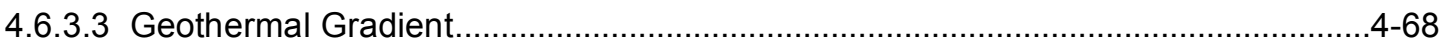

4.6.3.4 Thermal Properties of Rocks and Fluids ................................................... $4-69$

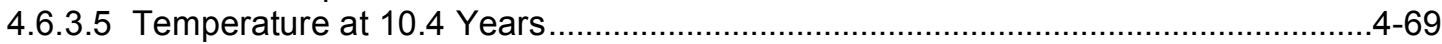

4.6.3.6 Temperature before 10.4 Years .................................................................. $4-70$

4.6.3.7 Temperature after 10.4 Years ...................................................................... 4 -73 


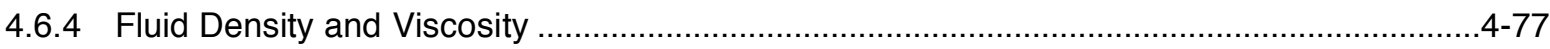

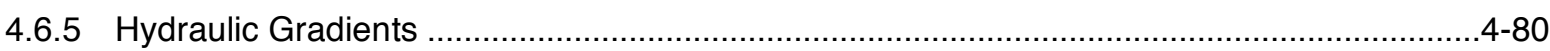

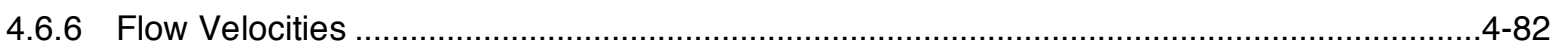

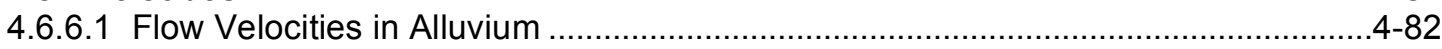

4.6.6.2 Flow Velocities in Altered Zones ....................................................................... $4-93$

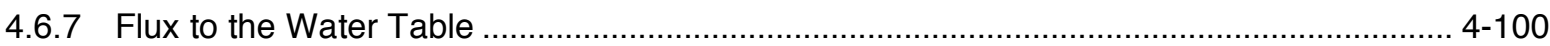

4.6.8 Tritium Transport Characteristics.................................................................................. 4-101

4.6.8.1 NUFT Simulation of ${ }^{3} \mathrm{H}$ Transport ............................................................... 4-102

4.6.8.2 Comparison of NUFT and CRUNCH Streamline Simulation of Tracer

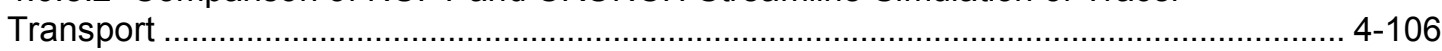

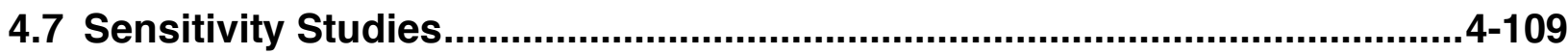

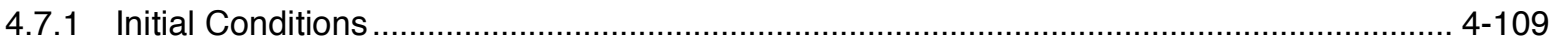

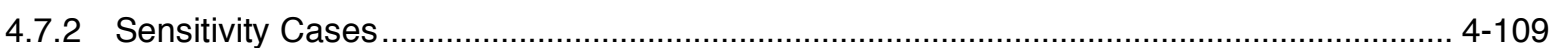

4.7.2.1 No Pumping Case ............................................................................................ 4-110

4.7.2.2 Initial Heat and Pressure ............................................................................ 4-111

4.7.2.3 Boiling Cases.......................................................................................... 4-112

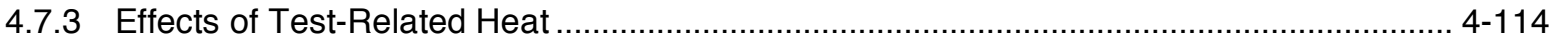

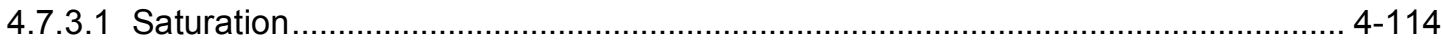

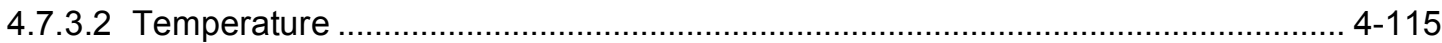

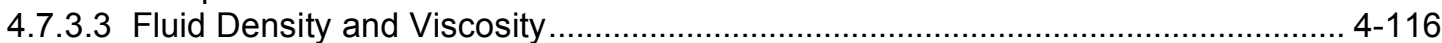

4.7.3.4 Flow Velocity............................................................................................ 4-117

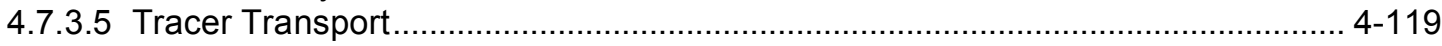

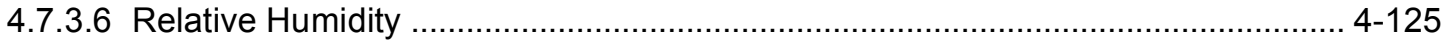

4.7.4 Effects of Diffusion and Numerical Dispersion ............................................................ 4-126

\subsection{Effects of Nonlinear Geochemistry............................................................129}

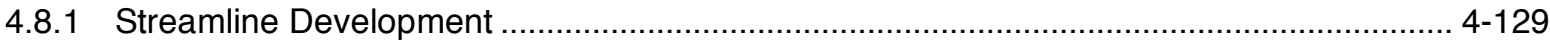

4.8.1.1 Streamline Path Computation ...................................................................... 4-131

4.8.1.2 Generating a Set of Streamlines ............................................................... 4-132

4.8.1.3 Streamline Flux Assignment................................................................ 4-132

4.8.1.4 Streamline Application in a Transient Flow Field .............................................. 4-134

4.8.2 Formulation of Model Geochemical Processes ............................................................. 4-135

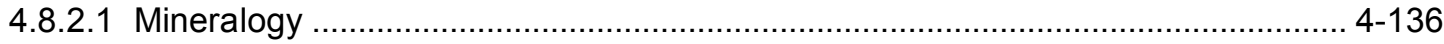

4.8.2.2 Major Element Aqueous Concentrations ……................................................. 4-140

4.8.2.3 Radionuclide Concentrations .................................................................... 4-142

4.8.2.4 Major Element and Radionuclide Aqueous Speciation .................................... 4-148

4.8.2.5 Major Element and Radionuclide Surface Complexation ................................... 4-152

4.8.2.6 Major Element and Radionuclide Ion Exchange ............................................. 4-156

4.8.2.7 Major Element and Radionuclide Mineral Solubility ........................................ 4-159

4.8.2.8 Major Element and Radionuclide Mineral Dissolution/Precipitation Rates .......... 4-166

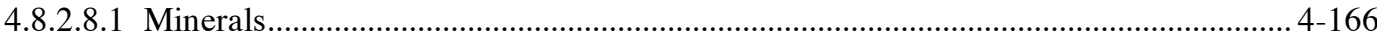

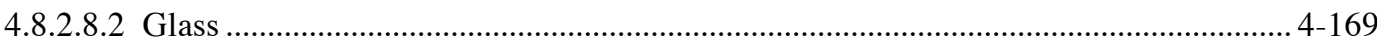

4.8.2.8.2.1 The Glass Dissolution Rate Equation ..................................................... 4-170

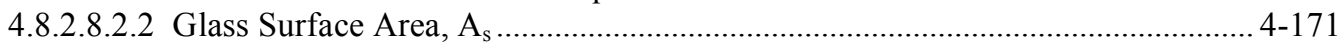

4.8.2.8.2.3 Rate Coefficient $k$ and Product Terms $a_{i}{ }^{{ }_{i}}$, and Activation Energy, $E_{a} \ldots \ldots \ldots \ldots \ldots . . .14-172$

4.8.2.8.2.4 The Saturation Term $\left(1-(\mathrm{Q} / \mathrm{K})^{1 / \sigma}\right)^{v}$............................................................. 4-175

4.8.2.8.2.5 The Close-to-Saturation Rate $\mathrm{k}_{\mathrm{f}}$.................................................................... 4-176 
4.8.3 Streamline Simulations

4.8.3.1 Thermal Effects on Glass Dissolution

\section{Chapter 5}

5 HYDROLOGIC SOURCE TERM MODELS

5.1 Overview. $.5-1$

5.2 Updated Conceptual Models for Flow and Transport $.5-1$

5.2.1 Formulation of Simplified Model Geochemical Processes ............................................5-1

5.2.1.1 Simplified Glass Dissolution Model ...................................................................

5.2.1.2 Simplified Radionuclide Retardation Model..............................................5-6

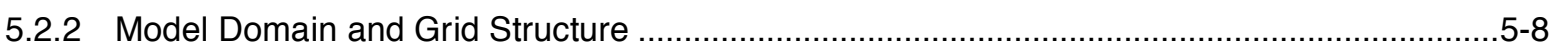

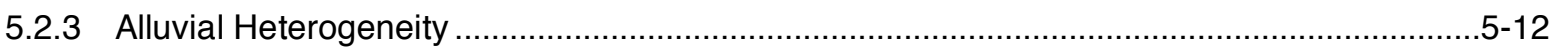

5.2.4 Boundary Conditions, Model Initialization, and Realization Selection...............................5-16

\subsection{Flow and Transport Model Simulation of the RNM Experiment ...................5-21}

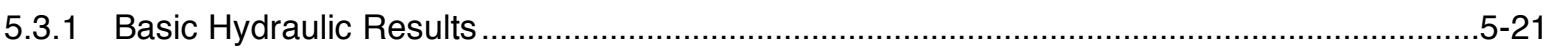

5.3.2 Simulation of Radionuclide Transport to RNM-2S .............................................................

5.3.3 Analysis of Radionuclide Recirculation ...................................................................... $5-27$

5.3.4. Simulated Radionuclide Breakthrough at RNM-2S........................................................ $5-30$

5.3.5 Comparison of ParFlow/SLIM and NUFT/CRUNCH Transport Simulation Results .............5-36

5.3.6 Comparison of ParFlow/SLIM and NUFT/CRUNCH Simulation Results to Data.................5-40

5.3.6.1 RNM-1 Radionuclide Initial Concentrations......................................................5-40

5.3.6.2 RNM-1, RNM-2S, and UE-5n Radionuclide Concentrations During and After

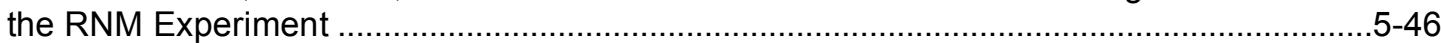

5.4 Ditch Hydrologic Source Term ...............................................................5-52

5.4.1 Simulation of Radionuclide Breakthrough Across the Water Table ......................................5-52

5.4.2 Ditch Hydrologic Source Term Results for 1,000 Years....................................................5-54

5.5 Additional Interpretations and Discussion..................................................5-67 


\section{Chapter 6}

6 CONSIDERATIONS FOR APPLYING HST RESULTS IN THE CAU MODEL

6.1 Background

6.2 Considerations for Applying the Steady-State HST Elsewhere in Frenchman Flat. $6-2$

\subsection{Additional Considerations for Applying the Transient HST at the} Cambric Site.

6.4 Differences between the HST and CAU Model-Generated Flow Gradients at CAMBRIC.........................................................................................6-4

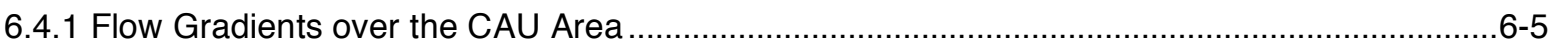

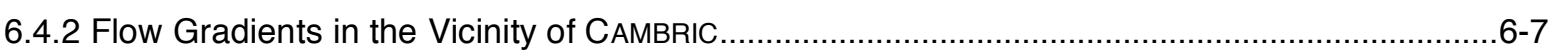

\section{Chapter 7}

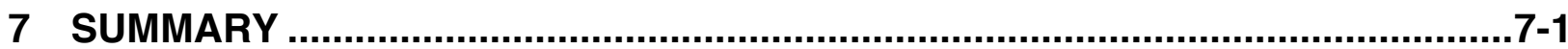

7.1 HST Modeling Approach ..................................................................................

7.1.1 Calibration and Assessment: NUFT/CRUNCH ...............................................................

7.1.2 HST Simulations: ParFlow/SLIM ............................................................................................

7.2 HST Simulation Objectives ...............................................................................

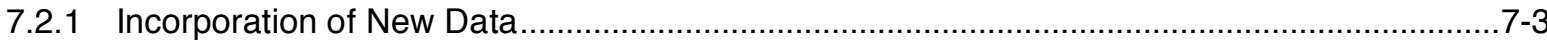

7.2.1.1 Geology, Mineralogy, and Hydrostratigraphy ........................................................

7.2.1.2 RNM-2S Multiple Well Aquifer Test (MWAT) .....................................................

7.2.1.3 Water Levels and Hydraulic Gradients ........................................................

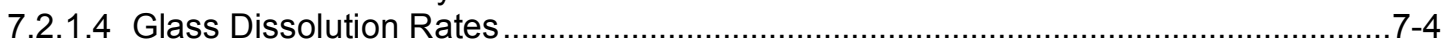

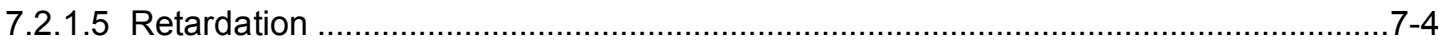

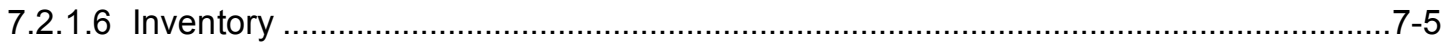

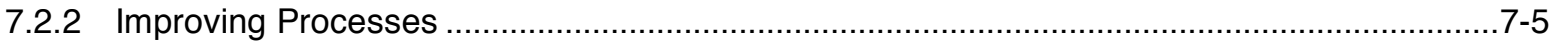

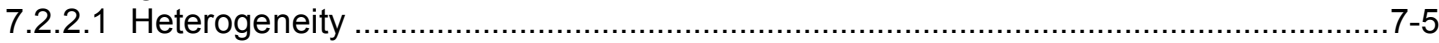

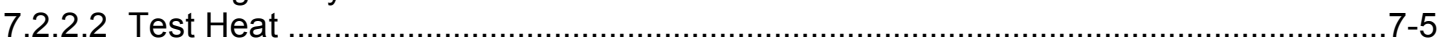

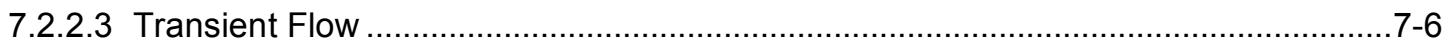

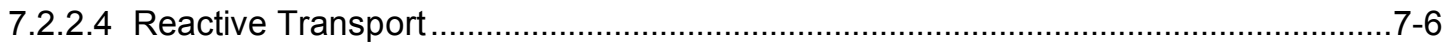

7.3 Results and Conclusions ...................................................................................

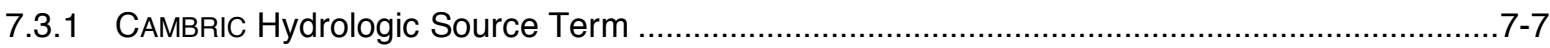

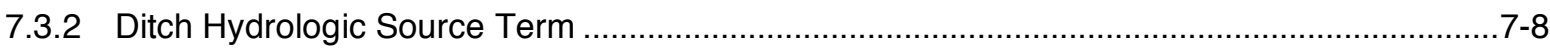

7.3.3 Effects of Physical and Chemical Heterogeneity ….........................................................

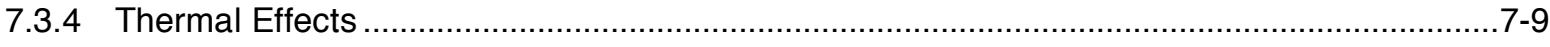

7.3.5 Considerations for Applying HST Results in the CAU Model ............................................. $7-10$ 
7.3.5.1 Considerations for Applying the Steady-State HST Elsewhere in Frenchman Flat

7.3.5.2 Additional Considerations for Applying the Transient HST at CAMBRIC

\section{Chapter 8}

8 References

8-1

Chapter 9

9 Distribution List

$9-1$ 


\section{List of Figures}

\section{Chapter 1}

Figure 1.1 Aerial view of Frenchman Flat, NTS, showing locations of CAMBRIC (U-5e), nearby boreholes and monitoring wells, the CAMBRIC ditch, as well as DILUTED WATERS (U-5a) and WishBONE (U-5b) tests. The red box indicates the horizontal extent of the model domain used for HST simulations.

Figure 1.2: Schematic of the CAMBRIC test area in Frenchman Flat at the NTS, showing the test emplacement hole (U-5e), cavity and collapsed chimney, pumping well RNM2S, drainage ditch, lysimeter trench, and monitoring wells UE-5n, ER-5-4, and ER-5$4 \# 2$. Known tritium pathways are shown in red.

Figure 1.3 Tritium $(3 \mathrm{H})$ activity and $36 \mathrm{Cl}$ concentrations observed in the pumping well (RNM-2S) between the initiation (1975) and cessation of pumping (1991), and in an isolated measurement made in 2000 . Rising $3 \mathrm{H}$ activity in monitoring well UE-5n beginning in 1991 is also shown. All data are decay corrected to May 14, 1965.

\section{Chapter 2}

Figure 2.1 Schematic map of the Nevada Test Site showing Frenchman Flat.

Figure 2.2 Conceptual structural model of Frenchman Flat basin (Bechtel Nevada, 2005b, Figure 3.2).

Figure 2.3 Schematic representation of alluvial deposition in Frenchman Flat within surrounding structural blocks. Yellow areas represent alluvial fans of distinct provenance, while stippled areas represent interfingering of alluvial fans. Upper left shows equal deposition originating from all structural blocks. Upper right illustrates deposition in the last 7.3 million years. Lower left shows alluvial fan development during episodic preferential fault activity (modified from Warren et al., 2002).

Figure 2.4 Cross sections through Frenchman Flat base case HFM, modified from

Bechtel Nevada (2005b). The W-E section is aligned approximately with line D-D' in

Figure 1.1.

Figure 2.5 Close-in map of the Frenchman Flat area showing locations of CAMBRIC (U-5e), Diluted Waters (U-5a) and Wishbone (U-5b) tests, the CAMBric ditch and playa discharge area, and nearby boreholes and monitoring wells. Other nearby wells and boreholes, slightly beyond the boundaries of the map, include WW-5A, WW-5C, UE-5 PW-2, and UE-5 PW-3.

Figure 2.6 Map of the CAMBRIC site shows the ditch and nearby wells. Flow directions away from U-5e, as based upon water levels in UE-5n, RNM-2S, and ER-5-4 upper, are shown as computed from the mean observations (black dot and arrow) and a series of 400 random head measurements sampled from within the measured uncertainties or ranges indicated in Table 2.1 (gray dots without arrows).

Figure 2.8 Vertical distribution of hydraulic conductivity beneath the water table, as measured from core and well-test analyses in RNM-1 and RNM-2S (from Hoffman et al.,1977; Stone, 1975; and Ramspott and McArthur, 1977; as reinterpreted by Burbey and Wheatcraft. 1986).

Figure 2.9 Alluvial layers distinguished at ER-5-4. Approximate relative position of CAMBRIC is superposed in red (modified from Figure 2, Warren et al., 2002). 
Figure 2.10 Schematic of mineral abundance as a function of depth in ER-5-4 for five radionuclide sorbing minerals. Layers are taken from Warren et al. (2002).

\section{Chapter 3}

Figure 3.1 Phenomenology of an underground nuclear explosion showing expansion of the shock front, accretion of melt glass puddle, redistribution of more volatile radionuclides - initially as gases, later as condensates - and collapse of the chimney.

Figure 3.2 Relative gamma counts for four drillback holes (U-5e PS 1A, U-5e PS 1AS, U-5e PS 1ASS, and RNM-1) through the CAMBRIC cavity. The circle identifies a 13.4-m cavity radius.

Figure 3.3 Relative gamma activity as a function of radial distance away from the working point.

Figure 3.4 Relative gamma activity as a function of vertical depth with 0 coincident with the working point depth and bottom of cavity at $13.4 \mathrm{~m}$.

Figure 3.5 Diagram of RNM-1 completion, including location of cemented annulus (Hoffman et al., 1977), locations of five groundwater sampling zones (I to V), and RNM-

1 temperature log completed on May 8, 1974.

Figure 3.6 Comparison of selected RST inventories from various sources. Bowen et al. (2001) data include approximate uncertainties associated with test-specific radionuclide inventory calculations.

Figure 3.7 Tritium (O) and ${ }^{85} \mathrm{Kr}(\mathrm{X})$ concentrations in waters extracted from the RNM-1 core as a function of sample vertical depth from ground surface. WP indicates working point depth. Lines on the $y$-axis indicate the top and bottom of a 13.4-m cavity radius.

Figure 3.8 Tritium $(\mathrm{O})$ and ${ }^{85} \mathrm{Kr}(\mathrm{X})$ concentrations in waters extracted from the RNM-1 core as a function of radial distance from the working point. Cavity radius is $13.4 \mathrm{~m}$.

Figure 3.9 Cesium-137 concentrations in the RNM-1 core as a function of sample vertical depth from ground surface. WP indicates working point depth. Lines on the $y$ axis indicate the top and bottom of a 13.4-m cavity.

Figure 3.10 Cesium-137 concentrations in the RNM-1 core as a function of radial distance from the working point. Cavity radius is $13.4 \mathrm{~m}$.

Figure 3.11 Radionuclide concentrations during pumping from Zone II of RNM-1. See

Figure 3.5 for location information.

Figure 3.12 Radionuclide concentrations during pumping from Zone III of RNM-1. See Figure 3.5 for location information.

Figure 3.13 Radionuclide concentrations during pumping from Zone IV of RNM-1. See Figure 3.5 for location information.

Figure 3.14 Radionuclide concentrations during pumping from Zone V of RNM-1. See Figure 3.5 for location information.

Figure 3.15 Piper diagram of major element chemistry of the pumped waters from five distinct zones within RNM-1. Ambient water chemistry from nearby wells (Table 2.2) is also plotted. 
Figure 3.16 Tritium concentration at three wells near the CAMBRIC test: RNM-1 $(\Delta)$, RNM-2S (+), and UE-5n (o). Relative concentration is the observed concentration divided by the predicted total test-derived source term (2.08 moles). Initial RNM-1 sampling at various depth intervals (Table 3.5 ) is shown in pink.....

Figure 3.17 Krypton-85 concentration at three wells near the CAMBRIC test: RNM-1 $(\Delta)$, RNM-2S (+), and UE-5n (o). Relative concentration is the observed concentration divided by the predicted total test-derived source term. Initial RNM-1 sampling at various depth intervals (Table 3.5) is shown in pink.

Figure 3.18 Cesium-137 (blue) and ${ }^{239,240} \mathrm{Pu}$ (red) concentration at two wells near the CAMBRIC test: RNM-1 $(\Delta)$ and RNM-2S (+). Relative concentration is the observed concentration divided by the predicted total test-derived source term in the rubble and water.

Figure 3.19 Ruthenium-106 (blue) and ${ }^{125} \mathrm{Sb}$ (red) concentration at two wells near the CAMBRIC test: RNM-1 $(\Delta)$ and RNM-2S $(+)$. Relative concentration is the observed concentration divided by the predicted total test-derived source term in the rubble and water.

Figure 3.20 Strontium-90 (blue) and ${ }^{99} \mathrm{Tc}$ (red) concentration at three wells near the CAMBRIC test: RNM-1 $(\Delta)$, RNM-2s (+), and UE-5n (o). Relative concentration is the observed concentration divided by the predicted total test-derived source term in the rubble and water.

Figure 3.21 Chlorine-36 (blue) and ${ }^{14} \mathrm{C}$ (red) concentration breakthrough at three wells near the CAMBRIC test: RNM-1 $(\Delta)$, RNM-2S (+), and UE-5n (o).

Figure 3.22 Iodine-129 (blue) and ${ }^{237} \mathrm{~Np}$ (red) concentration breakthrough at three wells near the CAMBRIC test: RNM-1 $(\Delta)$, RNM-2S (+), and UE-5n (o).

\section{Chapter 4}

Figure 4.1 Three-dimensional distribution of hydrofacies category numbers located by NUFT simulation grid cell (not to scale).

Table 4.4. Lateral and vertical extent of alluvial layers assumed in the NUFT model relative to the CAMBRIC working point.

Figure 4.2 Depth comparison of grain-size distribution from sieve data for UE-5n (Figure 5, Ramspott and McArthur, 1977) with alluvial layer contacts identified in UE- $5 n$ in Figure 22 by Warren et al. (2002) and Layer $2 b$ interpreted from analysis of the RNM-2S MWAT.

Figure 4.3 Comparison of pump-test derived hydraulic conductivities (dots) from Stoller-Navarro (2004b, p. 5-22), depth interval for range of hydraulic conductivity estimates representative of lithologic texture (dashed rectangles), and mean lateral hydraulic conductivities of alluvial layers in NUFT and ParFlow models (vertical bars).

Figure 4.4 Horizontal permeability for NUFT base-case simulations as calibrated to the MWAT.

Figure 4.5. Temperature profiles, lithology, and well construction for borehole UE-5n, from Gillespie (2005). Darkened portion of well construction diagram indicates where casing was cemented in the borehole, and stippled pattern indicates location of perforated interval between 219.5 and $222.5 \mathrm{~m}$ depth 
Figure 4.6 Well RNM-2S completion diagram (Stoller-Navarro, 2004a). 4-36

Figure 4.7 Comparison of observed (circles) and NUFT-modeled (lines) drawdown at observation wells RNM-1, RNM-2, and both ER-5-4 upper (ER-5-4 uc) and ER-5-4 piezometer (ER-5-4 pz).

Figure 4.8 Comparison of NUFT simulation results for models with gravel pack (solid line) and without gravel pack (dashed line), and measured drawdown (circles) at pumping well RNM-2S.

Figure 4.9 Comparison of drawdown data at MWAT observation wells RNM-1, RNM-2, ER-5-4 (uc), and ER-5-4 (pz) to NUFT simulated response using USGS (2004) hydraulic properties fit to ER-5-4 drawdown response.

Figure 4.10 Comparison of drawdown data at MWAT observation wells RNM-1, RNM-2, ER-5-4 (uc), and ER-5-4 (pz) to NUFT simulated response using StollerNavarro (2004a) hydraulic properties fit to RNM-1 drawdown response.

Figure 4.11 Comparison of drawdown data at MWAT observation wells RNM-1, RNM-2, ER-5-4 (uc), and ER-5-4 (pz) to NUFT simulated response using StollerNavarro (2004a) hydraulic properties fit to RNM-2 drawdown response.

Figure 4.12 Comparison of drawdown data at MWAT observation wells RNM-1, RNM-2, ER-5-4 (uc), and ER-5-4 (pz) to NUFT simulated response using StollerNavarro (2004a) hydraulic properties fit to ER-5-4 (uc) drawdown.

Figure 4.13 Calibration of NUFT model alluvial layer hydraulic properties to tracer breakthrough (green line) to measured decay-corrected ${ }^{3} \mathrm{H}$ breakthrough data (red circles) at RNM-2S pumping well during the RNM experiment. $4-46$

Figure 4.14 NUFT simulation of UE-5n hydraulic head (relative to bottom of NUFT simulation)

Figure 4.15 Large-scale cutaway view of NUFT simulation of the saturation field near CAMBRIC at (a) 0.0 and (b) $12.3 \mathrm{y}$.

Figure 4.16 Large-scale cutaway view of NUFT simulation of saturation field near CAMBRIC at 25.5 and $50 \mathrm{y}$.

Figure 4.17 Small-scale cutaway views of NUFT simulation of saturation field near CAMBRIC at (a) 10.4 , (b) 12.3 , (c) 15.7 , (d) 25.5 , and (e) $50 \mathrm{y}$

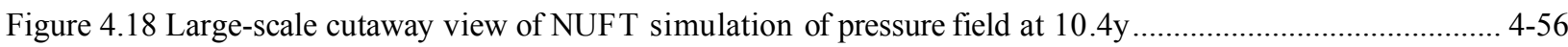

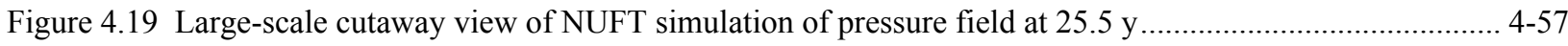

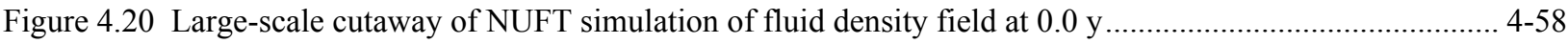

Figure 4.21 Large-scale cutaway of NUFT simulation of hydraulic head field at 10.4 y .................................. 4-59

Figure 4.22 Large-scale cutaway of NUFT simulation of hydraulic head field at $25.5 \mathrm{y}$ 4-60

Figure 4.23 Large-scale cutaway of NUFT simulation of hydraulic head field at $25.5 \mathrm{y}$, with color scale favoring view of hydraulic head in vadosezone..... 4-61

Figure 4.24 Large-scale cutaway view of NUFT simulation of hydraulic head at $10.4 \mathrm{y}$ at CAMBRIC and nearby wells.... 
Figure 4.25 Large-scale cutaway view of NUFT simulation of hydraulic head at $12.3 \mathrm{y}$ at

CAMBRIC and nearby wells. 4-63

Figure 4.26 Large-scale cutaway view of NUFT simulation of hydraulic head at $25.5 \mathrm{y}$ at

CAMBRIC and nearby wells. 4-64

Figure 4.27 Large-scale cutaway view of NUFT simulation of hydraulic head at $50 \mathrm{y}$ at

CAMBRIC and nearby wells.

Figure 4.28 Small-scale cutaway views of NUFT simulation of hydraulic head near

CAMBRIC at (a) 10.4, (b) 12.3 , (c) 15.7 , (d) 25.5 , and (e) $50 \mathrm{y}$.

Figure 4.29 NUFT simulation of mean, minimum, and maximum melt glass zone temperature for base case with pumping.

Figure 4.30 Small-scale view of NUFT simulation temperature field at $10.4 \mathrm{y}$.

Figure 4.31 NUFT simulation temperature fields near melt glass, cavity, chimney, and compressed zones at $0.01,0.036,0.1,0.36,1.0,3.3$, and $10 \mathrm{y}$.

Figure 4.32 Large-scale cutaway view of NUFT simulation temperature field at $10.4 \mathrm{y}$

near CAMBRIC and nearby wells.

Figure 4.33 Large-scale cutaway view of NUFT simulation of temperature field at $25.5 \mathrm{y}$ near CAMBRIC and nearby wells.

Figure 4.34 Large-scale cutaway view of NUFT simulation of temperature field at $50 \mathrm{y}$ near CAMBRIC and nearby wells.

Figure 4.35 Small-scale cutaway views of NUFT simulation of temperature near

CAMBRIC at $10.4,12.3,15.7$, and $25.5 \mathrm{y}$..... $4-76$

Figure 4.36 NUFT simulation of mean, minimum, and maximum fluid density in (a) melt glass zone, (b) cavity, (c) compressed zone, and (d) lower chimney.

Figure 4.37 NUFT simulation of mean, minimum, and maximum fluid viscosity in (a) melt glass zone, (b) cavity, (c) compressed zone, and (d) lower chimney.

Figure 4.38 NUFT simulation of downgradient, transverse, and vertical components of mean hydraulic gradient through the (a) melt glass zone, (b) cavity, (c) compressed zone, and (d) lower chimney.

Figure 4.39 Cross section through the downgradient plane of NUFT simulation showing ambient flow velocity vectors overlain on permeability field.

Figure 4.40 Cross section through the downgradient plane of NUFT simulation showing flow velocity vectors overlain on permeability field at $60 \mathrm{~s}$ after initializing residual heat associated with the CAMBRIC test.

Figure 4.41 Cross section through the downgradient plane of NUFT simulation showing flow velocity vectors overlain on permeability field at $25.5 \mathrm{y}$, near the end of the 600 -gpm pumping stage at RNM-2S.

Figure 4.42 NUFT simulation of minimum, maximum, and average flow velocities near the water table in Layer 2a. 
Figure 4.43 NUFT simulation of minimum, maximum, and average flow velocities in Layer $2 b$.

Figure 4.44 NUFT simulation of the downgradient (northeast) direction flow velocities near wells UE-5n, ER-5-4 piezometer, and ER-5-4 lower screened interval.

Figure 4.45 NUFT simulation of the transverse (northwest) direction flow velocities near wells UE-5n, ER-5-4 piezometer, and ER-5-4 lower screened interval.

Figure 4.46 NUFT simulation of the vertical direction flow velocities near wells UE-5n, ER-5-4 piezometer, and ER-5-4 lower screened interval.

Figure 4.47 NUFT simulation of mean, minimum, and maximum fluid flow velocities for the downgradient (NE), transverse (SE), and vertical directions in the melt glass zone plotted on (a) a linear time scale and (b) a logarithmic time scale.

Figure 4.48 NUFT simulation of mean, minimum, and maximum fluid flow velocities for the downgradient (NE), transverse (SE), and vertical directions in the cavity plotted on (a) a linear time scale and (b) a logarithmic time scale.

Figure 4.49 NUFT simulation of mean, minimum, and maximum fluid flow velocities for the downgradient (NE), transverse (SE), and vertical directions in the compressed zone plotted on (a) a linear time scale and (b) a logarithmic time scale.

Figure 4.50 NUFT simulation of mean, minimum, and maximum fluid flow velocities for the downgradient (NE), transverse (SE), and vertical directions in the lower chimney plotted on (a) a linear time scale and (b) a logarithmic time scale

Figure 4.51 NUFT simulation of flow velocity superposed on temperature near altered zones at (a) $60 \mathrm{~s}$, (b) $0.01 \mathrm{y}$, (c) $0.036 \mathrm{y}$, (d) $0.10 \mathrm{y}$, (e) $0.36 \mathrm{y}$, and (f) $1.00 \mathrm{y}$. Arrows point in the direction of flow and arrow color indicates the magnitude of flow velocity.

Figure 4.52 NUFT simulation of flow velocity superposed on temperature near altered zones at (a) $3.3 \mathrm{y}$, (b) $10 \mathrm{y}$, (c) $12.1 \mathrm{y}$, (d) $19.9 \mathrm{y}$, and (e) $50 \mathrm{y}$. Arrows point in the direction of flow and arrow color indicates the magnitude of flow velocity

Figure 4.53 NUFT simulation vertical flux of total water crossing water table. 4-101

Figure 4.54 NUFT simulation of ${ }^{3} \mathrm{H}$ transport at $10.4 \mathrm{y}$ (includes effects of decay) 4-103

Figure 4.55 NUFT simulation of ${ }^{3} \mathrm{H}$ transport at $12.3 \mathrm{y}$ (includes effects of decay)....................................... 4-103

Figure 4.56 NUFT simulation of ${ }^{3} \mathrm{H}$ transport at 15.6 y (includes effects of decay).........................................

Figure 4.57 NUFT simulation of ${ }^{3} \mathrm{H}$ transport at $25.5 \mathrm{y}$ (includes effects of decay) 4-105

Figure 4.58 NUFT simulation of ${ }^{3} \mathrm{H}$ transport at $50 \mathrm{y}$ (includes effects of decay). 4-105

Figure 4.59 Location of top and bottom extent of ${ }^{3} \mathrm{H}$ concentrations above background relative to CAMBRIC working point (includes effects of decay).

Figure 4.60 Comparison of simulations of tracer transport at $10.4 \mathrm{y}$ for (a) NUFT, (b)

CRUNCH streamline, and (c) NUFT with zero molecular diffusivity.

Figure 4.61 Comparison of NUFT simulation of melt glass temperature history with and without pumping at RNM-2S. 
Figure 4.62 Comparison of NUFT simulation tracer breakthrough curves for base case, no-heat, and high-pressure initial conditions sensitivity cases.

Figure 4.63 NUFT simulation of mean melt glass zone saturation under nine boiling condition cases.

Figure 4.64 NUFT simulations of mean temperature in melt glass zone comparing base case to nine boiling cases.

Figure 4.65 NUFT simulation of mean (a) fluid density and (b) fluid viscosity in melt glass zone for base, no-heat, high-pressure, and boiling cases.

Figure 4.66 NUFT simulation of flow velocity under boiling conditions superposed on temperature near altered zones at (a) $60 \mathrm{~s}$, (b) $0.01 \mathrm{y}$, (c) $0.04 \mathrm{y}$, (d) $0.08 \mathrm{y}$, (e) $0.33 \mathrm{y}$, and (f) $1.00 \mathrm{y}$.

Figure 4.67 NUFT simulation of flow velocity under boiling conditions superposed on temperature near altered zones at (a) $3 \mathrm{y}$ and (b) $10.0 \mathrm{y}$.

Figure 4.68 NUFT simulation of tracer concentration at $10 \mathrm{y}$ for (a) no-heat, (b) base, and (c) boiling cases at initial melt glass temperature of $350{ }^{\circ} \mathrm{C}$ and 0.99 saturation.

Figure 4.69 NUFT simulation under boiling case (1) with initial melt glass temperature of $350{ }^{\circ} \mathrm{C}$ and saturation of 0.99 showing simulated liquid-phase tracer concentration and gas-phase tracer and water concentration at (a) initial condition, (b) $10 \mathrm{~min}$, (c) $8 \mathrm{~h}$, (d) $4 \mathrm{~d}$, (e) $1 \mathrm{y}$, (f) $10 \mathrm{y}$, (g) $100 \mathrm{y}$, and (h) $900 \mathrm{y}$

Figure 4.70 Comparison of NUFT simulation of tracer breakthrough behavior for base, no-heat, high-pressure, and boiling cases at breakthrough planes located (a) $23 \mathrm{~m}$, (b) 92 $\mathrm{m}$, and (c) $268 \mathrm{~m}$ downgradient of the CAMBRIC working point.

Figure 4.71 NUFT simulations of mean relative humidity in melt glass zone for nine boiling cases.

Figure 4.72 NUFT simulation of tracer breakthrough at 23-, 92-, and 268-m

downgradient breakthrough planes for base, dispersion correction (Dis Cor), dispersion correction and zero diffusion (Dis Cor \& $\mathrm{Dif}=0$ ), and zero diffusion ( $\mathrm{Dif}=0$ ).

Figure 4.73 NUFT simulation of tracer concentration field at $10 \mathrm{y}$ for (a) base case, (b) dispersion correction (Dis Cor), (c) dispersion correction and zero diffusion (Dis Cor \& $\mathrm{Dif}=0$ ), and $(\mathrm{d})$ zero diffusion $(\mathrm{Dif}=0$ )

Figure 4.74 Comparison of redox measurements made in the field (Finnegan et al., 2005), redox measurements made on fluid in contact with heated nuclear melt glass (40 to $200{ }^{\circ} \mathrm{C}$, Zavarin et al., 2003), and the stability diagram for $\mathrm{Fe}$ species in solution ( $\mathrm{Fe}$ speciation constants from Johnson and Lundeen, 1997).

Figure 4.75 Comparison of redox measurements made in the field (Finnegan et al., 2005), redox measurements made on fluid in contact with heated nuclear melt glass (40 to $200{ }^{\circ} \mathrm{C}$, Zavarin et al., 2003), and the stability diagram for $\mathrm{Pu}$ species in solution $(\mathrm{Pu}$ speciation constants reported in Table 4.13). Location of $\mathrm{f}\left(\mathrm{O}_{2(\mathrm{~g})}\right)=10^{-5}, 10^{-15}$, and $10^{-25}$ bars, and initial condition used in unclassified CHESHIRE HST simulations is also plotted.

Figure 4.76 Dissolution rates for synthetic volcanic glasses measured at $65{ }^{\circ} \mathrm{C}$ by Mazer (1987). These rates are for experimental conditions far from saturation with respect to the glass. 
Figure 4.77 Fit (thick black line) to $65^{\circ} \mathrm{C}$ dacite dissolution data of Mazer (1987) (thick red line). The $\mathrm{pH}$-dependent rate is fit using a sum of three rates: a pOH-dependent rate, a $\mathrm{pH}$-independent rate, and a $\mathrm{pH}$-dependent rate (thin black lines). One mol of glass is defined as $100 \mathrm{~g}$.

Figure 4.78 Far-from-saturation surface-area-normalized dissolution rates for CAMBRIC glass as a function of temperature and $\mathrm{pH}$.

Figure 4.79 Streamlines originating from melt glass zone at (a) $0.1 \mathrm{y}$, and subsequently evolved through the pumping stage between 10.4 and $25.6 \mathrm{y}$ for locations between the

CAMBRIC source and (b) the pumping well and (c) overall flow system.

Figure 4.80 The effect of activation energy and temperature on dissolution rates as a function of temperature.

Figure 4.81 Glass dissolution rates from streamline simulations superimposed on model glass dissolution rates as a function of $\mathrm{pH}$ and temperature for activation energy of 15 $\mathrm{kcal} / \mathrm{mol}$ and ignoring saturation effects.

Figure 4.82 Streamline simulation of melt glass dissolution rate, temperature, $\mathrm{pH}$, and $\mathrm{SiO}_{2}$ concentration at $0.0266,0.72$, and 9.0 y since the CAMBRIC test. Areas shaded in black indicate zones where reactive transport was not simulated.

Figure 4.83 Simulated radionuclide class cumulative moles that reached the RNM-2S pumping well in the first $25 \mathrm{y}$ after the CAMBRIC test.

Figure 4.84 Temperature history and cumulative glass dissolution as a function of time. $4-183$

Figure 4.85 Oblique cross sections through pumping well RNM-2S and the center of CAMBRIC test-altered zones showing concentration fields for melt glass zone tracer, ${ }^{237} \mathrm{~Np}$, and ${ }^{241} \mathrm{Pu}$ at $0.1,0.7,9.0$, and $25.6 \mathrm{y}$ after the CAMBRIC test.

Figure 4.86 Downgradient migration of TracerR radionuclide class at $10 \mathrm{y}$. $4-185$

Figure 4.87 Evolution of radionuclide retardation $(\log (R))$ with time for $\mathrm{Am},{ }^{41} \mathrm{Ca}$, and Cs radionuclide classes.

Figure 4.88 Evolution of radionuclide retardation $(\log (R))$ with time for $\mathrm{Eu}, \mathrm{Ni}$, and $\mathrm{Np}$ radionuclide classes

Figure 4.89 Evolution of radionuclide retardation $(\log (R))$ with time for ${ }^{241} \mathrm{Pu}, \mathrm{Pu}$, and

Sm radionuclide classes.

Figure 4.90 Evolution of radionuclide retardation $(\log (R))$ with time for $\mathrm{Sr}$ and $\mathrm{U}$ radionuclide classes.

\section{Chapter 5}

Figure 5.1 Glass dissolution rates from NUFT/CRUNCH simulations (colored circles identify glass dissolution rate and $\mathrm{pH}$ for each node in the glass zone) superimposed on model (far-from-saturation) glass dissolution rates as a function of $\mathrm{pH}$ at four different temperatures $\left(150,100,60\right.$, and $\left.25^{\circ} \mathrm{C}\right)$. Large circles simulate the change in $\mathrm{pH}$ and glass dissolution rate at the four temperatures based on the ParFlow/SLIM glass dissolution rate algorithm. 
Figure 5.2 Mean glass zone temperature and cumulative dissolved glass fraction as a function of time for the NUFT/CRUNCH calculations (solid line) and ParFlow/SLIM model glass dissolution algorithm (dashed line).

Figure 5.3 Plan view of the rotated ParFlow model domain (box ABCD) and surrounding wells in NAD27 coordinates. The larger box shows the extent of the HSU features obtained as a subset of the CAU-scale geologic model (Bechtel Nevada, 2005b).

Figure 5.4 Plan view of ParFlow model domain (box ABCD) and surrounding wells in local $x(\mathrm{AB})$ and $y(\mathrm{AD})$ coordinates $(\mathrm{m})$. The fine-mesh region is located within the green box. The red, blue, and blue-green lines correspond to vertical breakthrough planes 1-3 used in Tompson et al. (2005) and discussed in Section 5.4.5

Figure 5.6 Hydraulic conductivity field used in the ParFlow model with a box denoting the surface projection of the fine resolution mesh region.

Figure 5.7 Close-in view of the ParFlow model hydraulic conductivity field showing units within the fine-mesh region indicated in Figure 5.6. Note that because the hydraulic conductivity values for AL8 and PCU1L are similar they appear as the same color in this figure.

Figure 5.8 Detail of hydraulic conductivity distributions in the ParFlow model close to the CAMBRIC test area showing altered zones and heterogeneous layers.

Figure 5.9 Comparison of simulated steady-state ParFlow water levels, simulated base case and alternative CAU flow model water levels, and measured levels and their uncertainties.

Figure 5.10 Location of the ditch and playa influx boundaries in the ParFlow model. The location of U-5e (filled circle), RNM-2S (x), and the fine-mesh region (inside the rectangular area) are also shown. Coordinates are in meters and are local to the model domain.

Figure 5.11 Observed (red) and simulated (gray) breakthrough of ${ }^{3} \mathrm{H}$ at RNM-2S based upon 15 realizations of hydraulic conductivity in the fine resolution area of the ParFlow model. The black curve represents the average of the 15 simulated curves.

"Recirculation" effects, as discussed in Section 5.3.3 of this report, were not included in the simulations.

Figure 5.12 Observed (red) and simulated breakthrough of ${ }^{3} \mathrm{H}$ at RNM-2S for the two best-fit realizations, R14 (blue) and R6 (green), of hydraulic conductivity in the fine resolution area of the ParFlow model. "Recirculation" effects, as discussed in Section 5.3.3, were not included in the simulations.

Figure 5.13 Simulated saturation profile after $8 \mathrm{y}$ of pumping and ditch infiltration (1983).

Figure 5.14 Simulated water levels at various depths in UE-5n, RNM-2S, and ER-5-4.

Figure 5.15 Observed and simulated water levels at UE-5n, located $106 \mathrm{~m}$ from the ditch. Observed values are plotted as symbols and the solid red line is the ParFlow simulation. Figure modified from Stoller-Navarro (2004a).

Figure 5.16 Plot of $x, y$, and $z$ velocities with time for two locations at the water table (WT) and in layer AL2b (2b). 
Figure 5.17 Plot of $x$ - and $y$-direction velocities in three wells surrounding the CAMBRIC test.

Figure 5.18 Simulated and observed ${ }^{3} \mathrm{H}$ breakthrough at RNM-2S. Simulated

breakthrough sources include the cavity, the ditch only, and mass that has recycled

through the well-ditch system. Note the ditch-only source uses the observations as a

ditch initial concentration.

Figure 5.19 Mass (in moles) of ${ }^{3} \mathrm{H}$ simulated to have been entrained in pumping well

RNM-2S. Mass is the fraction of the total source term used from Bowen et al. (2001). A

zero value indicates mass of ${ }^{3} \mathrm{H}$ that did not breakthrough in RNM-2S. (Note the log

scale.).

Figure 5.21 Plot of total radionuclide mass as a function of number of times it arrived at RNM-2S. Mass totals to the initial condition in cavity, altered zone, and melt glass.

Mass corresponding to a zero on the $x$-axis never reaches the well, and mass plotted two or greater on the $x$-axis recycles between the well and ditch.

Figure 5.22a Breakthrough of radionuclides at RNM-2S from the NUFT/CRUNCH model (black) and ParFlow/SLIM model (red). Calcium-41, ${ }^{59} \mathrm{Ni},{ }^{63} \mathrm{Ni},{ }^{90} \mathrm{Sr},{ }^{135} \mathrm{Cs},{ }^{137} \mathrm{Cs}$,

${ }^{151} \mathrm{Sm},{ }^{150} \mathrm{Eu},{ }^{152} \mathrm{Eu},{ }^{154} \mathrm{Eu},{ }^{166} \mathrm{Ho}$, and ${ }^{241} \mathrm{Am}$ radionuclides had no breakthrough in either model. All calculations used the RST from Bowen et al. (2001).

Figure 5.22b Breakthrough of radionuclides at RNM-2S from the NUFT/CRUNCH model (black) and ParFlow/SLIM model (red). Calcium-41, ${ }^{59} \mathrm{Ni},{ }^{63} \mathrm{Ni},{ }^{90} \mathrm{Sr},{ }^{135} \mathrm{Cs},{ }^{137} \mathrm{Cs}$,

${ }^{151} \mathrm{Sm},{ }^{150} \mathrm{Eu},{ }^{152} \mathrm{Eu},{ }^{154} \mathrm{Eu},{ }^{166} \mathrm{Ho}$, and ${ }^{241} \mathrm{Am}$ radionuclides had no breakthrough in either model. All calculations used the RST from Bowen et al. (2001).

Figure 5.23a Alpha-decaying radionuclide breakthrough at RNM-2S from the

NUFT/CRUNCH model (black) and ParFlow/SLIM model (red). Americium-241 had no

breakthrough in either model. All calculations used the RST from Bowen et al. (2001).

The blue line represents background activity from natural $U$ isotopes.

Figure 5.23b Beta-decaying radionuclide breakthrough at RNM-2S from the

NUFT/CRUNCH model (black) and ParFlow/SLIM model (red). Nickel-63, ${ }^{90} \mathrm{Sr},{ }^{135} \mathrm{Cs}$,

${ }^{137} \mathrm{Cs},{ }^{151} \mathrm{Sm},{ }^{152} \mathrm{Eu},{ }^{154} \mathrm{Eu}$, and ${ }^{166} \mathrm{Ho}$ radionuclides had no breakthrough in either model.

All calculations used the RST from Bowen et al. (2001)....

Figure 5.23c EC/IT-decaying radionuclide breakthrough at RNM-2S from the NUFT/CRUNCH model (black) and ParFlow/SLIM model (red). Calcium-41, ${ }^{59} \mathrm{Ni}$,

${ }^{150} \mathrm{Eu}$, and ${ }^{152} \mathrm{Eu}$ radionuclides had no breakthrough in either model. All calculations used the RST from Bowen et al. (2001)

Figure 5.24 Comparison of breakthrough between NUFT/CRUNCH (dashed lines) and ParFlow/SLIM (solid lines) in RNM-2S. The thin solid line shows Np breakthrough with a $\mathrm{K}_{\mathrm{d}}$ reduced by $10^{0.5}$

Figure 5.25 Uranium retardation factors and concentration cross sections between the CAMBRIC cavity and the RNM-2S pumping well in the NUFT/CRUNCH (A, B) and ParFlow/SLIM (C) models.

Figure 5.26 Simulated aqueous $\mathrm{Cs}, \mathrm{Sr}$, and $\mathrm{Pu}$ radionuclide class concentrations in the CAMBRIC cavity (log scale) at 12 y (NUFT/CRUNCH model). 
Figure 5.27 Measured (blue), NUFT/CRUNCH (black), and ParFlow/SLIM (red) ${ }^{3} \mathrm{H}$ concentrations in three wells near the CAMBRIC test: RNM-1 (triangle), RNM-2S (plus sign), and UE-5n (circle). Simulated concentrations are adjusted to the CAMBRIC-specific ${ }^{3} \mathrm{H}$ inventory estimate of Hoffman et al. (1977).

Figure 5.28 TracerR concentration as a function of time in the NUFT/CRUNCH simulations.

Figure 5.29 Measured (blue), NUFT/CRUNCH (black), and ParFlow/SLIM (red) ${ }^{85} \mathrm{Kr}$ concentrations in three wells near the CAMBRIC test: RNM-1 (triangle), RNM-2S (plus sign), and UE-5n (circle). Simulated concentrations are adjusted to the CAMBRIC-specific ${ }^{85} \mathrm{Kr}$ inventory estimate of Hoffman et al. (1977).

Figure 5.30 Cs radionuclide class concentrations in the CAMBRIC cavity during the RNM experiment.

Figure 5.31 Pu radionuclide class concentrations in the CAMBRIC cavity during the RNM experiment.

Figure 5.32 $\mathrm{Sr}$ radionuclide class concentrations in the CAMBRIC cavity during the RNM experiment.

Figure 5.33 Measured (blue), NUFT/CRUNCH (black), and ParFlow/SLIM (red) ${ }^{99} \mathrm{Tc}$ concentrations in three wells near the CAMBRIC test: RNM-1 (triangle), RNM-2S (plus sign), and UE-5n (circle). Simulated concentrations are adjusted to the CAMBRIC-specific ${ }^{99} \mathrm{Tc}$ inventory estimate of Schroeder et al. (1993).

Figure 5.34 Measured (blue), NUFT/CRUNCH (black), and ParFlow/SLIM (red) ${ }^{36} \mathrm{Cl}$ concentrations in three wells near the CAMBRIC test: RNM-1 (triangle), RNM-2S (plus sign), and UE-5n (circle). Simulation results are based on the average Frenchman Flat source term reported by Bowen et al. (2001).

Figure 5.35 Measured (blue), NUFT/CRUNCH (black), and ParFlow/SLIM (red) ${ }^{129} \mathrm{I}$ concentrations in three wells near the CAMBRIC test: RNM-1 (triangle), RNM-2S (plus sign), and UE-5n (circle). Simulation results are based on the average Frenchman Flat source term reported by Bowen et al. (2001).

Figure 5.36 Results for tracer transport at different points in time during the simulation $(10.4,14,17,18,26$, and $27 \mathrm{y}$, from top left) focused on the region near the cavity. The upper left panel represents tracer transport after $10.4 \mathrm{y}$ of ambient migration, just before the onset of pumping. The last panel represents tracer transport at $27 \mathrm{y}, 2 \mathrm{y}$ after the cessation of pumping. Note the pathway from cavity to well and from ditch to water table.

Figure 5.37 Plot of molar fluxes at plane 1 for radionuclide classes $\mathrm{Ca}, \mathrm{Cs}, \mathrm{Eu}, \mathrm{Ni}, \mathrm{Sm}$, and $\mathrm{Sr}$

Figure 5.38 Plot of molar flux at plane 1 for radionuclide class $\mathrm{Pu}+$ $5-55$

Figure 5.39 Plot of molar flux at plane 1 for radionuclide class ${ }^{241} \mathrm{Pu}$. $5-55$

Figure 5.40 Plot of molar fluxes at plane 1 for radionuclide class Am $5-56$

Figure 5.41 Plot of molar flux at plane 4 for radionuclide class U. $5-56$

Figure 5.42 Plot of molar fluxes at planes 1-3 for radionuclide class $\mathrm{U}$ 
Figure 5.43 Plot of molar fluxes at planes 1-3 for radionuclide class TracerR

Figure 5.44 Plot of molar flux at plane 4 for radionuclide class TracerR.

Figure 5.45 Plot of molar fluxes at planes 1-3 for radionuclide class TracerL.

Figure 5.46 Plot of molar flux at plane 4 for radionuclide class TracerL. $5-60$

Figure 5.47 Plot of molar flux at plane 1 for radionuclide class $\mathrm{Np}$. 5-61

Figure 5.48 Plot of molar flux at plane 4 for radionuclide class $\mathrm{Np}$.

Figure 5.49 Plot of simulated TracerR migration $65.75 \mathrm{y}$ after the CAMBRIC test, after drainage of the vadose zone is mostly complete. An aerial photograph of the NTS is included for reference.

Figure 5.50 Plot of simulated TracerL migration $65.75 \mathrm{y}$ after the CAMBRIC test, after drainage of the vadose zone is mostly complete. An aerial photograph of the NTS is included for reference.

Figure 5.51 Plot of simulated U migration 65.75 y after the CAMBRIC test, after drainage of the vadose zone is mostly complete. An aerial photograph of the NTS is included for reference.

Figure 5.52 Plot of simulated Np1 migration $65.75 \mathrm{y}$ after the CAMBRIC test, after drainage of the vadose zone is mostly complete. An aerial photograph of the NTS is included for reference.

Figure 5.53 Plot of simulated Np2 migration $65.75 \mathrm{y}$ after the CAMBRIC test, after drainage of the vadose zone is mostly complete. An aerial photograph of the NTS is included for reference.

Figure 5.54 Plot of simulated tracer (TracerR) migration at $20 \mathrm{y}$ after the CAMBRIC test. The test location and vicinity wells are shown, as are two cross sections of hydraulic conductivity in grayscale. Note that this simulation does not include decay.

Figure 5.55 Plot of simulated tracer (TracerR) migration at $50 \mathrm{y}$ after the Cambric test. The test location and a number of Frenchman Flat wells are shown for reference, as are two cross sections of hydraulic conductivity in grayscale. Note that this simulation does not include decay.

Figure 5.56 Plot of simulated ${ }^{3} \mathrm{H}$ migration at 10, 20, 30, 40, 50, and $100 \mathrm{y}$ after the CAMBRIC test. An aerial photograph of the NTS is included for reference. All concentrations include radioactive decay. 


\section{Chapter 6}

Figure 6.1 Mean water-level elevations and uncertainty range for wells screened in alluvium in Frenchman Flat. Estimates of maximum and minimum north-to-south CAU-scale horizontal hydraulic gradients fit within the uncertainty range of all of the data. The median estimate averages the maximum and minimum gradients.

Figure 6.2 Close-up view of the CAMBRIC site shows the ditch, nearby wells, and locations of three vertical breakthrough planes. Approximate flow directions away from U5 e are from water levels in UE-5n, RNM-2S, and ER-5-4 (upper) (1) computed from the observation (black arrow) in Table 2.1 and a series of 400 random head observations falling within the measured uncertainties indicated in Table 2.1 (gray dots without arrows); (2) simulated by 50 steady-state ParFlow realizations (green) reported in Tompson et al., (2005); and (3) simulated by 8 CAU model runs (blue squares) reported by Nicole Denovio (personal communication, 2005). The distance between U-5e and each "point" is proportional to the magnitude of the head gradient. The observed gradient magnitude (black arrow) is 0.0013 . 


\section{List of Tables}

\section{Chapter 2}

Table 2.1. Summary of contemporary, steady-state water levels measured in wells near the CAMBRIC test (Nicole Denovio, personal communication, July 26, 2005). The shaded rows correspond to the near-field well triangle (see text).

Table 2.2. Groundwater composition in wells located near the CAMBRIC site....

Table 2.3. Average mineralogy (weight percent) in the alluvial layers defined by Warren et al. (2002).

\section{Chapter 3}

Table 3.1. Summary of available unclassified radiologic source term data for the

CAMBRIC site. All data decay are corrected to $t_{0}$, May 14,1965

Table 3.2. Radionuclide partitioning (IAEA, 1998a).

Table 3.3. Radioisotope concentrations in rock separates from RNM-1 near the working point of CAMBRIC

Table 3.4. Radioisotope concentrations in core from RNM-1

Table 3.5. Average concentrations of radionuclides detected in pumped waters at RNM-1.

Table 3.6. Calculated $\mathrm{K}_{\mathrm{d}} \mathrm{S}$ for radionuclides based on data in Tables 3.4 and 3.5.

Table 3.7. Average major element concentrations in pumped waters at RNM-1

\section{Chapter 4}

Table 4.1. Minimum and maximum extent of the NUFT simulation domain relative to

CAMBRIC working point

Table 4.2. NUFT flow simulation discretization information with cell minimum (min), coordinate location, and cell size for each cell number in each direction....

Table 4.3. Category number, label, and characteristics of NUFT simulation hydrofacies. 4-13

Table 4.4. Lateral and vertical extent of alluvial layers assumed in the NUFT model relative to the Cambric working point.

Table 4.5. Hydraulic properties of hydrofacies defined in the NUFT and ParFlow basecase simulations with hydraulic conductivities $\left(\mathrm{K}_{\mathrm{G}}\right.$ or $\left.\mathrm{K}_{\mathrm{h}}, \mathrm{K}_{\mathrm{v}}\right)$ based upon pure water at $24{ }^{\circ} \mathrm{C}$. Cells with no data refer to units or parameters not covered in respective model (NUFT or ParFlow) or gridded (fine or coarse) portion of model. Porosity column data in the ParFlow model applies to both coarse and fine grids.

Table 4.6. Comparison of alluvial aquifer hydraulic properties estimated by USGS (2004) and Stoller-Navarro (2004a) using RNM-2S MWAT data. 
Table 4.7. Initial pressure, saturation, and temperature distributions in altered zones for

Table 4.8. Initial mineralogy of hydrofacies distributed within the NUFT flow model

domain.

Table 4.9. Unclassified radiologic source term and radionuclide partitioning between the glass and water at CAMBRIC $t_{0}$.

Table 4.10. Initial partitioning of radionuclide classes. ....................................................................... $4-146$

Table 4.11 Basis species used in thermodynamic database.

Table 4.12. Parameters in extended Debye-Huckel activity coefficient model as a function

of temperature $\left({ }^{\circ} \mathrm{C}\right)$. 4-148

Table 4.13. Logarithm of equilibrium constants $(K)$ of aqueous reactions used in streamline simulations

Table 4.14. Mineral characteristics used to define reactions on mineral surfaces. 4-151

Table 4.15. Surface complexation reaction for iron oxides using the NEM. 4-152

Table 4.16. Surface complexation reactions for aluminosilicates using the NEM. 4-153

Table 4.17. Surface complexation reactions for calcite using the NEM

Table 4.18. Vanselow ion exchange reaction constants for smectite, illite/mica, and clinoptilolite.

Table 4.19. Solubility of radionuclide-containing secondary mineral phases.

Table 4.20. Solubility of secondary mineral phases

Table 4.21. Solubility of nuclear melt glass.

Table 4.22. Kinetic parameters for radionuclide-bearing mineral dissolution/precipitation 4-168

Table 4.23. Kinetic parameters for secondary mineral dissolution/precipitation. 4-168

Table 4.24. CAMBRIC melt glass dissolution rate constants at standard state $\left(25^{\circ} \mathrm{C}\right) .\left[\mathrm{H}^{+}\right]$ and $[\mathrm{OH}]$ refer to the activity of these species. In low ionic strength solutions, the activity is similar to the concentration of these species in solution.

\section{Chapter 5}

Table 5.1. Values for mean and standard deviation of $Z=\log _{10} R=\log _{10}\left(1+\rho_{b} K_{d} / \phi\right)$ used to populate the spatially variable retardation values for the sorbing radionuclide classes

Table 5.2. Hydrostratigraphic units used in the ParFlow domain and corresponding index.

Table 5.3. Radionuclide class $\mathrm{K}_{\mathrm{d}} \mathrm{S}$ distributed within the ParFlow/SLIM model domain. 


\section{Chapter 6}

Table 6.1. Coordinates and steady-state water level elevations and uncertainties for wells screened in alluvium within the Frenchman Flat CAU (modified from Stoller-Navarro, 2006 and Stoller-Navarro, 2004c). These data are updated from those shown in Table

2.1 . 


\section{$1 \quad$ Introduction}

\section{$1.1 \quad$ Background}

Over 800 underground nuclear tests were conducted at the Nevada Test Site (NTS), roughly a third of which were beneath the water table (USDOE, 1997b, 2000). The total inventory of radionuclides associated with below-water-table tests at NTS has been estimated to include over $10^{8}$ curies $(\mathrm{Ci})$ of radioactivity associated with 43 long-lived radioisotopes (Bowen, et al., 2001).

In recent years, there has been mounting concern about the environmental risks posed by residual radioactivity from these tests, and, in particular, the potential for the radioactivity to enter and migrate in groundwater (USDOE, 1997a, b). The risks are dependent, in part, on the physical, chemical, and radiochemical mechanisms that control how radionuclides are generated and distributed in the subsurface during a test, how they become dissolved or otherwise incorporated in groundwater after a test, and how they migrate in groundwater away from a test.

Most underground testing locations are hundreds of meters or more beneath the ground surface and are difficult to access for characterization and monitoring. As a result, recent efforts to assess how test-related radionuclides enter and move through groundwater over long periods of time, both at NTS and elsewhere, have tended to rely heavily on computer-based simulation models (USDOE, 1997a; IAEA, 1998a, b, c; Pohll et al., 1998, 1999; Tompson et al., 1999, 2002; Pawloski et al., 2000; and Wolfsberg et al., 2001). Such models have been designed to increase understanding of the complex mechanisms involved in radionuclide release and migration in the local or near-field scale surrounding a test location. Models may also evaluate radionuclide migration and associated uncertainties over larger intermediate or regional hydrologic scales or assist in the design of data acquisition strategies for future validation and characterization purposes.

From a localized perspective, the nature, extent, and rate of radionuclide migration in groundwater away from an underground test location, as derived from the initial post-test distribution of radioactivity, is collectively called the hydrologic source term (HST) for that test. Modeling the HST for tests (e.g., Tompson et al., 1999, 2002 and Pawloski et al., 2000, 2001) typically couples near-field simulation models of hydrothermal groundwater flow and reactive transport to one or more physical and chemical models of the natural and altered geologic environment surrounding the test cavity and a conceptualization of the form, distribution, and amount of residual radioactivity in this environment. Results of such coupled models can be interpreted, simplified, and/or otherwise used to guide the rate of radioactivity specified at multiple test locations in intermediate- or regional-scale transport models and to further understand the nature of the processes associated with radionuclide release. 


\subsection{Objectives of the Current Work}

The objective of Phase II HST work is to develop a better understanding of the evolution of the HST for 1,000 years at the CAMBRIC underground nuclear test site in Frenchman Flat at the NTS. This work provides a better understanding of activities as they actually occurred, incorporates improvements based on recent data acquisition, and provides a basis to use the CAMBRIC site for model validation and monitoring activities as required by the UGTA Project. CAMBRIC was the only test in Frenchman Flat detonated under the water table and best represents a fully saturated environment.

These simulations are part of a broad Phase II Frenchman Flat Corrective Action Unit (CAU) flow and transport modeling effort being conducted by the Department of Energy (DOE) Underground Test Area (UGTA) Project. HST simulations provide, either directly or indirectly, the source term used in the CAU model to calculate a contaminant boundary. Work described in this report augments Phase I HST calculations at CAMBRIC conducted by Tompson et al. (1999) and Pawloski et al. (2001). Phase II HST calculations have been organized to calculate source terms under two scenarios:

- A representation of the transient flow and radionuclide release behavior at the CAMBRIC site that is more specific than Tompson et al. (1999). This model reflects the influence of the background hydraulic gradient, residual test heat, pumping experiment, and ditch recharge, and takes into account improved data sources and modeling approaches developed since the previous efforts. Collectively, this approach will be referred to as the transient CAMBRIC source term. This report describes the development of the transient CAMBRIC HST.

- A generic release model made under steady-state flow conditions, in the absence of any transient effects, at the same site with the same radiologic source term. This model is for use in the development of simpler release models for the other nine underground test sites in the Frenchman Flat CAU. This approach will be referred to as the steady-state (non-transient) CAMBRIC source term. This work is described in a separate report (Tompson et al., 2005).

In the remaining sections of Chapter 1, a brief synopsis of the CAMBRIC test and related field investigations and studies will be presented, followed by a review of the modeling approach used in the current work. 


\subsection{History of Activities and Studies Related to CAMBRIC}

\subsubsection{The CAmbric Test}

The CAMBRIC test was conducted beneath Frenchman Flat at the NTS on May 14, 1965 (USDOE, 2000). The detonation point was in alluvium, $294 \mathrm{~m}$ beneath the ground surface and approximately $74 \mathrm{~m}$ beneath the ambient water table. The announced energy-equivalent yield of the test was 0.75 kilotons $(\mathrm{kt})$. The explosion created a cavity approximately $27 \mathrm{~m}$ in diameter that was subsequently filled in by collapsed alluvium and later resaturated with groundwater (Bryant, 1992; Hoffman et al., 1977). The collapsed "chimney" did not extend as far as the ground surface because there was no observable crater.

Figure 1.1 illustrates the configuration of the emplacement hole (U-5e), the post-test drillback well (RNM-1), and several other features and monitoring wells in the immediate vicinity. The locations of the WiSHBONE (U-5a) and DiLUTED WATERS (U-5b) tests, also conducted in 1965, are shown (with surface craters). CAMBRIC is relatively unique at the NTS in that it has been extensively characterized and monitored for post-test environmental impacts. Some aspects of these activities are briefly summarized below. 


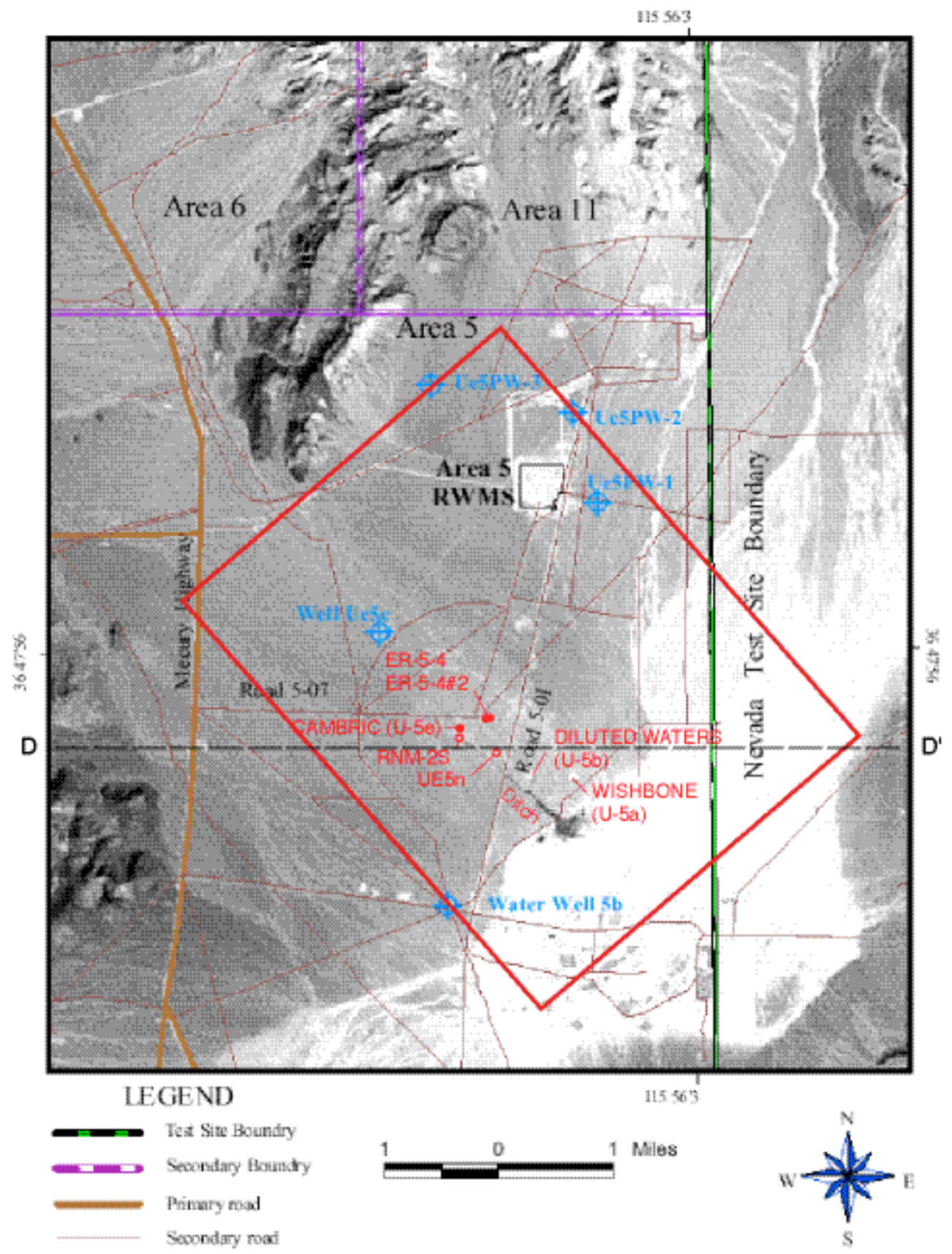

Figure 1.1 Aerial view of Frenchman Flat, NTS, showing locations of CAMBRIC (U-5e), nearby boreholes and monitoring wells, the CAMBRIC ditch, as well as DILUTED WATERS (U-5a) and WISHBONE (U-5b) tests. The red box indicates the horizontal extent of the model domain used for HST simulations. 


\subsubsection{The Radionuclide Migration Experiment}

Beginning in October 1975, approximately $10 \mathrm{y}$ after the detonation, groundwater adjacent to the CAMBRIC test cavity was pumped steadily for $16 \mathrm{y}$, with a few short interruptions, in order to elicit information on test-related radionuclide migration (RNM) in the saturated zone (Hoffman et al., 1977; Daniels, 1982 and Bryant, 1992).

As shown in Figure 1.2, the pumping well (RNM-2S) is located approximately $91 \mathrm{~m}$ south of the emplacement hole (U-5e) and is screened over an approximately $25-\mathrm{m}$ interval between depths of 316 and $341 \mathrm{~m}$, slightly below the elevation of the test cavity. A monitoring well (UE-5n), $529 \mathrm{~m}$ away from the pumping well and $106 \mathrm{~m}$ perpendicular to the ditch, is screened in the saturated zone over a 3-m interval just below the water table. The pumping well

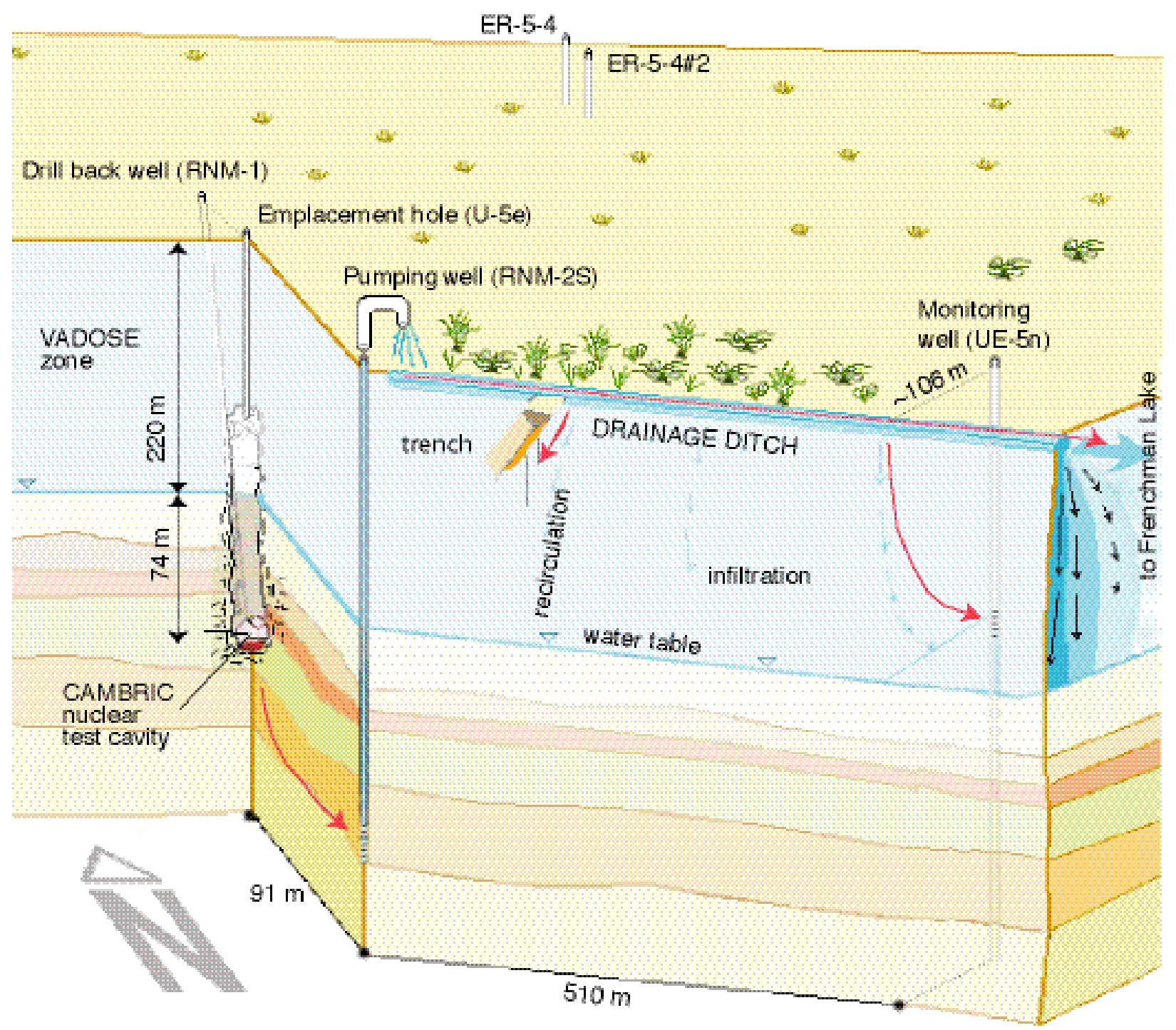

Figure 1.2 Schematic of the CAMBRIC test area in Frenchman Flat at the NTS, showing the test emplacement hole (U-5e), cavity and collapsed chimney, pumping well RNM-2S, drainage ditch, lysimeter trench, and monitoring wells UE-5n, ER-5-4, and ER-5-4\#2. Known tritium pathways are shown in red. 
effluent was regularly monitored for its radionuclide content. The effluent was discharged to an unlined ditch (Figures 1.1 and 1.2) and allowed to flow towards the Frenchman Lake playa, approximately $1.6 \mathrm{~km}$ to the southeast. Over the $16 \mathrm{y}$ of the experiment, extensive growth of saltcedar and cattails, both invasive nonnative shrubs, developed along the ditch.

Radionuclides regularly observed in the pumping well effluent included tritium $\left({ }^{3} \mathrm{H}\right.$ or $\mathrm{T}$, occurring in molecular water as HTO), ${ }^{36} \mathrm{Cl},{ }^{85} \mathrm{Kr}$, and ${ }^{129} \mathrm{I}$ (Bryant, 1992). Sporadic observations of ${ }^{106} \mathrm{Ru}$ and ${ }^{99} \mathrm{Tc}$ were also made in samples. Figure 1.3 shows the ${ }^{3} \mathrm{H}$ activity and ${ }^{36} \mathrm{Cl}$ concentration measured in the effluent between the start of pumping in October 1975 until its cessation in the fall of 1991 (all data are decay corrected to May 14, 1965). An isolated ${ }^{3} \mathrm{H}$ measurement made in 2000 is also shown. The recovery curves appear to reflect relatively "complete" breakthrough profiles for these radionuclides, which are generally quite mobile in groundwater. Similar behavior was observed for ${ }^{85} \mathrm{Kr}$ and ${ }^{129} \mathrm{I}$ (not shown; see Bryant, 1992). Relatively "immobile" species such as ${ }^{90} \mathrm{Sr},{ }^{137} \mathrm{Cs}$, and ${ }^{238,239} \mathrm{Pu}$ were looked for but never detected. Detection of other radionuclides was not formally pursued during the pumping test, although test-related ${ }^{14} \mathrm{C}$ was later identified in the pumping well in 2000 (Tompson et al., 2006) indicating its apparent co-migration with other mobile radionuclides pumped and discharged into the ditch.

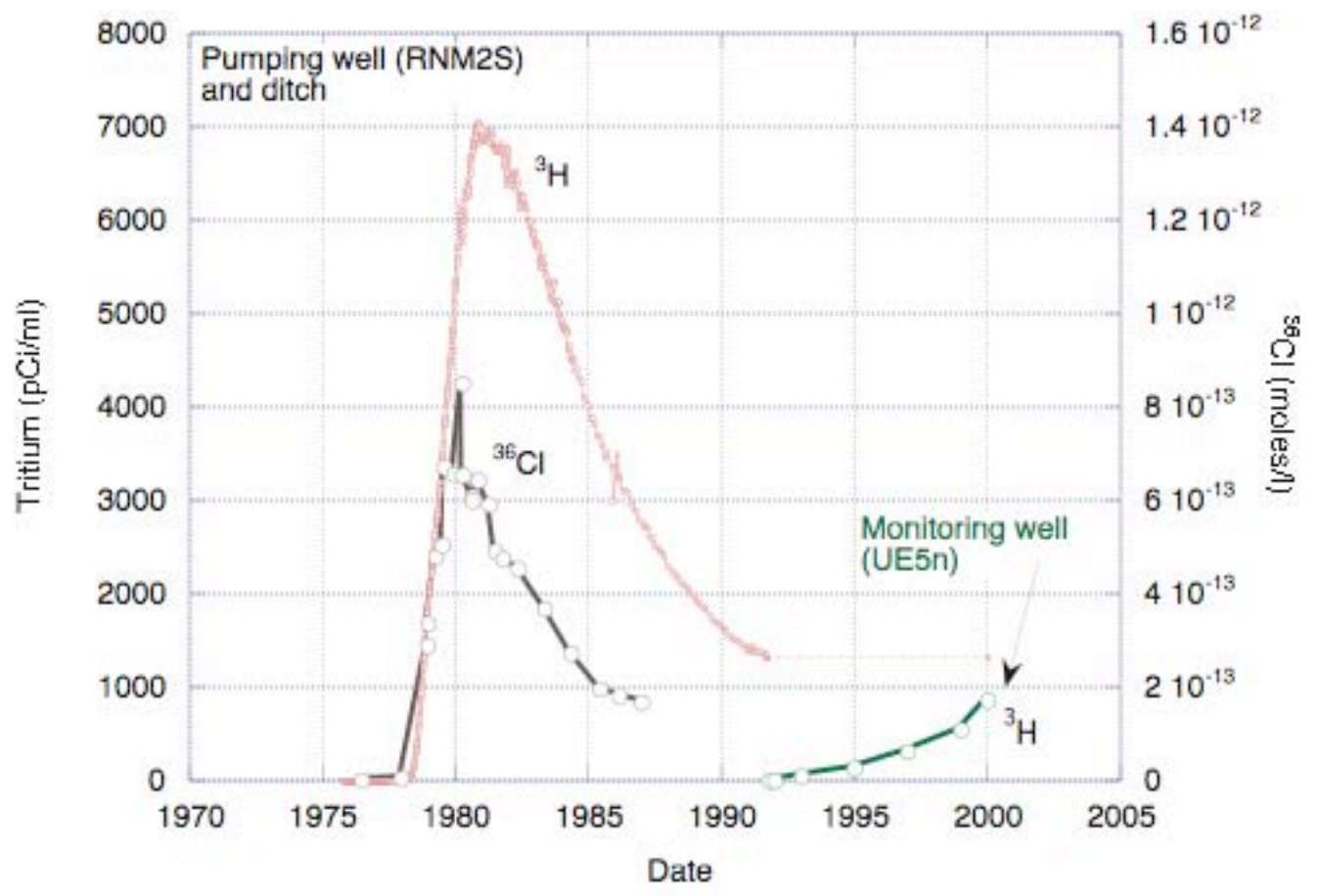

Figure 1.3 Tritium $\left({ }^{3} \mathrm{H}\right)$ activity and ${ }^{36} \mathrm{Cl}$ concentrations observed in the pumping well (RNM-2S) between the initiation (1975) and cessation of pumping (1991), and in an isolated measurement made in 2000. Rising ${ }^{3} \mathrm{H}$ activity in monitoring well UE-5n beginning in 1991 is also shown. All data are decay corrected to May $14,1965$. 
As shown in Figure 1.3, the first arrivals of ${ }^{3} \mathrm{H}$ and ${ }^{36} \mathrm{Cl}$ were not observed until after more than two years $(900 \mathrm{~d})$ of pumping, and only after the initial pumping rate (300 gpm, or $1,635 \mathrm{~m}^{3} / \mathrm{d}$ ) was doubled (to $600 \mathrm{gpm}$, or $3,270 \mathrm{~m}^{3} / \mathrm{d}$ ) after $700 \mathrm{~d}$. The first arrival times for ${ }^{85} \mathrm{Kr}$ and ${ }^{129} \mathrm{I}$ (not shown) were generally similar. The peak ${ }^{3} \mathrm{H}$ concentration was observed in 1981 .

The peak concentration of ${ }^{36} \mathrm{Cl}$ occurred somewhat earlier, while peak concentrations of ${ }^{85} \mathrm{Kr}$ and ${ }^{129} \mathrm{I}$ (not shown) were substantially delayed. Measured concentrations of ${ }^{106} \mathrm{Ru}$ and ${ }^{99} \mathrm{Tc}$ were too infrequent to allow similar comparisons. Differences in the shapes of these profiles have been attributed to detonation effects that affect the initial distribution of residual radioactivity (Bryant, 1992; Guell and Hunt, 2003; and Tompson et al., 2002), as well as slight differences in the overall mobility of the radionuclides in groundwater.

\subsubsection{Source Term Model Studies}

A number of extensive analyses and modeling studies of radionuclide migration between the CAMBRIC test cavity and the pumping well were conducted both during and after the RNM experiment (Hoffman et al., 1977; Bryant, 1992; LATA, 1982; Daniels et al., 1982; Burbey and Wheatcraft, 1986; Guell and Hunt, 2003; Ogard et al., 1988; and Tompson et al., 1999, 2002).

The earlier modeling studies reported by LATA (1982), Daniels et al. (1982), Burbey and Wheatcraft (1986), and Ogard et al. (1988) are each focused on the movement of ${ }^{3} \mathrm{H}$ and ${ }^{36} \mathrm{Cl}$ in the saturated zone connecting the cavity area and the pumping well. They are based upon relatively simplified conceptualizations of the hydrologic system and nuclear explosion phenomenology (see Tompson et al., 1999, for a review). They all use a series of radionuclide inventories and "exchange zone" estimates provided by Hoffman et al. (1977) to define the initial distributions of ${ }^{3} \mathrm{H}$ and ${ }^{36} \mathrm{Cl}$. In addition, they typically use the existing pumping well breakthrough profiles, in some sense, as a model calibration target.

The later work of Guell and Hunt (2003) also considers the movement of ${ }^{85} \mathrm{Kr}$ between the cavity and the pumping well. The authors consider more carefully the effects of phenomenology and its role in the partitioning of ${ }^{85} \mathrm{Kr}$ between liquid water and gas phases present after detonation. Such partitioning moderates the fraction of ${ }^{85} \mathrm{Kr}$ available to dissolve into water and move toward the pumping well.

The HST simulations (Tompson et al. 1999, 2002) are focused on the CAMBRIC test and represent one of the first efforts under the UGTA project to simulate an HST at NTS using a reactive flow and transport modeling approach. As such, greater consideration was given to phenomenologic effects on the initial distribution of radionuclides and the geochemical processes that affect their release into groundwater and mobility in groundwater. A significant effort was applied to develop a framework that modeled the flow regime in detail and captured the appropriate physical and chemical processes that occurred over the duration of the simulations.

Despite the relative abundance of information available from previous studies at the CAMBRIC site, portions of Tompson et al. (1999, 2002) HST simulations were simplified because of data limitations and a perceived need for generalization of the results. For example, 
- Transient effects arising from test heat, groundwater pumping, and ditch recharge at the site were not incorporated. ${ }^{1}$

- Only an estimated unclassified inventory of a limited number of radionuclides was available (from the report of Hoffman, et al., 1977).

- Only a small number of radionuclides (5) in this inventory and their associated geochemical reactions were incorporated in the work.

Since the completion of the Tompson et al. reports $(1999,2002)$, it has become increasingly apparent that a number of issues need to be addressed in updated simulation efforts. These include:

- Incorporation of test-related hydrothermal flow effects (as in Pawloski et al., 2001).

- Use of the recent Bowen et al. (2001) unclassified radionuclide inventory.

- Addressing a greater number of radionuclides and associated geochemical reactions.

- Inclusion of transient flow conditions related to the RNM pumping experiment and the recirculation of fluids and radionuclides between the discharge ditch and the water table (see below and Tompson et al., 2006).

- Employing newly acquired geologic and hydrologic data obtained at the CAMBRIC site in the past few years, such as the ER-5-4 wells (Warren et al., 2002; Carle et al., 2002; and Bechtel Nevada, 2005) and the RNM-2S Multiple Well Aquifer Test (USGS, 2004 and Stoller-Navarro, 2004a).

\subsubsection{Ditch Studies}

During the RNM experiment, there was little interest in the fate of radionuclides once they were discharged into the ditch. The perception at the time was that infiltration of contaminated effluent into the $220 \mathrm{~m}$ of unsaturated alluvium would not constitute a significant threat to recontamination of groundwater. This concern was challenged in the mid 1980s and early 1990s with a series of soil moisture and water quality measurements. The infiltration of water and migration of ${ }^{3} \mathrm{H}$ and ${ }^{36} \mathrm{Cl}$ were measured horizontally to about $7 \mathrm{~m}$ and vertically to at least $30 \mathrm{~m}$ beneath and away from the ditch (Buddemeier et al., 1991 and Ross and Wheatcraft, 1994).

In the 1980s, a series of flume-based measurements of the ditch flow rate between the pumping well and Frenchman Lake indicated that a loss of approximately $175 \mathrm{gpm}$ (or $954 \mathrm{~m}^{3} / \mathrm{d}$, roughly one third of the upstream flow rate) occurred over an approximate 1,000-m distance (Bryant, 1992). This loss of water amounts to approximately $0.01 \mathrm{~kg} / \mathrm{s}$ per m of ditch length (yet was estimated by Ross and Wheatcraft, 1994, to be closer to $0.02 \mathrm{~kg} / \mathrm{s}$ per m of ditch length). Small diurnal fluctuations in these flow rates have also been observed and attributed to daily

\footnotetext{
${ }^{1}$ With the exception of preliminary ${ }^{3} \mathrm{H}$ transport calculations conducted for model calibration purposes.
} 
transpiration behavior in the saltcedar and cattail vegetation surrounding the ditch. Based upon these observations, it had been suggested that infiltrated water $\left(\right.$ and $\left.{ }^{3} \mathrm{H}\right)$ could reach the water table in approximately 9 y (Bryant, 1992). Despite the ditch water losses into the subsurface, a sizeable amount did reach the Frenchman Lake playa proper (Figure 1.1), where it was allowed to infiltrate further or evaporate. On the playa itself, the ditch discharge was confined to a relatively small area bounded by a semicircular retaining wall. Specific infiltration rates of water in the playa were not measured.

Between 1991 and 1993, regular tests of groundwater in monitoring well UE-5n, $529 \mathrm{~m}$ away from the pumping well and $106 \mathrm{~m}$ perpendicular to the ditch, began to show rising levels of ${ }^{3} \mathrm{H}$ at the water table, as shown in Figure 1.3, apparently confirming that infiltrated radionuclides had reached groundwater after transiting the roughly $220 \mathrm{~m}$ of unsaturated alluvium (Davisson et al., 1994). These data suggested a 13- to $15-\mathrm{y}$ transit time for ${ }^{3} \mathrm{H}$ to first move vertically from the ditch to the water table and then horizontally to the monitoring well. These measurements were initially made on bailed samples taken from the well and continued regularly using pumped samples through 2002 (Rose et al., 2002). Notably, there were no observations of ${ }^{14} \mathrm{C}$ or ${ }^{85} \mathrm{Kr}$ in UE-5n, suggesting their preferential retention or volatilization during transit to the water table.

A recent modeling and ${ }^{3} \mathrm{H}$ age-dating study (Tompson et al., 2006) showed that 3 to $5 \mathrm{y}$ of this transit time occurred solely in the vadose zone. It also suggested that over the course of the RNM experiment, a portion of the pumping well effluent, once discharged and infiltrated, reached the saturated zone to be eventually recaptured by pumping well RNM-2S. Unpublished isotope data collected from RNM-1 at the same time also suggest that some of the recirculation pathways in this cycle reentered the CAMBRIC cavity before recapture.

\subsubsection{ER-5-4 Wells and the RNM-2S Multiple Well Aquifer Test}

Following the Phase I Frenchman Flat CAU flow and transport modeling effort, which included the previous source term work at CAMBRIC (Tompson et al., 1999), the UGTA Project installed wells ER-5-4 and ER-5-4\#2 in Frenchman Flat, near CAMBRIC (Figure 1.2). The purpose of these wells was to gather more hydraulic, chemical, and geologic information about the alluvium and deeper hydrostratigraphic units underlying it in the vicinity of tests in central Frenchman Flat, including CAMBRIC (IT Corporation, 2001, 2003).

Much of the information collected from these wells and their subsequent testing and development phases was used to update the conceptual and parametric models used in this report. The work of Warren et al. (2002) and Carle et al. (2002) served to provide a better definition of the alluvial layering and distribution of reactive minerals in Frenchman Flat. The work of Stoller-Navarro (2004a) and USGS (2004) interpret the RNM-2S Multiple Well Aquifer Test (MWAT) conducted in 2003. Here, the original pumping well used in the RNM experiment (RNM-2S) was pumped for several weeks in order to observe drawdown and recovery behavior in ER-5-4, ER-5-4\#2, UE-5n, RNM-1, and RNM-2 (not shown in Figure 1.2). The RMS-2S 
MWAT provided a basis to measure larger-scale aquifer parameters and improve and calibrate the models upon which the work in this report is based.

It is notable that analyses of drilling effluent from the construction of well ER-5-4 revealed a consistent ${ }^{3} \mathrm{H}$ signature $(\sim 5,000 \mathrm{pCi} / \mathrm{L})$ in the saturated zone between depths of 290 to $310 \mathrm{~m}$. These depths are similar to the CAMBRIC detonation point depth. Although these data have been considered "anomalous" (IT Corporation, 2001), and no similar measurement was detected in the construction of nearby well ER-5-4\#2 (IT Corporation, 2003), the location and consistency of the signal will be considered in evaluating our results.

\section{$1.4 \quad$ Modeling Approach in the Current Work}

The remaining content of this report will be organized around four principal topics.

\subsubsection{Revised Conceptual Models}

In Chapters 2 and 3, the natural and altered physical setting of the formation in which CAMBRIC was conducted is reviewed to define an appropriate hydrogeologic and geochemical conceptual model for the source term simulations.

Chapter 2 includes a general description of Frenchman Flat geology, an updated intermediate-scale hydrostratigraphic framework model, and a revised local-scale model of alluvial layering. Descriptions of nearby boreholes, an assessment of the magnitude and variability of physical properties and mineralogic composition, groundwater composition, and inferred local hydraulic gradients are provided.

Chapter 3 reviews nuclear explosion phenomenology as well as an updated model of the geometry and nature of the cavity, chimney, compressed and melt glass zones near the working point. A discussion of test-related heat is also provided, as well as a review of the existing and revised information on the inventory used to specify the radionuclides of interest for the model and their initial distribution.

\subsubsection{Calibration and Assessment Models}

Chapter 4 focuses on a number of calibration and assessment models developed to refine the conceptual models used in the source term simulations and assess the nature and importance of processes potentially relevant to the evolution of the HST. For clarity, this effort will be described in terms of a four-step approach.

In step 1 of this effort, an isothermal groundwater flow model is developed and calibrated to the MWAT to refine the definition and parametric specification of important hydrofacies and altered zones in the system and to compare with previous MWAT interpretations. This hydrogeologic model assumes there is no lasting hydrothermal flow behavior related to the test at the time of the MWAT or any residual transient flow effects associated with the RNM experiment. 
In step 2, the calibrated hydrogeologic model developed in step 1 is used to build a hydrothermal groundwater flow model to assess the importance and longevity of test-related heat on buoyancy-driven groundwater flow. This model is also used to identify reasonable cooling rates for use in the melt glass dissolution model in the HST simulations. The approach is based upon previous studies (e.g., Pawloski et al., 2001 and Carle et al., 2003) and is supplemented with pertinent site-related temperature data. This model is conducted over a time period starting at zero time ( $\mathrm{t}_{0}$, or 1965) and ending before the initiation of pumping associated with the RNM experiment $\left(\mathrm{t}_{0}+10 \mathrm{y}\right.$, or 1975).

In step 3, the hydrothermal groundwater flow model is subjected to the transient pumping associated with the RNM experiment (starting at $\mathrm{t}_{0}+10 \mathrm{y}$, or 1975), and augmented with a groundwater transport model. The goal is to assess how well the combined model matches the ${ }^{3} \mathrm{H}$ elution curve measured in the RNM experiment (Figure 1.3). No ditch infiltration effects are included in this model.

In step 4, groundwater flow results from step 3 are used to develop a streamline reactive transport model (e.g., Pawloski et al., 2001 and Maxwell et al., 2003). It assesses the importance of nonlinear geochemical reaction effects between the cavity and the pumping well over a time period ranging from zero time $\left(\mathrm{t}_{0}\right.$, or 1965), to the initiation of RNM pumping $\left(\mathrm{t}_{0}+\right.$ $10 \mathrm{y}$, or 1975), and through the $16 \mathrm{y}$ of RNM pumping $\left(\mathrm{t}_{0}+10 \mathrm{y}+16 \mathrm{y}\right.$ or 1991). As in earlier HST studies, the results of this model are used, among other things, to assess the viability of using simplified retardation models. As before, no ditch infiltration effects are included in this model.

\subsubsection{Hydrologic Source Term Models}

Chapter 5 is devoted to the HST model development and application over a 1,000-y time frame, based upon the results of the calibration and assessment work developed in Chapter 4. This work includes transient groundwater flow and ditch infiltration effects associated with the RNM experiment and is simplified further from the hydrothermal flow results obtained in Chapter 4. This model also includes the effects of physical and chemical heterogeneity. A total of 36 radionuclides distributed in 13 unique classes are considered in the associated retardationbased transport model. Model analyses provide insights into radionuclide migration over several key time periods:

- The ten years following the test zero time $\left(\mathrm{t}_{0}+10 \mathrm{y}\right)$

- Over the course of the RNM pumping experiment $\left(\mathrm{t}_{0}+10 \mathrm{y}+16 \mathrm{y}\right)$

- In the immediate time frame following the cessation of pumping (e.g., $\mathrm{t}_{0}+10 \mathrm{y}+$ $16 \mathrm{y}+25 \mathrm{y})$

- Over the longer time frame following the cessation of pumping to $1,000 \mathrm{y}$. 
Specific source term behavior associated with ditch infiltration is provided as are insights into recirculation behavior suggested earlier by Tompson et al. (2006) and radionuclide observations in well UE-5n.

\subsubsection{Considerations for Applying HST Results in the CAU Model}

Chapter 6 describes considerations for using HST simulations, in general, to develop simplified source term models for use in CAU-scale transport studies. The coarse grid resolution of the CAU model is unable to reproduce all of the processes included in HST modeling. Distillation of HST model information into a form amenable for the CAU model is required.

Additional considerations for applying the transient HST at CAMBRIC or how the steady state HST results may be applied for the nine other tests in Frenchman Flat is also discussed. 


\section{$2 \quad$ Natural Physical and Chemical Setting}

\subsection{Hydrogeologic Setting of Frenchman Flat}

\subsubsection{Geology of Frenchman Flat}

Frenchman Flat is located in the southeast corner of NTS (Figure 2.1). It is an intermountain basin formed by Tertiary-age faulting typical of the Basin and Range physiographic province. Rocks exposed in the highlands around the margins of Frenchman Flat are composed of Paleozoic sedimentary rocks to the south and east and Cenozoic volcanic and tuffaceous sedimentary rock to the north and west. Paleozoic rocks, which dip generally south and east, form the basement of the basin. At the deepest portion of the basin, up to $1,300 \mathrm{~m}$ of south- and southeastdipping volcanic rock and north-dipping tuffaceous sediments overlie the Paleozoic basement, while 1,500 m of Miocene to Quaternary alluvium overlie these.

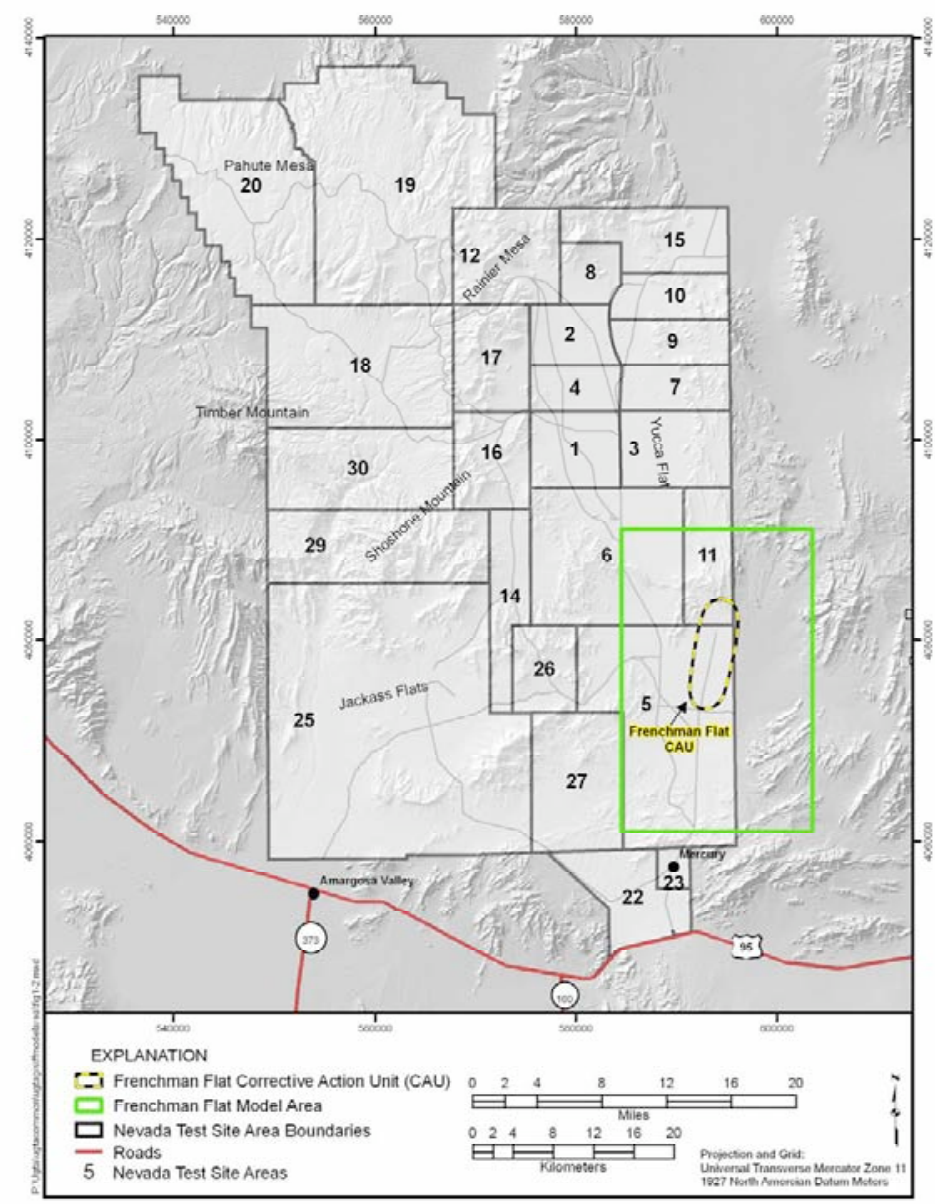

Figure 2.1 Schematic map of the Nevada Test Site showing Frenchman Flat. 
The basin was formed by the northeast termination of the Rock Valley fault zone within an extensional imbricate fan (Figure 2.2). Formation of the fan structure has resulted in a series of oblique-slip faults that flare out to the north and northwest from the Rock Valley fault zone (Bechtel Nevada, 2005b). The faults drop the basin down to the south, east, and north, forming an east-southeast-tilted, half-graben-type basin beneath the central portion of Frenchman Flat, and a structural platform beneath the northern portion.

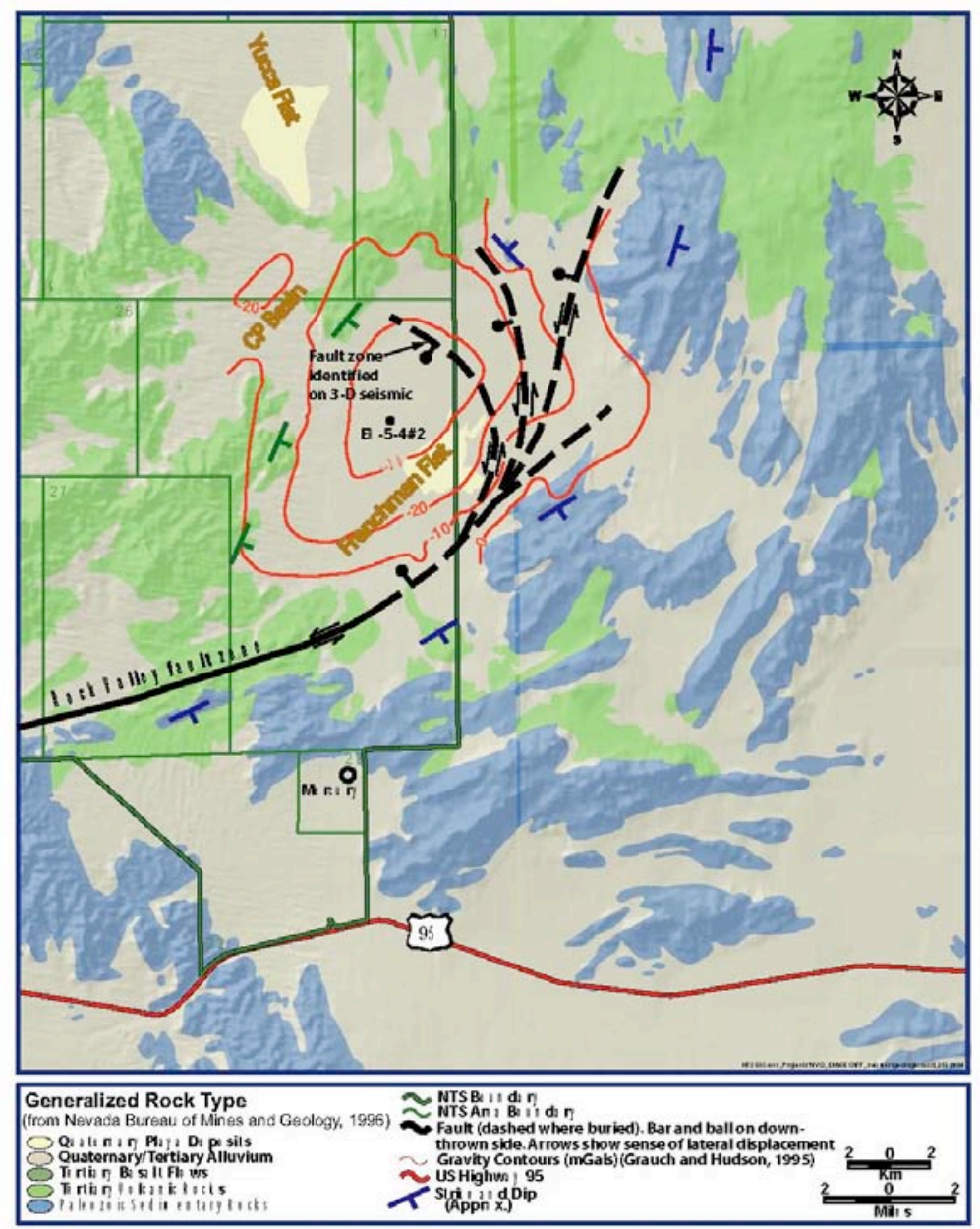

Figure 2.2 Conceptual structural model of Frenchman Flat basin (Bechtel Nevada, 2005b, Figure 3.2).

The uplifted source rock formations (Rock Valley, Massachusetts Mountain, Buried Hills, and Ranger Mountains) enable distinction of provenance within alluvial deposits in Frenchman Flat. The alluvial fan depositional patterns have varied over time with the relative rates of uplift, basin subsidence, and climate. Figure 2.3, from Warren et al. (2002), shows schematically how differences in alluvial depositional patterns over time would lead to variation in alluvial texture and mineralogy in the vertical sequence near CAMBRIC. The yellow areas indicate alluvial fans of distinct provenance, while the stippled areas represent co-mingling of different alluvial fans. 

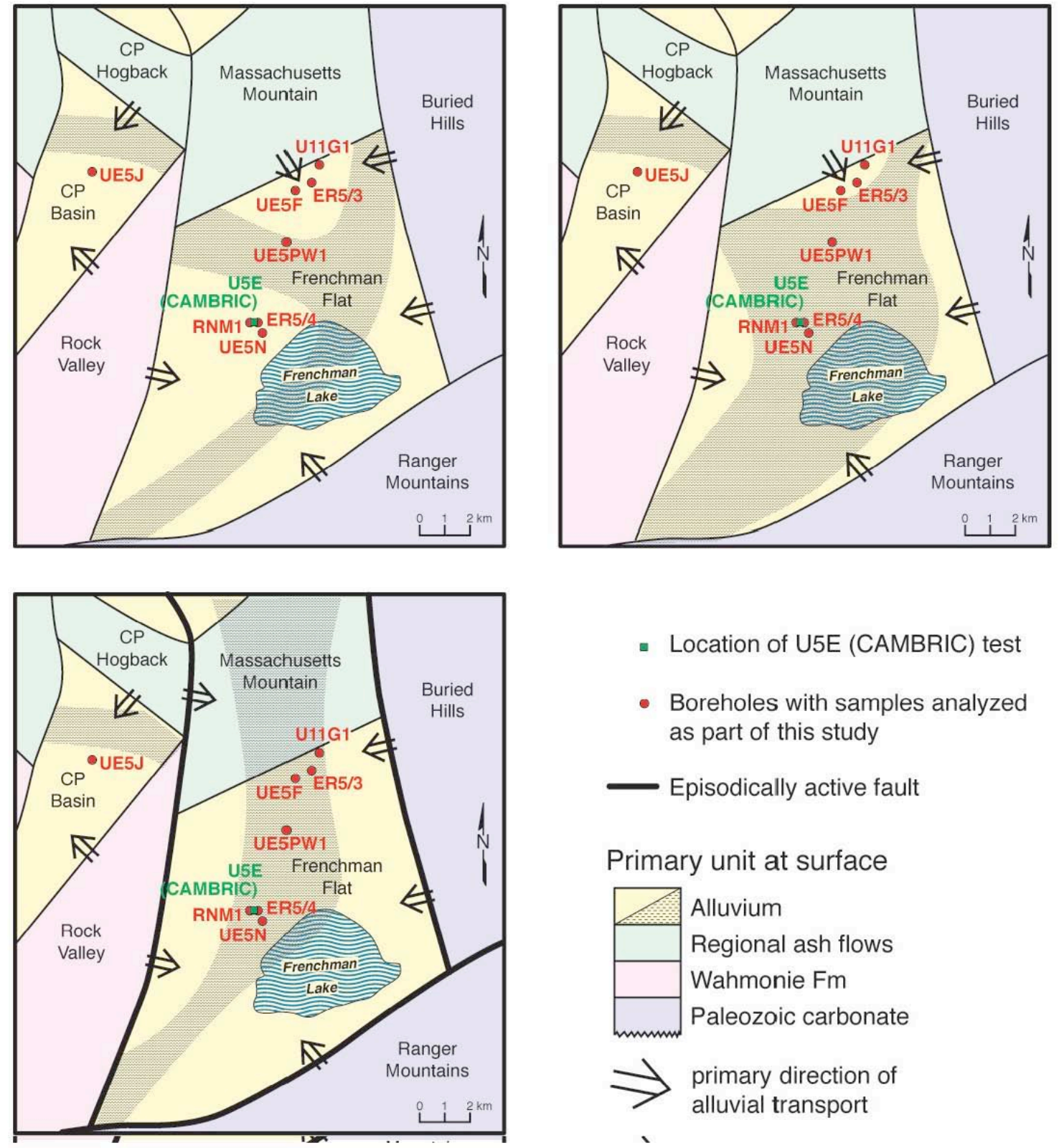

- Location of U5E (CAMBRIC) test

- Boreholes with samples analyzed as part of this study

Episodically active fault

Primary unit at surface

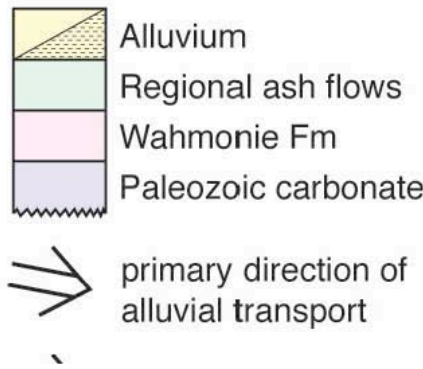

Figure 2.3 Schematic representation of alluvial deposition in Frenchman Flat within surrounding structural blocks. Yellow areas represent alluvial fans of distinct provenance, while stippled areas represent interfingering of alluvial fans. Upper left shows equal deposition originating from all structural blocks. Upper right illustrates deposition in the last 7.3 million years. Lower left shows alluvial fan development during episodic preferential fault activity (modified from Warren et al., 2002). 


\subsubsection{Conceptual Groundwater Flow Model}

Frenchman Flat is part of the Ash Meadows groundwater subbasin. The conceptual model of groundwater flow through Frenchman Flat is that the bulk of the flow occurs in the lower carbonate aquifer, and that the lower carbonate aquifer is the only subsurface pathway by which groundwater enters and exits Frenchman Flat beneath the volcanic and alluvial material (Laczniak et al., 1996). A minor amount of water may leak from the alluvial aquifer through the volcanic confining units, which overly the lower carbonate aquifer over much of Frenchman Flat. Thus, flow in the alluvial system, in which underground nuclear testing was conducted, is semi-independent from the regional carbonate flow system.Hydrostratigraphic Framework Model

\subsubsection{Hydrostratigraphic Framework Model}

A hydrostratigraphic framework model (HFM) has been developed to support Phase II groundwater flow and transport models in the Frenchman Flat CAU (Bechtel Nevada, 2005b). The model incorporates the 3D character and extent of hydrologically distinct stratigraphic units within the underlying basin as a means for mathematically defining the spatial distribution of parameters for flow and transport models. The base case model represents the most comprehensive structural interpretation. It is based on previous interpretations that have been augmented with newly acquired data. Several alternative models were also developed to encompass the geologic complexity in the system and the non-unique interpretations in the base model. All of the models discussed in this report are consistent with the base case HFM model.

Two cross sections through the base case HFM in the vicinity of the Cambric working point are shown in Figure 2.4. The Cambric test location is shown in the alluvium aquifer (AA) hydrostratigraphic unit. Close to Cambric are the playa confining unit (PCU1L), welded and vitric tuff units (TMWTA, TMVTA), tuff confining unit (LTCU), and, further away, the volcaniclastic unit (VCU) and the lower carbonate aquifer (LCA) unit. The PCU1U confining unit within the AA appears to conform to the synclinal dip of the Frenchman Flat basin, suggesting eastward downward tilt along the west-east cross section and nearly horizontal structure along the NNE-SSW cross section. 

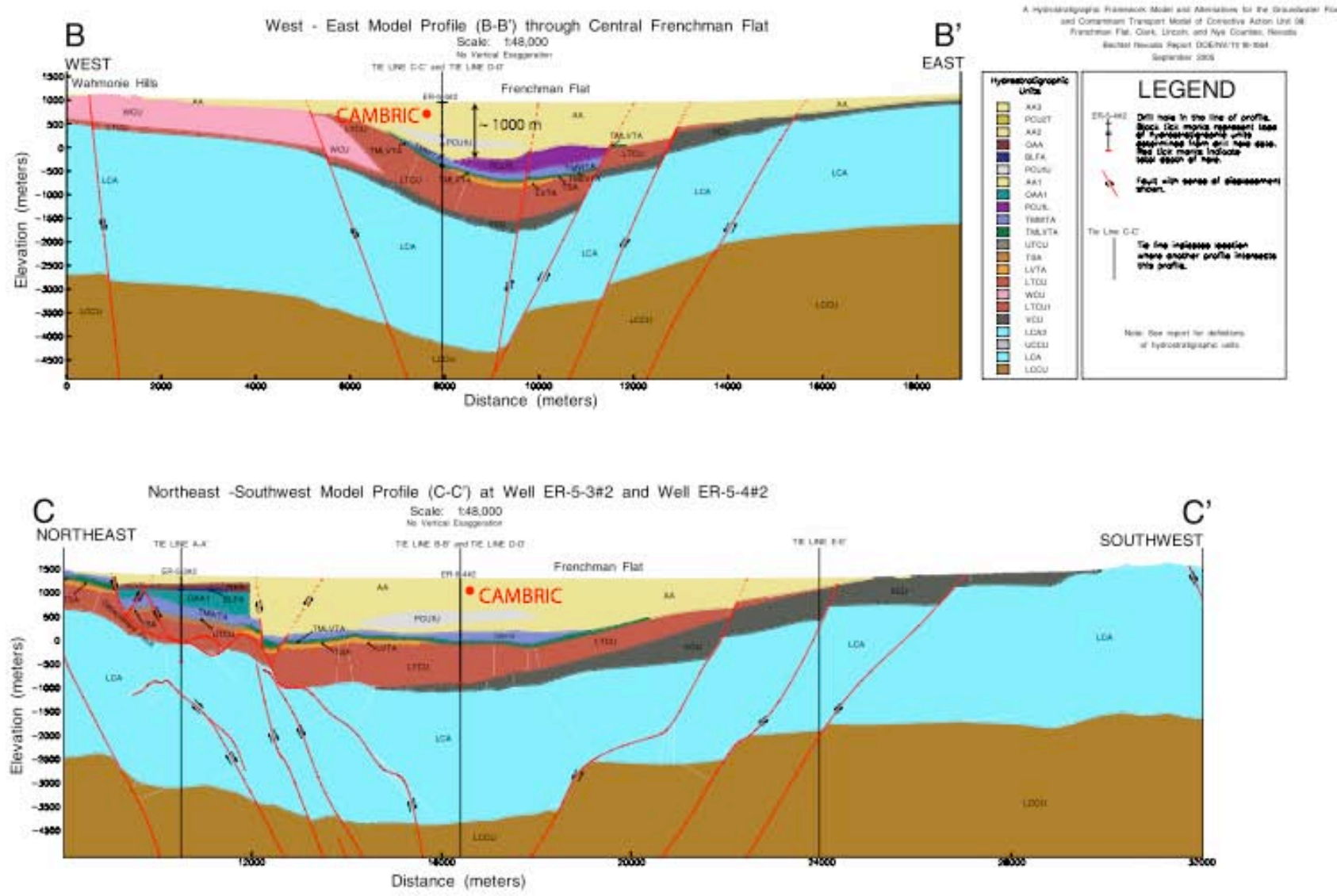

Figure 2.4 Cross sections through Frenchman Flat base case HFM, modified from Bechtel Nevada (2005b). The W-E section is aligned approximately with line D-D' in Figure 1.1. 


\subsection{The Near-Field Environment at CAMBric}

\subsubsection{Nearby Boreholes and Wells}

Existing boreholes and wells in the immediate vicinity of the CAMBRIC test include the emplacement hole U-5e, slanted reentry hole RNM-1, pumping wells RNM-2 and RNM-2S, and monitoring well UE-5n, all shown in Figure 2.5 (and in Figures 1.1 and 1.2). U-5e was drilled to a depth of $305 \mathrm{~m}$ in alluvium, just below the working point depth (294 m). RNM-1 was originally drilled as a post-test reentry hole and was recompleted in 1975 to a vertical depth of $370 \mathrm{~m}$ in support of the RNM pumping experiment (see Section 1.3.2). RNM-1 has several perforated intervals for sampling in the vicinity of the cavity (Figure 3.5). Pumping wells RNM-2 and RNM-2S were also drilled as part of the RNM experiment. RNM-2S is $91 \mathrm{~m}$ south of U-5e and was drilled to a depth of $341 \mathrm{~m}$ in alluvium. It has a slotted interval from $316-341 \mathrm{~m}$, below the CAMBRIC working point. RNM-2, located approximately $90 \mathrm{~m}$ southeast of U-5e, was drilled to a depth of $285 \mathrm{~m}$, perforated from $219-250 \mathrm{~m}$, but sloughed to $250 \mathrm{~m}$, limiting its use. It has been used on occasion for water level measurements. UE-5n, located about $560 \mathrm{~m}$ south of U-5e, was drilled to a depth of $514 \mathrm{~m}$ in alluvium. It has a 3-m perforated interval just below the water table, located at a depth of $214 \mathrm{~m}$ (Ramspott and McArthur, 1977).

In 2001, the UGTA program drilled ER-5-4 and ER-5-4 \#2 in south-central Frenchman Flat near CAMBRIC, for additional geologic and hydrologic characterization as part of the Phase II data acquisition activities for Frenchman Flat. ER-5-4 is approximately $340 \mathrm{~m}$ northeast of U-5e. ER-5-4 was drilled to a depth of $1,137 \mathrm{~m}$ and has two slotted intervals, from 539-644 $\mathrm{m}$ and 955-1,021 $\mathrm{m}$ depth. The upper interval is in alluvium and the lower interval is in $200 \mathrm{~m}$ of the AA and $19 \mathrm{~m}$ of the Timber Mountain Welded Tuff Aquifer (TM-WTA). A piezometer, installed in the casing annulus from 220-248 m depth, is also in alluvium. ER-5-4 \#2 is roughly $30 \mathrm{~m}$ south of ER-5-4 and was drilled to a depth of $2,134 \mathrm{~m}$, penetrating the entire section of alluvium and reaching the LTCU. ER-5-4 \#2 has one 50-m slotted section from 1,977-2,029 m depth in the TCU. These two wells were used in the MWAT conducted in 2003 (see Section 1.3.5). 


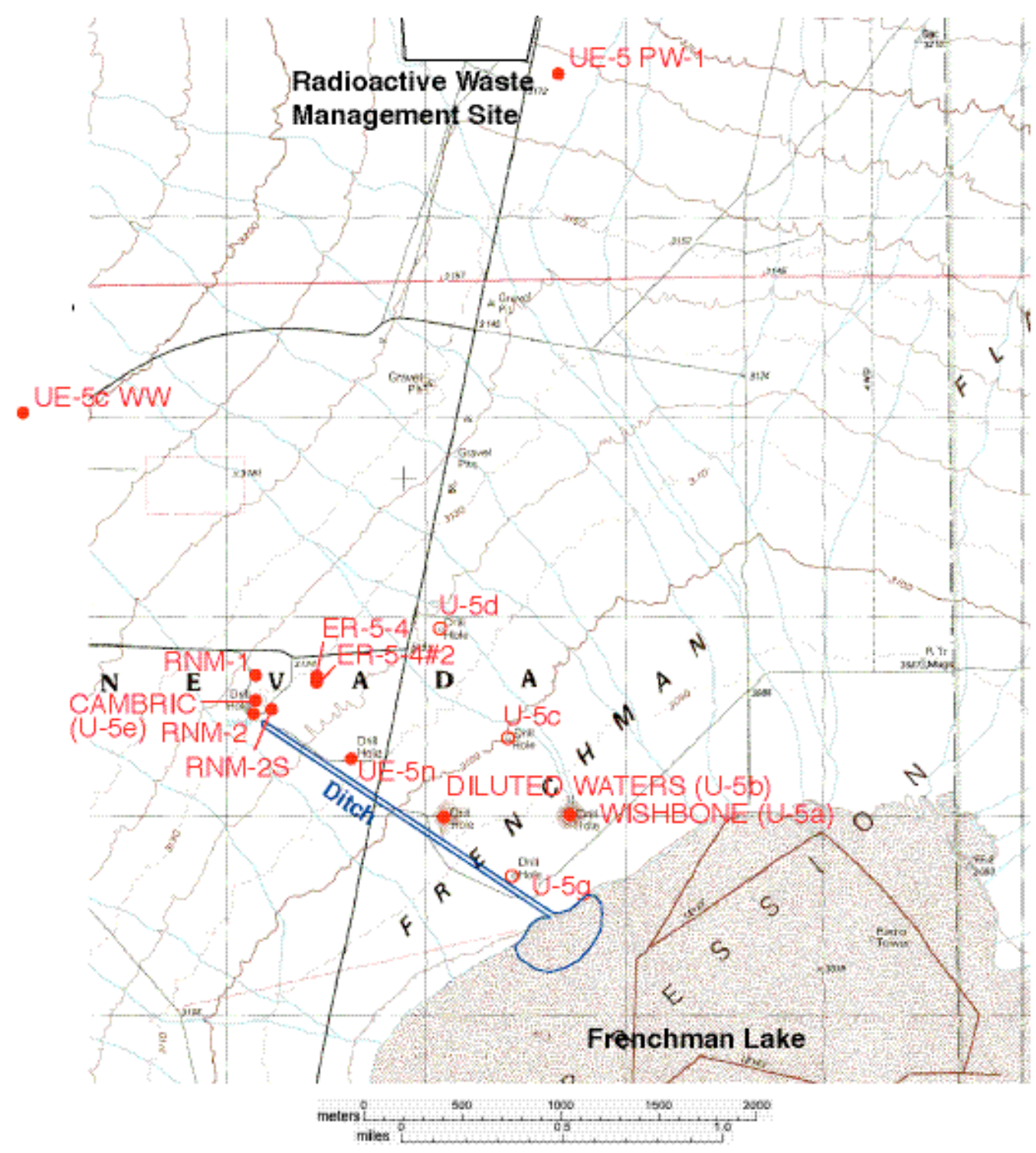

- WW-5B

Figure 2.5 Close-in map of the Frenchman Flat area showing locations of CAMBRIC (U-5e), DILUTED WATERS (U-5a) and WISHBONE (U-5b) tests, the CAMBRIC ditch and playa discharge area, and nearby boreholes and monitoring wells. Other nearby wells and boreholes, slightly beyond the boundaries of the map, include WW-5A, WW-5C, UE-5 PW-2, and UE-5 PW-3.

Other boreholes in the vicinity of the CAMBRIC test include the emplacement holes for the WiSHBONE (U-5a) and DiLUTED WATERS (U-5b) tests, completed to depths of 191 and $206 \mathrm{~m}$ in alluvium, respectively, and water wells WW-5a, WW-5b, WW-5c, and UE-5c WW (all in alluvium). Nearby drill holes U-5c, U-5d, and U-5g are relatively shallow holes drilled in alluvium. The vadose zone science boreholes UE-5 PW1, UE-5 PW2, and UE-5 PW3 are situated near the Radioactive Waste Management Site, 
approximately $3.5 \mathrm{~km}$ north of CAMBRIC (Figure 2.5). These were all completed in alluvium and are deep enough to provide water level information. REECO (1994) and Istok, et al. (1994) provide detailed lithologic descriptions of the alluvium and its spatial variability in this area.

Wells WW-5a, WW-5b, WW-5c, and UE-5c WW are four of ten water wells in the Frenchman Flat area and vicinity that have been regularly producing water for NTS needs, some since as early as the 1950s. RNM-2S can be considered an eleventh pumping well in this series. Pumping data from ten water wells suggests that total annual groundwater extraction from the area was relatively low before the early 1960s and reached an approximate plateau between mid 1960 and 2000 (Stoller-Navarro, 2004b). The added pumping from RNM-2S roughly doubled the total area extraction rate during its period of operation between 1976 and 1991. Additional information on these and other nearby wells can be found in Stoller-Navarro (2004b).

\subsubsection{Hydraulic Gradients}

Hydraulic gradients in the vicinity of CAMBRIC are low (Stoller-Navarro, 2006b). Water levels in the surrounding wells have fluctuated historically, reflecting, in part, impacts of pumping from the water supply wells and RNM-2S in the Frenchman Flat area and vicinity and from other variations in aquifer recharge and discharge. Since the total extraction rate has been roughly constant between the mid 1960s and 2000 (with the exception of RNM-2S), the degree of water level variation over this period as a result of pumping in the ten wells has not been significant and supports the concept of a steady state CAU flow model. Table 2.1 shows target (measured) water levels and associated uncertainties (reflecting perceived transient fluctuations and measurement errors) used in the Phase II CAU flow model. The uncertainty in RNM-1 data is larger than that at other wells and is related to the difficulty in determining the vertical depth of this slant hole. Additional information is reported in Stoller-Navarro (2004b).

The water level information in ER-5-4 upper, RNM-2S, and UE-5n (shaded rows in Table 2.1) has been used to estimate an average horizontal gradient (0.0013) and flow direction at the CAMBRIC working point. These are shown in Figure 2.6 by an arrow attached to U-5e indicating an "observed" direction of flow that is slightly to the east of north. The length of the arrow (or distance from U-5e to the arrow's endpoint) is proportional to the magnitude of the gradient. 
Table 2.1. Summary of contemporary, steady-state water levels measured in wells near the CAMBRIC test (Nicole Denovio, personal communication, July 26, 2005). The shaded rows correspond to the near-field well triangle (see text).

\begin{tabular}{|c|c|c|}
\hline Well Name & $\begin{array}{c}\text { Contemporary steady-state } \\
\text { water-level elevation } \\
(\mathbf{m} \text { ams } \mathbf{)}\end{array}$ & $\begin{array}{c}\text { Total uncertainty } \\
\mathbf{( + / - , ~} \mathbf{m})\end{array}$ \\
\hline ER-5-4 upper & 733.38 & 0.43 \\
\hline ER-5-4 lower & 733.38 & 0.43 \\
\hline ER-5-4 (piezometer) & 733.53 & 0.43 \\
\hline ER 5-4 \#2 & \multicolumn{2}{|c|}{ Not reported } \\
\hline RNM-1 & 731.37 & 4.40 \\
\hline RNM-2 & 733.55 & 0.88 \\
\hline RNM-2S & 733.68 & 0.46 \\
\hline UE-5 PW-1 & 733.79 & 0.71 \\
\hline UE-5 PW-2 & 733.74 & 0.75 \\
\hline UE-5 PW-3 & 733.75 & 0.71 \\
\hline UE-5c WW & 734.56 & 0.62 \\
\hline UE-5n & 733.78 & 0.47 \\
\hline WW-5A & 730.62 & 1.14 \\
\hline WW-5B & 734.00 & 1.15 \\
\hline WW-5C & 730.60 & 1.29 \\
\hline
\end{tabular}




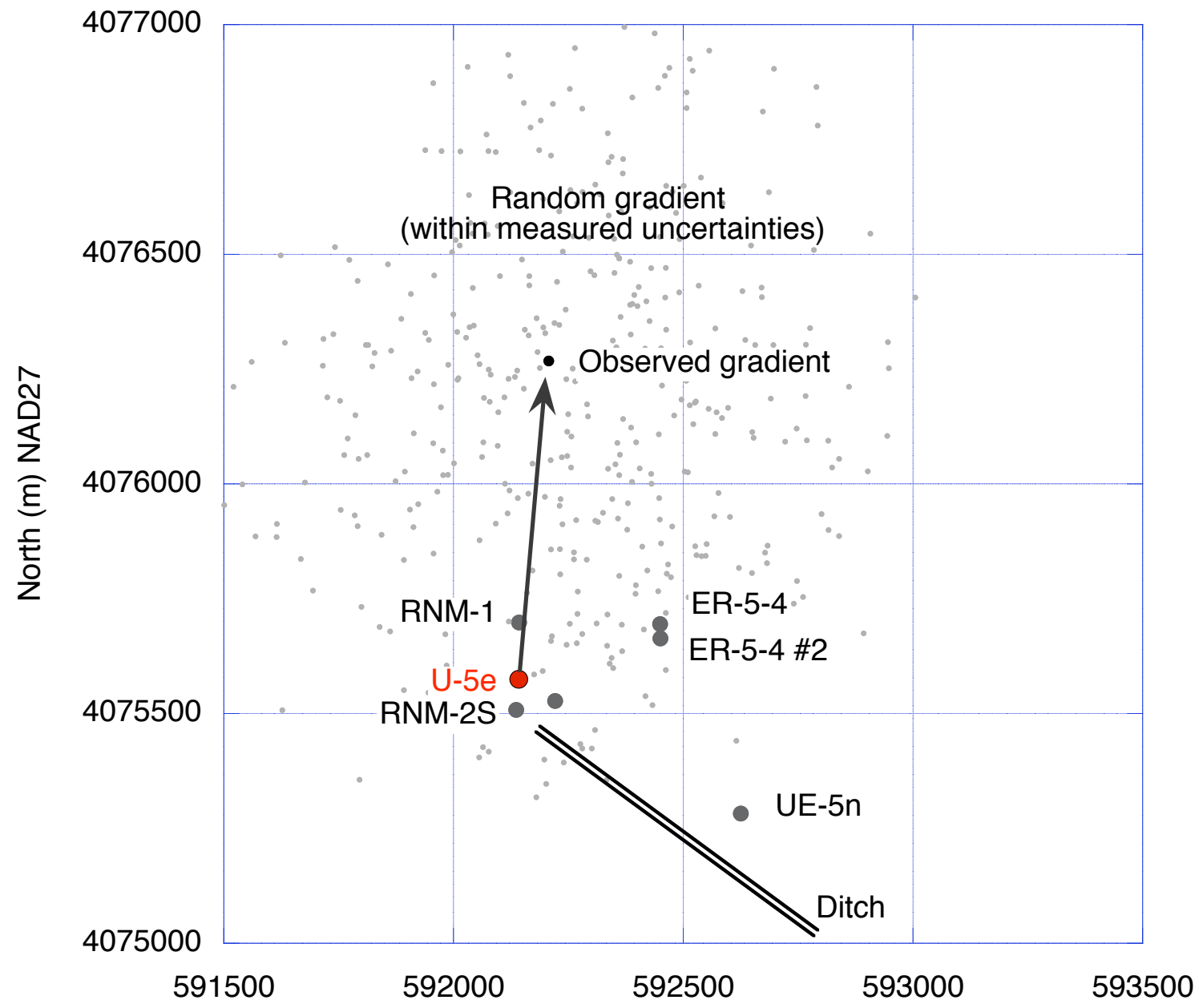

East (m) NAD27

Figure 2.6 Map of the CAMBRIC site shows the ditch and nearby wells. Flow directions away from U-5e, as based upon water levels in UE-5n, RNM-2S, and ER-5-4 upper, are shown as computed from the mean observations (black dot and arrow) and a series of 400 random head measurements sampled from within the measured uncertainties or ranges indicated in Table 2.1 (gray dots without arrows).

Figure 2.6 also shows a range of analogous water flow directions and magnitudes (gray dots without arrows) that reflect the uncertainty in the measured water levels in ER-5-4 upper, RNM-2S, and UE-5n. Each of the dots reflects a gradient determined from 400 random head measurements sampled at the three wells. The random water levels are based on the mean contemporary elevation in each well combined with a uniformly random deviation derived from the cited uncertainties or ranges indicated in the third column of Table 2.1. Overall, the cloud of dots that reflect uncertainty in the measured water level data generally indicates flow directions between NW and NE and gradient magnitudes ranging from 0 to 0.0025 . Note that it is possible to have flow in any direction given the cited uncertainties in the water level measurements. 


\subsubsection{Groundwater Composition}

The groundwater in the vicinity of CAMBRIC is a low ionic strength sodium bicarbonate water typical of volcanic and alluvial aquifers at NTS (Stoller-Navarro, 2004b). Table 2.2 lists groundwater chemistry data obtained from four wells close to CAMBRIC. The groundwater chemistry near CAMBRIC is expected to be more like the chemistry observed in RNM-1, RNM-2S, and UE-5n. The water chemistry observed in ER-5-4 is somewhat more alkaline than the other three, most likely due to its deeper completion within the alluvial aquifer in Frenchman Flat.

Table 2.2 also includes the water chemistry used in the Phase I HST model of Tompson et al. (1999). Importantly, the average water chemistry reported here for wells RNM-1, RNM-2S, and UE-5n does not differ significantly from that used in Phase I calculations. 
CHAPTER 2: NATURAL PHYSICAL AND CHEMICAL SETTING

Table 2.2. Groundwater composition in wells located near the CAMBRIC site.

\begin{tabular}{|c|c|c|c|c|c|c|c|c|c|c|c|c|c|}
\hline Well & $\mathrm{pH}$ & $\begin{array}{c}\text { Alkalinity } \\
\text { as } \mathrm{HCO}_{3}\end{array}$ & $\mathbf{C a}$ & $\mathrm{Cl}$ & $\mathrm{K}$ & Mg & $\mathrm{Na}$ & $\mathrm{SO}_{4}$ & $\mathbf{F}$ & $\mathrm{SiO}_{2}$ & $\mathrm{Sr}$ & Cs & $\mathbf{U}$ \\
\hline RNM-1 $^{1}$ & 8.20 & 171 & 15.0 & 17.0 & 7.9 & 4.50 & 61.0 & 33.0 & 0.60 & 72.0 & $2.38^{2}$ & $0.02^{2}$ & $3.7^{2}$ \\
\hline $\mathrm{RNM}^{-2 \mathrm{~S}^{1}}$ & 8.20 & 168 & 17.0 & 13.7 & 9.2 & 5.60 & 63.0 & 37.0 & 0.41 & 79.6 & $0.14^{2}$ & - & $4.5^{2}$ \\
\hline UE- $5 n^{1}$ & 8.70 & 162 & 8.6 & 12.9 & 8.0 & 2.00 & 76.0 & 32.0 & 0.70 & 58.6 & $0.05^{2}$ & $0.03^{2}$ & $3.1^{2}$ \\
\hline ER-5-4 ${ }^{1}$ & 8.71 & 288 & 2.0 & 26.0 & 12.0 & 0.05 & 180.0 & 120.0 & 6.60 & 79.2 & $0.04^{2}$ & $0.09^{2}$ & $12.2^{2}$ \\
\hline $\begin{array}{l}\text { Phase I } \\
\text { Cambric } \\
\text { model }^{3}\end{array}$ & 8.00 & 177 & 16.0 & 16.0 & 8.0 & 4.00 & 63.0 & 32.0 & - & 65.0 & & & \\
\hline $\begin{array}{l}\text { Avg RNM-1, } \\
\text { RNM-2S, } \\
\text { UE-5n } \\
\text { standard } \\
\text { deviation }\end{array}$ & $\begin{array}{l}8.37 \\
0.29\end{array}$ & 167.0 & 13.5 & $\begin{array}{l}14.5 \\
2.2\end{array}$ & 0.7 & 1.8 & $\begin{array}{l}66.7 \\
8.1\end{array}$ & $\begin{array}{r}34.0 \\
2.6\end{array}$ & $\begin{array}{l}0.57 \\
0.15\end{array}$ & $\begin{array}{r}70.1 \\
10.6\end{array}$ & $\begin{array}{l}0.09 \\
1.3\end{array}$ & $\begin{array}{l}0.03 \\
0.01\end{array}$ & $\begin{array}{l}3.8 \\
0.7\end{array}$ \\
\hline $\begin{array}{l}\text { Avg RNM-1, } \\
\text { RNM-2S, } \\
\text { UE-5n }\end{array}$ & & $2.74 \times 10^{-3}$ & $3.38 \times 10^{-4}$ & $4.10 \times 10^{-4}$ & $2.14 \times 10^{-4}$ & $1.66 \times 10^{-4}$ & $2.90 \times 10^{-3}$ & $3.54 \times 10^{-4}$ & $3.00 \times 10^{-5}$ & $1.17 \times 10^{-3}$ & $1.05 \times 10^{-6}$ & $1.88 \times 10^{-10}$ & $1.58 \times 10^{-8}$ \\
\hline
\end{tabular}




\subsubsection{Alluvium Composition and Structure}

Some of the earliest data on alluvium structure and composition in the vicinity of CAMBRIC were derived from the lithologic and gravity logs obtained from UE-5n and mineralogic analyses of core and sidewall samples obtained from UE-5n and RNM-1 (Ramspott and McArthur, 1977 and Daniels and Thompson, 1984). The alluvium is dominated by clasts of Tertiary tuff and rhyolitic lava. It consists of interbedded sands, gravels, silts, and clays composed of feldspar and lesser amounts of quartz, calcite, amphibole, clinoptilolite (a zeolite), smectite, kaolinite, montmorillonite, and goethite (an iron oxide). The lithology in UE-5n is generally similar over its depth, but has apparent variations in its layering and overall material composition. There is an ash-fall tuff at $195 \mathrm{~m}$ depth that potentially serves as a stratigraphic marker in the overall timeline of alluvium deposition. In addition, there is a clear lithologic change at $286 \mathrm{~m}$ depth in the saturated zone, below which the rock is more indurated and correlated with greater zeolite content and larger fractions of finegrained material (Figure 2.7).

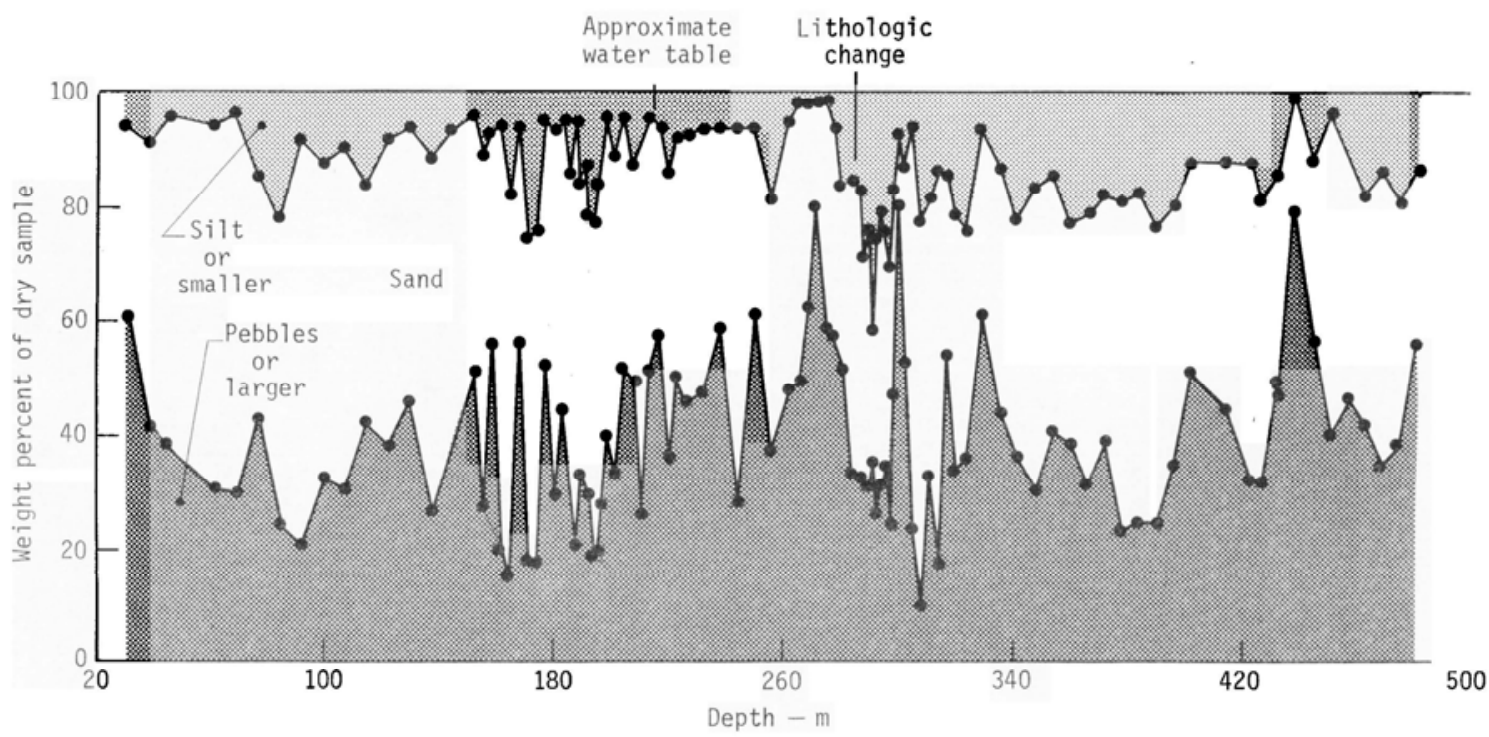

Figure 2.7 Variation of size fraction of alluvium with depth sampled from well UE-5n using sieve and hydrometer analyses (Ramspott and McArthur, 1977).

Figure 2.7 indicates a noticeable degree of spatial variability in the physical composition of the alluvium over depth, which is consistent with observations of layering in the lithologic $\log$ and mineralogic variability in the core samples taken from UE-5n. This kind of variability can give rise to variations in the hydrologic and chemical properties of the material, such as hydraulic conductivity, porosity, and chemical sorptive capacity. For example, Figure 2.8 shows the vertical distribution of hydraulic conductivity values obtained from several core and well-test analyses in RNM-1 and RNM-2S reported by Hoffman et al. (1977), Stone (1975), and Ramspott and McArthur (1977), as reinterpreted by Burbey and Wheatcraft (1986). 


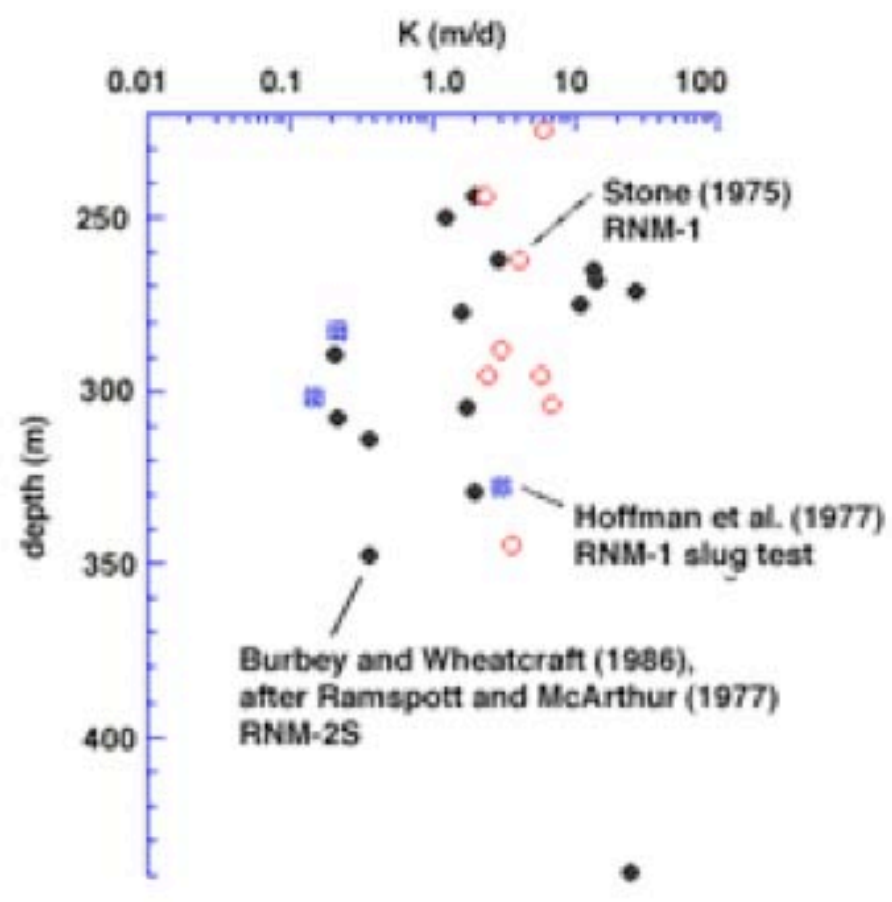

Figure 2.8 Vertical distribution of hydraulic conductivity beneath the water table, as measured from core and well-test analyses in RNM-1 and RNM-2S (from Hoffman et al.,1977; Stone, 1975; and Ramspott and McArthur, 1977; as reinterpreted by Burbey and Wheatcraft. 1986).

The lithologic, mineralogic, and hydrologic data obtained from RNM-1, RNM-2S, and UE-5n were used to develop the conceptual model of alluvium composition and structure in the earlier Phase I CAMBRIC HST simulations (Tompson et al., 1999). More recently, additional lithologic descriptions and associated mineralogic analyses have become available from ER-5-4 and ER-5-4 \#2 (Stoller-Navarro, 2004a, Bechtel, 2005a). Warren et al. (2002), Carle et al. (2002), and Zavarin et al. (2006a) examined the spatial variability of alluvium mineralogy in ER-5-4. Warren et al. (2002) combined lithologic and mineralogic data in ER-5-4 to improve the overall lithologic description of alluvial layering in the area (Figure 2.9). This synthesis was also based on correlations of alluvial layering developed between ER-5-4, UE-5n, and RNM-1 using mineralogic abundances.

Warren et al. (2002) distinguished twelve alluvium layers to define unique hydrologic and chemical zones in the current HST model described in Chapters 4 and 5. These layers have distinct textural properties, ranging in grain size from silty clay (unit A of Layer 9) to pebbly sandy conglomerate (Layer 2) and distinct mineralogic contents, as can be identified in Table 2.3 and Figure 2.10. 
CHAPTER 2: NATURAL PHYSICAL AND CHEMICAL SETTING

Table 2.3. Average mineralogy (weight percent) in the alluvial layers defined by Warren et al. (2002).

\begin{tabular}{|c|c|c|c|c|c|c|c|c|c|c|c|c|c|c|}
\hline Unit $^{1}$ & Feldspar & Glass & $\begin{array}{l}\text { Cristo- } \\
\text { balite }\end{array}$ & Opal & Quartz & Tidymite & $\begin{array}{l}\text { Horn- } \\
\text { blende }\end{array}$ & Calcite & Dolomite & Hematite & Kaolinite & Mica & Smectite & $\begin{array}{l}\text { Clinop- } \\
\text { tilolite }\end{array}$ \\
\hline 1 & 60 & - & - & 8.0 & 13.3 & - & 0.8 & 4.0 & 2.5 & 1.7 & & 5.5 & 5.5 & 2.5 \\
\hline 2 & 45.1 & 11.5 & 5.6 & 0.0 & 10.9 & 2.7 & 0.3 & 3.4 & 0.0 & 0.4 & 0.3 & 2.6 & 11.2 & 3.9 \\
\hline 3 & 46.3 & 0.0 & 2.3 & 4.2 & 8.2 & 0.7 & 0.9 & 0.9 & 0.0 & 0.4 & 0.0 & 4.6 & 10.5 & 21.6 \\
\hline 4 & 50.3 & 0.0 & 1.3 & 0.0 & 9.9 & 0.0 & 1.1 & 1.9 & 0.0 & 0.5 & 0.0 & 6.2 & 12.2 & 17.3 \\
\hline 5 & 42.1 & 15.6 & 1.3 & 0.0 & 8.0 & 0.0 & 0.9 & 2.6 & 0.0 & 0.5 & 0.2 & 6.7 & 10.5 & 12.2 \\
\hline 6 & 46.3 & 20.8 & 4.2 & 0.0 & 4.9 & 0.9 & 1.0 & 0.9 & 0.0 & 0.5 & 0.2 & 4.5 & 13.3 & 2.6 \\
\hline 7 & 41.8 & 20.1 & 4.8 & 0.0 & 4.9 & 1.2 & 0.7 & 3.4 & 0.1 & 0.6 & 0.3 & 4.3 & 13.8 & 2.6 \\
\hline 8 & 32.2 & 27.5 & 3.1 & 0.0 & 5.0 & 0.5 & 0.3 & 2.7 & 0.0 & 0.6 & 0.3 & 3.3 & 22.2 & 1.3 \\
\hline 9 & 17.4 & 11.2 & 0.9 & 0.0 & 12.8 & 0.0 & 0.2 & 14.1 & 5.7 & 0.2 & 0.3 & 2.9 & 30.3 & 3.4 \\
\hline 10 & 42.0 & 22.2 & 3.4 & 0.0 & 6.5 & 0.0 & 0.9 & 3.6 & 0.0 & 0.5 & 0.2 & 3.7 & 16.4 & 0.3 \\
\hline 11 & 48.4 & 3.6 & 4.8 & 7.2 & 4.0 & 0.0 & 1.2 & 3.4 & 0.0 & 0.5 & 0.0 & 4.1 & 11.1 & 11.0 \\
\hline 12 & 45.6 & 22.5 & 2.3 & 0.0 & 6.5 & 0.0 & 0.5 & 1.9 & 0.0 & 0.6 & 0.0 & 2.4 & 14.9 & 0.5 \\
\hline
\end{tabular}

${ }^{1}$ Layer 1 mineralogy from UE-5n (Ramspott and McArthur, 1977, and Beiriger, 1977). All other layer mineralogies are derived from data identified in ER-5-4 (Warren et al., 2002). 


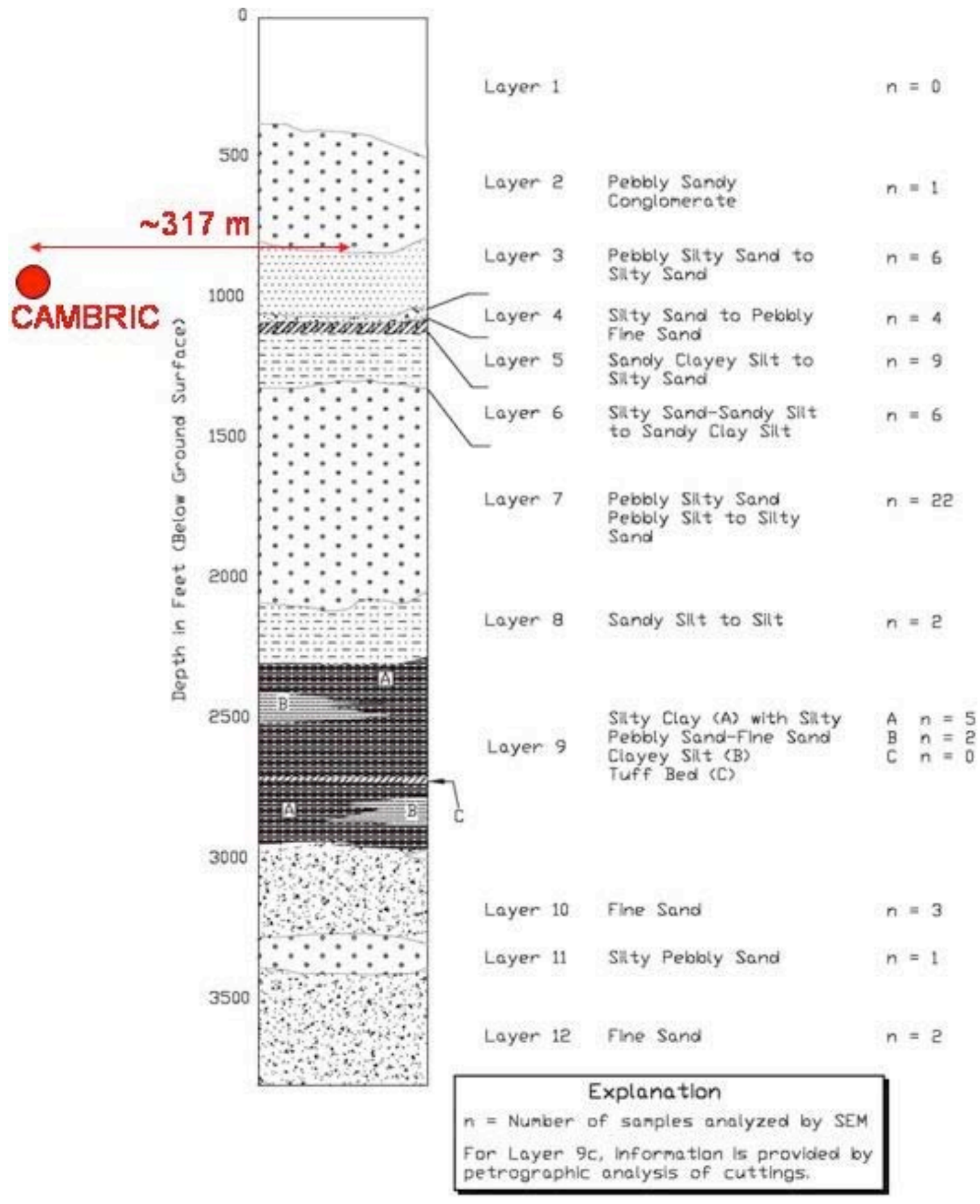

Figure 2.9 Alluvial layers distinguished at ER-5-4. Approximate relative position of CAMBRIC is superposed in red (modified from Figure 2, Warren et al., 2002).

The layers can serve as templates for defining intermediate-scale spatial variation in bulk hydraulic and chemical properties within Frenchman Flat alluvium. The mineralogic characteristics of a layer may be used to establish positive or negative correlations with hydraulic properties. For example, because clay or zeolite content will 
often correlate negatively with permeability, the mineralogic characteristics of each layer may be used to establish hydraulic properties. Because Layer 9 is rich in smectite and low in feldspar, this layer might be expected to have a relatively low permeability. This assumption is consistent with CAU-scale hydrostratigraphic models that identified the layer of Frenchman Flat alluvium as having significantly lower permeability. Similarly, because Layer 2 has the lowest concentration of combined smectite and clinoptilolite, it would be expected to have a higher permeability, as confirmed from calibrations with the MWAT (Chapter 4).

Based on data shown in Figures 2.7, 2.8, and 2.10, finer scale variability in the hydrologic and chemical characteristics in each of the layers may exist. These will be addressed further in Chapters 4 and 5. 
CHAPTER 2: NATURAL PHYSICAL AND CHEMICAL SETTING

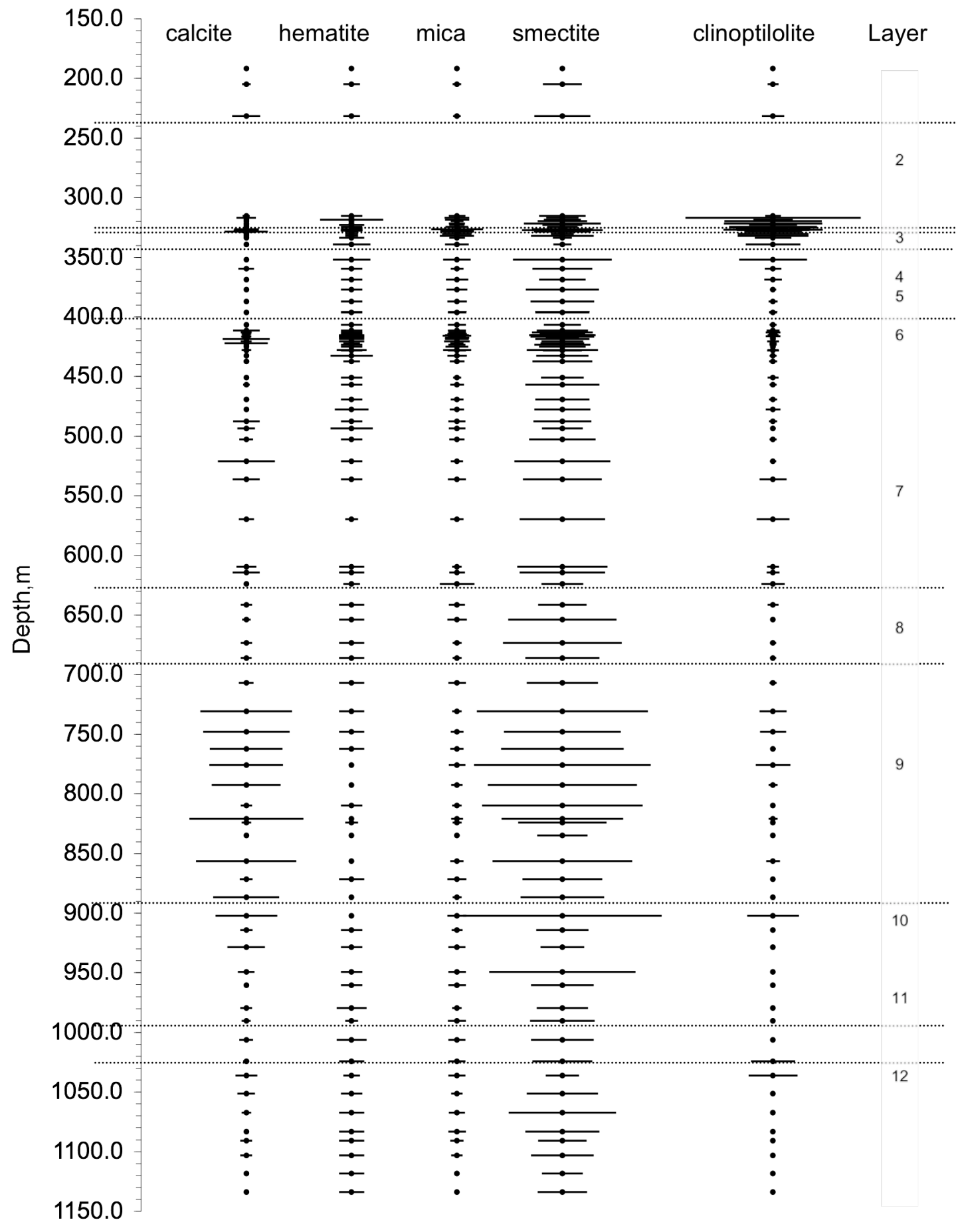

Figure 2.10 Schematic of mineral abundance as a function of depth in ER-5-4 for five radionuclide sorbing minerals. Layers are taken from Warren et al. (2002). 


\section{$3 \quad$ Altered Physical and Chemical Setting}

\subsection{Phenomenology}

The detonation of a nuclear device releases an immense amount of energy that vaporizes the device and rock surrounding the explosion point (Borg et al., 1976; Germain and Kahn, 1968; IAEA, 1998; and Office of Technology Assessment, 1989). High temperatures and a compressive shock wave generated by the explosion produce a cavity and fracture or alter the rock beyond the cavity, as shown in Figure 3.1. The cavity reaches maximum size about $500 \mathrm{~ms}$ after detonation. Its size is a function of the energy of the explosion, the depth of burial, and the strength of the geologic media. For tests conducted in the saturated zone, groundwater vaporizes in the immediate cavity region while groundwater mounding may occur further away (Borg et al., 1976; Burkhard and Rambo, 1991; and Knox et al., 1965).

In the seconds and minutes following detonation, temperatures cool, gas pressures dissipate, and components of the cavity gas begin to condense in an order determined by their relative vapor pressures. First among these components are the rock and heavier radionuclide elements that, along with molten rock lining the cavity walls, accumulate as a melt glass puddle at the bottom of the cavity. Within seconds to days after the test, the overlying rock collapses into the cavity, creating a chimney column of rubble that may extend to the ground surface where a collapse crater forms. Groundwater will begin to refill the cavity if the detonation point is below the water table. The high temperatures associated with a nuclear explosion can last many years (Carle et al., 2003).

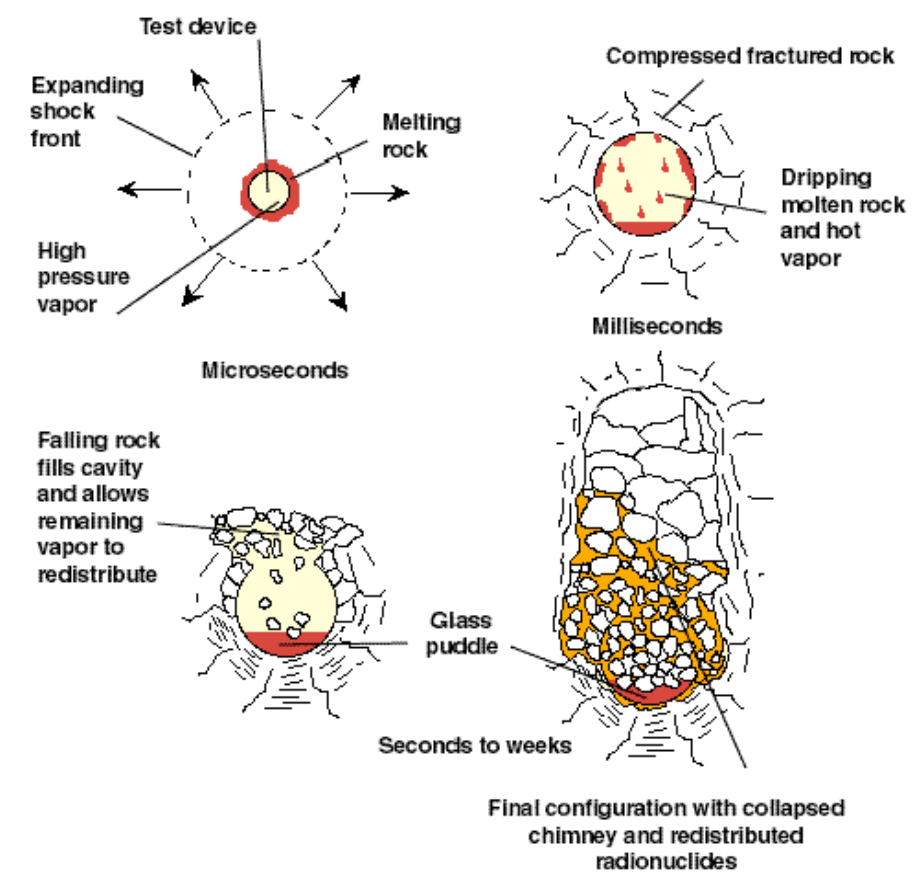

Figure 3.1 Phenomenology of an underground nuclear explosion showing expansion of the shock front, accretion of melt glass puddle, redistribution of more volatile radionuclides - initially as gases, later as condensates - and collapse of the chimney. 


\subsection{Cavity, Chimney, and Compressed Zones}

In 1965, the CAMBRIC cavity radius was measured using high-intensity gamma logs from drillback holes U-5e PS 1A, U-5e PS 1AS, and U-5e PS 1ASS. Radii of $43.16 \mathrm{ft}, 45.35 \mathrm{ft}$, and $43.22 \mathrm{ft}(13.2 \mathrm{~m}, 13.8 \mathrm{~m}$, and $13.2 \mathrm{~m})$, respectively, were measured. The average cavity radius based on the three drillback holes is $13.4 \mathrm{~m}$. In 1975, Hoffman et al. (1977) determined the CAMBRIC cavity radius to be $10.9 \mathrm{~m}$ from a high-intensity gamma log in RNM-1. A 3D plot of the four high-intensity gamma logs (Figure 3.2) illustrates the inconsistency between cavity radii determined from the RNM-1 data and the 1965 data. The inconsistency is most easily observed when plotting the high-intensity gamma data as a function of the radial distance from the working point (Figure 3.3). The three post-test high-intensity gamma logs from 1965 suggest that the cavity radius is between 13 and $14 \mathrm{~m}$. The RNM-1 high-intensity gamma log suggests that the cavity radius is between 10 and $11 \mathrm{~m}$. It is possible that the low gamma activity observed at the bottom of RNM-1 resulted from chimney rubble that mixed in with the puddle glass at the bottom of the cavity; it is also possible that the cavity deviates from an ideal spherical geometry.

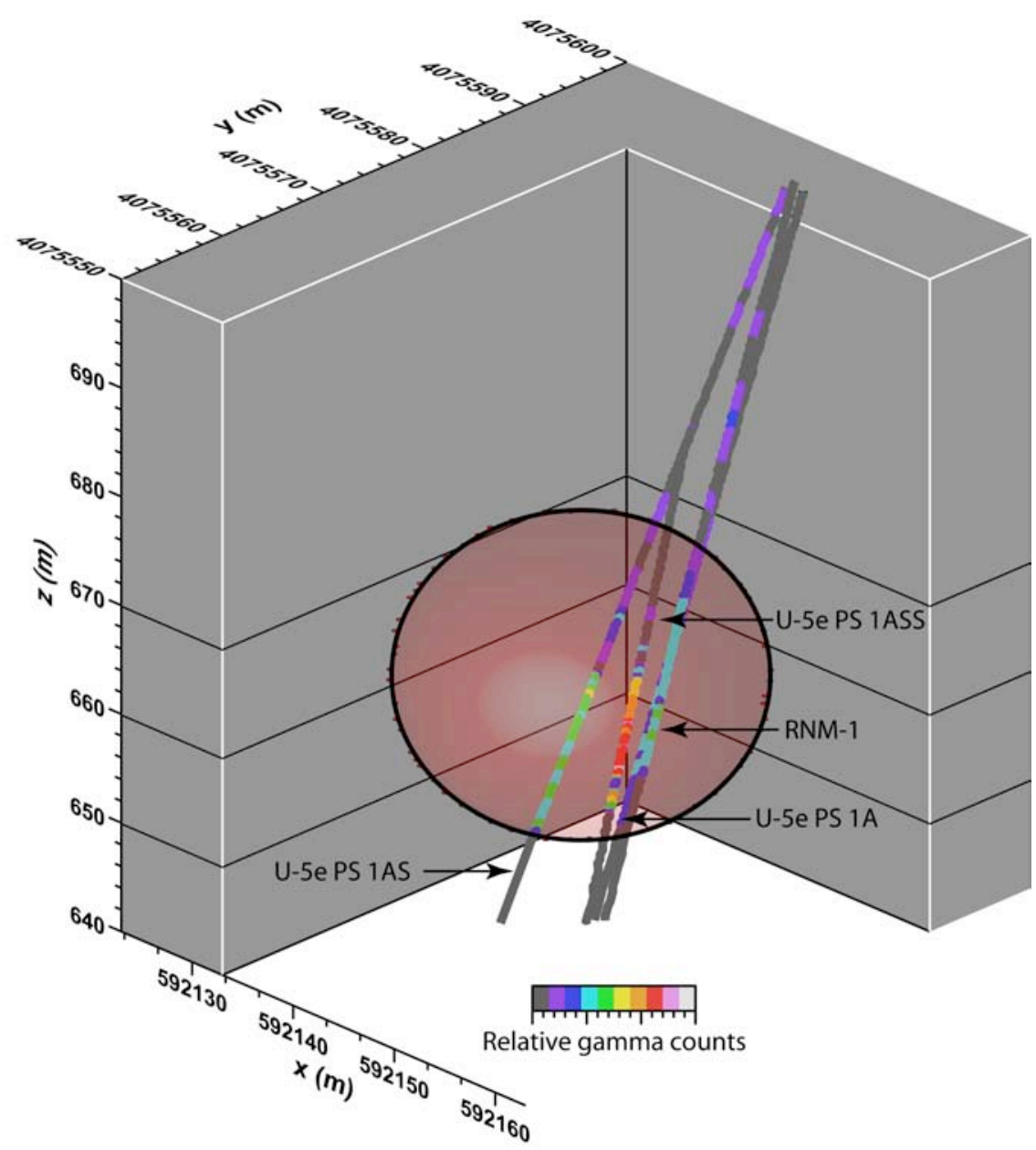

Figure 3.2 Relative gamma counts for four drillback holes (U-5e PS 1A, U-5e PS 1AS, U-5e PS 1ASS, and RNM-1) through the CAMBRIC cavity. The circle identifies a 13.4-m cavity radius. 


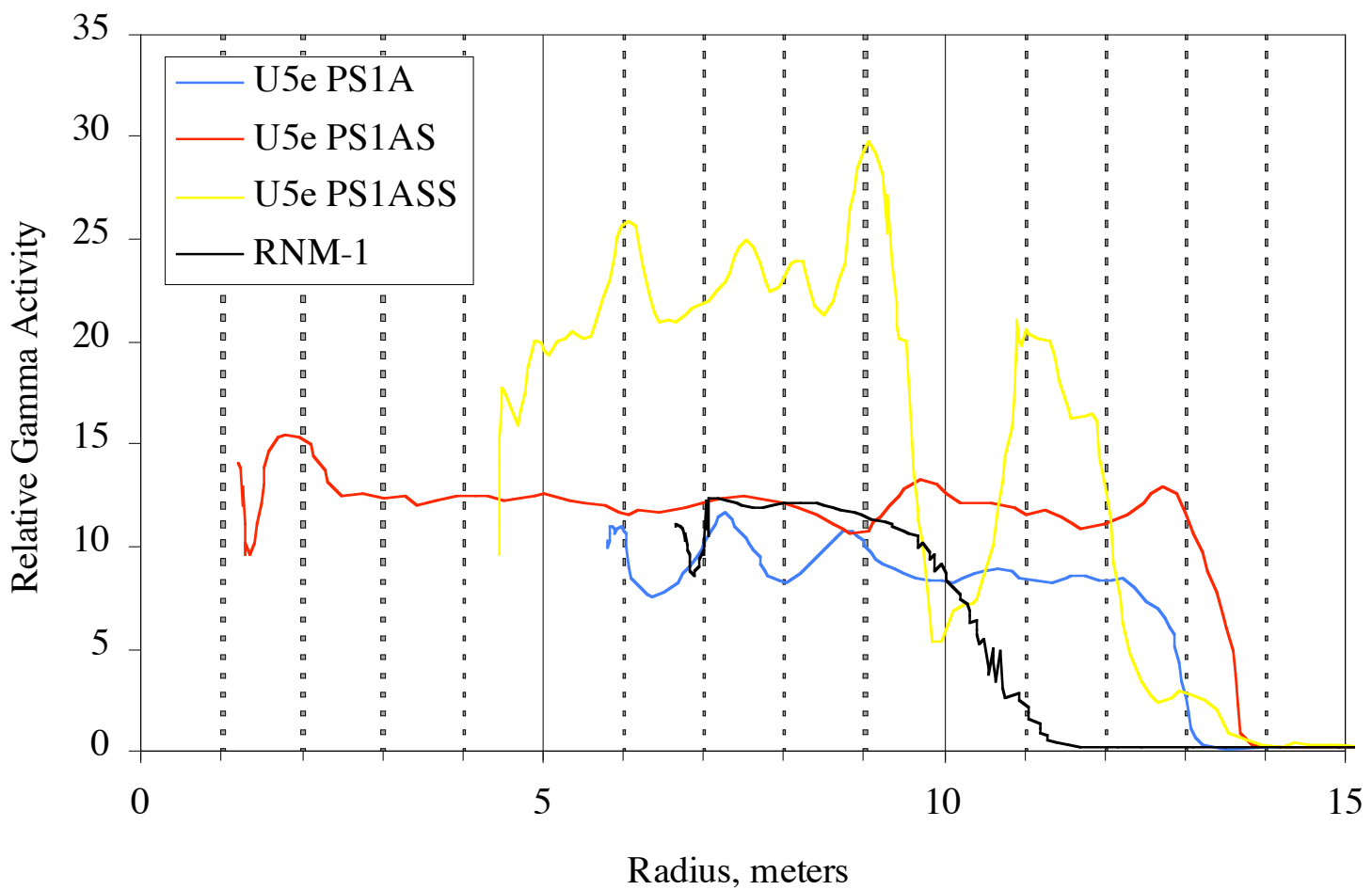

Figure 3.3 Relative gamma activity as a function of radial distance away from the working point.

(1999):

The cavity radius can be estimated using the empirical model reported in Pawloski

$$
\mathrm{R}_{\mathrm{c}}=70.2 \mathrm{y}^{1 / 3} /\left(\rho_{\mathrm{ob}} \times \mathrm{DOB}\right)^{1 / 4}
$$

where $y$ is the test yield $(\mathrm{kt}), \rho_{\mathrm{ob}}$ is the overburden density $\left(\mathrm{g} / \mathrm{cm}^{3}\right)$, and DOB is the depth of burial (m). With a depth of burial of $294.3 \mathrm{~m}$, an announced yield of $0.75 \mathrm{kt}$, and an overburden density ranging from 1.6 to $2.0 \mathrm{~g} / \mathrm{cm}^{3}$, the predicted cavity radius lies between 12.9 and $13.7 \mathrm{~m}$. These estimated values are in good agreement with the CAMBRIC cavity radius determined using the 1965 high-intensity gamma logs. Based on this analysis, the best estimate of the CAMBRIC cavity radius is $13.4 \mathrm{~m}$.

The chimney that formed above the CAMBRIC working point extended above the water table but did not reach the ground surface. The radius of the chimney is expected to be similar to the cavity radius $(13.4 \mathrm{~m})$, although it has not been measured at CAMBRIC. Hoffman et al. (1977) suggested that the chimney radius might be larger than the 10.9-m cavity radius estimated from the RNM-1 high-intensity gamma log. 
The compressed zoned surrounding the cavity is composed of alluvium. However, the size of the compressed zone is poorly constrained. In the CAMBRIC calculations of Tompson et al. (1999), an 18-m-radius "exchange volume" was identified. This volume was based on the Tritium Exchange Radius (TER) estimated by Hoffman et al. (1977) and Burbey and Wheatcraft (1986). The TER is defined as the radius of the spherical volume of alluvium needed to account for all ${ }^{3} \mathrm{H}$ inventory at a particular measured ${ }^{3} \mathrm{H}$ concentration (in this case, the ${ }^{3} \mathrm{H}$ concentration measured in RNM-1). In the CAMBRIC calculations of Tompson et al. (1999), the center of the exchange volume was shifted upward by $8 \mathrm{~m}$ from the cavity center. In addition, a low permeability "crush up" zone was included below the cavity (Tompson et al., 1999, Figure 36), which coincides with the models of Daniels (1982) and Guell and Hunt (2003). In reality, few data are available to test the validity of the representation of the zone immediately outside the cavity. Equating the compressed zone radius with the TER is a simplistic but not altogether unreasonable conceptual model. It may be the most appropriate description of the compressed zone given the few data available to constrain the conceptual model.

\subsection{Melt Glass Zone}

The melt glass zone at the bottom of the cavity is never composed of pure nuclear melt glass. Instead, it is a mixture of nuclear melt glass and infallen rubble. The fraction of rubble that mixes with melt glass is dependent primarily on the collapse time of the cavity. If the cavity collapses within minutes after a test, a large quantity of rubble can be incorporated into the melt. If the cavity collapses hours after a test, much of the glass solidifies before chimney rubble drops into the cavity. For example, the HARD HAT test cavity collapsed 11 hours after detonation; its glass zone was composed of $73 \%$ glass by volume (Boardman, 1966). The GNOME cavity, on the other hand, collapsed very early and the percent melt glass in the puddle was found to be between 23 and 31\% (Boardman, 1966).

The thickness and volume of the glass zone for the CAMBRIC test may be estimated from the high-intensity gamma logs and sidewall sampling conducted in the various drillback holes. From the 1965 high-intensity gamma logs, it appears that high activity is dispersed throughout the bottom half of the CAMBRIC cavity (Figure 3.4). This high activity is typically associated with refractory radionuclides and would suggest that the nuclear melt glass zone thickness may be as much as $13 \mathrm{~m}$. Assuming that the melt glass zone is composed solely of nuclear melt glass, the predicted thickness of the glass zone would only be $2.6 \mathrm{~m}$ (assuming all the glass collects as a basal spherical segment). ${ }^{1}$ The high-intensity gamma log data suggest that much of the CAMBRIC melt glass zone is composed of infallen rubble.

Both the 1965 drillback holes and the 1976 re-completion of RNM-1 included sidewall sampling of glass and rubble material. From the three 1965 drillback holes, high activity samples were collected over a zone of 3.5 to $7 \mathrm{~m}$ above the cavity bottom. During RNM-1 sampling, high-Pu glasses were found as high as $9.8 \mathrm{~m}$ above the cavity bottom. It should not be surprising that the nuclear melt glass is distributed heterogeneously and that the top of the glass zone is difficult to identify. Shortly after the test and as the cavity collapsed, some of the glass

\footnotetext{
${ }^{1}$ The calculation of glass volume was made assuming $700 \mathrm{t}$ of glass are produced per kt yield and a glass bulk density of $2.0 \mathrm{~g} / \mathrm{cm}^{3}$.
} 


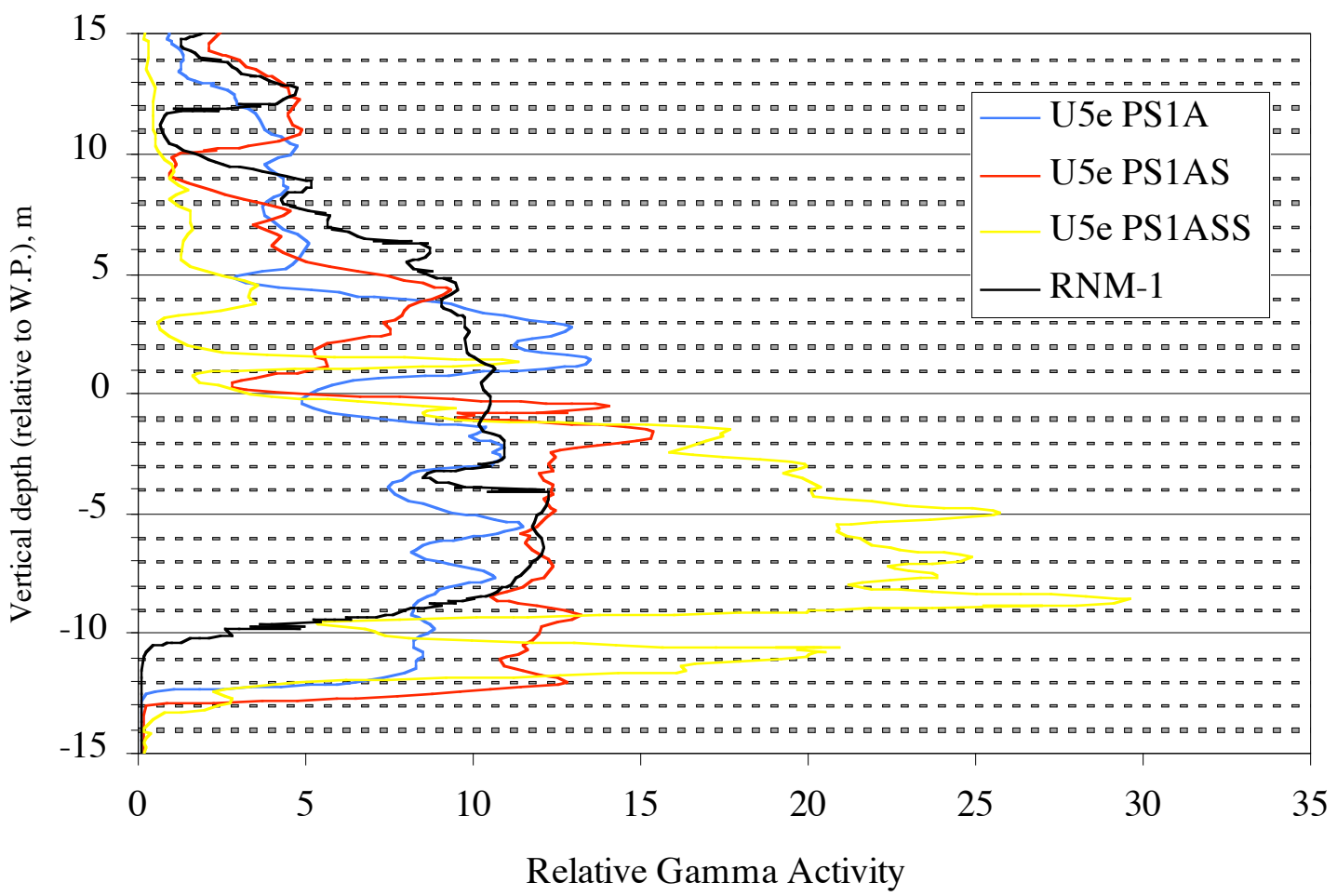

Figure 3.4 Relative gamma activity as a function of vertical depth with 0 coincident with the working point depth and bottom of cavity at $13.4 \mathrm{~m}$.

likely splashed and redistributed higher up into the cavity. Based on the high-intensity gamma logs and sidewall sampling, the glass zone is on the order of $7 \mathrm{~m}$ thick (the upper end of the sampled glass zone thickness but significantly lower than the glass zone thickness based on gamma logs). Based on the estimate of $700 \mathrm{t}$ nuclear melt glass produced per kt yield, the glass zone is composed of $15.5 \%$ nuclear melt glass. The remaining portion of the glass zone is assumed to be composed of infallen rubble.

\section{$3.4 \quad$ Test Heat}

The temperature at CAMBRIC was measured on only one occasion, May 8, 1974, nearly nine years after the CAMBRIC test, in RNM-1 (Figure 3.5). To evaluate the quality of the temperature log recorded that day, the borehole history must be understood. Based on the RNM-1 history, by May 4, 1974, a 9-7/8-in borehole had been drilled to a 1,250-ft slant depth (total slant depth corrected to 1,260 ft on May 7). 


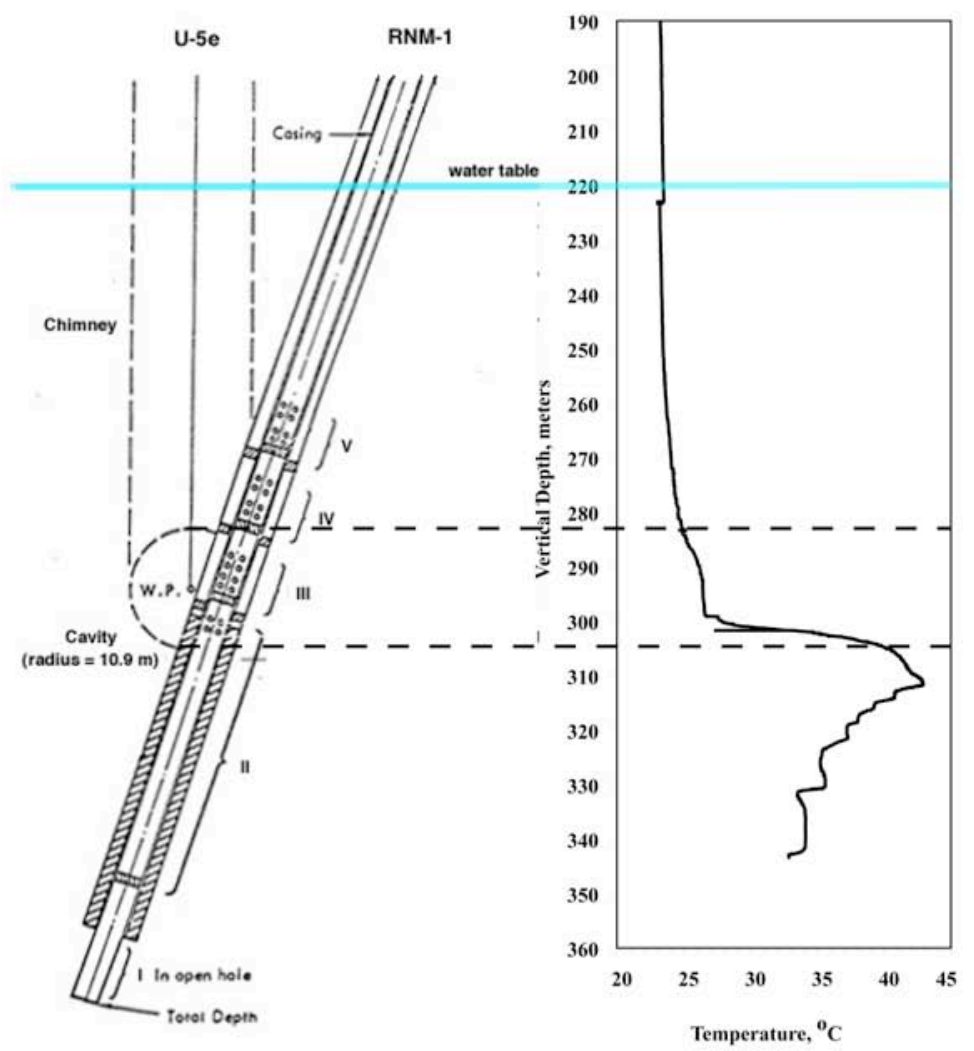

Figure 3.5 Diagram of RNM-1 completion, including location of cemented annulus (Hoffman et al., 1977), locations of five groundwater sampling zones (I to V), and RNM-1 temperature log completed on May 8, 1974.

On May 7, 1974, a 5-1/2-in-O.D. casing was run to 1,259 ft (358 vertical m). A 2-3/8-in tubing with a stab-in tool was run to $1,214 \mathrm{ft}$ ( 345 vertical $\mathrm{m})$. The tubing was used to cement the annulus with $75 \mathrm{ft}^{3}$ of neat cement containing $3 \% \mathrm{CaCl}_{2}$. Assuming the cement was intended to seal the well between the casing (5-1/2-in O.D.) and the original drilled borehole (9 7/8 in), $75 \mathrm{ft}^{3}$ of cement would ideally fill $204 \mathrm{ft}$ of the casing annulus. This would cement the casing between 1,259 and 1,055 ft (358 and 300 vertical m), which is consistent with the figure in Hoffman et al. (1977) showing a cemented annulus between 300 and $360 \mathrm{~m}$ vertical depth (Figure 3.5).

The next day, May 8, a temperature log was run to 1,205 ft inside the 2-3/8-in tubing, along with fluid density and neutron logs. The tubing was then removed, and another neutron and nuclear annulus investigation $\log$ was run to 1,206 ft. The borehole history reports that cement was in the annulus to $1,066 \mathrm{ft}$ (consistent with the predicted value).

By comparing the location of the temperature spike to the location of the cement (Figure 3.5), it is clear that the temperature spike observed in the log is the result of cement curing. While the large temperature anomaly measured below the cavity is not the result of testrelated heat, there is a small temperature increase above the cemented zone. This temperature increase is located in the cavity/chimney and is on the order of $3{ }^{\circ} \mathrm{C}$. 


\subsection{Radiologic Source Term}

The radiologic source term (RST) is the total inventory of radioactive components associated with an underground nuclear test. The RST for a particular test is classified because isotope ratios may reveal information about the device and its performance. The CAMBRIC test RST is not an exception.

While the true (classified) radiologic inventory for the CAMBRIC test is not available for this report, there are several unclassified RST inventories that can be reported. These unclassified radiologic inventories include:

- The estimated RST reported in Hoffman et al. (1977) for CAMBRIC.

- The estimated RST reported in Hoffman et al. (1979) for CAMBRIC.

- The ${ }^{99}$ Tc inventory for CAMBRIC estimated by Schroeder et al. (1993).

- The Hoffman et al. (1977) estimated RST recalculated by Smith (1995b).

- The average unclassified RST reported by Bowen et al. (2001) for Frenchman Flat. ${ }^{2}$

The first four RSTs were estimated from unclassified CAMBRIC-specific calculations with assumptions on the performance of the CAMBRIC event. The fifth RST was based on the total radiologic inventory from all underground nuclear tests conducted in Frenchman Flat (Bowen et al., 2001). The Bowen et al. (2001) inventory for Frenchman Flat was calculated by summing the test-specific inventories of all ten tests detonated in Frenchman Flat. While the summed total RST for Frenchman Flat is unclassified, test-specific RSTs for each underground nuclear test conducted in Frenchman Flat are classified.

The Phase I unclassified CAMBRIC simulations reported in Tompson et al. (1999) were based on a combination of source term data from the first four RST sources. The ${ }^{3} \mathrm{H},{ }^{85} \mathrm{Kr}$, ${ }^{90} \mathrm{Sr}$, and ${ }^{137} \mathrm{Cs}$ inventories were taken from Smith (1995b). The ${ }^{99} \mathrm{Tc}$ inventory was taken from Schroeder et al. (1993). Inventories for ${ }^{106} \mathrm{Ru},{ }^{125} \mathrm{Sb},{ }^{144} \mathrm{Ce}$, and ${ }^{147} \mathrm{Pm}$ were taken from Table I in Hoffman (1979) and decay corrected to $t_{0}$ with half-lives reported in Tompson (1999). ${ }^{3}$ The ${ }^{155} \mathrm{Eu}$ inventory was also taken from Hoffman (1979) but decay correction was, apparently, neglected. The ${ }^{238} \mathrm{U},{ }^{239} \mathrm{Pu}$, and ${ }^{241} \mathrm{Am}$ inventories were taken from Hoffman et al. (1977).

Data from all five sources are reported in Table 3.1, and radionuclide inventories with more than one source are plotted in Figure 3.6. All data were decay corrected to $t_{0}$, May 14, 1965. Hoffman et al. (1977) reported inventories at $t_{0}$, Table I in Hoffman (1979) reported inventories $10 \mathrm{y}$ after $\mathrm{t}_{0}$, Schroeder et al. (1993) reported the ${ }^{99} \mathrm{Tc}$ inventory at $\mathrm{t}_{0}$, Smith (1995b) reported inventories at $t_{0}$, and Bowen et al. (2001) reported inventories at September 23, 1992. Decay correction to $t_{0}$ of the Bowen et al. (2001) inventory included not only the decay but also the ingrowth correction for the following decay chain:

$$
{ }^{241} \mathrm{Pu} \quad{ }^{241} \mathrm{Am} \quad{ }^{237} \mathrm{~Np} .
$$

\footnotetext{
${ }^{2}$ To arrive at an average Frenchman Flat radionuclide inventory, the total RST for Frenchman Flat reported in Bowen et al. (2001) is divided by the total number of underground nuclear tests conducted in Frenchman Flat (10). ${ }^{3}$ Data reported in Table I of Hoffman (1979) is the source term at $10 \mathrm{y}$. Note that the half-lives used by Tompson et al. (1999) to correct to $t_{0}$ are slightly different from those reported in Hoffman (1979) Table I. This difference results in some inconsistencies between the decay-corrected inventories of Tompson et al. (1999) and those calculated in Hoffman (1979) Table II and Hoffman (1977) Table VII.
} 
Interestingly, when compared to the estimated CAMBRIC inventories of Hoffman et al. (1977), Schroeder et al. (1993), and Smith (1995b), the Bowen et al. (2001) unclassified average Frenchman Flat inventory tends to overestimate the inventory of low atomic number $(Z)$ radionuclides while underestimating the inventories of high $Z$ radionuclides. Nevertheless, radionuclide inventories from the various sources all fall within approximately one order of magnitude of each other.

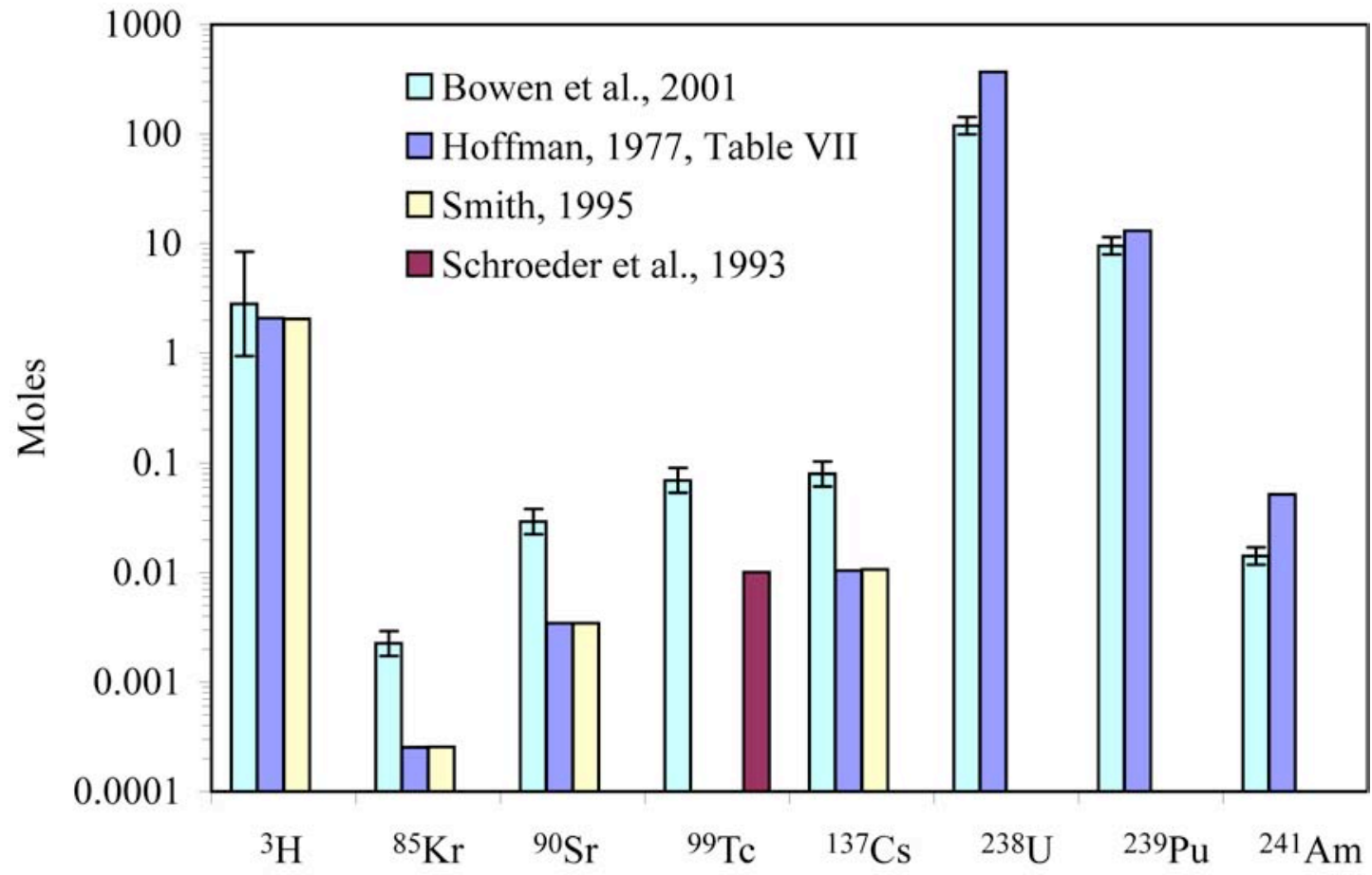

Figure 3.6 Comparison of selected RST inventories from various sources. Bowen et al. (2001) data include approximate uncertainties associated with test-specific radionuclide inventory calculations. 
Table 3.1. Summary of available unclassified radiologic source term data for the CAMBRIC site. All data decay are corrected to $t_{0}$, May 14, 1965.

\begin{tabular}{|c|c|c|c|c|c|c|}
\hline & Half Life $(y)$ & $\begin{array}{c}\text { Hoffman et } \\
\text { al. (1977), } \\
\text { Table VII }\end{array}$ & $\begin{array}{c}\text { Hoffman } \\
\text { (1979), } \\
\text { Table I }\end{array}$ & $\begin{array}{c}\text { Schroeder } \\
\text { et al. } \\
(1993)\end{array}$ & $\begin{array}{l}\text { Smith } \\
(1995 b)\end{array}$ & $\begin{array}{c}\text { Bowen et al. } \\
(2001)\end{array}$ \\
\hline & & \multicolumn{5}{|c|}{ 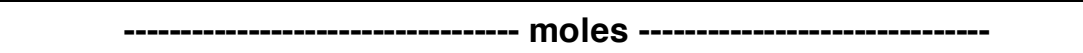 } \\
\hline${ }^{3} \mathrm{H}$ & 12.32 & 2.08 & 2.06 & & 2.04 & 2.80 \\
\hline${ }^{14} \mathrm{C}$ & $5.72 \times 10^{3}$ & & & & & $1.07 \times 10^{-1}$ \\
\hline${ }^{26} \mathrm{Al}$ & $7.10 \times 10^{5}$ & & & & & $1.40 \times 10^{-3}$ \\
\hline${ }^{36} \mathrm{Cl}$ & $3.01 \times 10^{5}$ & & & & & $7.50 \times 10^{-1}$ \\
\hline${ }^{39} \mathrm{Ar}$ & 269 & & & & & $4.98 \times 10^{-4}$ \\
\hline${ }^{40} \mathrm{~K}$ & $1.27 \times 10^{9}$ & & & & & $5.86 \times 10^{2}$ \\
\hline${ }^{41} \mathrm{Ca}$ & $1.03 \times 10^{5}$ & & & & & 1.89 \\
\hline${ }^{59} \mathrm{Ni}$ & $7.60 \times 10^{4}$ & & & & & $3.47 \times 10^{-2}$ \\
\hline${ }^{63} \mathrm{Ni}$ & 100 & & & & & $5.68 \times 10^{-3}$ \\
\hline${ }^{85} \mathrm{Kr}$ & 10.76 & $2.53 \times 10^{-4}$ & $2.52 \times 10^{-4}$ & & $2.56 \times 10^{-4}$ & $2.25 \times 10^{-3}$ \\
\hline${ }^{90} \mathrm{Sr}$ & 28.78 & $3.45 \times 10^{-3}$ & $3.50 \times 10^{-3}$ & & $3.44 \times 10^{-3}$ & $2.92 \times 10^{-2}$ \\
\hline${ }^{93} \mathrm{Zr}$ & $1.50 \times 10^{6}$ & & & & & $4.69 \times 10^{-2}$ \\
\hline${ }^{93 \mathrm{~m}} \mathrm{Nb}$ & 16.1 & & & & & 0 \\
\hline${ }^{94} \mathrm{Nb}$ & $2.00 \times 10^{4}$ & & & & & $3.90 \times 10^{-3}$ \\
\hline${ }^{99} \mathrm{Tc}$ & $2.13 \times 10^{5}$ & & & $1.01 \times 10^{-2}$ & & $6.96 \times 10^{-2}$ \\
\hline${ }^{106} \mathrm{Ru}$ & 1.02 & $7.64 \times 10^{-3}$ & $8.02 \times 10^{-3}$ & & & \\
\hline${ }^{107} \mathrm{Pd}$ & $6.50 \times 10^{6}$ & & & & & $3.55 \times 10^{-2}$ \\
\hline${ }^{113 m} \mathrm{Cd}$ & 14.1 & & & & & $4.53 \times 10^{-5}$ \\
\hline${ }^{121 \mathrm{~m}} \mathrm{Sn}$ & 55 & & & & & $3.58 \times 10^{-4}$ \\
\hline${ }^{125} \mathrm{Sb}$ & 2.76 & $3.16 \times 10^{-4}$ & $2.98 \times 10^{-4}$ & & & \\
\hline${ }^{126} \mathrm{Sn}$ & $2.50 \times 10^{5}$ & & & & & $5.73 \times 10^{-3}$ \\
\hline${ }^{129} I$ & $1.57 \times 10^{7}$ & & & & & $1.99 \times 10^{-2}$ \\
\hline${ }^{135} \mathrm{Cs}$ & $2.30 \times 10^{6}$ & & & & & $8.76 \times 10^{-2}$ \\
\hline${ }^{137} \mathrm{Cs}$ & 30.07 & $1.04 \times 10^{-2}$ & $1.05 \times 10^{-2}$ & & $1.07 \times 10^{-2}$ & $7.97 \times 10^{-2}$ \\
\hline${ }^{144} \mathrm{Ce}$ & 0.78 & $5.89 \times 10^{-3}$ & $6.31 \times 10^{-3}$ & & & \\
\hline${ }^{147} \mathrm{Pm}$ & 2.62 & $3.42 \times 10^{-3}$ & $3.45 \times 10^{-3}$ & & & \\
\hline${ }^{151} \mathrm{Sm}$ & 90 & & & & & $9.17 \times 10^{-3}$ \\
\hline${ }^{150} \mathrm{Eu}$ & 36 & & & & & $1.68 \times 10^{-7}$ \\
\hline${ }^{152} \mathrm{Eu}$ & 13.54 & & & & & $1.16 \times 10^{-2}$ \\
\hline${ }^{154} \mathrm{Eu}$ & 8.593 & & & & & $5.73 \times 10^{-3}$ \\
\hline${ }^{155} \mathrm{Eu}$ & 4.76 & $3.59 \times 10^{-4}$ & $3.58 \times 10^{-4}$ & & & \\
\hline${ }^{166 m} \mathrm{Ho}$ & 1200 & & & & & $6.90 \times 10^{-4}$ \\
\hline
\end{tabular}


Table 3.1. Summary of available unclassified radiologic source term data for the CAMBRIC site. All data decay are corrected to $t_{0}$, May 14, 1965.

\begin{tabular}{|l|l|l|l|l|l|l|}
\hline & Half Life (y) & $\begin{array}{c}\text { Hoffman et } \\
\text { al. (1977), } \\
\text { Table VII }\end{array}$ & $\begin{array}{c}\text { Hoffman } \\
\text { (1979), } \\
\text { Table I }\end{array}$ & $\begin{array}{c}\text { Schroeder } \\
\text { et al. } \\
(\mathbf{1 9 9 3 )}\end{array}$ & $\begin{array}{c}\text { Smith } \\
(\mathbf{1 9 9 5 b})\end{array}$ & $\begin{array}{c}\text { Bowen et al. } \\
(\mathbf{2 0 0 1})\end{array}$ \\
\hline${ }^{232} \mathrm{Th}$ & $1.40 \times 10^{10}$ & & & & & $4.68 \times 10^{2}$ \\
\hline${ }^{232} \mathrm{U}$ & 69.8 & & & & & $2.63 \times 10^{-7}$ \\
\hline${ }^{233} \mathrm{U}$ & $1.59 \times 10^{5}$ & & & & & $5.94 \times 10^{-5}$ \\
\hline${ }^{234} \mathrm{U}$ & $2.46 \times 10^{5}$ & & & & & $2.97 \times 10^{-2}$ \\
\hline${ }^{235} \mathrm{U}$ & $7.04 \times 10^{8}$ & & & & & 1.69 \\
\hline${ }^{236} \mathrm{U}$ & $2.34 \times 10^{7}$ & & & & & $1.96 \times 10^{-2}$ \\
\hline${ }^{238} \mathrm{U}$ & $4.47 \times 10^{9}$ & $3.69 \times 10^{2}$ & & & & $1.19 \times 10^{2}$ \\
\hline${ }^{237} \mathrm{~Np}$ & $2.14 \times 10^{6}$ & & & & & $6.37 \times 10^{-3}$ \\
\hline${ }^{238} \mathrm{Pu}$ & 87.7 & & & & & $9.84 \times 10^{-3}$ \\
\hline${ }^{239} \mathrm{Pu}$ & $2.41 \times 10^{4}$ & $1.30 \times 10^{1}$ & & & & 9.55 \\
\hline${ }^{240} \mathrm{Pu}$ & $6.56 \times 10^{3}$ & & & & & $6.42 \times 10^{-1}$ \\
\hline${ }^{241} \mathrm{Pu}$ & 14.4 & & & & & $6.63 \times 10^{-2}$ \\
\hline${ }^{242} \mathrm{Pu}$ & $3.75 \times 10^{5}$ & & & & & $3.02 \times 10^{-3}$ \\
\hline${ }^{241} \mathrm{Am}$ & 432.7 & $5.19 \times 10^{-2}$ & & & & $1.42 \times 10^{-2}$ \\
\hline${ }^{243} \mathrm{Am}$ & $7.37 \times 10^{3}$ & & & & & 0 \\
\hline${ }^{244} \mathrm{Cm}$ & 18.1 & & & & & 0 \\
\hline
\end{tabular}




\subsection{Initial Radionuclide Distributions}

\subsubsection{Predicted Partitioning of Radionuclides}

The physical and chemical distribution of the RST is heterogeneous and a function of the device design, geologic media, radionuclide properties, and cavity growth and collapse history. A number of investigations at the NTS have yielded information regarding the initial distribution of radionuclides after a nuclear test (Kersting, 1996; Smith, 1995b; Mathews et al., 1994; Smith et al., 1996; and Thompson, 1996). Tritium is present primarily as tritiated water and is located in the interstitial water. Refractory radionuclides (e.g., $\mathrm{Pu}, \mathrm{Am}, \mathrm{Np}, \mathrm{Ce}$, and Eu) with higher boiling points and lower vapor pressures are largely incorporated in the melt glass that coalesces at the base of the cavity. Radionuclides with boiling points between that of tritiated water and refractory radionuclides (e.g., Sr and Cs) will be heterogeneously distributed in and near the cavity and chimney and in the melt glass. If the melt glass is still molten when rubble above the cavity collapses, the glassy material may splash and distribute refractory material more broadly in the cavity region.

The distribution of some fission products is affected by the behavior of its parental precursors. The radionuclides ${ }^{90} \mathrm{Sr}$ and ${ }^{137} \mathrm{Cs}$ are particularly good examples because they have noble gas precursors that can be transported away from the detonation point before their decay to less volatile daughter products (Smith et al., 1996). In some instances, prompt injection of nuclear material along fractures or zones of weakness as the cavity grows may deposit radionuclides outside the immediate vicinity of the cavity and chimney system (Nimz and Thompson, 1992 and Smith et al., 1996).

An estimate of radionuclides partitioning between glass, rubble, water, and gas was reported by the IAEA (1998a) and is reproduced in Table 3.2. Only those radionuclides for which an inventory exists (i.e., Table 3.1) are listed. The glass fraction includes radionuclides partitioned into the solidified melt that is found primarily at the bottom of a cavity but also on the cavity walls and splashed up into the cavity during chimney collapse. The rubble fraction includes the radionuclides distributed primarily on crushed rock surfaces in the cavity and chimney. The gas fraction includes the radionuclides that never condense, are distributed in the gas phase, and are partly dissolved in interstitial waters. The water fraction includes the radionuclides that exist in the interstitial water (like ${ }^{3} \mathrm{H}$ ). Importantly, IAEA (1998a) states that the fraction of radionuclides initially distributed on crushed rock surfaces will ultimately be in equilibrium with the radionuclide levels in the interstitial waters. In effect, the distribution between the water, gas, and rubble fractions will be governed by the sorption, precipitation, and gas phase solubility reactions. 
Table 3.2. Radionuclide partitioning (IAEA, 1998a).

\begin{tabular}{|c|c|c|c|c|c|}
\hline \multirow[t]{2}{*}{ Radionuclide } & \multirow[t]{2}{*}{ Half Life $(y)$} & \multicolumn{4}{|c|}{ Partitioning, percent } \\
\hline & & glass & rubble & gas & water \\
\hline${ }^{3} \mathrm{H}$ & 12.32 & 0 & 0 & 2 & 98 \\
\hline${ }^{14} \mathrm{C}$ & $5.72 \times 10^{3}$ & 0 & 10 & 80 & 10 \\
\hline${ }^{36} \mathrm{Cl}$ & $3.01 \times 10^{5}$ & 50 & 40 & 0 & 10 \\
\hline${ }^{41} \mathrm{Ca}$ & $1.03 \times 10^{5}$ & 70 & 30 & 0 & 0 \\
\hline${ }^{59} \mathrm{Ni}$ & $7.60 \times 10^{4}$ & 95 & 5 & 0 & 0 \\
\hline${ }^{63} \mathrm{Ni}$ & 100 & 95 & 5 & 0 & 0 \\
\hline${ }^{85} \mathrm{Kr}$ & 10.76 & 0 & 10 & 80 & 10 \\
\hline${ }^{90} \mathrm{Sr}$ & 28.78 & 40 & 60 & 0 & 0 \\
\hline${ }^{93} \mathrm{Zr}$ & $1.50 \times 10^{6}$ & 95 & 5 & 0 & 0 \\
\hline${ }^{93 \mathrm{~m}} \mathrm{Nb}$ & 16.1 & 95 & 5 & 0 & 0 \\
\hline${ }^{99} \mathrm{Tc}$ & $2.13 \times 10^{5}$ & 80 & 20 & 0 & 0 \\
\hline${ }^{106} \mathrm{Ru}$ & 1.02 & 70 & 30 & 0 & 0 \\
\hline${ }^{107} \mathrm{Pd}$ & $6.50 \times 10^{6}$ & 70 & 30 & 0 & 0 \\
\hline${ }^{113 \mathrm{~m}} \mathrm{Cd}^{1}$ & 14.1 & 70 & 30 & 0 & 0 \\
\hline${ }^{121 \mathrm{~m}} \mathrm{Sn}$ & 55.0 & 60 & 40 & 0 & 0 \\
\hline${ }^{126} \mathrm{Sn}$ & $2.50 \times 10^{5}$ & 70 & 30 & 0 & 0 \\
\hline${ }^{125} \mathrm{Sb}$ & 2.76 & 70 & 30 & 0 & 0 \\
\hline $129 \mid$ & $1.57 \times 10^{7}$ & 50 & 40 & 0 & 10 \\
\hline${ }^{135} \mathrm{Cs}$ & $2.30 \times 10^{6}$ & 20 & 80 & 0 & 0 \\
\hline${ }^{137} \mathrm{Cs}^{2}$ & 30.1 & $25 / 40$ & $75 / 60$ & 0 & 0 \\
\hline${ }^{147} \mathrm{Pm}$ & 2.62 & 95 & 5 & 0 & 0 \\
\hline${ }^{151} \mathrm{Sm}$ & 90.0 & 95 & 5 & 0 & 0 \\
\hline${ }^{152} \mathrm{Eu}$ & 13.5 & 95 & 5 & 0 & 0 \\
\hline${ }^{154} \mathrm{Eu}$ & 8.59 & 95 & 5 & 0 & 0 \\
\hline${ }^{155} \mathrm{Eu}$ & 4.76 & 95 & 5 & 0 & 0 \\
\hline${ }^{233} U$ & $1.59 \times 10^{5}$ & 90 & 10 & 0 & 0 \\
\hline${ }^{236} \mathrm{U}$ & $2.34 \times 10^{7}$ & 90 & 10 & 0 & 0 \\
\hline${ }^{237} \mathrm{~Np}$ & $2.14 \times 10^{6}$ & 95 & 5 & 0 & 0 \\
\hline${ }^{238} \mathrm{Pu}^{1}$ & 87.7 & 98 & 2 & 0 & 0 \\
\hline${ }^{239} \mathrm{Pu}$ & $2.41 \times 10^{4}$ & 98 & 2 & 0 & 0 \\
\hline${ }^{240} \mathrm{Pu}$ & $6.56 \times 10^{3}$ & 98 & 2 & 0 & 0 \\
\hline${ }^{241} \mathrm{Pu}$ & 14.4 & 98 & 2 & 0 & 0 \\
\hline${ }^{242} \mathrm{Pu}$ & $3.75 \times 10^{5}$ & 98 & 2 & 0 & 0 \\
\hline${ }^{241} \mathrm{Am}$ & 432.7 & 98 & 2 & 0 & 0 \\
\hline
\end{tabular}

${ }^{1} \mathrm{Pu}$ and Am isotopes were assigned a partitioning ratio of 98:2 in Volume 3 of the IAEA report (1998a). However, more conservative estimates were reported elsewhere (e.g., partitioning ratio of 95:5 in Volume 4 of the IAEA report).

${ }^{2}$ Two partitioning ratios are reported for ${ }^{137} \mathrm{Cs}$ based on data from two testing locations (Mururoa and Fangataufa) and may reflect a difference in the average yield of tests at the two locations. 
The IAEA (1998a) partitioning data originate from nuclear test radiochemical diagnostics measurements (i.e., Borg, 1975) augmented by general thermodynamic properties of the elements (i.e., boiling points and vapor pressures). Unlike most RST radionuclides, the partitioning behavior of ${ }^{90} \mathrm{Sr}$ and ${ }^{137} \mathrm{Cs}$ between rubble and melt glass is strongly dependent on the cooling rates and the presence of volatile, noncondensible gases (i.e., $\mathrm{CO}_{2}$ and $\mathrm{H}_{2}$ ). Due to the low yield of the CAMBRIC test (and implied faster quenching of the melt glass) as well as the presence of carbonate in the surrounding media ( 0 to 10 volume percent calcite), the fraction of ${ }^{90} \mathrm{Sr}$ and ${ }^{137} \mathrm{Cs}$ in CAMBRIC rubble is expected to be higher than in Table $3.2(75 \%$ and $90 \%$, respectively, Tompson et al., 1999). Evidence of ${ }^{90} \mathrm{Sr}$ and ${ }^{137} \mathrm{Cs}$ partitioning into CAMBRIC rubble is described below.

\subsubsection{Measured Partitioning of Radionuclides}

Hoffman et al. (1977) conducted a large characterization effort during the drilling of RNM-1 into the CAMBRIC cavity. These data are the most direct information regarding the characteristics and partitioning of radionuclides at CAMBRIC. The data provide the starting point from which a representation of CAMBRIC is developed for modeling purposes.

During RNM-1 drilling, a number of sidewall core samples were collected. Tritium and ${ }^{85} \mathrm{Kr}$ were extracted from the fluid. Figures 3.7 and 3.8 plot the measured concentration of these radionuclides as a function of vertical depth and radius relative to the working point. The highest concentrations of both radionuclides were centered around the working point.

Concentrations decrease rapidly with radial distance away from the working point. For the three samples with the highest concentration, the ratio varies between 6,000 and 20,000. The RST ratio predicted by Hoffman and others for the CAMBRIC test (Table 3.1) is 8,000, consistent with observed data. The sample ${ }^{3} \mathrm{H} /{ }^{85} \mathrm{Kr}$ ratios are not consistently higher or lower than the RST ratio. Thus, it appears that the majority of ${ }^{85} \mathrm{Kr}$ was retained in the aqueous phase and not lost to air in the overlying vadose zone.

The TER is defined as the radius of a spherical volume of alluvium needed to account for all $\mathrm{RST}^{3} \mathrm{H}$ at a particular measured ${ }^{3} \mathrm{H}$ concentration. Using the highest ${ }^{3} \mathrm{H}$ concentration in Figure 3.7, an RST based on Hoffman et al. (1977), and an alluvium porosity in the cavity and compressed zone of $32 \%$, the TER is $21.8 \mathrm{~m}$. A similar exchange radius can be calculated using the available ${ }^{85} \mathrm{Kr}$ data $\left({ }^{85} \mathrm{Kr}\right.$ exchange radius). Using ${ }^{85} \mathrm{Kr}$, the exchange radius is $20.7 \mathrm{~m}$. Both values indicate that these radionuclides are very likely distributed well beyond the cavity. 
CHAPTER 3: ALTERED PHYSICAL AND CHEMICAL SETTING

Tritium Concentration, mol/L

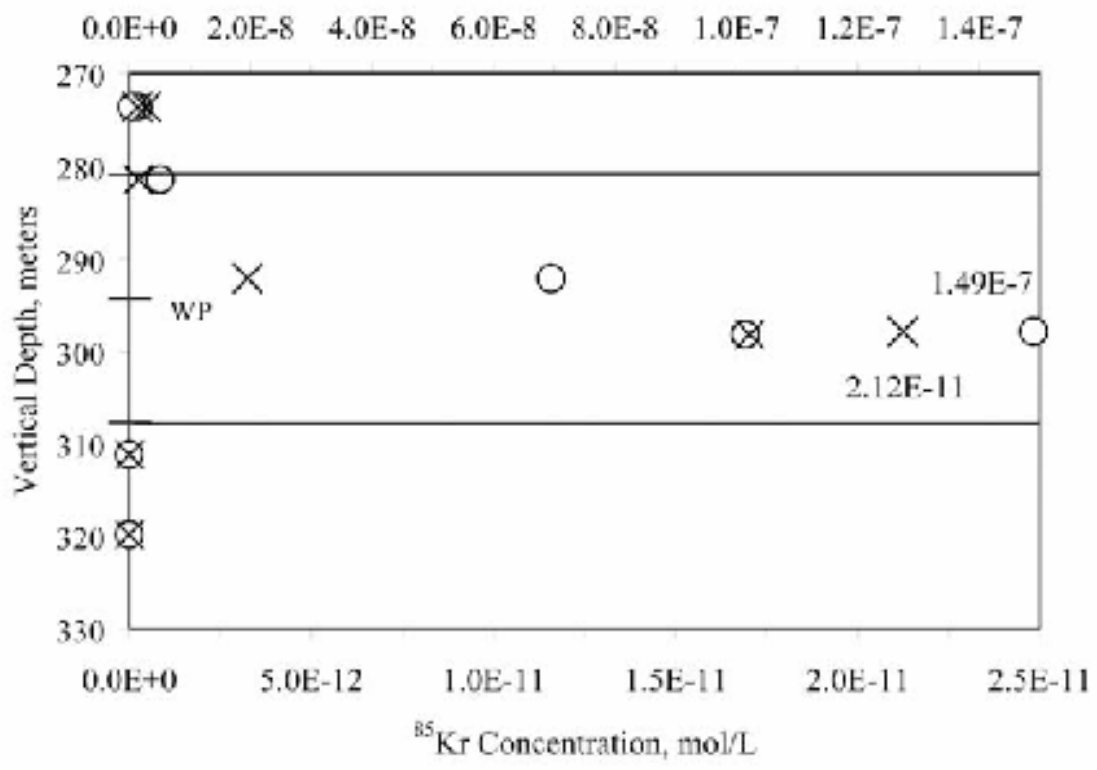

Figure 3.7 Tritium (O) and ${ }^{85} \mathrm{Kr}(\mathrm{X})$ concentrations in waters extracted from the RNM-1 core as a function of sample vertical depth from ground surface. WP indicates working point depth. Lines on the $y$-axis indicate the top and bottom of a 13.4-m cavity radius.

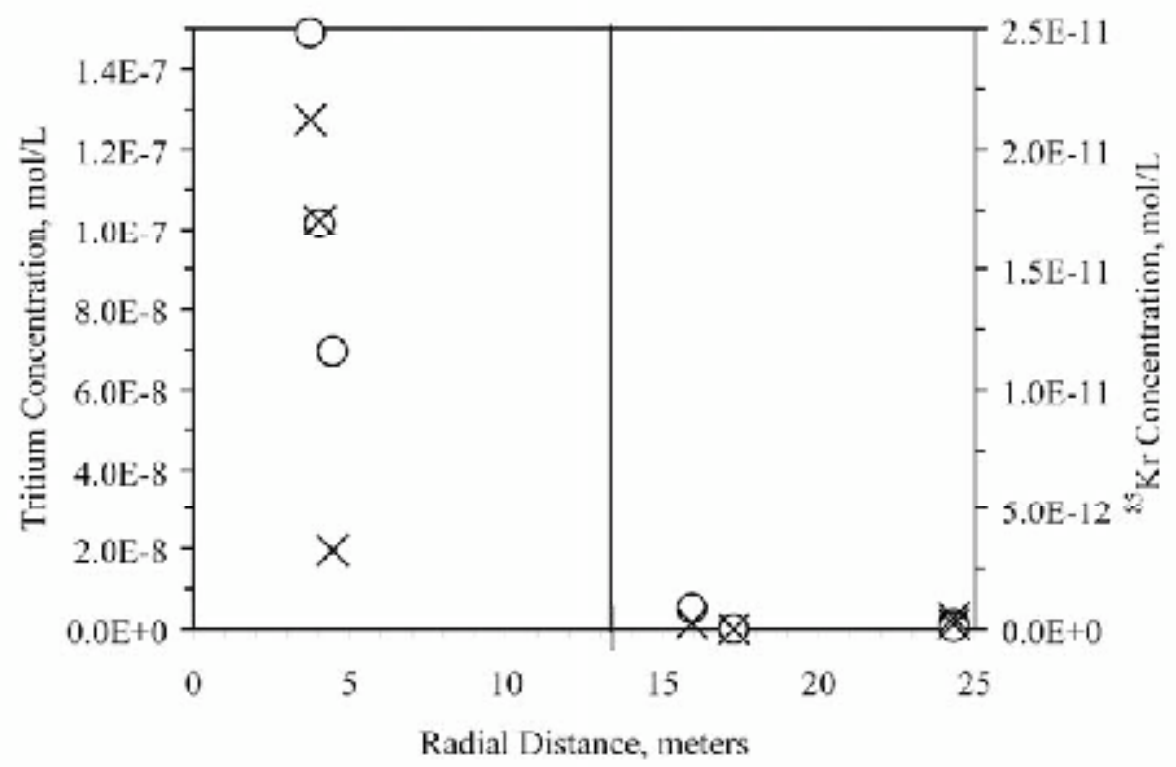

Figure 3.8 Tritium (O) and ${ }^{85} \mathrm{Kr}(\mathrm{X})$ concentrations in waters extracted from the RNM-1 core as a function of radial distance from the working point. Cavity radius is $13.4 \mathrm{~m}$. 
The distribution of ${ }^{137} \mathrm{Cs}$ in sidewall core samples is plotted in Figures 3.9 and 3.10. Cesium-137 is the only strongly sorbing radionuclide that was detected outside the cavity. Its parent, ${ }^{137} \mathrm{Xe}$, is a noble gas and has a half-life of $3.8 \mathrm{~min}$. The unretarded migration of ${ }^{137} \mathrm{Xe}$ at early time results in ${ }^{137} \mathrm{Cs}$ distribution outside the CAMBRIC cavity. A similar distribution pattern is expected for ${ }^{90} \mathrm{Sr}$, whose parent radionuclide is ${ }^{90} \mathrm{Rb}\left(\mathrm{t}_{1 / 2}=158 \mathrm{~s}\right)$ and grandparent is ${ }^{90} \mathrm{Kr}$ $\left(\mathrm{t}_{1 / 2}=32 \mathrm{~s}\right)$.

The initial concentration of ${ }^{137} \mathrm{Cs}$ in the rubble and melt glass fractions of the CAMBRIC cavity can be predicted by assuming an exchange radius of $18 \mathrm{~m}$, the ${ }^{137} \mathrm{Cs}$ RST reported in Hoffman et al. (1977), 90\% partitioning to the rubble (as recommended in Tompson et al., 1999), a rock density of $2.5 \mathrm{~g} / \mathrm{cm}^{3}$, a porosity of $32 \%$, and $700 \mathrm{t}$ glass produced per kt yield, as recommended by Pawloski (1999). Based on these values, the predicted ${ }^{137} \mathrm{Cs}$ concentration in the rubble and in glass is $2 \times 10^{-13}$ and $2 \times 10^{-12} \mathrm{~mol} / \mathrm{g}$, respectively. These values compare well with observed concentrations in the exchange volume rubble (Figure 3.10). The highest observed ${ }^{137} \mathrm{Cs}$ concentration (Figure 3.9, $9 \times 10^{-13} \mathrm{~mol} / \mathrm{g}$ ) is located near the glass zone and is likely to be a mixture of rubble and glass. The highest ${ }^{137} \mathrm{Cs}$ concentration outside the cavity is $2.4 \times 10^{-13} \mathrm{~mol} / \mathrm{g}$, in good agreement with predicted rubble ${ }^{137} \mathrm{Cs}$ concentrations. Note that if the partitioning ratios recommended by the IAEA were used $(75 \%$ in rubble for small tests), the predicted ${ }^{137} \mathrm{Cs}$ concentration in the rubble and glass would be $2 \times 10^{-13}$ and $5 \times 10^{-12}$ $\mathrm{mol} / \mathrm{g}$, respectively.

To identify the concentrations of ${ }^{137} \mathrm{Cs}$ and other radionuclides in the glass and rubble fraction of the CAMBRIC cavity, Hoffman et al. (1977) separated melt glass from native material in a few cores (Table 3.4). For the native and fine fragments, ${ }^{137} \mathrm{Cs}$ concentrations ranged from 1 to $5 \times 10^{-13} \mathrm{~mol} / \mathrm{g}$. Concentrations in glass fragments were approximately $2 \times 10^{-12} \mathrm{~mol} / \mathrm{g}$. Predicted concentrations in the rubble and glass match well with these measured data.

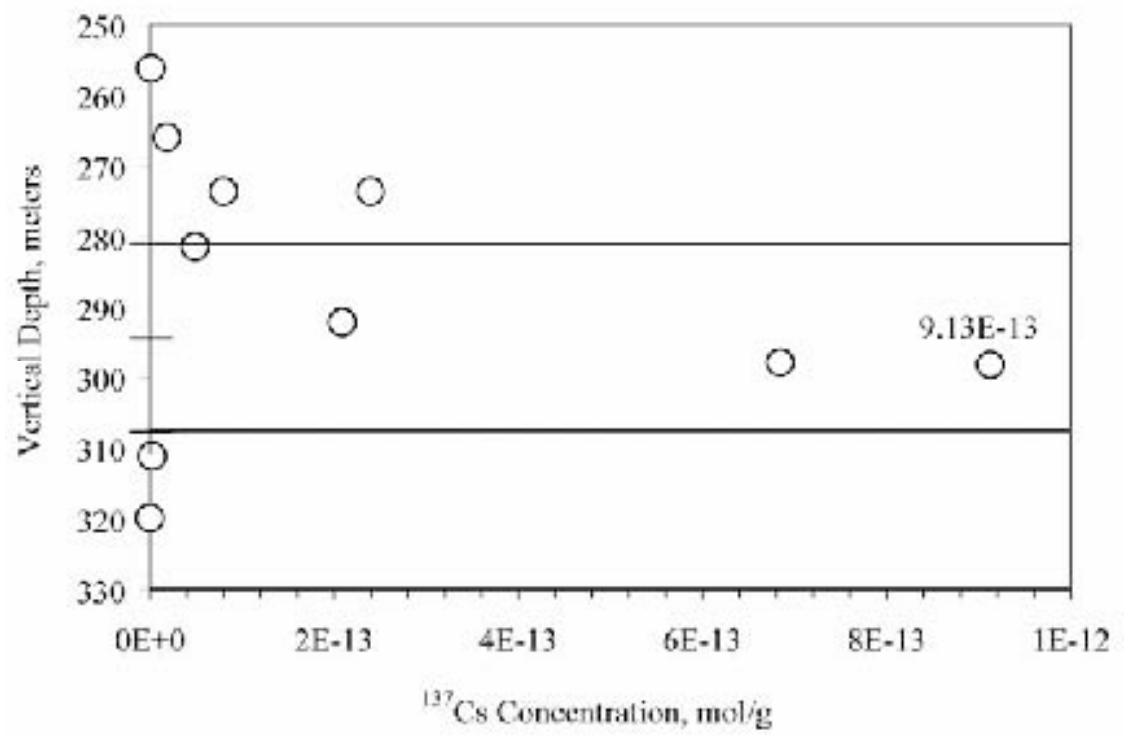

Figure 3.9 Cesium-137 concentrations in the RNM-1 core as a function of sample vertical depth from ground surface. WP indicates working point depth. Lines on the $y$-axis indicate the top and bottom of a 13.4-m cavity. 


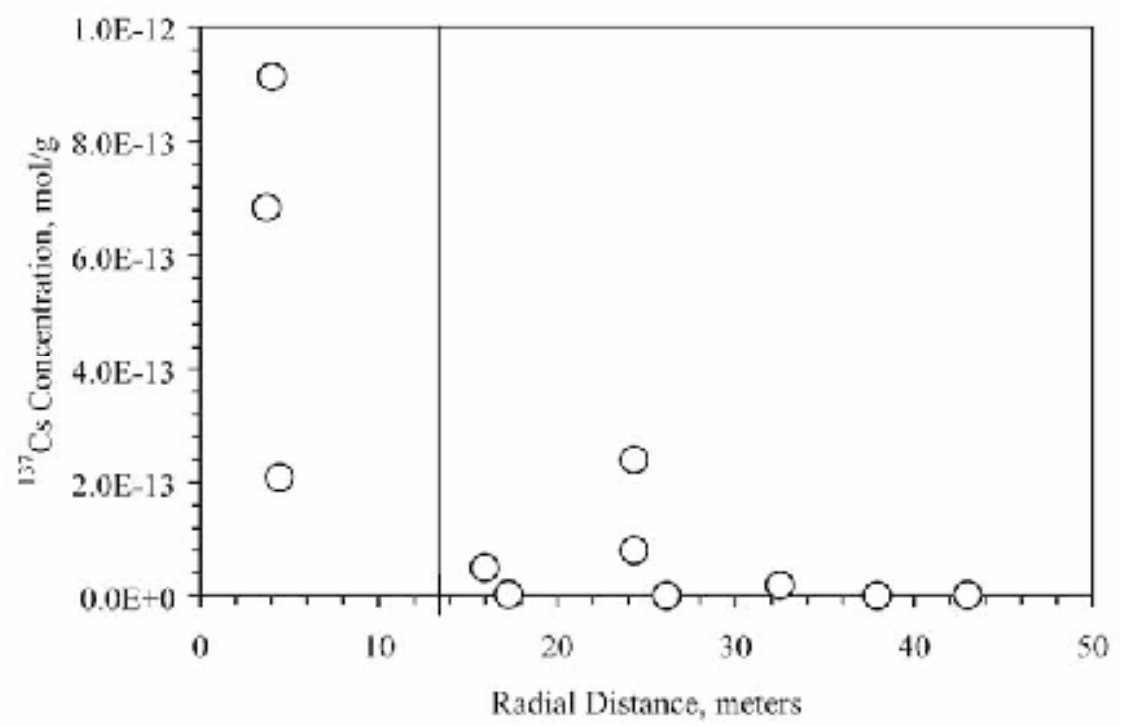

Figure 3.10 Cesium-137 concentrations in the RNM-1 core as a function of radial distance from the working point. Cavity radius is $13.4 \mathrm{~m}$.

Radionuclide concentrations in several core samples from RNM-1 are listed in Table 3.3. Radionuclide concentrations in separated melt glass, native material, and interstitial waters are listed in Table 3.4. Both tables list the range of concentrations predicted for rubble and glass based on the RST of Hoffman et al. (1977), the IAEA (1998a) partitioning ratios, and the parameters used in the ${ }^{137} \mathrm{Cs}$ calculation above. For all radionuclides, the predicted concentrations for rubble and glass bracket the majority of measured radionuclide concentrations in Table 3.3. They also tend to match the native and glass fraction concentrations reported in Table 3.4. The predicted ${ }^{137} \mathrm{Cs}$ concentration in glass is somewhat higher than measured. As stated earlier, Tompson et al. (1999) suggested that ${ }^{137} \mathrm{Cs}$ partitioning into the rubble may be unusually high because of the small yield of the CAMBRIC test and the high calcite concentrations in the alluvium.

The amount of glass produced by the CAMBRIC test can be calculated using the measured radionuclide concentrations in the melt glass. Based on the concentrations of ${ }^{144} \mathrm{Ce}$, ${ }^{147} \mathrm{Pm},{ }^{155} \mathrm{Eu},{ }^{239} \mathrm{Pu}$, and ${ }^{241} \mathrm{Am}$, the RST values from Hoffman et al. (1977), and assuming that refractory radionuclides are quantitatively incorporated into the melt glass, the tons of glass produced per kt of yield at CAMBRIC is $526 \pm 145$. This value is low but statistically comparable to the $700 \mathrm{t} / \mathrm{kt}$ yield recommended by Pawloski (1999) and used throughout this study.

As part of the RNM-1 drillback operations, five separate RNM-1 zones were packed off for groundwater sampling. The location of the five zones is shown in Figure 3.5. Radionuclide concentrations from the pumped zones are reported in Table 3.5 and plotted in Figures 3.11 to 3.14 . The ${ }^{3} \mathrm{H}$ concentration $\left(3.1( \pm 0.7) \times 10^{-7} \mathrm{~mol} / \mathrm{L}\right)$ can be used to calculate a TER. Using the parameters listed in an earlier TER calculation (page 3-13), one standard deviation range in ${ }^{3} \mathrm{H}$ concentration results in a TER range of 16.0 to $18.6 \mathrm{~m}$. At the end of 
pumping, pressure tube samples were taken and analyzed for ${ }^{3} \mathrm{H}$ and ${ }^{85} \mathrm{Kr}$ (Table 3.5). The calculated TER using the pressure tube samples is consistent with pumped samples. However, the exchange radius calculated using ${ }^{85} \mathrm{Kr}$ is much larger. Based on the ${ }^{3} \mathrm{H} /{ }^{85} \mathrm{Kr}$ ratio in the four pressure tube samples, it appears that ${ }^{85} \mathrm{Kr}$ is depleted in the lower two zones and slightly enriched in the upper two zones. This may be an indication of upward migration of ${ }^{85} \mathrm{Kr}$ gas at an early time. However, a similar conclusion could not be made from the core samples. Hoffman et al. (1977) suggested that some degassing of ${ }^{85} \mathrm{Kr}$ in pressure tube samples may have occurred prior to analysis.

Table 3.6 lists the calculated $\mathrm{K}_{\mathrm{d}} \mathrm{s}$ based on the native or fine material radionuclide concentrations (Table 3.4) and aqueous radionuclide concentrations from porewater samples (Table 3.4) or aqueous radionuclide concentrations from pumped samples (Table 3.5). When pore water radionuclide concentrations were not reported, pumped water radionuclide concentrations from the same depth interval were used. The $\mathrm{K}_{\mathrm{d}} \mathrm{s}$ for all four radionuclides listed in Table 3.5 are high, suggesting that these radionuclides will be greatly retarded. Measured Cs and Sr transport rates in column flow-through experiments conducted by Zavarin et al. (2002) suggest that $\mathrm{Cs}$ and $\mathrm{Sr} \mathrm{K}_{\mathrm{d}} \mathrm{S}$ are on the order of $10^{3} \mathrm{~mL} / \mathrm{g}$, consistent with these calculations. 
CHAPTER 3: ALTERED PHYSICAL AND CHEMICAL SETTING

Table 3.3. Radioisotope concentrations in rock separates from RNM-1 near the working point of CAMBRIC.

\begin{tabular}{|c|c|c|c|c|c|c|c|c|c|c|}
\hline $\begin{array}{c}\text { Vertical } \\
\text { depth }\end{array}$ & Material & Radius & ${ }^{90} \mathrm{Sr}$ & ${ }^{125} \mathrm{Sb}$ & ${ }^{137} \mathrm{Cs}$ & ${ }^{144} \mathrm{Ce}$ & ${ }^{147} \mathrm{Pm}$ & ${ }^{155} \mathrm{Eu}$ & ${ }^{239} \mathrm{Pu}$ & ${ }^{241} \mathrm{Am}$ \\
\hline (m) & & $(\mathrm{m})$ & \multicolumn{8}{|c|}{ - } \\
\hline $\begin{array}{l}\text { Rubble, } \\
\text { predicted }\end{array}$ & & & $5 E-14$ & $2 \mathrm{E}-15$ & $2 \mathrm{E}-13^{2}$ & $\begin{array}{l}\text { not } \\
\text { reported }^{3}\end{array}$ & $4 \mathrm{E}-15$ & $4 \mathrm{E}-16$ & $6 \mathrm{E}-12$ & $2 \mathrm{E}-14$ \\
\hline $\begin{array}{l}\text { Glass, } \\
\text { predicted }\end{array}$ & & & $3 \mathrm{E}-12$ & $4 \mathrm{E}-13$ & $5 \mathrm{E}-12^{2}$ & $\begin{array}{l}\text { not } \\
\text { reported }^{3}\end{array}$ & $6 \mathrm{E}-12$ & $6 \mathrm{E}-13$ & $2 \mathrm{E}-8$ & $1 \mathrm{E}-10$ \\
\hline 273.6 & sand & 24.3 & $1.56 \mathrm{E}-14$ & $\mathrm{na}^{1}$ & $1.29 \mathrm{E}-13$ & $1.08 \mathrm{E}-13$ & $8.26 \mathrm{E}-18$ & na & $1.09 \mathrm{E}-13$ & na \\
\hline 273.6 & fines & 24.3 & $2 \mathrm{E}-14$ & na & $2.01 \mathrm{E}-13$ & $1.18 \mathrm{E}-13$ & $1.98 \mathrm{E}-18$ & na & $2.1 \mathrm{E}-13$ & na \\
\hline & & & \multicolumn{8}{|c|}{ - } \\
\hline 273.6 & water & 24.3 & $\mathrm{bd}^{1}$ & na & $1.52 \mathrm{E}-14$ & na & na & na & $<3 \mathrm{E}-14$ & na \\
\hline & & & \multicolumn{8}{|c|}{ - } \\
\hline 297.9 & native & 3.7 & $3.63 E-13$ & $2.75 \mathrm{E}-14$ & $1.52 \mathrm{E}-13$ & bd & na & $2.34 \mathrm{E}-14$ & 1.15E-09 & $2.4 \mathrm{E}-12$ \\
\hline 297.9 & fine & 3.7 & $7.98 \mathrm{E}-14$ & $1.36 \mathrm{E}-13$ & $5.69 \mathrm{E}-13$ & $\mathrm{bd}$ & na & $9 \mathrm{E}-14$ & $4.25 \mathrm{E}-09$ & $1.04 \mathrm{E}-11$ \\
\hline 297.9 & fused & 3.7 & $2.79 \mathrm{E}-12$ & $\mathrm{bd}$ & 2.62E-12 & $1.38 \mathrm{E}-11$ & $1.49 \mathrm{E}-11$ & $1.02 \mathrm{E}-12$ & 4.56E-08 & $1.09 \mathrm{E}-10$ \\
\hline 298.5 & native & 4.3 & $1.12 \mathrm{E}-13$ & $\mathrm{bd}$ & $1.44 \mathrm{E}-13$ & bd & na & bd & $7.9 \mathrm{E}-12$ & $\mathrm{bd}$ \\
\hline 298.5 & fused & 4.3 & $2.21 \mathrm{E}-12$ & $2.64 \mathrm{E}-13$ & $2.01 \mathrm{E}-12$ & $1.16 \mathrm{E}-11$ & $1.19 \mathrm{E}-11$ & $7.8 \mathrm{E}-13$ & $3.65 \mathrm{E}-08$ & $9.26 \mathrm{E}-11$ \\
\hline & & & \multicolumn{8}{|c|}{ - } \\
\hline 298.5 & water & 4.3 & 8.06E-14 & na & $<1.5 \mathrm{E}-13$ & na & na & na & $1.88 \mathrm{E}-13$ & na \\
\hline $\mathrm{pCi} / \mathrm{mol}^{4}$ & & & $1.19 \mathrm{E}+12$ & $1.30 \mathrm{E}+17$ & $1.19 \mathrm{E}+16$ & $4.58 \mathrm{E}+17$ & $1.36 \mathrm{E}+17$ & $7.51 \mathrm{E}+16$ & $1.48 \mathrm{E}+13$ & $8.27 \mathrm{E}+14$ \\
\hline
\end{tabular}

${ }^{1} \mathrm{bd}=$ below detection limit; $\mathrm{na}=$ not analyzed; isotopes were all below detection limit above 292 meter vertical depth.

${ }^{2}$ Calculated using the partitioning ratios of 25:75 glass:rubble.

${ }^{3}$ IAEA (1998a) partitioning ratio not reported.

${ }^{4}$ Conversion factor for calculating $\mathrm{pCi}$ from mol. 
Table 3.4. Radioisotope concentrations in core from RNM-1.

\begin{tabular}{|c|c|c|c|c|c|c|c|c|c|c|c|}
\hline $\begin{array}{l}\text { Vertical } \\
\text { depth }\end{array}$ & Radius & ${ }^{60} \mathrm{Co}$ & ${ }^{106} \mathrm{Ru}$ & ${ }^{125} \mathrm{Sb}$ & ${ }^{134} \mathrm{Cs}$ & ${ }^{144} \mathrm{Ce}$ & ${ }^{152} \mathrm{Eu}$ & ${ }^{154} \mathrm{Eu}$ & ${ }^{155} \mathrm{Eu}$ & ${ }^{239} \mathrm{Pu}$ & ${ }^{241} \mathrm{Am}$ \\
\hline$(\mathrm{m})$ & $(\mathrm{m})$ & \multicolumn{10}{|c|}{ |- } \\
\hline $\begin{array}{l}\text { Rubble, } \\
\text { predicted }\end{array}$ & & 2 & $6 \mathrm{E}-14$ & $2 \mathrm{E}-15$ & 2 & 2 & 2 & 2 & $4 \mathrm{E}-16$ & $6 \mathrm{E}-12$ & $2 E-14$ \\
\hline $\begin{array}{l}\text { Glass, } \\
\text { predicted }\end{array}$ & & 2 & $1 \mathrm{E}-11$ & $4 \mathrm{E}-13$ & 2 & 2 & 2 & 2 & $6 \mathrm{E}-13$ & $2 \mathrm{E}-8$ & $1 \mathrm{E}-10$ \\
\hline 292.1 & 4.5 & $5.98 \mathrm{E}-16$ & $\mathrm{bd}^{1}$ & $1.04 \mathrm{E}-15$ & $\mathrm{Bd}$ & $\mathrm{bd}$ & $\mathrm{bd}$ & $7.58 \mathrm{E}-16$ & $7.2 \mathrm{E}-16$ & $\mathrm{na}^{1}$ & na \\
\hline 292.1 & 4.5 & $1.33 \mathrm{E}-15$ & $2.45 \mathrm{E}-14$ & $2.71 \mathrm{E}-15$ & $1.82 \mathrm{E}-17$ & $\mathrm{bd}$ & $\mathrm{bd}$ & $6.5 \mathrm{E}-17$ & $1.32 \mathrm{E}-15$ & $\mathrm{bd}$ & 1.47E-13 \\
\hline 297.9 & 3.7 & $7.24 \mathrm{E}-14$ & $9.41 \mathrm{E}-13$ & $9.78 \mathrm{E}-14$ & $9.09 \mathrm{E}-15$ & $1.28 \mathrm{E}-12$ & $1.11 \mathrm{E}-14$ & $4.98 \mathrm{E}-15$ & $7.02 \mathrm{E}-14$ & 1.32E-09 & 7.14E-12 \\
\hline 297.9 & 3.7 & $1.63 \mathrm{E}-13$ & 1.16E-12 & $2.04 \mathrm{E}-13$ & $1.53 \mathrm{E}-14$ & $2.36 \mathrm{E}-12$ & $9.36 \mathrm{E}-15$ & $8.01 \mathrm{E}-15$ & $1.64 \mathrm{E}-13$ & na & na \\
\hline 297.9 & 3.7 & $6.28 \mathrm{E}-14$ & $6.96 \mathrm{E}-13$ & $7.38 \mathrm{E}-14$ & $8.18 E-15$ & $9.83 E-13$ & $9.61 \mathrm{E}-15$ & $4.06 \mathrm{E}-15$ & $5.46 \mathrm{E}-14$ & 1.52E-09 & $6.1 \mathrm{E}-12$ \\
\hline 298.2 & 4.0 & 8.9E-14 & $1.68 \mathrm{E}-12$ & $1.75 \mathrm{E}-13$ & $1.49 \mathrm{E}-14$ & $2.06 \mathrm{E}-12$ & 1.3E-14 & $6.28 \mathrm{E}-15$ & $1.1 \mathrm{E}-13$ & 2.6E-09 & $1.05 \mathrm{E}-11$ \\
\hline 298.2 & 4.0 & $1.74 \mathrm{E}-13$ & $1.29 \mathrm{E}-12$ & $2.55 \mathrm{E}-13$ & $2.06 \mathrm{E}-14$ & $3.54 \mathrm{E}-12$ & $1.4 \mathrm{E}-14$ & $1.09 \mathrm{E}-14$ & $2.17 \mathrm{E}-13$ & na & na \\
\hline 311.2 & 17.3 & bd & bd & bd & $\mathrm{Bd}$ & bd & $6.81 \mathrm{E}-16$ & bd & $6.6 \mathrm{E}-16$ & na & na \\
\hline 319.9 & 26.1 & bd & bd & bd & $\mathrm{Bd}$ & bd & bd & bd & $b d$ & na & na \\
\hline 319.9 & 26.1 & $2.66 \mathrm{E}-17$ & bd & $5.91 \mathrm{E}-17$ & $\mathrm{Bd}$ & bd & bd & $6.5 \mathrm{E}-17$ & $\mathrm{bd}$ & $\mathrm{bd}$ & $3.81 \mathrm{E}-15$ \\
\hline 331.5 & 37.9 & bd & bd & bd & $\mathrm{Bd}$ & bd & bd & bd & bd & na & na \\
\hline $\mathrm{pCi} / \mathrm{mol}^{3}$ & & $6.78 E+16$ & $3.49 E+17$ & $1.30 \mathrm{E}+17$ & $1.73 E+17$ & $4.58 E+17$ & $2.64 \mathrm{E}+16$ & $4.16 \mathrm{E}+16$ & $7.51 \mathrm{E}+16$ & $1.48 \mathrm{E}+13$ & $8.27 E+14$ \\
\hline
\end{tabular}

bd = below detection limit; na = not analyzed; isotopes were all below detection limit above 292 meter vertical depth.

${ }^{2}$ IAEA (1998a) partitioning ratio not reported.

${ }^{3}$ Conversion factor for calculating $\mathrm{pCi}$ from mol. 
CHAPTER 3: ALTERED PHYSICAL AND CHEMICAL SETTING

Table 3.5. Average concentrations of radionuclides detected in pumped waters at RNM-1.

\begin{tabular}{|c|c|c|c|c|c|c|c|c|c|c|}
\hline Zonel $^{1}$ & Tritium & Tritium $^{2}$ & ${ }^{85} \mathrm{Kr}^{2}$ & ${ }^{106} \mathrm{Ru}$ & ${ }^{125} \mathrm{Sb}$ & ${ }^{137} \mathrm{Cs}$ & ${ }^{90} \mathrm{Sr}$ & ${ }^{144} \mathrm{Ce}$ & ${ }^{147} \mathrm{Pm}$ & ${ }^{239} \mathrm{Pu}$ \\
\hline & \multicolumn{10}{|c|}{ 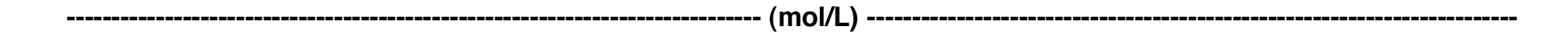 } \\
\hline II avg. & 3.1E-07 & 3.3E-07 & $9.0 \mathrm{E}-12$ & 8.7E-12 & $3.8 \mathrm{E}-13$ & 7.0E-14 & 3.0E-13 & $9.2 \mathrm{E}-13$ & $6.5 \mathrm{E}-16$ & 2.3E-13 \\
\hline sd & 6.7E-08 & & & $2.4 \mathrm{E}-12$ & $2.2 \mathrm{E}-13$ & $1.5 \mathrm{E}-14$ & $5.6 \mathrm{E}-14$ & $4.8 \mathrm{E}-13$ & $1.2 \mathrm{E}-17$ & $1.8 \mathrm{E}-13$ \\
\hline III avg. & 2.2E-07 & 2.4E-07 & $1.3 \mathrm{E}-11$ & $4.8 E-12$ & $9.4 \mathrm{E}-14$ & $6.5 \mathrm{E}-14$ & $2.5 \mathrm{E}-13$ & - & - & 7.7E-14 \\
\hline sd & 5.1E-09 & & & $3.2 \mathrm{E}-13$ & $8.8 \mathrm{E}-15$ & $2.4 \mathrm{E}-15$ & $3.1 \mathrm{E}-15$ & - & - & - \\
\hline IV avg. & 4.9E-09 & 5.3E-09 & $9.5 \mathrm{E}-13$ & - & - & $3.4 \mathrm{E}-14$ & $2.1 \mathrm{E}-13$ & - & - & - \\
\hline sd & 2.3E-10 & & & - & - & 5.6E-15 & $7.5 \mathrm{E}-15$ & - & - & - \\
\hline V avg. & 1.7E-09 & 1.3E-09 & $1.7 \mathrm{E}-13$ & - & - & $5.6 \mathrm{E}-15$ & 8.6E-15 & - & - & - \\
\hline sd & 3.3E-11 & & & - & - & $2.2 \mathrm{E}-15$ & $8.4 \mathrm{E}-16$ & - & - & - \\
\hline $\mathrm{pCi} / \mathrm{mol}^{3}$ & $2.91 \mathrm{E}+16$ & $2.91 \mathrm{E}+16$ & $3.32 E+16$ & $3.49 \mathrm{E}+17$ & $1.30 \mathrm{E}+17$ & $1.19 \mathrm{E}+16$ & 1.19E+12 & $4.58 \mathrm{E}+17$ & 1.36E+17 & $1.48 \mathrm{E}+13$ \\
\hline
\end{tabular}

${ }^{1}$ The location of the sampling zone is identified in Figure 3.5.

${ }^{2}$ Measured in pressurized water samples taken at the end of pumping.

${ }^{3}$ Conversion factor for calculating pCi from mol.

Table 3.6. Calculated $\mathrm{K}_{\mathrm{d}} \mathrm{s}$ for radionuclides based on data in Tables 3.4 and 3.5.

\begin{tabular}{|c|c|c|c|c|}
\hline & ${ }^{90} \mathrm{Sr}$ & ${ }^{125} \mathrm{Sb}$ & ${ }^{137} \mathrm{Cs}$ & ${ }^{239} \mathrm{Pu}$ \\
\hline & \multicolumn{4}{|c|}{ 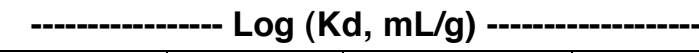 } \\
\hline Average & 2.5 & 2.2 & 3.8 & 6.2 \\
\hline Standard deviation & 0.6 & 0.5 & 0.3 & 1.4 \\
\hline
\end{tabular}




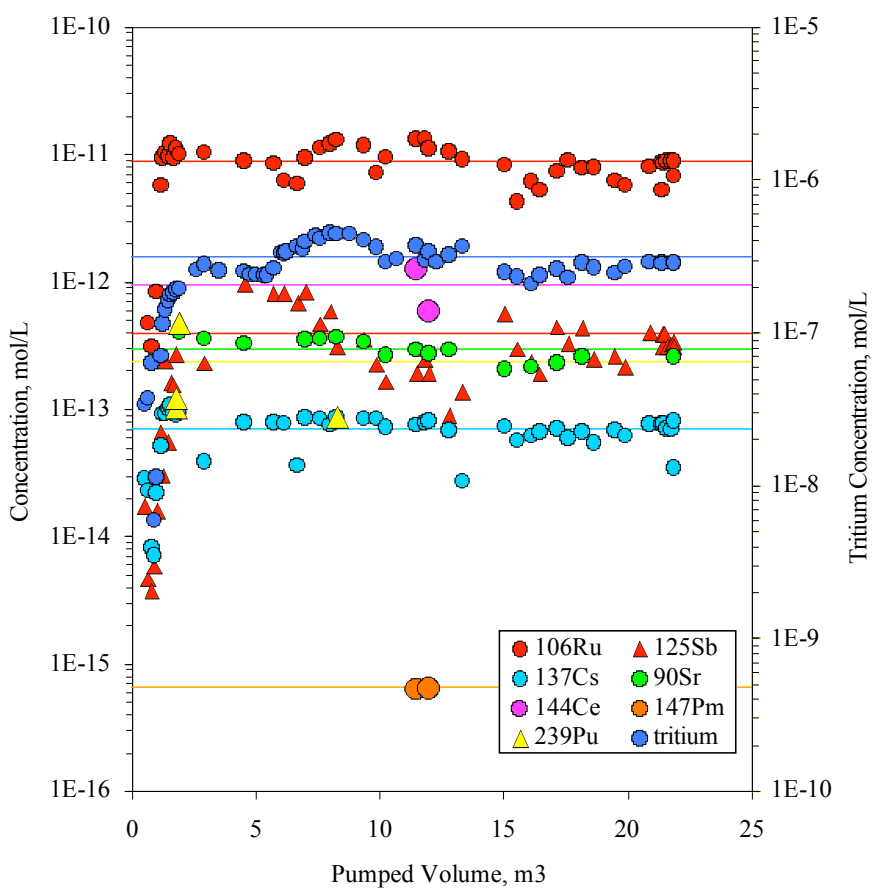

Figure 3.11 Radionuclide concentrations during pumping from Zone II of RNM-1. See Figure 3.5 for location information.

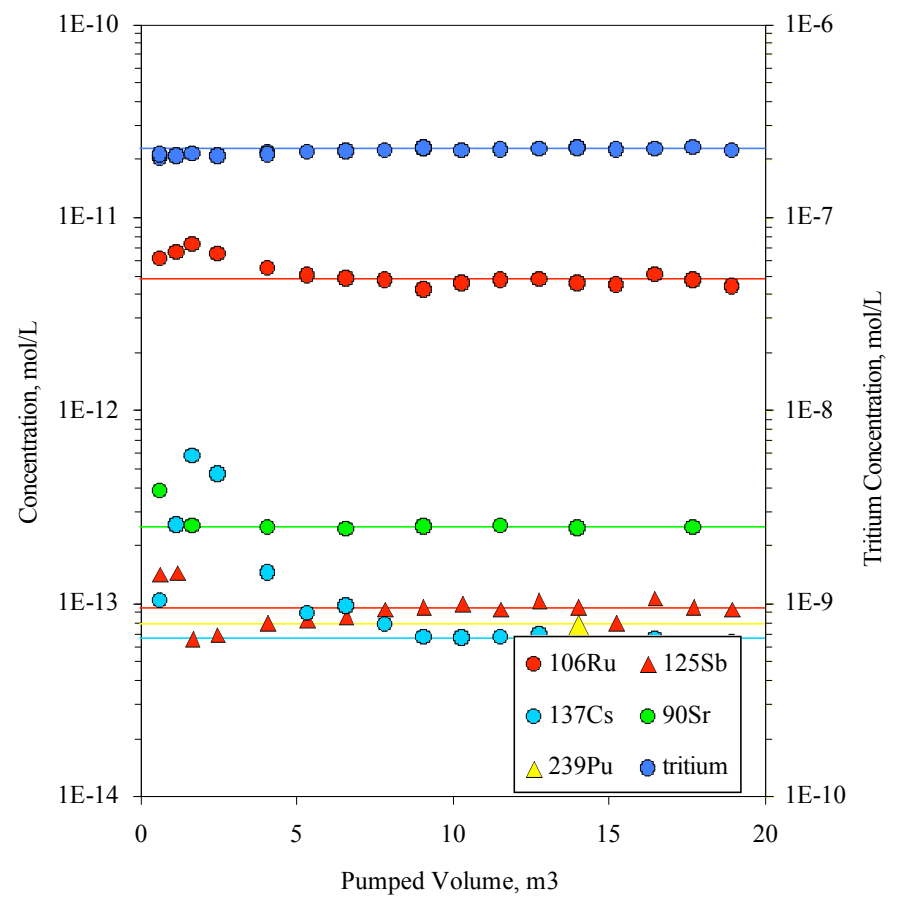

Figure 3.12 Radionuclide concentrations during pumping from Zone III of RNM-1. See Figure 3.5 for location information. 
CHAPTER 3: ALTERED PHYSICAL AND CHEMICAL SETTING

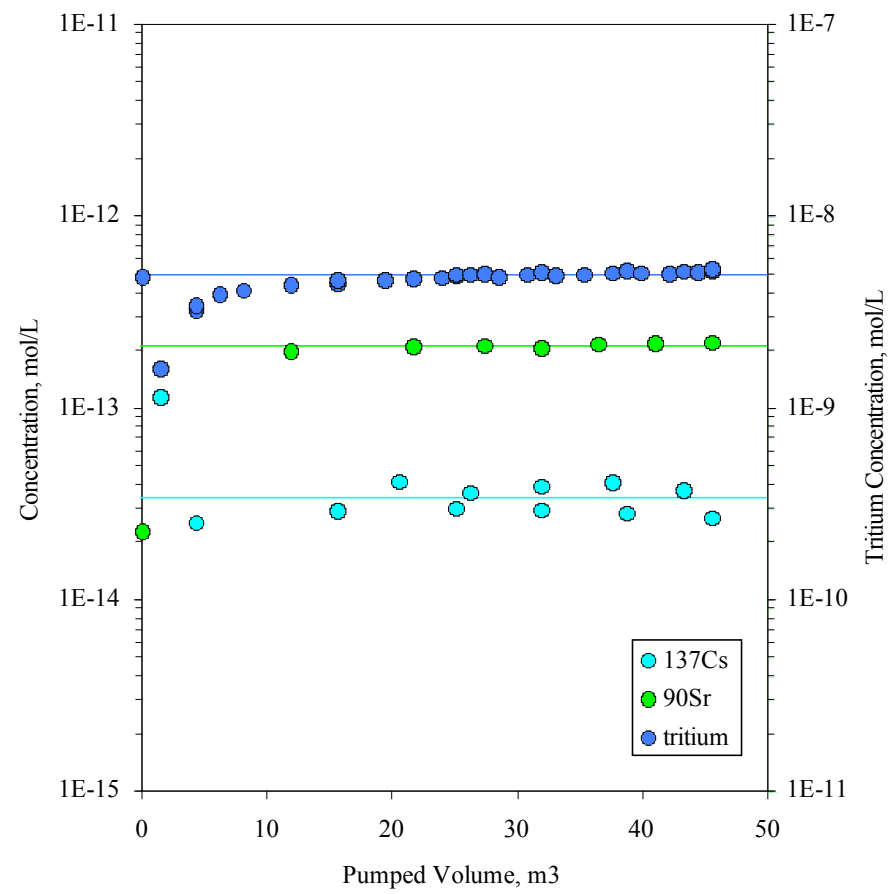

Figure 3.13 Radionuclide concentrations during pumping from Zone IV of RNM-1. See Figure 3.5 for location information.

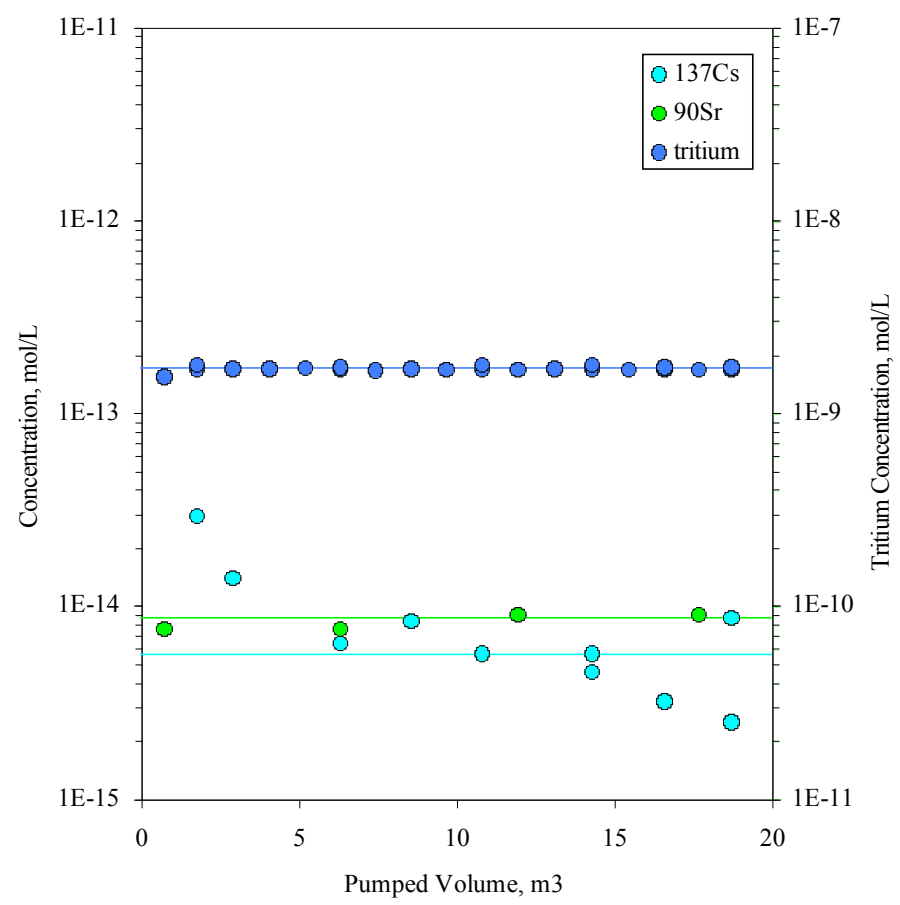

Figure 3.14 Radionuclide concentrations during pumping from Zone V of RNM-1. See Figure 3.5 for location information. 
Table 3.7 reports the major element chemistry of waters pumped from the five zones perforated in RNM-1. It is interesting to compare these values to the ambient groundwater chemistry in the vicinity of the CAMBRIC test (Table 2.1). Significant changes in the groundwater chemistry appear to have occurred as a result of the CAMBRIC test (Figure 3.15). Interestingly, the lowest zone, Zone I, appears to have been affected the least, which is consistent with the very low levels of radionuclides encountered at this depth interval. Zone II water appears to be affected the most, with higher sulfate and chloride concentrations and an overall increase in total dissolved salts. However, it should be noted that this zone's water chemistry may have been affected by cement that filled the annulus (Figure 3.5). Zones III, IV, and V have unusually low pHs and increased concentrations of $\mathrm{Ca}$ and $\mathrm{Mg}$. Interestingly, only Zone II is significantly supersaturated with respect to calcite $(\log (\mathrm{Q} / \mathrm{K})=0.8)$. Carbon dioxide (gaseous) fugacities in Zones 3 and 4 are quite high and may be the result of glass dissolution and secondary mineral precipitation reactions as well as $\mathrm{CO}_{2}(\mathrm{~g})$ released from calcite decomposition after the CAMBRIC test detonation. High levels of $\mathrm{CO}_{2}(\mathrm{~g})$ have been observed after a test, particularly in rocks with high calcite or dolomite contents.

Table 3.7. Average major element concentrations in pumped waters at RNM-1.

\begin{tabular}{|c|c|c|c|c|c|c|c|c|c|c|}
\hline Zone & $\mathrm{pH}$ & $\mathrm{Na}$ & K & $\mathrm{Mg}$ & $\mathrm{Ca}$ & $\mathrm{Sr}$ & $\mathbf{F}$ & $\mathbf{C l}$ & $\mathrm{HCO}_{3}^{-}$ & $\mathrm{SO}_{4}^{2-}$ \\
\hline & & \multicolumn{9}{|c|}{ 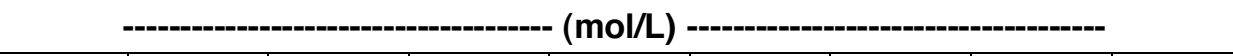 } \\
\hline I & 8.1 & 2.7E-3 & $1.9 \mathrm{E}-4$ & $1.8 \mathrm{E}-4$ & $4.2 \mathrm{E}-4$ & $3.4 \mathrm{E}-6$ & $3.2 E-5$ & 7.7E-4 & 2.7E-3 & $3.4 \mathrm{E}-4$ \\
\hline II & 8.4 & $5.4 \mathrm{E}-3$ & 4.7E-4 & $2.5 \mathrm{E}-4$ & $1.3 E-3$ & 4.3E-5 & $1.0 \mathrm{E}-4$ & $2.8 \mathrm{E}-3$ & $2.1 \mathrm{E}-3$ & $2.1 \mathrm{E}-3$ \\
\hline III & 7.2 & $5.6 \mathrm{E}-3$ & $5.2 \mathrm{E}-4$ & $1.0 \mathrm{E}-3$ & $1.8 \mathrm{E}-3$ & $1.3 \mathrm{E}-5$ & $2.1 \mathrm{E}-5$ & $1.3 \mathrm{E}-3$ & $7.8 \mathrm{E}-3$ & $1.5 \mathrm{E}-3$ \\
\hline IV & 7.0 & $4.2 E-3$ & $4.9 \mathrm{E}-4$ & $1.6 \mathrm{E}-3$ & $2.3 E-3$ & $9.9 \mathrm{E}-6$ & $1.2 \mathrm{E}-5$ & $9.2 \mathrm{E}-4$ & $9.1 \mathrm{E}-3$ & $1.2 \mathrm{E}-3$ \\
\hline V & 7.4 & $3.1 \mathrm{E}-3$ & 3.0E-4 & $8.4 \mathrm{E}-4$ & $1.2 \mathrm{E}-3$ & 7.4E-6 & $1.6 \mathrm{E}-5$ & $5.5 \mathrm{E}-4$ & $5.8 \mathrm{E}-3$ & $7.4 \mathrm{E}-4$ \\
\hline
\end{tabular}


CHAPTER 3: ALTERED PHYSICAL AND CHEMICAL SETTING

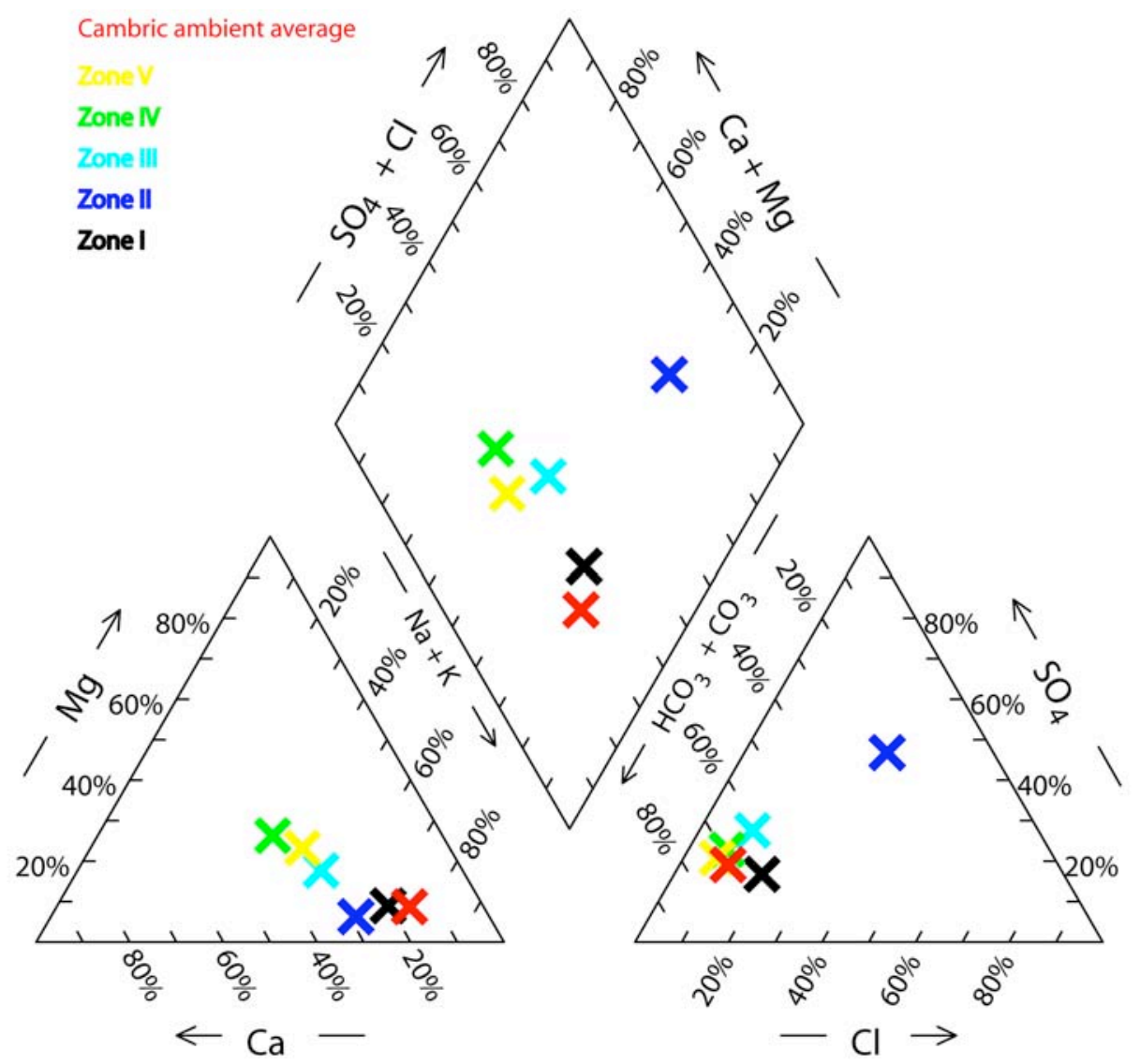

Figure 3.15 Piper diagram of major element chemistry of the pumped waters from five distinct zones within RNM-1. Ambient water chemistry from nearby wells (Table 2.2) is also plotted. 


\subsection{Radionuclide Transport Behavior During the Pumping Experiment}

As described in Section 1.3.2, beginning in October 1975, approximately $10 \mathrm{y}$ after detonation, groundwater adjacent to the CAMBRIC test cavity was pumped steadily for $16 \mathrm{y}$, with a few short interruptions, in order to elicit information on test-related radionuclide migration in the saturated zone (Hoffman et al., 1977; Daniels, 1982; and Bryant, 1992). The well was pumped at a rate of $300 \mathrm{gpm}$ for the first 700 days and at a rate of $600 \mathrm{gpm}$ thereafter. The pumping well (RNM-2S) is located approximately $91 \mathrm{~m}$ south of the emplacement hole and is screened over a $25-\mathrm{m}$ interval slightly below the elevation of the test cavity (Figure 1.2). A monitoring well (UE-5n) is located $529 \mathrm{~m}$ away from the pumping well and $106 \mathrm{~m}$ perpendicular to the ditch and is screened just below the water table. The pumping well effluent was regularly monitored for its radionuclide content, and well UE-5n and the RNM-1 were sampled occasionally. The effluent from RNM-2S was discharged to an unlined ditch and allowed to flow towards the Frenchman Lake playa, approximately $1.6 \mathrm{~km}$ to the southeast.

The ${ }^{3} \mathrm{H}$ concentration at RNM-1, RNM-2S, and UE-5n is plotted in Figure 3.16. At the start of pumping, the ${ }^{3} \mathrm{H}$ concentration in RNM-1 dropped exponentially with time. At about $28 \mathrm{y}$, after pumping was halted, the ${ }^{3} \mathrm{H}$ concentration in RNM-1 began to rise slightly with time. A similar rise was observed in UE-5n and may be the result of ${ }^{3} \mathrm{H}$ migration from the vadose zone to these wells. The concentration in RNM-2S peaked at around $15 \mathrm{y}$ and was followed by a steady decline. After pumping was stopped, the ${ }^{3} \mathrm{H}$ concentration in RNM-2S changed very little with time.

To compare the transport behavior of the various radionuclides, it is instructive to examine their concentration in relative terms. Figure 3.16 includes a plot of the relative ${ }^{3} \mathrm{H}$ concentration, in which the breakthrough concentration is divided by the RST for that radionuclide (the RST of Hoffman et al., 1977, is used here). One can assume that any non-sorbing tracer that is initially distributed in the same way as ${ }^{3} \mathrm{H}$ would have an identical breakthrough profile.

In general, the behavior of ${ }^{85} \mathrm{Kr}$ appears to be quite similar to that of ${ }^{3} \mathrm{H}$, as shown in Figure 3.17. However, one clear difference is the apparent absence of ${ }^{85} \mathrm{Kr}$ in UE-5n. This may be the result of ${ }^{85} \mathrm{Kr}$ noble gas loss to the atmosphere during the migration of pumped waters in the CAMBRIC ditch and through the vadose zone. Another interesting observation is that relative ${ }^{85} \mathrm{Kr}$ concentrations in RNM-1 are consistently higher than ${ }^{3} \mathrm{H}$ but consistently lower in RNM-2S samples. This may relate to differences in the initial distribution of these two radionuclides, with greater ${ }^{85} \mathrm{Kr}$ distribution higher in the chimney of the CAMBRIC test. 

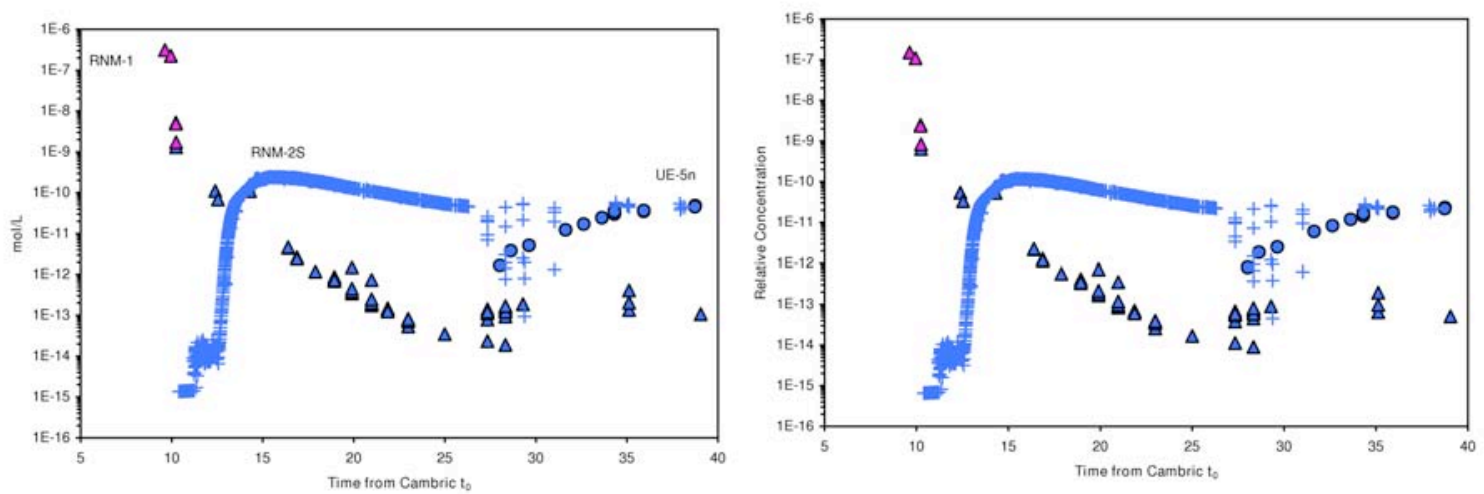

Figure 3.16 Tritium concentration at three wells near the CAMBRIC test: RNM-1 $(\Delta)$, RNM-2S (+), and UE-5n (o). Relative concentration is the observed concentration divided by the predicted total test-derived source term (2.08 moles). Initial RNM-1 sampling at various depth intervals (Table 3.5) is shown in pink.
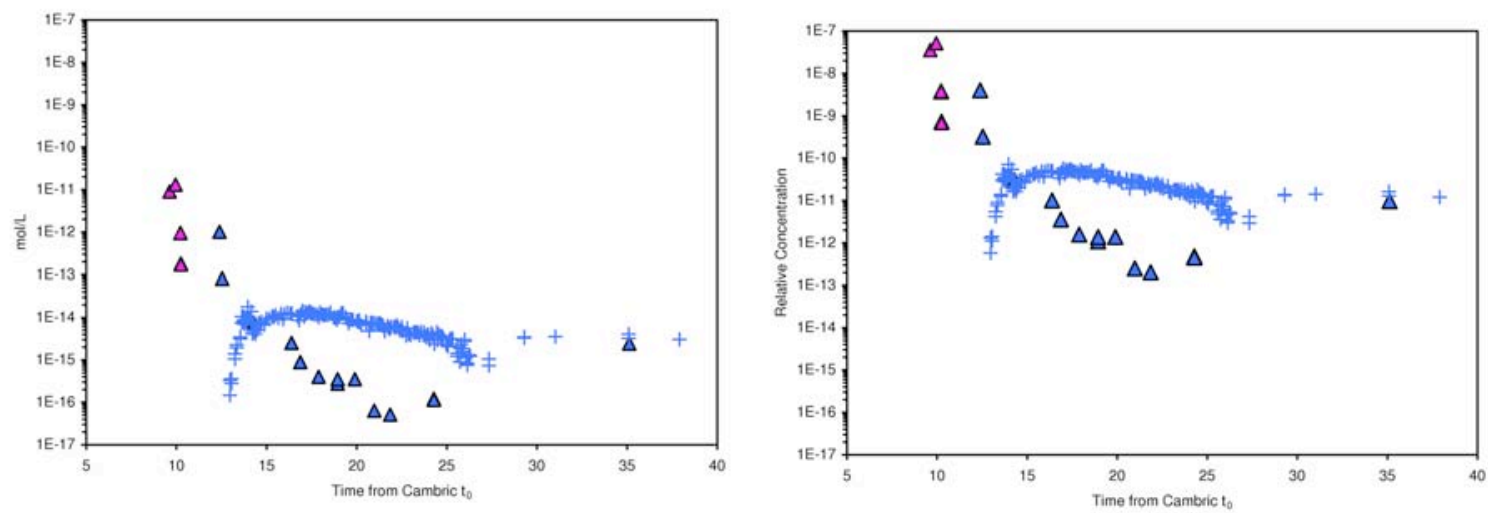

Figure 3.17 Krypton-85 concentration at three wells near the CAMBRIC test: RNM-1 $(\Delta)$, RNM-2S $(+)$, and UE-5n (0). Relative concentration is the observed concentration divided by the predicted total test-derived source term. Initial RNM-1 sampling at various depth intervals (Table 3.5 ) is shown in pink.

The migration behavior of $\mathrm{Cs}$ and $\mathrm{Pu}$ is dramatically different from ${ }^{3} \mathrm{H}$ and ${ }^{85} \mathrm{Kr}$ (Figure 3.18). No ${ }^{137} \mathrm{Cs}$ or ${ }^{239,240} \mathrm{Pu}$ has been observed at UE-5n. Extremely low concentrations were reported at the RNM-2S pumping well and only at the time of peak tracer breakthrough. The data at RNM-2S suggest that a very small fraction of ${ }^{137} \mathrm{Cs}$ and ${ }^{239,240} \mathrm{Pu}$ may have migrated unretarded, possibly by colloid-facilitated transport.

However, Buddmeier and Isherwood (1985) critically evaluated these measurements and concluded that they cannot be positively distinguished from blanks. Based on analysis of sample blanks, sample contamination could account for concentrations on the order of $10^{-17} \mathrm{~mol} / \mathrm{L}$ for ${ }^{137} \mathrm{Cs}$ and $10^{-16} \mathrm{~mol} / \mathrm{L}$ for ${ }^{239,240} \mathrm{Pu}$. Thus, ${ }^{137} \mathrm{Cs}$ and ${ }^{239,240} \mathrm{Pu}$ breakthrough at $\mathrm{RNM}-2 \mathrm{~S}$ is inconclusive. 
Interestingly, the ${ }^{137} \mathrm{Cs}$ concentration reaches steady state in RNM-1 rather early in the pumping experiment and remains constant. It is likely that the strongly sorbing radionuclide reached a sorption equilibrium with the surrounding rock. This would produce a stable aqueous ${ }^{137} \mathrm{Cs}$ concentration in the cavity. When plotted on the relative scale, it is apparent that the $\mathrm{Pu}$ is less mobile than $\mathrm{Cs}{ }^{4}{ }^{4}$ This suggests that $\mathrm{Pu}$ sorbs more strongly to the alluvium than Cs. It may also be indicative of the irreversible sorption or slow desorption of $\mathrm{Pu}$, which has been reported in the literature (e.g., Lu et al., 1999).
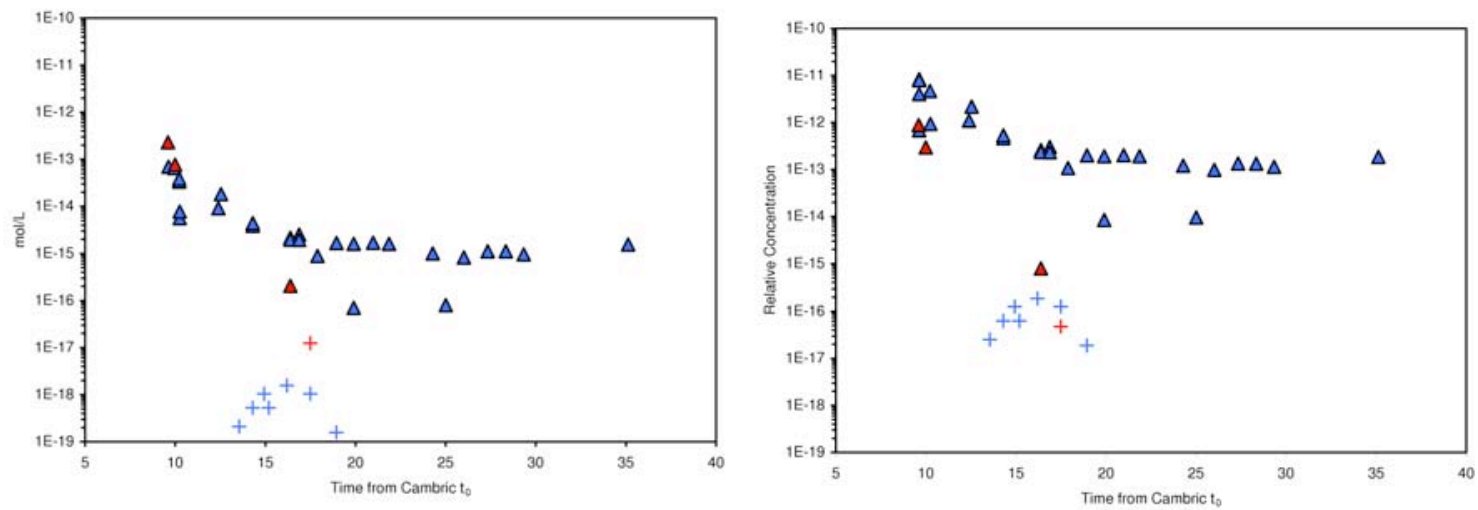

Figure 3.18 Cesium-137 (blue) and ${ }^{239,240} \mathrm{Pu}$ (red) concentration at two wells near the CAMBRIC test: RNM-1 $(\Delta)$ and RNM-2S $(+)$. Relative concentration is the observed concentration divided by the predicted total test-derived source term in the rubble and water.
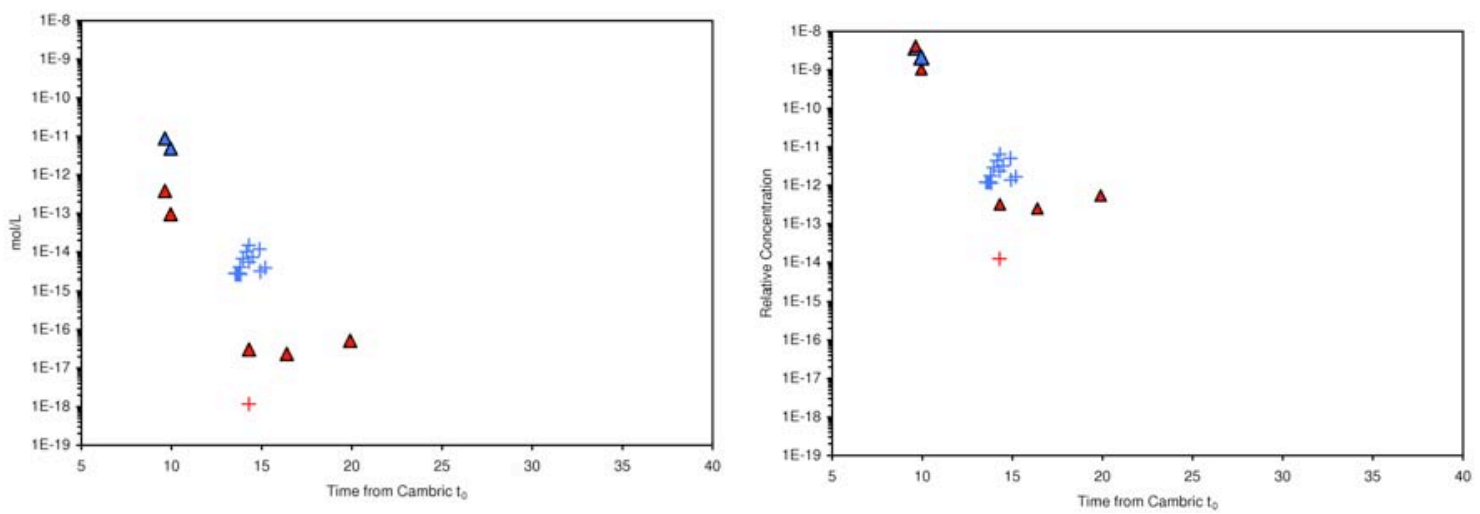

Figure 3.19 Ruthenium-106 (blue) and ${ }^{125} \mathrm{Sb}$ (red) concentration at two wells near the CAMBRIC test: RNM-1 $(\Delta)$ and RNM-2S (+). Relative concentration is the observed concentration divided by the predicted total test-derived source term in the rubble and water.

\footnotetext{
${ }^{4}$ To account for partitioning into the glass zone, the relative concentrations were calculated using the RST from Hoffman et al. (1977) and included only the rubble and water fractions of the source term based on partitioning from IAEA (1998a).
} 

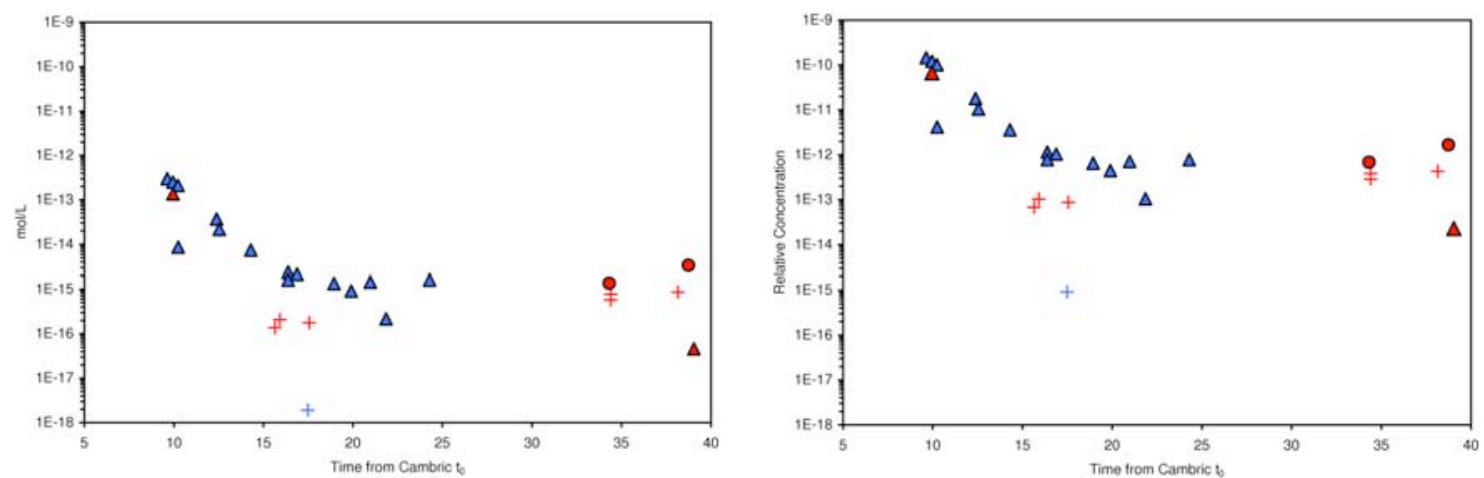

Figure 3.20 Strontium-90 (blue) and ${ }^{99} \mathrm{Tc}$ (red) concentration at three wells near the CAMBRIC test: RNM-1 $(\Delta)$, RNM-2s (+), and UE-5n (o). Relative concentration is the observed concentration divided by the predicted total test-derived source term in the rubble and water.

The migration rates of ${ }^{106} \mathrm{Ru}$ and ${ }^{125} \mathrm{Sb}$ appear to be similar (Figure 3.19). Both appear to be more mobile than ${ }^{239} \mathrm{Pu}$ and ${ }^{137} \mathrm{Cs}$. However, the limited data available for these two radionuclides makes the comparison qualitative. In addition, the very short half-life of both radionuclides - 1.0 and $2.8 \mathrm{y}$, respectively - make these radionuclides irrelevant in the timeframe for modeling an HST.

Although relatively few data exist for ${ }^{90} \mathrm{Sr}$ and ${ }^{99} \mathrm{Tc}$, some conclusions can be made regarding their migration to the pumping well and to UE-5n (Figure 3.20). The retardation behavior of ${ }^{90} \mathrm{Sr}$ appears to be similar to that of ${ }^{137} \mathrm{Cs}$, with little or no migration to RNM-2S and development of a steady-state concentration at RNM-1 $\left({ }^{90} \mathrm{Sr}\right.$ concentration in RNM-1 is buffered by sorbed ${ }^{90} \mathrm{Sr}$ ).

Only one extremely low ${ }^{90} \mathrm{Sr}$ concentration was reported at RNM-2S. As in the case of ${ }^{137} \mathrm{Cs}$, colloid-facilitated transport appears to be extremely limited or non-existent. The observed ${ }^{90} \mathrm{Sr}$ at RNM-2S is likely to be indistinguishable from blank samples, as described in Buddemeier and Isherwood (1985). Thus, ${ }^{90} \mathrm{Sr}$ breakthrough at RNM-2S is inconclusive.

The migration of ${ }^{99} \mathrm{Tc}$ appears to be somewhat retarded. However, retardation may be relatively weak. Importantly, the relative concentration in UE-5n and RNM-2S is similar at a late time ( 35 to $40 \mathrm{y}$ ), which is consistent with the observed transport behavior of ${ }^{3} \mathrm{H}$. Relative ${ }^{99} \mathrm{Tc}$ concentrations in RNM-1 are far lower than in RNM-2S and UE-5n. It is unclear why ${ }^{99} \mathrm{Tc}$ relative concentrations between 15 and $20 \mathrm{y}$ at RNM-2S were much lower than ${ }^{3} \mathrm{H}$. However, the data suggest that ${ }^{99} \mathrm{Tc}$ cannot be entirely non-sorbing.

Hoffman et al. (1977) do not report a ${ }^{36} \mathrm{Cl},{ }^{14} \mathrm{C},{ }^{129} \mathrm{I}$, or ${ }^{237} \mathrm{~Np}$ source term for CAMBRIC. Thus, the relative breakthrough of these radionuclides cannot be calculated. However, the breakthrough behavior of these radionuclides is still worth examining. The breakthrough of ${ }^{36} \mathrm{Cl}$ appears to be quite similar to that of ${ }^{3} \mathrm{H}$ (Figure 3.21). Between 35 and $40 \mathrm{y}$, concentrations in UE-5n are somewhat higher than in RNM-2S and much higher than in RNM-1. The apparently more efficient migration of ${ }^{36} \mathrm{Cl}$ to UE-5n may be an indication of some ${ }^{3} \mathrm{H}$ loss during surface flow and evapotranspiration in the CAMBRIC 


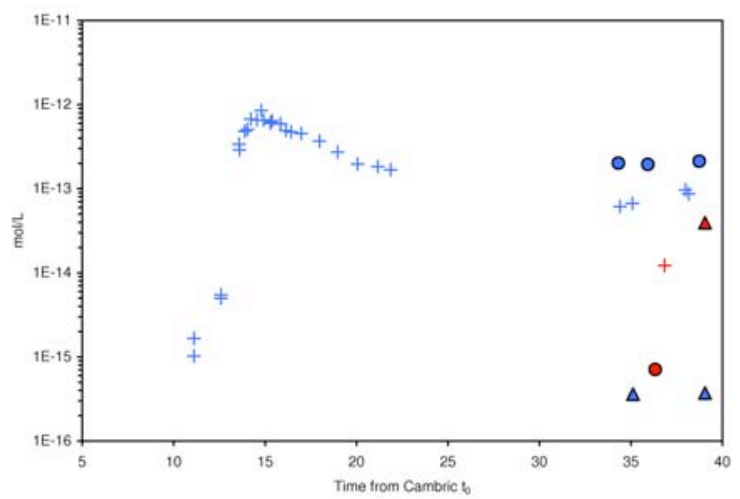

Figure 3.21 Chlorine-36 (blue) and ${ }^{14} \mathrm{C}$ (red) concentration breakthrough at three wells near the CAMBRIC test: RNM-1 $(\Delta)$, RNM-2S (+), and UE-5n (o).

trench. Interestingly, it appears that significant quantities of ${ }^{14} \mathrm{C}$ have not reached UE-5n in the $40 \mathrm{y}$ since the CAMBRIC test, indicating that ${ }^{14} \mathrm{C}$ is retarded. There are a number of processes that may control the migration of ${ }^{14} \mathrm{C}$ in this system. These include:

- Precipitation of calcite along the flowpath

- Surface exchange on the calcite surface

- Surface complexation to iron oxide and other mineral surfaces

- Losses to the vadose zone atmosphere

Importantly, the ${ }^{14} \mathrm{C}$ concentration in $\mathrm{RNM}-1$ is relatively high at $39 \mathrm{y}$ when compared to ${ }^{36} \mathrm{Cl}$. This suggests that ${ }^{14} \mathrm{C}$ release from the original source term location may be quite slow. However, additional data would be needed to further elucidate the transport behavior of ${ }^{14} \mathrm{C}$ at CAMBRIC.

The transport behavior of ${ }^{129} \mathrm{I}$ (Figure 3.22) is quite similar to other nonsorbing or weakly sorbing radionuclides (e.g., ${ }^{3} \mathrm{H},{ }^{99} \mathrm{Tc}$, and ${ }^{36} \mathrm{Cl}$ ). The concentration in RNM-1 decreases rapidly during pumping, it peaks at RNM-2S between 15 and $20 \mathrm{y}$, and its concentration at UE-5n approaches that of RNM-1 by $40 \mathrm{y}$. In general, the nonsorbing tracer concentration at RNM-1 at $40 \mathrm{y}$ tends to be lower than in the other two wells. However, concentration levels vary between the radionuclides and may be an indication of radionuclide release from the melt glass. For example, ${ }^{3} \mathrm{H}$ is not predicted to be incorporated into the melt glass and its concentration in RNM-1 is approximately 400 times lower than at the other two wells at $40 \mathrm{y}$. Chlorine-36 is 250 times lower while $50 \%$ of it is located in the glass. Technetium-99 is 20 times lower while $80 \%$ is located in the glass. Comparison of ${ }^{3} \mathrm{H},{ }^{99} \mathrm{Tc}$, and ${ }^{36} \mathrm{Cl}$ suggests that as more of the RST is distributed in the glass, the relative concentration in RNM-1 remains high. However, this correlation does not follow for ${ }^{129} \mathrm{I}$ and ${ }^{85} \mathrm{Kr}$. As discussed earlier, the initial distribution of ${ }^{85} \mathrm{Kr}$ may be unique because, as a noble gas, it may travel farther up the chimney than 
other non-gaseous radionuclides. The IAEA (1998a) predicts that, like ${ }^{36} \mathrm{Cl}, 50 \%$ of ${ }^{129} \mathrm{I}$ will be distributed in the melt glass. Thus, it would be expected that the relative concentrations of ${ }^{36} \mathrm{Cl}$ and ${ }^{129} \mathrm{I}$ are similar. However, the ${ }^{129} \mathrm{I}$ concentration in RNM-1 relative to the other two wells at $40 \mathrm{y}$ is much higher than for ${ }^{36} \mathrm{Cl}$. This suggests that either the fraction of ${ }^{129}$ I retained in the melt glass is much higher than predicted in IAEA (1998a) or ${ }^{129} \mathrm{I}$ is somewhat retarded. The latter is more likely though the retardation is, indeed, quite small.

Very few data are reported for ${ }^{237} \mathrm{~Np}$ (Figure 3.22). In fact, there are only three non-zero measurements reported: one measurement at each well at about $35 \mathrm{y}$. Due to the limited data set, it is rather difficult to interpret the observed transport behavior of ${ }^{237} \mathrm{~Np}$. These measured concentrations are quite uncertain (likely approaching the detection limit). Furthermore, the measured concentrations are higher than expected, particularly since the total ${ }^{237} \mathrm{~Np}$ inventory in Frenchman Flat amounts to only $6.37 \times 10^{-2}$ moles at CAMBRIC $t_{0}$. Nevertheless, it is worthwhile to investigate how this ${ }^{237} \mathrm{~Np}$ distribution may have come about. If ${ }^{237} \mathrm{~Np}$ were migrating as a tracer, the ${ }^{237} \mathrm{~Np}$ concentration in RNM-1 would be expected to be significantly lower than the other two wells at $35 \mathrm{y}$. If sorption was quite strong (e.g., ${ }^{137} \mathrm{Cs}$ and ${ }^{90} \mathrm{Sr}$ ), transport to UE-5n would not occur. Zavarin et al. (2002) performed flow-through experiments on UE-5n sediments and found ${ }^{237} \mathrm{~Np}$ to be retarded only slightly. Based on those flow-through experiments, the $\mathrm{K}_{\mathrm{d}}$ for ${ }^{237} \mathrm{~Np}$ is estimated to be on the order of $3.0 \mathrm{~mL} / \mathrm{g}$ with a resulting retardation factor of approximately 20 (using a bulk density of $2.0 \mathrm{~g} / \mathrm{cm}^{3}$ and a porosity of $30 \%$ ). This low retardation factor may be sufficient to allow some transport to UE-5n while retaining a significant portion on the source term at RNM-1. Significant concentrations in RNM-1 may also reflect the large fraction of ${ }^{237} \mathrm{~Np}$ that is associated with melt glass (approximately 95\%). Thus, it is possible to develop a realistic scenario by which ${ }^{237} \mathrm{~Np}$ concentrations in RNM-1, RNM-2S, and UE-5n would be similar at about $35 \mathrm{y}$. However, as noted earlier, due to the small number and uncertainty of these values, additional data collection would be needed to verify the transport behavior of ${ }^{237} \mathrm{~Np}$.

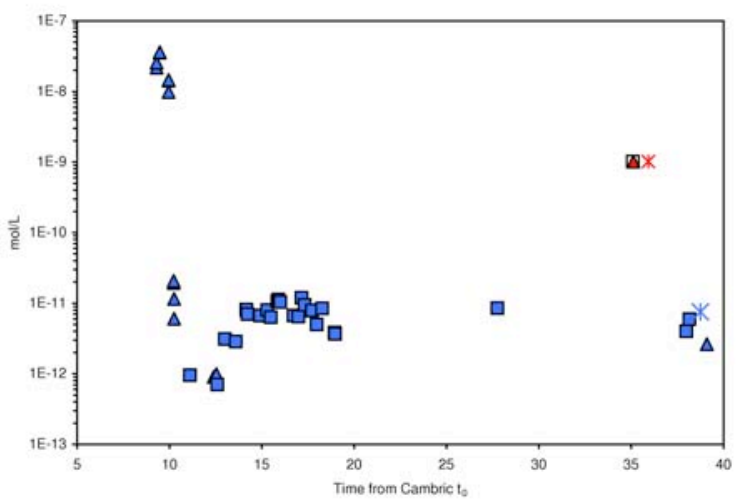

Figure 3.22 lodine-129 (blue) and ${ }^{237} \mathrm{~Np}$ (red) concentration breakthrough at three wells near the CAMBRIC test: RNM-1 $(\Delta)$, RNM-2S (+), and UE-5n (o). 


\section{$4 \quad$ Calibration and Assessment Models}

\subsection{Overview}

Calibration and assessment of the CAMBRIC HST model is necessary to verify that the hydrogeologic conceptual model and flow simulation parameters are consistent with known hydrogeologic data and interpretations near CAMBRIC and Frenchman Flat. Numerical flow and transport simulations are used extensively to perform this calibration and assessment. These simulations integrate data interpretation with physical and chemical processes including saturated and variably saturated transient groundwater flow, heat flow, physical and chemical heterogeneity, and nonreactive and reactive transport.

In both this chapter and Chapter 5, the specialized capabilities of LLNLdeveloped computer codes NUFT, ParFlow, and SLIM were used specifically to address the combined effects of test heat, hydraulic heterogeneity, transient unconfined groundwater flow, recirculation of groundwater through the vadose zone, and radionuclide transport. The NUFT code simulates variably saturated groundwater multiphase and multicomponent flow, heat flow, and transport using finite-differencebased Eulerian approaches. Transient groundwater flow fields from NUFT are used for streamline-based simulation of radionuclide transport using the reactive transport code CRUNCH. The ParFlow code efficiently simulates variably saturated groundwater flow for multimillion cell problems on a parallel computing platform using finite-difference algorithms. The SLIM code uses Langrangian (particle) methods to simulate nonreactive transport and reactive transport assuming linear sorption given flow fields generated externally by ParFlow. Once the calibration and assessment stage was completed, the resulting ParFlow flow simulations were used in simulation of radionuclide transport for the transient CAMBRIC HST (Chapter 5).

Neither the combined NUFT/CRUNCH nor combined ParFlow/SLIM simulation approaches by themselves can address all of the flow and transport phenomena considered necessary for calibration, assessment, and source term model development. This is why both the NUFT/CRUNCH and ParFlow/SLIM approaches were separately and sequentially used in the calibration and assessment phase (this chapter) and the source term model phase (Chapter 5) of this work. The NUFT simulations of groundwater flow focus on the relatively short-term (within $50 \mathrm{y}$ ) and near-field (less than 300-m scale) combined effects of test heat, local hydraulic gradient, pumping from RNM-2S, and CAMBRIC ditch discharge on the groundwater flow field near CAMBRIC. The NUFT flow simulations provide an integrated assessment of transient groundwater flow affected by test heat, pumping effects, and CAMBRIC ditch discharge that is used for the streamline-based modeling of reactive transport using CRUNCH (Section 4.8). With the exception of test heat, the ParFlow simulations also address the short-term and nearfield effects on groundwater flow including hydraulic gradient, pumping from RNM-2S, and CAMBRIC ditch discharge. In addition, the high-resolution capabilities of ParFlow enable consideration of macrodispersive effects of alluvial heterogeneity and merging of the HST-scale model with CAU-scale hydrostratigraphic units in central Frenchman Flat. The combination of the high resolution of ParFlow flow model with the computationally efficient particle-based transport simulation using SLIM enables assessment of long-term 
(greater than $50 \mathrm{y}$ ), larger-scale (greater than $300 \mathrm{~m}$ ), and multiple realizations of flow and transport near CAMBRIC.

Conceptual development of the hydrogeologic model for the NUFT and ParFlow flow simulations begins with characterization of alluvial hydrofacies and heterogeneity (Section 4.2). The hydrogeologic model conceptualization further considers test-related altered zones and thermal effects, intermediate-scale alluvial layering and intra-layer heterogeneity, and calibration to the RNM-2S MWAT and ${ }^{3} \mathrm{H}$ breakthrough data at RNM-2S. The hydrogeologic model for the ParFlow/SLIM simulations superposes smaller-scale heterogeneity onto the intermediate-scale layered heterogeneities in the NUFT simulations, while also incorporating large CAU-scale heterogeneities over distances of kilometers. The added resolution in the ParFlow/SLIM simulations is designed to better address longer-term effects of macrodispersion from small-scale heterogeneity within alluvial layers while also considering effects of pumping from RNM-2S and CAMBRIC ditch discharge.

Simulation of flow behavior near CAMBRIC requires interpretation of data for conceptualization of spatial distribution of hydraulic properties (Section 4.3) and groundwater flow conditions (Section 4.4). The primary sources of relevant information for near-field hydrogeologic model conceptualization are lithologic descriptions, singlewell hydraulic testing data, the RNM-2S MWAT, and water level and pressure information used to infer hydraulic gradients.

The NUFT code's flow and simulation capabilities used in this CAMBRIC HST modeling work include unconfined (water table) aquifer conditions, variable saturation, thermal, multiphase (e.g., simultaneous gas and liquid), and multicomponent (e.g., air, water, contaminant, etc.) flow and transport. The NUFT code is applied in different cases that incorporate all or portions of the above-mentioned capabilities. Most of the NUFTrelated flow and transport results discussed in this chapter, unless specified otherwise, relate to the CAMBRIC HST base-case transient flow conditions (Section 4.6) used for the streamline-based CRUNCH simulation of reactive transport of radionuclides (Section 4.8.3). Simplified water table aquifer system conditions are simulated for interpretation of the RNM-2S MWAT (Section 4.5.1). Other NUFT simulation sensitivity study cases are designed to assess effects of different initial temperature distributions, two-phase water flow (including consideration of boiling), and transport of water gas in the cavity (Section 4.7).

The NUFT code was used in four stages of flow-model calibration and assessment to:

- Reinterpret the RNM-2S MWAT and calibrate to ${ }^{3} \mathrm{H}$ breakthrough data at RNM-2S (Section 4.5)

- Describe and evaluate transient flow and transport simulation results for the base-case hydrogeologic model (Section 4.6)

- Interpret results from sensitivity studies primarily focused on thermal effects (Section 4.7)

- Describe and evaluate results from CRUNCH streamline-based simulation of nonlinear reactive transport (Section 4.8) 
In Chapter 5, the ParFlow/SLIM models are used to:

- Study long-term (1,000-y) isothermal flow behavior under pumping and ditch recharge conditions associated with the RNM experiment, considering both saturated and variably saturated flow

- Develop the specific hydrologic source term over 1,000 y for CAMBRIC under these flow conditions

Both the NUFT/CRUNCH and ParFlow/SLIM simulations for the HST focus on development of separate base-case models for which the hydrogeologic conceptual models and flow and transport parameters are fixed in each case. The NUFT/CRUNCH and ParFlow/SLIM base-case models, though not identical, are designed to be mutually consistent with respect to representation of hydrogeologic, geochemical, and test-related factors that could impact radionuclide transport behavior. Sensitivity studies are performed to examine effects on simulation results relative to the base case for flowrelated parameters, including heat, in Section 4.7 and for reactive transport-related parameters in Chapter 5.

\subsection{Hydrogeologic Model Conceptualization}

This section describes geologic, hydrogeologic, and test-related phenomenological data and interpretation considered in developing hydrogeologic conceptual models of the CAMBRIC test site within Frenchman Flat.

\subsubsection{Frenchman Flat Hydrostratigraphic Units}

Cross sections of the hydrostratigraphic sequence in Frenchman Flat are shown in Figure 2.4. Quaternary- to Tertiary-age alluvial deposits fill the Frenchman Flat basin to thicknesses of 1,000 m or more near CAMBRIC (Bechtel Nevada, 2005b). In the CAU model, alluvial deposits situated near CAMBRIC are categorized by CAU hydrostratigraphic units (HSU) as the alluvial aquifer (AA). A playa confining unit (PCU1U) is situated within the AA unit beneath CAMBRIC at depths of about 697 and 900 m, based on lithologic data for ER-5-4 (Warren et al., 2002 and Bechtel Nevada, 2005b).

The vertical sequence of HSUs between the lower carbonate aquifer (LCA) and Frenchman Flat alluvial aquifer (AA) include the volcaniclastic confining unit (VCU), lower tuff confining unit (LTCU), lower vitric tuff aquifer (LVTA), Topopah Spring aquifer (TSA), Timber Mountain lower vitric tuff aquifer (TMLVTA), Timber Mountain welded tuff aquifer (TMWTA), and lower playa confining unit (PCU1L). 


\subsubsection{Layered Conceptual Model and Hydrofacies}

The lithologic interpretations of Ramspott and McArthur (1977) and Warren et al. (2002) (shown schematically in Figure 2.10) suggest distinctive alluvial layers within the alluvial deposits of Frenchman Flat. However, layer dip angles and bounding surfaces, in reality, are expected to vary laterally. Additionally, lithologic, textural, and mineralogic characteristics are expected to vary laterally and with depth. Nonetheless, the alluvial layers do provide a correlative structural framework to address intermediate-scale heterogeneity within the AA hydrostratigraphic unit. Unfortunately available data are insufficient to construct the 3D structure of alluvial layering near CAMBRIC.

A 3D seismic reflection survey conducted in Frenchman Flat has imaged the PCU1U (Layer 9) within the alluvial deposits and has suggested possible locations for some contacts between "younger" alluvium and "older" alluvium (Bechtel Nevada, 2005b). The PCU1U is interpreted from seismic data to have shallow synclinal eastward dip within Frenchman Flat basin. The 3D seismic survey data lack resolution to image or interpret shallow alluvial hydrostratigraphy or layering within the Frenchman Flat alluvial deposits.

Given apparent contrasts in hydraulic and mineralogic properties between different alluvial layers near CAMBRIC, a layered hydrogeologic conceptual model was assumed as an approximation to local hydrological and mineralogical stratigraphy. The true alluvial hydrostratigraphy is undoubtedly much more complex than horizontal layers. A horizontally layered conceptual model of alluvial heterogeneity is accepted as a relatively crude approximation, geologically, to the true alluvial hydrostratigraphy near CAMBRIC. It would be possible to construct more geologically realistic interpretations of the alluvial hydrostratigraphy, but not without considerable subjectivity and uncertainty.

Drill holes RNM-1, RNM-2, and RNM-2S are closest to CAMBRIC, but provide relatively scant lithologic information. Hoffman et al. (1977) note that sediments were generally finer grained in RNM-2 below a depth of $230 \mathrm{~m}$. The lithologic information from ER-5-4 provides the most complete description of the alluvial layering to a depth of over 1,000 m. The lithologic column of ER-5-4 given by Warren et al. (2002, p. 51) and shown in Figure 2.9 was used to define depth ranges for alluvial hydrofacies - rock units with distinctive hydraulic properties. All layers are assumed horizontal, which is certainly an approximation to dip angles of $4.0^{\circ}$ to $9.7^{\circ}$ for the Layer 2-3 contact and the Layer 5-6 contact as interpreted by Warren et al. (2002). Three adjustments were made relative to the ER-5-4 alluvial layer contacts in consideration of other information: 
- The Layer 2-3 contact is positioned $8 \mathrm{~m}$ lower, moved from 254 to $262 \mathrm{~m}$ in depth. Warren et al. indicate that the basal elevation of Layer 2 is at least $8.7 \mathrm{~m}$ lower at RNM-1 than at ER-5-4. However, Stoller-Navarro (2006a) indicate that water levels are consistently about $2.5 \mathrm{~m}$ lower in RNM-1 compared to ER-5-4 (piezometer), RNM-2, RNM-2S, and UE-5n, suggesting that the estimated depth for the slant-drilled RNM-1 is approximately $2.5 \mathrm{~m}$ too low at the vicinity of the water table (in Layer 2). Correcting for the water table discrepancy, the basal elevation of Layer 2 would then be approximately $6.2 \mathrm{~m}$ (instead of $8.7 \mathrm{~m}$ ), or more, lower at RNM-1 than at ER-5-4.

- The thickness of Layer 4 was increased from 3.4 to $4 \mathrm{~m}$ to better accommodate the 2-m grid block thickness in the ParFlow flow model.

- The Layer 3-4 contact was moved up by $4 \mathrm{~m}$. Layer 4 is situated within the depth range of the screened interval of RNM-2S. Moving the Layer 34 contact up by $4 \mathrm{~m}$ improved calibration to both drawdown response and ${ }^{3} \mathrm{H}$ breakthrough at RNM-2S from the RNM experiment.

An important feature is to fix the hydrogeologic location of the working point. The CAMBRIC test working point depth of $294 \mathrm{~m}$ is most likely situated in Layer 3. Layer 3 , described predominately as silty sand, is relatively finer grained and lower in permeability than Layer 2, which is described as a gravelly sand or pebbly sandy conglomerate (Warren et al., 2002). Based on the Layer 2-3 contact depth range estimates of between 266 to $299 \mathrm{~m}$ given by Warren et al. (2002), it is possible that the CAMBRIC working point could have been situated in Layer 2. However, Hoffman et al. (1977, p. 28) estimated relatively low hydraulic conductivity of $0.15 \mathrm{~m} / \mathrm{d}$ within the CAMBRIC cavity, which presumably consists of collapsed alluvium from above the working point depth and beyond the cavity radius. The relatively low permeability of the collapsed cavity material suggests that CAMBRIC was situated well below the Layer 2-3 contact. An integrated analysis of the RNM-2S MWAT (Section 4.5.1) indicates that the permeability of Layer 3 is as much as two orders of magnitude lower than the permeability of Layer 2 .

Layer 4 is described as GRAVEL COBBLE/BOULD in the Well ER-5-4 lithologic log provided by Stoller-Navarro (2004a). Layer 4 is thin at ER-5-4 and was not observed in UE-5n (Warren et al., 2002). The depth of Layer 4 at ER-5-4 is situated below the CAMBRIC cavity and within the screened interval of RNM-2S. Thus, Layer 4 or similar coarse-grained unit(s) between CAMBRIC and the screened interval of RNM-2S could have significant effect on drawdown response and breakthrough behavior at RNM-2S from the CAMBRIC RNM experiment. Analysis of the drawdown response at RNM-2S required a higher permeability unit, such as for Layer 4 within the RNM-2S screened interval, compared to permeabilities of Layer 3 and Layer 5. 
Layers 1 (entirely in the vadose zone), 2, 3, and 4 are the most important layers affecting near-field flow and radionuclide transport related to estimation of the CAMBRIC source term and calibration to data related to the RNM experiment. The RNM-2S MWAT provides further insight into permeability of Layers 1-4 in addition to Layers 5-8. Layer 9 functions as an aquitard (PCU1U), while Layers 10-12 comprise a deeper aquifer. Section 4.3 discusses layer and hydrofacies hydraulic properties.

The basal portion of Layer 2, specified in NUFT and ParFlow simulations as Layer $2 b$, may play an important role in groundwater flow and transport as a particularly transmissive zone located below the water table within Frenchman Flat alluvium. Several lines of evidence indicate presence of a highly transmissive and laterally extensive layer of alluvium near the base of Layer 2 within the vicinity of CAMBRIC:

- Pumping-test data in Frenchman Flat indicate hydraulic conductivities up to $45 \mathrm{~m} / \mathrm{d}$ within the depth range of Layer $2 \mathrm{~b}$ (Figure 4.3).

- Calibration to the RNM-2S MWAT indicates lateral hydraulic conductivity of $24 \mathrm{~m} / \mathrm{d}$ at the base of Layer 2 (Section 4.5.1).

- The texture of Layer 2 is described by Warren et al. (2002, Figure 2.9) as "pebbly sandy conglomerate," while all other layers (Layers 3-8) located below the water table and above the PCU1U confining unit (Layer 9) are finer-grained silts or silty sands, except for the thin Layer 4 (another highpermeability layer).

- Based on particle size distribution data for RNM-1, Stone (1975) estimates higher hydraulic conductivity of $6.5 \mathrm{~m} / \mathrm{d}$ in a $10-\mathrm{m}$ interval near the base of Layer 2 compared to a $38-\mathrm{m}$ interval above (3.1 to $4.1 \mathrm{~m} / \mathrm{d}$ ).

- Sieve data at UE-5n (Figure 4.2), over $500 \mathrm{~m}$ distant from CAMBRIC, indicate an increase in coarse-grained material and decrease in finegrained material within the basal $17 \mathrm{~m}$ of Layer 2 (Ramspott and McArthur, 1977). From the UE-5n sieve data, Burbey and Wheatcraft (1986) estimate hydraulic conductivity ranging from 11.2 to $26.5 \mathrm{~m} / \mathrm{d}$ within a 10-m interval at the base of Layer 2 (Section 4.3.1.2).

- An erosional contact exists between Layers 2 and 3 (Warren et al., 2002). The sharp transition from deposition of relatively fine-grained silty alluvium to coarse-grained conglomerate of Layer 2 suggests rapid increase in rates of basin subsidence and/or uplift of the Rock Valley structural block (Warren et al., 2002). Presence of more coarse-grained alluvium within the basal $10 \mathrm{~m}$ of Layer 2 suggests an initial period of relatively higher-energy flow conditions or greater sediment supply, both of which could be attributed to rapid source block uplift or basin subsidence rates. Lateral extent of episodic alluvial fan depositional packages could be on the order of kilometers, as indicated by Figure 2.3. 
- By correlating the RNM-2S pumping test analysis of drawdown response at RNM-2S, RNM-1, RNM-2, and ER-5-4 (Section 4.5.1) with sieve data and hydraulic conductivity estimates at RNM-1 and UE-5n, a relatively high transmissivity at the base of Layer 2 could extend laterally near CAMBRIC over distances of at least hundreds of meters.

- In the most recent previous investigations of ${ }^{3} \mathrm{H},{ }^{36} \mathrm{Cl}$, and ${ }^{85} \mathrm{Kr}$ transport associated with the RNM-2S experiment, a high-permeability interval was assumed near the base of Layer 2 to achieve calibration to breakthrough at RNM-2S. Burbey and Wheatcraft (1986) and Guell and Hunt (2003) assume hydraulic conductivities of $7.5 \mathrm{~m} / \mathrm{d}$ and $15 \mathrm{~m} / \mathrm{d}$, respectively, in a 15-m-thick interval near the base of Layer 2 .

- Water level data within the Frenchman Flat CAU indicate a very small horizontal hydraulic gradient of uncertain direction (Sections 2.2.2 and 6.4). The small horizontal hydraulic gradient within the Frenchman Flat CAU could be explained by a laterally extensive high-permeability zone below the water table combined with low horizontal groundwater flux in Frenchman Flat.

Unfortunately, the lateral extent of a high-permeability basal zone in Layer 2 is not well constrained beyond ER-5-4, RNM-1, and UE-5n. It is possible that coarsegrained zones are arranged in discontinuous lenses, as could occur from episodic flooddominated deposition. If channel belts developed (e.g., from high flow rates combined with excessive sediment load), a zone of coarse-grained deposits could be quite interconnected and laterally extensive to distances of hundreds of meters or more laterally and kilometers longitudinally. In either case, a single, connected zone of coarse-grained deposits is not expected to be continuous throughout Frenchman Flat.

\subsubsection{Advantages and Disadvantages of a Layered Conceptual Model}

Several advantages of using a layered conceptual model instead of a homogeneous conceptual model for hydrogeologic interpretation (USGS, 2004 and Stoller-Navarro, 2004a) are:

- Consideration of variation of hydraulic properties related to the vertical succession of alluvial hydrostratigraphy near CAMBRIC, particularly the strong contrast of hydraulic properties between the Layer 2-3 contact

- Consideration of laterally-continuous zones of relatively high or low permeability

- Consistency with available lithologic, mineralogic, and aquifer testing data

- Consideration of field observations indicating the alluvial fan deposits are layered

There are several obvious disadvantages of a layered conceptual model used for calibration to the MWAT and subsequently for modeling flow and transport adjacent to CAMBRIC: 
- Random heterogeneity exists within the layers. Intra-layer heterogeneity may have little effect on flow calibration, but such small-scale heterogeneity will cause macrodispersion. The high-resolution ParFlow simulation code, in conjunction with the SLIM code's particle tracking techniques, are used to address small scale intra-layer heterogeneity (Chapter 5).

- In reality, the layers are not tabular. Indeed, Warren et al. (2002) suggest that the composite thickness of Layers 3-5 is $91.4 \mathrm{~m}$ at ER-5-4, $102.1 \mathrm{~m}$ at UE-5n, and less than $54 \mathrm{~m}$ thick at RNM-1. Unfortunately, data are too sparse at RNM-1 to confidently constrain the structure of the alluvial layering. Warren et al. (2002) further point out that contacts between Layers 2 and 3 and Layers 5 and 6 show dips between $4^{\circ}$ and $10^{\circ}$ at azimuths ranging from east through southwest. The contact between Layer 2 and 3 is erosional.

- Layer bulk hydraulic and mineralogic properties likely vary both laterally and vertically as related morphology of alluvial deposition. For example, grain size will likely increase toward the alluvial fan source areas. Mineralogy will vary with position depending on shifts in depositional patterns and diagenic processes.

The combination of unknown alluvial layer stratigraphy, heterogeneity, lateral and vertical gradations, dip angles, and erosional surfaces near CAMBRIC cause considerable uncertainty in the conceptualization and prediction of flow and transport. The assumption of a layered heterogeneity is only a first approximation to the true heterogeneity within the alluvium adjacent to CAMBRIC.

\subsubsection{Alluvial Heterogeneity}

As noted in Chapter 2, there is noticeable small-scale spatial variability in the physical composition of the alluvium over depth. This variability can give rise to variations in the hydrologic and chemical properties of the material, such as hydraulic conductivity, porosity, and chemical sorptive capacity, both within the alluvial layers as well as the altered material surrounding the working point (see below). Although not included in the NUFT calculations described in this chapter, a finer level of detail is used in the ParFlow/SLIM calculations of Chapter 5 to represent small-scale heterogeneity of the material properties within the layers and altered zones surrounding the cavity and ditch infiltration areas. The approach employs a stochastic, spatially correlated Gaussian random field model to represent heterogeneity in the hydraulic conductivity in each layer. This parallels the approach used to represent heterogeneity in the previous CAMBRIC HST calculations (Tompson et al., 1999).

The parametric characteristics of the stochastic conductivity distribution specified in the alluvial layers were chosen to be consistent with available information on alluvial heterogeneity (as in Tompson et al., 1999), and also ensure that the effective (scaled-up) conductivities associated with each distribution in each layer match their homogeneous counterparts developed in the NUFT calibration and assessment simulations in this chapter. The homogeneous layer conductivities developed in the 
NUFT calibration represent effective scale properties for each alluvial layer. Additional details can be found in the discussions below, in Chapter 5, and in Tompson et al. (2005).

\subsubsection{Altered Zones}

The term "altered zones" is used to group the zones of rock or hydrofacies associated with thermal, shock, or mechanical collapse-related disturbances caused by the CAMBRIC test. In the NUFT and ParFlow simulations, the altered zones are superposed over the alluvial layers. The altered zones include:

- melt glass zone

- cavity

- compressed zone

- pimento

- chimney

The melt glass zone is distinguished by presence of melt glass commingled with collapse debris. The cavity consists of collapse debris within the former spherical extent of melted and vaporized rock, but not including the melt glass zone. The compressed zone is a spherical shell outside the cavity composed of shocked in-situ rock, not including the collapsed portion above the cavity. The "pimento" refers to the location of the former portion of the compressed zone that collapsed downward toward the cavity. The chimney consists of alluvium collapsed downward toward the cavity. The chimney is divided into hydrofacies related to different alluvial layers.

As discussed in Section 4.3.2, each altered zone hydrofacies is assumed to have a distinctive set of hydraulic properties. Undoubtedly, the actual hydraulic property distributions in the altered zones likely exhibit spatial trends in hydraulic properties. For example, the melt glass zone may have a higher proportion of melt glass toward the bottom with more rubble higher in the zone, and the compressed zone may be decreasingly shocked and compressed with increasing radial distance. Such spatial trends in altered zone hydrofacies hydraulic properties are not considered in the NUFT and ParFlow simulations for lack of characterization information and simulation resolution.

\subsubsection{Simulation Domain and Discretization}

\subsubsection{Simulation Area}

Both the NUFT and ParFlow simulations of groundwater flow use similar rectangular domains to bound extent of the area of flow and transport simulation. Each rectangular domain is rotated counterclockwise $41^{\circ}$ to align with surface features, particularly the CAMBRIC ditch, the geomorphology of Frenchman Flat near CAMBRIC, and distant water wells (Figure 1.1). The length, width, and depth of the two domains differ slightly, as described below.

Both the NUFT and ParFlow flow simulation domains use "telescoping grids" where discretization or size of grid blocks varies within the finite-difference mesh. Gridblock size variation is designed to decrease computational burden without compromising resolution of flow and transport behavior of importance to modeling the HST, 
particularly the CAMBRIC test-altered zones, the RNM-2S pumping well, the CAMBRIC ditch, and impacts of small-scale hydraulic and mineralogic heterogeneity.

\subsubsection{NUFT Simulation Domain and Grid}

The NUFT flow simulation domain is a rectangular box. The size of the NUFT flow simulation domain is $6,000 \mathrm{~m}$ by $7,500 \mathrm{~m}$ by $1,000 \mathrm{~m}$ in the $x, y$, and $z$ directions, respectively. The positive $z$ direction is vertically upward, and the positive $x$ and y directions are northeast and northwest in the horizontal plane. Specifically, the $x$ direction is $\mathrm{N} 41 \mathrm{E}$ (northeast), and the y direction is $\mathrm{N} 49 \mathrm{~W}$ (northwest). The origin of the coordinate system, $x, y, z=(0,0,0)$, is the CAMBRIC working point at $294 \mathrm{~m}$ below ground surface. The minimum and maximum limits of the rectangular domain relative to the CAMBRIC working point are shown in Table 4.1. The bottom of the domain, $706 \mathrm{~m}$ below the working point and 1,000 m below the ground surface, is $44 \mathrm{~m}$ below sea level.

The NUFT flow simulation domain extends above the ground surface to include the CAMBRIC ditch source. An extra 1-m-thick layer of cells is added above the ground surface for an atmospheric boundary condition. For simplification, the NUFT flow simulation assumes the ground surface is horizontal with respect to the elevation of the ground surface located $294 \mathrm{~m}$ above the CAMBRIC working point.

The NUFT flow simulation domain or grid is discretized into 308,637 cells; 69,63 , and 71 cells in the northeast, northwest, and vertical directions, respectively. The number of grid cells was computationally limited by available single-processor RAM of $4 \mathrm{~GB}$ and practical considerations of computational processing time lasting days to weeks. Table 4.2 shows northeast, northwest, and vertical cell sizes starting from each coordinate minimum. The NUFT coordinate system minima begin at the lower (outside) edge of the first cell for each direction, such that coordinate minimum of the first cell in each direction is located on the outside edge of the flow simulation domain.

Table 4.1. Minimum and maximum extent of the NUFT simulation domain relative to CAMBRIC working point.

\begin{tabular}{|l|l|l|l|}
\hline \multicolumn{1}{|c|}{ Direction } & \multicolumn{1}{|c|}{$\boldsymbol{x}$} & \multicolumn{1}{c|}{$\boldsymbol{y}$} & \multicolumn{1}{c|}{$\boldsymbol{z}$} \\
\hline Minimum & $-2,000 \mathrm{~m}$ & $-4,000 \mathrm{~m}$ & $-706 \mathrm{~m}$ \\
\hline Maximum & $4,000 \mathrm{~m}$ & $3,500 \mathrm{~m}$ & $+295 \mathrm{~m}$ \\
& & & $(1 \mathrm{~m}$ above ground surface $)$ \\
\hline
\end{tabular}


Table 4.2. NUFT flow simulation discretization information with cell minimum ( $\mathrm{min}$ ), coordinate location, and cell size for each cell number in each direction.

\begin{tabular}{|c|c|c|c|c|c|c|c|c|c|c|c|c|c|}
\hline \multirow[b]{2}{*}{ Cell \# } & \multicolumn{2}{|c|}{ Northeast (m) } & \multicolumn{2}{|c|}{ Southeast (m) } & \multicolumn{2}{|c|}{ Vertical (m) } & \multirow[b]{2}{*}{ Cell \# } & \multicolumn{2}{|c|}{ Northeast (m) } & \multicolumn{2}{|c|}{ Southeast (m) } & \multicolumn{2}{|c|}{ Vertical (m) } \\
\hline & Min & Size & Min & Size & Min & Size & & Min & Size & Min & Size & Min & Size \\
\hline 1 & $-2,000$ & 500 & $-4,000$ & 500 & -706 & 100 & 38 & -14 & 2 & -6 & 2 & 6 & 2 \\
\hline 2 & $-1,500$ & 300 & $-3,000$ & 1,500 & -606 & 203 & 39 & -12 & 2 & -4 & 2 & 8 & 2 \\
\hline 3 & $-1,200$ & 300 & $-2,000$ & 800 & -403 & 27 & 40 & -10 & 2 & -2 & 2 & 10 & 2 \\
\hline 4 & -900 & 250 & $-1,200$ & 450 & -376 & 24 & 41 & -8 & 2 & 0 & 2 & 12 & 2 \\
\hline 5 & -650 & 200 & -750 & 300 & -352 & 15 & 42 & -6 & 2 & 2 & 2 & 14 & 2 \\
\hline 6 & -450 & 120 & -450 & 125 & -337 & 41 & 43 & -4 & 2 & 4 & 2 & 16 & 2 \\
\hline 7 & -330 & 80 & -325 & 89 & -296 & 49 & 44 & -2 & 2 & 6 & 2 & 18 & 2 \\
\hline 8 & -250 & 60 & -236 & 61 & -247 & 31 & 45 & 0 & 2 & 8 & 2 & 20 & 2 \\
\hline 9 & -190 & 40 & -175 & 40 & -216 & 10 & 46 & 2 & 2 & 10 & 2 & 22 & 2 \\
\hline 10 & -150 & 25 & -135 & 27 & -206 & 30 & 47 & 4 & 2 & 12 & 2 & 24 & 2 \\
\hline 11 & -125 & 17 & -108 & 18 & -176 & 40 & 48 & 6 & 2 & 14 & 2 & 26 & 3 \\
\hline 12 & -108 & 18 & -90 & 12 & -136 & 29 & 49 & 8 & 2 & 16 & 2 & 29 & 3 \\
\hline 13 & -96 & 8 & -78 & 8 & -107 & 21 & 50 & 10 & 2 & 18 & 3 & 32 & 3 \\
\hline 14 & -88 & 5 & -70 & 5 & -86 & 14 & 51 & 12 & 2 & 21 & 5 & 35 & 4 \\
\hline 15 & -83 & 3.5 & -65 & 3.5 & -72 & 12 & 52 & 14 & 2 & 26 & 8 & 39 & 4 \\
\hline 16 & -79.5 & 2.5 & -61.5 & 2.5 & -60 & 8 & 53 & 16 & 2 & 34 & 13 & 43 & 3 \\
\hline 17 & -77 & 1.8 & -59 & 1.8 & -52 & 4 & 54 & 18 & 2 & 47 & 20 & 46 & 3 \\
\hline 18 & -75.2 & 1.2 & -57.2 & 1.2 & -48 & 4 & 55 & 20 & 3 & 67 & 33 & 49 & 5 \\
\hline 19 & -74 & 0.8 & -56.0 & 0.8 & -44 & 4 & 56 & 23 & 5 & 100 & 45 & 54 & 5 \\
\hline 20 & -73.2 & 0.4 & -55.2 & 0.4 & -40 & 4 & 57 & 28 & 8 & 145 & 65 & 59 & 20 \\
\hline 21 & -72.8 & 0.8 & -54.8 & 0.8 & -36 & 4 & 58 & 36 & 12 & 210 & 100 & 79 & 24 \\
\hline 22 & -72 & 1.2 & -54.0 & 1.2 & -32 & 4 & 59 & 48 & 18 & 310 & 140 & 103 & 24 \\
\hline 23 & -70.8 & 1.8 & -52.8 & 1.8 & -28 & 4 & 60 & 66 & 26 & 450 & 250 & 127 & 25 \\
\hline 24 & $\begin{array}{l}-69 \\
\end{array}$ & 3 & -51.0 & 2.5 & -24 & 3 & 61 & 92 & 48 & 700 & 500 & 152 & 25 \\
\hline 25 & -66 & 5 & -48.5 & 3.5 & -21 & 3 & 62 & 130 & 56 & 1,200 & 800 & 177 & 25 \\
\hline 26 & -63 & 5 & -45 & 5 & -18 & 2 & 63 & 186 & 82 & 2,000 & 1,500 & 202 & 25 \\
\hline 27 & -58 & 5 & -40 & 5 & -16 & 2 & 64 & 268 & 182 & & & 227 & 22 \\
\hline 28 & -53 & 5 & -35 & 5 & -14 & 2 & 65 & 450 & 250 & & & 249 & 19 \\
\hline 29 & -48 & 5 & -30 & 5 & -12 & 2 & 66 & 700 & 400 & & & 268 & 12 \\
\hline 30 & -43 & 5 & -25 & 4 & -10 & 2 & 67 & 1,100 & 700 & & & 280 & 7 \\
\hline 31 & -38 & 5 & -21 & 3 & -8 & 2 & 68 & 1,800 & 1,200 & & & 287 & 4 \\
\hline 32 & -33 & 5 & -18 & 2 & -6 & 2 & 69 & 3,000 & 1,000 & & & 291 & 2 \\
\hline 33 & -28 & 4 & -16 & 2 & -4 & 2 & 70 & & & & & 293 & 1 \\
\hline 34 & -24 & 3 & -14 & 2 & -2 & 2 & 71 & & & & & 294 & 1 \\
\hline 35 & -21 & 3 & -12 & 2 & 0 & 2 & 72 & & & & & & \\
\hline 36 & -18 & 2 & -10 & 2 & 2 & 2 & 73 & & & & & & \\
\hline 37 & -16 & 2 & -8 & 2 & 4 & 2 & & & & & & & \\
\hline
\end{tabular}

\subsubsection{ParFlow Simulation Domain and Grid}

The ParFlow simulation domain is also a rectangular box, roughly equivalent to the NUFT simulation domain in size and orientation. The bottom of the domain is sea level. The coordinate system is rotated $90^{\circ}$ with respect to NUFT axes such that the positive $x$ - and $y$-axes point to the southeast ( $\mathrm{S} 49 \mathrm{E}$ ) and northeast (N $41 \mathrm{E})$, respectively. The origin of the coordinate system is anchored at sea level $(z=0)$ and all vertical coordinates reflect elevation above sea level (masl). The $x y$ origin is located at the western-most corner of the domain. The lengths of the northeast/southwest and northwest/southeast boundaries (7,600 $\mathrm{m}$ and 6,400) are slightly larger than the NUFT model dimensions and were adjusted to intersect WW-5b, UE-5 PW2 and UE-5 PW3. The CAMBRIC working point in the ParFlow domain is $(x, y, z)=(3,492 \mathrm{~m}, 1,967 \mathrm{~m}$, $662 \mathrm{~m}$ ). The upper surface of the ParFlow model is the ground surface and was adjusted to account for slight variations in topography. As described further in Chapter 5, a nested 
computational mesh was employed in the ParFlow model. It included a highly resolved, fine mesh $(4 \times 4 \times 2 \mathrm{~m})$ in the areas of the model surrounding the ditch and CAMBRIC test cavity, and a coarse mesh (typical scale $200 \times 300 \times 50 \mathrm{~m}$ ) that telescoped outward to the model boundaries, ultimately generating over 24 million grid blocks.

\subsubsection{Hydrofacies Geometry}

Within the NUFT and ParFlow simulation domains, hydraulic properties are distributed categorically. Each category is referred to as a hydrofacies to indicate a rock unit with distinctive hydraulic properties. Additional rock type categories are used in the NUFT model to identify cell locations for initial and boundary conditions.

Selection of hydrofacies is based on combined interpretation of CAU alluvial units in Frenchman Flat, alluvial layers distinguished by Warren et al. (2002), chemofacies distinguished by Carle et al. (2003), interpretation of the MWAT (USGS 2004 and Stoller-Navarro, 2004a), and altered zones created by the CAMBRIC test (Hoffman et al., 1977, Burbey and Wheatcraft, 1986 and Tompson et al., 1999).

A brief description of characteristics of each hydrofacies is given in Table 4.3. Within the finite difference grid, geometry for each hydrofacies consists of either rectangular boxes or agglomerations of rectangular boxes within cylindrical or spherical shapes. All alluvial layers are shaped as horizontal rectangular boxes except where altered zones associated with the CAMBRIC test and zones associated with RNM-2S are superimposed onto the finite difference grid. The CAMBRIC altered zones are defined by grid blocks whose centers fall within portions of spherical or cylindrical shapes (e.g., cavity or chimney). Other hydrofacies are used to accommodate special boundary conditions including pumping from well RNM-2S, flow down the RNM-2S gravel pack (GRAV), CAMBRIC ditch infiltration (DITCH), and the atmosphere (ATM). For example, in the NUFT model the screened interval and gravel pack hydrofacies for RNM-2S consist of a single 0.4-m-square cross-sectional area, based on the cross-sectional area of the borehole minus the well casing outer diameter. Figure 4.1 shows the 3D distribution of hydrofacies categories dimensioned by grid cell (not to scale). The category numbers can be cross-referenced to the hydrofacies using Table 4.3. The atmosphere category (3), located across vertical (up direction) grid cell 71, is not shown in Figure 4.1 to reveal the top locations of the ALv (2), AL2v (5), and DITCH (25) categories. Exact dimensions of the hydrofacies geometry are given in Table 4.4. 
Table 4.3. Category number, label, and characteristics of NUFT simulation hydrofacies.

\begin{tabular}{|c|c|c|}
\hline \# & Label & Characteristics \\
\hline 1 & $\mathrm{AL}$ & Background alluvium, saturated zone \\
\hline 2 & ALv & Background alluvium, vadose zone \\
\hline 3 & ATM & Atmosphere \\
\hline 4 & AL1v & Warren et al. (2002) alluvial Layer 1, in vadose zone \\
\hline 5 & AL2v & Warren et al. (2002) alluvial Layer 2, in vadose zone \\
\hline 6 & AL2a & Warren et al. (2002) alluvial Layer 2, upper portion, saturated zone \\
\hline 7 & $\mathrm{AL} 2 \mathrm{~b}$ & Warren et al. (2002) alluvial Layer 2, lower portion, saturated zone \\
\hline 8 & AL3 & Warren et al. (2002) alluvial Layer 3 \\
\hline 9 & AL4 & Warren et al. (2002) alluvial Layer 4 \\
\hline 10 & AL5 & Warren et al. (2002) alluvial Layer 5 \\
\hline 11 & AL6 & Warren et al. (2002) alluvial Layer 6 \\
\hline 12 & AL7 & Warren et al. (2002) alluvial Layer 7 \\
\hline 13 & AL8 & Warren et al. (2002) alluvial Layer 8 \\
\hline 14 & AL9 & Warren et al. (2002) alluvial Layer 9 \\
\hline 15 & AL10 & Warren et al. (2002) alluvial Layer 10 \\
\hline 16 & $\mathrm{CZ}$ & Compressed Zone \\
\hline 17 & CHM1 & Portion of CAMBRIC chimney associated with AL3, top dropped 5m \\
\hline 18 & $\mathrm{CHM} 2$ & Portion of CAMBRIC chimney associated with AL2b, top dropped 3m \\
\hline 19 & CHM3 & Portion of CAMBRIC chimney associated with AL2a, top not dropped \\
\hline 20 & CAV & Cavity (not including melt glass zone) \\
\hline 21 & MG & Melt glass zone \\
\hline 22 & PIM & Portion of CAMBRIC chimney within radius of compressed zone \\
\hline 23 & GRAV & Cells associated with gravel pack of RNM-2S \\
\hline 24 & RNM-2S & Cells associated with slotted interval of RNM-2S \\
\hline 25 & DITCH & CAMBRIC ditch \\
\hline
\end{tabular}



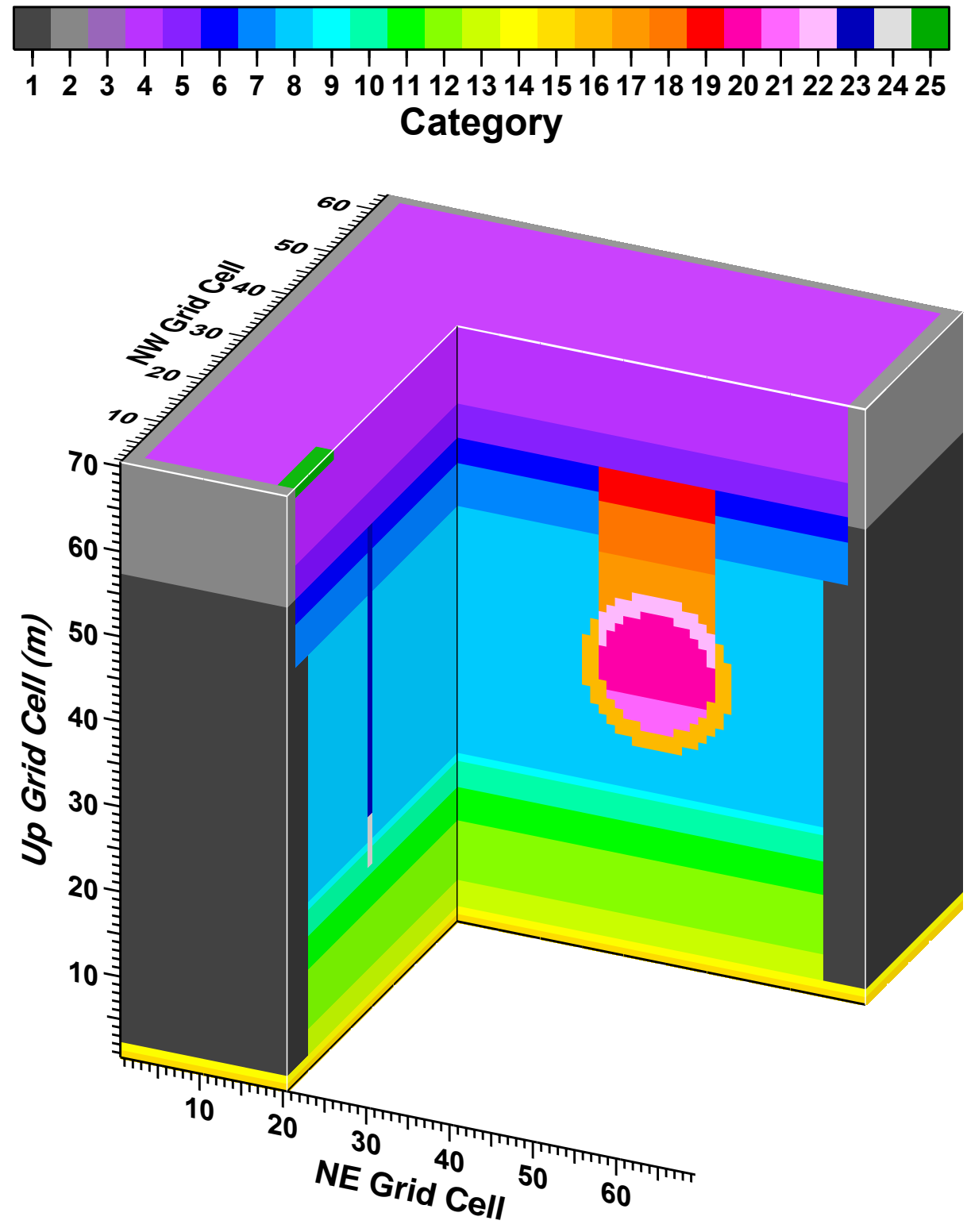

Figure 4.1 Three-dimensional distribution of hydrofacies category numbers located by NUFT simulation grid cell (not to scale). 


\subsubsection{Alluvial Aquifer and Background Alluvium}

The NUFT simulation domain is located in the southern portion of the CAU modeling domain of Frenchman Flat. The CAU HSUs included in the NUFT simulation domain are the alluvial aquifer, AA, and upper playa confining unit, PCU1U. For simplification of bulk properties distant from the CAMBRIC test, the hydrofacies AL and ALv are defined effectively as "background alluvium" for the saturated and vadose zone, respectively. The background alluvium hydrofacies are used to connect alluvial Layers 28 to the outer edge of the NUFT flow simulation domain, particularly to hydraulically connect hydrostatic pressure boundary conditions at minimum and maximum $x$-direction cells below the water table in Layers 2-8 (upper alluvium portion of AA above the PCU1U).

\subsubsection{Alluvial Layers}

At the scale of the HST model, heterogeneity related to alluvial layering will play a large role in radionuclide transport. The alluvial layers represent zonal heterogeneity of textural, hydraulic, mineralogic, and sorption properties (e.g., effective $K_{d}$ ) within Frenchman Flat alluvium. As discussed in Section 4.2.2, the alluvial layer depth intervals are primarily based on the lithologic interpretation of data from ER-5-4 by Warren et al. (2002). Lateral extent of the alluvial layers is highly uncertain. Based on mineralogy, Carle et al. (2002) show that some alluvial layers may persist for at least hundreds of meters, and Layer 1 and 2 may persist for kilometers. Layers 1 and 2 are distinguished by a majority of sediments derived from volcanic rocks to the north, and thus represent alluvial sedimentation episodes that extend from northern to central Frenchman Flat.

The NUFT simulation domain extends to the bottom of Layer 10 of Warren et al. (2002), which corresponds to a depth of about 1,000 m near CAMBRIC. All of the alluvial layers are conceptualized as horizontal in the NUFT simulation. Lateral continuity and lenticularity of individual layers could not be assessed within Frenchman Flat alluvium near CAMBRIC. Individual layer thickness and contact elevation could change dramatically horizontally on scales of tens of meters, and lateral variability is unpredictable. The assumption of horizontal layers is a gross simplification given that the layers may be aligned to angles of deposition, deformation, or surfaces of erosion (Warren et al., 2002). The NUFT model incorporates a horizontal representation of alluvial layering as a first approximation to the unknown alluvial layering structure, as discussed previously in Sections 4.2.2 and 4.2.3. The intent of the layered model structure is to consider gross hydrogeologic impacts of the alluvial layering immediately adjacent to the CAMBRIC test. Table 4.4 shows the lateral and vertical extent of the alluvial layers assumed in the NUFT model.

In the ParFlow model, three levels of detail have been used to describe the geologic structure employed in the model domain. The outermost is the most recent hydrostratigraphic (HSU) framework model (Bechtel Nevada, 2005b) exactly as is being used to develop the Frenchman Flat CAU flow model (Stoller-Navarro, 2006b). In the central portion of the domain, a similarly layered alluvium configuration is specified, paralleling Layers 2-9 in the NUFT model. Within the central portions of these layers themselves, as well as most of the altered zones near the working point, a finer level of 
detail is used to represent small-scale heterogeneity in the geologic material properties, as is discussed in Chapter 5.

All alluvial layers are resolved with variable vertical (z) grid spacing.

Accuracy in geometric representation of the alluvial layers is limited by uncertainty in the alluvial layering structure and other unknown discontinuities (e.g., faults, erosional surfaces, deformation, lateral depositional trends, etc.) within Frenchman Flat. Alluvial Layers 3-8 are resolved in the NUFT model only near CAMBRIC to $450 \mathrm{~m}$ horizontal distance $(-450 \mathrm{~m}<$ northeast $<450 \mathrm{~m} ;-450 \mathrm{~m}<$ northwest $<450 \mathrm{~m})$. Alluvial Layers 1 , $2 \mathrm{a}$, and $2 \mathrm{~b}$ span greater lateral distances $(-1,200 \mathrm{~m}<$ northeast $<1,800 \mathrm{~m} ;-2,000 \mathrm{~m}<$ northwest $<2,000 \mathrm{~m}$ ) to accommodate ditch infiltration and recirculation. However, layers $1,2 \mathrm{a}$, and $2 \mathrm{~b}$ may not, in reality, be as laterally extensive considering underground mapping at hole U1a (Sigmund Drellack, personal communication, 2006). Beyond the lateral extent of Layers 1-8, bulk effective hydraulic properties of background alluvium (AL and ALv) are assumed. Layers 9 and 10 span the entire lateral extent of the model and enable enforcement of lower boundary conditions for fluid flow and heat. Layer 9 acts as a semi-confining unit, while Layer 10 serves as a deeper aquifer with a lower hydraulic head relative to the shallow aquifer system between Layers $2-8$. Inclusion of Layers 9 and 10 (versus a no-flow boundary condition at the bottom of Layer 8) enables a fixed-temperature and fixed-pressure lower boundary condition. Use of fixed-temperature conditions at the lower and upper boundary conditions enables the NUFT flow simulations to include a geothermal gradient. The fixed-pressure lower boundary condition enables NUFT flow simulations to include consideration of a downward hydraulic gradient observed at drill hole ER-5-4.

Table 4.4. Lateral and vertical extent of alluvial layers assumed in the NUFT model relative to the Cambric working point.

\begin{tabular}{|l|l|l|l|l|l|l|l|}
\hline $\begin{array}{c}\text { Hydro- } \\
\text { facies }\end{array}$ & $\mathbf{X} \min (\mathbf{m})$ & $\mathbf{X} \max (\mathbf{m})$ & $\mathbf{Y} \min (\mathbf{m})$ & $\mathbf{Y} \max (\mathbf{m})$ & $\mathbf{Z} \mathbf{m i n}(\mathbf{m})$ & $\mathbf{Z} \mathbf{m a x}(\mathbf{m})$ & $\begin{array}{c}\text { Depth } \\
\text { Range }(\mathbf{m})\end{array}$ \\
\hline AL1v & $-1,200$ & 1,800 & $-2,000$ & 2,000 & +177 & +294 & $0-117$ \\
\hline AL2v & $-1,200$ & 1,800 & $-2,000$ & 2,000 & +73 & +177 & $117-221$ \\
\hline AL2a & $-1,200$ & 1,800 & $-2,000$ & 2,000 & +49 & +73 & $221-245$ \\
\hline AL2b & $-1,200$ & 1,800 & $-2,000$ & 2,000 & +32 & +49 & $245-262$ \\
\hline AL3 & -450 & 450 & -450 & 450 & -30 & +32 & $262-330$ \\
\hline AL4 & -450 & 450 & -450 & 450 & -34 & -30 & $330-334$ \\
\hline AL5 & -450 & 450 & -450 & 450 & -52 & -34 & $334-346$ \\
\hline AL6 & -450 & 450 & -450 & 450 & -107 & -52 & $346-401$ \\
\hline AL7 & -450 & 450 & -450 & 450 & -337 & -107 & $401-631$ \\
\hline AL8 & -450 & 450 & -450 & 450 & -403 & -337 & $631-697$ \\
\hline AL9 & $-2,000$ & 4,000 & $-4,000$ & 3,500 & -606 & -403 & $697-900$ \\
\hline AL10 & $-2,000$ & 4,000 & $-4,000$ & 3,500 & -706 & -606 & $900-1,000$ \\
\hline
\end{tabular}




\subsubsection{Altered Zones}

The altered zones are hydrofacies associated with the CAMBRIC test-related effects - the cavity, melt glass, chimney, and compressed zone:

- The cavity hydrofacies (CAV) is assumed spherical with a radius of $13.4 \mathrm{~m}$ centered at the CAMBRIC working point, excluding the melt glass.

- The melt glass zone hydrofacies (MG) is the lower 7.4-m portion of a sphere with a radius of $13.4 \mathrm{~m}$ centered at the CAMBRIC working point (294 $\mathrm{m}$ below ground surface). Thus, the top of the melt glass zone is $6 \mathrm{~m}$ below the CAMBRIC working point.

- The chimney is assumed cylindrical with a radius of $13.4 \mathrm{~m}$ centered at the CAMBRIC working point. The chimney extends from the top of the spherical cavity to $+79 \mathrm{~m}$ above the CAMBRIC working point. The chimney is subdivided into three hydrofacies (CHM3, CHM2, and CHM1) based on down-dropped and bulked zones derived from Layers 2a, 2b, and 3, respectively. CHM1 extends from the top of the cavity to $+27 \mathrm{~m}$; $\mathrm{CHM} 2$ extends from +27 to $+46 \mathrm{~m}$, and CHM3 extends from +46 to $+79 \mathrm{~m}$ above the CAMBRIC working point.

- The compressed zone hydrofacies (CZ) assumes the shape of a spherical bowl, defined by a sphere with a radius of $18 \mathrm{~m}$ centered at the CAMBRIC working point that excludes the volume occupied by the chimney, cavity, and melt glass zone.

- The pimento (PIM) hydrofacies is a portion of the chimney formerly occupied by the compressed zone prior to cavity collapse.

Hydrofacies geometries in the NUFT flow simulation domain are assigned more resolution and detail through grid refinement in the vicinity of the CAMBRIC test, the CAMBRIC ditch, and RNM-2S. The NUFT simulation grid "telescopes" out to the minimum and maximum lateral extent of the model domain given in Table 4.1. The NUFT flow simulation grid resolves most of the altered zones, including cavity, melt glass zone, compressed zone, pimento, and lower chimney (CHM1), with cells shaped as 2-m cubes. The middle and upper portions of the chimney (CHM2 and CHM3) are resolved with cells shaped as 2-m squares with variable vertical resolution of 3 to $4 \mathrm{~m}$ for CHM2 and 3 to $20 \mathrm{~m}$ for CHM3. A 20-m-thick cell at the top of CHM3 straddles the water table at distances between $+59 \mathrm{~m}$ to $+79 \mathrm{~m}$ above CAMBRIC. This cell allows the NUFT model to accommodate transient water table changes (due to pumping at RNM-2S and water table mounding from the ditch) without frequently switching back and forth between fully and partially saturated conditions (between one-phase liquid flow and twophase liquid and gas flow). Frequent switching between one-phase and two-phase flow at grid cells causes considerable delay in the NUFT flow simulations.

\subsubsection{RNM-2S}

The NUFT simulation grid includes a telescoped discretization to better represent transient flow near drill hole RNM-2S, which was pumped between 1975 and 1991 for the RNM experiment. 
To represent the hydraulic properties of the 17.5-in.-diameter borehole for the RNM-2S well, the NUFT simulation grid is discretized to the cross-sectional grid resolution of a $0.4-\mathrm{m}$ by $0.4-\mathrm{m}$ square at the NUFT grid location $-76.2 \mathrm{~m}<x<-75.8 \mathrm{~m}$ and $-55.2 \mathrm{~m}<\mathrm{y}<-54.8 \mathrm{~m}$, where $x$ represents the northeast (downgradient) direction and y represents the southeast direction. The RNM-2S well construction includes a gravel pack that extends above the water table (Stoller-Navarro, 2004a). The NUFT simulation grid does not resolve the well casing under the assumption that the gravel pack is the limiting hydraulic conductance for flow within the screened interval, and that the gravel pack provides the through-going conduit for flow within the borehole above the screened interval. As such, the RNM-2S gravel pack provides a possible migration route for radionuclide transport from the CAMBRIC source via transport through the chimney and Layer $2 b$, or indirectly through recirculation from the CAMBRIC ditch after being captured by pumping at RNM-2S. Storage properties of the grid blocks associated with RNM-2S are assumed to consist of a combination of storage from gravel pack porosity and volume within the 8.921-in. internal diameter of the well casing.

A similar treatment of RNM-2S is included in the ParFlow model as described in Chapter 5.

\subsubsection{CAMBRIC Ditch and Atmosphere}

The CAMBRIC ditch is aligned toward the southeast or y direction in the NUFT simulations and $x$ direction in the ParFlow simulations.

In the NUFT simulations, the CAMBRIC ditch is located at ground surface $(z=$ $+294 \mathrm{~m}$ ) between $-56 \mathrm{~m}<x<-54 \mathrm{~m}(2-\mathrm{m}$ ditch width) and $-2,000 \mathrm{~m}<\mathrm{y}<-88.75 \mathrm{~m}$ (1,911-m ditch length). This configuration places the ditch about $50 \mathrm{~m}$ southeast of well RNM-2S. The simulated ditch location does not exactly correspond to the true ditch location. This simplification was made to reduce the number of grid cells by aligning the ditch along the same $y$-coordinate as well RNM-2S. The "atmosphere" hydrofacies (ATM) is located between $+294 \mathrm{~m}<z<+295 \mathrm{~m}$. The atmosphere hydrofacies enforces an averaged atmospheric boundary condition for temperature $\left(21.25^{\circ} \mathrm{C}\right)$, pressure $(101,325 \mathrm{~Pa})$, and saturation (0.0) at the upper $z$-coordinate edge of the NUFT simulation domain.

Both the CAMBRIC ditch and a portion of Frenchman Lake are included in the ParFlow model to allow RNM-2S effluent to infiltrate. This configuration is described more fully in Chapter 5.

\subsection{Hydraulic Properties}

This section describes data and interpretation relevant to characterization of hydraulic properties including porosity, grain size distribution, hydraulic conductivity, and specific yield within alluvium and test-related altered zones near CAMBRIC. Further interpretation of hydraulic properties, including hydraulic conductivity, specific storage, and specific yield, is given in Section 4.5 in reference to calibration to the RNM-2S

MWAT and calibration to ${ }^{3} \mathrm{H}$ breakthrough data at RNM-2S during the RNM experiment. 


\subsubsection{Alluvium}

\subsubsection{Porosity}

Data relevant for estimation of porosity of Frenchman Flat alluvium include measurements from core samples and geophysical logs including gravimetry, gamma, acoustic velocity, neutron, and resistivity (Hoffman et al., 1977, Ramspott and McArthur, 1977; Pawloski, Lawrence Livermore National Laboratory, personal communication, 1996; and Stoller-Navarro, 2004a,b). Comparison of measurements of bulk density, grain density, and saturation provides the most direct means for estimation of porosity. Of the geophysical logs, only gravimetry provides an estimate of bulk density. Porosity can be estimated by combining bulk density estimates from core samples or gravimetry with measurements of grain density and saturation from core samples or other means as follows:

$$
\phi=\frac{\rho_{g}-\rho_{b}}{\rho_{g}-S \rho_{w}}
$$

where:

$$
\begin{aligned}
& \phi=\text { porosity } \\
& \rho_{g}=\text { grain density } \\
& \rho_{b}=\text { bulk density } \\
& \rho_{w}=\text { water density } \\
& S=\text { saturation }
\end{aligned}
$$

This equation is simplified under dry or saturated conditions. For saturated conditions, such as for gravimetry below the water table, the estimation of porosity from Equation (4.1) reduces to:

$$
\phi=\frac{\rho_{g}-\rho_{b}}{\rho_{g}-\rho_{w}}
$$

For dry conditions, such as from dried core samples, the estimation of porosity from Equation (4.1) reduces to:

$$
\phi=\frac{\rho_{g}-\rho_{b}}{\rho_{g}}
$$

Pawloski (Lawrence Livermore National Laboratory, personal communication, 1996) compares bulk density and grain density data to obtain a porosity estimate for "younger alluvium" of 0.36 with a standard deviation of 0.03 based on core samples from UE-5k, UE-5n, UE-11a, UE-11c, U-11g, UE-5 PW-1, UE-5 PW-2, and UE-5 PW-3 in Frenchman Flat.

Gravimetry provides a bulk estimate at a scale of tens of meters or greater, which is more relevant to flow and transport properties than the meter or less scale of porosity estimates obtained from core samples and other geophysical logs. A borehole gravimetry study was performed in drill hole UE-5n to a depth of $442 \mathrm{~m}$ (Ramspott and 
McArthur, 1977). This study also included porosity estimates obtained from core samples and gamma logs.

Porosity is expected to decrease with depth in Frenchman Flat alluvium (Stoller-Navarro, 2005a). Hoffman et al. (1977) calculated porosities of 0.31 to 0.41 for samples obtained below the water table in RNM-1. Based on data from UE-5n, Ramspott and McArthur (1977) estimate a porosity of 0.36 above the water table (based on data from depths between 20.0 and $152.4 \mathrm{~m}$ ) and 0.32 below the water table (based on data between 307.8 and $442.0 \mathrm{~m}$ ). Ramspott and McArthur (1977) provide additional estimates of porosity for specific depth ranges. Between depths of $154 \mathrm{~m}$ and the water table $(214 \mathrm{~m})$, porosity estimates range from 0.34 to 0.37 . Between the water table and a lithologic change to more indurated and silty alluvium at $286.5 \mathrm{~m}$, porosity estimates range between 0.29 and 0.35. Alluvial Layer 2 distinguished at ER-5-4, UE-5n, and RNM-1 by Warren et al. (2002) would largely, if not completely, occupy the depth range between $152.4 \mathrm{~m}$ and $286.5 \mathrm{~m}$.

Hydrofacies Layer 2 spans above and below the water table. For simplification, a porosity of 0.36 is assumed throughout Layers 1 and 2, including hydrofacies Layers $2 \mathrm{a}$ and $2 \mathrm{~b}$ specified in the NUFT and ParFlow flow simulations. Porosity of 0.32 is assigned to Layers 3, 4, 5, and 6, which are all are situated above $442 \mathrm{~m}$ depth in ER-5-4. For simplicity, porosity of 0.32 is extended to Layers 7 and 8 , and a decrease in porosity to 0.30 is assumed for Layers 9 and 10.

\subsubsection{UE-5n Grain-Size Distribution and Alluvial Layers}

Grain-size distribution provides insight into estimation of porosity and permeability. Figure 4.2 compares grain size fractions from sieve analyses performed on numerous sidewall core samples obtained from UE-5n (Ramspott and McArthur, 1977) with alluvial layers identified in UE-5N by Warren et al. (2002, Figure 22). Figure 4.2 also shows inferred thickness of the basal "Layer $2 b$ " as interpreted from RNM-2S MWAT data (Section 4.5.1). The grain-size distribution data for UE-5n indicate that sand and gravel ("pebbles or larger") are generally the dominant grain size within alluvium from the surface to a depth of $485 \mathrm{~m}$. One might conclude, based on the two dominant grain sizes, that the alluvium at UE-5n is texturally either sandy gravel or gravelly sand. However, increase in fines ("silt or smaller") within an otherwise sand or gravel dominated material will decrease both porosity and permeability. The UE-5n sieve data indicate a prominent increase in "silt or smaller" grains below the Layer 2-3 contact of Warren et al. (2002) at $279 \mathrm{~m}$ depth and below a "lithologic change" of Ramspott and McArthur (1977) at the depth of $286.5 \mathrm{~m}$. A distinct 10- to 15-m-thick zone of very little $(\sim 2 \%)$ "silt or smaller" and abundant "pebbles or larger" occurs directly above the Layer 2-3 contact. Burbey and Wheatcraft (1986) estimate hydraulic conductivity between 11.2 and $26.5 \mathrm{~m} / \mathrm{d}$ based on grain size data within the depth range of 265.2 and $275.2 \mathrm{~m}$ in UE-5n, compared to 1.96 to $2.87 \mathrm{~m} / \mathrm{d}$ between depths of 243.8 and $262.1 \mathrm{~m}$ in Layer 2 . These grain size data from UE-5n, in combination with pumping-test data (Section 4.3.1.3) and MWAT reinterpretation (Section 4.5.1), further suggest a distinct transition in hydraulic properties between Layers 2 and 3, including the following: 


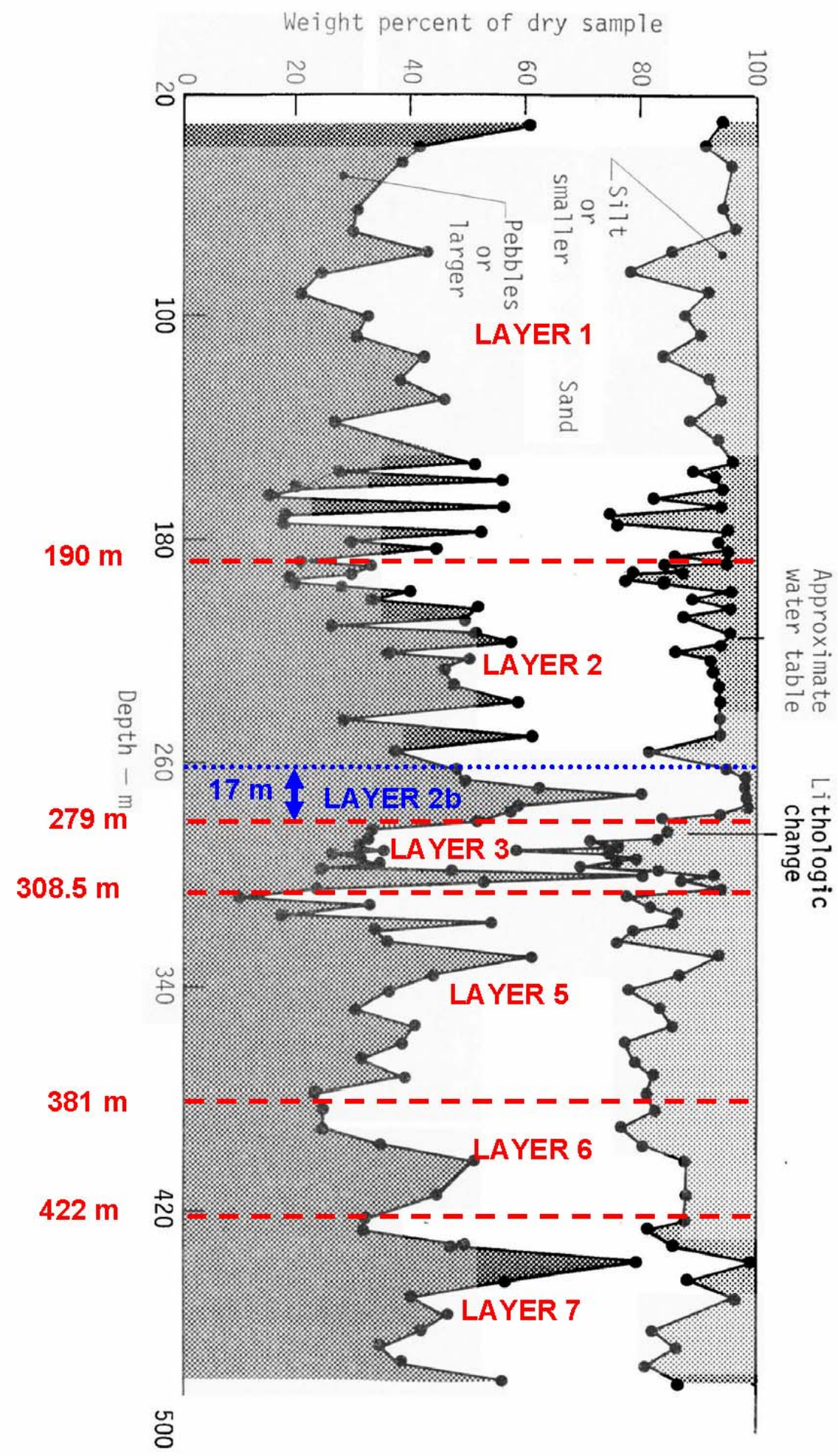

Figure 4.2 Depth comparison of grain-size distribution from sieve data for UE-5n (Figure 5, Ramspott and McArthur, 1977) with alluvial layer contacts identified in UE-5n in Figure 22 by Warren et al. (2002) and Layer 2b interpreted from analysis of the RNM-2S MWAT. 
- Higher porosity in Layer 2 relative to Layer 3.

- Higher permeability in Layer 2 relative to Layer 3.

- Higher permeability at the basal portion of Layer 2 compared to the upper section of Layers 1 or 2.

The presence of a distinct coarse-grained basal 10-m portion of alluvium in Layer 2 with abundant gravel and little fines is consistent with the Warren et al. (2002) interpretation of an erosional contact at the base of Layer 2. Interpretation of the RNM-2S MWAT (Section 4.5.1) indicates a hydraulic conductivity of $24 \mathrm{~m} / \mathrm{d}$ for Layer $2 \mathrm{~b}$, the basal $17 \mathrm{~m}$ of Layer 2, compared to $3.9 \mathrm{~m} / \mathrm{d}$ for Layer 2a. Correlation across locations of UE-5n and MWAT wells (RNM-2S, RNM-1, RNM-2, and ER-5-4) indicates that the basal portion of Layer 2 is a relatively high-permeability zone approximately 10 to $17-\mathrm{m}$ thick and has a lateral extent of at least $500 \mathrm{~m}$ near CAMBRIC.

Warren et al. (2002) used mineralogic, chemical, and lithologic data to correlate Layers 1, 2, 3, 5, 6, and 7 between ER-5-4 and UE-5n. In UE-5n, Layers 3, 5, and 6 appear to have similar grain-size distribution, with greater fraction of fines compared to Layers 1, 2, and 7 (Figure 4.2). Interpretation of the MWAT indicates a hydraulic conductivity between 0.14 to $0.17 \mathrm{~m} / \mathrm{d}$ for Layers 3,5 , and 6 compared to 2.0 to $24 \mathrm{~m} / \mathrm{d}$ for Layers 1,2 , and 7 . The finer-grained alluvium has lower hydraulic conductivity than coarser-grained alluvium, as expected. Thus, comparison of the grainsize distributions from the UE-5n sieve data with MWAT layer-specific interpretations of hydraulic conductivity further supports extension of Layers 1, 2, 3, 5, 6, and 7 beyond the vicinity of CAMBRIC to UE-5n, over $500 \mathrm{~m}$ away, as interpreted by Warren et al. (2002).

Warren et al. (2002) identified Layer 4 in ER-5-4 as a thin (3.4-m-thick) relatively coarse-grained zone. Interpretation of the RNM-2S MWAT in Section 4.5.1 indicates a thin zone with relatively high transmissivity of $40 \mathrm{~m}^{2} / \mathrm{d}$ may correlate to Layer 4 at ER-5-4 within the slotted interval of RNM-2S. Warren et al. (2002) cited lack of sufficient sample spacing to identify a Layer 4 in UE-5n. However, the UE-5n sieve data from Ramspott and McArthur (1977) show a thin and distinctively coarse-grained zone at the base of Layer 3 (Figure 4.2). Thus, data from UE-5n, ER-5-4, and the RNM-2S MWAT indicate that thin coarse-grained zones of relatively high-permeability tend to occur between Layers 3 and 5 near CAMBRIC. Lateral continuity of these thin coarse-grained zones may not necessarily be characterized as continuous layers, but rather as discrete lenses, channels, or channel belts that may or may not be interconnected over a scale of hundreds of meters or greater.

\subsubsection{Hydraulic Conductivity and Specific Yield}

Pump test interpretations usually provide the most realistic estimates of intermediate-scale hydraulic properties. Stoller-Navarro (2004b, p. 5-22) plots pumptest-derived hydraulic conductivity data versus depth for alluvial deposits in Frenchman Flat. Figure 4.3 compares these hydraulic conductivity data to alluvial texture as a function of depth and typical hydraulic conductivity. Hydraulic conductivities ranging between 0.09 and $0.4 \mathrm{~m} / \mathrm{d}$ are consistent with silt or silty sand textures. High hydraulic conductivities ranging between 4 and $50 \mathrm{~m} / \mathrm{d}$ are consistent with a gravelly sand or sandy gravel texture. Intermediate pump-test derived hydraulic conductivities between about 
0.5 and $3 \mathrm{~m} / \mathrm{d}$ may represent interbedded zones or fine sand texture. The highest pumptest-derived hydraulic conductivity of $45 \mathrm{~m} / \mathrm{d}$ occurs at about $260 \mathrm{~m}$ depth, which corresponds to the base of Layer 2 in the NUFT and ParFlow models. The second-highest value of about $15 \mathrm{~m} / \mathrm{d}$ occurs at about $335 \mathrm{~m}$ depth, which is near the depth of Layer 4 in the NUFT and ParFlow models and is also within the slotted interval (316.4 to $341.1 \mathrm{~m}$ depth) of RNM-2S, the pumping well for the RNM experiment and the MWAT.

Figure 4.3 also shows mean hydraulic conductivities (vertical bars) of alluvial layers (1-10) for the NUFT and ParFlow models as derived from reinterpretationof the hydraulic response to the MWAT (Section 4.5.1). The mean hydraulic conductivities are consistent with both the MWAT and the lithologic description for ER-5-4. The upper "gravelly sand" alluvial Layers 1 and 2 correspond to higher hydraulic conductivities with a range of 3 to $45 \mathrm{~m} / \mathrm{d}$. The finer grained Layers $3,5,6$, and 8 correspond to relatively lower hydraulic conductivities within the range of 0.09 to $0.4 \mathrm{~m} / \mathrm{d}$. Layer 4 is not observed at UE-5n and is thin at ER-5-4, with a thickness about $3.4 \mathrm{~m}$. It is likely that Layer 4 has high hydraulic conductivity given that gravel with cobbles and boulders are present within its depth range in the ER-5-4 lithologic log (Stoller-Navarro, 2004a, p. 17). Layer 7 is generally coarser-grained and more pebbly than Layers 3, 5, 6, and 8.

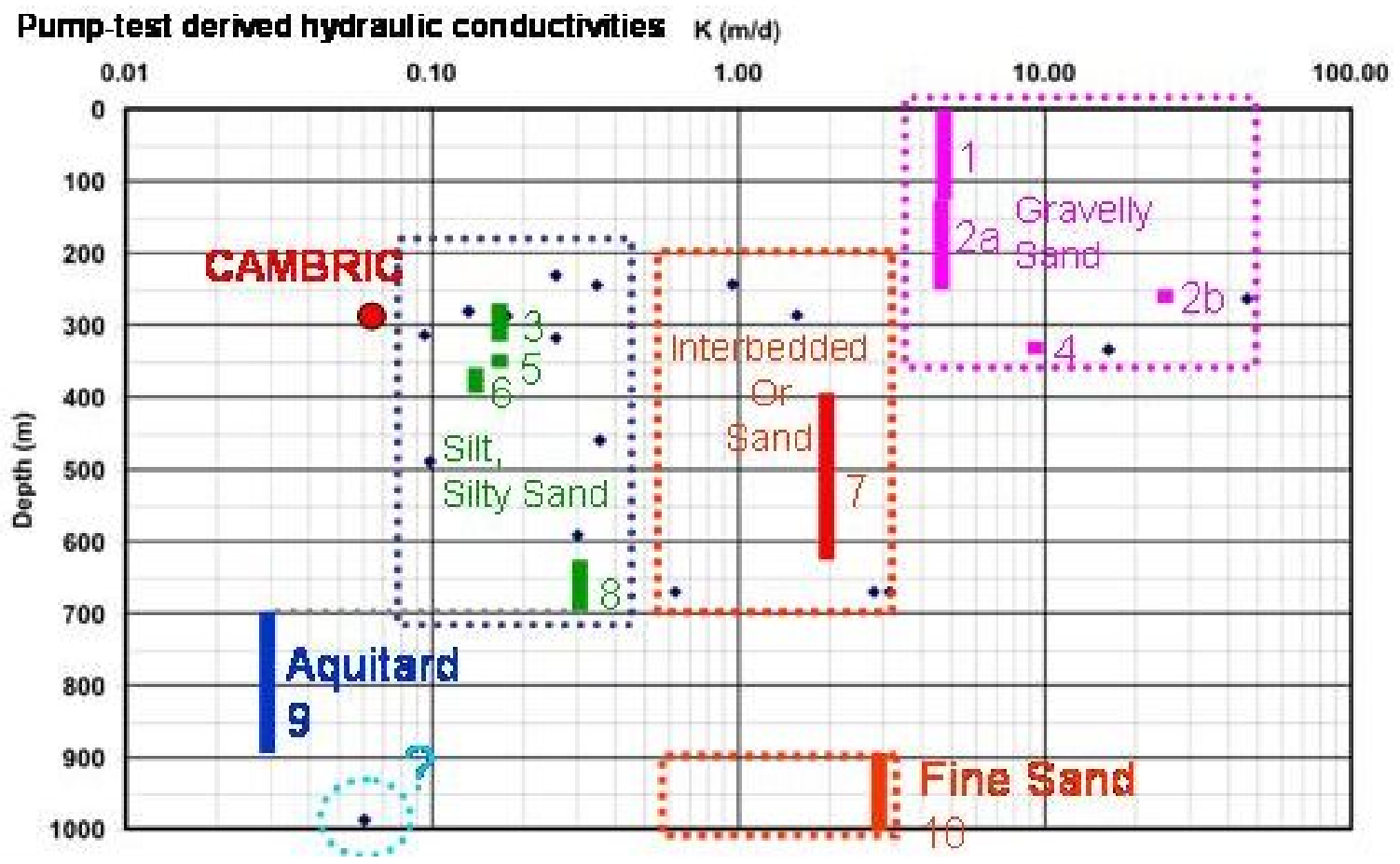

Figure 4.3 Comparison of pump-test derived hydraulic conductivities (dots) from Stoller-Navarro (2004b, p. 5-22), depth interval for range of hydraulic conductivity estimates representative of lithologic texture (dashed rectangles), and mean lateral hydraulic conductivities of alluvial layers in NUFT and ParFlow models (vertical bars). 
Pumping-test data in Figure 4.3 also suggest a distinctly higher permeability zone at the base of Layer 2. One datum at an approximate depth of $260 \mathrm{~m}$ indicates a hydraulic conductivity of approximately $45 \mathrm{~m} / \mathrm{d}$, the highest pumping test-derived hydraulic conductivity estimate in Frenchman Flat. Figure 5.4 of Stoller-Navarro (2004b) indicates that this $45-\mathrm{m} / \mathrm{d}$ pumping test datum was obtained in central Frenchman Flat near CAMBRIC. The depth of the measurement falls within the assumed depth range for Layer $2 \mathrm{~b}$. A hydraulic conductivity measurement of $45 \mathrm{~m} / \mathrm{d}$ is consistent with a grain-size distribution of sand and gravel with little fines, as observed within the approximate 260to 275-m depth range in UE-5n (Figure 4.2). Therefore, a combination of textural characteristics and erosional contact interpretation (Warren et al., 2002), grain-size distribution (Ramspott and McArthur, 1977), pumping-test data (Stoller-Navarro, 2004b), and this reinterpretationof the MWAT pumping test (Section 4.5.1) indicate that the highest permeability alluvium in Frenchman Flat near CAMBRIC occurs near the base of alluvial Layer 2 described by Warren et al. (2002).

Importantly, a distinct erosional contact between Layers 2 and 3 and a larger coarse-grained fraction in Layer 2 suggests a significant shift in depositional process involving a decrease in basin level and higher energy of deposition and a decrease in base level within the alluvial sequence of Frenchman Flat. A lack of fines and a decrease in base level could be explained by an open, rather than closed, basin (Warren et al., 2002). The combination of an erosional contact and an open drainage could produce lengthy channel-related deposition of relatively coarse-grained materials. However, no evidence has been found for past existence of an open basin at Frenchman Flat. Alternately, the apparent decrease in basin level near present-day CAMBRIC could be caused by uplift relative to the bottom of the basin, perhaps by either normal faulting or north-tonorthwest trending folding apparent in the synclinal structure of the basin (Figure 2.2). Evidence for a persistently closed basin includes three mapped playas within the alluvial section (Bechtel-Nevada, 2005).

Layers 1-8 represent the upper portion of the AA alluvial aquifer above $697 \mathrm{~m}$ depth and the PCU1U corresponding to the 1,600-ft aquifer thickness scenario examined by the USGS for analysis of the MWAT (USGS, 2004). RNM-2S is screened between a depth of 316.4 and $341.1 \mathrm{~m}$. Interpretation of the MWAT by the USGS (2004) indicates a bulk hydraulic conductivity of $0.37 \mathrm{~m} / \mathrm{d}$, which is consistent with the silt and silty sand Layers 3, 5, and 6 that constitute the bulk of the alluvial deposits surrounding the screened interval in the pumping well RNM-2S. A $0.37-\mathrm{m} / \mathrm{d}$ hydraulic conductivity is also consistent with silt or silty sand texture and most of the pump-test-derived hydraulic conductivities given by Stoller-Navarro (2004b) for that depth range (Figure 4.3). Given the range of textural properties and pump-test-derived hydraulic conductivity, some alluvium in Frenchman Flat, particularly Layers 2 and 4, may have bulk hydraulic conductivities of approximately two orders of magnitude greater than the silty zones prevalent near the depth of the CAMBRIC working point and the screened interval of RNM-2S. Hydraulic conductivities for the deepest Layers 9 (the PCU1U confining unit) and 10 (in the lower part of AA) can be inferred from lithology and calibration of the flow model (Section 4.5). 


\subsubsection{Comparison to Previous Hydraulic Conductivity Estimates near CAMBRIC}

Hoffman et al. (1977) report that average hydraulic conductivity of RNM-1 sidewall samples estimated from grain-size distribution was about $4 \mathrm{~m} / \mathrm{d}$. This estimate is consistent with the interpretations for Layer 2a hydraulic conductivity. Hoffman et al. (1977) also report a hydraulic conductivity estimate of $1.5 \mathrm{~m} / \mathrm{d}$ in RNM-2S, which corresponds to a transmissivity of $37 \mathrm{~m}^{2} / \mathrm{d}$ based on the screened interval length of 24.7-m. The reinterpretation of the MWAT at the RNM-2S screened interval, which includes hydraulic conductivities of $9.16 \mathrm{~m} / \mathrm{d}$ over a 4-m thickness (Layer 4) and $0.17 \mathrm{~m} / \mathrm{d}$ over the remaining screened interval (Layers 3 and 5), suggests a transmissivity of $40 \mathrm{~m}^{2} / \mathrm{d}$ at RNM-2S. Thus, Layer 3, 4, and 5 hydraulic conductivity estimates from reinterpretation of the MWAT are consistent with previous estimates of transmissivity within the RNM-2S slotted interval.

Water wells WW-5b and WW-5c are located approximately 3 and $5 \mathrm{~km}$, respectively, south of CAMBRIC. Hoffman et al. (1977) report a hydraulic conductivity of $1.4 \mathrm{~m} / \mathrm{d}$ at WW-5b. The similarity of Hoffman et al. (1977) hydraulic conductivity estimates at RNM-2S $(1.5 \mathrm{~m} / \mathrm{d})$ and WW-5b $(1.4 \mathrm{~m} / \mathrm{d})$ suggests the possibility of a combination of finer-grained (e.g., Layers 3 or 5) and coarser-grained (e.g., Layers 2 or 4) alluvium, as in RNM-2S, over the perforated interval of 213 to $274 \mathrm{~m}$ in WW-5b. Hoffman et al. (1977) report a hydraulic conductivity of about $0.2 \mathrm{~m} / \mathrm{d}$ for WW-5c, which suggests mostly, if not all, finer-grained alluvium (e.g., Layers 3, 5, and 6) over the perforated interval of 270 to $362 \mathrm{~m}$ in WW-5c.

\subsubsection{Altered Zones}

There is very limited data to infer hydraulic properties of the altered zones (i.e., the cavity, melt glass, compressed zone, and chimney) resulting from the CAMBRIC test. Hydraulic conductivities were estimated from water level recovery after slug withdrawal tests in the CAMBRIC drillback hole RNM-1 (Hoffman et al., 1977). Slug test results indicated hydraulic conductivities of $0.15 \mathrm{~m} / \mathrm{d}$ in the lower cavity and $0.22 \mathrm{~m} / \mathrm{d}$ in the upper cavity. These hydraulic conductivity estimates appear reasonable, falling near the lower end of the hydraulic conductivity range for surrounding silt and silty-sandtextured alluvium (Figure 4.3) and very near this study's estimate of $0.17 \mathrm{~m} / \mathrm{d}$ for Layers 3 and 5.

This study defines a melt glass zone to correspond to the lower cavity of Hoffman et al. (1977). Conceptually, the melt glass zone is assumed to consist of collapse debris and melt glass. If actual melt glass constitutes only a fraction of the melt glass zone, the permeability of the melt glass zone is expected to be dominated by alluvial collapse debris. The $0.15-\mathrm{m} / \mathrm{d}$ estimate of hydraulic conductivity for the lower cavity by Hoffman et al. (1977) appears to be a reasonable estimate to use for this study's melt glass zone. The remainder of the cavity is assumed to consist primarily of alluvial collapse debris similar to the chimney. This study also uses the Hoffman et al. (1977) $0.22-\mathrm{m} / \mathrm{d}$ estimate of upper cavity hydraulic conductivity to estimate permeability for this study's cavity. Three separate chimney segments are differentiated according to the infallen alluvial layers. 
Outside the cavity, Hoffman et al. (1977) observed "very slow water-level recovery" in screened intervals thought to be in the chimney. However, it is possible that these observations were actually taken within the compressed zone, assuming the compressed zone is of relatively low permeability compared to surrounding silt or siltysand-textured alluvium. In this study, compressed zone permeability of $1.8 \times 10^{-15} \mathrm{~m}^{2}$ $\left(0.0017 \mathrm{~m} / \mathrm{d}\right.$ at $\left.24^{\circ} \mathrm{C}\right)$ is estimated through calibration to the RNM experiment breakthrough history of ${ }^{3} \mathrm{H}$ at RNM-2S (Section 4.5.2).

\subsubsection{NUFT Simulation Hydraulic Properties}

Spatial variation of hydraulic properties in the NUFT simulation is characterized by hydrofacies categories related to the alluvial layers, altered zones, and boundary conditions (e.g., the pumping well, atmosphere, and CAMBRIC ditch). Table 4.5 shows the hydrofacies' hydraulic properties of porosity, horizontal and vertical permeability, vertical:horizontal permeability anisotropy ratio, and horizontal and vertical hydraulic conductivity. Hydraulic conductivity values in Table 4.5 are approximated from permeability values assuming pure water at $24^{\circ} \mathrm{C}$ at atmospheric pressure. Ambient temperature near the CAMBRIC test is about $24^{\circ} \mathrm{C}$ (Figure 3.5). Figure 4.4 shows a 3D perspective view of the horizontal permeability structure used in the NUFT base-case simulation.

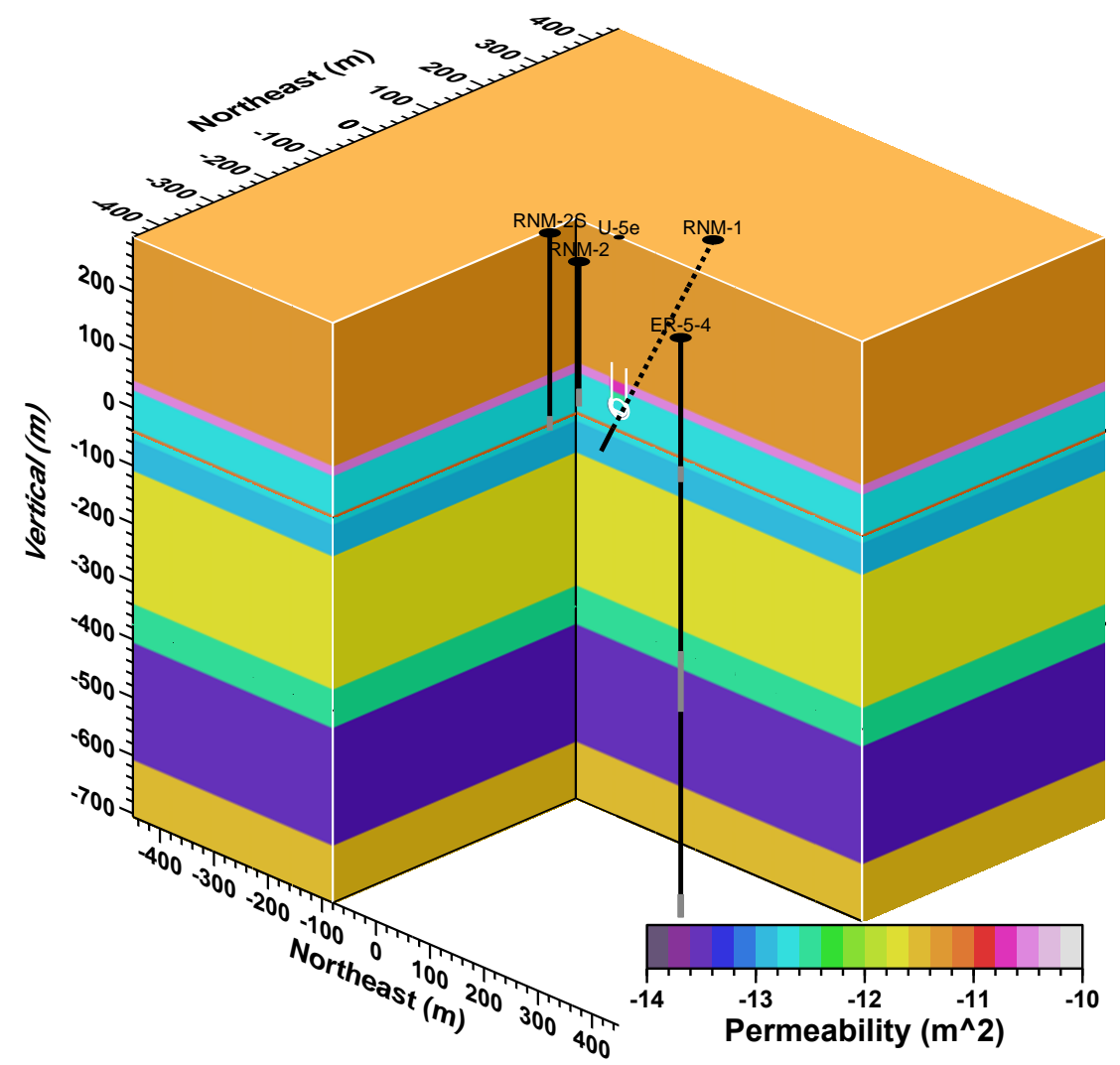

Figure 4.4 Horizontal permeability for NUFT base-case simulations as calibrated to the MWAT. 
CHAPTER 4: CALIBRATION AND ASSESSMENT MODELS

Table 4.5. Hydraulic properties of hydrofacies defined in the NUFT and ParFlow base-case simulations with hydraulic conductivities ( $\mathrm{K}_{\mathrm{G}}$ or $\mathrm{K}_{\mathrm{h}}$, $\mathrm{K}_{\mathrm{v}}$ ) based upon pure water at $24^{\circ} \mathrm{C}$. Cells with no data refer to units or parameters not covered in respective model (NUFT or ParFlow) or gridded (fine or coarse) portion of model. Porosity column data in the ParFlow model applies to both coarse and fine grids.

\begin{tabular}{|c|c|c|c|c|c|c|c|c|c|c|c|c|c|}
\hline & \multirow{4}{*}{ Unit } & \multirow{2}{*}{\multicolumn{3}{|c|}{ NUFT Grid }} & \multicolumn{9}{|c|}{ ParFlow Grid } \\
\hline & & & & & & Coarse $\mathrm{g}$ & id portion & & & & ne grid portion & & \\
\hline & & \multirow{2}{*}{$\phi$} & \multirow{2}{*}{$\begin{array}{l}k_{h} \\
\left(m^{2}\right)\end{array}$} & \multirow{2}{*}{$\begin{array}{l}k_{v} \\
\left(m^{2}\right)\end{array}$} & \multirow{2}{*}{$\phi$} & \multirow{2}{*}{$\begin{array}{l}K_{h} \\
(m / d)\end{array}$} & \multirow{2}{*}{$\begin{array}{l}\mathrm{K}_{\mathrm{v}} \\
(\mathrm{m} / \mathrm{d})\end{array}$} & \multicolumn{4}{|c|}{ Stochastic hydraulic conductivity distribution } & \multicolumn{2}{|c|}{$\begin{array}{l}\text { Constant hydraulic } \\
\text { conductivity }\end{array}$} \\
\hline & & & & & & & & $\sigma_{f}$ & $\lambda_{v} \quad(m)$ & $\lambda_{\mathrm{h}} \quad(\mathrm{m})$ & $\mathrm{K}_{\mathrm{G}}(\mathrm{m} / \mathrm{d})$ & $\mathrm{K}_{\mathrm{h}} \quad(\mathrm{m} / \mathrm{d})$ & $\mathrm{K}_{\mathrm{v}} \quad(\mathrm{m} / \mathrm{d})$ \\
\hline \multirow{13}{*}{ Layers } & ATM & 0.99 & $0.00 \mathrm{E}+00$ & $1.00 \mathrm{E}-09$ & & & & \multirow{7}{*}{$\begin{array}{l}1.50 \\
1.50\end{array}$} & \multirow[b]{6}{*}{6.00} & \multirow[b]{6}{*}{14.29} & \multirow[b]{6}{*}{$2.37 \mathrm{E}+00$} & & \\
\hline & $A L$ & 0.36 & $2.54 \mathrm{E}-13$ & 1.27E-13 & & & & & & & & & \\
\hline & ALv & 0.36 & 2.54E-13 & 1.27E-13 & & & & & & & & & \\
\hline & AL1v & 0.36 & 4.27E-12 & $6.10 \mathrm{E}-13$ & & & & & & & & & \\
\hline & AL2v & 0.36 & 4.27E-12 & $6.10 \mathrm{E}-13$ & & & & & & & & & \\
\hline & AL2a & 0.36 & $4.21 \mathrm{E}-12$ & 2.10E-12 & 0.36 & $3.91 \mathrm{E}+00$ & $1.96 \mathrm{E}+00$ & & & & & & \\
\hline & $A L 2 b$ & 0.36 & $2.60 \mathrm{E}-11$ & $1.30 \mathrm{E}-11$ & 0.36 & $2.42 E+01$ & $1.21 \mathrm{E}+01$ & & 6.00 & 14.29 & $1.47 \mathrm{E}+01$ & & \\
\hline & AL3 & 0.32 & $1.86 \mathrm{E}-13$ & $9.30 \mathrm{E}-14$ & 0.32 & $1.73 \mathrm{E}-01$ & $8.65 \mathrm{E}-02$ & 1.50 & 6.00 & 14.29 & $1.05 \mathrm{E}-01$ & & \\
\hline & AL4 & 0.32 & $9.76 \mathrm{E}-12$ & 4.88E-12 & 0.32 & $9.16 \mathrm{E}+00$ & $4.58 \mathrm{E}+00$ & 1.50 & 6.00 & 14.29 & $5.55 E+00$ & & \\
\hline & AL5 & 0.32 & $1.86 \mathrm{E}-13$ & $9.30 \mathrm{E}-14$ & 0.32 & $1.73 \mathrm{E}-01$ & 8.65E-02 & 1.50 & 6.00 & 14.29 & $1.05 \mathrm{E}-01$ & & \\
\hline & AL6 & 0.32 & $1.53 \mathrm{E}-13$ & $7.67 \mathrm{E}-14$ & 0.32 & 1.43E-01 & $7.15 \mathrm{E}-02$ & 1.50 & 6.00 & 14.29 & 8.64E-02 & & \\
\hline & $\mathrm{AL} 7$ & 0.32 & $2.15 \mathrm{E}-12$ & $1.08 \mathrm{E}-12$ & 0.32 & $2.00 \mathrm{E}+00$ & $1.00 \mathrm{E}+00$ & & & & & & \\
\hline & AL8 & 0.32 & $3.22 \mathrm{E}-13$ & $1.61 \mathrm{E}-13$ & 0.32 & $3.00 \mathrm{E}-01$ & $1.50 \mathrm{E}-01$ & & & & & & \\
\hline \multirow{5}{*}{ Zones } & AL $9^{* *}$ & 0.30 & 3.22E-14 & $1.61 \mathrm{E}-14$ & $* *$ & $* *$ & $* *$ & & & & & & \\
\hline & AL10* & 0.30 & $3.22 \mathrm{E}-12$ & $1.61 \mathrm{E}-12$ & * & * & * & & & & & & \\
\hline & $\mathrm{CHM} 3$ & 0.36 & $4.21 \mathrm{E}-12$ & $4.21 \mathrm{E}-12$ & 0.36 & & & 1.50 & 6.00 & 14.29 & $2.37 \mathrm{E}+00$ & & \\
\hline & $\mathrm{CHM} 2$ & 0.36 & $2.42 \mathrm{E}-11$ & $2.42 \mathrm{E}-11$ & 0.36 & & & 1.50 & 6.00 & 14.29 & $1.47 \mathrm{E}+01$ & & \\
\hline & $\mathrm{CHM} 1$ & 0.36 & $2.79 \mathrm{E}-13$ & $2.70 E-13$ & 0.36 & & & 1.50 & 6.00 & 14.29 & $1.05 \mathrm{E}-01$ & & \\
\hline
\end{tabular}




\section{CHAPTER 4: CALIBRATION AND ASSESSMENT MODELS}

Table 4.5. Hydraulic properties of hydrofacies defined in the NUFT and ParFlow base-case simulations with hydraulic conductivities ( $K_{G}$ or $K_{h}$, $\mathrm{K}_{\mathrm{v}}$ ) based upon pure water at $24^{\circ} \mathrm{C}$. Cells with no data refer to units or parameters not covered in respective model (NUFT or ParFlow) or gridded (fine or coarse) portion of model. Porosity column data in the ParFlow model applies to both coarse and fine grids.

\begin{tabular}{|c|c|c|c|c|c|c|c|c|c|c|c|c|c|}
\hline & \multirow{4}{*}{ Unit } & \multirow{2}{*}{\multicolumn{3}{|c|}{ NUFT Grid }} & \multicolumn{9}{|c|}{ ParFlow Grid } \\
\hline & & & & & \multicolumn{3}{|c|}{ Coarse grid portion } & \multicolumn{6}{|c|}{ Fine grid portion } \\
\hline & & \multirow{2}{*}{$\phi$} & \multirow{2}{*}{$\begin{array}{l}\mathrm{k}_{\mathrm{h}} \\
\left(\mathrm{m}^{2}\right)\end{array}$} & \multirow{2}{*}{$\begin{array}{l}\mathrm{k}_{\mathrm{v}} \\
\left(\mathrm{m}^{2}\right)\end{array}$} & \multirow{2}{*}{$\phi$} & \multirow{2}{*}{$\begin{array}{l}\mathrm{K}_{\mathrm{h}} \\
(\mathrm{m} / \mathrm{d})\end{array}$} & \multirow{2}{*}{$\begin{array}{l}K_{v} \\
(m / d)\end{array}$} & \multicolumn{4}{|c|}{ Stochastic hydraulic conductivity distribution } & \multicolumn{2}{|c|}{$\begin{array}{l}\text { Constant hydraulic } \\
\text { conductivity }\end{array}$} \\
\hline & & & & & & & & $\sigma_{f}$ & $\lambda_{v} \quad(m)$ & $\lambda_{\mathrm{h}} \quad(\mathrm{m})$ & $\mathrm{K}_{\mathrm{G}}(\mathrm{m} / \mathrm{d})$ & $\mathrm{K}_{\mathrm{h}} \quad(\mathrm{m} / \mathrm{d})$ & $\mathrm{K}_{\mathrm{v}} \quad(\mathrm{m} / \mathrm{d})$ \\
\hline & PIM & 0.36 & $2.79 \mathrm{E}-13$ & $2.79 \mathrm{E}-13$ & 0.36 & & & 1.00 & 6.00 & 6.00 & $2.20 \mathrm{E}-01$ & & \\
\hline & CAV & 0.32 & $2.37 \mathrm{E}-13$ & $2.37 E-13$ & 0.32 & & & 1.00 & 6.00 & 6.00 & $2.20 \mathrm{E}-01$ & & \\
\hline & MG & 0.29 & $1.61 \mathrm{E}-13$ & $1.61 \mathrm{E}-13$ & 0.29 & & & 1.00 & 6.00 & 6.00 & $1.50 \mathrm{E}-01$ & & \\
\hline & $\mathrm{CZ}$ & 0.27 & $1.80 \mathrm{E}-15$ & $1.80 \mathrm{E}-15$ & 0.27 & & & 1.50 & 6.00 & 14.29 & 1.67E-03 & & \\
\hline & GRAV & 0.50 & 3.35E-09 & $3.35 \mathrm{E}-09$ & & & & & & & & & \\
\hline & RNM-2S & 0.50 & $3.35 \mathrm{E}-09$ & $3.35 \mathrm{E}-09$ & & & & & & & & & \\
\hline & GRAV2 & & & & 0.36 & & & & & & & $2.42 \mathrm{E}+01$ & $5.50 \mathrm{E}+01$ \\
\hline & GRAV3 & & & & 0.32 & & & & & & & $1.86 \mathrm{E}-01$ & $3.10 E+01$ \\
\hline & GRAV4 & & & & 0.32 & & & & & & & $9.20 \mathrm{E}+00$ & $4.00 \mathrm{E}+01$ \\
\hline & GRAV5 & & & & 0.32 & & & & & & & $1.86 \mathrm{E}-01$ & $3.10 \mathrm{E}+01$ \\
\hline & DITCH & 0.36 & $4.27 \mathrm{E}-12$ & $6.10 \mathrm{E}-13$ & & & & & & & & & \\
\hline \multirow[t]{9}{*}{ HSUs } & AA3 & & & & 0.36 & $1.23 \mathrm{E}+00$ & $6.15 \mathrm{E}-01$ & 1.50 & 6.00 & 46.15 & $2.06 \mathrm{E}+00$ & & \\
\hline & PCU2T & & & & 0.32 & $1.00 \mathrm{E}+00$ & $5.00 \mathrm{E}-01$ & 1.50 & 6.00 & 18.20 & $2.35 \mathrm{E}-01$ & & \\
\hline & AA2 & & & & 0.36 & $1.23 E+00$ & $6.15 \mathrm{E}-01$ & 1.50 & 6.00 & 46.15 & $2.06 \mathrm{E}+00$ & & \\
\hline & OAA & & & & 0.32 & $3.70 \mathrm{E}+00$ & $1.85 \mathrm{E}+00$ & & & & & & \\
\hline & PCU2B & & & & 0.32 & $1.00 \mathrm{E}+00$ & $5.00 \mathrm{E}-01$ & & & & & & \\
\hline & BLFA & & & & 0.32 & 4.07E-01 & $2.04 \mathrm{E}-01$ & & & & & & \\
\hline & PCU1U & & & & 0.36 & $1.00 \mathrm{E}+00$ & $5.00 \mathrm{E}-01$ & & & & & & \\
\hline & $\mathrm{AA} 1^{*}$ & & & & 0.32 & $3.00 \mathrm{E}+00$ & $1.50 \mathrm{E}+00$ & & & & & & \\
\hline & OAA1 & & & & 0.32 & $3.70 \mathrm{E}+00$ & $1.85 E+00$ & & & & & & \\
\hline
\end{tabular}


CHAPTER 4: CALIBRATION AND ASSESSMENT MODELS

Table 4.5. Hydraulic properties of hydrofacies defined in the NUFT and ParFlow base-case simulations with hydraulic conductivities $\left(\mathrm{K}_{\mathrm{G}}\right.$ or $\mathrm{K}_{\mathrm{h}}$ $\mathrm{K}_{\mathrm{v}}$ ) based upon pure water at $24^{\circ} \mathrm{C}$. Cells with no data refer to units or parameters not covered in respective model (NUFT or ParFlow) or gridded (fine or coarse) portion of model. Porosity column data in the ParFlow model applies to both coarse and fine grids.

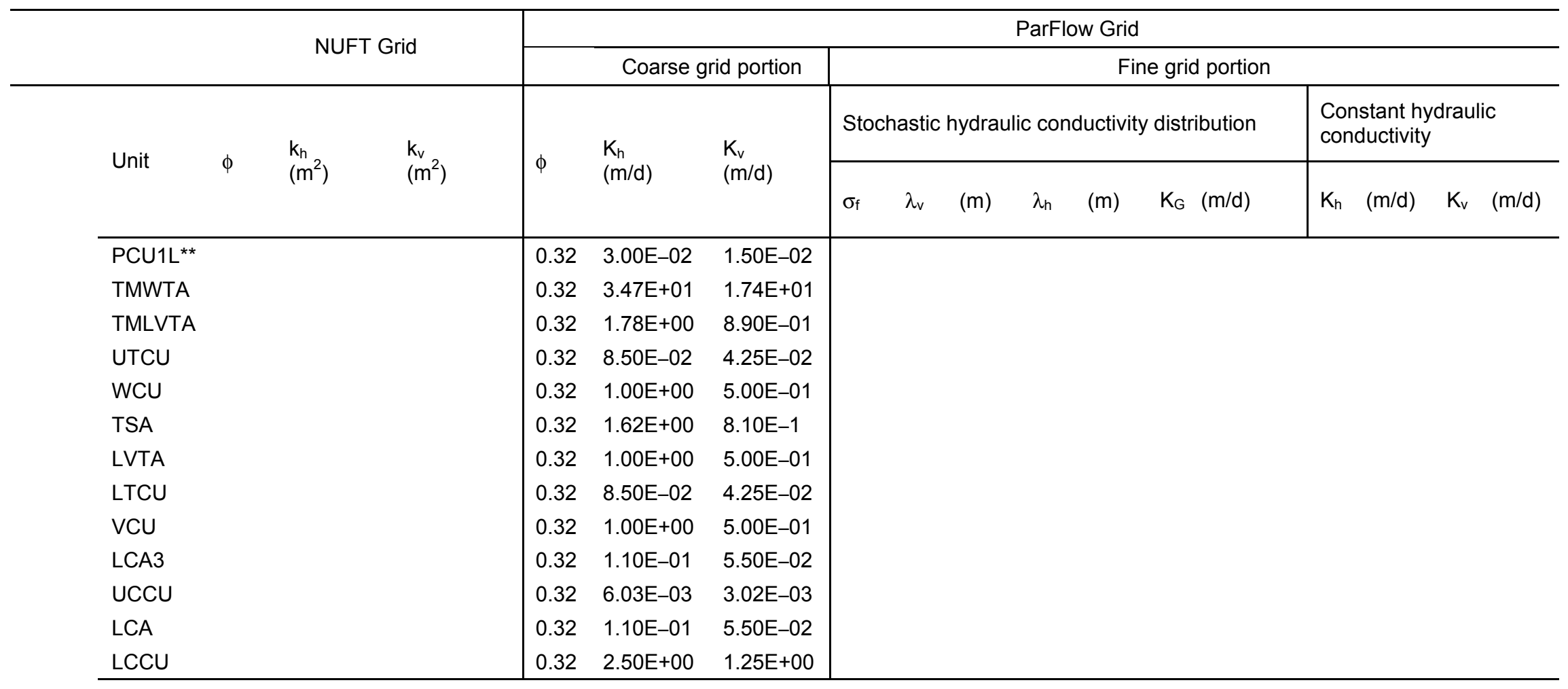

* The AL9 zone in the NUFT model is contained as part of

the greater PCU1L zone in ParFlow. PCU1L in ParFlow uses equivalent values to AL9 in NUFT model

** The AL10 zone in the NUFT model is contained as part of

the greater AA1 zone in ParFlow. AA1 in ParFlow uses

equivalent values to AL10 in NUFT model. 


\subsubsection{Intra-Hydrofacies Heterogeneity}

The ParFlow model utilizes a Gaussian random field model to specify intrahydrofacies permeability within the local layers and altered zones surrounding the cavity and ditch infiltration areas. The parametric characteristics of the stochastic conductivity distribution specified in the alluvial layers are shown in the appropriate rows of Table 4.5. These were developed from the observations and inferences used in Tompson et al. (1999) and the procedure outlined in Appendix B of Tompson et al. (2005).

The specifications used to define the scalar-valued stochastic conductivity ( $\mathrm{K}, \mathrm{m} / \mathrm{d}$ ) distributions in ParFlow sought to ensure that the effective (scaled-up) horizontal hydraulic conductivities associated with the distribution in each layer or zone match their calibrated counterparts in NUFT. The procedure involved choosing plausible values for the $\ln \mathrm{K}$ variance and vertical spatial correlation scales $\left(\sigma_{f, j}^{2}\right.$ and $\left.\lambda_{v, j}\right)$ for each layer $j$ a priori. Specifically, set $\sigma_{f, j}=1.5$ and $\lambda_{v, j}=6 \mathrm{~m}$ in all ParFlow layers was chosen, as used in Tompson et al. (2005) and in Table 20 of Tompson et al., (1999). The procedure in Appendix B of Tompson et al.(2005) allowed the horizontal correlation scales and geometric mean hydraulic conductivities to be subsequently calculated.

\subsection{Groundwater Flow Conditions}

\subsubsection{Water Level Elevations}

Water level elevations in RNM-2, RNM-2S, ER-5-4 (piezometer and composite), and UE-5n near CAMBRIC generally fall within range of $1 \mathrm{~m}$, with estimated mean contemporary steady-state water elevations ranging between 733.34 and $733.84 \mathrm{~m}$ elevation (Stoller-Navarro, 2004a). The surface elevation at U-5e (CAMBRIC test hole) is 956.09-m. Water level elevation data indicate a water level depth of approximately 222 to $223 \mathrm{~m}$ beneath the ground surface at CAMBRIC. As discussed in Section 4.2.2, estimated water level elevations in RNM-1 may be too low due to error in the estimated coordinates of this slant-drilled well.

\subsubsection{Hydraulic Gradients}

The magnitude of the horizontal hydraulic gradient in the vicinity of CAMBRIC is very small. Hoffman et al. (1977) estimated a southeastward gradient of 0.001 near the RNM experiment site, but qualify water table contours used for this estimate as "highly speculative." Stoller-Navarro (2004a) estimated a horizontal hydraulic gradient between 0.0003 and 0.0013 in the vicinity of RNM-2S near CAMBRIC. Uncertainties in the water level measurements cause uncertainty in the estimation of both magnitude and direction of the lateral hydraulic gradient. Section 2.2.3 discusses estimation of the horizontal hydraulic gradient near CAMBRIC in greater detail.

A vertical hydraulic gradient measurement was obtained between the two lower completion intervals of ER-5-4 (Stoller-Navarro, 2004a). Usually, the two lower screened intervals in ER-5-4 are open to yield a composite water level measurement. Between April and September 2004, a bridge plug was installed between the two lower screened intervals, and pressure transducers were installed. The pressure data indicated no pressure change in the topmost lower screened interval and a decrease in pressure in 
the bottommost lower screened interval. This pressure change corresponded to a head decrease of about $1.2 \mathrm{~m}$. Considering the difference in depth between the top and bottom of the two lower screened intervals, Stoller-Navarro (2004b) estimated a downward gradient of 0.003 . In terms of the alluvial layering model (Warren et al., 2002), the top lower interval is located in Layer 8 and the bottom lower interval is located in Layer 10. These data confirm that Layer 9, a playa-confining unit (CAU model unit PCU1U) consisting of interbedded clays and sands, acts as a semi-confining unit. The downward hydraulic gradient apparently occurs primarily across Layer 9. Otherwise, no strong vertical hydraulic gradients are evident near CAMBRIC in the saturated zone within the upper alluvium including Layers 2-8.

\subsubsection{Geothermal Gradient and Residual Test Heat}

As described in Chapter 3, one temperature log was obtained May 8, 1974, in RNM-1. This temperature log provides information on the local geothermal gradient and residual test heat. However, the drill-hole construction history must be factored into interpretation of this temperature log. The upper portion of the temperature log shown in Figure 3.5 was used to deduce possible residual test-related heat and the geothermal gradient above the CAMBRIC test. There is a significant temperature increase above the cemented zone. This temperature increase correlates with the location of the cavity/chimney and is on the order of 1.5 to $2.5^{\circ} \mathrm{C}$. A geothermal gradient of $24^{\circ} \mathrm{C} / \mathrm{km}$ was determined by continuing downward the trend of the data related to test-related heat.

Gillespie (2005) compares two temperature logs obtained from UE-5n in July 1992 and May 2004 (Figure 4.5). The two logs show similar temperature profiles, with slightly cooler temperatures in the July 1992 temperature $\log$ by 0.1 to $0.2^{\circ} \mathrm{C}$ between depths of about 220 and $225 \mathrm{~m}$ and 0.2 to $0.3^{\circ} \mathrm{C}$ between depths of about 295 and $360 \mathrm{~m}$. The July 1992 temperature log shows frequent variability suggesting measurement error. Nonetheless, both logs, particularly the May 2004 log, show distinct changes in the temperature gradient with depth. The temperature gradient increases markedly between depths of about 285 and $305 \mathrm{~m}$, which correlates to Layer 3 . The changes in temperature gradient can be attributed to either changes in thermal conductivity or changes in groundwater flow patterns. Either higher thermal conductivity or increased lateral groundwater flow velocity can produce smaller vertical geothermal gradients. The relatively small temperature gradients between depths of 225 and $285 \mathrm{~m}$ and 305 and $330 \mathrm{~m}$ could be attributed to increased lateral groundwater flow velocity associated with relatively higher permeability. Alluvial composition at depths less than $330 \mathrm{~m}$ is dominated by lava of the Wahmonie Formation and, thus, large changes in thermal conductivity are not expected. At UE-5n, the depth range of 225 to $285 \mathrm{~m}$ correlates to alluvial Layer 2, and the depth range of 305 to $330 \mathrm{~m}$ would straddle Layer 4 (if laterally extensive), both of which are high-permeability zones. Thus, the temperature logs at UE-5n further indicate that the alluvial layers near CAMBRIC have different permeability, particularly across the contact between Layers 2 and 3. Alternately, the differences in thermal profiles for " 23 Jul 1992" and "20 May 2004" in Figure 4.5 could be attributed to a small $\left(\sim 0.2\right.$ to $\left.0.3{ }^{\circ} \mathrm{C}\right)$ calibration difference combined with colder CAMBRIC ditch infiltration water entering Layer 2. Figure 4.33 shows that the NUFT simulations predict ditch infiltration would be colder than groundwater below the water table. 

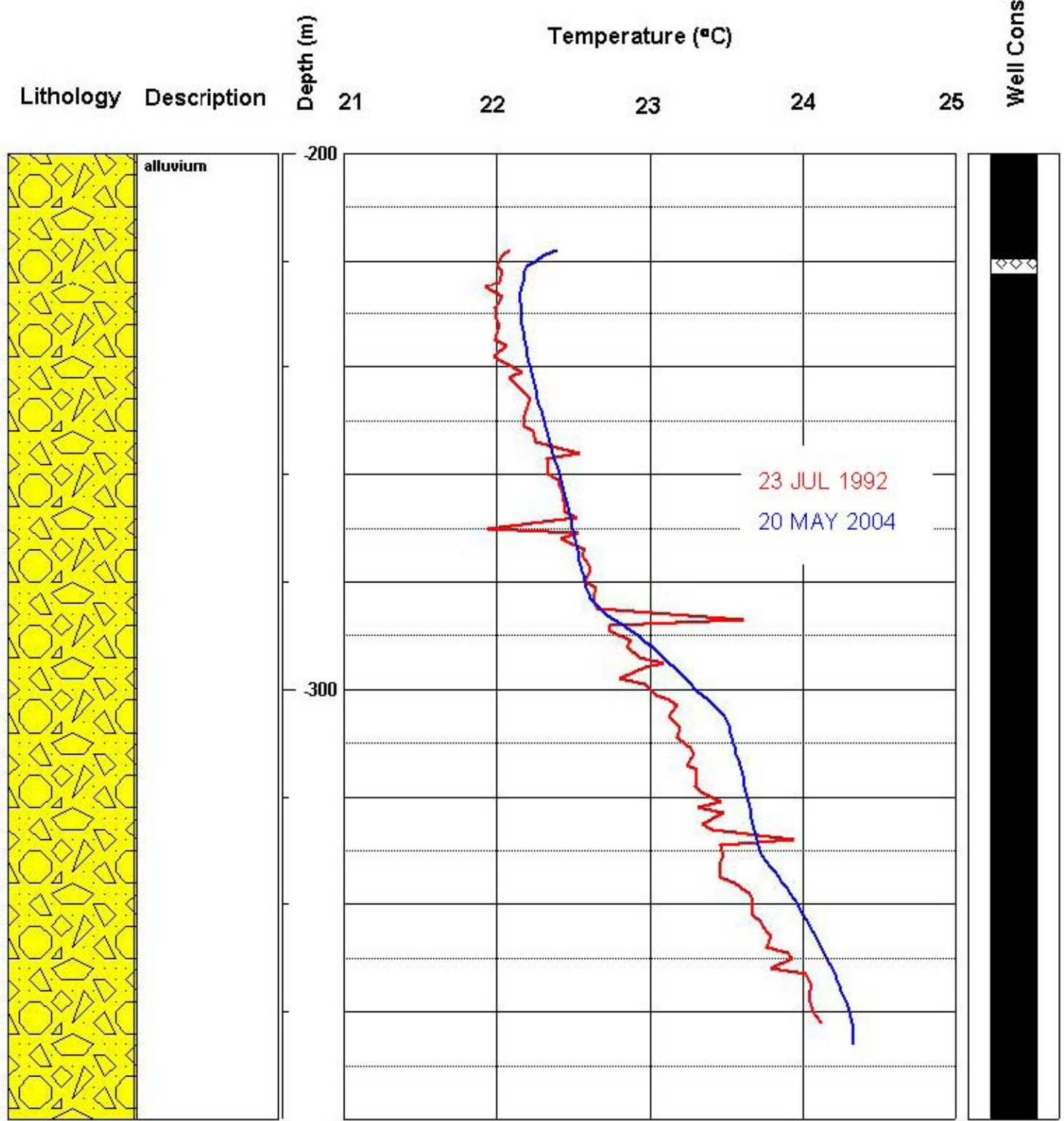

Figure 4.5. Temperature profiles, lithology, and well construction for borehole UE-5n, from Gillespie (2005). Darkened portion of well construction diagram indicates where casing was cemented in the borehole, and stippled pattern indicates location of perforated interval between 219.5 and $222.5 \mathrm{~m}$ depth. 


\subsubsection{Model Boundary Conditions}

In both the NUFT and ParFlow flow simulations, boundary conditions are implemented on a regional scale to approximate groundwater flow conditions near CAMBRIC. Section 2.2.2 discusses local ambient hydraulic gradient assumed for the NUFT and ParFlow simulations. The NUFT simulations add thermal boundary conditions to approximate the geothermal gradient near CAMBRIC.

\subsubsection{NUFT Simulations}

The NUFT flow simulations implement boundary conditions for pressure, saturation, temperature, and concentration of air. To approximate a local northeast hydraulic gradient, fixed hydrostatic pressure conditions are implemented at the updgradient $(\mathrm{x}=-2,000 \mathrm{~m})$ and downgradient $(\mathrm{x}=+4,000 \mathrm{~m})$ locations within the saturated zone between Layers 2 and 8 . The difference in pressures between the upgradient and downgradient boundaries impart an approximate $21-\mathrm{m}$ head difference from southeast to northwest. However, the higher permeability layers sandwiched within the lower permeability background alluvium (AL hydrofacies) result in an approximate 0.0008 horizontal hydraulic gradient local to CAMBRIC as discussed in Section 4.4.2. No flow conditions are implemented on the southeast $(y=-4,000 \mathrm{~m})$ and northwest $(y=+3,500 \mathrm{~m})$ sides of the model. To approximate a local downward hydraulic gradient between Layers 8 and 10, a fixed-pressure boundary condition is applied at the base of Layer 10. This basal pressure boundary condition is set to a hydraulic head that is about $1 \mathrm{~m}$ lower than the hydraulic head in Layers 1 to 8 near CAMBRIC, thereby inducing a downward hydraulic gradient mostly evident across Layer 9, the PCU1U. The vertical hydraulic conductivity $\left(K_{v}\right)$ of $0.015 \mathrm{~m} / \mathrm{d}$ assumed for layer 9 is expected to be an upper limit - the highest value of $K_{v}$ that could induce a vertical gradient similar to the observations at ER-5-4.

The NUFT flow simulations also implement constant temperature conditions at the lower and upper boundaries. To impart a geothermal gradient in the NUFT flow simulation, temperature is fixed as a boundary condition of $28.5^{\circ} \mathrm{C}$ at the bottom boundary ( $-706 \mathrm{~m}$ relative to CAMBRIC) and $21.25^{\circ} \mathrm{C}$ at the upper boundary (cell center at +294.5 m relative to CAMBRIC).

The NUFT simulations assume a pumping rate at RNM-2S of $18.92 \mathrm{~kg} / \mathrm{s}$ (300 gpm) between 10.4 and $12.3 \mathrm{y}$ and $37.86 \mathrm{~kg} / \mathrm{s}(600 \mathrm{gpm})$ between 12.3 and $25.6 \mathrm{y}$. The NUFT simulations assume infiltration along the CAMBRIC ditch occurs at a rate of $10.6 \mathrm{~kg} / \mathrm{s}$ between 10.4 and $12.3 \mathrm{y}$ and $21.2 \mathrm{~kg} / \mathrm{s}$ between 12.3 and $25.6 \mathrm{y}$ over a ditch length of $1,910 \mathrm{~m}$. No infiltration is assumed in the playa. Thus, the NUFT simulations assume approximately $56 \%$ of the liquid pumped from RNM- $2 \mathrm{~S}$ is returned to the subsurface. The remaining $44 \%$ is assumed lost to evapotranspiration or ponding in the playa.

The boundary conditions used in the development of the ParFlow model are similar, although ParFlow was not used for calibration and assessment purposes. These are discussed in more detail in section 5.2.4. 


\subsubsection{Model Initial Conditions}

\subsubsection{NUFT Simulations}

For the NUFT flow simulations, initial conditions for ambient flow are obtained from the ending state of an initial 100,000-y "equilibrium" NUFT nonisothermal flow simulation using the boundary conditions described in section 4.4.4.1. This equilibrium run allows heat, groundwater, and air flow to equilibrate to the boundary conditions before initializing transient effects of the CAMBRIC test, including heat, pressure, and saturation conditions, and the RNM experiment pumping and infiltration from the ditch.

Test-heat-related thermal effects are implemented in the base-case NUFT flow simulation by initializing temperature at $170{ }^{\circ} \mathrm{C}$ in the melt glass zone and $40{ }^{\circ} \mathrm{C}$ in the cavity. The $170^{\circ} \mathrm{C}$ initial melt glass zone temperature is slightly below the boiling temperature of water under hydrostatic pressure conditions for the depth of the CAMBRIC test below the water table. Section 4.7 investigates more complex test-related effects on saturation, pressure, and temperature, including boiling conditions.

The initial conditions used in the development of the transient ParFlow model were developed from the steady-state, isothermal flow configuration described in Tompson (2005), and are discussed in more detail in section 5.2.4. ParFlow was not used for calibration and assessment purposes.

\subsection{Flow Model Calibration}

This section describes calibration of hydraulic and thermal properties for the NUFT flow model. The principal flow model calibration data sets are:

- The RNM-2S MWAT

- Tritium breakthrough measured at RNM-2S during the RNM experiment

- The alluvial layering hydrostratigraphic framework described by Warren et al. (2002) and discussed in Section 4.2.2

The calibrated flow parameters are used for simulation of the base-case NUFT groundwater and heat flow simulation results described in Section 4.6 which, in turn, are used for the CRUNCH streamline-based simulations of reactive transport of radionuclides (Section 4.8).

Porosity values and permeability values derived for the NUFT flow model (Section 4.3.3) are used either directly or as effective values in the ParFlow flow simulations (Sections 4.3.4 and 4.3.5).

\subsubsection{RNM-2S MWAT}

The MWAT was conducted by pumping RNM-2S at constant rate of approximately 600 gpm for 75 days beginning on April 26, 2003. Water level responses were monitored at RNM-2S, RNM-1, RNM-2, and ER-5-4 (piezometer and composite screened interval). These aquifer test data provide an opportunity to evaluate the permeability structure of the alluvial aquifer near CAMBRIC. When these data were 
interpreted, it was found that the RNM-2S well construction and alluvial layering structure impact the drawdown responses.

\subsubsection{RNM-2S Well Construction}

RNM-2S was completed April 1, 1974. As indicated by the well completion diagram (Figure 4.6), RNM-2S was constructed with casing having an internal diameter of $22.66 \mathrm{~cm}$ (8.921 in.) and an external diameter of $24.45 \mathrm{~cm}$ (9.625 in.). The borehole was drilled at $44.45 \mathrm{~cm}$ (17.5 in.) in diameter. The slotted interval spans a depth range of 316.4 to $341.1 \mathrm{~m}$.

The well was constructed with a gravel pack that extends from 210.3 to $341.4 \mathrm{~m}$ in depth. The water table is about $223.6 \mathrm{~m}$ in depth in the well completion diagram (Figure 4.6). Thus, the gravel pack extends from below the slotted interval to above the water table. The $44.45-\mathrm{cm}$-diameter RNM-2S borehole provides a hydraulic connection between the water table, Layers $2 \mathrm{a}$ and $2 \mathrm{~b}$, and the depth range of Layers 3 , 4, and 5. Moreover, as pumping occurs in RNM-2S, drawdown in the well will induce downward flow through the gravel pack. The extensive gravel pack at RNM-2S raises a possibility that long-term pumping at RNM-2S for the RNM experiment combined with percolation of CAMBRIC ditch discharge to the water table could induce recirculation of pumped water back into the slotted interval of RNM-2S.

The vertically extensive gravel pack construction in RNM-2S also raises another possible radionuclide migration route: upward migration in the vicinity of the chimney to Layer $2 \mathrm{~b}$ as a result of test heat, then laterally through Layer $2 \mathrm{~b}$ and downward through the gravel pack as a result of pumping. Observed low-level ${ }^{3} \mathrm{H}$ breakthrough at RNM-2S prior to the major initial breakthrough after $12.32 \mathrm{y}$ could be explained by this mechanism. However, this gravel-pack-related mechanism for direct transport between CAMBRIC and RNM-2S would likely have only a slight and brief effect on overall radionuclide transport because the impact of test heat is relatively minor and the pumping at RNM-2S soon created a large capture zone with a dominantly downward hydraulic gradient near the CAMBRIC altered zones. 


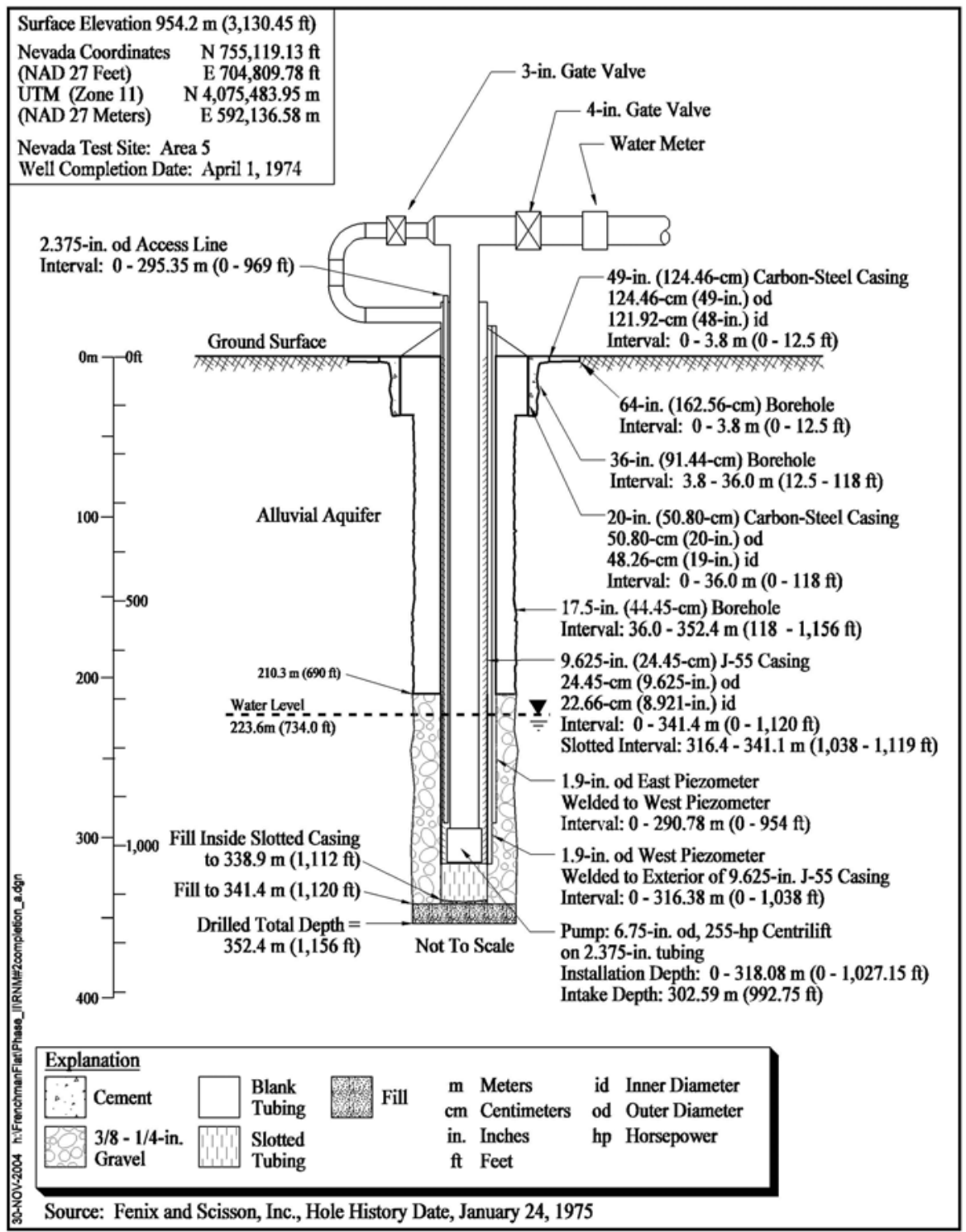

Figure 4.6 Well RNM-2S completion diagram (Stoller-Navarro, 2004a).

\subsubsection{NUFT Flow Simulation Calibration and Sensitivity Studies}

Hydraulic conductivity, specific storage, and specific yield values for alluvial layers were estimated from the data obtained from the RNM-2S MWAT. These data were also analyzed by Stoller-Navarro (2004a) and the USGS (2004) to obtain bulk hydraulic property estimates within the AA HSU near CAMBRIC. A different approach to analysis of the MWAT data was taken in this project to account for variations in permeability between different alluvial layers near CAMBRIC.

The alluvial layer model of Warren et al. (2002) was used in this project to define discrete hydrogeologic units (hydrofacies) having uniform hydraulic properties. Only alluvial Layers 2-8 of Warren et al. (2002) were considered for the MWAT calibration because Layer 1 is entirely in the vadose zone, and the clayey Layer 9 behaves 
hydraulically as the confining unit PCU1U (Stoller-Navarro, 2004a). The background alluvium hydrofacies (AL and ALv) are fixed with geometry and grid spacing as indicated in Figure 4.1 and Table 4.2 and with a horizontal permeability of $2.45 \times 10^{-13} \mathrm{~m}^{2}$ $(0.24 \mathrm{~m} / \mathrm{d})$ according to USGS (2004) bulk transmissivity estimates of the entire alluvial section in Frenchman Flat near CAMBRIC.

The objective here was to find a collection of hydraulic properties that would simultaneously fit both the MWAT drawdown responses observed in wells RNM-1, RNM-2, shallow ER-5-4 (piezometer), and ER-5-4 (upper), and would be consistent with the textural description and depth ranges of the alluvial layers (Warren et al., 2002). An iterative procedure was taken, using uniform alluvial hydraulic properties estimated from the MWAT by the USGS (2004). Sensitivity cases were run for the hydraulic properties of each layer. Later, Layer 2 was subdivided into Layer $2 a$ and Layer $2 b$ to provide better fit to the data. Calibrated layer hydraulic properties are given in Table 4.5. Calibrated specific storage is $8.0 \times 10^{-6} \mathrm{~m}^{-1}$ for all layers, and calibrated specific yield is 0.165 for Layers $2 \mathrm{a}, 2 \mathrm{~b}$, and 3 (layers wherein the water table declined from the MWAT). The specific yield of 0.165 is consistent with an assumption of 0.36 porosity and 0.5 residual saturation in Layer 2a, where the water table is located during transient pumping conditions. Given assumptions of 0.36 porosity and 0.5 residual saturation, specific yield in an unconfined aquifer would not be expected to be greater than 0.18 , the product of porosity and residual saturation. A specific yield estimate less than the product of porosity and residual saturation can be attributed to delayed drainage of the vadose zone as the water table lowers in response to pumping.

Figure 4.7 compares the observed and modeled drawdown at wells RNM-1, RNM-2S, ER-5-4 piezometer (pz), and ER-5-4 upper completion zone (uc). The observed response for ER-5-4 (pz) (blue circles) is delayed from the modeled response (blue line), which could be explained by equipment difficulty causing delayed measurement response (Bill Fryer, Stoller-Navarro, personal communicaton, May 2005). In Figure 4.8, modeled drawdown response in the pumping well RNM-2S closely matches available measured data. This model fit includes consideration of a gravel pack extending from the bottom of RNM-2S to above the water table. Hydraulic conductivities of Layers 3 and 4 needed to be adjusted slightly to obtain consistency with the ${ }^{3} \mathrm{H}$ breakthrough curve at RNM-2S from the RNM experiment (Figure 4.13) and the MWAT. Hydraulic properties were manually adjusted until a satisfactory fit to the MWAT drawdown and ${ }^{3} \mathrm{H}$ breakthrough data was obtained. Details for all calibrated hydraulic properties for alluvial layers, altered zones, and intra-hydrofacies heterogeneity are given in Section 4.3. 


\section{RNM-2s Multi Well Aquifer Test}

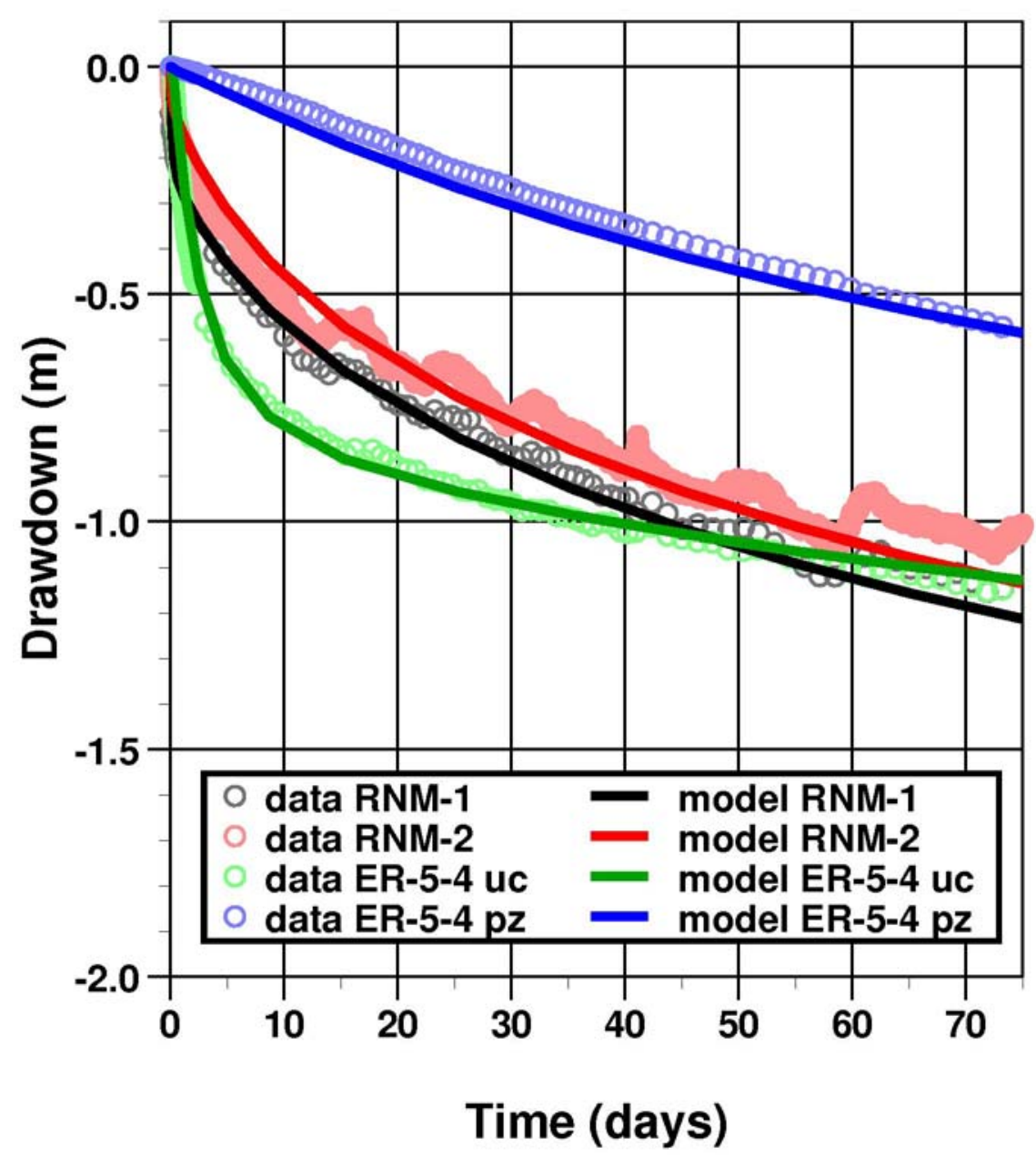

Figure 4.7 Comparison of observed (circles) and NUFT-modeled (lines) drawdown at observation wells RNM-1, RNM-2, and both ER-5-4 upper (ER-5-4 uc) and ER-5-4 piezometer (ER-5-4 pz). 


\section{MWAT - RNM-2s}

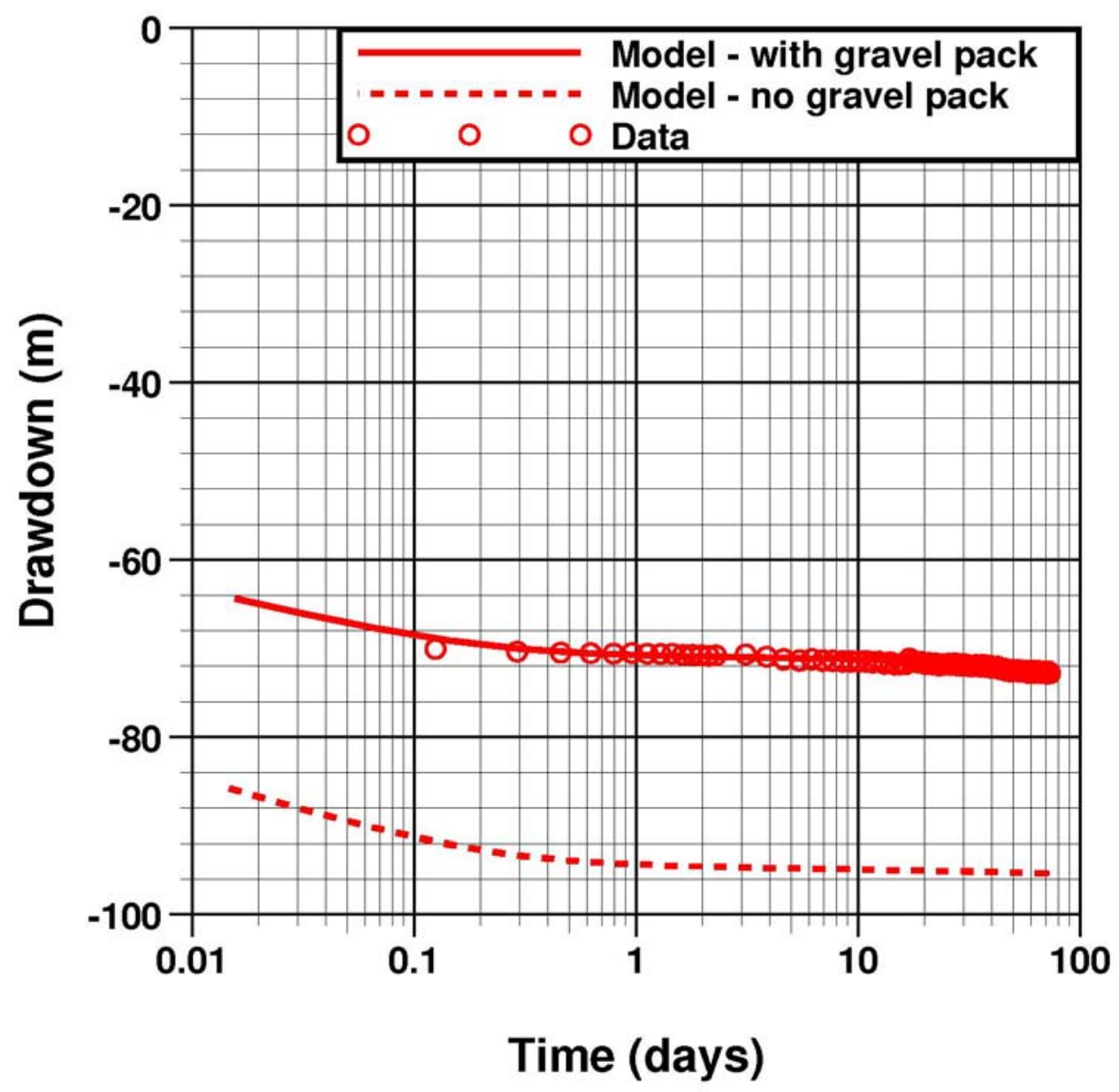

Figure 4.8 Comparison of NUFT simulation results for models with gravel pack (solid line) and without gravel pack (dashed line), and measured drawdown (circles) at pumping well RNM-2S.

\subsubsection{Comparison to Previous MWAT Interpretations}

The USGS (2004) and Stoller-Navarro (2004a) have also used RNM-2S MWAT data to interpret hydraulic properties near CAMBRIC. USGS (2004) used both analytical and numerical methods, while Stoller-Navarro (2004a) used only analytical methods.

In the USGS (2004) approach, the numerical model MODFLOW and the Moench analytical solution were applied. The MODFLOW model was applied in a 3D quarter-space (assuming radial symmetry about the pumping well). The Moench analytical solution is 2D and assumed radial symmetry about the pumping well. In both cases, the in-situ aquifer system was assumed homogeneous except for heterogeneities in hydraulic properties related to the RNM-2S pumping well or the test-related altered zones. Drawdown data were examined for wells RNM-2S, RNM-1, RNM-2, and ER-5-4 in the upper (uc) and the piezometer (pz). The analyses yielded estimates for one set of alluvial aquifer hydraulic properties - horizontal hydraulic conductivity, vertical hydraulic conductivity, specific storage, and specific yield - to fit to the drawdown data 
at all four wells. The fitting process emphasized matching to the drawdown response at ER-5-4 (uc). Analyses were carried out for upper alluvial aquifer saturated zone thickness of either 1,600 or $3,000 \mathrm{ft}$, which corresponds to the base of alluvial Layers 8 and 10, respectively. Thus a total of four cases were examined-analytical and numerical methods for saturated zones thicknesses of 1,600 and 3,000 ft.

In the Stoller-Navarro (2004a) approach, the analytical method nSIGHTS was applied assuming 2D radial symmetry about the pumping well. Drawdown data were examined for wells RNM-1, RNM-2, and ER-5-4 (uc). A saturated zone thickness of 2,954 $\mathrm{ft}$ is assumed, which corresponds to the entire section of alluvial deposits near CAMBRIC, including the PCU1U. The drawdown data for each of these three wells were analyzed independently, yielding three sets of estimates of hydraulic properties.

Table 4.6 compares estimates of alluvial aquifer hydraulic properties by the USGS (2004), Stoller-Navarro (2004a), and this LLNL-HST study using the RNM-2S MWAT data. The USGS (2004) estimates bracket a relatively small range for each parameter compared to the Stoller-Navarro (2004a) estimates. This difference in interpretations is primarily attributed to the USGS (2004) approach of accepting a large mismatch under the simplified assumption of a homogenous conceptual model and the Stoller-Navarro (2004a) approach of emphasizing the matching of drawdown data sets individually to wells to more closely match the data irrespective of using different homogeneous conceptual models. Both approaches have limitations associated with the assumption of a homogenous conceptual model:

- The USGS (2004) approach produces a small range of uncertainty in hydraulic conductivity given known spatial variability in Frenchman Flat.

- The Stoller-Navarro (2004a) approach produces a wide variation in bulk effective hydraulic properties for Frenchman Flat alluvium.

Neither the USGS (2004) or Stoller-Navarro (2004a) approach attempts to estimate variation of hydraulic conductivity in Frenchman Flat near CAMBRIC, particularly as it relates to the alluvial layering hydrostratigraphy. Additionally, neither of these approaches based on homogeneous conceptual models closely fit the drawdown data simultaneously at all wells, including the pumping well, as compared to a layered conceptual model.

Table 4.6. Comparison of alluvial aquifer hydraulic properties estimated by USGS (2004) and Stoller-Navarro (2004a) using RNM-2S MWAT data.

\begin{tabular}{|l|l|l|l|l|}
\hline \multicolumn{1}{|c|}{ Analysis } & \multicolumn{1}{c|}{$\mathbf{K}_{\mathbf{h}}(\mathbf{m} / \mathbf{s})$} & \multicolumn{1}{c|}{$\mathbf{K}_{\mathbf{z}}(\mathbf{m} / \mathbf{s})$} & \multicolumn{1}{c|}{ Spec. Stor. $\left.\mathbf{( m}^{-1}\right)$} & \multicolumn{1}{c|}{ Specific Yield } \\
\hline USGS a-1600 & $4.0 \times 10^{-6}$ & $2.0 \times 10^{-6}$ & $6.6 \times 10^{-6}$ & 0.19 \\
\hline USGS a-3000 & $2.9 \times 10^{-6}$ & $1.2 \times 10^{-6}$ & $3.3 \times 10^{-6}$ & 0.19 \\
\hline USGS n-1600 & $4.2 \times 10^{-6}$ & $3.8 \times 10^{-6}$ & $1.0 \times 10^{-5}$ & 0.22 \\
\hline USGS n-3000 & $3.1 \times 10^{-6}$ & $2.2 \times 10^{-6}$ & $6.6 \times 10^{-6}$ & 0.21 \\
\hline SN RNM-1 & $3.2 \times 10^{-5}$ & $1.0 \times 10^{-5}$ & $7.9 \times 10^{-4}$ & 0.287 \\
\hline SN RNM-2 & $3.6 \times 10^{-6}$ & $8.5 \times 10^{-7}$ & $5.7 \times 10^{-6}$ & 0.031 \\
\hline SN ER-5-4 uc & $7.2 \times 10^{-6}$ & $2.0 \times 10^{-8}$ & $1.4 \times 10^{-7}$ & 0.002 \\
\hline LLNL-HST & Table 4.5 & Table 4.5 & $8.0 \mathrm{E}-6$ & 0.165 \\
\hline
\end{tabular}




\section{RNM-2s Multi Well Aquifer Test}

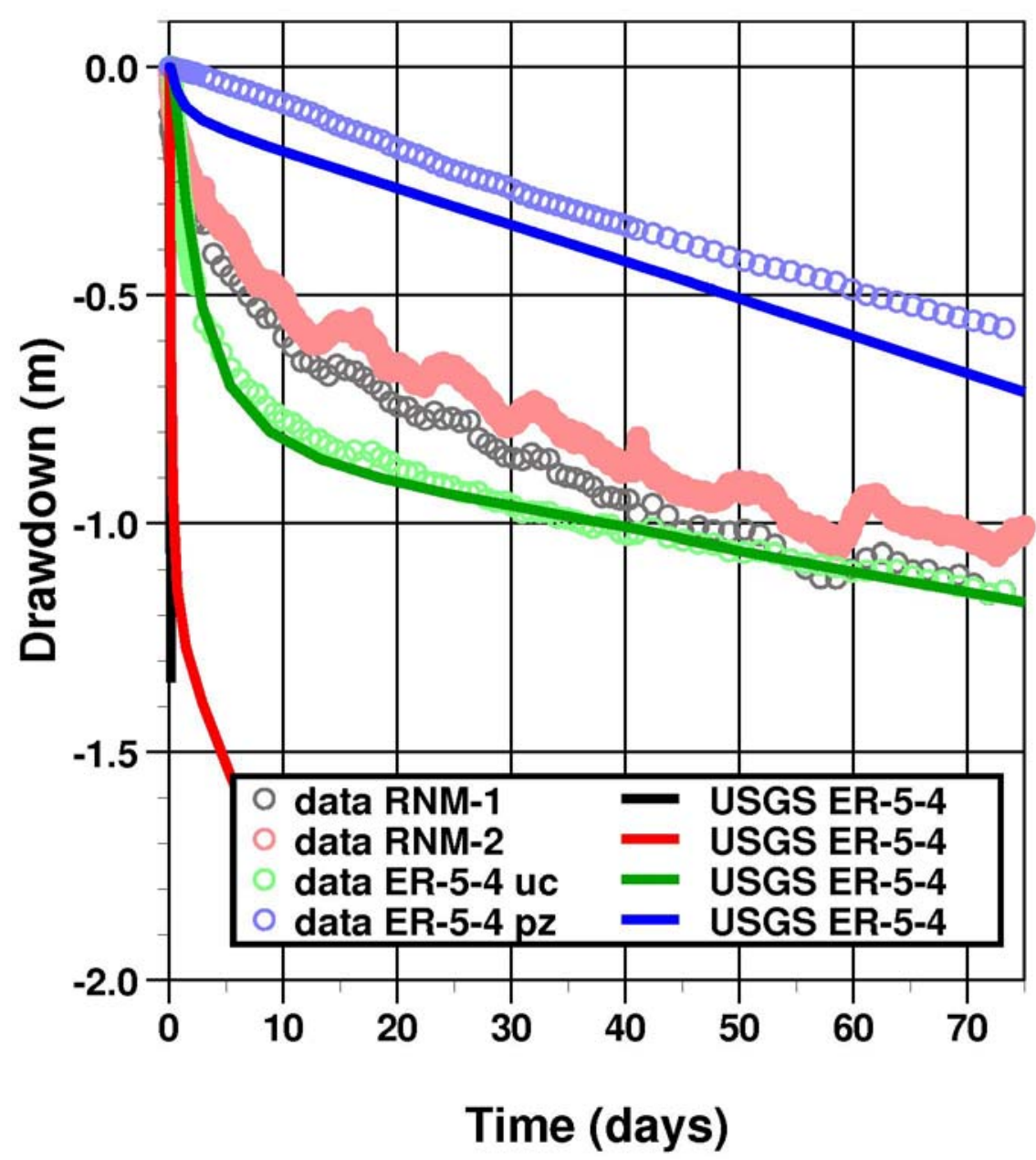

Figure 4.9 Comparison of drawdown data at MWAT observation wells RNM-1, RNM-2, ER-5-4 (uc), and ER-5-4 (pz) to NUFT simulated response using USGS (2004) hydraulic properties fit to ER-5-4 drawdown response.

Figure 4.9 compares drawdown data to simulated drawdown response using the NUFT model with the USGS (2004) hydraulic properties for the analytical 1,600-ft aquifer thickness (a-1600) homogeneous conceptual model, as given in Table 4.6. These hydraulic properties provide an excellent fit to the ER-5-4 (uc) drawdown response, indicating that the NUFT model and the USGS analytical modeling results are computationally consistent. However, the fits to RNM-1, RNM-2 and ER-5-4 (pz) are not particularly close. The USGS (2004) made additional adjustments to hydraulic properties in altered zones near the CAMBRIC test and the developed zone near the RNM-2S screened interval to improve fit drawdown response at RNM-1 and RNM-2S. However, these adjustments did not produce fits to RNM-1, RNM-2, and ER-5-4 (pz) drawdown that were comparable in closeness of fit to ER-5-4 (uc) drawdown, nor did these adjustments produce overall fits to drawdown comparable to results of using a layer model as shown in Figures 4.7 and Figure 4.8. 
Figures 4.10-4.12 compare simulated drawdown response using the NUFT model with the Stoller-Navarro (2004a) hydraulic properties fit to RNM-1, RNM-2, and ER-5-4 (uc) drawdown response as given in Table 4.6 assuming a homogeneous conceptual model. In Figure 4.10, drawdown using the NUFT model with StollerNavarro (2004a) hydraulic properties fit to RNM-1 drawdown response provides a general match to the shape of the RNM-1, RNM-2, and ER-5-4 (pz) drawdown response, but not overall magnitude. Figure 4.11 using Stoller-Navarro (2004a) hydraulic properties fit to RNM-2 drawdown response yields similar results, but with better agreement to RNM-2 drawdown. Figure 4.12, using Stoller-Navarro (2004a) hydraulic properties fit to ER-5-4 (uc) drawdown response, shows much greater simulated drawdown for all wells and overall poor fit. The differences in NUFT simulated drawdown responses and nSIGHTS drawdown responses may be largely attributed to differences in the manner of application of nSIGHTS and NUFT. For example, the Stoller-Navarro ER-5-4 (uc) drawdown response estimates of 0.002 for specific yield is extremely low and the $360: 1$ for horizontal:vertical anisotropy ratio in hydraulic conductivity is extremely large for an alluvial aquifer.

The main purpose of comparing previous MWAT interpretations with this study's reinterpretation of the MWAT is to rationalize this study's use of a layered hydrogeologic conceptual model for HST calculations in Frenchman Flat, considering that homogeneous conceptual models have been prevalent in some recent work (USGS, 2004 and Stoller-Navarro, 2004a). Notably, Burbey and Wheatcraft (1986), Guell and Hunt (2003), and Tompson et al. (1999) recognized and included layer-related heterogeneities in previous radionuclide transport studies of CAMBRIC. However, these studies were carried out prior to the MWAT, which has since yielded much direct insight into hydraulic property distributions near CAMBRIC. Combining results presented in this section with discussion in Section 4.2 shows that a layered hydrogeologic conceptual model is consistent with interpretation of both geologic and MWAT hydraulic testing data. Nonetheless, a layered hydrologeologic conceptual model remains simplistic compared to the true, but unknown, alluvial hydrostatigraphy as discussed in Section 4.2.2. 


\section{RNM-2s Multi Well Aquifer Test}

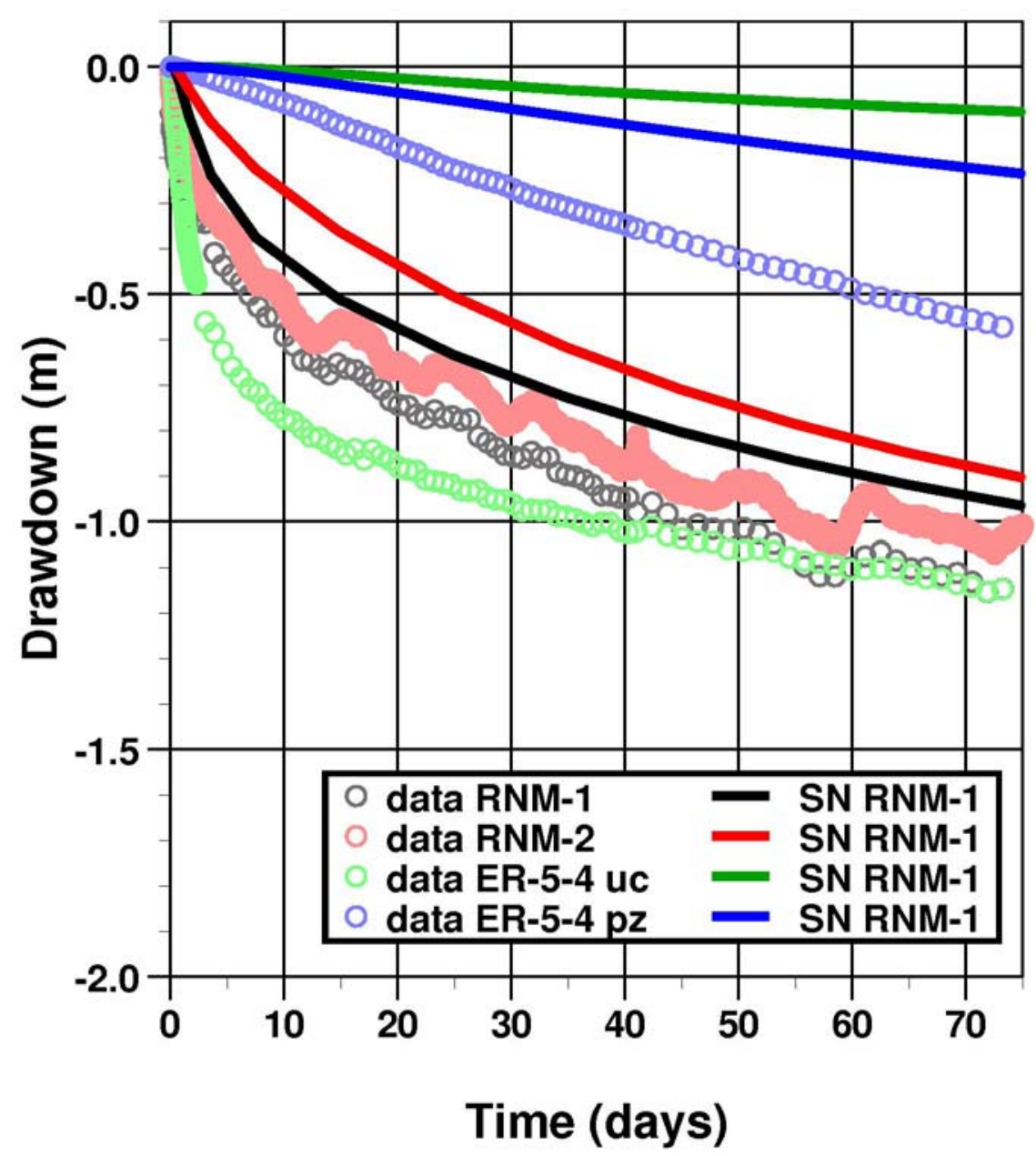

Figure 4.10 Comparison of drawdown data at MWAT observation wells RNM-1, RNM-2, ER-5-4 (uc), and ER-5-4 (pz) to NUFT simulated response using Stoller-Navarro (2004a) hydraulic properties fit to RNM-1 drawdown response. 


\section{RNM-2s Multi Well Aquifer Test}

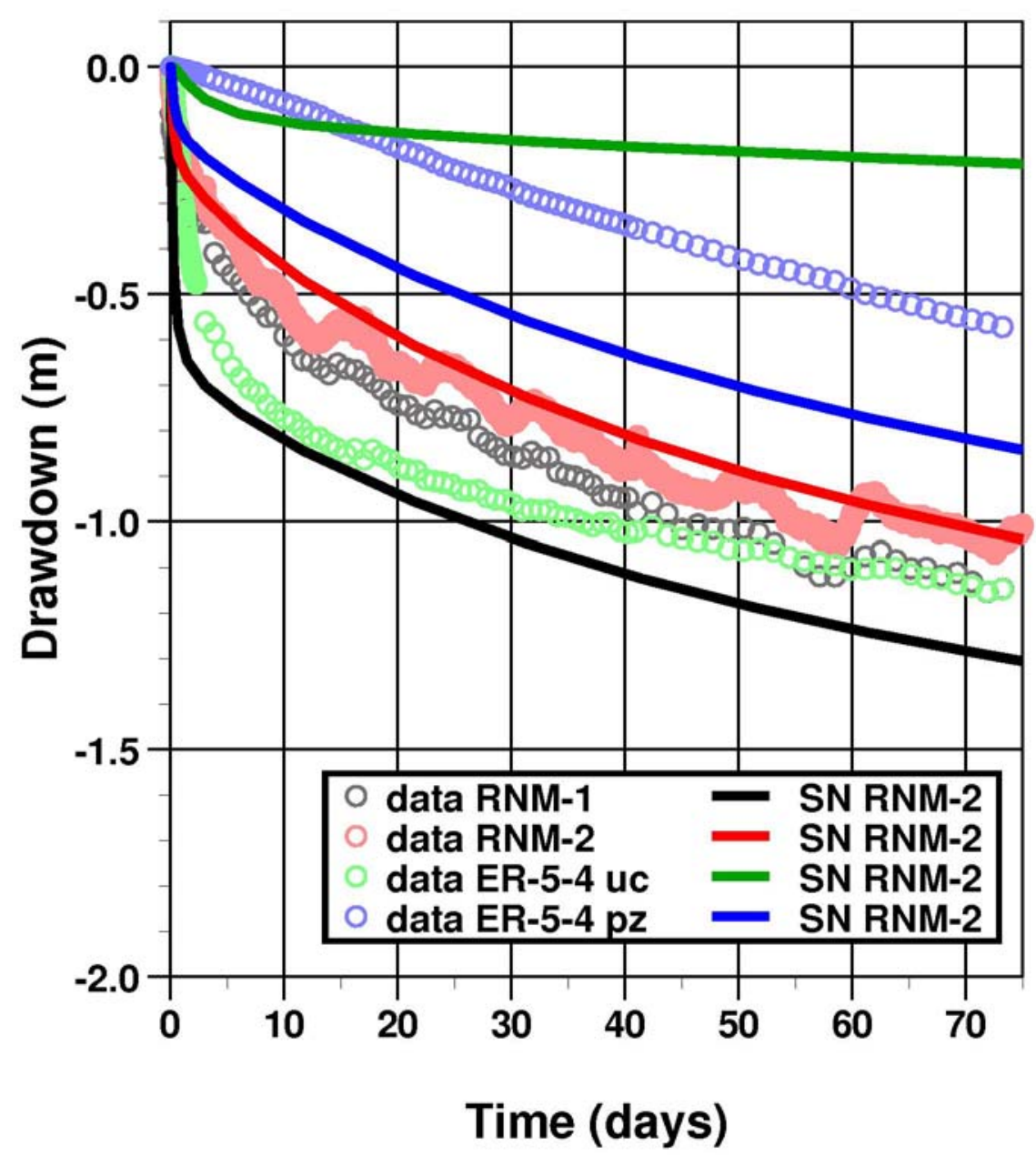

Figure 4.11 Comparison of drawdown data at MWAT observation wells RNM-1, RNM-2, ER-5-4 (uc), and ER-5-4 (pz) to NUFT simulated response using Stoller-Navarro (2004a) hydraulic properties fit to RNM-2 drawdown response. 


\section{RNM-2s Multi Well Aquifer Test}

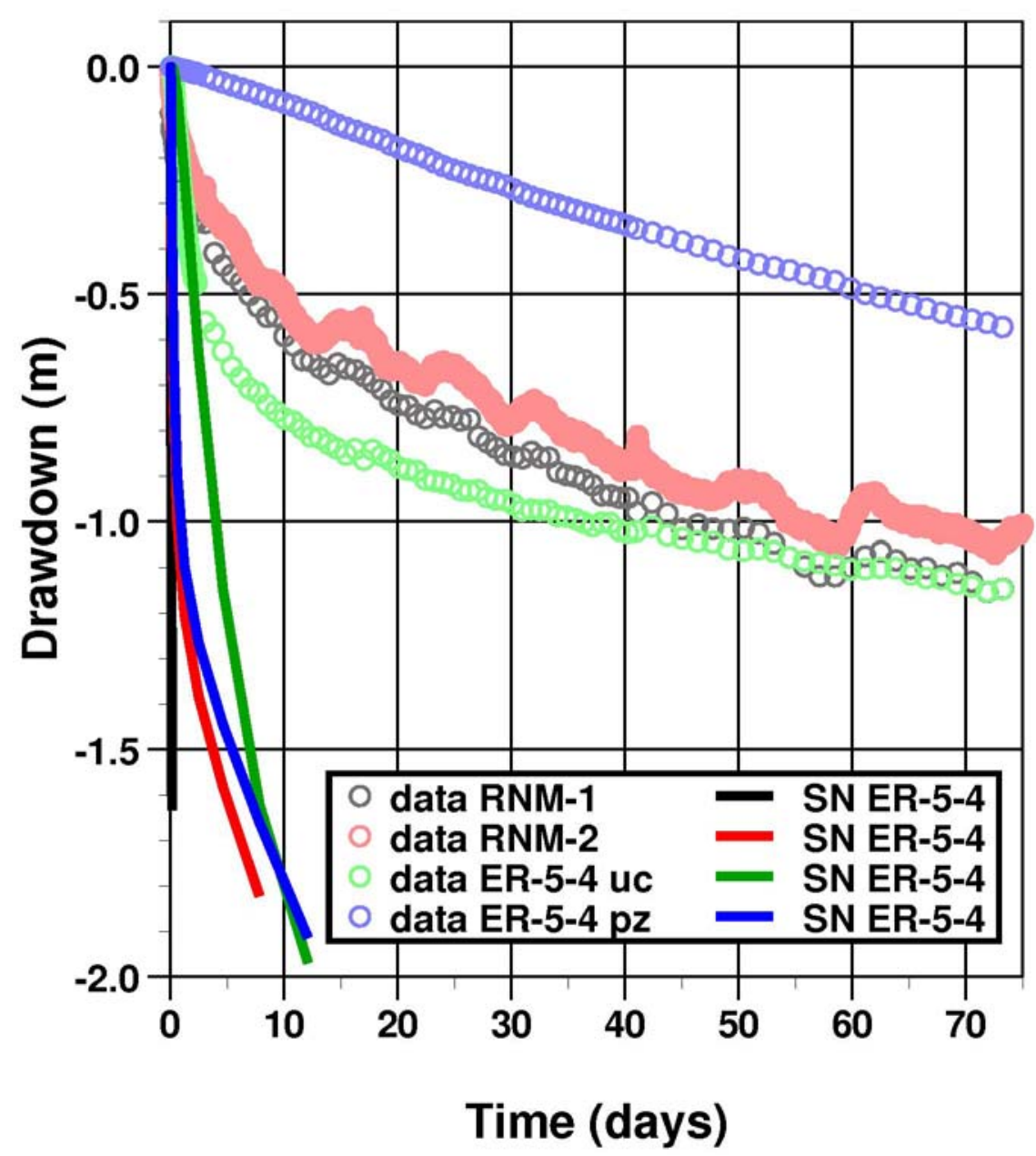

Figure 4.12 Comparison of drawdown data at MWAT observation wells RNM-1, RNM-2, ER-5-4 (uc), and ER-5-4 (pz) to NUFT simulated response using Stoller-Navarro (2004a) hydraulic properties fit to ER-5-4 (uc) drawdown. 


\subsubsection{Calibration to the RNM Experiment}

In the RNM experiment, groundwater was pumped at a rate of approximately 300 gpm between 10.4 and 12.3 y after the CAMBRIC test, followed by 600 gpm out to $25.5 \mathrm{y}$ after the CAMBRIC test. Concentrations of ${ }^{3} \mathrm{H}$ and other test-related radionuclides were monitored at RNM-2S and UE-5n (Bryant, 1992).

The RNM experiment provides additional information that can be used to help constrain the hydraulic properties and hydrogeologic conceptual model near CAMBRIC:

- Tritium breakthrough at RNM-2S provides a tracer for flow of water originating from the CAMBRIC source and migrating to RNM-2S as a result of pumping.

- Consideration of a hydraulic connection between the RNM-2S slotted interval and Layer 2 through the RNM-2S gravel pack provides explanation for evidence of recirculation of discharge from the CAMBRIC ditch to the slotted interval of RNM-2S.

- Radionuclide breakthrough and change in water levels at UE-5n provides further evidence of the effects of RNM-2S pumping and infiltration from the CAMBRIC ditch.

\subsubsection{Tritium Breakthrough at RNM-2S}

Significant initial breakthrough of CAMBRIC test-related ${ }^{3} \mathrm{H}$ was observed shortly after the pumping rate was increased from 300 to 600 gpm at about $12.3 \mathrm{y}$ after the CAMBRIC test. The half-life of ${ }^{3} \mathrm{H}$ is $12.32 \mathrm{y}$. Test-related ${ }^{3} \mathrm{H}$ data shown in Figure 4.13 were corrected for decay to the time of the CAMBRIC test.

\section{Tritium Breakthrough at RNM-2S}

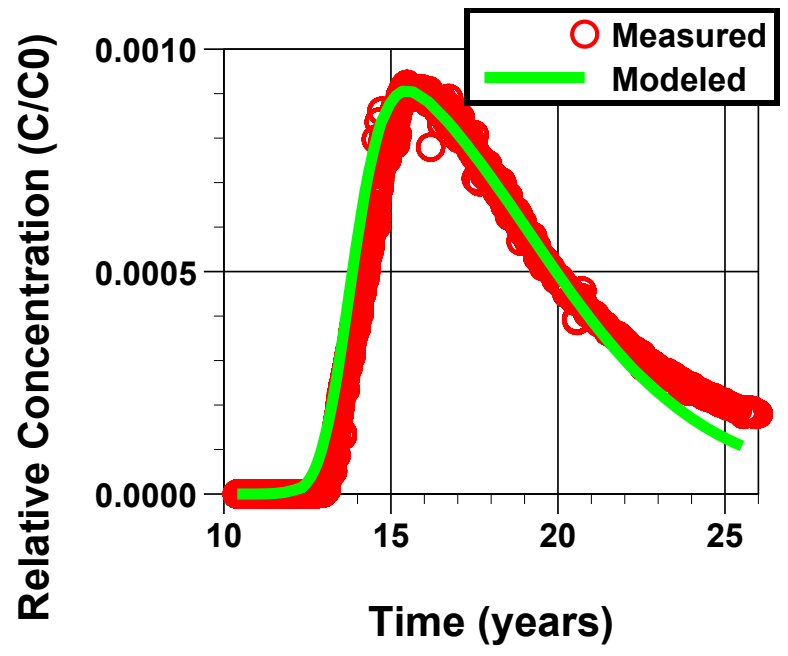

Figure 4.13 Calibration of NUFT model alluvial layer hydraulic properties to tracer breakthrough (green line) to measured decay-corrected ${ }^{3} \mathrm{H}$ breakthrough data (red circles) at RNM-2S pumping well during the RNM experiment. 
In attempting to calibrate to ${ }^{3} \mathrm{H}$ breakthrough data at RNM-2S, tracer transport simulations using both NUFT and ParFlow/SLIM showed much sensitivity to the permeability of the compressed zone. This degree of sensitivity was viewed favorably for calibration because no other data have yielded a quantitative estimate of permeability of the compressed zone. Permeability of the compressed zone was found to affect both timing and shape of the breakthrough curve, as previously investigated by Guell and Hunt (2003). The depth of Layer 4 was found to also affect the timing of breakthrough. Final calibration to both MWAT and RNM-2S ${ }^{3} \mathrm{H}$ breakthrough was achieved by lowering initial estimates of compressed zone permeability and lowering the depth of Layer 4. Slight adjustments to the permeabilities of Layer 3, 4, and 5 were also implemented. Table 4.5 lists these final NUFT simulation permeabilities calibrated to both MWAT and RNM-2S ${ }^{3} \mathrm{H}$ breakthrough. Tritium breakthrough results using NUFT final calibration are shown in Figure 4.13. The modeled breakthrough curve provides a reasonable match to the measurements. Mismatch at the tail could be easily attributed to either underestimation of recirculation from ditch discharge in the NUFT simulations, oversimplification of the initial distribution of ${ }^{3} \mathrm{H}$, or oversimplification of the permeability/porosity structure of the compressed zone.

Undoubtedly, the RNM-2S ${ }^{3} \mathrm{H}$ breakthrough data could be fitted by multiple sets of model parameters, particularly in regard to the spatial distribution of permeability. For example, in preparation of the HST flow simulation using ParFlow, Section 5.2.3 examines the breakthrough behavior for 50 permeability realizations having stochastically-generated intra-alluvium heterogeneity within the alluvial layers and disturbed zone. One of the 50 realizations closely matches both observed RNM-2S ${ }^{3} \mathrm{H}$ breakthrough and MWAT drawdown behavior. Although the layered conceptual model is the same for both the NUFT and ParFlow flow simulations, the intra-layer permeability distributions are very different-homogeneous and heterogenous, respectively. The wide variation in ${ }^{3} \mathrm{H}$ breakthrough for the 50 ParFlow permeability realizations indicates intralayer heterogeneity could also contribute to non-uniqueness of interpreting the ${ }^{3} \mathrm{H}$ breakthrough behavior. Combining intra-layer heterogeneity with other larger-scale uncertainties such as alluvial layer structure and disturbed zone geometry and inhomogeneity, the interpretation of the ${ }^{3} \mathrm{H}$ breakthrough behavior at RNM-2S is nonunique in multiple respects. On the other hand, this study's combined interpretation of prior pumping data, alluvial texture and layering, MWAT response, and RNM-2S ${ }^{3} \mathrm{H}$ breakthrough data provides relatively rigorous constraints on the bulk hydraulic properties of alluvial layers near CAMBRIC, particularly for Layer 3 within which the CAMBRIC test was located.

\subsubsection{CAMBRIC Ditch Recirculation}

In Chapter 5, the results of the ParFlow/SLIM simulations examine additional behavior related to the recirculation of ${ }^{3} \mathrm{H}$ and other radionuclides between the ditch, the groundwater table, and RNM-2S. As discussed in Chapter 1, the notion of recirculation was suggested from earlier isotopic measurements discussed by Tompson et al. (2006). 


\subsubsection{Radionuclide Breakthrough at UE-5n}

In Chapter 5, the results of the ParFlow/SLIM simulations examine additional behavior related to the breakthrough of ${ }^{3} \mathrm{H}$ and other radionuclides at UE-5n. As noted in Chapter 1 and Tompson et al. (2006), the reappearance of ${ }^{3} \mathrm{H}$ and other radionuclides in UE-5n has been observed since 1991.

\subsubsection{Water Level Measurements at UE-5n}

Water levels have been collected at UE-5n since 1976. Water level measurements varied sporadically until late 1988. Water levels in UE-5n were relatively stable until late 1991 when water levels abruptly rose about $0.6 \mathrm{~m}$ in four months, then gradually decreased over a period of years.

NUFT simulation hydraulic head at UE-5n, shown in Figure 4.14, produces a rise in hydraulic head after pumping ceases at RNM-2S in late 1991, or $25.5 \mathrm{y}$ after the CAMBRIC test. The simulated ambient head $(\sim 735.4 \mathrm{~m})$ at UE-5N is generally about $1.5 \mathrm{~m}$ higher than measured heads, primarily as a result of the finite grid resolution of the NUFT simulation. The simulated peak of hydraulic head rises about $0.6 \mathrm{~m}$ above the ambient head. A similar rise in hydraulic head is seen in water level data for UE-5n (Stoller-Navarro, 2004b). This rise in hydraulic head above the ambient head is likely caused by infiltration from the CAMBRIC ditch. Thus, the simulated transient effect of the ditch infiltration generally matches water level data from UE-5n. However simulated transient heads induced by pumping generally do not match the data. The water level data show sporadic variations during pumping at RNM-2S, but these variations are not obviously related to pumping. Discrepancies between the simulation and UE-5n water level data could be related to data quality, heterogeneities, anisotropy, or simulation inaccuracy. For example, ParFlow simulation heads at UE-5n (Figure 5.15) show closer fit to observations during pumping at RNM-2S because ditch infiltration from the ParFlow simulation raises head more than the NUFT simulation. As mentioned before, the NUFT simulation does not have good resolution at the water table because of the difficulty of switching between one- and two-phase flow. Additionally, the NUFT simulation does not have good resolution at UE-5n, which is located beyond the volume of fine discretization. 
Hydraulic Head at UE5N

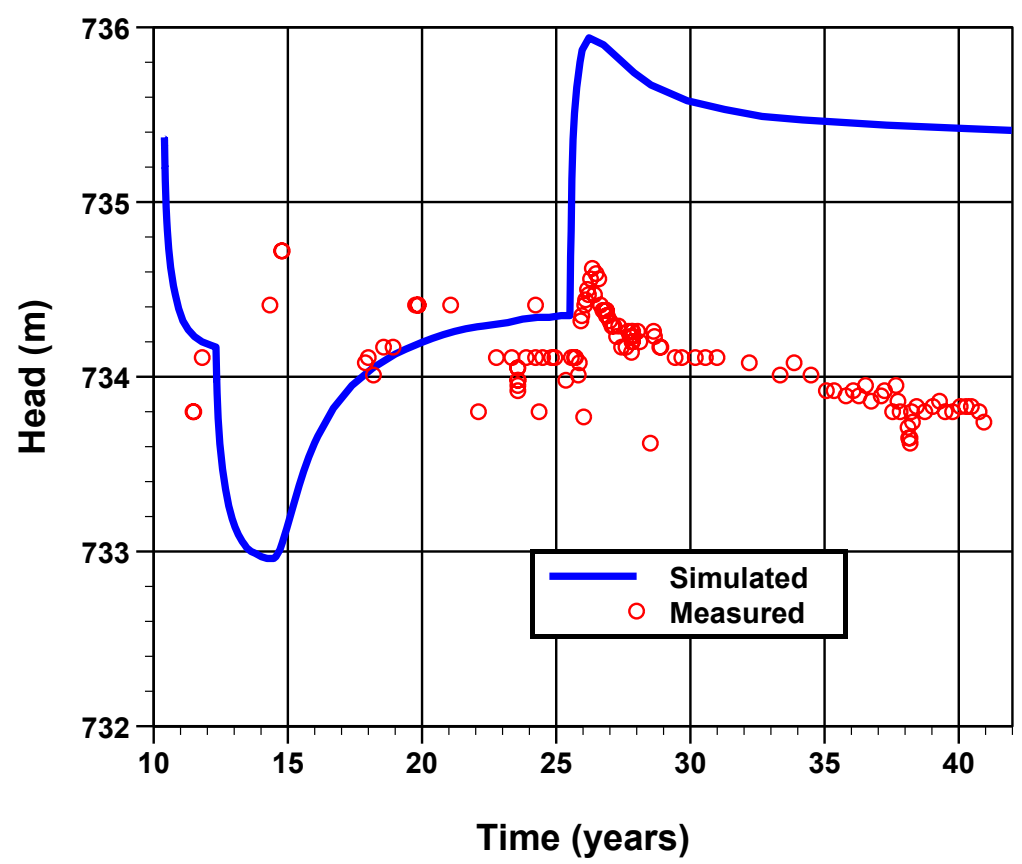

Figure 4.14 NUFT simulation of UE-5n hydraulic head (relative to bottom of NUFT simulation).

\subsection{NUFT Transient Flow Simulation Results}

This section presents base-case transient flow simulation results from the calibrated NUFT model. As described in Section 4.2.6, the NUFT model domain extends several kilometers laterally. However, the NUFT flow simulations focus on the domain within a few hundred meters of CAMBRIC. All alluvial layers are resolved only within $450 \mathrm{~m}$ laterally of CAMBRIC. The outer portion of the NUFT flow simulation domain serves as a buffer zone between the outer boundary conditions and the transient flow conditions near CAMBRIC. Specifically, the outer portion of the NUFT simulation is telescoped out to accommodate transient flow by distancing no-flow boundaries and constant head boundary conditions.

Given the telescoped flow domain, most results of NUFT transient flow simulations are given for volumes within tens or hundreds of meters from CAMBRIC. Much of the transient flow simulation results in this section are presented as 3D visualizations of state variables including saturation, pressure, hydraulic head, temperature, and tracer $\left(\right.$ or $\left.{ }^{3} \mathrm{H}\right)$ transport. These $3 \mathrm{D}$ visualizations are presented at two scales:

- A large scale showing state variable fields over distances of hundreds of meters from CAMBRIC including locations of nearby wells ER-5-4, RNM-1, RNM-2, RNM-2S, and UE-5n

- A small scale showing state variable fields within tens of meters of CAMBRIC 
The initial state condition for the NUFT transient flow model at time zero is an ambient flow field, which is created by running an initializing flow simulation for $100,000 \mathrm{y}$ with the same boundary conditions used in the base case. Many of the 3D visualizations shown are chosen at key junctures in the history of the RNM experiment:

- $0.0 \mathrm{y}=$ time of CAMBRIC test (year 1965.4)

- $10.4 \mathrm{y}=$ beginning of 300 gallon per minute (gpm) pumping stage at RNM-2S

- $12.3 \mathrm{y}=$ end of 300-gpm RNM-2S pumping stage and beginning of 600 -gpm pumping stage

- 15 to $16 \mathrm{y}=$ peak of ${ }^{3} \mathrm{H}$ breakthrough at RNM-2S

- $25.5 \mathrm{y}=$ end of 600 -gpm RNM-2S pumping stage

\subsubsection{Variable Saturation}

Variable saturation is considered in both the NUFT and ParFlow simulations. Saturation (S) ranges from 0.0 at the upper atmospheric boundary above the ground surface to 1.0 below the water table. The vadose zone is approximately 221 to $223 \mathrm{~m}$ thick above CAMBRIC. Based on estimates of residual saturation in drill hole UE-5n by Ramspott and McArthur (1977), a residual saturation $\left(\mathrm{S}_{\mathrm{r}}\right)$ of 0.5 is assumed for the vadose zone. Capillary pressure $\left(p_{c}\right)$, saturation $(S)$, and permeability in the vadose zone are modeled according to the familiar VanGenuchten formulations:

$$
\begin{aligned}
& p_{a}-p_{w}=p_{c}(S)=\frac{1}{\alpha^{*}} \cdot\left(S^{*-1 / m}-1\right)^{1-m} \\
& \mathbf{k}(S)=\mathbf{k}_{\mathrm{sat}} k_{r}(S) \text { or } \mathbf{K}(S)=\mathbf{K}_{\mathrm{sat}} k_{r}(S)
\end{aligned}
$$

where the relative permeability is given by

$$
k_{r}(S)=\left(S^{*}\right)^{1 / 2}\left(1-\left(1-\left(S^{*}\right)^{1 / m}\right)^{m}\right)^{2}
$$

Here $p_{a}$ is the (static atmospheric) gas phase pressure, $p_{w}$ is the water phase pressure (both $\left.\mathrm{M} / \mathrm{LT}^{2}\right), S^{*}=\left(S-S_{r}\right) /\left(1-S_{r}\right)$, and $\alpha^{*}=\alpha / \rho g$, where $\alpha$ and $m$ are moisture retention parameters $\left(\mathrm{L}^{-1}\right.$ and dimensionless, respectively), $\rho$ is the water density, and $g$ is the gravitational acceleration.

Figures 4.15 and 4.16 plot large-scale perspectives of the NUFT simulation of the saturation field near CAMBRIC at $0.0 \mathrm{y}, 12.3 \mathrm{y}, 25.5 \mathrm{y}$, and $50 \mathrm{y}$. At $0.0 \mathrm{y}$, the saturation field represents ambient flow conditions; saturation is near 0.5 in the vadose zone and 1.0 below the water table. At $12.3 \mathrm{y}$, the $300 \mathrm{gpm}$ pumping stage at RNM-2S and discharge into the CAMBRIC ditch has operated for $1.9 \mathrm{y}$; saturation has increased in the vadose zone below the CAMBRIC ditch to a depth of over $120 \mathrm{~m}$. At $25.5 \mathrm{y}$, the 600 -gpm pumping stage has completed; after over $11 \mathrm{y}$ of ditch infiltration, saturation has increased to over 0.8 units beneath the ditch in the $221 \mathrm{~m}$ between the ground surface and the water table. At $50 \mathrm{y}$, saturation remains elevated to about 0.6 units in the vadose zone beneath the ditch. 
Figure 4.17 shows small-scale visualizations of the NUFT flow simulation saturation field near CAMBRIC for $10.4,12.3,15.7,25.5$, and $50 \mathrm{y}$. At $15.7 \mathrm{y}$, when ${ }^{3} \mathrm{H}$ breakthrough peaked at RNM-2S (Figure 4.13), the NUFT simulation indicates that infiltration from the CAMBRIC ditch has not yet reached the water table. The NUFT simulation indicates that groundwater pumped out of RNM-2S and discharged into the CAMBRIC ditch would not return to RNM-2S until after peak ${ }^{3} \mathrm{H}$ breakthrough was observed at RNM-2S. 


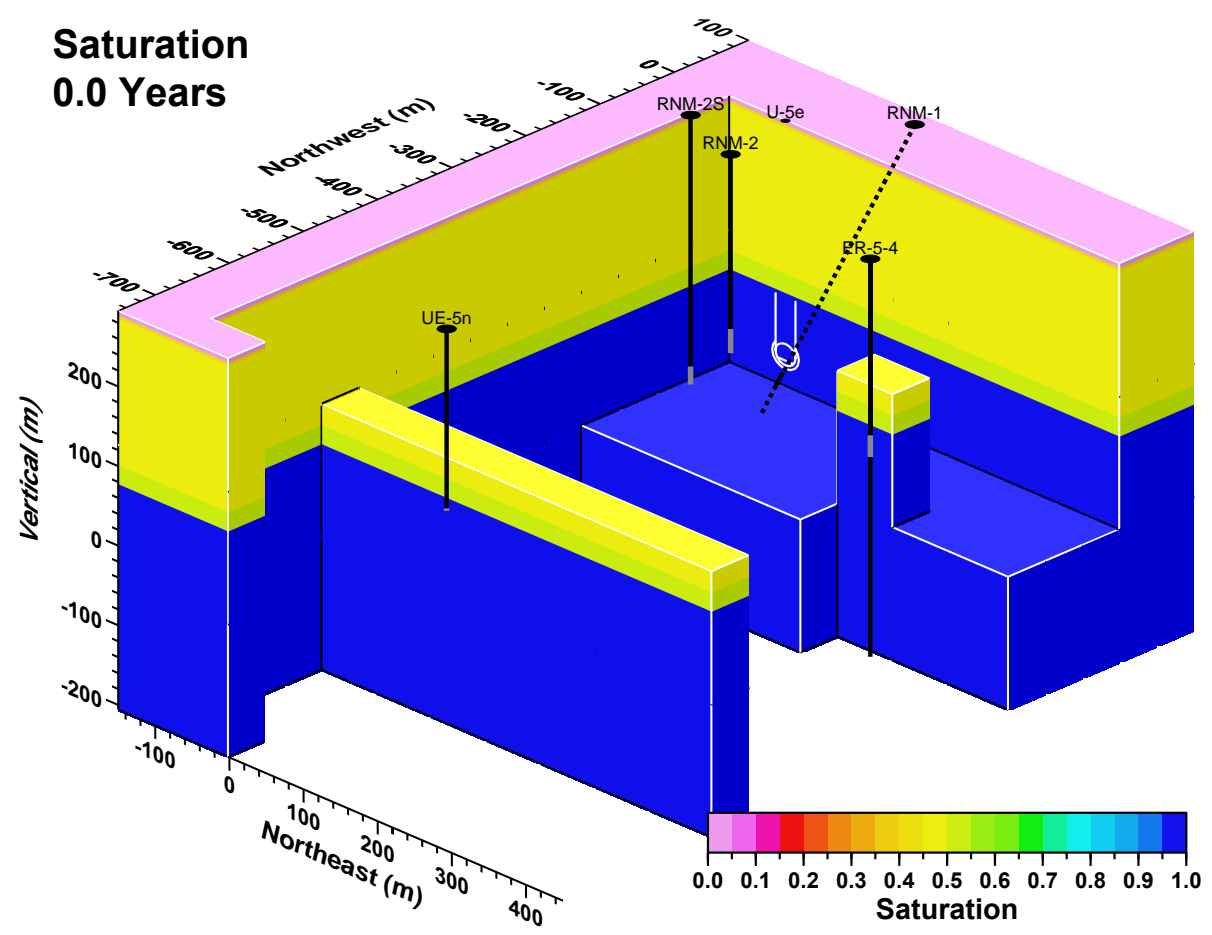

(a)

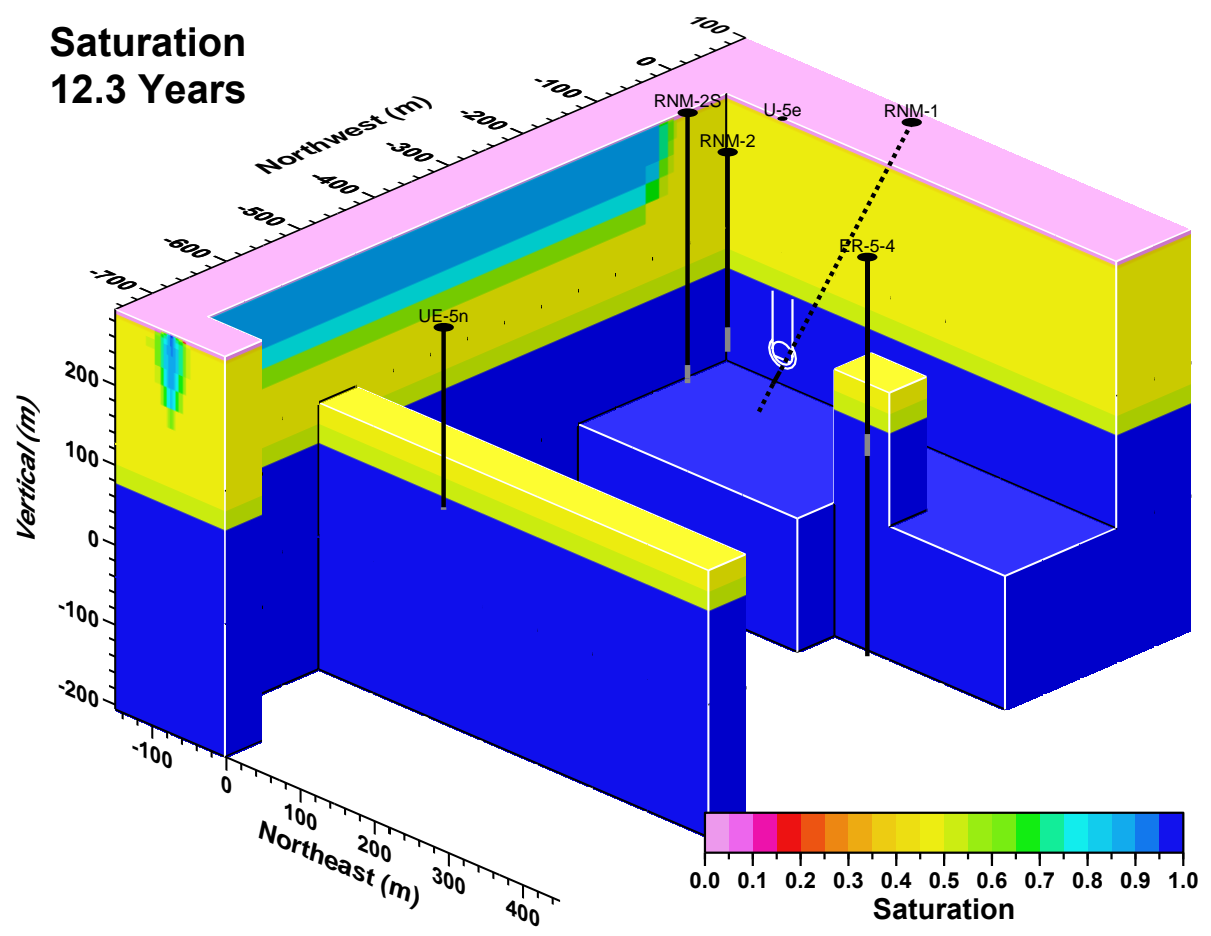

(b)

Figure 4.15 Large-scale cutaway view of NUFT simulation of the saturation field near CAMBRIC at (a) 0.0 and (b) $12.3 \mathrm{y}$. 


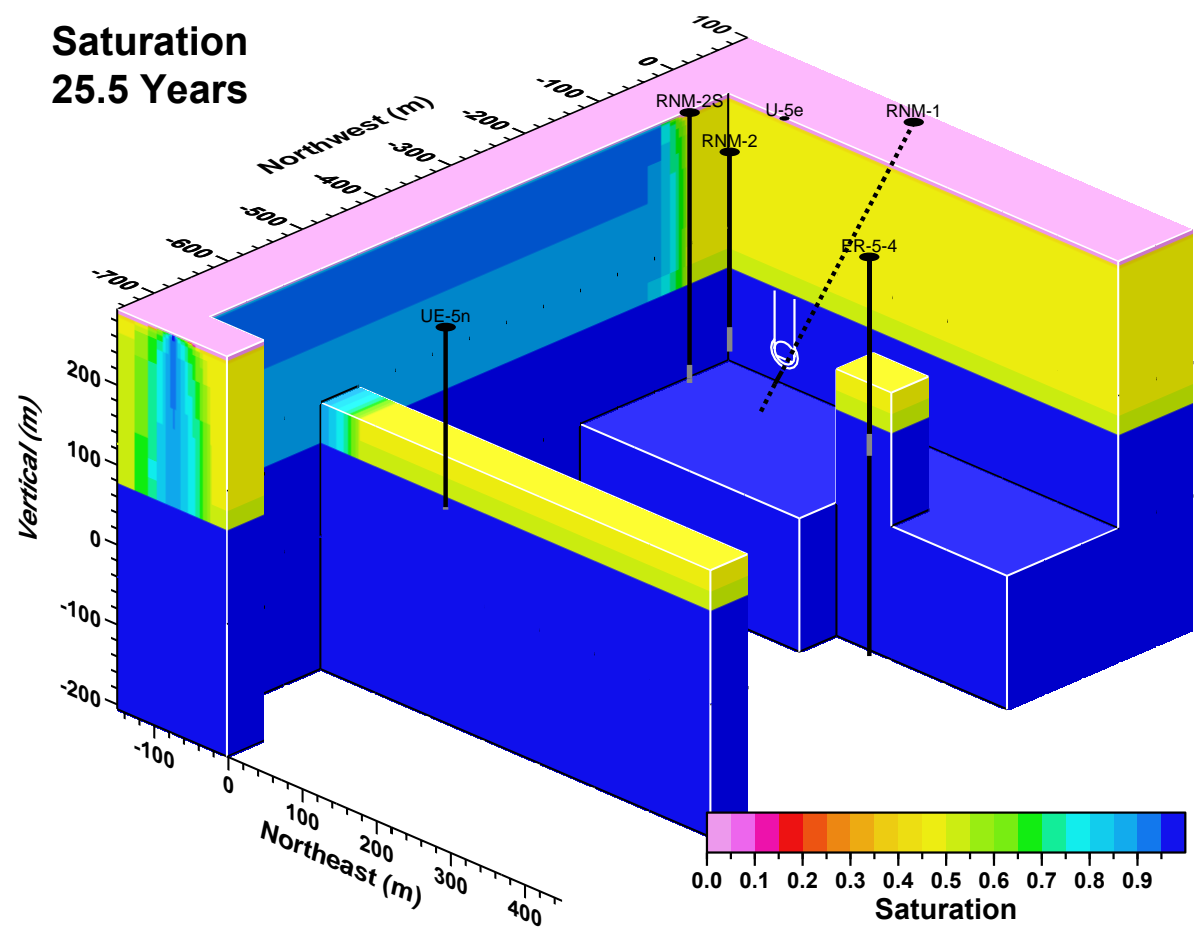

(a)

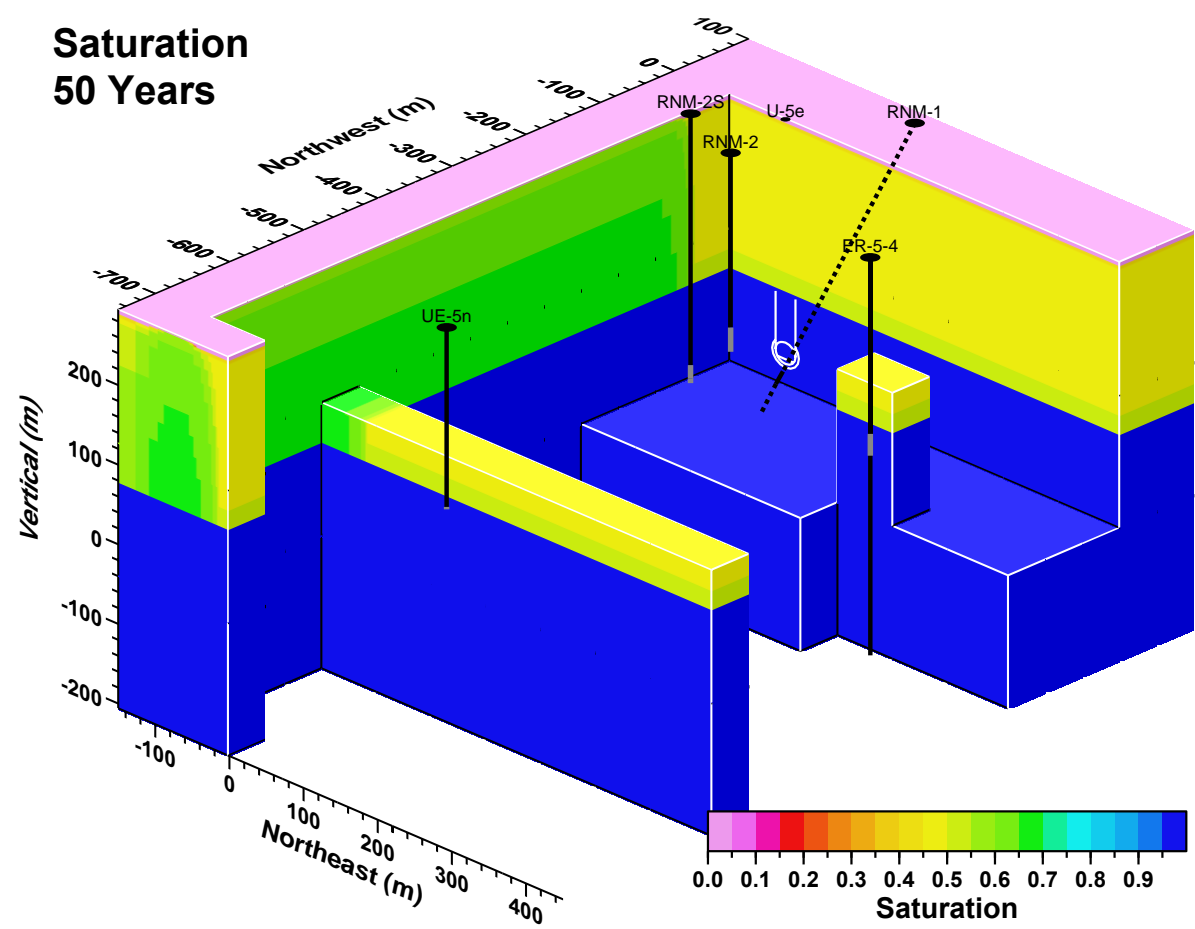

(b)

Figure 4.16 Large-scale cutaway view of NUFT simulation of saturation field near CAMBRIC at 25.5 and $50 \mathrm{y}$. 

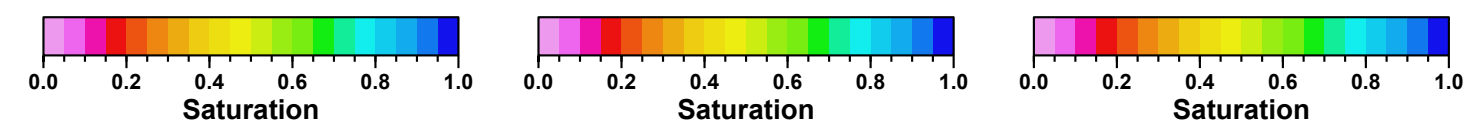

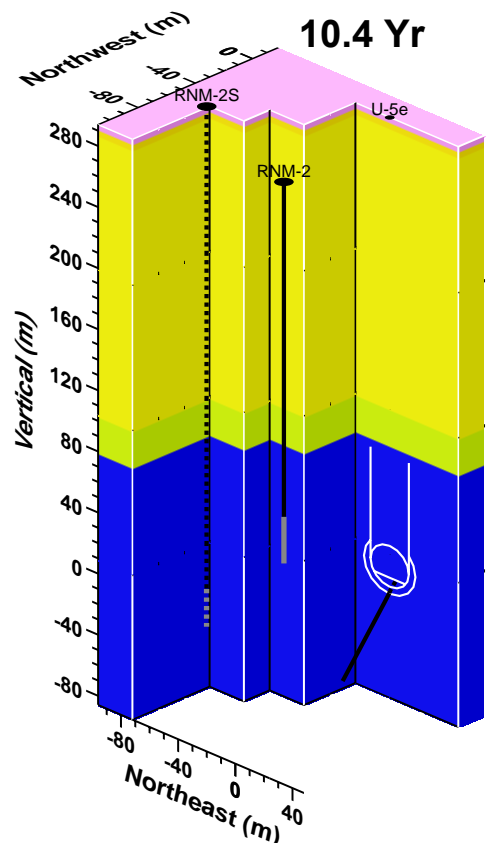

(a)
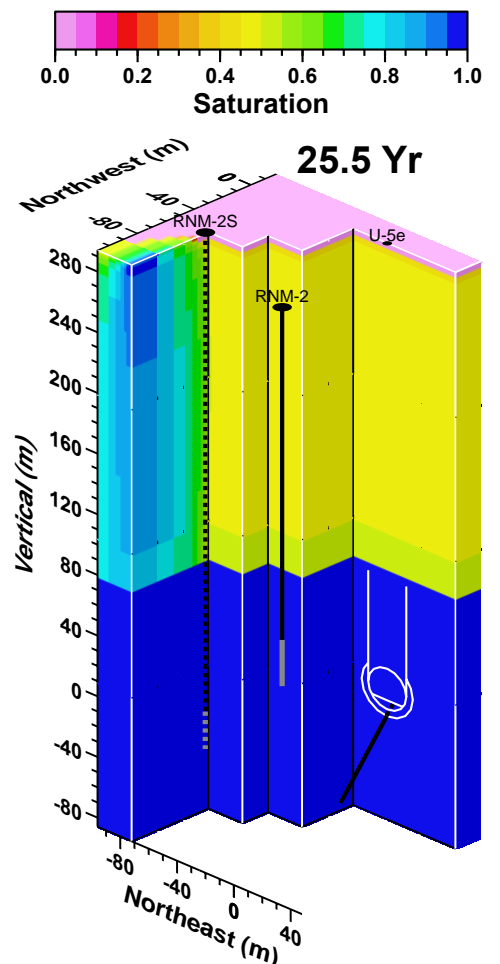

(d)

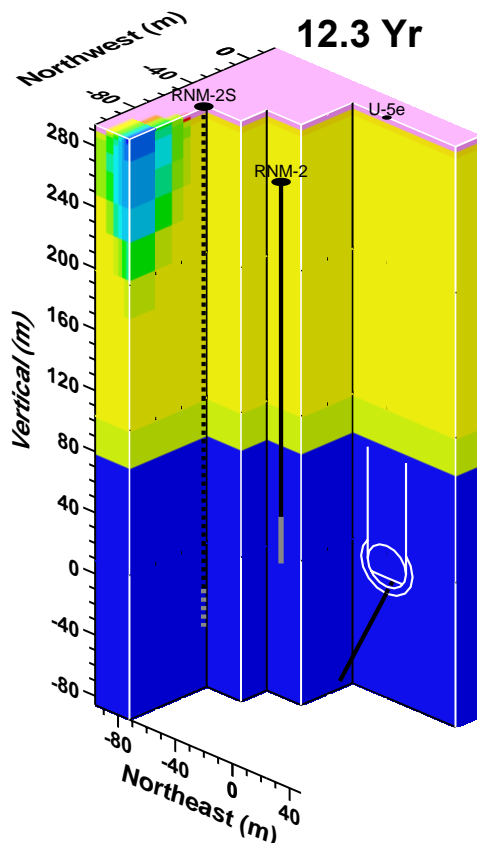

(b)
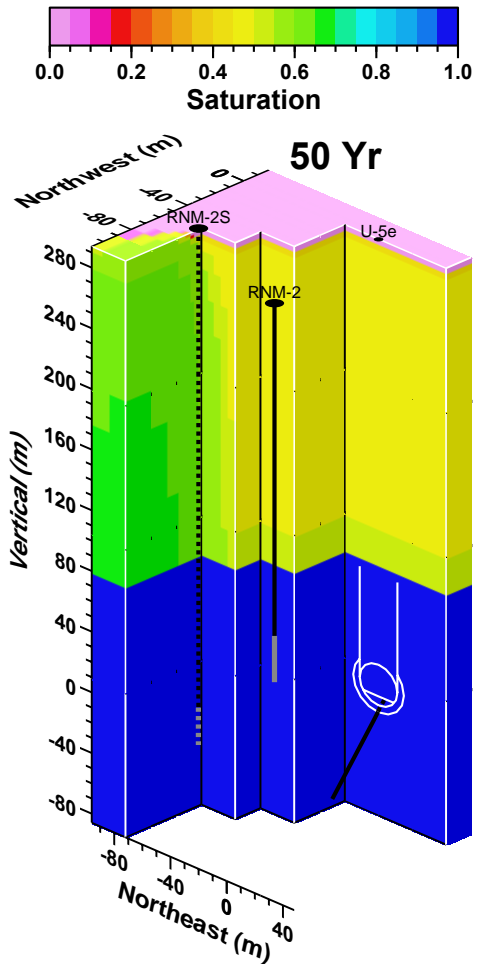

(e)

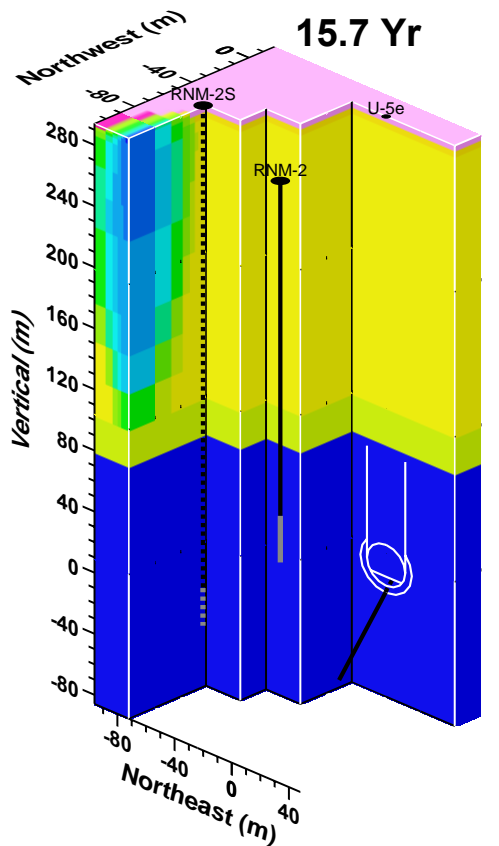

(c)

Figure 4.17 Small-scale cutaway views of NUFT simulation of saturation field near CAMBRIC at (a) 10.4, (b) 12.3, (c) 15.7, (d) 25.5, and (e) $50 \mathrm{y}$. 


\subsubsection{Hydraulic Pressure and Head}

The NUFT code simulates pressure as a state variable rather than hydraulic head. Hydraulic head is actually a simplified abstraction of porous media flow physics assuming fluid density, fluid viscosity, and gravity are constant. In the NUFT simulations, fluid density and viscosity are variable, and only gravity is assumed constant. Over depth ranges of hundreds of meters, as in the Frenchman Flat alluvial basin, fluid density varies considerably with pressure and temperature. Viscosity varies significantly at high temperatures, particularly temperatures up to $170{ }^{\circ} \mathrm{C}$ as attributed to residual heat in the melt glass zone after the CAMBRIC test (Sections 4.6.4 and 4.7.3.3).

Figures 4.18 and 4.19 show base-case NUFT simulation pressure fields at 10.4 and $25.5 \mathrm{y}$, respectively. Between 10.4 and $25.5 \mathrm{y}$, the pressure field increases very slightly in the vadose zone, then increases nearly linearly with depth below the water table. The pressure field at $10.4 \mathrm{y}$ reflects ambient flow conditions. At $25.5 \mathrm{y}$, a decrease in pressure is evident near RNM-2S as a result of over $15 \mathrm{y}$ of pumping for the RNM experiment. However, the pressure field remains difficult to use for interpretation of flow conditions compared to hydraulic head.

Figure 4.20 shows the base-case NUFT simulation fluid density field for water at $0.0 \mathrm{y}$. Ambient water density varies between about 997.7 and $999.5 \mathrm{~kg} / \mathrm{m}^{3}$ from the combined effects of the geothermal gradient and large pressure variation. While this approximate $0.2 \%$ variation in fluid density may appear small, it is important to consider in comparing pressure to hydraulic head estimates or water levels. For example, if the average density of a 500-m-high water column is $0.1 \%$ greater than the top density, the bottom hydrostatic pressure is about $500 \mathrm{~Pa}$ higher compared to the hydrostatic pressure estimated from constant density at the top density. Five hundred pascals represents about $0.05 \mathrm{~m}$ of hydraulic head. In the vicinity of CAMBRIC, where hydraulic gradients are of the order of 0.001 , correction for density variation will be necessary to correctly convert between pressure and hydraulic head.

Hydraulic head is inferred from the NUFT simulation pressure fields by using the CAMBRIC working point as the reference elevation and subtracting a downward integration of the product of fluid density and gravity from the top of the water table. Thus, hydraulic head values for the NUFT simulation are calculated relative to the CAMBRIC working point instead of sea level, largely to maintain consistency with the vertical coordinate system used throughout Chapter 4. Figures 4.21 and 4.22 show largescale visualizations of NUFT simulation hydraulic head at 10.4 and $25.5 \mathrm{y}$ using the same color scale. The hydraulic head field at 10.4 y reflects the assumed ambient flow field. The 3D simulation results emphasize that the 3D head gradient varies with location. The magnitude of the horizontal gradient in the upper alluvium (Layers 2-8) averages about 0.0008 and, thus, is near the middle of the estimated range of 0.0003 and 0.0013 given by Stoller-Navarro (2004b). A slight downward hydraulic gradient is evident in the upper alluvium, while a relatively large downward vertical gradient occurs between Layers 8 and 10 as evident by a head difference of over $1 \mathrm{~m}$. This downward hydraulic gradient is estimated at $0.003 \mathrm{~m}$ from differences in pressure between the ER-5-4 lower and deepscreened interval, which bracket PCU1U (Layer 9). The simulated downward hydraulic gradient across Layer 9 is consistent with pressure differences measured across the upper and lower screened intervals of ER-5-4, as discussed in Section 4.6.5. The downward 
hydraulic gradient within Layer 9 could be higher than 0.003 because Layer 9 corresponds to the PCU1U confining unit (Bechtel Nevada, 2005b). At $25.5 \mathrm{y}$, a large cone of depression has evolved around RNM-2S, and water table mounding has taken effect beneath the CAMBRIC ditch. Figure 4.23 also shows hydraulic head at $25.5 \mathrm{y}$, but with a color scale favoring a view of hydraulic head in the vadose zone. Hydraulic head in the vadose zone largely reflects change in elevation.

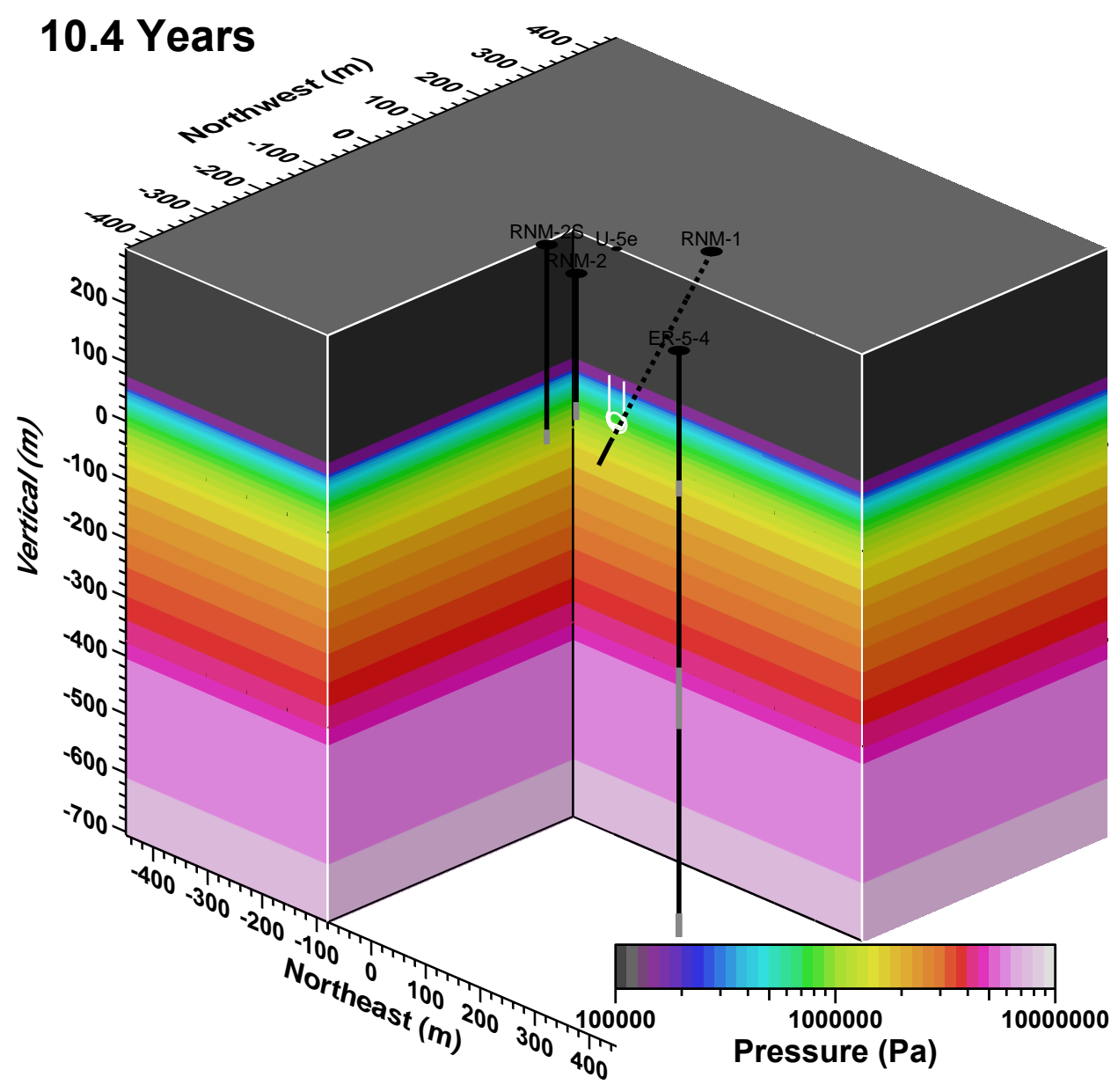

Figure 4.18 Large-scale cutaway view of NUFT simulation of pressure field at $10.4 \mathrm{y}$. 


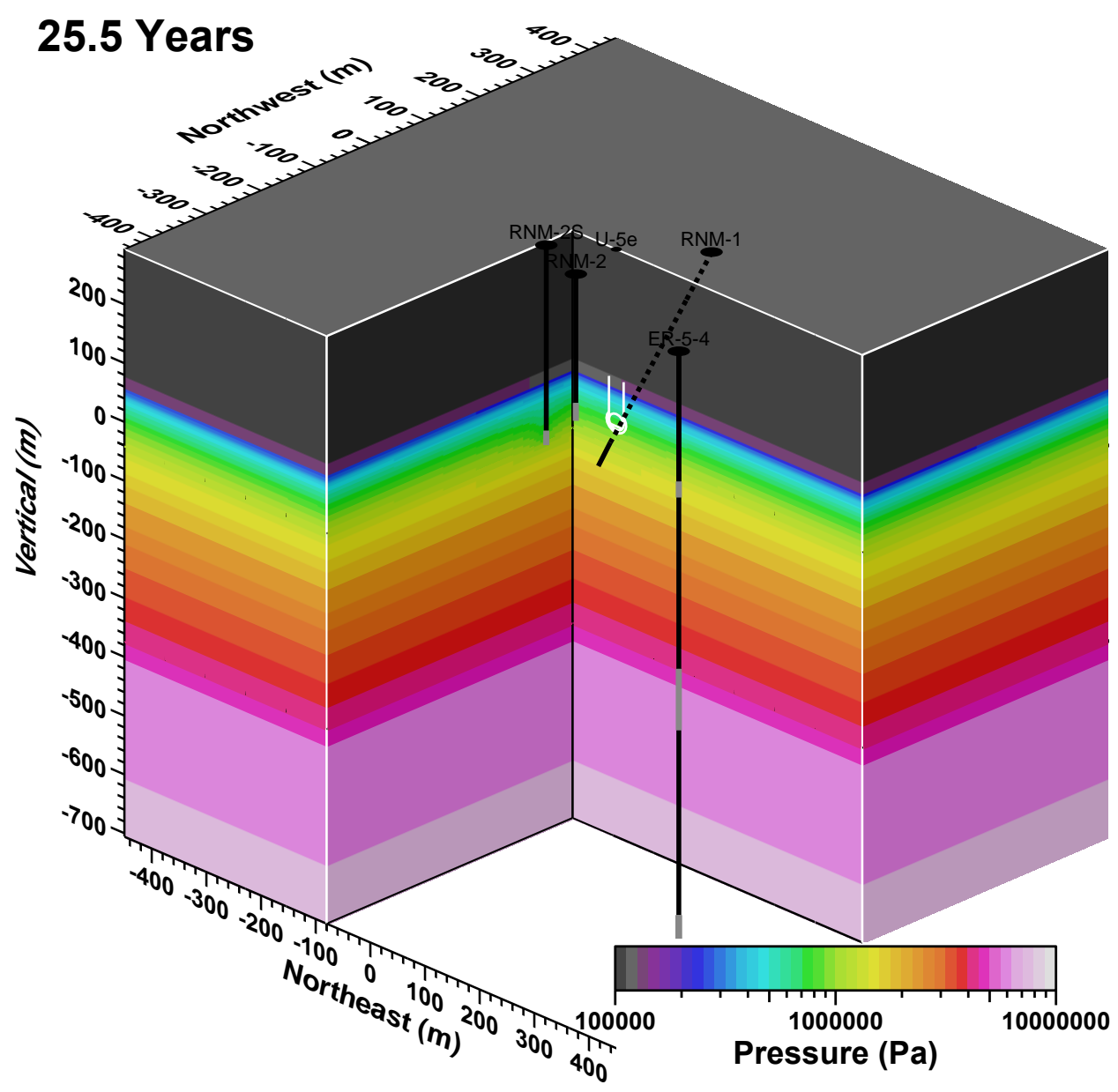

Figure 4.19 Large-scale cutaway view of NUFT simulation of pressure field at $25.5 \mathrm{y}$. 


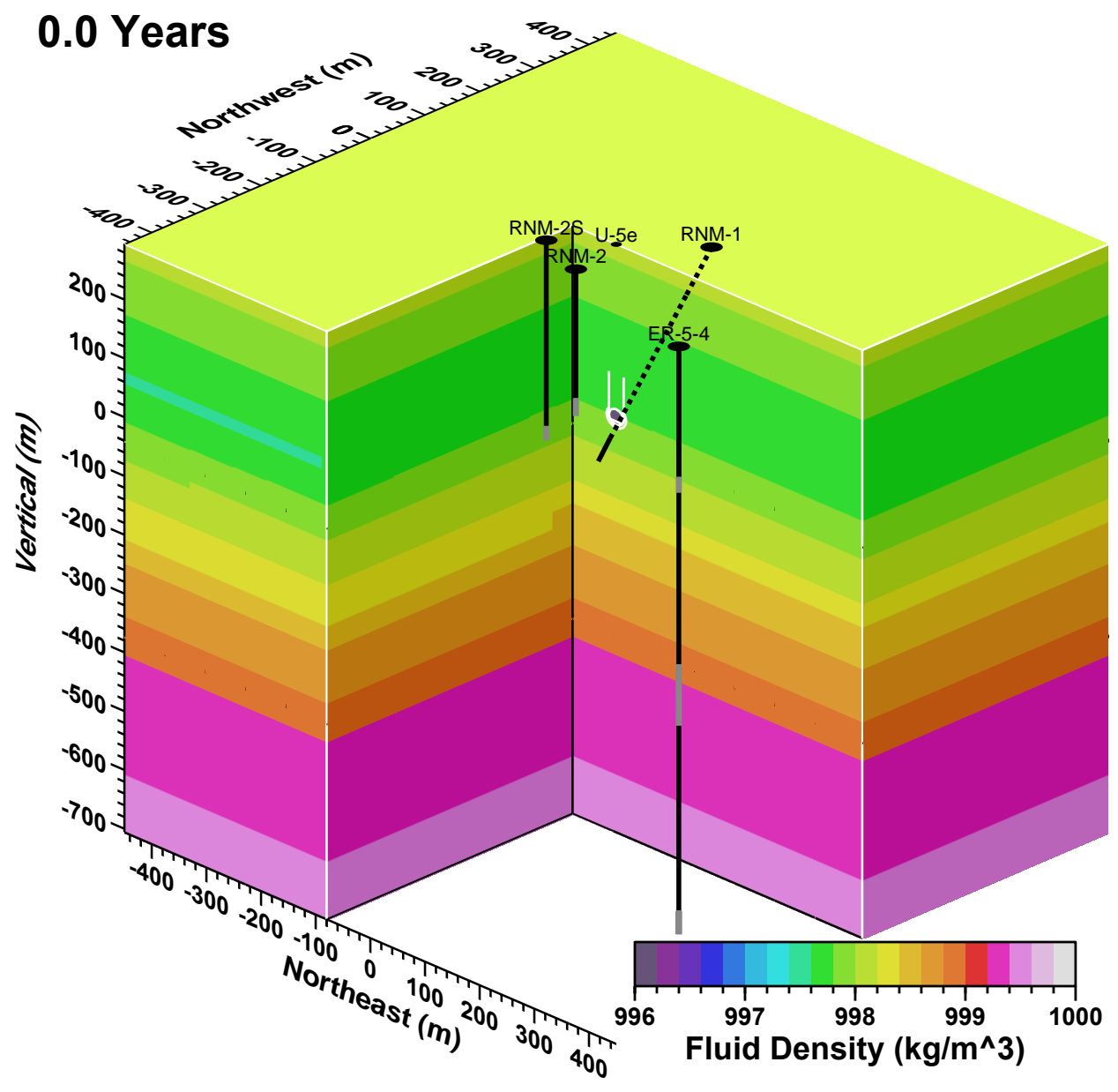

Figure 4.20 Large-scale cutaway of NUFT simulation of fluid density field at $0.0 \mathrm{y}$. 


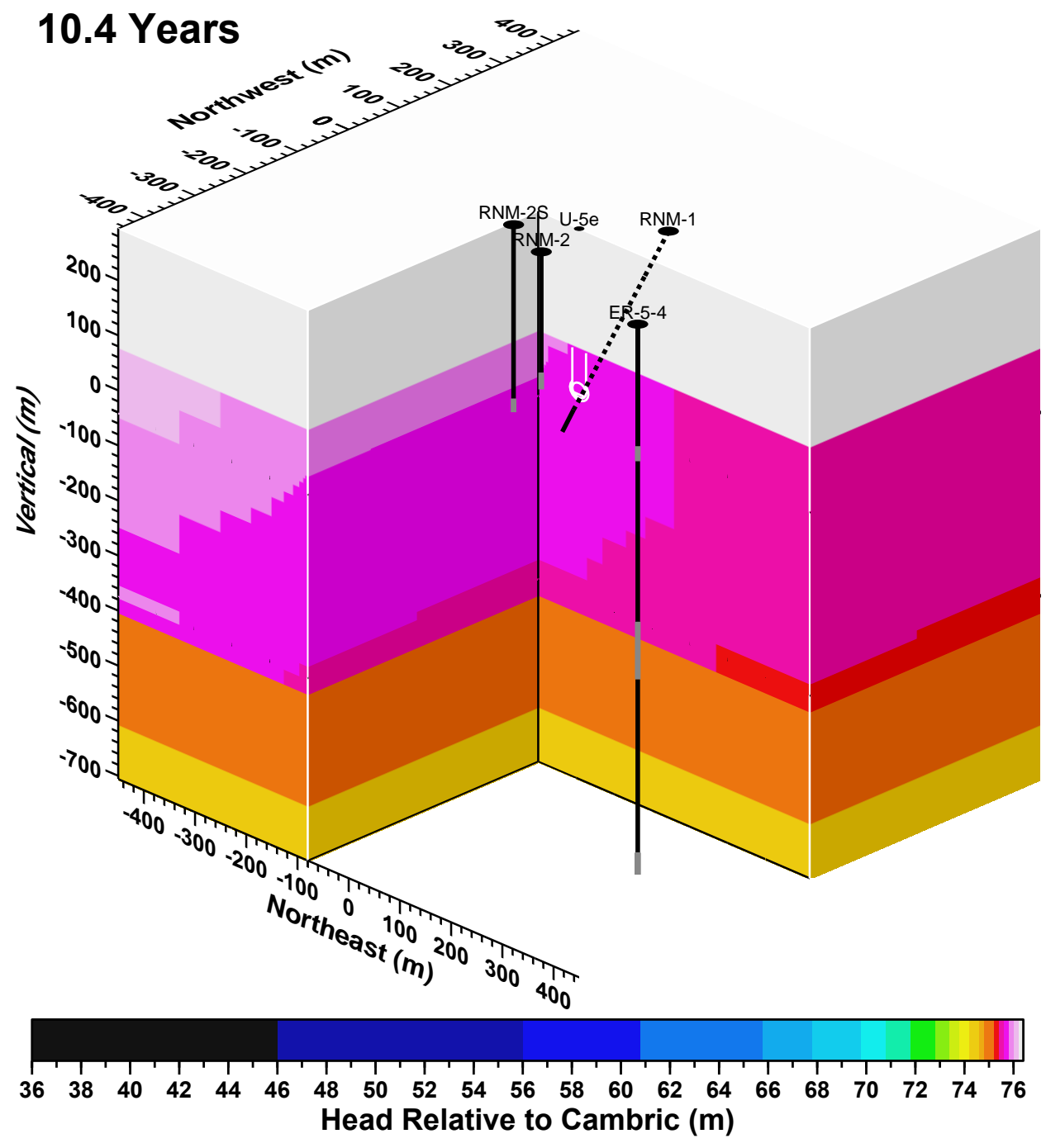

Figure 4.21 Large-scale cutaway of NUFT simulation of hydraulic head field at $10.4 \mathrm{y}$. 


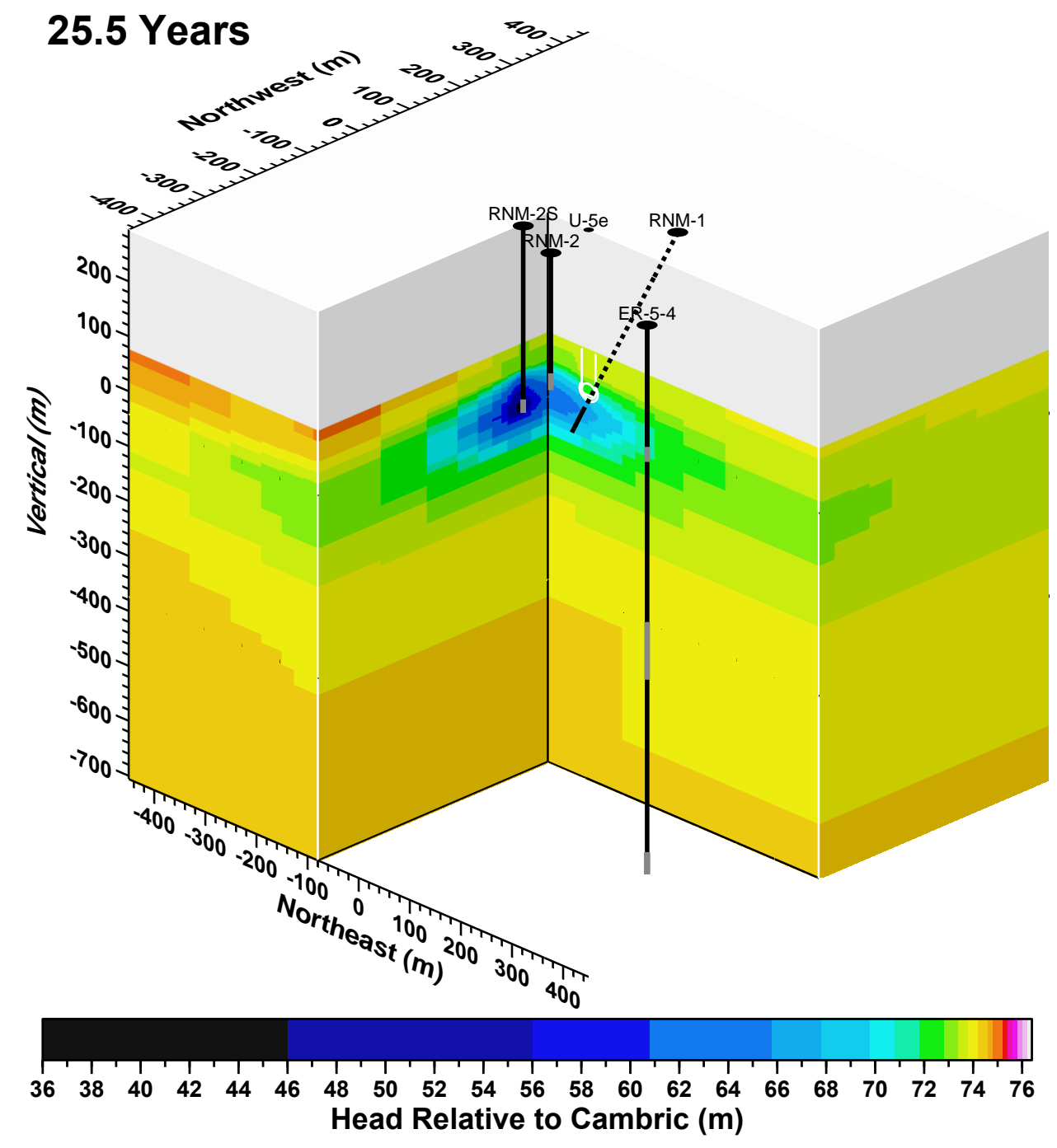

Figure 4.22 Large-scale cutaway of NUFT simulation of hydraulic head field at $25.5 \mathrm{y}$. 


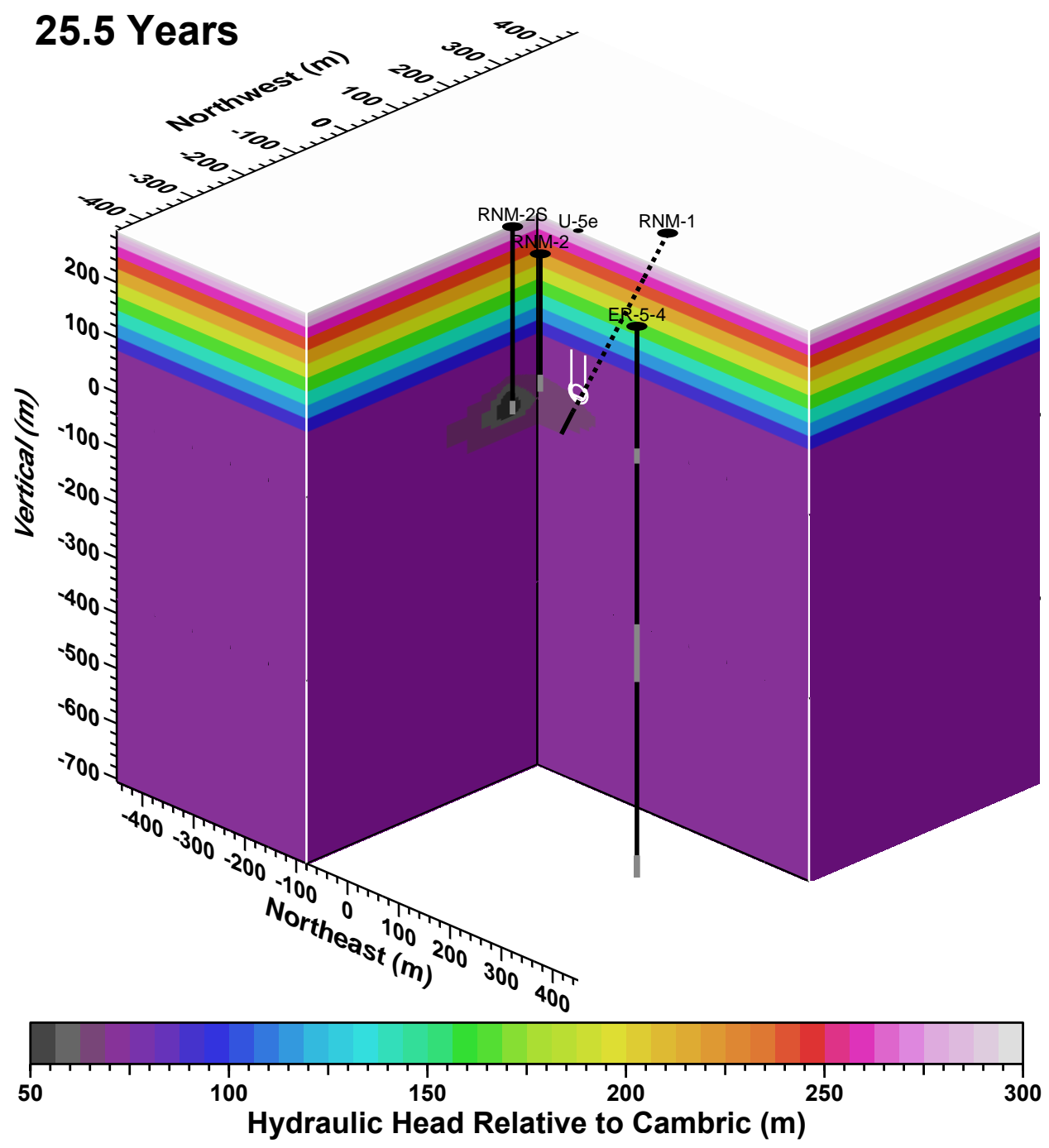

Figure 4.23 Large-scale cutaway of NUFT simulation of hydraulic head field at $25.5 \mathrm{y}$, with color scale favoring view of hydraulic head in vadose zone. 


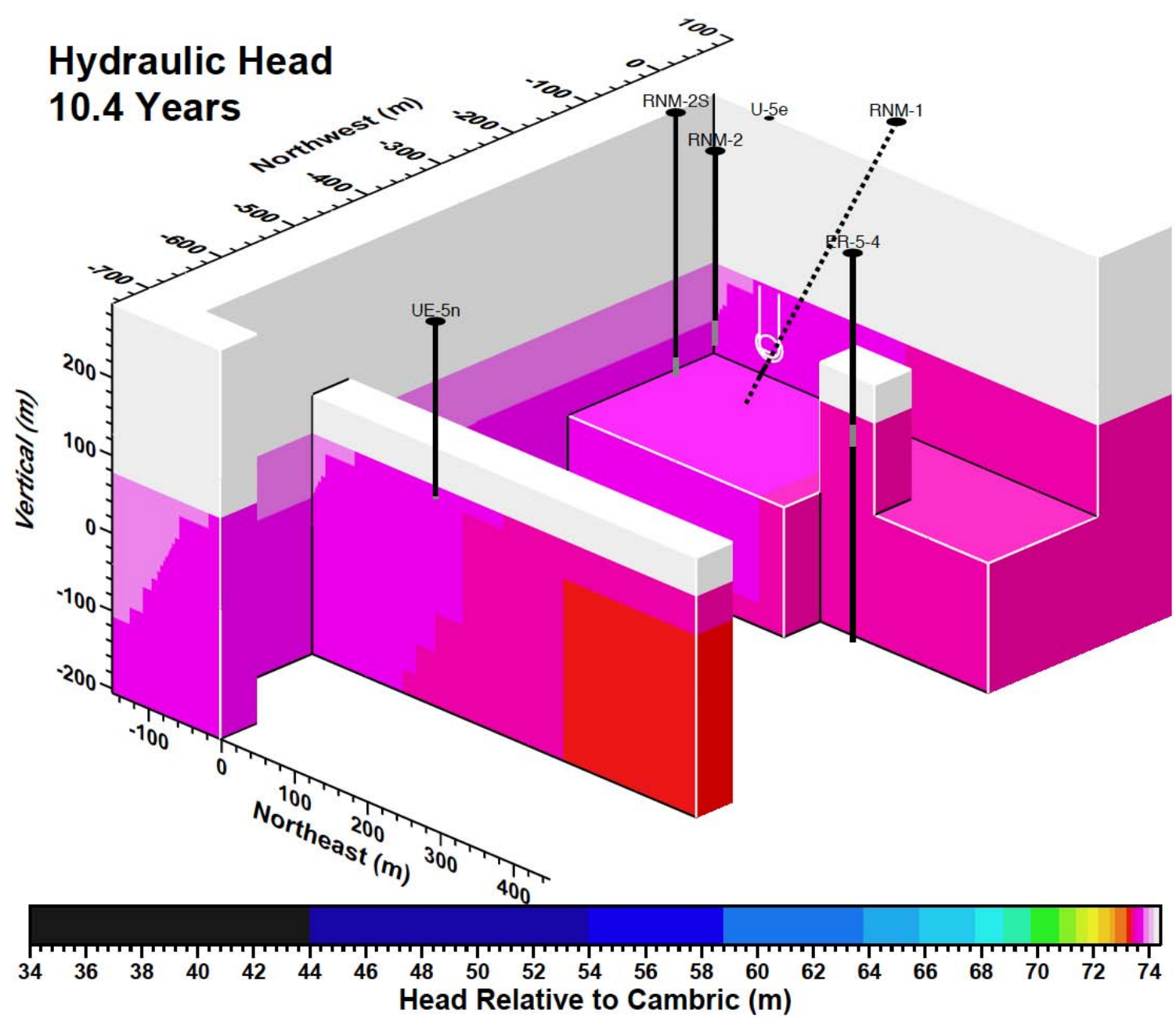

Figure 4.24 Large-scale cutaway view of NUFT simulation of hydraulic head at $10.4 \mathrm{y}$ at CAMBRIC and nearby wells.

Figures 4.24-4.27 show large-scale cutaway views of hydraulic head at 10.4, 12.3, 25.5, and $50 \mathrm{y}$ at CAMBRIC and nearby wells. Hydraulic heads at 10.4 and $50.0 \mathrm{y}$ are nearly identical, indicating that by 2015 , the flow field will return to ambient conditions after termination of pumping and infiltration from the RNM experiment in 1990. However, the NUFT simulation does not include consideration of the RNM-2S MWAT in 2003, which involved 75 d of pumping RNM-2S at 600 gpm (Stoller-Navarro, 2004a). The hydraulic head field at 12.3 y shows drawdown from pumping at RNM-2S at $300 \mathrm{gpm}$ for $1.9 \mathrm{y}$ and shortly before the pumping rate was increased to $600 \mathrm{gpm}$. By $25.5 \mathrm{y}$, after $13.2 \mathrm{y}$ of pumping at $600 \mathrm{gpm}$, the cone of depression has reached its maximum effect given the finite extent of the model and the use of constant head boundary conditions. 


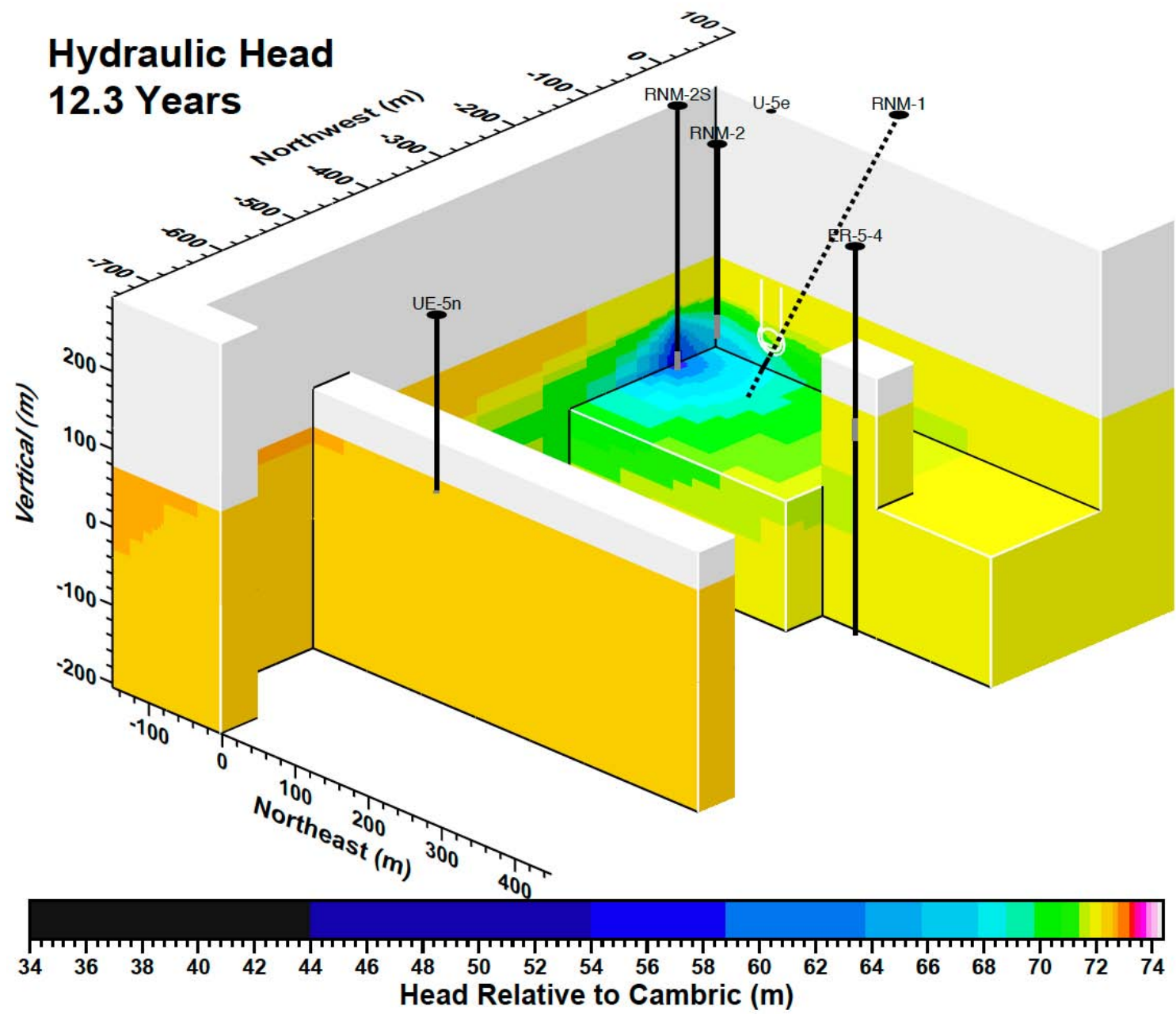

Figure 4.25 Large-scale cutaway view of NUFTsimulation of hydraulic head at $12.3 \mathrm{y}$ at CAMBRIC and nearby wells. 


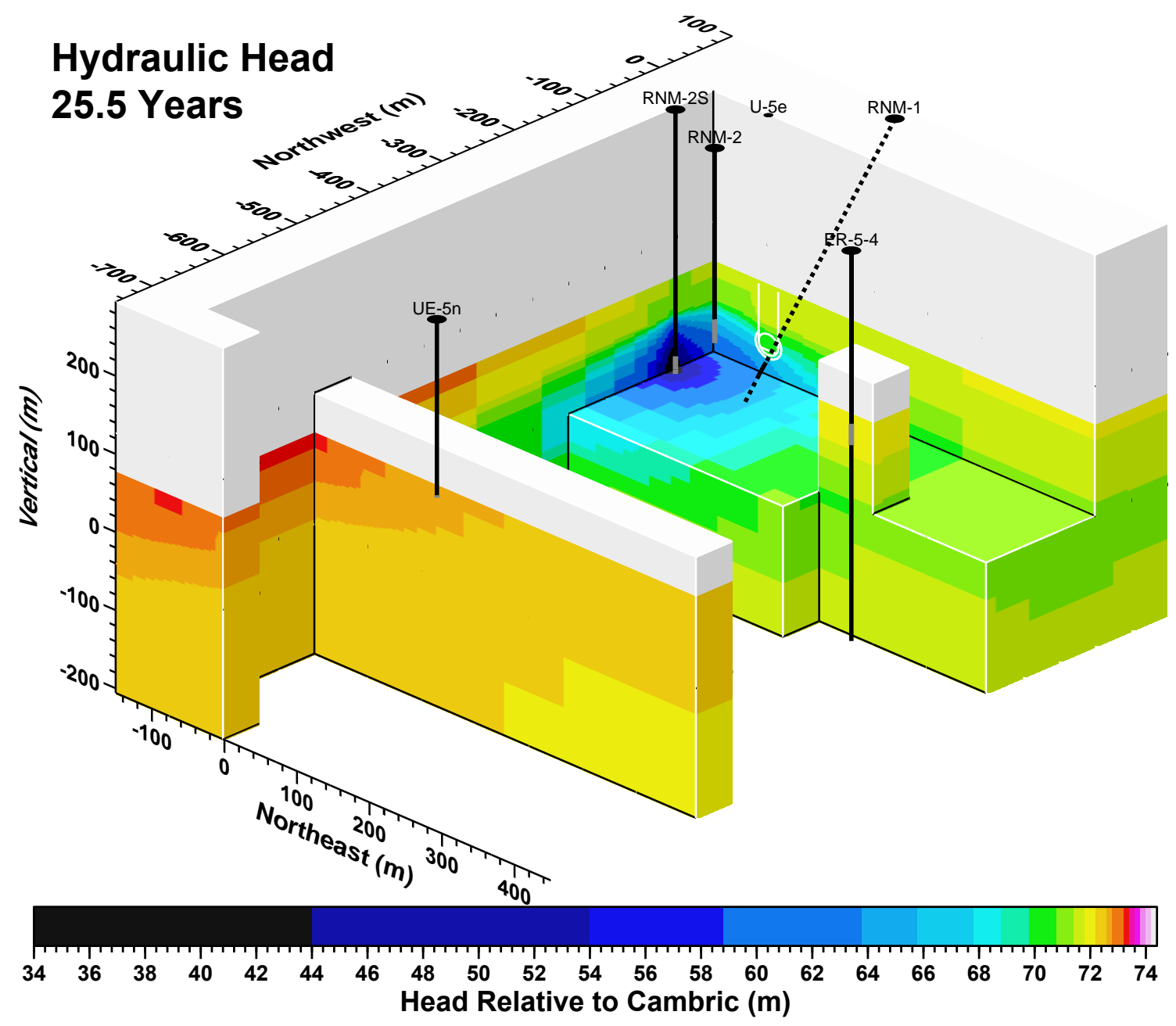

Figure 4.26 Large-scale cutaway view of NUFT simulation of hydraulic head at $25.5 \mathrm{y}$ at CAMBRIC and nearby wells. 


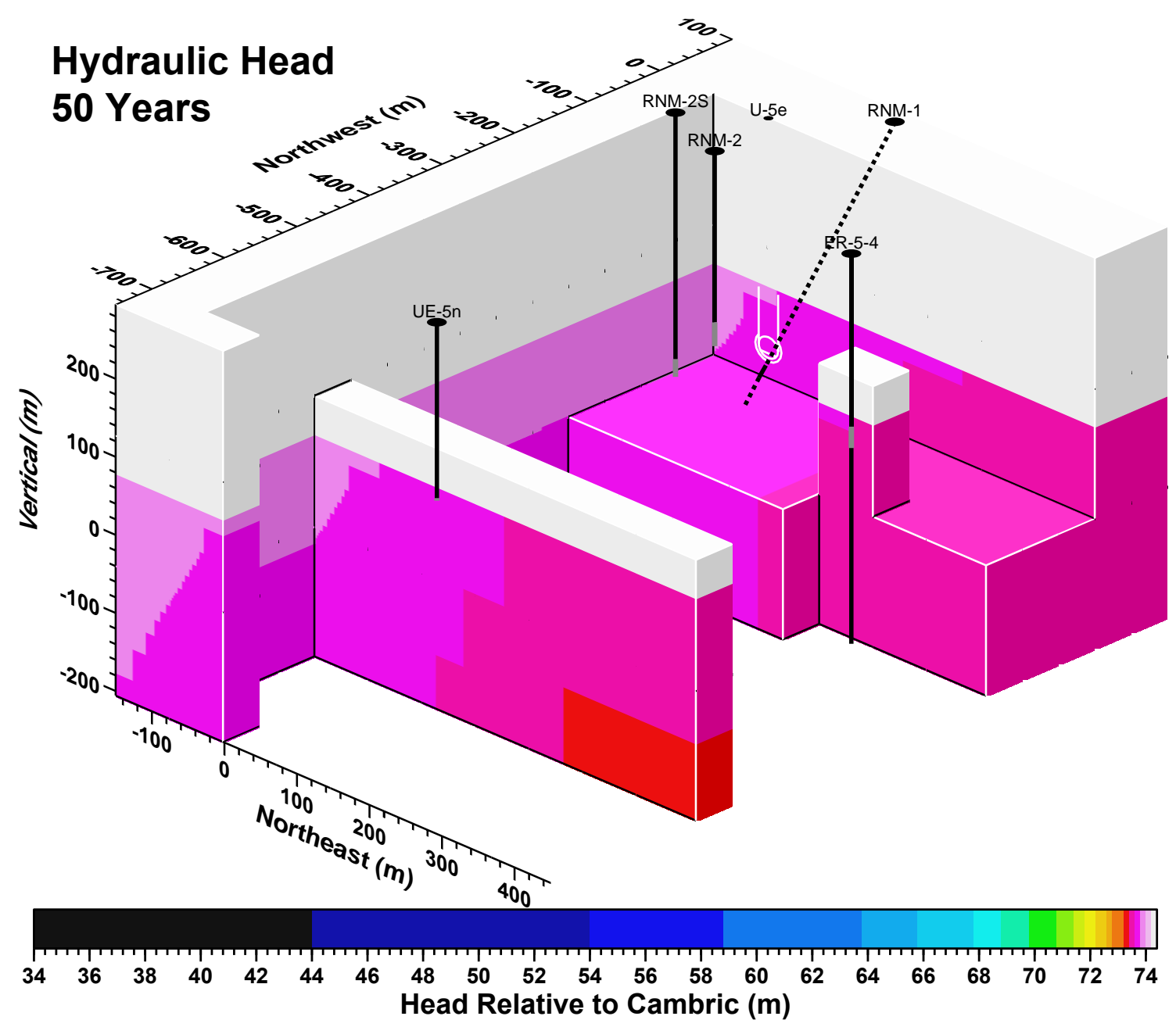

Figure 4.27 Large-scale cutaway view of NUFT simulation of hydraulic head at $50 \mathrm{y}$ at CAMBRIC and nearby wells.

Figure 4.28 shows small-scale cutaway views of NUFT simulation of hydraulic head near CAMBRIC at 10.4, 12.3, 15.7, 25.5, and $50 \mathrm{y}$. Between 12.3 and $15.7 \mathrm{y}$, the cone of depression associated with RNM-2S pumping approximately doubles in magnitude of drawdown as pumping increases from 300 to $600 \mathrm{gpm}$. By $25.5 \mathrm{y}$, hydraulic head increases about $0.5 \mathrm{~m}$ above CAMBRIC as a result of infiltration from discharge into the CAMBRIC ditch. By $50 \mathrm{y}$, hydraulic head is very similar to ambient conditions at $10.4 \mathrm{y}$. 

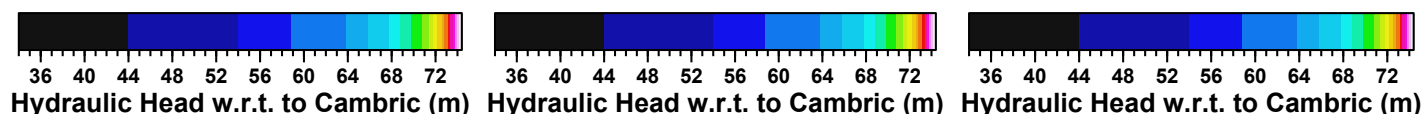

Hydraulic Head w.r.t. to Cambric $(m)$ Hydraulic Head w.r.t. to Cambric $(m)$ Hydraulic Head w.r.t. to Cambric (m)

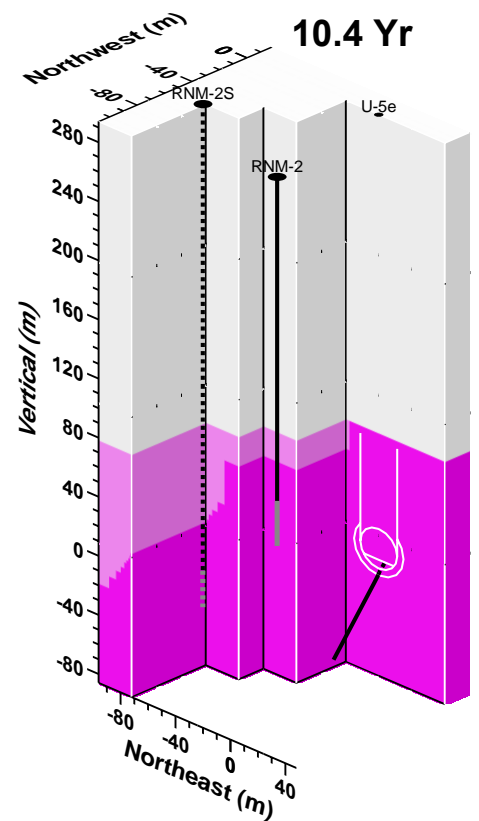

(a)

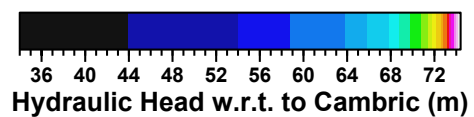

Hydraulic Head w.r.t. to Cambric (m)

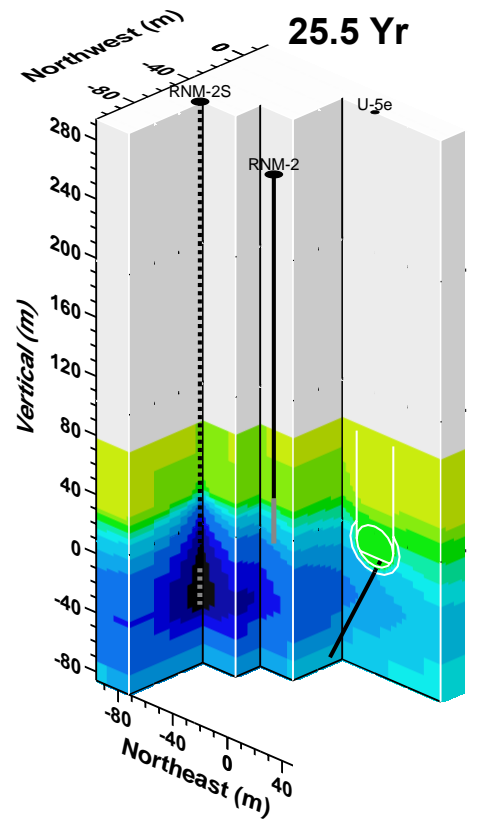

(d)

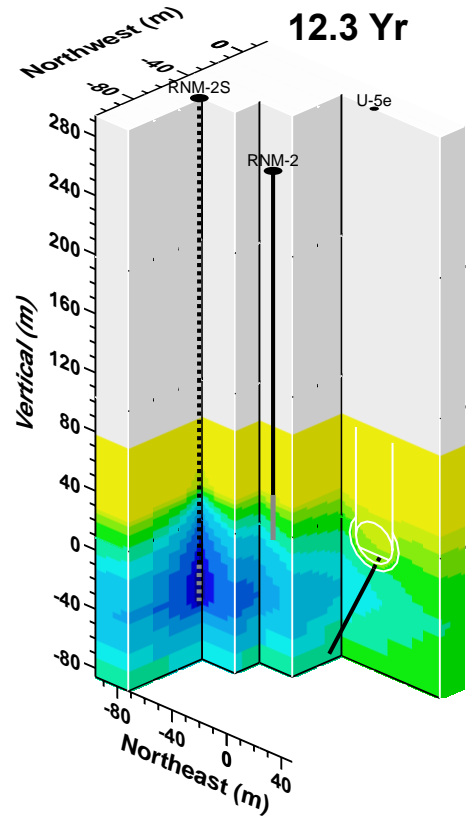

(b)

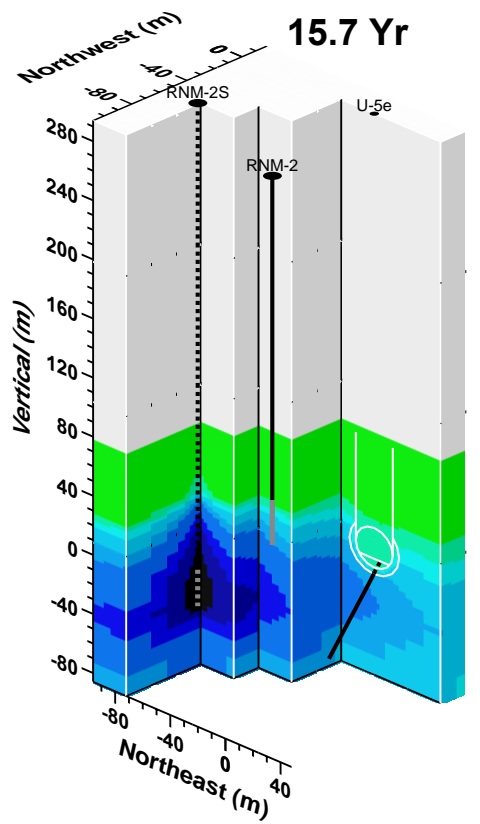

(c)
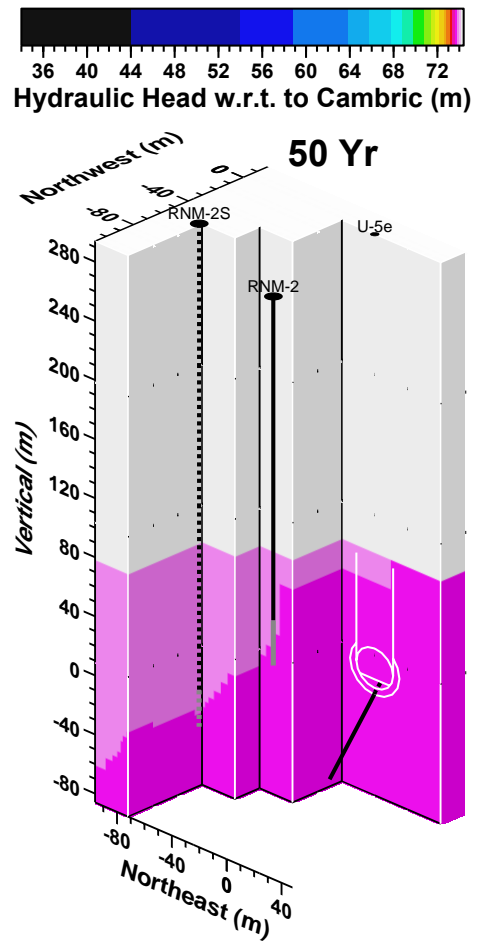

(e)

Figure 4.28 Small-scale cutaway views of NUFT simulation of hydraulic head near CAMBRIC at (a) 10.4, (b) 12.3, (c) 15.7, (d) 25.5, and (e) $50 \mathrm{y}$. 


\subsubsection{Temperature}

The NUFT flow simulation is non-isothermal because both fluid and heat flow are simulated simultaneously. Consequently, temperature is a state variable in the NUFT flow simulations.

\subsubsection{Test-Related Heat}

Most energy released by an underground nuclear test is converted to thermal energy. Test-related heat adds thermal energy to the groundwater flow system. Much of the test-related heat released is subsequently absorbed by phase transformations-from rock vapor, to rock liquid, to solid rock, and from water vapor to liquid water.

Melt glass temperature is unknown prior to $9 \mathrm{y}$ after the CAMBRIC test, when a single temperature $\log$ was obtained within RNM-1 (Section 3.4). This temperature log indicated a cavity/chimney temperature in the range of 2 to $3{ }^{\circ} \mathrm{C}$ above ambient.

The base-case NUFT simulation assumes that post-test phase transformations are complete such that rock is in the solid phase and water is only in the liquid phase below the water table. Given that the CAMBRIC test was situated $294 \mathrm{~m}$ below ground surface (Section 4.2.2) and that water levels above CAMBRIC are 222 to $223 \mathrm{~m}$ below ground surface (Section 4.4.1), the hydrostatic pressure at the CAMBRIC working point is approximately 71 to $72 \mathrm{~m}$. Figure 4.29 shows the NUFT base-case simulation of mean, minimum, and maximum temperature within the melt glass zone, including the influence of pumping from well RNM-2s on the flow field. The NUFT base-case simulation assumes an initial melt glass zone temperature of $170{ }^{\circ} \mathrm{C}$, which represents the boiling temperature for water at a hydrostatic pressure of $73 \mathrm{~m}$, which would exist 1 to $2 \mathrm{~m}$ below the CAMBRIC working point. The assumption of a $170{ }^{\circ} \mathrm{C}$ melt glass zone initial temperature is equivalent to an assumption that the initial conditions represent a time soon after boiling of water has ceased, which is expected to be within hours or days after detonation. Nine years after the CAMBRIC test, the simulated melt glass zone temperature drops to about $27^{\circ} \mathrm{C}$, or approximately $3{ }^{\circ} \mathrm{C}$ above the ambient $24^{\circ} \mathrm{C}$. After pumping begins at $10.4 \mathrm{y}$, melt glass temperature is seen to drop more rapidly, continuing to decline slightly below the ambient temperature. This temperature drop is caused by RNM-2S pumping, which pulls in cooler water from above the CAMBRIC cavity downward through the melt glass zone. Sensitivity cases involving boiling conditions for water and pumping effects are examined in Section 4.7.

The assumption of an initial melt glass zone temperature based on nearhydrostatic pressure is different from the assumption made for the CHESHIRE HST model for Pahute Mesa (Pawloski et al., 2002). CHESHIRE was situated in rhyolitic lavas where chimney and cavity formation produced a large increase in porosity and vertical permeability relative to the in-situ rocks. The porosity increase (or formation of void space) produced unsaturated conditions in the cavity and chimney, and the highpermeability chimney provided hydraulic connection to atmospheric pressure. The CAMBRIC test was situated in alluvial deposits, and cavity and chimney collapse in alluvium do not produce a large porosity and permeability increase like the CHESHIRE test. The chimney and cavity rubble remain at near-saturated conditions such that fluid pressure could rapidly return to near-hydrostatic conditions. Consequently, the assumption is made that the initial melt glass temperature is related to the boiling point of water at a hydrostatic pressure equivalent to a water column $73 \mathrm{~m}$ in height. 


\section{Melt Glass Temperature}

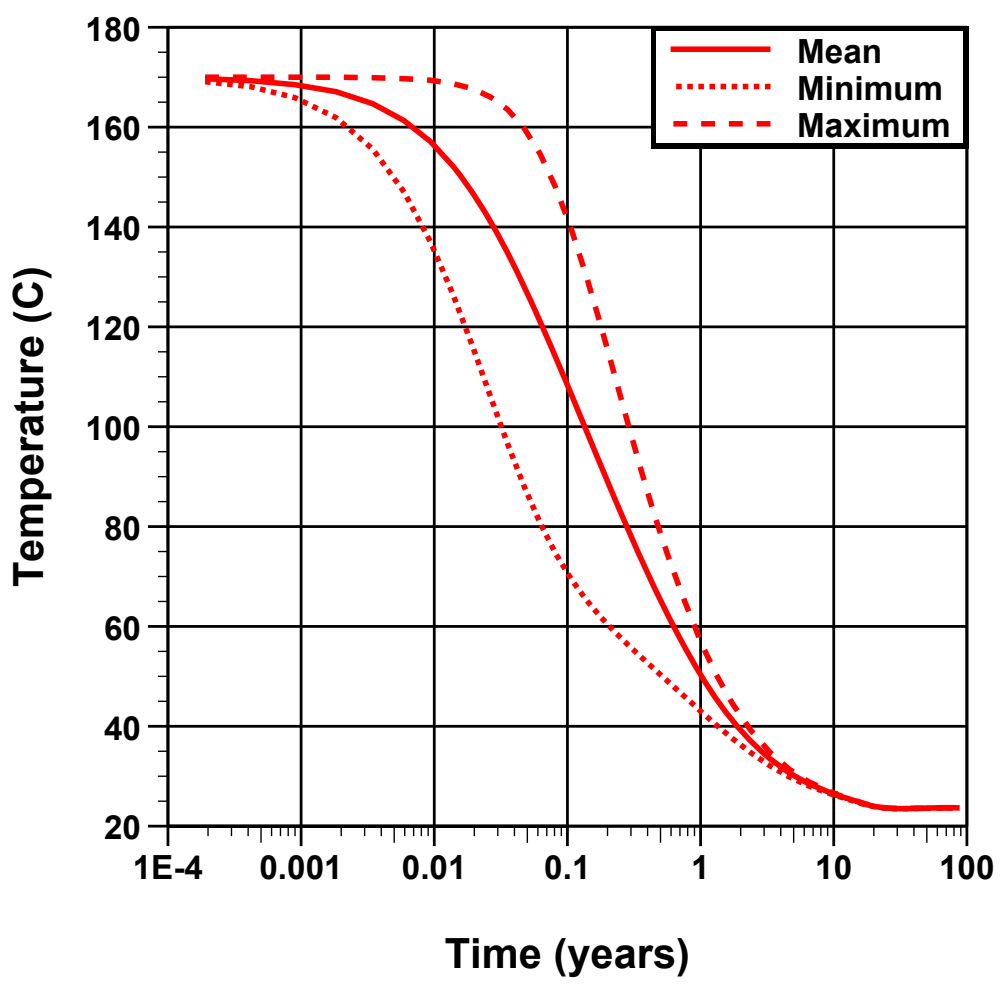

Figure 4.29 NUFT simulation of mean, minimum, and maximum melt glass zone temperature for base case with pumping.

\subsubsection{Data}

The CAMBRIC site has limited temperature data—only a single temperature $\log$ measured in RNM-1 obtained about $10.4 \mathrm{y}$ after detonation. These data are described in more detail in Sections 3.4 and 4.4.3. The NUFT flow simulations cannot be calibrated to temperature before or after 10.4 y because of lack of data. The overall lack of temperature data quantity (i.e., repeat measurements) and quality (i.e., not affected by drilling operations) pertinent to test-related heat at CAMBRIC contributes to uncertainty in assessing the thermal effects on groundwater flow and radionuclide transport. Section 4.7.2 provides sensitivity studies on effects of initial test heat on groundwater flow and tracer transport.

\subsubsection{Geothermal Gradient}

As described in Section 4.4.3, the temperature data do enable inference of a geothermal gradient for locations above the CAMBRIC test. To impart a geothermal gradient in the NUFT flow simulation, temperature is fixed as a boundary condition of $28.5^{\circ} \mathrm{C}$ at the bottom $(-706 \mathrm{~m})$ and $21.25^{\circ} \mathrm{C}$ at the top (cell center at $+294.5 \mathrm{~m}$ ). 


\subsubsection{Thermal Properties of Rocks and Fluids}

Thermal conductivity of clastic sedimentary rocks typically ranges from 1 to 3 Watts per meter per Kelvin ( $\mathrm{W} \mathrm{m}^{-1} \mathrm{~K}^{-1}$ ) (Gillespie, 2005, Tables 3 and 5). Thermal conductivity is slightly to moderately higher in saturated rock compared to dry rock. The NUFT simulations assume typical thermal conductivity values of $1.5 \mathrm{~W} \mathrm{~m}^{-1} \mathrm{~K}^{-1}$ for dry rock and $2.0 \mathrm{~W} \mathrm{~m}^{-1} \mathrm{~K}^{-1}$ for saturated rock, with a linear dependence on saturation. The assumption of $2.0 \mathrm{~W} \mathrm{~m}^{-1} \mathrm{~K}^{-1}$ thermal conductivity for saturated rocks provides reasonable calibration to an estimated 1 to $2{ }^{\circ} \mathrm{C}$ residual temperature anomaly associated with the CAMBRIC test.

The NUFT simulations assume a typical specific heat capacity value of 840 Joules per kilogram per Kelvin $\left(\mathrm{J} \mathrm{kg}^{-1} \mathrm{~K}^{-1}\right)$ for all rocks. Steam (look-up) tables are used for specific enthalpy for water in liquid and gas phase. The NUFT simulations assume a typical value of $1,009 \mathrm{~J} \mathrm{~kg}^{-1} \mathrm{~K}^{-1}$ for the specific heat capacity of gaseous air.

\subsubsection{Temperature at 10.4 Years}

The time of $10.4 \mathrm{y}$ after the CAMBRIC test corresponds to construction of RNM-1 and subsequent data collection. Figure 4.30 shows a large-scale view of the NUFT simulation temperature field at $10.4 \mathrm{y}$. This simulated temperature field at $10.4 \mathrm{y}$ is consistent with the limited temperature data obtained during construction of RNM-1 in 1975, which provide the only thermal calibration data for CAMBRIC. The simulated vertical gradient in temperature is fit to the estimated geothermal gradient. The consideration of residual heat from the CAMBRIC test, accomplished through initial melt glass zone temperature of $170{ }^{\circ} \mathrm{C}$ and cavity temperature of $40{ }^{\circ} \mathrm{C}$, results in temperatures of 1.5 to $2.5^{\circ} \mathrm{C}$ above background near CAMBRIC at $10.4 \mathrm{y}$, as suggested from the RNM-1 temperature data from 1975 (Section 4.4.3). However, no additional temperature data are available to calibrate the simulation at other times, particularly before 1975 . 


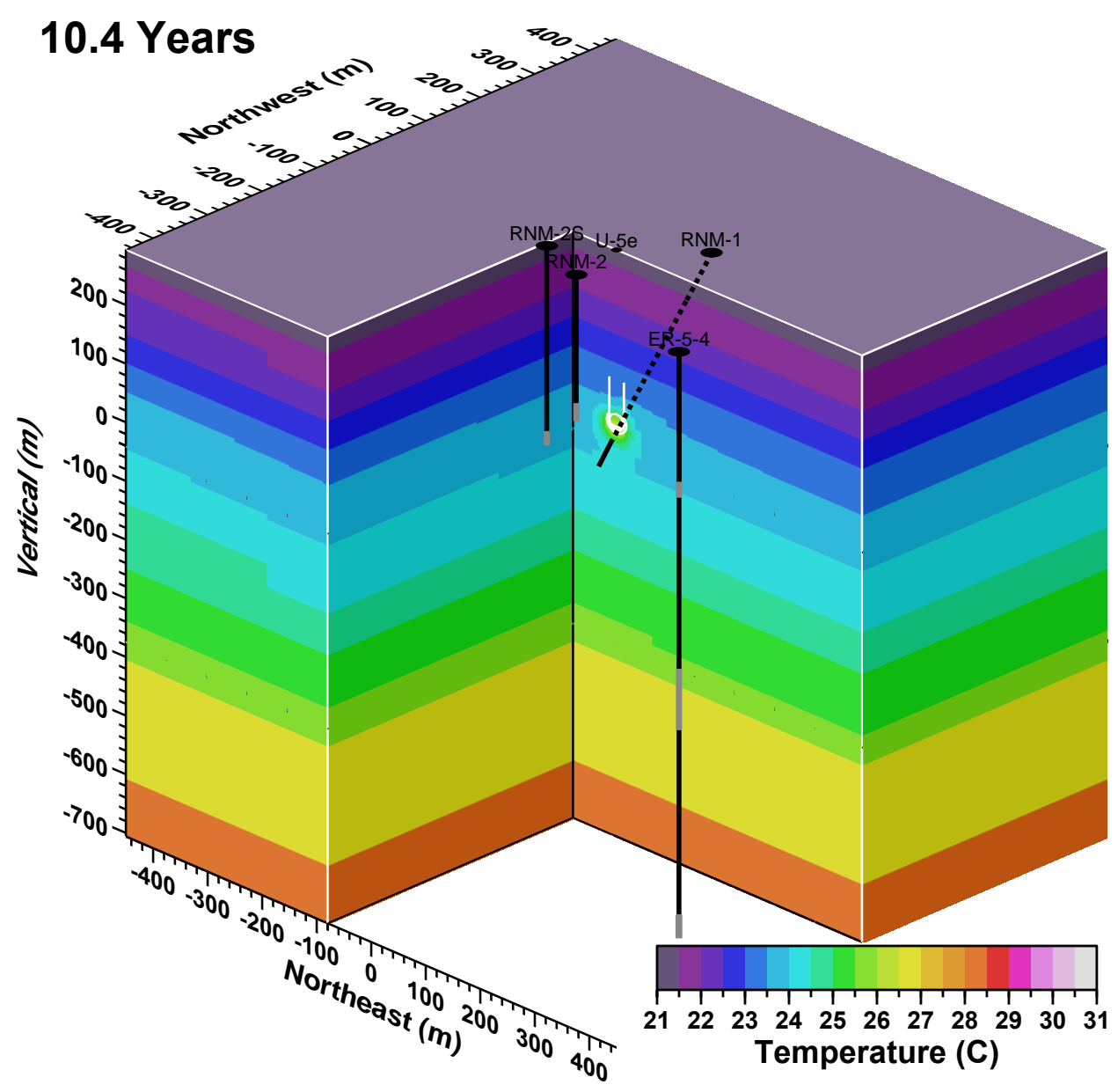

Figure 4.30 Small-scale view of NUFT simulation temperature field at $10.4 \mathrm{y}$.

\subsubsection{Temperature before $10.4 \mathrm{Y}$}

A main objective of performing the NUFT transient flow simulations is to assess the effects of residual heat from the CAMBRIC test. The NUFT simulations indicate that if melt glass zone temperatures of $170{ }^{\circ} \mathrm{C}$ or more exist as residual test heat shortly after detonation, temperatures would subside to a few degrees above ambient conditions before $10.4 \mathrm{y}$, or before the advent of pumping at RNM-2S for the RNM experiment.

The ambient local flow conditions in alluvium near CAMBRIC involve very small horizontal hydraulic gradients of 0.0003 to 0.0013 and immeasurably small vertical gradients most likely inducing downward flow. Assuming CAMBRIC is situated in Layer 3 where the permeability of alluvial aquifer materials is relatively low for Frenchman Flat, the ambient flow conditions near CAMBRIC would produce relatively little advection in Layer 3 within a 10.4 y timeframe. However, the introduction of residual heat from the CAMBRIC test could increase flow velocities near CAMBRIC, particularly in the upward direction as a result of decreased density and viscosity of heated groundwater. Upward flow velocities would represent a flow-reversal from ambient flow conditions assuming a 
downward component to the hydraulic gradient. The effects of residual heat on flow and transport are discussed in more detail in Sections 4.6.6, 4.6.8, and 4.7.

The NUFT base-case flow simulation assumes a $170{ }^{\circ} \mathrm{C}$ initial temperature in the melt glass zone and a $40{ }^{\circ} \mathrm{C}$ initial temperature in the cavity, compared to ambient temperatures ranging between 23 and $24{ }^{\circ} \mathrm{C}$ near the CAMBRIC altered zones. Before pumping at RNM-2S, the low-velocity ambient flow conditions favor conductivedominated transport of heat. Once pumping begins at RNM-2S, advection dominates transport of remaining residual heat from CAMBRIC.

Figure 4.31 illustrates the evolution of NUFT simulation temperature change very near CAMBRIC within $10.4 \mathrm{y}$. The time-evolution of heat flow is nearly symmetric in the northeast (downgradient) axis, indicating that local groundwater flow has little impact on lateral transport of heat near CAMBRIC. The time-evolution of heat from the melt glass zone is also relatively symmetric in the vertical axis. Considering that simulation permeability is two orders of magnitude greater above the melt glass (in the cavity) compared to below the melt glass (in the compressed zone), groundwater flow appears to have little impact on vertical transport of heat. Thus, the NUFT simulation indicates that transport of residual test heat under ambient flow conditions near CAMBRIC is dominated by thermal conduction rather than advection of heat by groundwater flow.

This simulation result of thermal conduction-dominated heat flow at CAMBRIC is different than for thermal groundwater flow simulations of the CHESHIRE test on Pahute Mesa (Pawloski et al., 2001). At CHESHIRE, several conditions favored more advective transport of heat in groundwater compared to CAMBRIC:

- Higher hydraulic gradient ( $\sim 0.01$ compared to $\sim 0.0008)$

- Higher-permeability in-situ rocks surrounding the test

- Higher-permeability chimney

- Higher-permeability crush zone

- More residual test heat to produce more extensive density contrast in groundwater to produce convection cells 

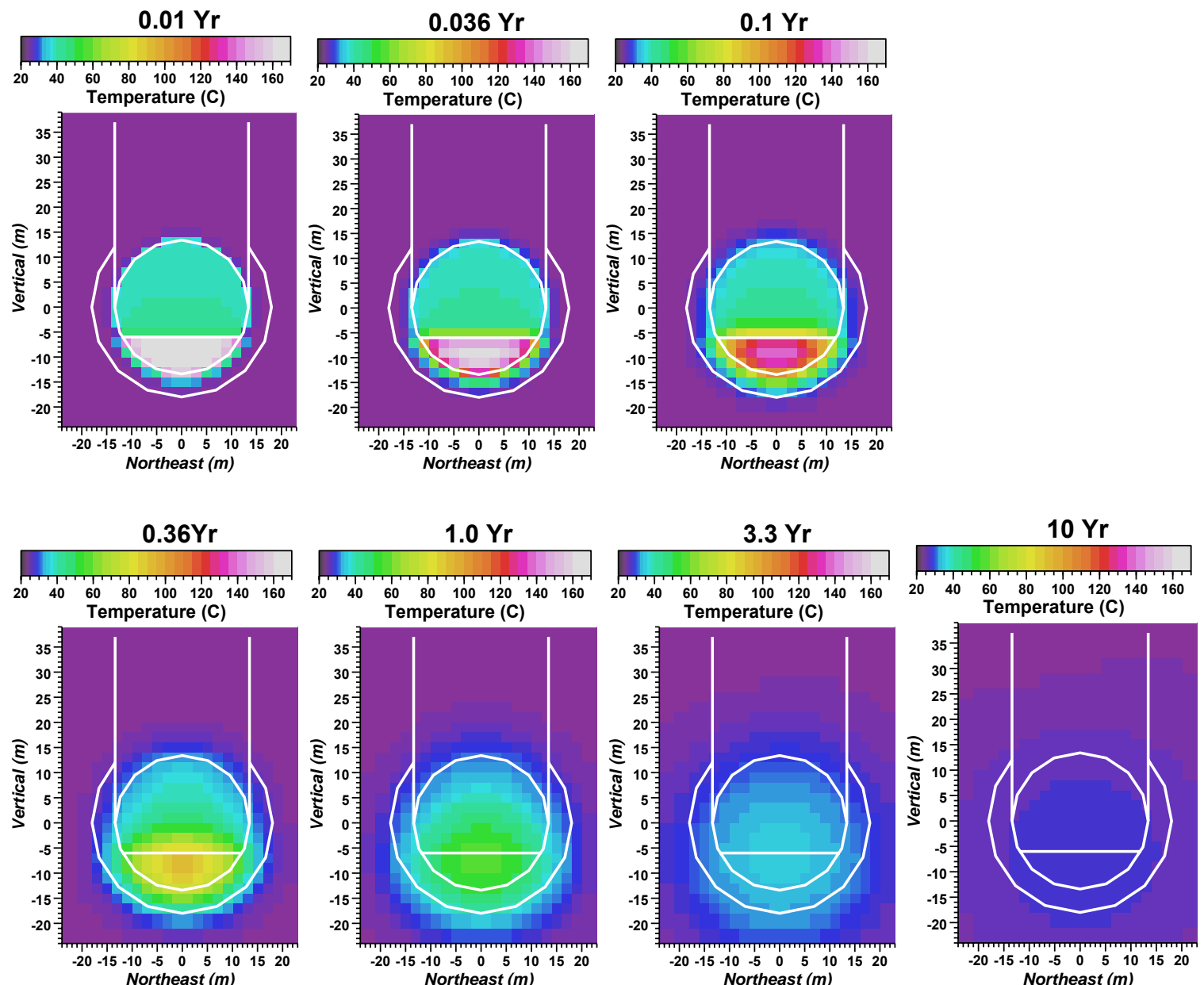

Figure 4.31 NUFT simulation temperature fields near melt glass, cavity, chimney, and compressed zones at $0.01,0.036,0.1,0.36,1.0,3.3$, and $10 \mathrm{y}$. 


\subsubsection{Temperature after 10.4 Years}

Heat affects transient groundwater flow by changing fluid density and viscosity over time. If variation of fluid density is rapid and fluid flow diffusivity is great enough, convection cells can occur, as indicated by thermal flow simulation of the CheshiRe test on Pahute Mesa (Pawloski et al., 2001). Heat anomalies can act as a form of tracer in transient groundwater flow systems, which was also observed and simulated for the CHESHIRE test (Pawloski et al., 2001). Figures 4.32-4.34 show large-scale cutaway views of NUFT simulation temperature fields at $10.4,25.5$, and $50 \mathrm{y}$. These views show two main thermal effects related to the CAMBRIC test and RNM experiment:

- Cooling of residual heat from CAMBRIC by $10.4 \mathrm{y}$

- Transport of heat by discharge into the CAMBRIC ditch

Based on the NUFT simulation after $10.4 \mathrm{y}$, the remaining thermal anomaly of a few degrees Celsius from residual heat from the CHESHIRE test is largely advected away by pumping from RNM-2S. Pumping at RNM-2S (300 to $600 \mathrm{gpm}$ ) causes downward groundwater movement and, thus, displacement of residual heat with cooler groundwater from above. By $25.5 \mathrm{y}$, the groundwater near CAMBRIC is slightly cooler relative to ambient conditions as a result of pumping at RNM-2S.

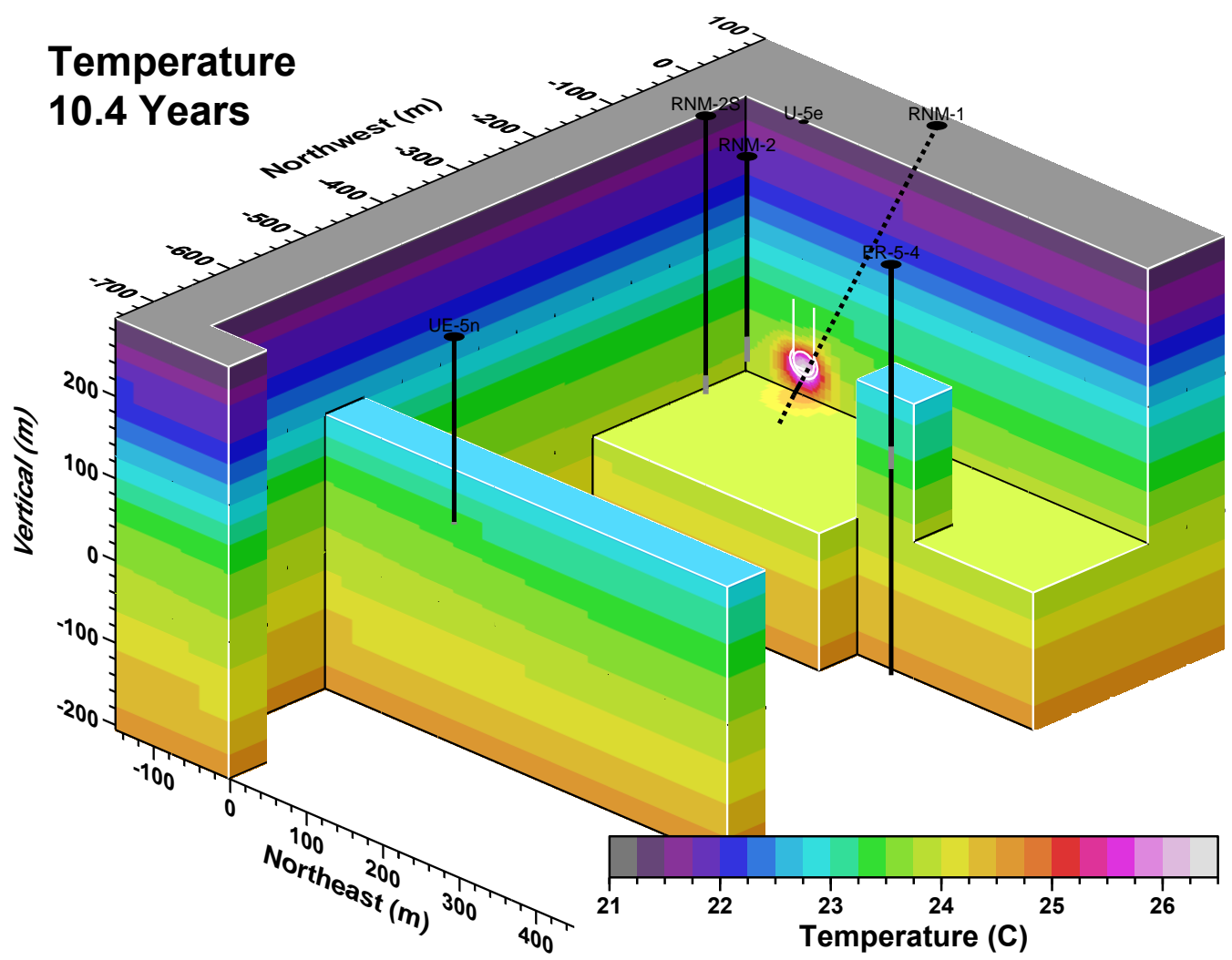

Figure 4.32 Large-scale cutaway view of NUFT simulation temperature field at 10.4 y near CAMBRIC and nearby wells. 
CAMBRIC ditch discharge is represented in the NUFT simulation as a source term boundary condition for liquid water. In the non-isothermal flow simulation, temperature must be specified for this ditch discharge source term. However, no data of ditch discharge temperature are available. In the NUFT simulation, temperature of the ditch discharge was assumed to be $23.0^{\circ} \mathrm{C}$, which is between the simulated ambient temperatures at the ground surface $\left(21.25^{\circ} \mathrm{C}\right)$ and the RNM-2S well screen $\left(\sim 23.8^{\circ} \mathrm{C}\right)$. For simplicity, no seasonal variations in temperature or discharge rate are assumed. The NUFT simulation indicates that if the temperature of ditch discharge is different than ambient temperature in both the vadose zone and saturated zone, infiltration of ditch discharge will cause a thermal anomaly. Assuming a ditch discharge temperature condition that is greater than the ambient temperatures in the upper vadose zone and lower than ambient temperature below the water table causes two effects:

- Higher temperatures for ditch infiltration flow in the upper vadose zone

- Lower temperatures for ditch infiltration flow in the saturated zone

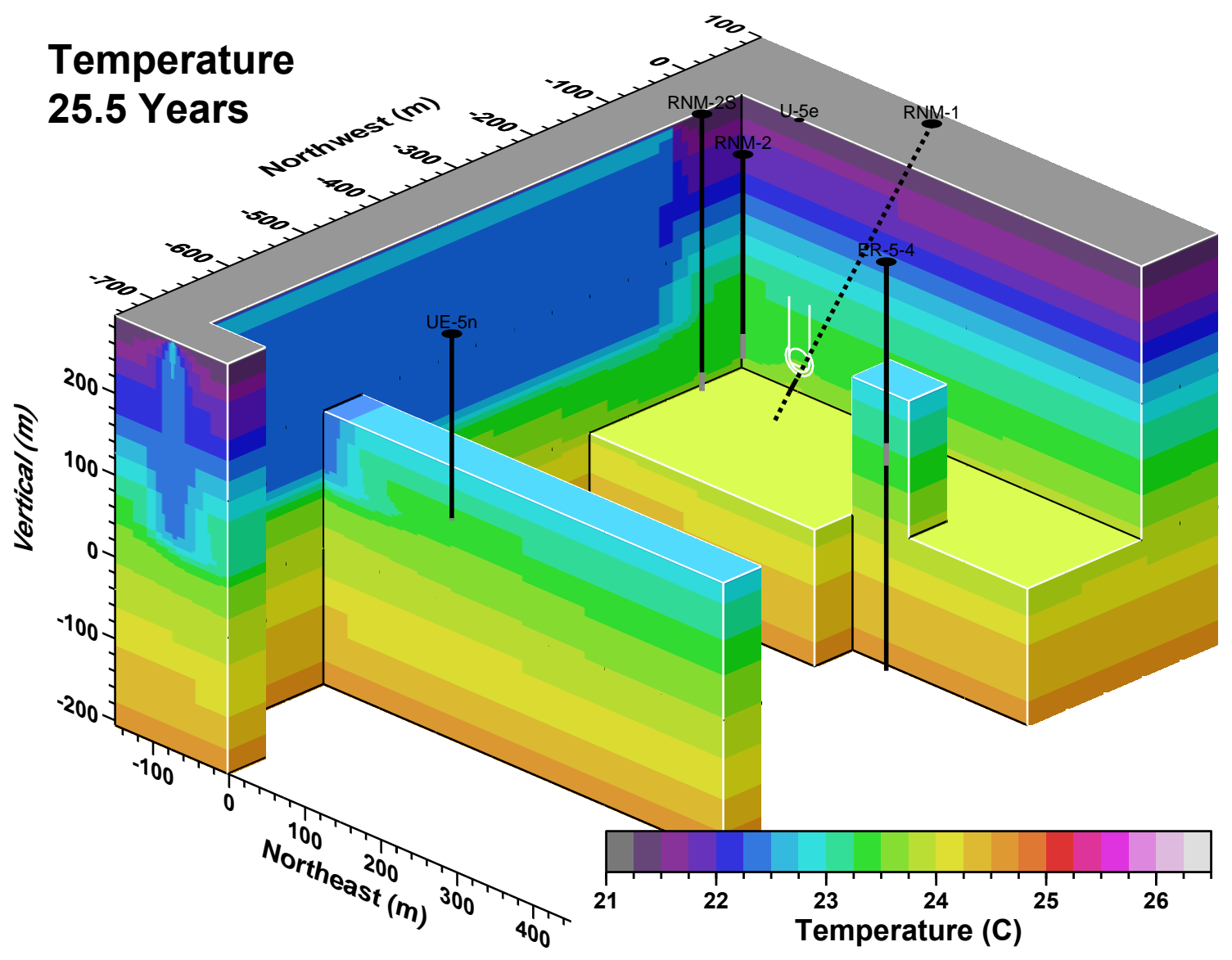

Figure 4.33 Large-scale cutaway view of NUFT simulation of temperature field at 25.5 y near CAMBRIC and nearby wells. 


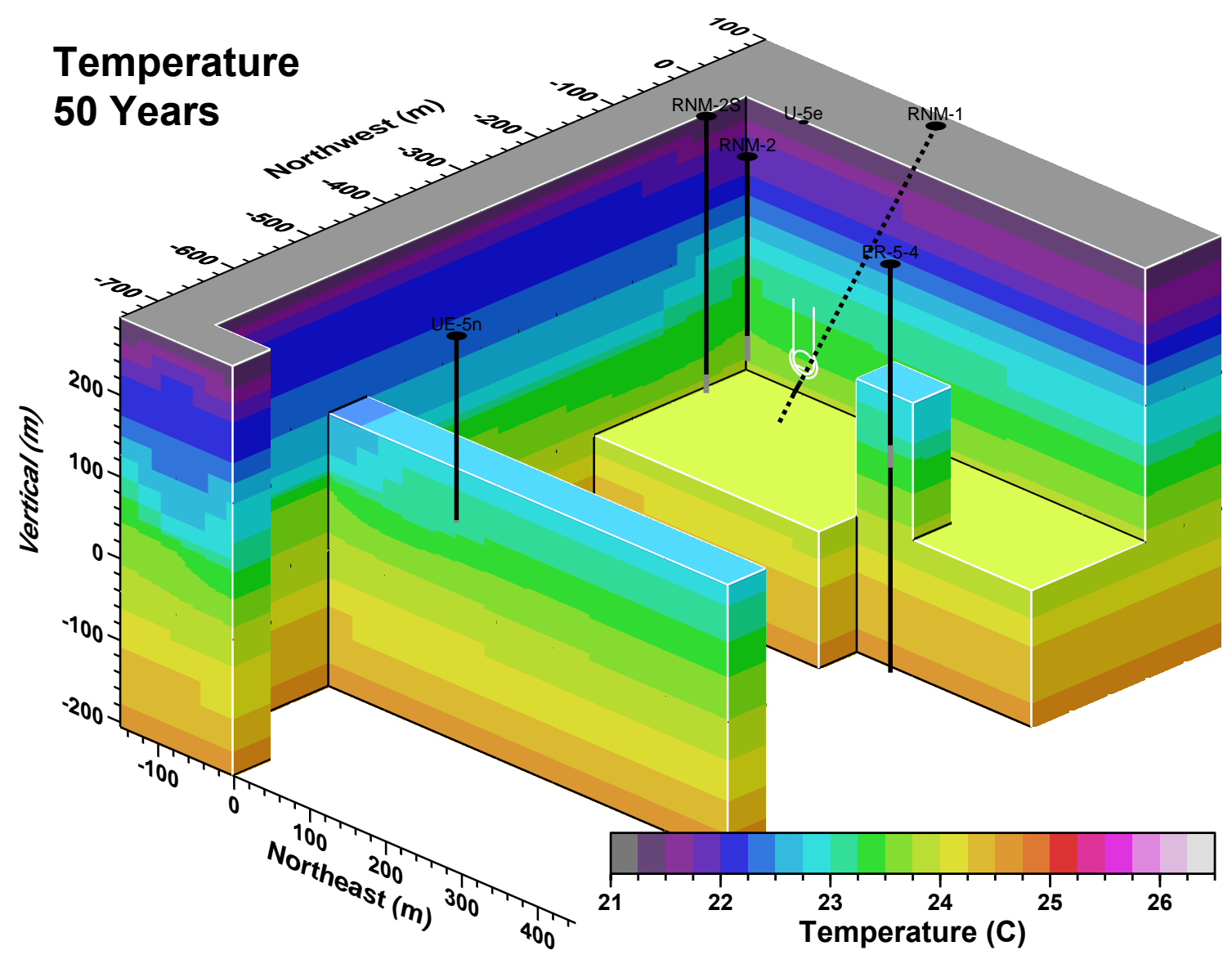

Figure 4.34 Large-scale cutaway view of NUFT simulation of temperature field at $50 \mathrm{y}$ near CAMBRIC and nearby wells.

Figure 4.35 shows small-scale cutaway views of NUFT simulation of temperature near CAMBRIC and RNM-2S. As pumping at RNM-2S commences after $10.4 \mathrm{y}$, the residual heat from the CAMBRIC test is drawn toward RNM-2S. These smallscale views show the NUFT simulation predicts no residual test heat at CAMBRIC or near RNM-2S upon completion of pumping at RNM-2S as part of the RNM experiment. 

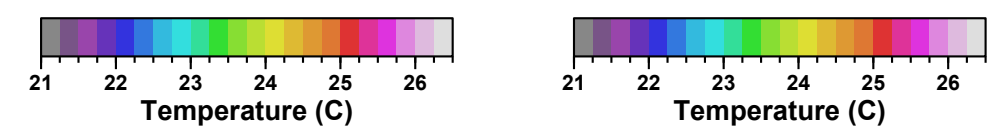

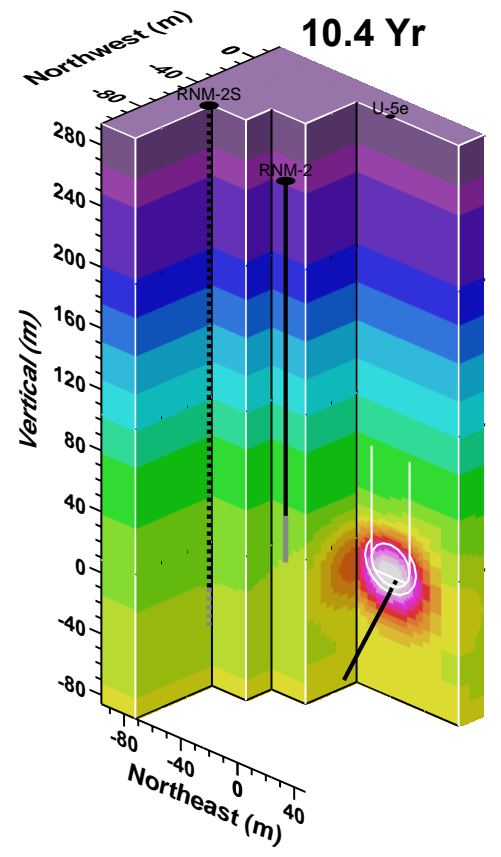

(a)
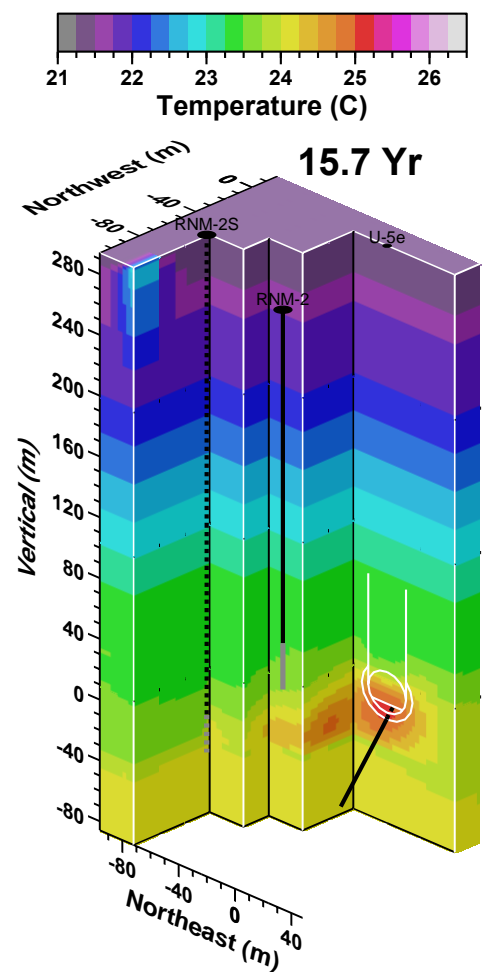

(c)

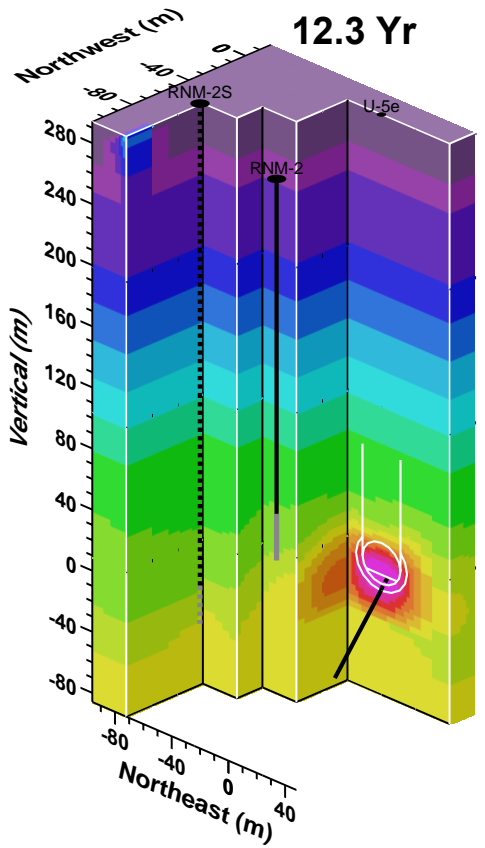

(b)
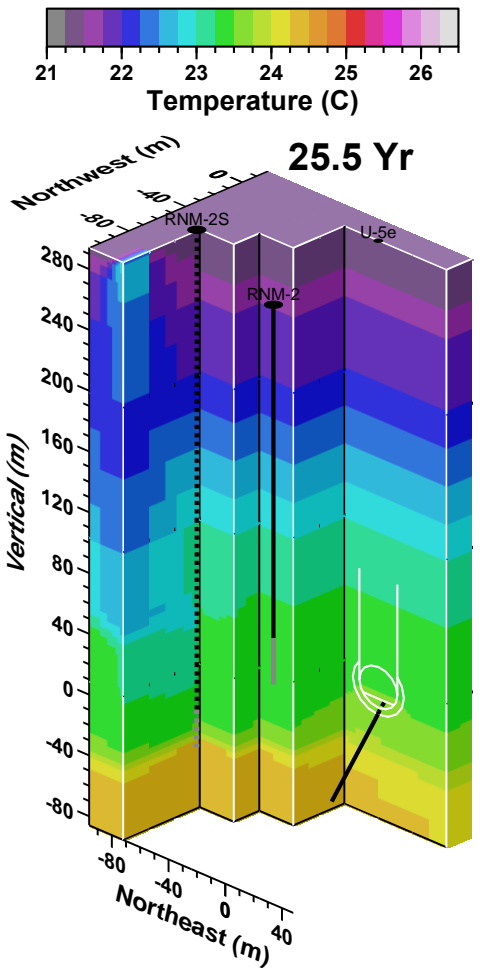

(d)

Figure 4.35 Small-scale cutaway views of NUFT simulation of temperature near CAMBRIC at 10.4, $12.3,15.7$, and $25.5 \mathrm{y}$. 


\subsubsection{Fluid Density and Viscosity}

Fluid density and viscosity vary with temperature and pressure. In the NUFT simulations, temperature varies between 21.25 and $170{ }^{\circ} \mathrm{C}$ and pressure varies between 0.1 and $7 \mathrm{MPa}$ (1 to 70 bars). The NUFT simulations use look-up tables and mathematical functions to account for variation in fluid density and viscosity with temperature and pressure.

Over the range of ambient temperatures and pressures in the NUFT simulations, water density varies from about 997.4 to $998.5 \mathrm{~kg} / \mathrm{m}^{3}$ over the entire depth range (Figure 4.20). Within the altered zones, test-related heat induces additional density variation relative to ambient conditions (Figure 4.36). The NUFT simulations indicate water density would be as low as $897 \mathrm{~kg} / \mathrm{m}^{3}$ in the melt glass zone, $966 \mathrm{~kg} / \mathrm{m}^{3}$ in the cavity, and $967 \mathrm{~kg} / \mathrm{m}^{3}$ in the compressed zone. The variations in fluid density within the altered zones are largely related to temperature variation. Throughout the entire NUFT simulation domain, the largest variations in water density are related to temperature variation.

Temperature variation also produces the largest variation in fluid viscosity. Figure 4.37 shows NUFT simulation viscosity variation over time in the altered zones. Ambient fluid viscosity is about $9.2 \times 10^{-4}$ Newton-seconds per square meter $\left(\mathrm{N}-\mathrm{s} / \mathrm{m}^{2}\right)$. NUFT simulation viscosity is as low as $1.6 \times 10^{-4} \mathrm{~N}-\mathrm{s} / \mathrm{m}^{2}$ in the melt glass zone, $3.2 \times 10^{-4} \mathrm{~N}-\mathrm{s} / \mathrm{m}^{2}$ in the cavity, and $3.3 \times 10^{-4} \mathrm{~N}-\mathrm{s} / \mathrm{m}^{2}$ in the compressed zone.

Small changes in density and viscosity in the lower chimney occur between about 0.1 and $11 \mathrm{y}$. Although these changes are not nearly as large as in the melt glass zone, cavity, and compressed zone, the existence and timing of density and viscosity changes in the chimney indicates some upward migration of test heat. From comparison of the initial temperature distribution in the altered zones to later temperature fields over time in Figure 4.37, the NUFT simulation indicates that test heat begins to migrate to grid cells above the cavity after about $0.1 \mathrm{y}$. As discussed earlier in Section 4.6.3.6, the migration of test heat from CAMBRIC appears to be largely conductive rather than convective. Thus, the slight variations in fluid density and viscosity in the lower chimney are largely attributable to conductive heat flow. Similarly, the variations in fluid density over time in the melt glass zone, cavity, and compressed zone are also largely attributable to conductive heat flow. 


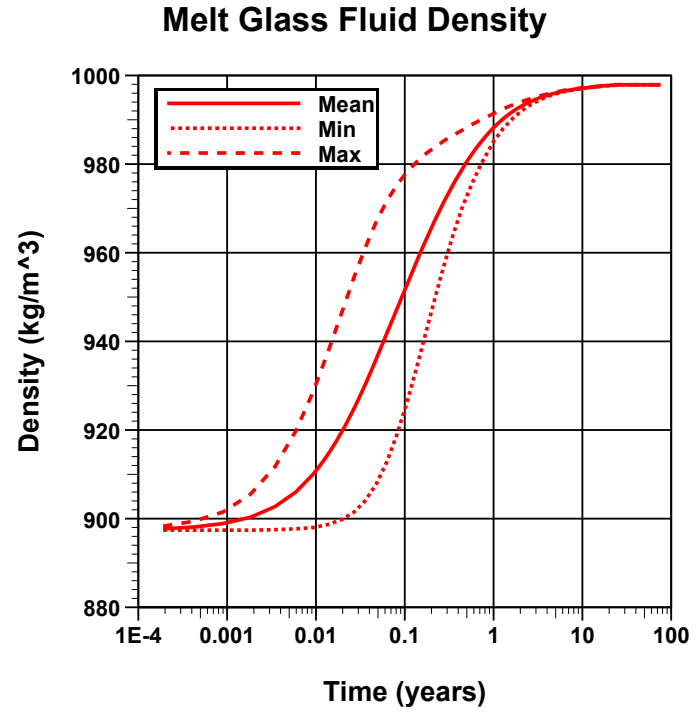

(a)

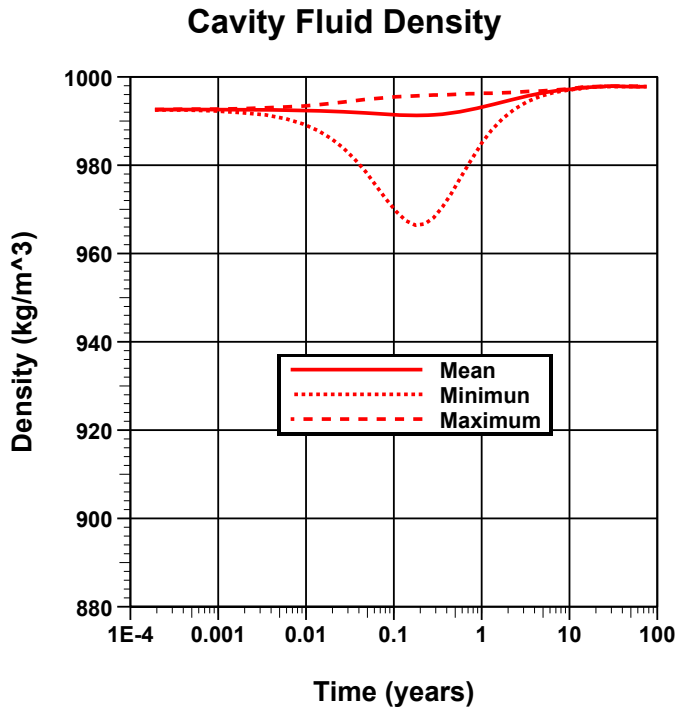

(b)

\section{Compressed Zone Fluid Density}

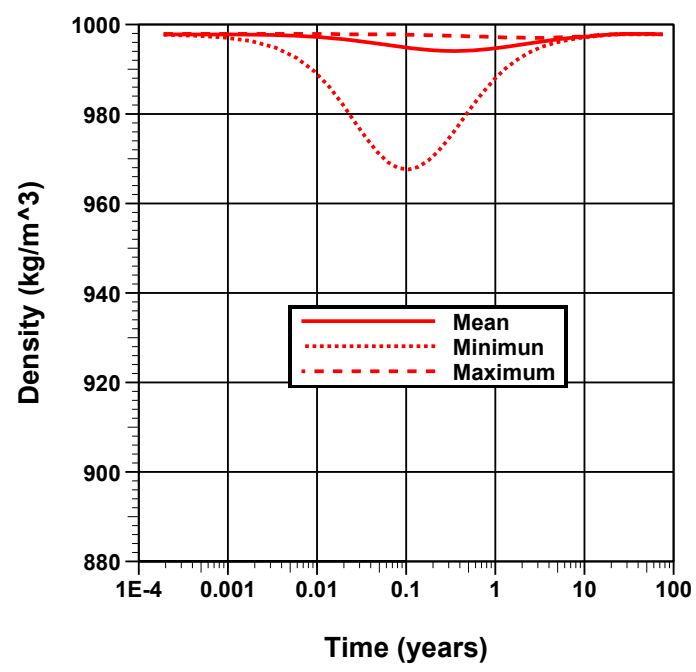

(c)

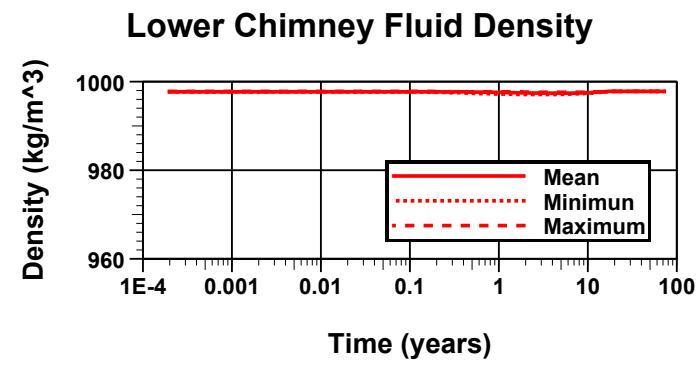

(d)

Figure 4.36 NUFT simulation of mean, minimum, and maximum fluid density in (a) melt glass zone, (b) cavity, (c) compressed zone, and (d) lower chimney. 
Melt Glass Fluid Viscosity

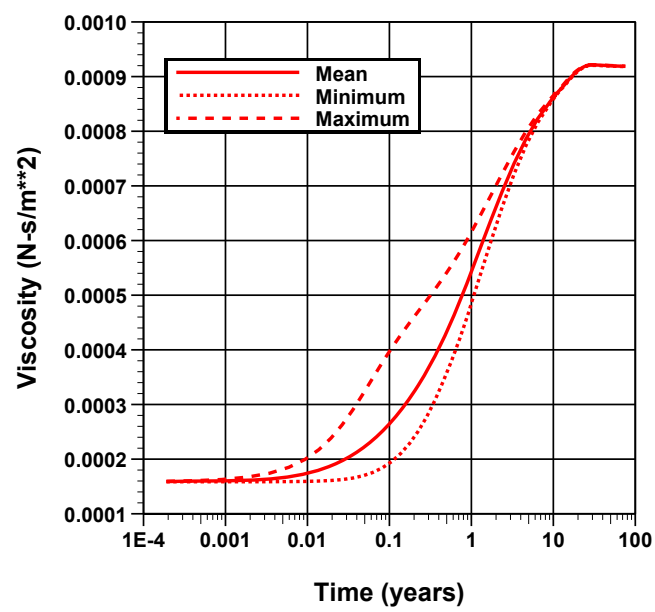

(a)

\section{Compressed Zone Fluid Viscosity}

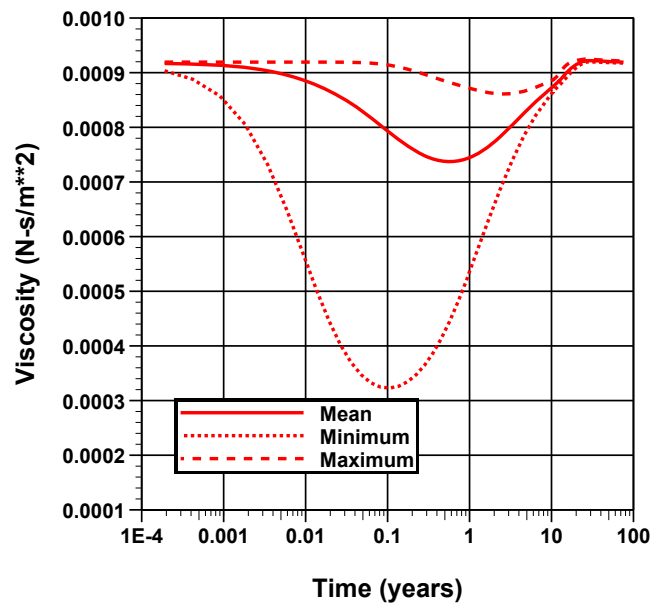

(c)

\section{Cavity Fluid Viscosity}

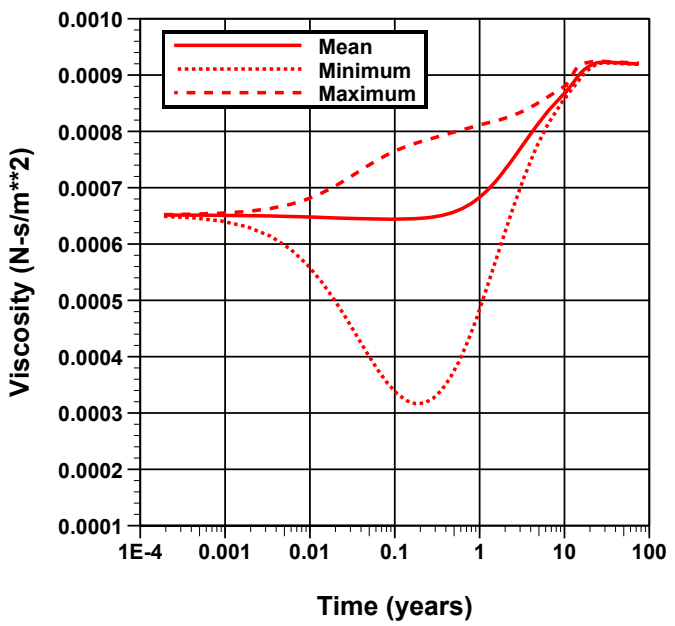

(b)

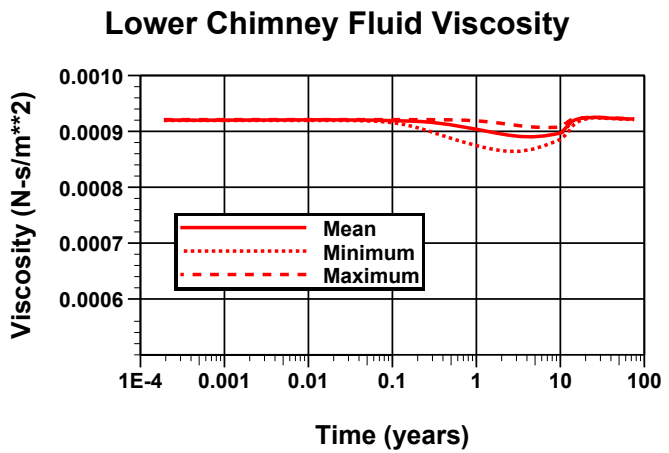

(d)

Figure 4.37 NUFT simulation of mean, minimum, and maximum fluid viscosity in (a) melt glass zone, (b) cavity, (c) compressed zone, and (d) lower chimney. 


\subsubsection{Hydraulic Gradients}

Hydraulic gradient measures the change in hydraulic head per unit distance. Hydraulic gradient is a 3D vector, because the gradient varies in space as a result of heterogeneity, sources/sinks, boundary conditions, thermal effects, etc. As discussed in Section 4.4.2, magnitudes of hydraulic gradients in the shallow alluvial aquifer near CAMBRIC are estimated to be between 0.0003 and 0.0013 in the lateral direction (StollerNavarro, 2004b). The uncertainty in water level measurements near CAMBRIC precludes measurement of a vertical hydraulic gradient in the shallow alluvium (Layer 8 and above). However, a pressure difference measurement between the two lower screened intervals of ER-5-4 suggests a $1.2 \mathrm{~m}$ decrease in hydraulic head with depth across the PCU1U (Layer 9). Hydraulically, the shallow alluvium (Layers 1-8) is relatively isolated from the deeper alluvium (Layer 10 and below) by the PCU1U.

The non-isothermal NUFT simulation uses pressure $(p)$ rather than hydraulic head $(\phi)$ as the state variable for formulating the equations of flow, as in the first equality of (4.6) below:

$$
\mathbf{q}=-\frac{k}{\mu} \nabla(p+\rho g z) \approx-\frac{k \rho g}{\mu} \nabla\left(\frac{p}{\rho g}+z\right)=-K \nabla \phi
$$

In this case, fluid density $(\rho)$ and viscosity $(\mu)$ vary with pressure and temperature, and, are therefore functions of space $(\mathbf{x})$ and time $(t)$. NUFT accounts for the pressure and temperature dependencies of the physical properties of the fluids and is generally formulated in terms of medium permeability $(k)$ as opposed to hydraulic conductivity $(K)$. Use of hydraulic head assumes that the fluid density and viscosity are constant, or approximately so, as invoked in the second and third terms on the right hand side of (4.6).

To compute an approximate hydraulic gradient $(\nabla \phi)$ from a NUFT simulation, (4.6) can be rearranged in terms of the gravity constant $g$, the computed values of $\rho$ and $\mu$, and the permeability as

$$
\nabla \phi(x, t) \approx-\mathbf{q} \frac{\mu(x, t)}{k(x) \rho(x, t) g} .
$$

Equation (4.7) is used to compute the hydraulic gradient from the fluid flux, viscosity, permeability, and density fields simulated from NUFT. Figure 4.38 shows graphs of NUFT simulation downgradient, transverse, and vertical components of mean hydraulic gradient through the altered zones over time. These hydraulic gradients are computed from the flux-based formulation of Equation (4.6) rather than the standard approach of computing a gradient from a hydraulic head field, which is fictitious under conditions of variable fluid density and viscosity. The standard head field approach is not directly applicable to systems with variable density and viscosity. 


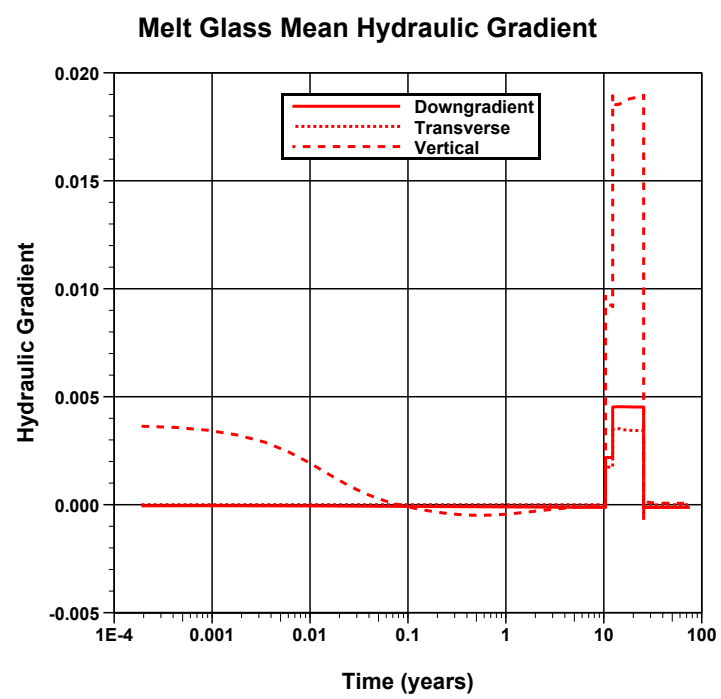

(a)

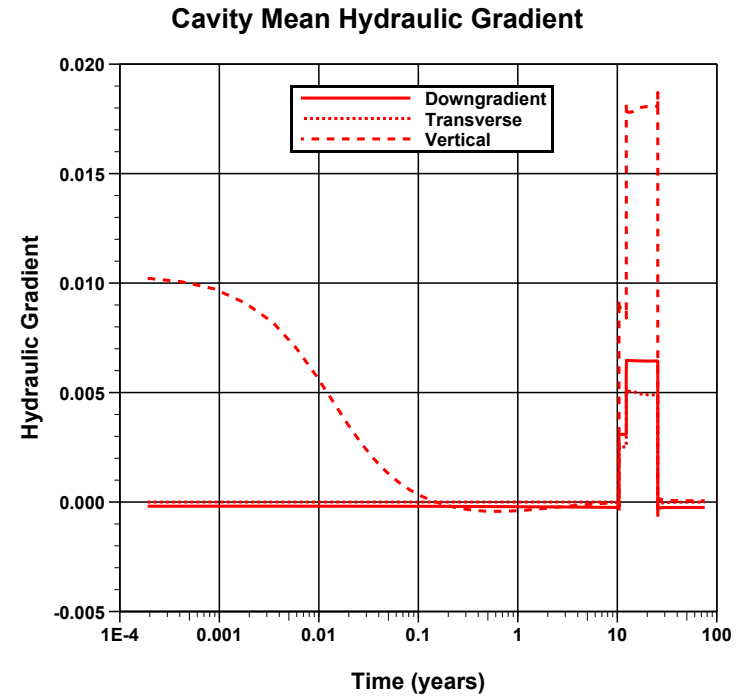

(b)

\section{Compressed Zone Mean Hydraulic Gradient}

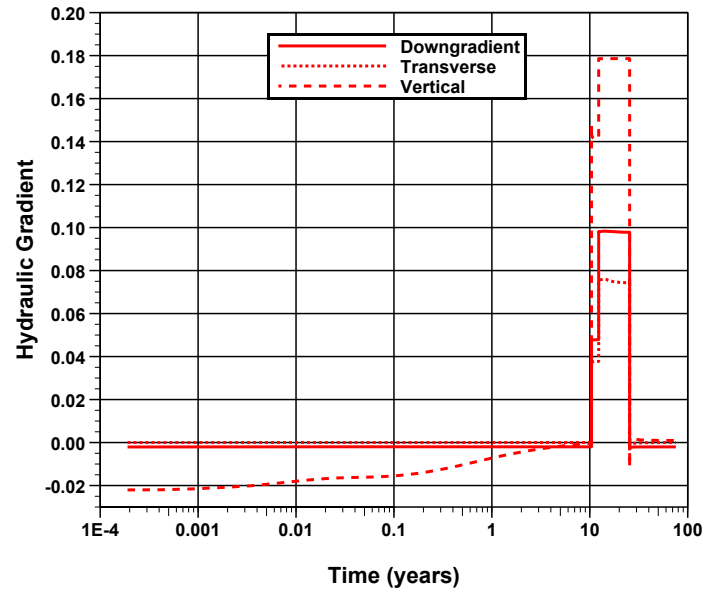

(c)
Lower Chimney Mean Hydraulic Gradient

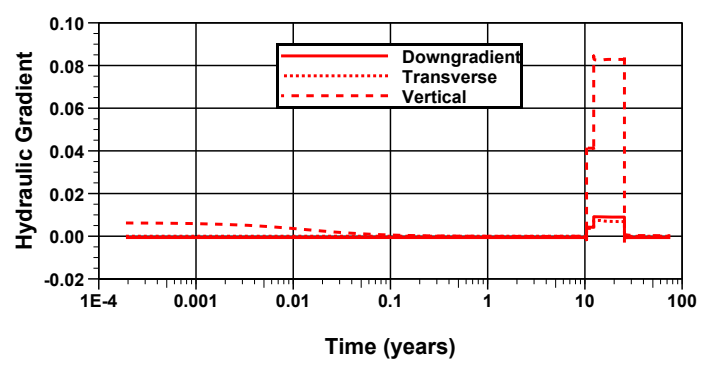

(d)

Figure 4.38 NUFT simulation of downgradient, transverse, and vertical components of mean hydraulic gradient through the (a) melt glass zone, (b) cavity, (c) compressed zone, and (d) lower chimney. 


\subsubsection{Flow Velocities}

Advection is the most dominant transport mechanism in groundwater for more mobile radionuclides. Groundwater flow velocities in the vicinity of CAMBRIC are expected to vary over time as a result of residual test heat and the effects of the RNM experiment, particularly pumping at RNM-2S and discharge at the CAMBRIC ditch.

For a given hydraulic gradient at constant temperature and pressure, flow velocities will vary proportionately to hydraulic conductivity and inversely proportionately to porosity. Permeabilities of alluvium are known to vary by over two orders of magnitude in shallow alluvium in Frenchman Flat according to pump test data (Figure 4.3, Stoller-Navarro, 2004b). Therefore, intermediate- and small-scale heterogeneities in permeability will cause considerable variation in flow velocity within the alluvial aquifer system in Frenchman Flat. Variations in porosity will have lesser impact on variations in flow velocity because porosity in alluvium does not vary as much as permeability. Additionally, lower porosity in alluvium typically correlates with lower permeability (except for clays) leading to a partial canceling effect on impact to flow velocity.

\subsubsection{Flow Velocities in Alluvium}

Under ambient conditions, NUFT simulation flow velocities in the upper alluvium below the water table (Layers 2-8) largely reflect the variation in permeability of the alluvial layers. Figure 4.39 shows a cross section oriented along a downgradient (northeast) vertical plane located through the CAMBRIC working point. Flow velocity vectors are largely pointed toward the downgradient direction, and flow velocity magnitudes are generally proportionate to layer permeability. The heterogeneity associated with the CAMBRIC altered zones causes some velocity variation near the CAMBRIC test. As discussed in Section 4.4.5.1, the ambient flow field is used as an initial condition prior to adding residual heat associated with the CAMBRIC test.

Figure 4.40 shows the effect of adding test-related heat on changing the flow velocity field. The changes in flow velocities between the ambient flow field (Figure 4.39) and the flow field $60 \mathrm{~s}$ after adding residual heat (Figure 4.40) are entirely caused by thermal effects. The test-related heat causes changes in flow velocities within tens of meters of the CAMBRIC altered zones. The effects of test heat on the flow velocity field are relatively minor compared to the effects from pumping at RNM-2S. Effects of test heat on flow velocities are examined in more detail in Sections 4.6.6.2 and 4.7.

Figure 4.41 shows the impact of pumping at RNM-2S on changing the flow velocity field. The changes in flow velocities between the ambient flow field (Figure 4.39) and the flow field $25 \mathrm{y}$ after the CAMBRIC test reflect the impact of pumping from RNM-2S for about $13 \mathrm{y}$ at a rate of $600 \mathrm{gpm}$. The pumping causes convergence of flow toward the RNM-2S slotted interval, which straddles Layer 4. RNM-2S is located about $72 \mathrm{~m}$ in the ambient upgradient direction (southwest) of the CAMBRIC working point. However, the pumping at RNM-2S causes large changes in the groundwater flow direction relative to ambient conditions. Relative to ambient conditions in Layers 2-6 near CAMBRIC, the horizontal component of flow velocity is largely reversed in direction, and flow velocity magnitudes are increased, particularly in Layers 3, 4, 5, and 6. 


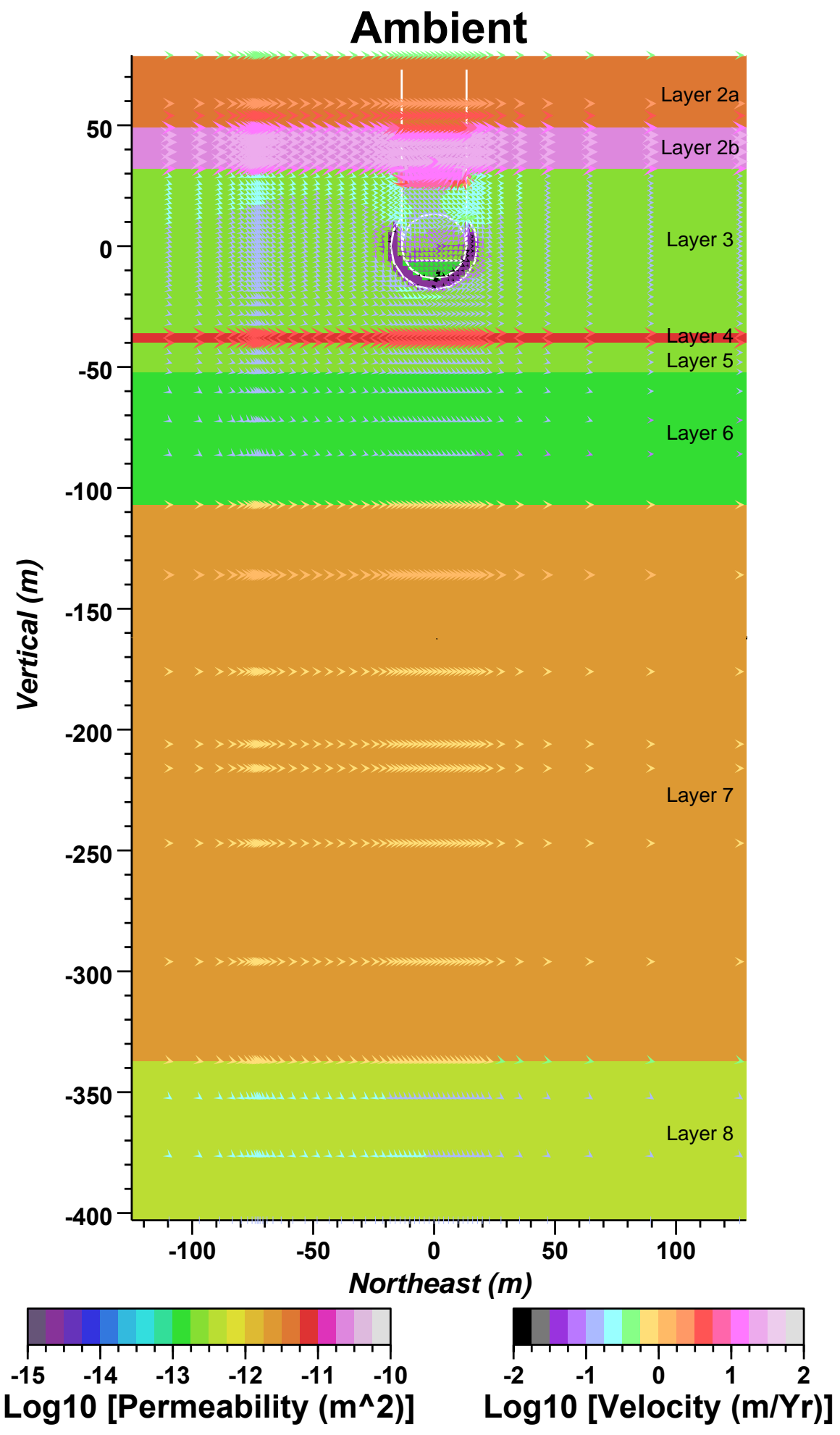

Figure 4.39 Cross section through the downgradient plane of NUFT simulation showing ambient flow velocity vectors overlain on permeability field. 


\section{0 s After Initial Condition, With Heat}

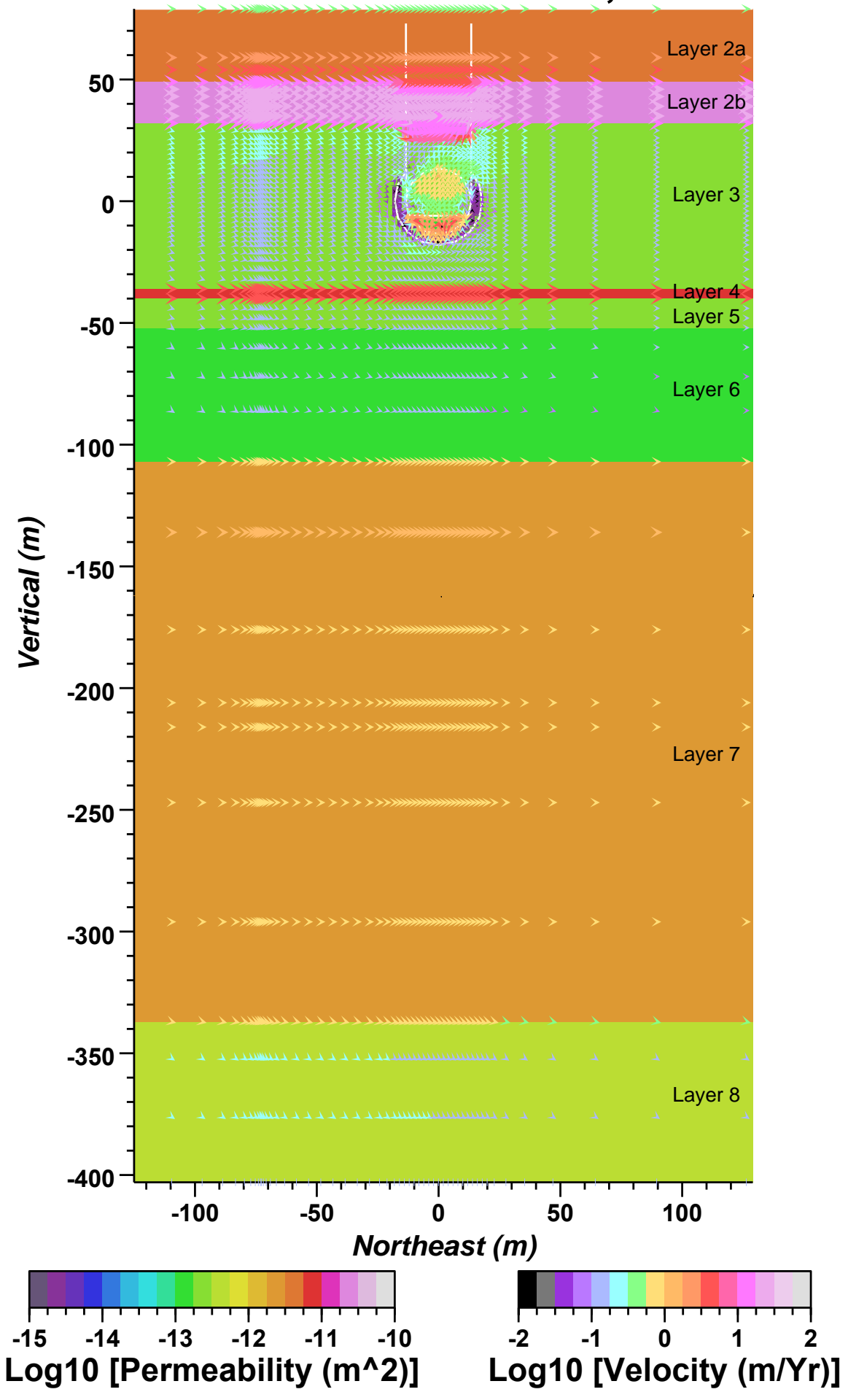

Figure 4.40 Cross section through the downgradient plane of NUFT simulation showing flow velocity vectors overlain on permeability field at $60 \mathrm{~s}$ after initializing residual heat associated with the CAMBRIC test. 


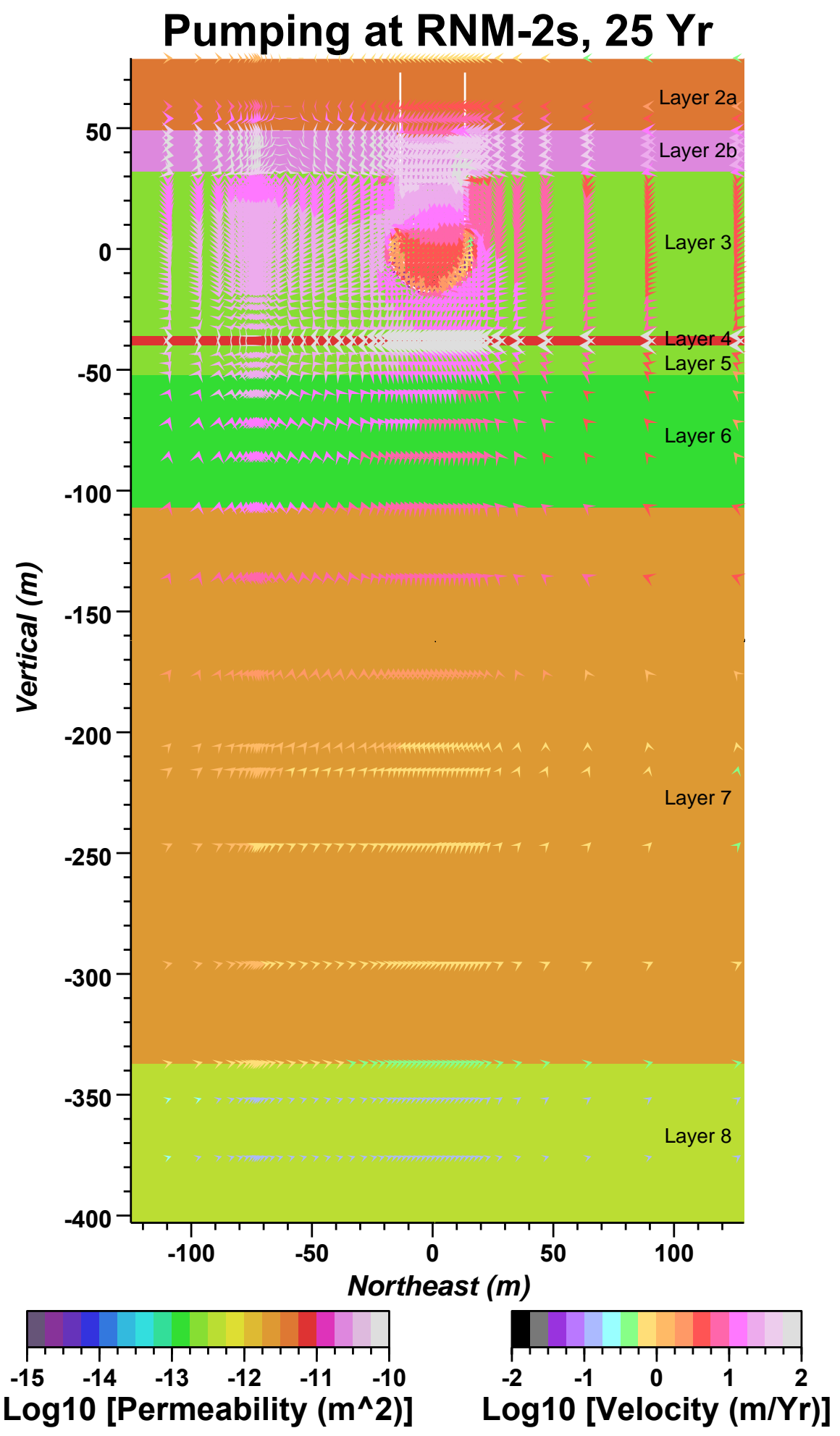

Figure 4.41 Cross section through the downgradient plane of NUFT simulation showing flow velocity vectors overlain on permeability field at $25.5 \mathrm{y}$, near the end of the 600 -gpm pumping stage at RNM-2S. 
In regard to long-term transport of relatively nonreactive radionuclides such as ${ }^{3} \mathrm{H}$ and ${ }^{237} \mathrm{~Np}$, flow velocities in the higher-permeability alluvium will be of greater concern because of the potential for greater transport distances. The alluvial layering hydrogeologic conceptual model provides a framework for investigating potential radionuclide transport distances in alluvial deposits with contrasting permeability. However, lateral continuity of the relatively higher-permeability alluvial layers is not well known. The relatively high-permeability alluvial layers (e.g., Layers 2 b and 4) could be localized within hundreds of meters of CAMBRIC. Nonetheless, the NUFT simulation of velocity variations in the layers provides useful insight into possible and realistic ranges of flow velocities in the Frenchman Flat alluvial deposits.

The RNM experiment also causes considerable variation in groundwater flow velocity in the alluvial deposits. Pumping at RNM-2S produces a large cone of depression at RNM-2S with convergent flow toward Layer 4. Secondly, infiltration to the water table of discharge from the ditch produces a mounding of the water table below the ditch. The mounding raises the water table at least $0.6 \mathrm{~m}$ at some locations as evident from water level measurements at UE-5n. Both the NUFT and ParFlow flow simulations predict water table mounding of this magnitude. Eventually, the mounding induces hydraulic gradients higher than ambient conditions and, thus, produces higher groundwater flow velocities than ambient conditions. The transient mounding effect produces a mechanism for transporting contaminants introduced by the ditch discharge at flow velocities greater than ambient conditions. Note that the mounding effect is transient and decays after ditch discharge ceases. The NUFT and ParFlow flow simulations enable analysis of the cumulative impact of the mounding effect on radionuclide transport over time, both as the mounding develops and decays.

Flow velocities at the water table below the ditch will be particularly impacted by the mounding effect, because the mound will induce the greatest change in hydraulic head at the water table. Figure 4.42 plots NUFT simulation minimum, maximum, and average flow velocity over time below the water table in Layer $2 \mathrm{a}$ for the downgradient (NE), transverse (NW), and vertical (up) directions. Flow velocities between 0 and $10.4 \mathrm{y}$ largely represent ambient conditions. Flow velocities between 10.4 and 12.3 y reflect RNM-2S pumping at the 300-gpm state, and flow velocities between 12.3 and $15.5 \mathrm{y}$ reflect RNM-2S pumping at the 600-gpm stage. After $15.5 \mathrm{y}$, magnitudes of average flow velocities show increase related to superposition of the infiltration mounding effect in addition to the effects of RNM-2S pumping. After $15.5 \mathrm{y}$, infiltration has reached the water table. The flow velocity magnitudes continue to increase (as the mound builds) until $25.5 \mathrm{y}$ when pumping at RNM-2S ceases. After $25.5 \mathrm{y}$, the flow field rapidly recovers within weeks from effects of RNM-2S pumping, however, the mounding effects persist. The differences in flow velocities relative to ambient conditions after $25.5 \mathrm{y}$ are mostly related to the mounding effect, which impacts flow velocities near the water table for at least $10 \mathrm{y}$ after pumping at RNM-2S has ceased. However, most of the residual effects of water table mounding occur within about $5 \mathrm{y}$ after pumping at RNM-2S has ceased. As expected, the mounding effect increases downward velocity near the water table after RNM-2S pumping ceases. In the downgradient (NE) direction, the mounding effect increases average flow velocity to about $5 \mathrm{~m} / \mathrm{y}$ relative to the ambient flow velocity of about $3 \mathrm{~m} / \mathrm{y}$ and increases maximum downgradient flow velocity from about $10 \mathrm{~m} / \mathrm{y}$ relative to the ambient maximum flow velocity of about $4 \mathrm{~m} / \mathrm{y}$. The maximum flow 
velocities reflect flow velocities toward the center of the vertical section of Layer $2 \mathrm{a}$. The mounding effect also affects transverse velocities. The maximum transverse velocities after RNM-2S pumping ceases reflect flow directions that are northwest toward RNM-2S and parallel to the ditch. The mounding effect toward the southeast of the ditch is not analyzed in the NUFT simulations due to lack of grid resolution.

The mounding effect would likely affect flow velocities in Layer $2 \mathrm{~b}$ (located below Layer 2a) because permeability in Layer $2 \mathrm{~b}$ is higher than Layer 2a. Figure 4.43 shows NUFT simulation minimum, maximum, and average flow velocities in Layer $2 b$. Similar to the flow velocities for Layer $2 \mathrm{a}$, the mounding effect begins to impact the flow velocities in Layer $2 b$ after about $15 \mathrm{y}$. After pumping ceases at RNM-2S, Layer $2 b$ flow velocities also show residual effects of the water table mounding. Similar to Layer 2a, most of the mounding effects on flow velocity occur within $5 \mathrm{y}$ after pumping ceases at RNM-2S. Effects on vertical (up) direction flow velocities are less on Layer $2 \mathrm{~b}$ compared to Layer 2a. However, the magnitudes of change in lateral flow velocity are greater in Layer $2 \mathrm{~b}$ than $2 \mathrm{a}$. In the downgradient (NE) direction, maximum flow velocities decrease from about 60 to $27 \mathrm{~m} / \mathrm{y}$, and average flow velocities decrease from about 35 to $23 \mathrm{~m} / \mathrm{y}$. In the transverse (NW) direction, maximum and average flow velocities decrease from about 30 and $12 \mathrm{~m} / \mathrm{y}$, respectively, to the ambient $0 \mathrm{~m} / \mathrm{y}$.

Figures 4.44-4.46 show downgradient (NE), transverse (NW) and vertical (up) NUFT simulation flow velocities at the approximated screened intervals for UE-5n, ER-5-4 piezometer, and ER-5-4 lower screened interval (the portion above the PCU1U confining unit). As discussed in Section 4.5.2.4, the NUFT simulation reproduces the water table mounding effect measured in UE-5n. Therefore, the NUFT simulation could be used to predict changes in flow velocity near UE-5n or other wells. ER-5-4 was not constructed until 12 y after pumping ceased at RNM-2S, so it is not likely to show evidence of residual water table mounding. The NUFT flow simulation indicates the water table mounding effect would significantly impact flow velocities near UE-5n, less at ER-5-4 piezometer, and very slightly at ER-5-4 lower screened interval. Thus, the mounding effect is greatest immediately downgradient of the ditch. The effect of water table mounding on flow velocities generally decreases with depth, except where a shallow, high-permeability zone such as Layer $2 \mathrm{~b}$ exists.

At locations near the water table, the NUFT simulations indicate that water mounding effects from the ditch discharge will significantly impact flow velocities for about 5 y after pumping ceases at RNM-2S. Noticeable changes in velocity persist beyond 5 to $10 \mathrm{y}$, but these are relatively small compared to ambient conditions. The changes in velocity persist according to the decay of the mounding. Water level measurements in UE-5n have monitored the buildup and decay of the mounding at that location. Both the NUFT and ParFlow simulations yield good calibration to the mounding observed at UE-5n. Therefore, the NUFT and ParFlow simulations provide realistic accounting for the effects of water table mounding on flow velocity change after RNM-2S pumping has ceased. 


\section{Water Table Velocities Along Length of Trench Downgradient (NE), Transverse (NW), Vertical (Up)}

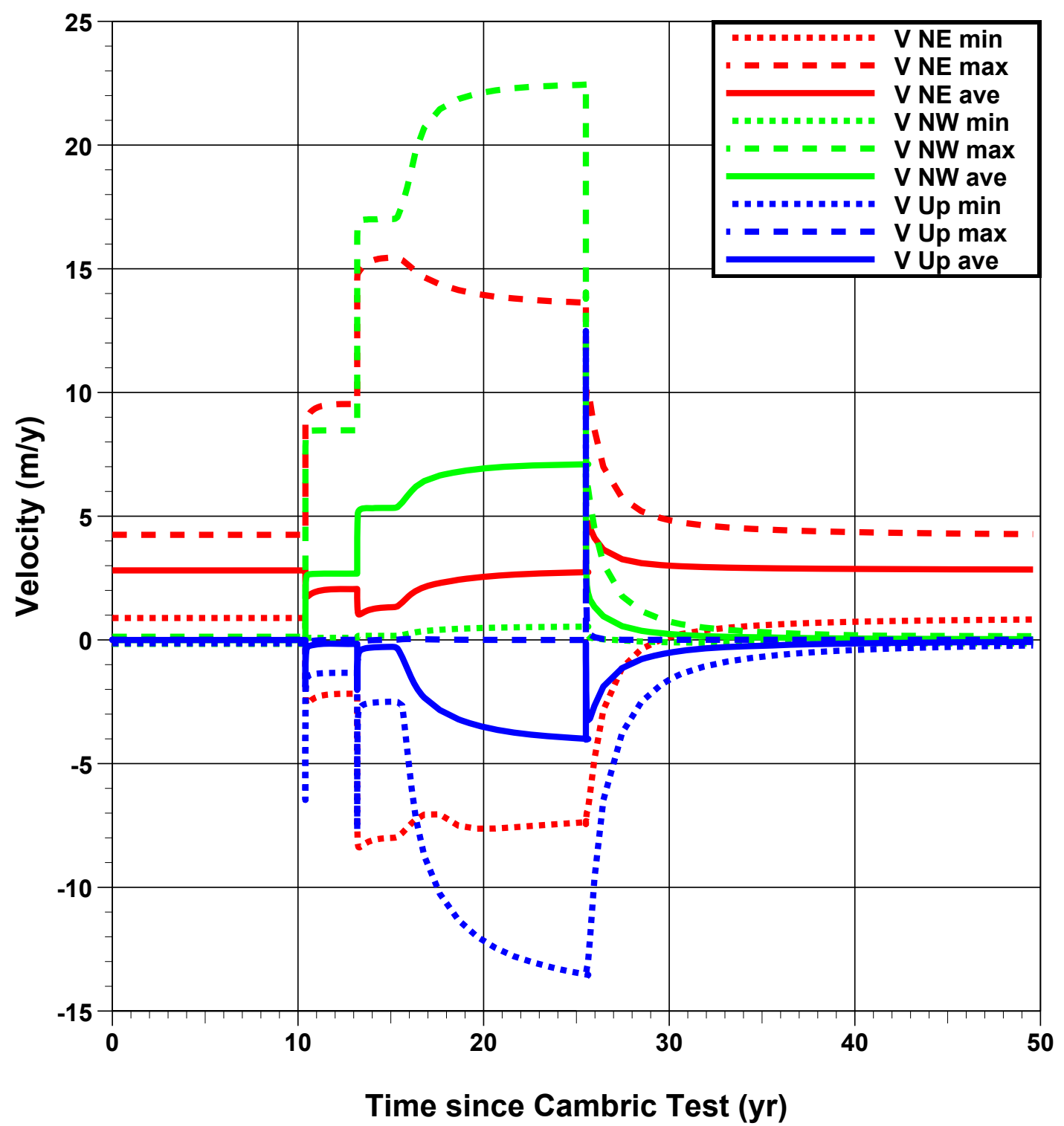

Figure 4.42 NUFT simulation of minimum, maximum, and average flow velocities near the water table in Layer $2 a$. 
Layer 2b Velocities Along Length of Trench Downgradient (NE), Transverse (NW), Vertical (Up)

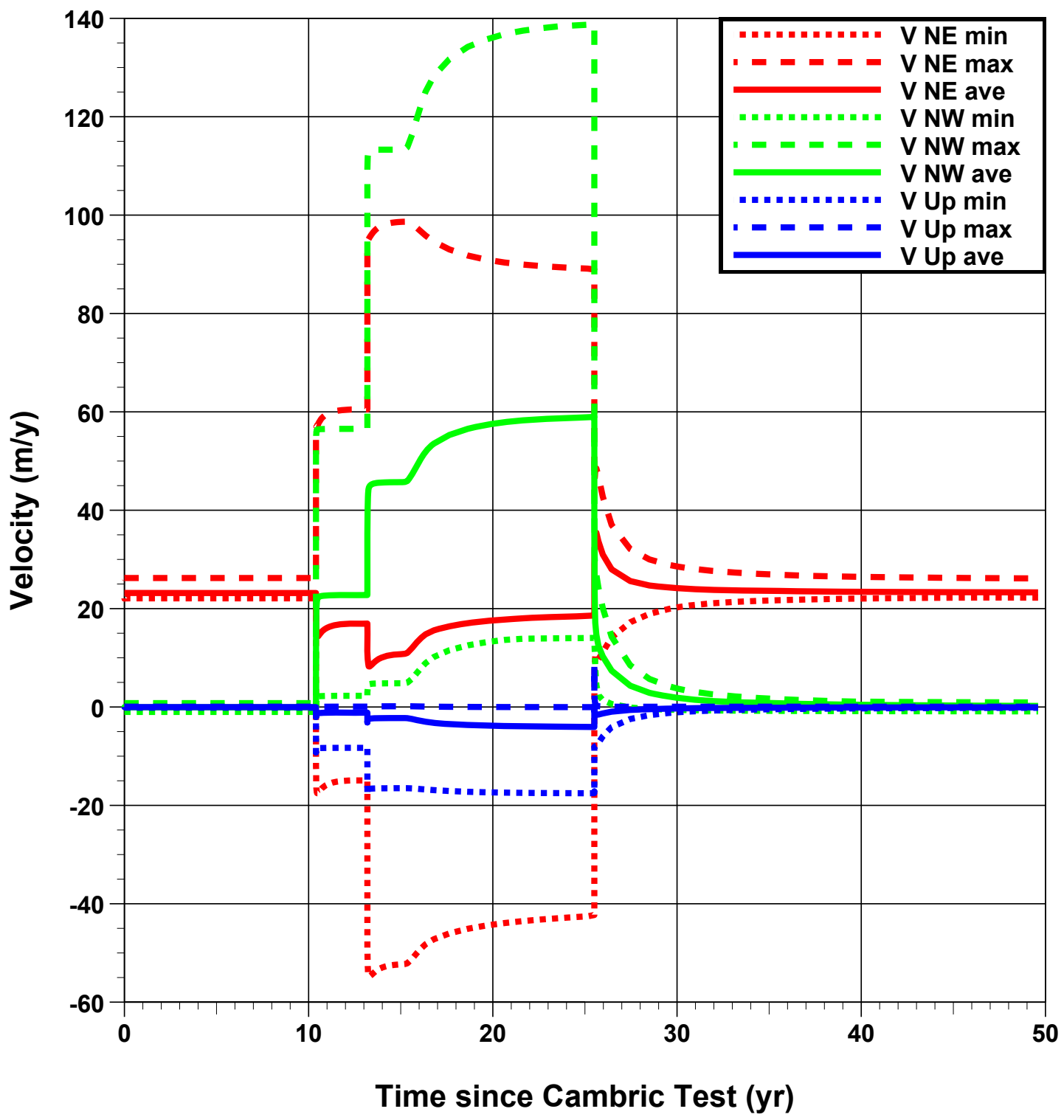

Figure 4.43 NUFT simulation of minimum, maximum, and average flow velocities in Layer $2 \mathrm{~b}$. 


\section{Downgradient (Northeast) Velocity}

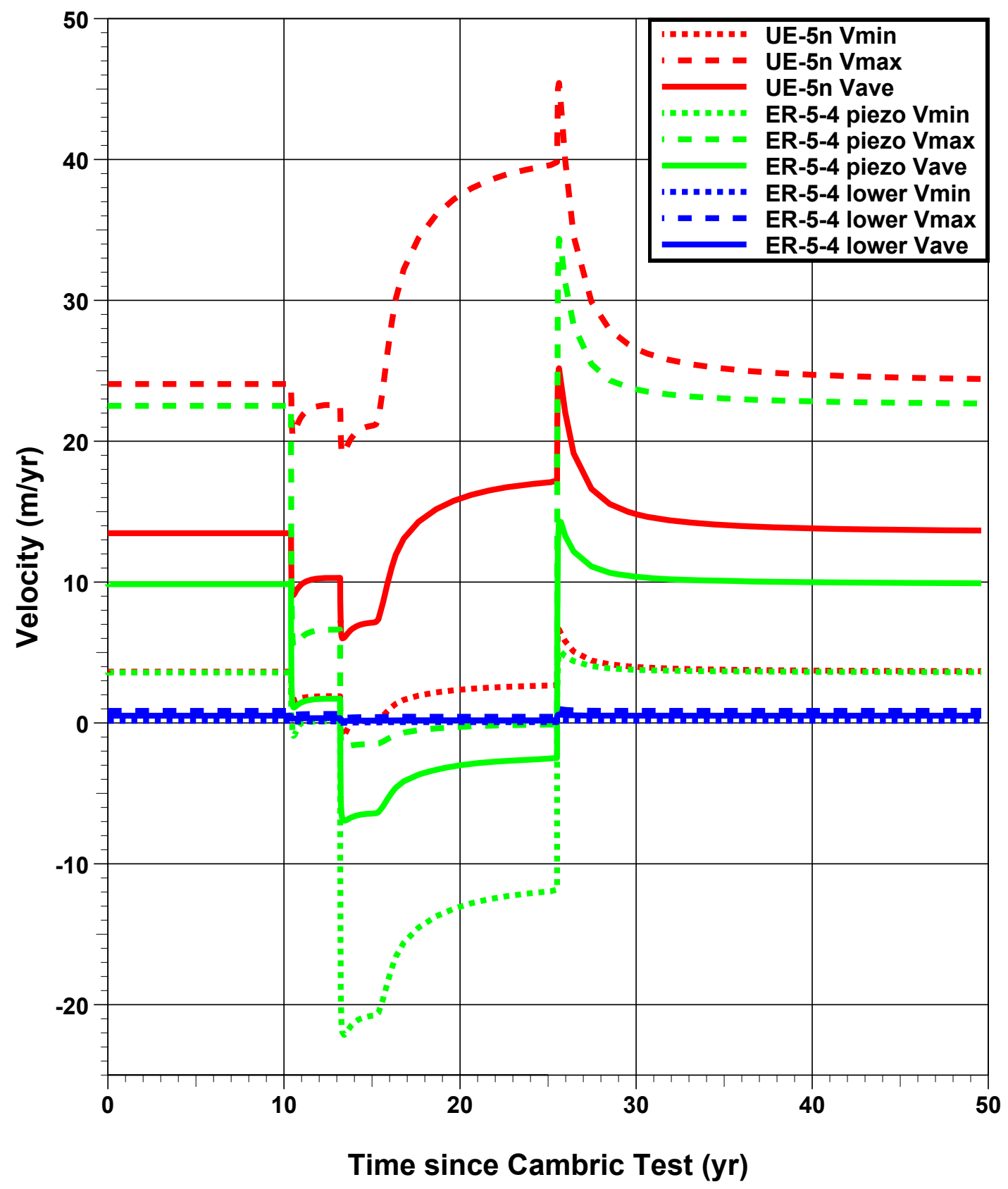

Figure 4.44 NUFT simulation of the downgradient (northeast) direction flow velocities near wells UE-5n, ER-5-4 piezometer, and ER-5-4 lower screened interval. 


\section{Transverse (Northwest) Velocity}

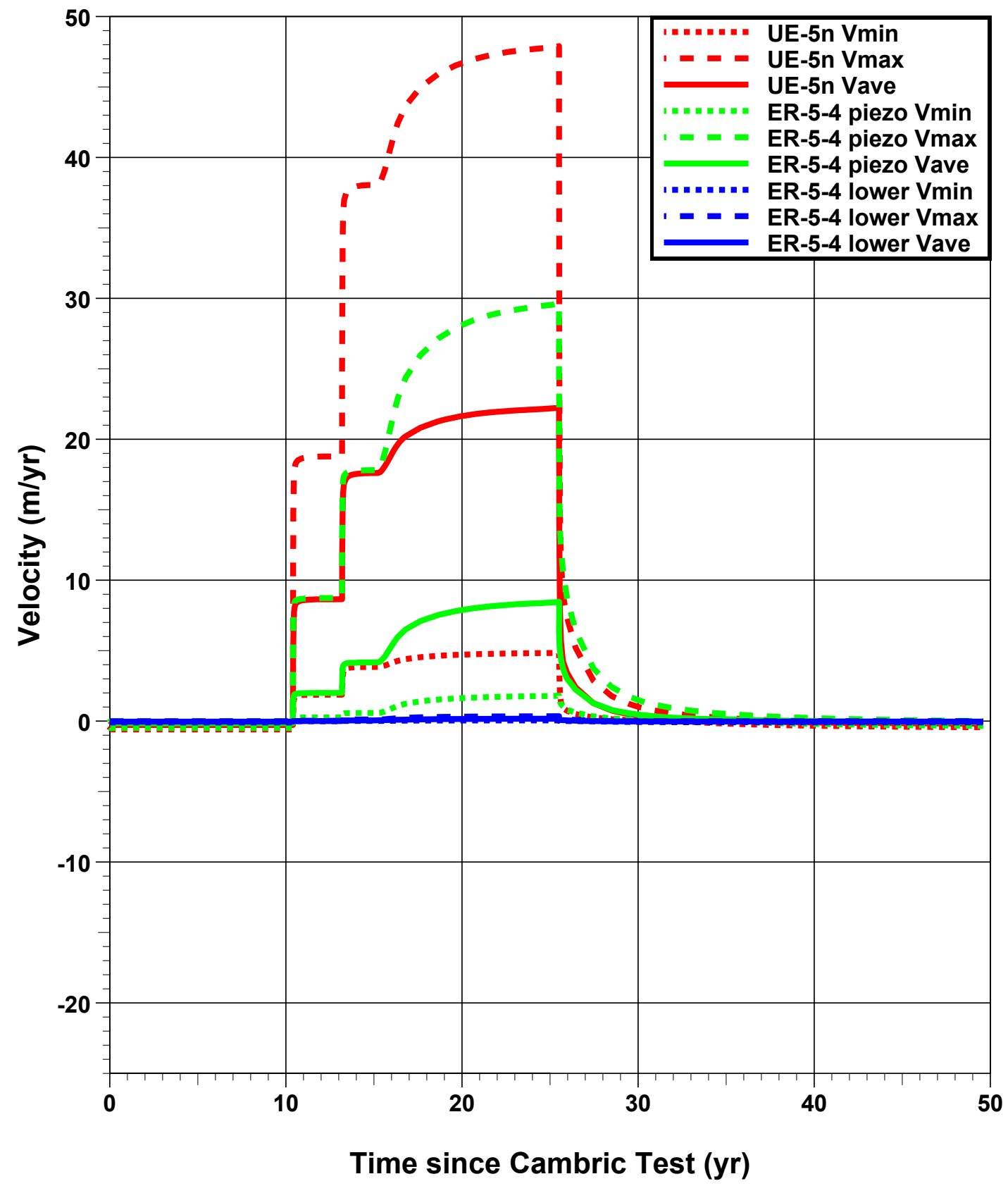

Figure 4.45 NUFT simulation of the transverse (northwest) direction flow velocities near wells UE-5n, ER-5-4 piezometer, and ER-5-4 lower screened interval. 


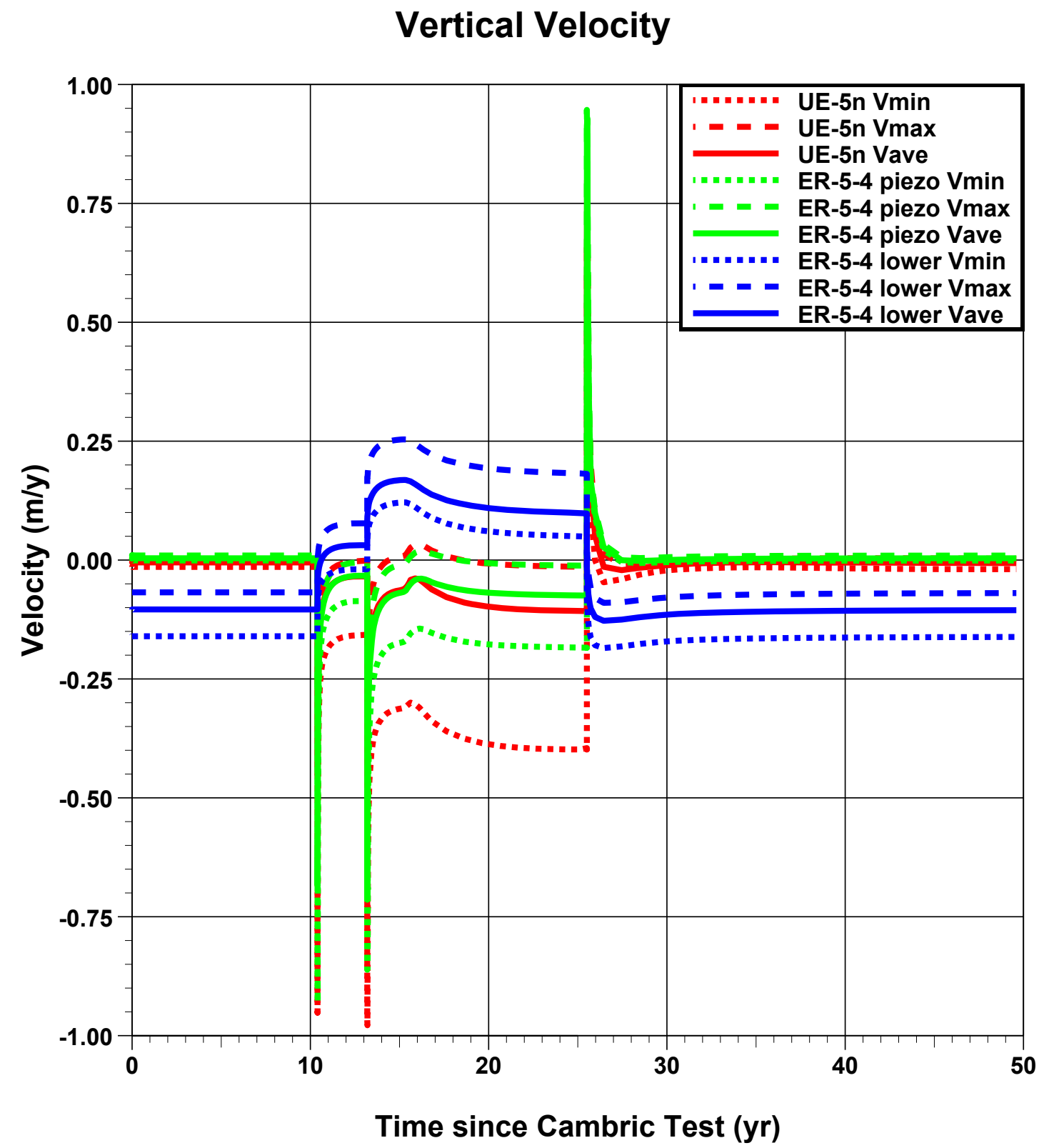

Figure 4.46 NUFT simulation of the vertical direction flow velocities near wells UE-5n, ER-5-4 piezometer, and ER-5-4 lower screened interval. 


\subsubsection{Flow Velocities in Altered Zones}

Flow velocities in the altered zones are affected by static and transient effects. The static effects are the permeability and porosity variations caused by the altered zones. Flow velocities in altered zones are also influenced by two transient effects: (1) test heat, and (2) pumping from RNM-2S. The effect of test heat is largely confined to within the $10.4 \mathrm{y}$ before pumping at RNM-2S begins. Between $10.4 \mathrm{y}$ and shortly after pumping at RNM-2S ceases, flow velocity in the altered zones is dominated by the RNM-2S pumping.

To help illustrate the relative effects of test heat and RNM-2S pumping of fluid flow, mean, minimum, and maximum flow velocity for the downgradient, transverse, and vertical directions are plotted on both linear and logarithmic time scale for each altered zone (Figures 4.47-4.50). The linear scale helps show the relative duration of the two transient effects, and the logarithmic scale helps resolve the time evolution of the thermal effects, which are relatively short-lived.

NUFT simulation melt glass zone mean, minimum, and maximum fluid velocity over time is plotted in Figure 4.47. The plots indicate that the largest flow velocities occur between about 0.01 and $0.1 \mathrm{y}$ as a result of test heat. However, the magnitude of mean flow velocities are either near zero (for downgradient and transverse directions) or smaller than RNM-2S pumping-related velocities (for vertical direction). The distribution of downgradient and transverse flow velocities compared to the distribution of vertical flow velocities indicates radial symmetry in the thermal effects on the melt glass zone. Before $0.1 \mathrm{y}$, mean vertical flow velocities are downward. The overall downward-direction flow before is related to increasing fluid density as melt glass zone cools relatively rapidly. Between 0.1 and $10 \mathrm{y}$, the mean fluid velocity in the melt glass zone is slightly upward, peaking out at less than $0.2 \mathrm{~m} / \mathrm{y}$ at about $0.35 \mathrm{y}$. The range of variation remains much larger than the mean velocity.

NUFT simulation of cavity velocity over time is plotted in Figure 4.48. Any significant effects of test heat on flow velocity in the cavity occur within $10 \mathrm{y}$. Maximum velocity magnitudes occur within $0.001 \mathrm{y}$ (within $\sim 8 \mathrm{~h}$ ). Test heat produces symmetric effects in the horizontal directions, whereas the vertical velocity distribution is asymmetric. The vertical asymmetries relate to the altered zone geometry and permeability variation and the gravity vector. Mean vertical velocities are negative before $0.2 \mathrm{y}$. The largest maximum vertical velocities occur at about $0.3 \mathrm{y}$. Pumping at RNM-2S produces sustained cavity flow velocities of several meters per year.

NUFT simulation compressed zone velocity over time is plotted in Figure 4.49. Test heat increases flow velocity in the compressed zone, but by only a few tenths of a meter per year within the first year after the CAMBRIC test. Pumping at RNM-2S produces sustained compressed zone flow velocities of as much as 1 to $2 \mathrm{~m} / \mathrm{y}$. However, these higher flow velocities occur mainly on the upper fringes of the compressed zone (Figure 4.49). Otherwise, compressed zone flow velocities are mostly within $1 \mathrm{~m} / \mathrm{y}$. 


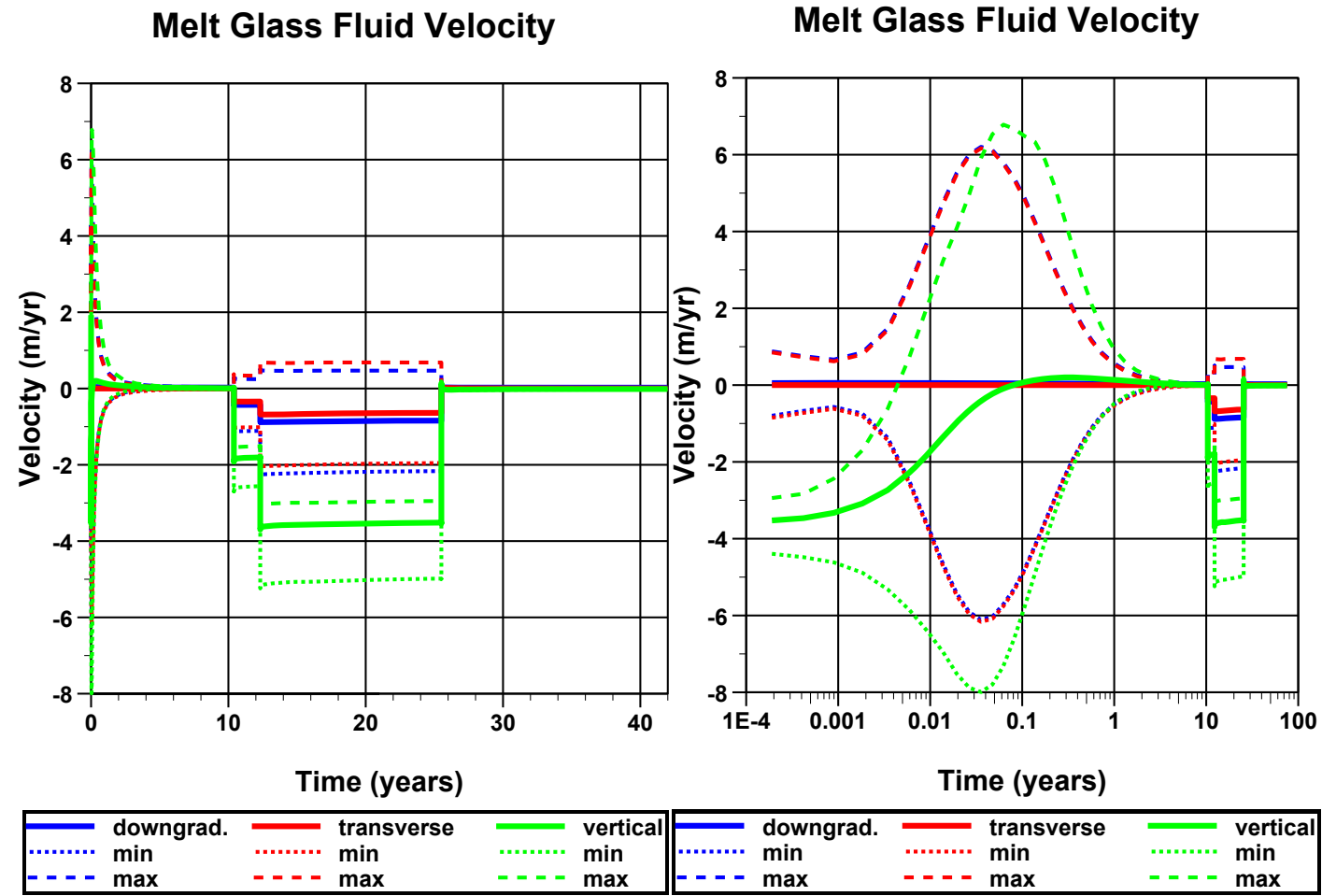

(a)

(b)

Figure 4.47 NUFT simulation of mean, minimum, and maximum fluid flow velocities for the downgradient (NE), transverse (SE), and vertical directions in the melt glass zone plotted on (a) a linear time scale and (b) a logarithmic time scale. 
Cavity Fluid Velocity

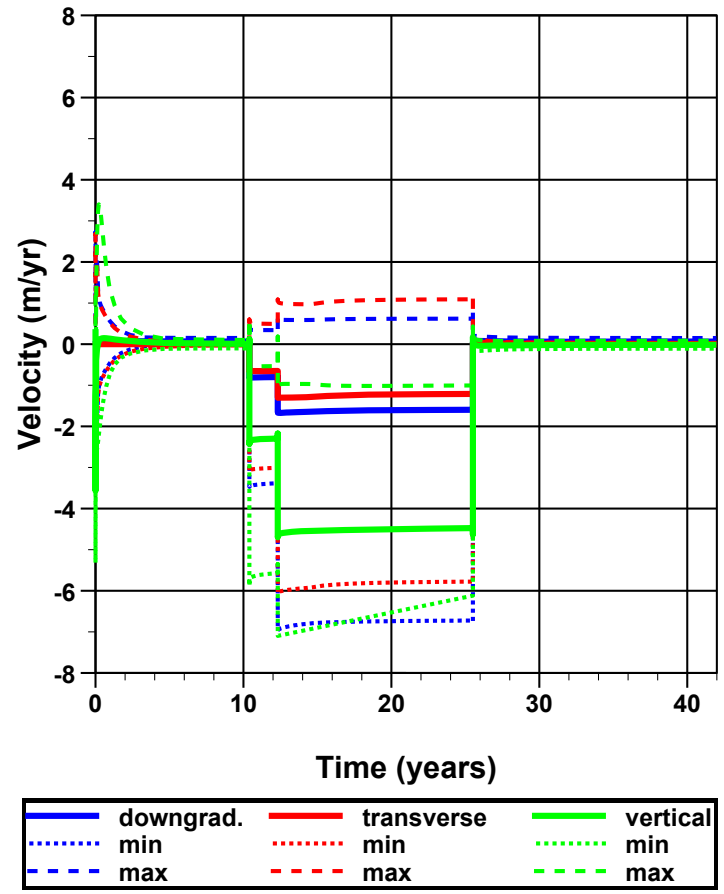

(a)
Cavity Fluid Velocity

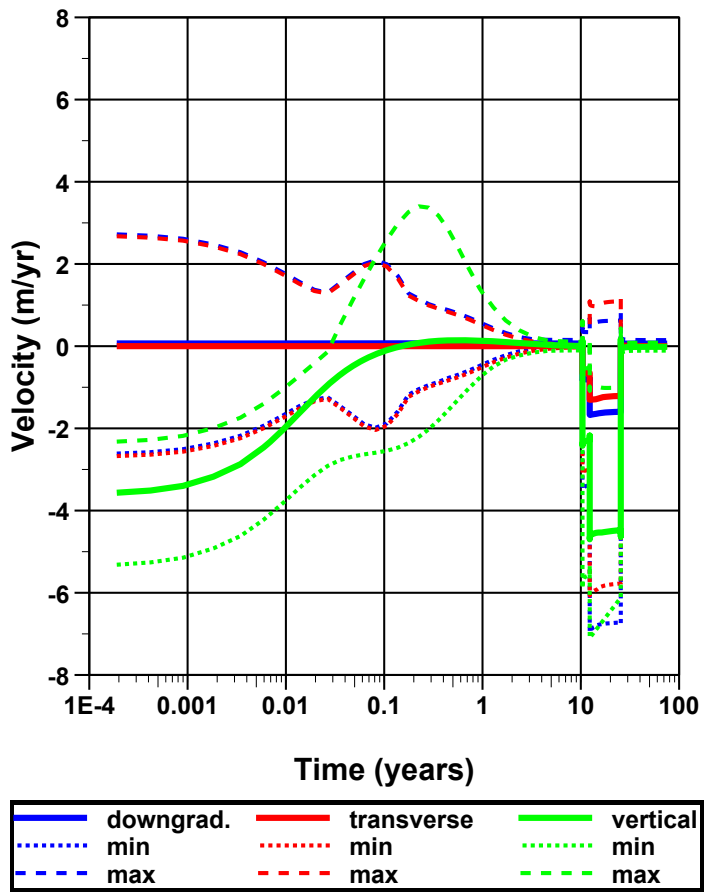

(b)

Figure 4.48 NUFT simulation of mean, minimum, and maximum fluid flow velocities for the downgradient (NE), transverse (SE), and vertical directions in the cavity plotted on (a) a linear time scale and (b) a logarithmic time scale. 
Compressed Zone Fluid Velocity

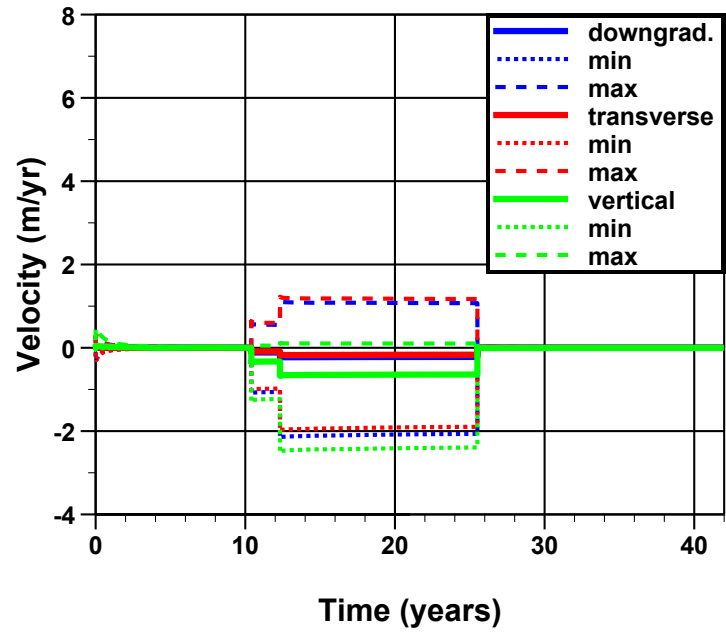

(a)

\section{Compressed Zone Fluid Velocity}

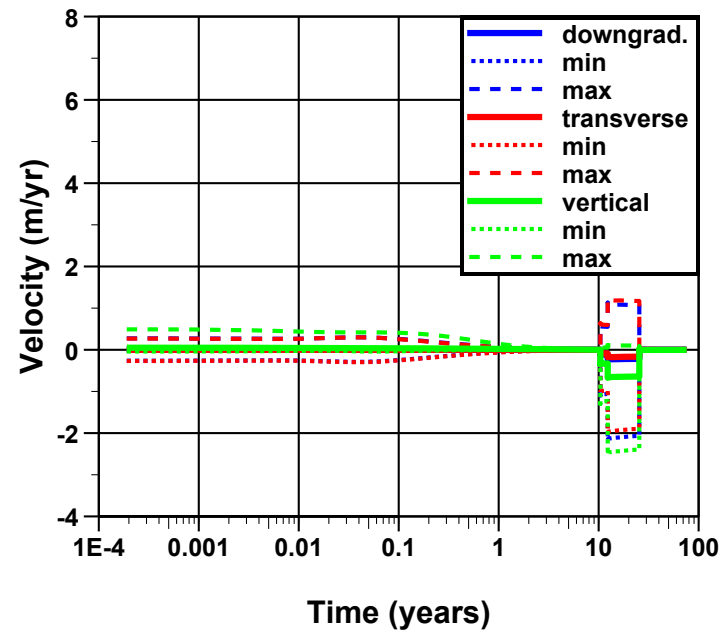

(b)

Figure 4.49 NUFT simulation of mean, minimum, and maximum fluid flow velocities for the downgradient (NE), transverse (SE), and vertical directions in the compressed zone plotted on (a) a linear time scale and (b) a logarithmic time scale.

\section{Lower Chimney Fluid Velocity}

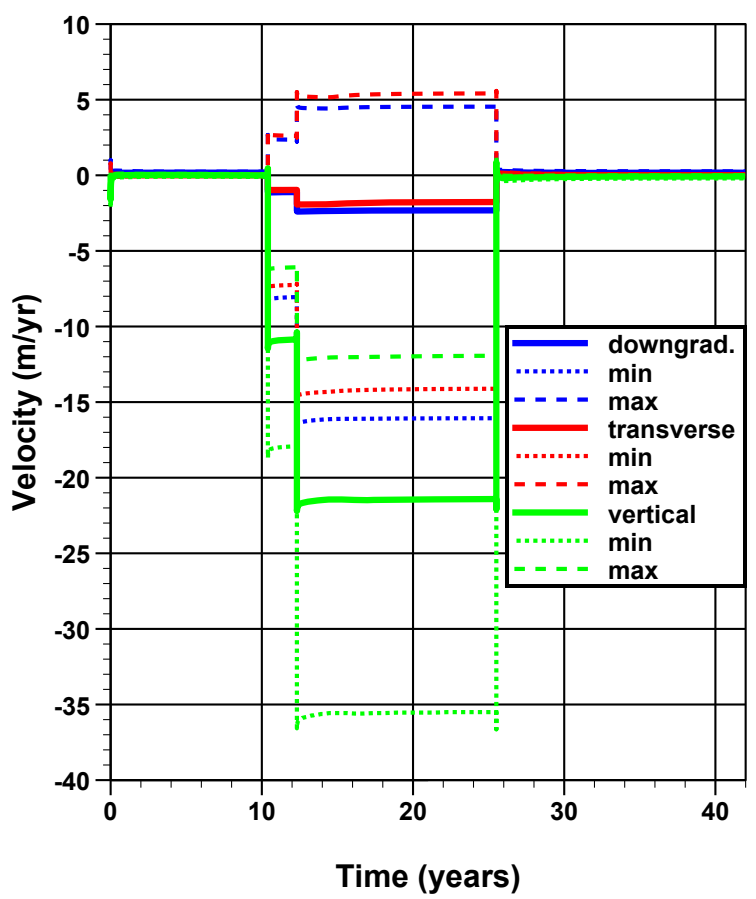

(a)

\section{Lower Chimney Fluid Velocity}

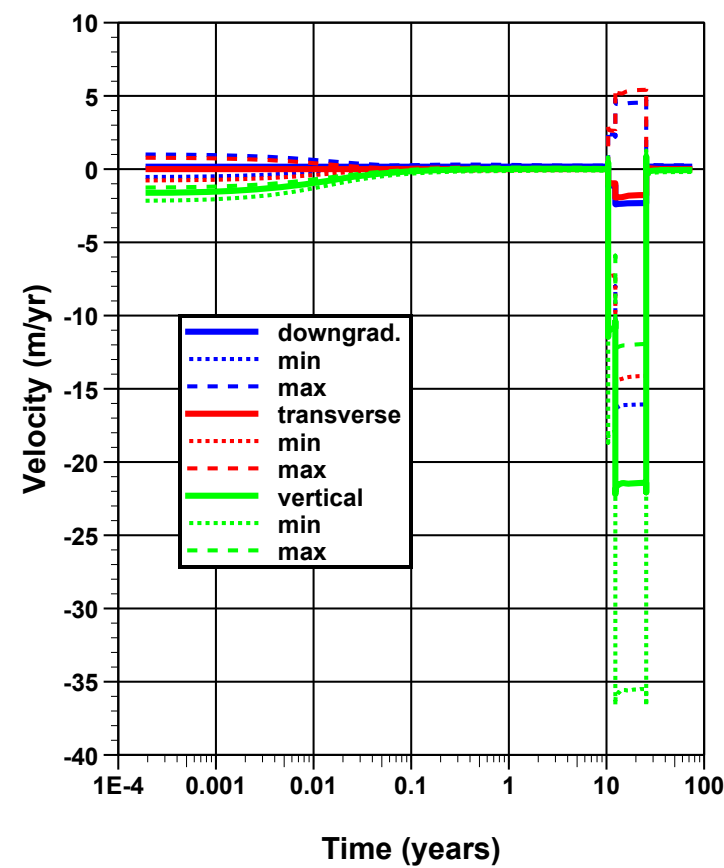

(b)

Figure 4.50 NUFT simulation of mean, minimum, and maximum fluid flow velocities for the downgradient (NE), transverse (SE), and vertical directions in the lower chimney plotted on (a) a linear time scale and (b) a logarithmic time scale. 
NUFT simulation of lower chimney flow velocity over time is plotted in Figure 4.50. Prior to $0.1 \mathrm{y}$, test heat induces downward flow in the lower chimney. This downward flow is part of an evolving thermal recirculation pattern illustrated in Figure 4.51. After $0.1 \mathrm{y}$, flow velocities within the lower chimney return to near-ambient conditions. Pumping at RNM-2S induces much stronger downward flow velocities (over $20 \mathrm{~m} / \mathrm{y}$ ) compared to thermal recirculation (up to 1 or $2 \mathrm{~m} / \mathrm{y}$ ) within $0.1 \mathrm{y}$. The flow simulations indicate the 16-y duration of pumping at RNM-2S would have flushed many pore-volumes of groundwater through the lower chimney, and this groundwater largely originated from the more-permeable Layer 2 as indicated by the simulated flow velocity fields shown in Figure 4.52. 


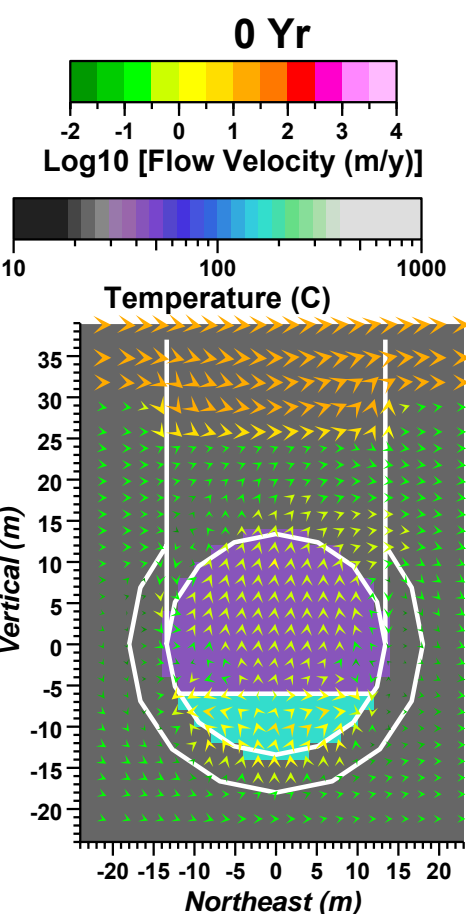

(a)

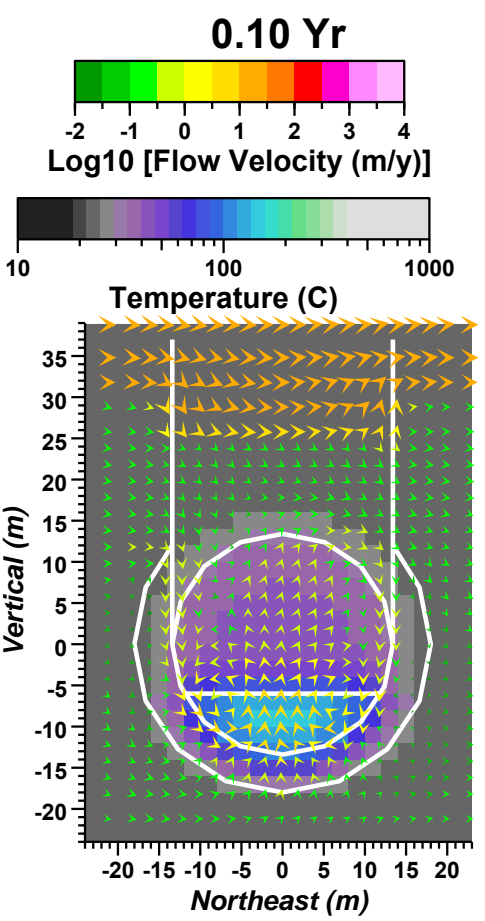

(d)

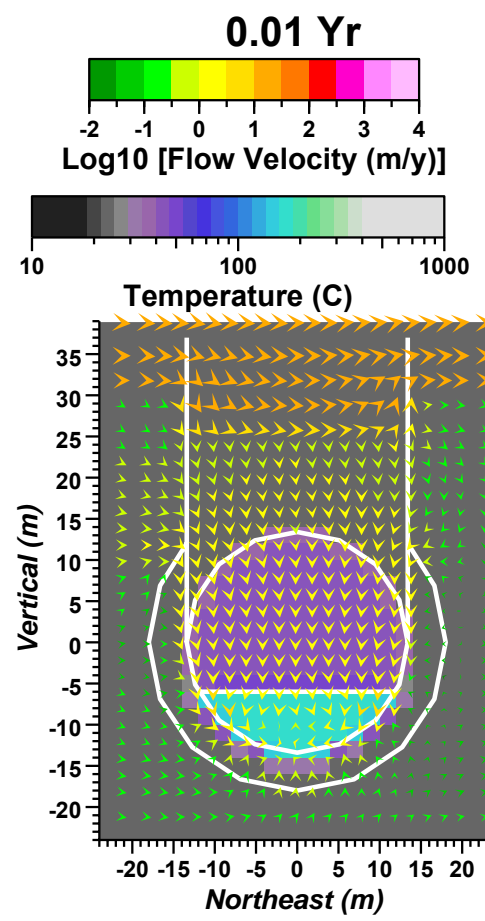

(b)
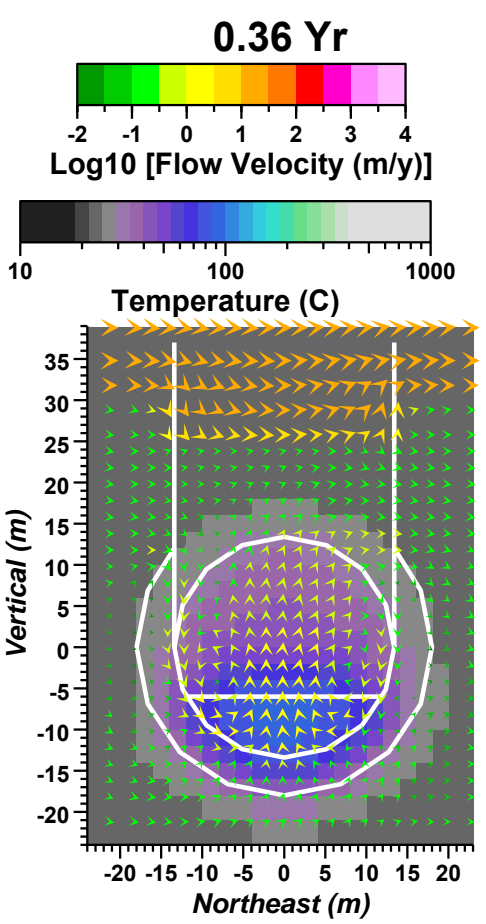

(e)

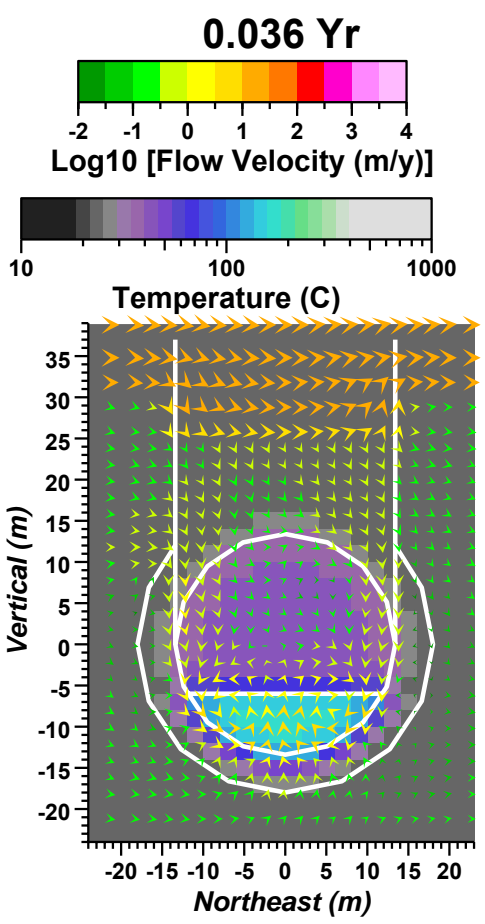

(c)
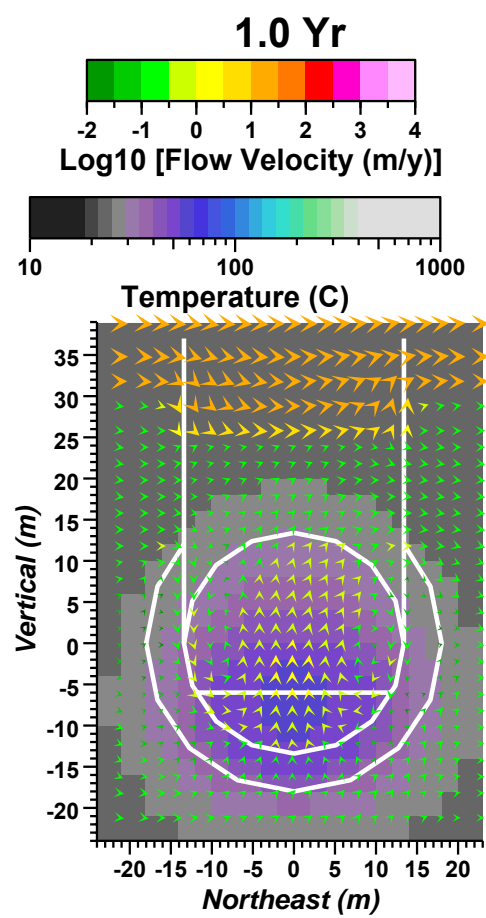

(f)

Figure 4.51 NUFT simulation of flow velocity superposed on temperature near altered zones at (a) $60 \mathrm{~s}$, (b) $0.01 \mathrm{y}$, (c) $0.036 \mathrm{y}$, (d) $0.10 \mathrm{y}$, (e) $0.36 \mathrm{y}$, and (f) $1.00 \mathrm{y}$. Arrows point in the direction of flow and arrow color indicates the magnitude of flow velocity. 
$3.3 \mathrm{Yr}$

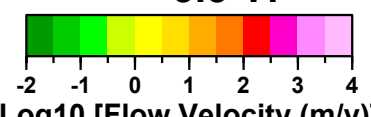

Log10 [Flow Velocity $(\mathrm{m} / \mathrm{y})$ ]
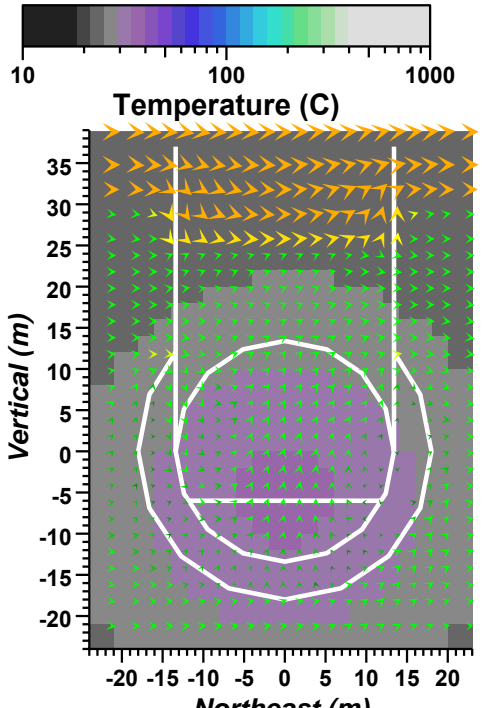

east $(m)$

\subsection{Yr}
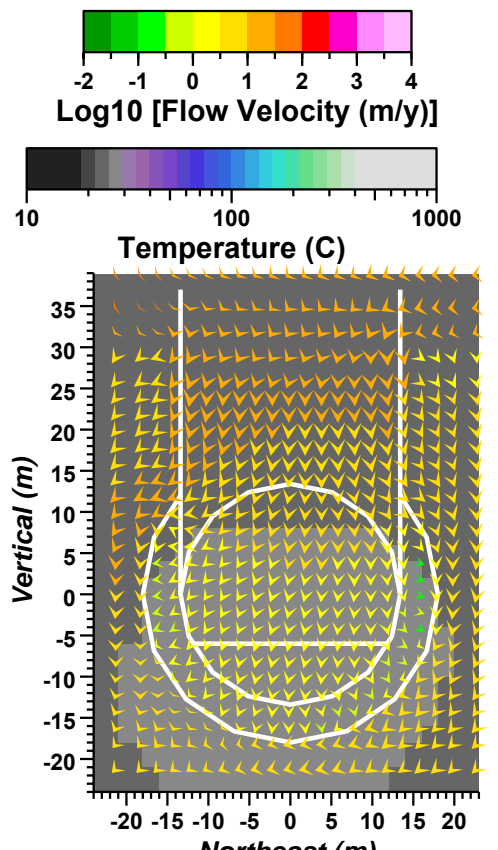

Northeast ( $m$ )

(c)
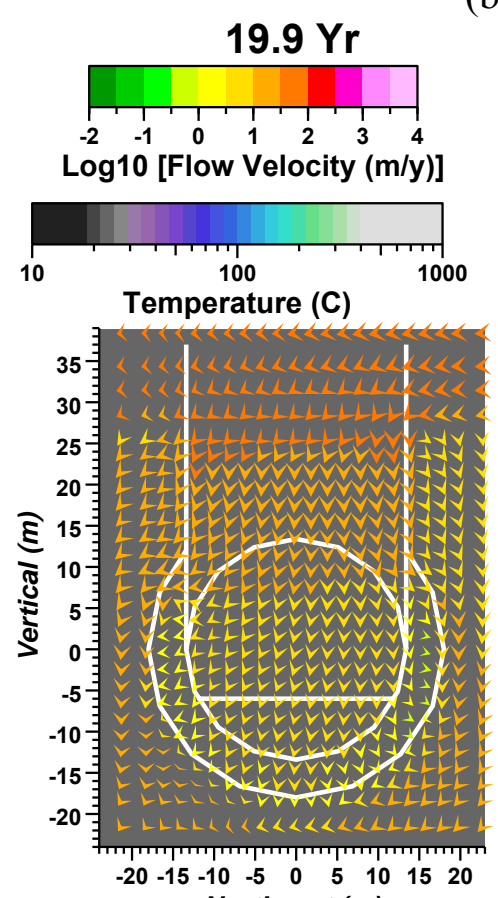

Northeast (m)

(d)
$10.0 \mathrm{Yr}$
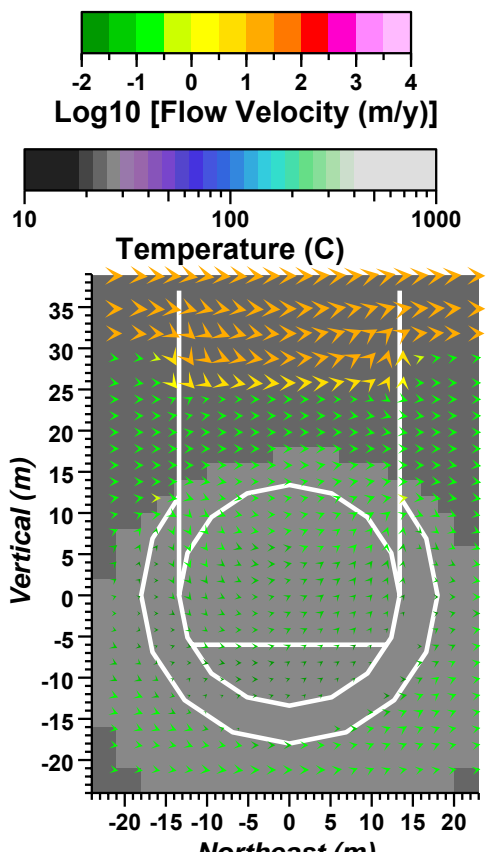

(b)

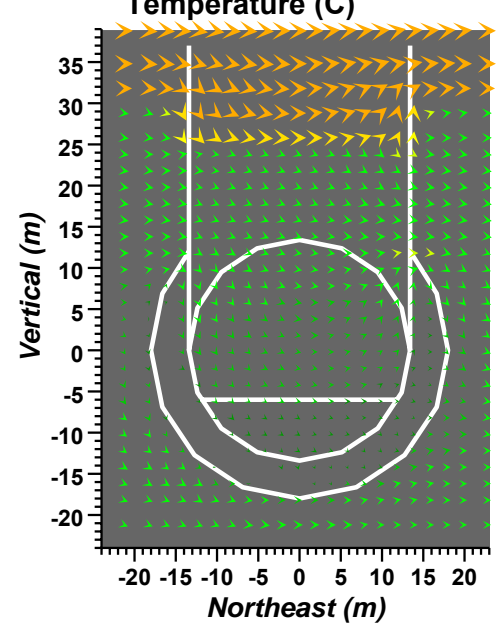

(e)

Figure 4.52 NUFT simulation of flow velocity superposed on temperature near altered zones at (a) $3.3 \mathrm{y}$, (b) $10 \mathrm{y}$, (c) $12.1 \mathrm{y}$, (d) $19.9 \mathrm{y}$, and (e) $50 \mathrm{y}$. Arrows point in the direction of flow and arrow color indicates the magnitude of flow velocity. 


\subsubsection{Flux to the Water Table}

Flux to the water table can be inferred from the NUFT simulations by integrating vertical flux along the cells positioned at the water table over time. However, time integration of water table vertical flux can be complicated by movement of the water table over time, particularly if the simulated water table moves vertically across different grid cells.

In the NUFT simulations, a 20-m-thick grid cell was positioned at the water table to prevent switching back and forth in time between one-phase and two-phase flow. This also simplifies measurement of vertical flux to the water table in the NUFT simulation because the simulated water table does not move out of this vertical cell in the vicinity of CAMBRIC. Thus, the NUFT simulation vertical flux to the water table can simply be integrated along this single 20 -m-thick layer of grid cells.

Figure 4.53 shows the NUFT simulation vertical flux of total water crossing the water table over time. The vertical flux is affected by pumping at RNM-2S and infiltration from ditch discharge. Pumping at RNM-2S induces downward flux at the water table that decays with time as the transient response to pumping in the saturated zone and drainage from the vadose zone approach states of equilibrium. Two stages of response in vertical flux to the water table due to pumping at RNM-2S are visible: (1) between 10.4 and $12.3 \mathrm{y}$, in response to the 300-gpm pumping stage, and (2) between 12.3 and approximately $15 \mathrm{y}$, in response to the 600-gpm pumping stage. After approximately $15 \mathrm{y}$, the downward flux to the water table increases in response to infiltration from ditch discharge. Soon after the infiltration reaches the water table, the flux to the water table is dominated by the infiltration instead of the direct effects of RNM-2S pumping. By $25 \mathrm{y}$, the simulated total flux at the water table reaches $20 \mathrm{~kg} / \mathrm{s}$, which equates to $317 \mathrm{gpm}$. The NUFT model input to the ditch is $21.2 \mathrm{~kg} / \mathrm{s}$. Thus, by $25 \mathrm{y}$, the NUFT model predicts that vertical flux to the water table is nearly equal to ditch discharge. By $25 \mathrm{y}$, the RNM experiment likely created a nearly equilibrated recirculation pattern from pumping at RNM-2S including:

- Discharge in the ditch

- Downward flow (infiltration) through about $220 \mathrm{~m}$ of vadose zone

- Flux or "recharge" to the water table

- Partial recirculation of the ditch recharge by infiltration through a combination of Layers 2a, 2b, 3, and 4, and the RNM-2S gravel pack 


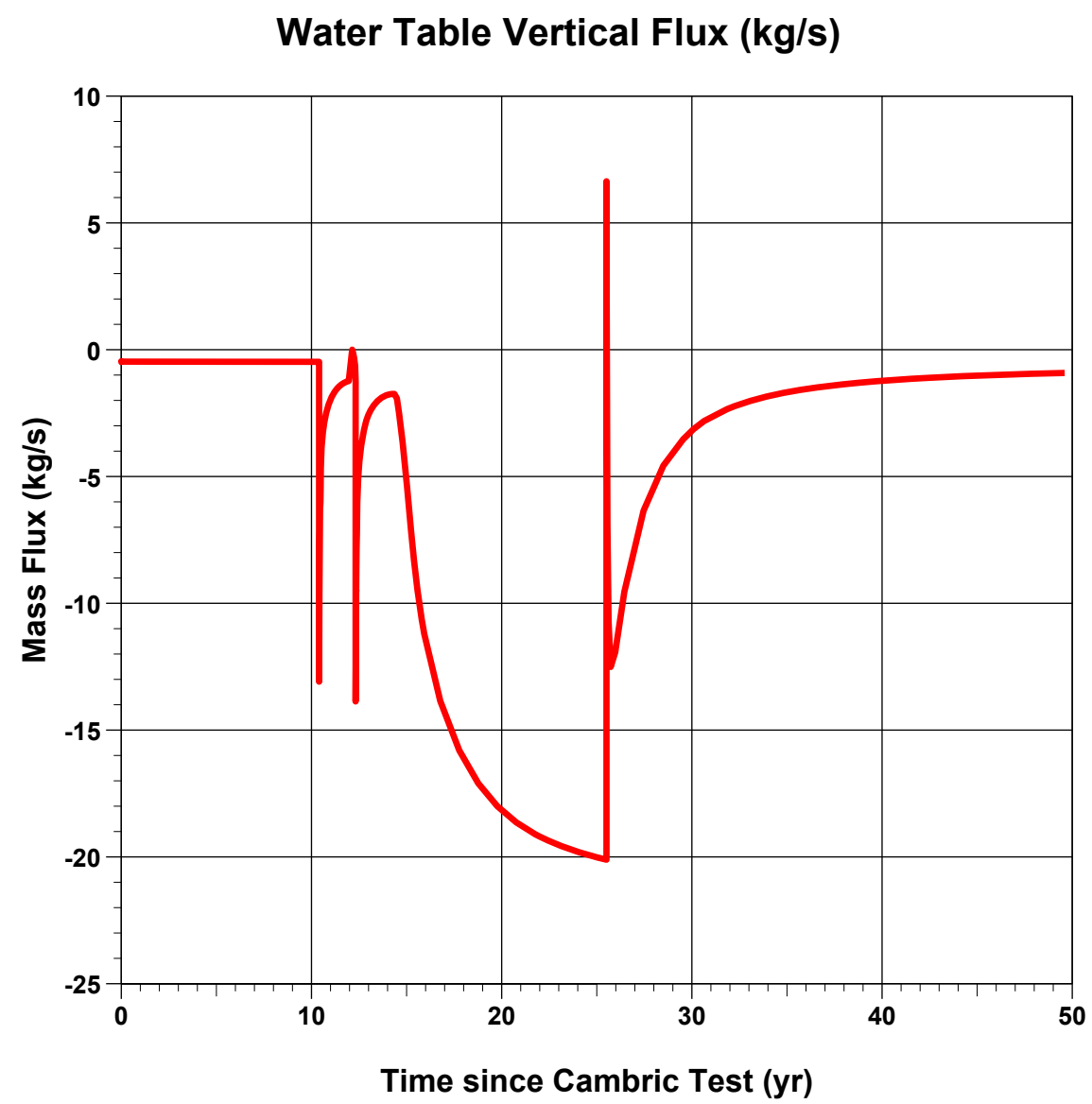

Figure 4.53 NUFT simulation vertical flux of total water crossing water table.

\subsubsection{Tritium Transport Characteristics}

Tracer tests, measurement of in-situ tracers (whether natural or man-made), and tracer simulation provide insights into patterns of groundwater flow and transport. The spatial extent of transport for a nonreactive tracer yields a measure of maximum possible extent of contamination originating from a source volume, such as the CAMBRIC test. At the CAMBRIC site, several factors would lead to increase the spatial extent of tracer transport originating from CAMBRIC, relative to advective transport in an ambient flow field:

- Molecular diffusion

- Dispersion, including macrodispersion from heterogeneity

- Variably saturated flow (shape of saturation front)

- Test heat

- Pumping from RNM-2S

- Ditch discharge

The NUFT simulations factor in all of the above contributors (except for dispersion) to tracer spreading, while the ParFlow simulations factor all but test heat. In 
regard to overall tracer spreading at the CAMBRIC site, dispersion will be of greater significance than test heat. The NUFT simulations of transport are prone to numerical dispersion, particularly as the grid cells telescope out in the lateral directions. Effects of numerical dispersion are further examined in Section 4.7.4.

\subsubsection{NUFT Simulation of ${ }^{3} \mathrm{H}$ Transport}

Tritium released from CAMBRIC provides a useful tracer of groundwater originating in the melt glass zone, cavity, and compressed zone. As discussed in Section 4.5.2.1, ${ }^{3} \mathrm{H}$ breakthrough at RNM-2S was used, in part, to calibrate hydraulic properties for the NUFT and ParFlow simulations. NUFT and ParFlow/SLIM simulations of ${ }^{3} \mathrm{H}$ transport are useful to predict potential ${ }^{3} \mathrm{H}$ migration patterns under the influence of transient flow caused by test heat, RNM-2S pumping, and ditch infiltration.

The effects of test heat, RNM-2S, and ditch infiltration contribute to both lateral and vertical spreading of ${ }^{3} \mathrm{H}$. A NUFT simulation of decay-corrected ${ }^{3} \mathrm{H}$ transport was initialized with uniform concentration in the cavity, melt glass zone, and compressed zone. Figure 4.54 shows a cutaway view of NUFT simulation of ${ }^{3} \mathrm{H}$ transport at $10.4 \mathrm{y}$, when only residual test heat and ambient flow conditions affect groundwater flow. At $10.4 \mathrm{y}$, the simulated ${ }^{3} \mathrm{H}$ concentration shows most extensive transport occurring by upward migration into Layer $2 \mathrm{~b}$. Some lateral migration occurs downgradient of the cavity and melt glass zone.

RNM-2S pumping induces lateral and downward flow from the CAMBRIC altered zones toward Layer 4 (or other permeable intervals beneath CAMBRIC in hydraulic connection to RNM-2S) and the RNM-2S slotted interval. Infiltration introduces ${ }^{3} \mathrm{H}$ to the water table beneath the CAMBRIC ditch and beyond. The combined effect of infiltration and RNM-2S pumping vertically spreads ${ }^{3} \mathrm{H}$ between the water table and the slotted interval of RNM-2S. 


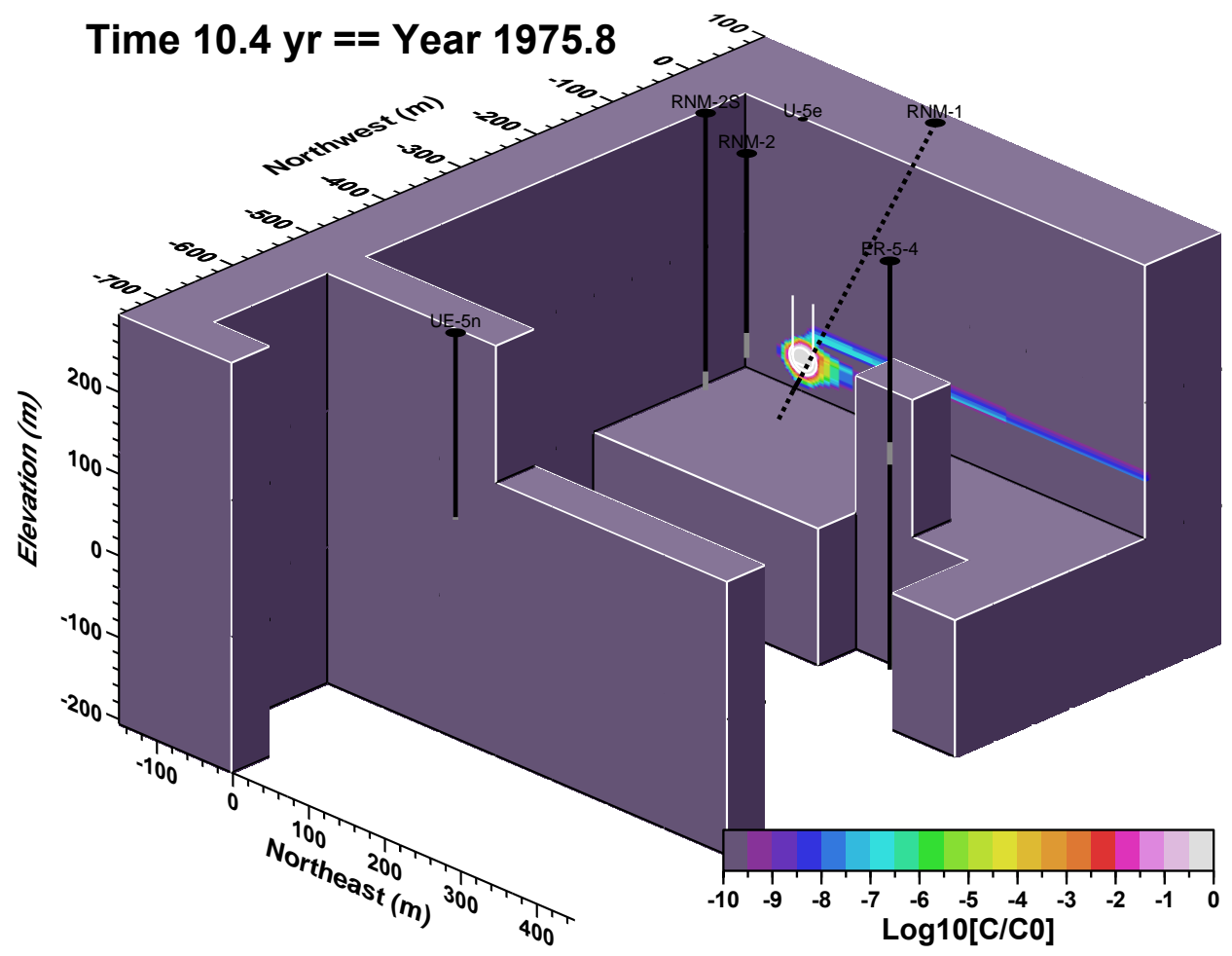

Figure 4.54 NUFT simulation of ${ }^{3} \mathrm{H}$ transport at 10.4 y (includes effects of decay).

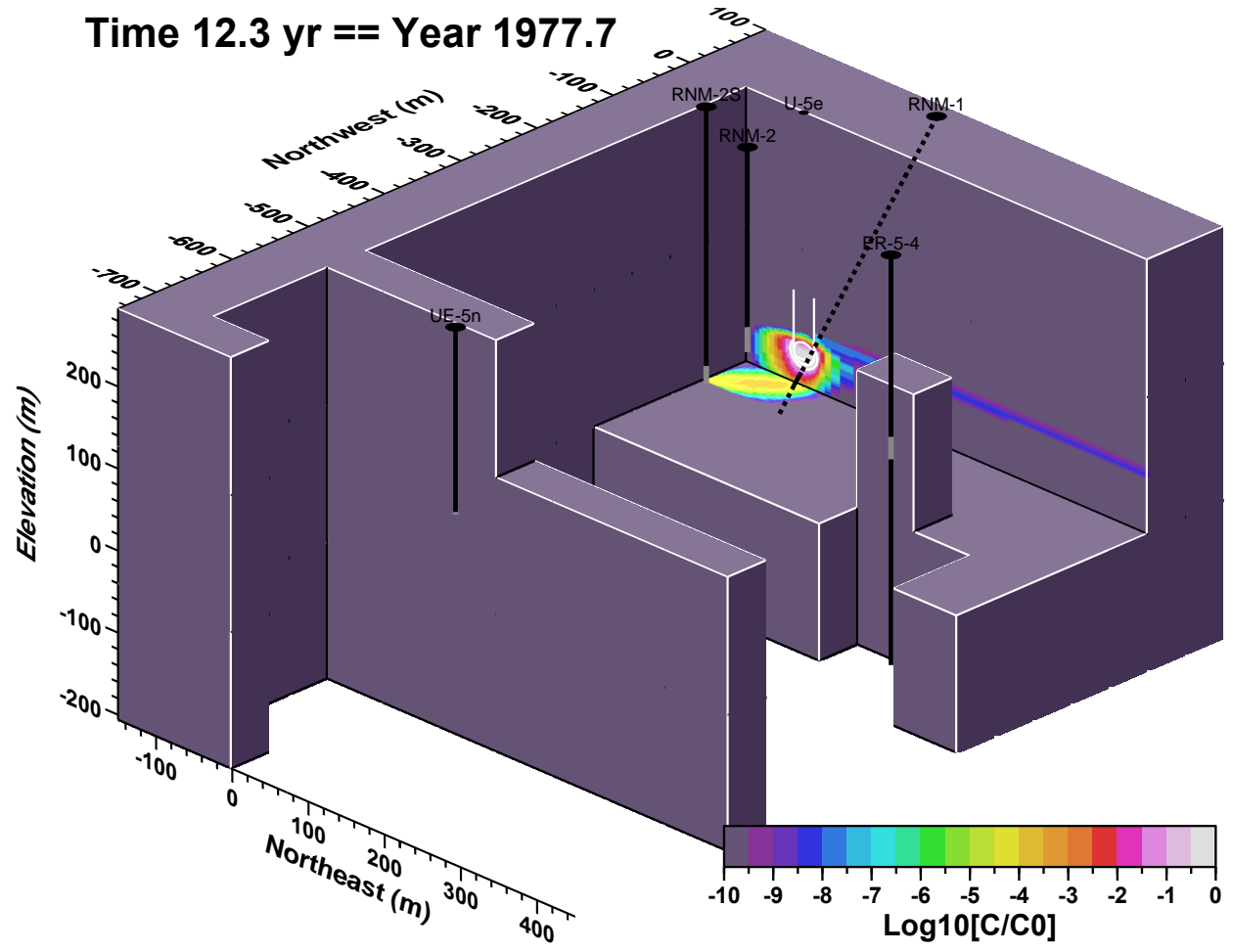

Figure 4.55 NUFT simulation of ${ }^{3} \mathrm{H}$ transport at $12.3 \mathrm{y}$ (includes effects of decay). 
By $12.3 \mathrm{y}$, the end of the 300 -gpm pumping stage at RNM-2S, ${ }^{3} \mathrm{H}$ originating from CAMBRIC begins to reach the slotted interval at RNM-2S (Figure 4.55). By $15.6 \mathrm{y}$, ${ }^{3} \mathrm{H}$ concentrations in RNM-2S have peaked. Meanwhile, ${ }^{3} \mathrm{H}$ that was discharged into the ditch after about $12.3 \mathrm{y}$ has reached the water table by $15.6 \mathrm{y}$ (Figure 4.56). By $25.5 \mathrm{y}$, near the end of the 600 -gpm RNM-2S pumping stage, ${ }^{3} \mathrm{H}$ has migrated hundreds of meters in Layer $2 \mathrm{a}$ and $2 \mathrm{~b}$ (Figure 4.57). Toward RNM-2S, the ${ }^{3} \mathrm{H}$ concentration is seen to progress downward through Layer 3 and adjacent to RNM-2S, suggesting that a fraction of ditch infiltration is being pumped by RNM-2S. After pumping at RNM-2S ceases, the pumping-induced cone of depression quickly rebounds, but the water table mounding caused by infiltration lasts for several years. The combination of ambient flow conditions and water table mounding influence ${ }^{3} \mathrm{H}$ transport. Groundwater flow velocities in Layers $2 \mathrm{a}$ and $2 \mathrm{~b}$, in particular, are temporarily boosted by the water table mound. Figure 4.58 shows NUFT simulation ${ }^{3} \mathrm{H}$ concentration at $50 \mathrm{y}$. Relative to $25.5 \mathrm{y}$, there is much more downgradient transport of ${ }^{3} \mathrm{H}$, mainly because RNM-2S no longer exerts a capture zone. Tritium concentrations in Layers $2 \mathrm{a}$ and $2 \mathrm{~b}$ decline due to dispersion and decay. Some relatively high ${ }^{3} \mathrm{H}$ concentrations occur in Layer 4 as the ambient flow conditions transport ${ }^{3} \mathrm{H}$ previously drawn toward RNM-2S. Notably, ${ }^{3} \mathrm{H}$ simulated in Layer 4 at ER-5-4 (25.5 y) is consistent with the observation of ${ }^{3} \mathrm{H}$ measured in ER-5-4 during drilling of the hole.

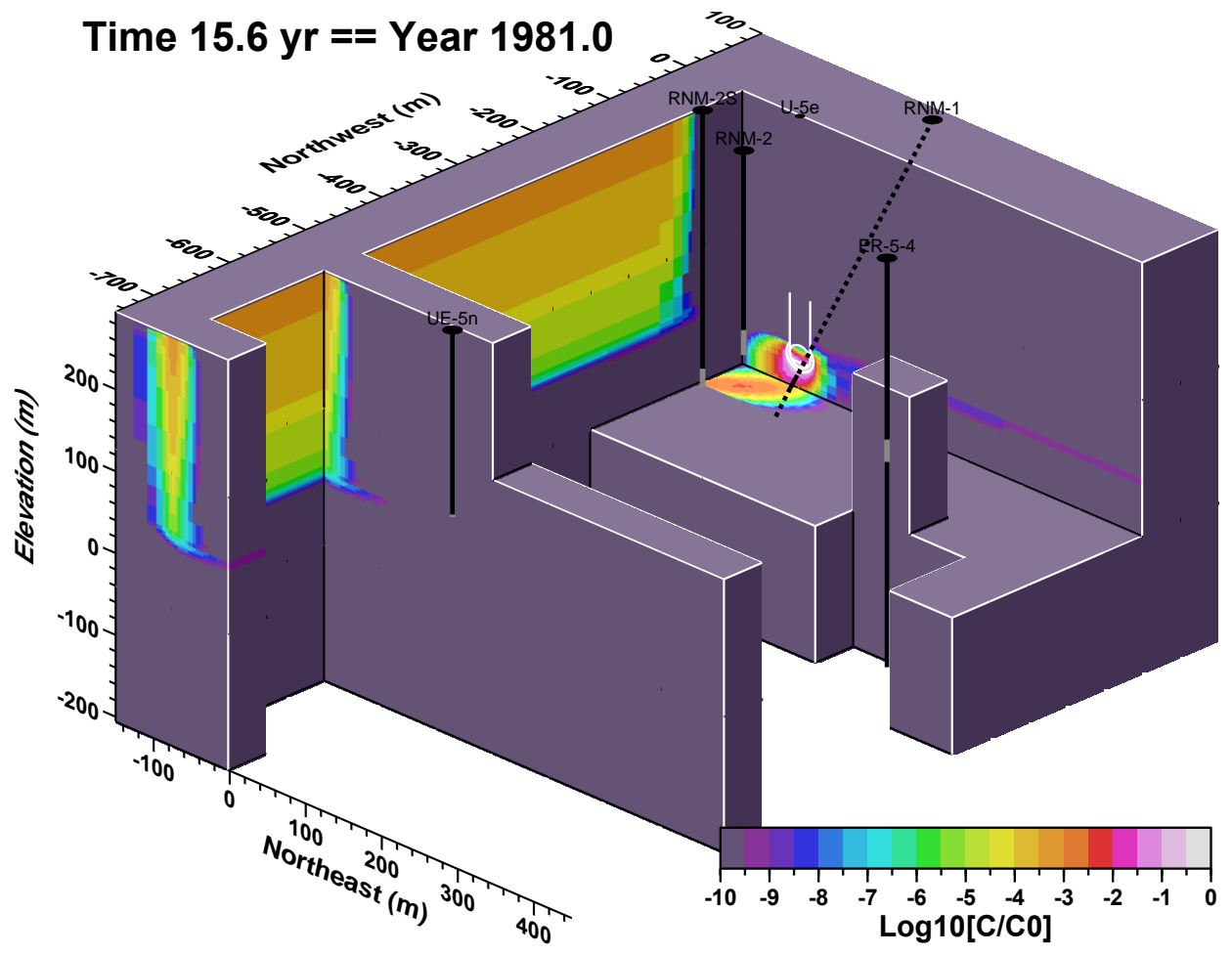

Figure 4.56 NUFT simulation of ${ }^{3} \mathrm{H}$ transport at $15.6 \mathrm{y}$ (includes effects of decay). 


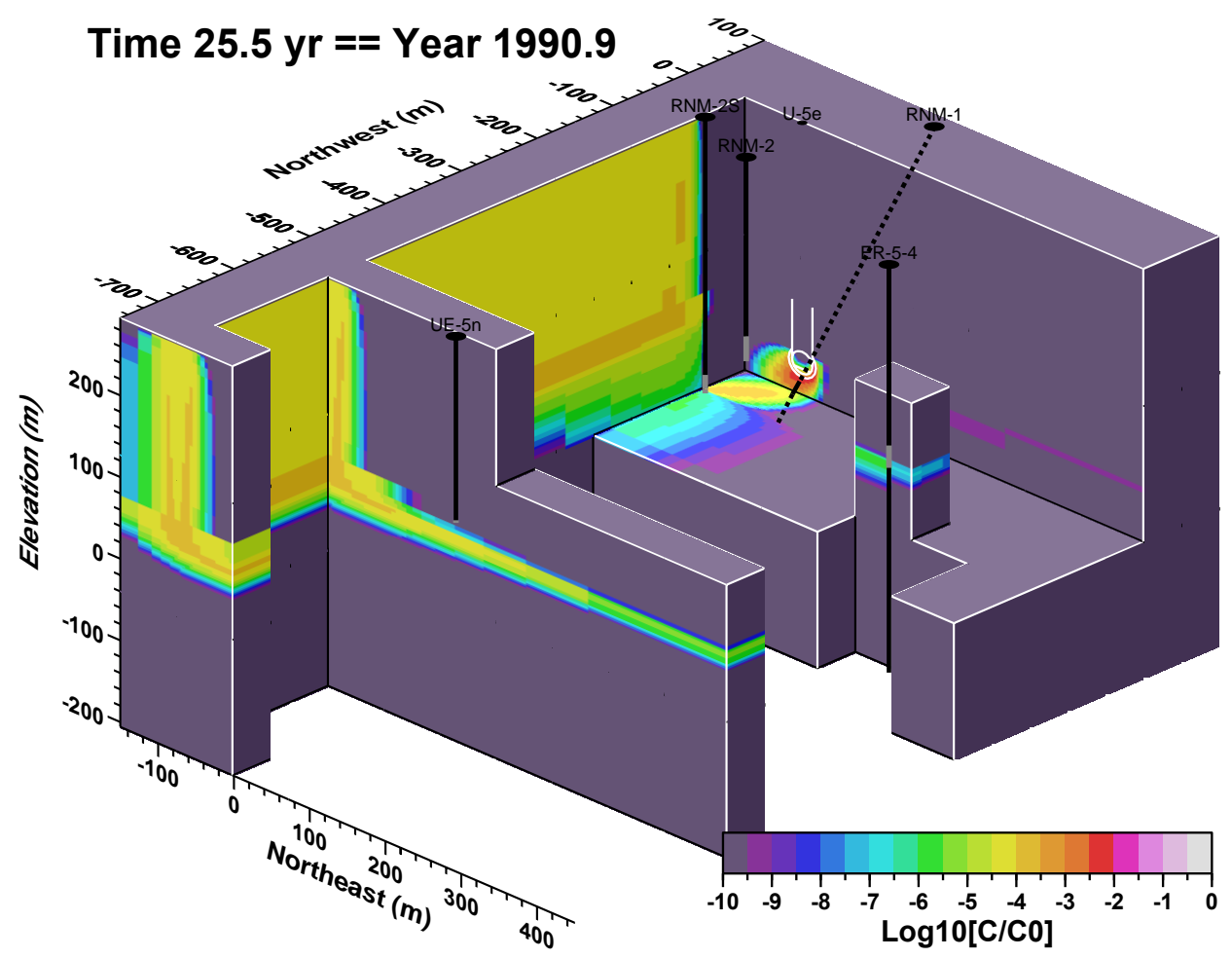

Figure 4.57 NUFT simulation of ${ }^{3} \mathrm{H}$ transport at $25.5 \mathrm{y}$ (includes effects of decay).

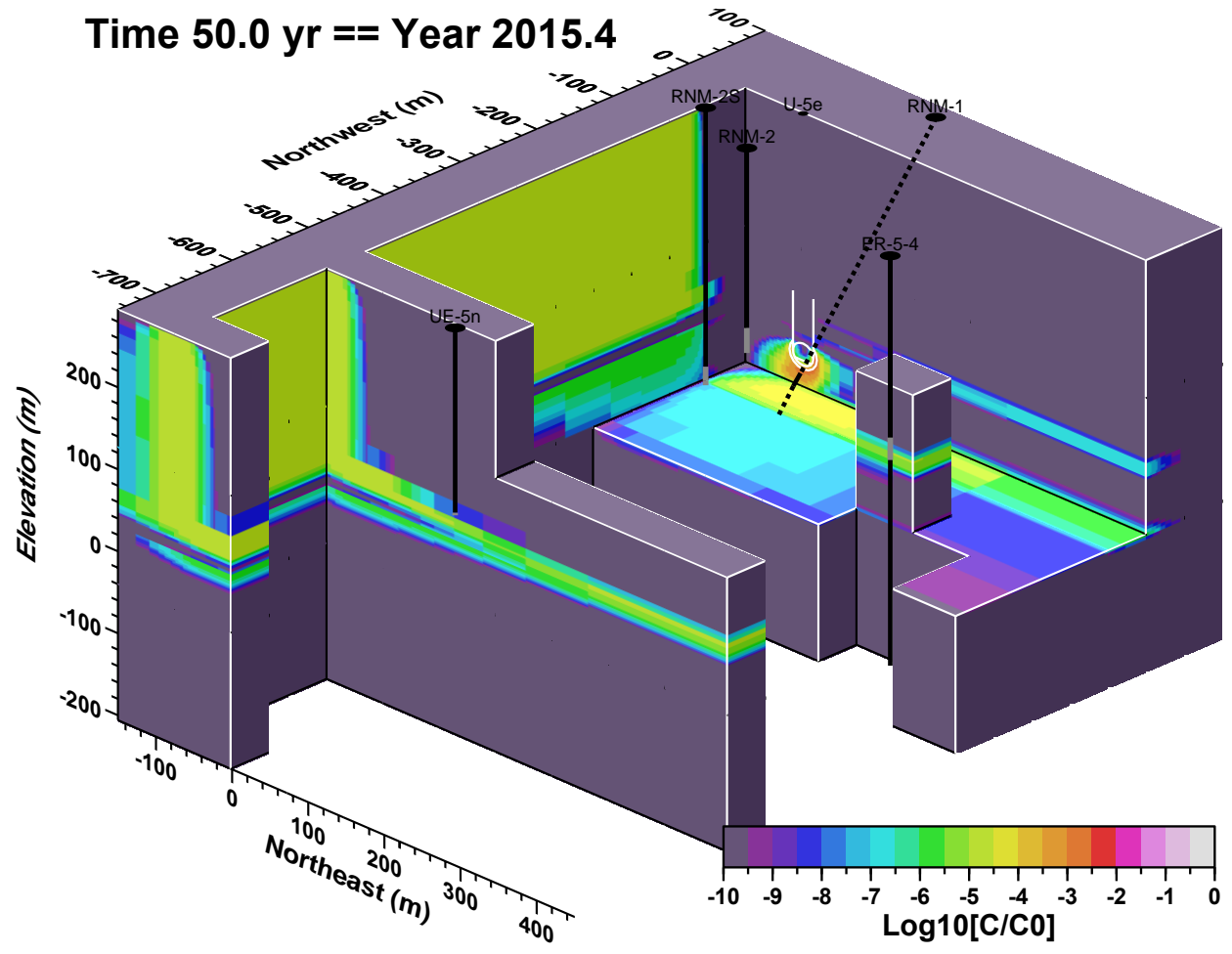

Figure 4.58 NUFT simulation of ${ }^{3} \mathrm{H}$ transport at $50 \mathrm{y}$ (includes effects of decay). 
Figure 4.59 shows NUFT simulation of the position, in coordinates relative to the CAMBRIC working point, of the maximum top and bottom extent of ${ }^{3} \mathrm{H}$ migration above a typical background concentration of $1 \times 10^{-18}$. At time zero, the NUFT simulation vertical $(Z)$ top and bottom of the ${ }^{3} \mathrm{H}$ source are located in grid blocks centered at $\pm 17 \mathrm{~m}$ vertically from the working point. The effect of test heat primarily contributes to an upward migration of ${ }^{3} \mathrm{H}$ before $10.4 \mathrm{y}$, to the top extent (top) of about $54 \mathrm{~m}$ above the CAMBRIC working point. Downward migration of ${ }^{3} \mathrm{H}$ to about $36 \mathrm{~m}$ below the CAMBRIC working point before $10.4 \mathrm{y}$ is primarily attributed to diffusion. Between 10.4 and $25.5 \mathrm{y}$, pumping at RNM-2S causes a downward migration of ${ }^{3} \mathrm{H}$ to the bottom of the slotted interval of RNM-2S at about $48 \mathrm{~m}$ below the CAMBRIC working point. The northeast and northwest locations of the bottom of the ${ }^{3} \mathrm{H}$ extent correspond to the position of RNM-2S relative to the CAMBRIC working point. After pumping commences at RNM-2S at $10.4 \mathrm{y}$, the maximum vertical extent of ${ }^{3} \mathrm{H}$ actually decreases as a result of downward groundwater flux near CAMBRIC. Shortly before $15 \mathrm{y}$, the top extent of ${ }^{3} \mathrm{H}$ abruptly rises to about $79 \mathrm{~m}$ above the CAMBRIC working point. The location $79 \mathrm{~m}$ above CAMBRIC corresponds to the top of the 20-m-thick grid block at the water table and, thus, indicates ${ }^{3} \mathrm{H}$ has reached the water table from infiltration of ditch discharge. Migration of the northwest coordinate for the top extent of ${ }^{3} \mathrm{H}$ to below $-500 \mathrm{~m}$ also indicates ${ }^{3} \mathrm{H}$ has reached the water table by ditch infiltration. After $25.5 \mathrm{y}$ when pumping ceases at RNM-2S, the bottom extent of ${ }^{3} \mathrm{H}$ migration moves downward from about 48 to $86 \mathrm{~m}$ below the CAMBRIC working point as a result of diffusion and a slight downward vertical gradient. The location of the bottom extent of ${ }^{3} \mathrm{H}$ migration remains near RNM-2S for nearly $50 \mathrm{y}$ after the CAMBRIC test. The location of the upper extent of ${ }^{3} \mathrm{H}$ migration remains spatially extensive at the water table for at least $75 \mathrm{y}$ after the test.

\subsubsection{Comparison of NUFT and CRUNCH Streamline Simulation of Tracer Transport}

The CRUNCH streamline reactive transport simulations use the NUFT simulation flow field to define transient streamlines. In the streamline method, 3D reactive transport is approximated by a collection of $1 \mathrm{D}$ reactive transport simulations along streamlines for a series of timesteps. Streamlines are redefined at each timestep as concentrations migrate in space. This approach is described in more detail in Section 4.8.1. Compared to the grid-based Eulerian transport simulation calculations performed by NUFT, the streamline approach is significantly different. However, both approaches should yield similar results, particularly at higher concentrations. Differences are bound to occur because the streamline approach must choose minimum cutoff concentrations to limit the number of streamlines at each timestep and the streamline approach does not include molecular diffusion. Both approaches impart no hydrodynamic dispersivity factors, although both approaches result in numerical dispersion. 


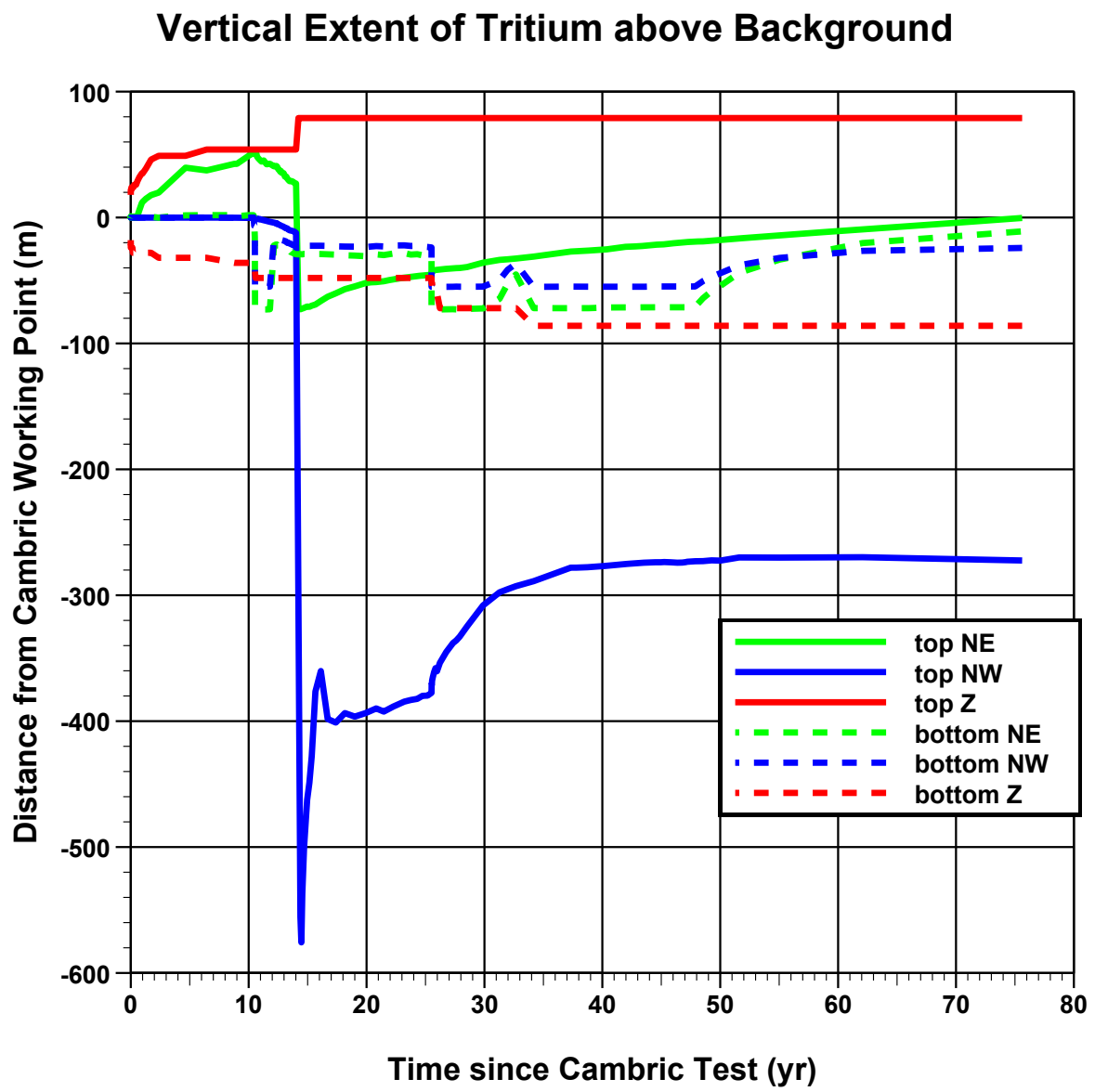

Figure 4.59 Location of top and bottom extent of ${ }^{3} \mathrm{H}$ concentrations above background relative to CAMBRIC working point (includes effects of decay).

Simulation of ${ }^{3} \mathrm{H}$ transport from CAMBRIC can be accomplished by applying decay to tracer transport. Thus, simulations of tracer transport are useful for understanding transport of ${ }^{3} \mathrm{H}$ or other relatively nonreactive radionuclides. Figure 4.60 compares simulations of tracer concentration at $10.4 \mathrm{y}$ produced for the NUFT base case, the CRUNCH streamline approach, and a NUFT base case with molecular diffusivity set to zero. For all three cases, the initial tracer source is a unit concentration located within an 18-m-radius sphere centered at the CAMBRIC working point. This initial source location corresponds to the melt glass zone, cavity, compressed zone, and portion of the chimney formerly occupied by the compressed zone (pimento). Comparison of the NUFT base case with and without molecular diffusivity shows the impact of molecular diffusivity. The NUFT simulation with molecular diffusivity set to zero compares more closely to the CRUNCH streamline result, with relative concentrations above $1 \times 10^{-5}$ comparing very closely. Both NUFT simulation cases produce more voluminous occurrences of tracer above the initial source area into Layer $2 \mathrm{~b}$ compared to the CRUNCH streamline simulation. However, these concentrations are very low: on the order of $1 \times 10^{-7}$ of the initial concentration. The $\mathrm{CRUNCH}$ streamline simulations simply do not resolve concentrations that low. Nonetheless, the magnitude of tracer concentration (in one streamline) for the CRUNCH streamline simulation compares well with the NUFT simulations. 


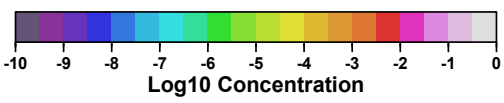

10.4 Years - NUFT

(a)

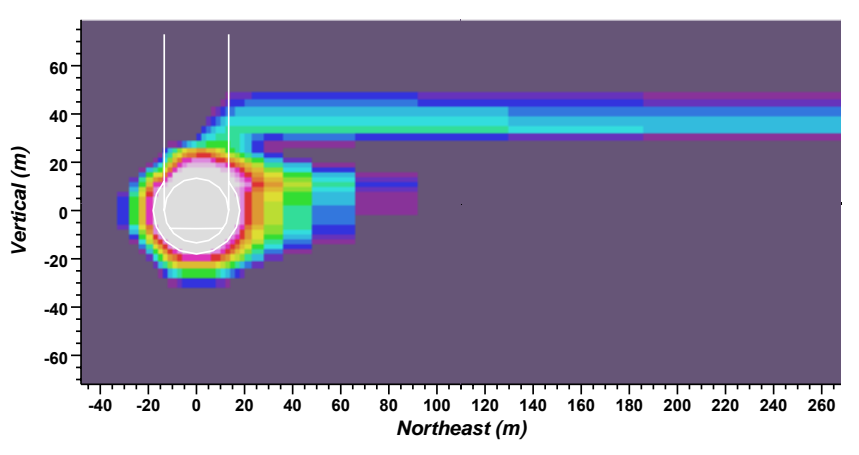

(b)

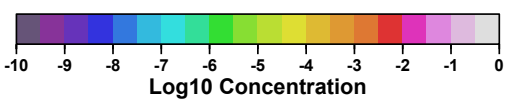

10.4 Years - Streamline
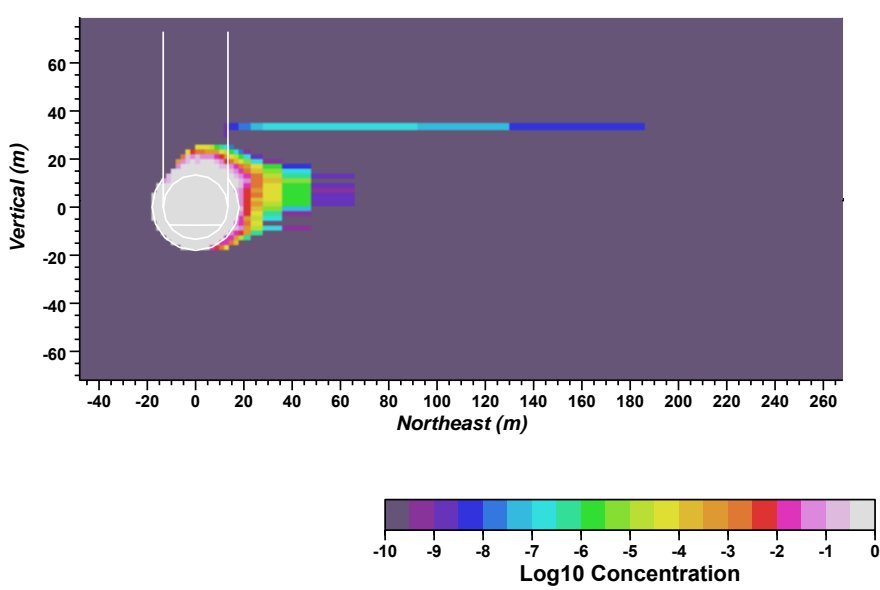

10.4 Years - NUFT with zero molecular diffusivity

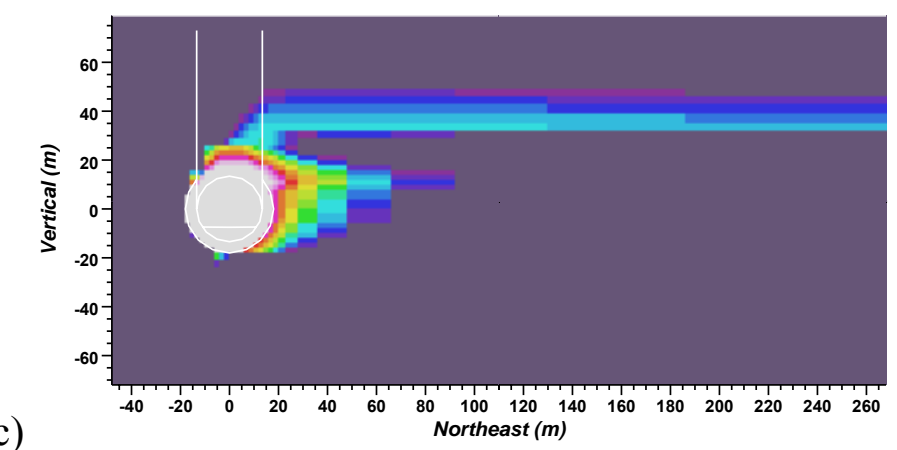

Figure 4.60 Comparison of simulations of tracer transport at $10.4 \mathrm{y}$ for (a) NUFT, (b) CRUNCH streamline, and (c) NUFT with zero molecular diffusivity. 


\subsection{Sensitivity Studies}

Sensitivity studies examined the effects on flow and transport from RNM-2S pumping and initial conditions, including test-heat distribution, boiling conditions, and initial pressure. Sensitivity studies did not evaluate the effects of the hydrogeologic conceptual model, including permeability values.

\subsubsection{Initial Conditions}

To simulate groundwater flow with consideration for test-related phenomenology at CAMBRIC, initial conditions must be inferred for two main reasons:

- Lack of characterization data within $10 \mathrm{y}$ after test

- Complexity of test-related phenomenology

While there is no substitute for lack of data, more complexity can be included in additional simulations to address some effects of test-related phenomenology.

Test-related effects of heat and pressure produce rapidly changing conditions in groundwater flow immediately after and within days of the test, including boiling, desaturation, and both increase and decrease of pressure relative to ambient conditions. It is difficult to judge whether short-lived test-related phenomenology, such as boiling or hydrodynamic shock pressures, will have significant effect on radionuclide transport. The NUFT base-case simulation makes simplified assumptions for initial conditions (e.g., boiling has ceased and pressure changes related to the nuclear explosion and cavity collapse have dissipated). One approach to evaluate simplifications in the base-case assumptions is to perform sensitivity studies that include consideration of effects of more complex early-time phenomenological conditions including non-ambient pressure, desaturation, and increased temperature, including boiling conditions.

The majority of the energy released from an underground nuclear test is converted to heat. Consequently, test-related heat can be expected to influence groundwater flow and radionuclide transport. At CAMBRIC, little information is available for thermal calibration and, therefore, considerable uncertainty remains toward accurately predicting the effects of test-related heat.

In this section, the effects of test-related heat, pressure, and saturation changes on groundwater flow are examined in more detail using additional NUFT simulations with different initial conditions. Some of these additional simulations are performed on a smaller, simplified, 3D domain to decrease computational burden. Sensitivity studies are performed to examine thermal effects related to RNM-2S pumping, boiling, and initial spatial distribution of test heat. Gas and liquid phase flow in the cavity and melt glass zone are examined in more detail. A range of initial conditions is used to examine overall effects of heat on groundwater flow and tracer transport.

\subsubsection{Sensitivity Cases}

Three main categories of sensitivity cases are examined: (1) no pumping from RNM-2S, (2) different initial heat and pressure without boiling conditions, and (3) boiling conditions. 


\subsubsection{No Pumping Case}

As pumping at RNM-2S impacts the flow field near CAMBRIC, it also impacts the melt glass temperature history. To examine the effect of RNM-2S pumping on the melt glass temperature history, melt glass temperature histories from two NUFT simulations - with and without pumping at RNM-2S - are compared. The effects of pumping occur after $10.4 \mathrm{y}$, when the melt glass zone has nearly cooled to within a few degrees Celsius of ambient temperature, such that the impact of pumping on the temperature history of the melt glass zone is relatively small. Pumping at RNM-2S draws groundwater from the CAMBRIC altered zones down and south toward the RNM-2S slotted interval. The downward component of flow pulls in cooler water from above the CAMBRIC cavity. Figure 4.61 compares simulated melt glass zone temperature with and without pumping at RNM-2S. In the "without pumping" scenario, melt glass temperature continues to decay slowly between 10.4 and $100 \mathrm{y}$ instead of cooling slightly below ambient temperature in the "with pumping" scenario before pumping ceases at $25.5 \mathrm{y}$. Cooling of the melt glass zone below ambient temperature indicates that the RNM-2S pumping induces advective flow of heat, whereas melt glass cooling without pumping is dominated by thermal conduction.

\section{Melt Glass Temperature}

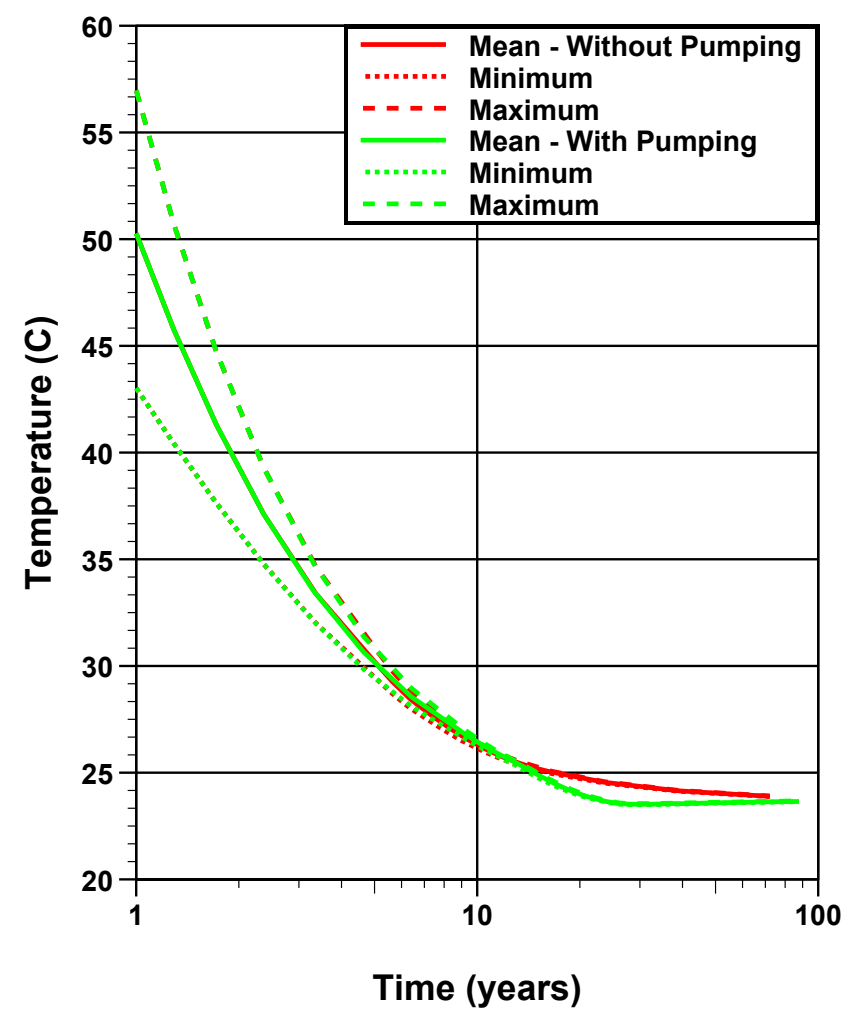

Figure 4.61 Comparison of NUFT simulation of melt glass temperature history with and without pumping at RNM-2S. 


\subsubsection{Initial Heat and Pressure}

Assumed initial conditions for temperature and pressure distribution are highly uncertain for CAMBRIC. While this uncertainty may be large, the long-term cumulative impacts of test-related heat and pressure on flow and transport may or may not be as large. One approach to examining this uncertainty is to conduct sensitivity studies on tracer transport under different initial conditions. In these sensitivity cases, tracer originates from within an 18-m radius at the CAMBRIC test (TracerR case). The sensitivity studies examine different initial temperatures, saturations, and pressures relative to the base case.

Two simple cases relative to the base case provide a starting point:

- No test heat

- High initial pressure in the melt glass zone and compressed zone

In the "no-heat" case, initial temperatures remain at the ambient simulated temperatures calibrated to the geothermal gradient. The no-heat case provides a baseline comparison for evaluating thermal effects. In the "high-pressure" case, initial pressure in the melt glass zone and compressed zone is elevated from ambient pressure to $6 \mathrm{MPa}$, which is approximately lithostatic pressure. Pressure near lithostatic is a plausible upper limit to cavity pressure prior to collapse. The compressed zone was created under high explosion pressure. Cavity pressure drops as gases condense. Cavity collapse would abruptly increase gas pressure between the top of the melt glass zone and bottom of the cavity. Boiling conditions in the melt glass zone produce high gas-phase water pressure.

For the no-heat and high-pressure sensitivity cases and other cases to follow, NUFT simulations include a tracer of 1.0 concentration originating within an $18-\mathrm{m}$ radius of the CAMBRIC working point. Figure 4.62 compares tracer breakthrough at three planes - 23, 92, and $268 \mathrm{~m}$ - downgradient of CAMBRIC. A different color is used for each breakthrough plane, while different line styles represent the base case (solid), noheat case (dashed), and high-pressure (dotted) case. At $23 \mathrm{~m}$, slight differences can be seen for all three cases, however, after $10 \mathrm{y}$, all three cases produce nearly identical results. At $92 \mathrm{~m}$ and $268 \mathrm{~m}$, only the no-heat case produces different breakthrough behavior compared to the base case. Initial pressure in the melt glass zone and compressed zone appears to have little impact on long-term transport behavior.

Significant differences in transport behavior between the base case and noheat case are evident in early breakthrough behavior. For the base case, a prominent first peak or breakthrough occurs at about 40 to $50 \mathrm{y}$ at the $92-\mathrm{m}$ breakthrough plane and 50 to $60 \mathrm{y}$ at the $268-\mathrm{m}$ breakthrough plane. However, for the no-heat case, the first peak is much less prominent. The first peak is related to small amounts of tracer moving upward and reaching Layer $2 \mathrm{~b}$ to cause early breakthrough. This sensitivity study indicates that test heat influences early, low-concentration tracer breakthrough behavior by increasing the rate of upward transport from the source region. As expected, test-related heat induces upward convection and, subsequently, relatively more upward transport. The early breakthrough behavior is caused by the combination of upward transport aided by test heat and higher flow velocity in Layer $2 \mathrm{~b}$ relative to Layer 3. 


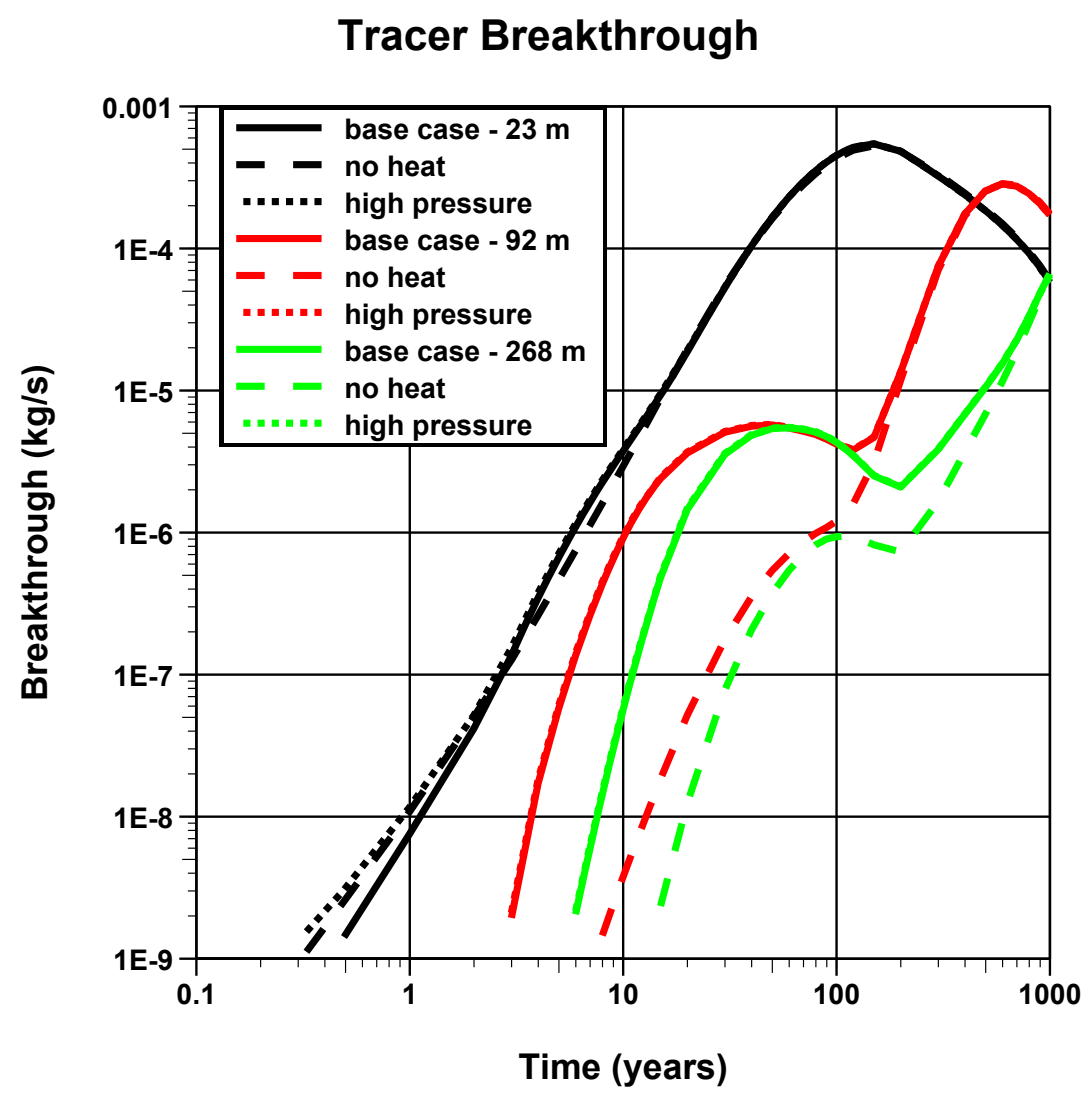

Figure 4.62 Comparison of NUFT simulation tracer breakthrough curves for base case, no-heat, and high-pressure initial conditions sensitivity cases.

\subsubsection{Boiling Cases}

Temperatures in the melt glass zone likely exceeded $170{ }^{\circ} \mathrm{C}$ soon after cavity collapse. The base-case flow and transport do not consider boiling because base-case initial conditions assume full saturation in the altered zones. Thus, the base-case simulation initial condition assumptions of temperatures at or below $170{ }^{\circ} \mathrm{C}$ are a simplification to accommodate single-phase, saturated flow in the melt glass zone.

As a multiphase, multicomponent, non-isothermal flow simulation code, the NUFT model can simulate multiphase flow with boiling conditions for water. Carle et al. (2003) used NUFT to simulate and analyze effects of boiling conditions for the Cheshire, Greeley, and Almendro tests on Pahute Mesa. For some tests, boiling may last for a few days (e.g., CHESHIRE) and in others, boiling may persist for years (e.g., ALMENDRO). 
Simulation of boiling conditions using NUFT requires some simplification of the model, including a reduction in the number of grid cells. To simulate boiling conditions at CAMBRIC, a smaller 3D mesh was developed with the following simplifications:

- Symmetry is assumed along the downgradient $(x-z)$ plane.

- The domain extends only from 0 to $+100 \mathrm{~m}$ in the transverse direction.

- The domain extends only from -150 to $+350 \mathrm{~m}$ in the downgradient direction.

- The vadose zone is accounted for by two layers.

- The ditch and RNM-2S are ignored; the simulations focus on the nonpumping stage before $10.4 \mathrm{y}$.

The smaller mesh still permits specification of local horizontal and vertical hydraulic gradients and geothermal gradient. The grid mesh measures 43:15:48 x:y:z for a total of 30,960 cells compared to 308,637 cells for the base-case NUFT simulation.

The boiling cases are initiated by changing the initial conditions for pressure, saturation, and temperature as indicated in Table 4.7. Three initial states for pressure and temperature distribution are indicated by (1), (2), and (3) in Table 4.7. For each of these three pressure and temperature states, melt glass saturation is initialized at $0.01,0.50$, and 0.99. Thus, nine boiling cases were run. The initial conditions for gas-phase pressure are based on vapor pressure of water at the given temperature. Initial pressures in the cavity, chimney, and pimento are below atmospheric as a result of expansion of collapse debris. Initial gas-phase pressure conditions set at water vapor pressures for the given temperature enable water gas (instead of air) to occupy the excess void space (and unsaturated conditions) relative to in-situ precollapse conditions under full saturation.

Table 4.7. Initial pressure, saturation, and temperature distributions in altered zones for NUFT simulation sensitivity cases under boiling conditions.

\begin{tabular}{|c|c|c|c|}
\hline Hydrofacies & Pressure (N) & Saturation & Temperature $\left({ }^{\circ} \mathrm{C}\right)$ \\
\hline Melt Glass Zone & $\begin{array}{c}\text { (1) } 16,532,187 \\
\text { (2) } 7,224,371 \\
\text { (3) } 2,409,509\end{array}$ & $0.01,0.50,0.99$ & $\begin{array}{l}\text { (1) } 350 \\
\text { (2) } 288 \\
\text { (3) } 222\end{array}$ \\
\hline Cavity & $\begin{array}{l}\text { (1) } 9,100 \\
\text { (2) } 11,160 \\
\text { (3) } 13,611 \\
\end{array}$ & 0.95 & $\begin{array}{l}\text { (1) } 44 \\
\text { (2) } 48 \\
\text { (3) } 52\end{array}$ \\
\hline Compressed Zone & $6,000,000$ & 1.0 & $\begin{array}{l}1 \text { (1) } 71 \\
\text { (2) } 81 \\
\text { (3) } 81 \\
\end{array}$ \\
\hline Chimney & 2,843 & 0.90 & Ambient \\
\hline Pimento & 2,878 & 0.90 & Ambient \\
\hline
\end{tabular}




\subsubsection{Effects of Test-Related Heat}

Effects of test-related heat related to groundwater flow and radionuclide transport may involve temporal and spatial variations in saturation, temperature, fluid density and viscosity, flow velocity, and relative humidity. Simulations of tracer transport provide some insights into the overall effects of these state-variable variations on groundwater flow.

\subsubsection{Saturation}

In the NUFT simulation base case, saturation remains constant in the CAMBRIC altered zone. In the boiling sensitivity cases, saturation varies in the melt glass zone both as an initial condition and a function of temperature under boiling conditions. Figure 4.63 plots NUFT simulation mean melt glass zone saturation as a function of time for the nine boiling cases. Under boiling conditions, saturation initially decreases.

Changing of liquid phase water to gas phase water under boiling conditions contributes to melt glass cooling. More liquid water is boiled out of the melt glass zone with higher initial melt glass zone temperature. In the $350^{\circ}-\mathrm{C}$ case with 0.99 initial saturation, saturation decreases to 0.04 .
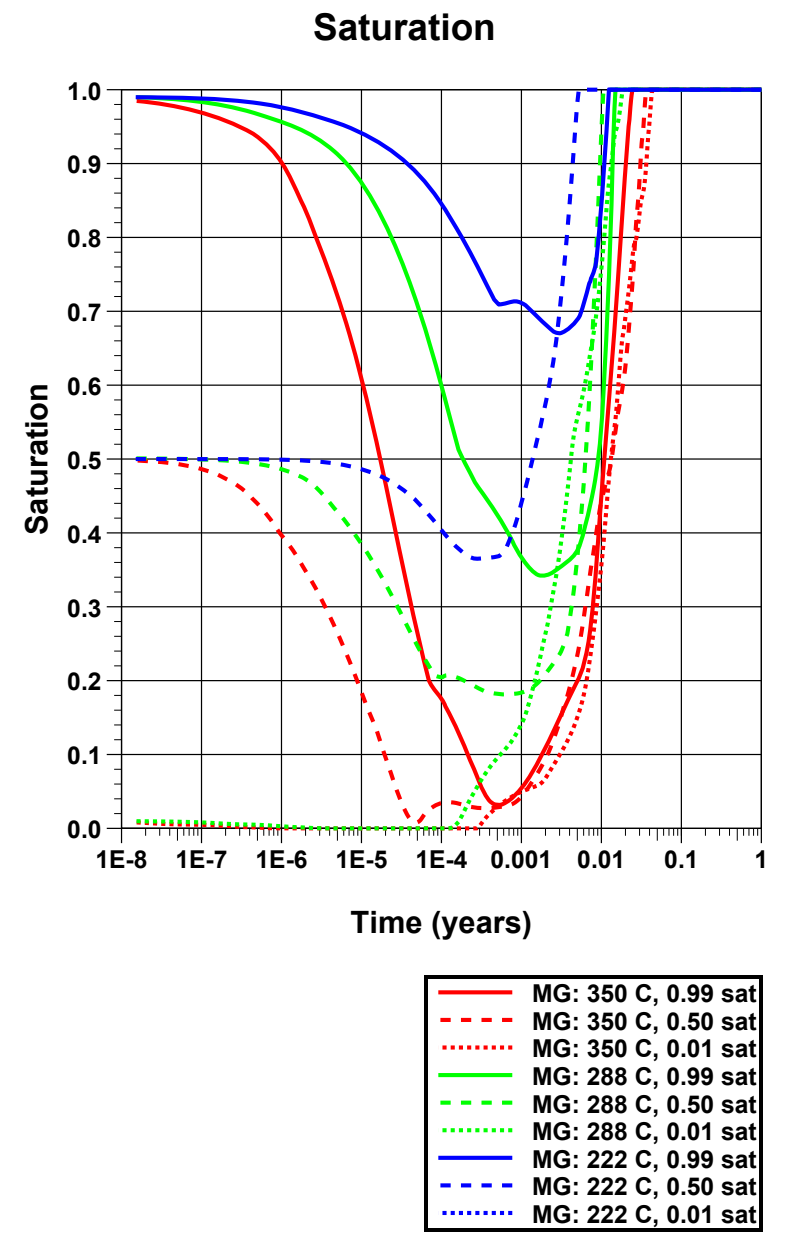

Figure 4.63 NUFT simulation of mean melt glass zone saturation under nine boiling condition cases. 


\subsubsection{Temperature}

After cavity collapse, melt glass cools rapidly through boiling. The boiling temperature will depend on pressure, which may range from atmospheric to hydrostatic depending on the mechanism and timing of cavity and chimney re-saturation (U.S. Geological Survey, 1973 and Carle et al., 2003). For larger tests on Pahute Mesa, boiling may persist in the melt glass for days to years depending largely on the size of the test, permeability of the melt glass and in-situ rocks, and the hydraulic gradient (Carle et al., 2003). The CAMBRIC test is relatively small and located in alluvium that has relatively high permeability. Therefore, boiling conditions resulting from the CAMBRIC test would not be expected to persist for more than a few days. Figure 4.64 compares NUFT simulations of mean melt glass zone temperature for the base case and the nine boiling cases described in Section 4.7.2.3. Interestingly, the nine boiling cases converge to similar mean melt glass zone temperatures despite different initial conditions. The boiling cases have similar total thermal energy and, thus, the NUFT simulations indicate that test-related thermal effects on melt glass zone temperature would largely depend on the total thermal energy produced by the test. The base-case simulation assumes less initial thermal energy than the boiling cases and, thus, simulated melt glass zone temperature for the base case is generally lower than for the boiling cases.

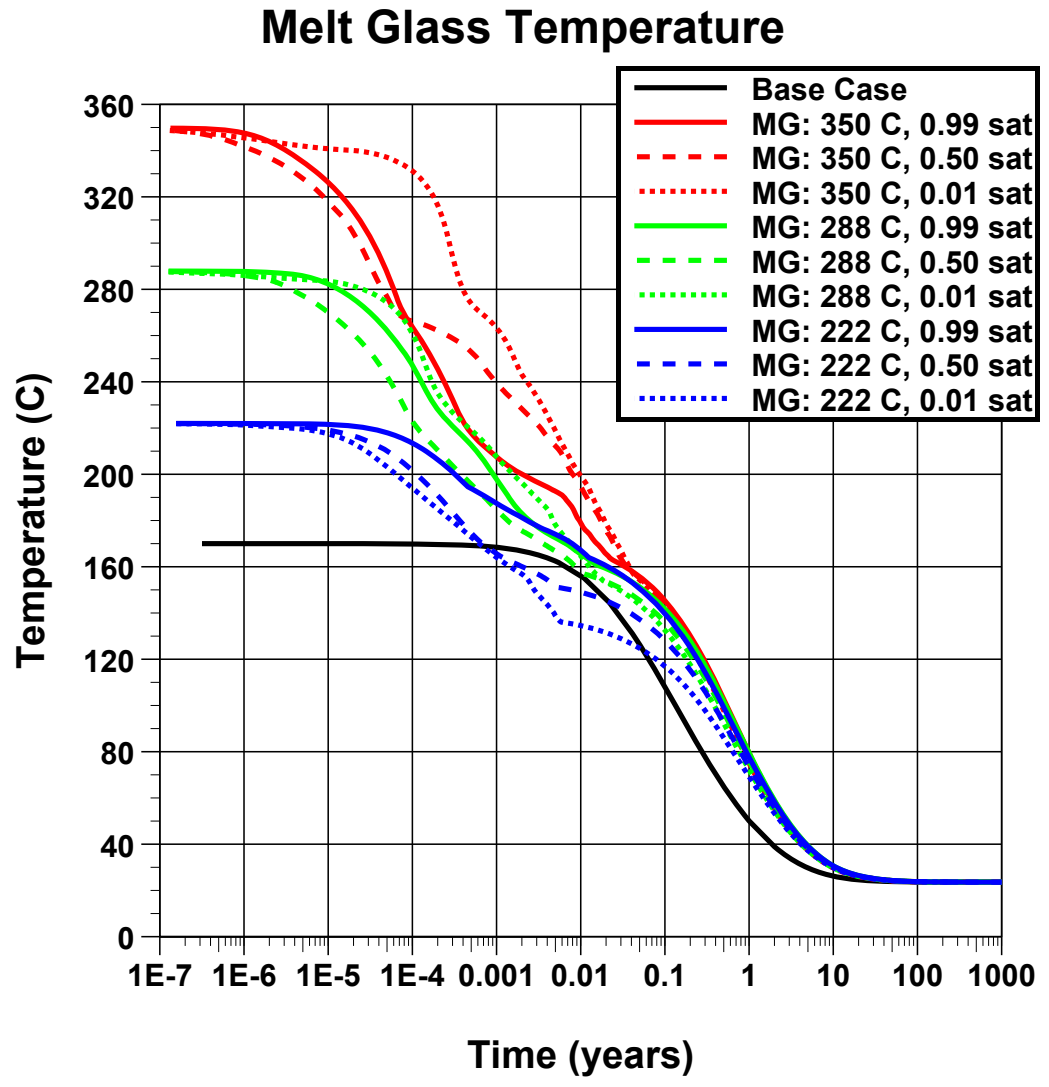

Figure 4.64 NUFT simulations of mean temperature in melt glass zone comparing base case to nine boiling cases. 


\subsubsection{Fluid Density and Viscosity}

As discussed previously in Section 4.6.4, fluid density and viscosity vary with temperature and pressure. Thus, prediction of test-related effects on fluid density and viscosity in the melt glass zone will largely depend on the assumed initial conditions for temperature and pressure. This is particularly true for temperature because heat flow appears to be dominated by conduction, and the assumed saturated thermal conductivity $2 \mathrm{~W} / \mathrm{m}-{ }^{\circ} \mathrm{K}$ is a realistic estimate within $\pm 50 \%$. Figure 4.65 shows NUFT simulation results for mean fluid density and viscosity in the melt glass zone for the base, no-heat, high-pressure, and nine boiling sensitivity cases. Each case produces a different profile, although the high-pressure case is nearly identical to the base case. Temperature does greatly influence fluid density and viscosity in the melt glass zone. The higher temperature boiling cases lower fluid viscosity by as much as 80 to $90 \%$ within $0.1 \mathrm{y}$ and $45 \%$ within $1 \mathrm{y}$ relative to the ambient temperature no-heat case. Fluid density in the boiling cases is lowered 5 to $30 \%$ within $0.1 \mathrm{y}$. Assuming no pumping, significant (over $1 \%$ difference) thermal effects on fluids could last about $50 \mathrm{y}$ for viscosity and about $5 \mathrm{y}$ for density.

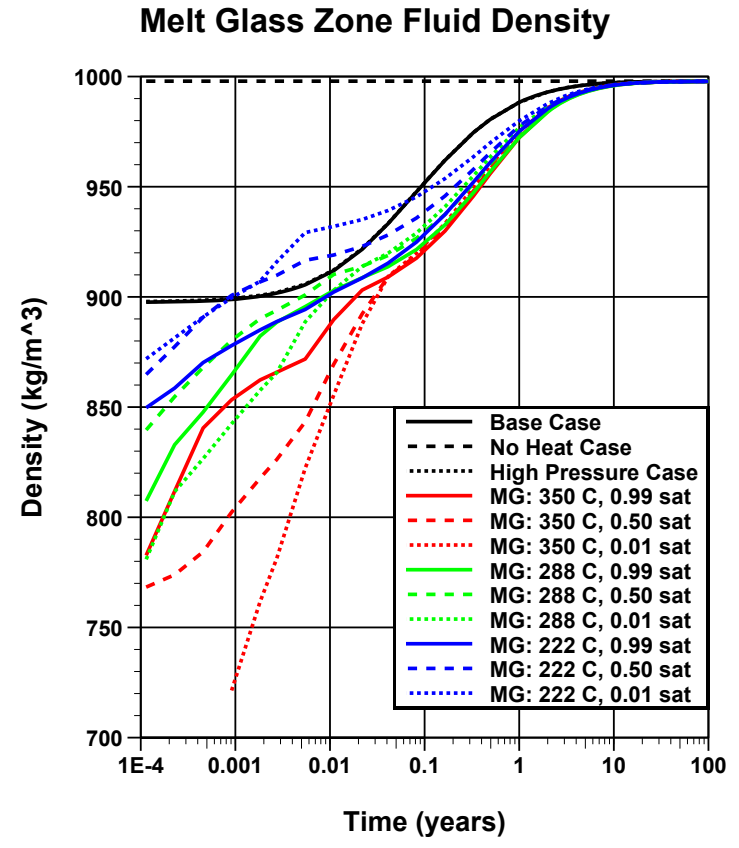

(a)

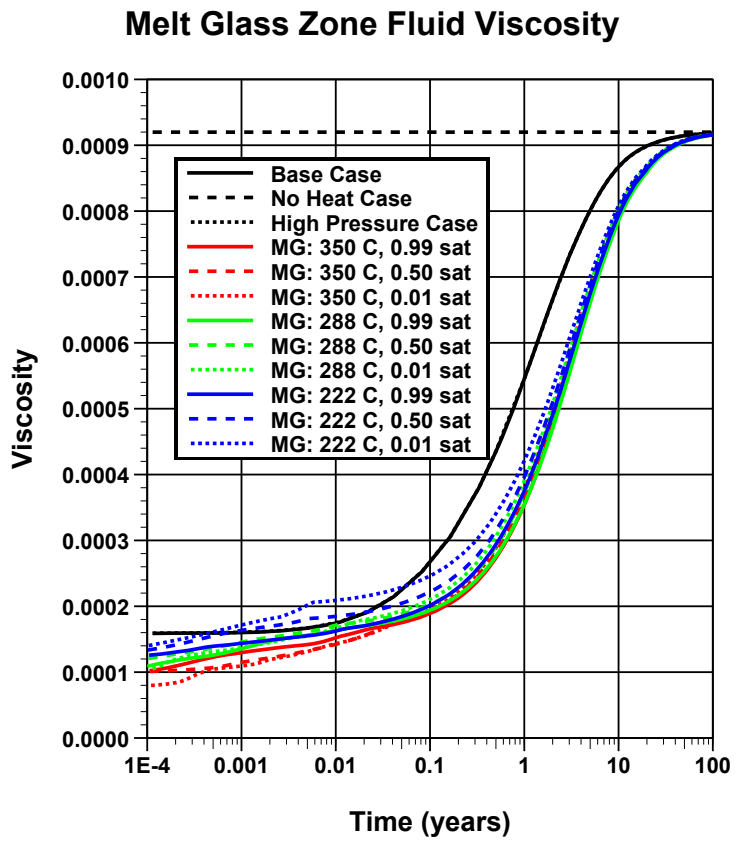

(b)

Figure 4.65 NUFT simulation of mean (a) fluid density and (b) fluid viscosity in melt glass zone for base, no-heat, high-pressure, and boiling cases. 


\subsubsection{Flow Velocity}

The boiling cases increase the level of complexity of flow near CAMBRIC relative to the base case. Changes in initial saturation and pressure combined with more test heat will undoubtedly alter the flow velocity field. However, the base case indicated that the effect of test heat on groundwater flow was relatively short lived. For a relatively small test such as CAMBRIC, consideration of more initial phenomenological complexity may not necessarily produce much long-term impact on the groundwater and temperature flow fields.

Of the boiling cases, case (1) with initial melt glass temperature of $350{ }^{\circ} \mathrm{C}$ and saturation of 0.99 contains the most initial heat in the melt glass zone. Figure 4.66 examines cross sections of flow velocity and temperature at similar times as Figures 4.51 and 4.52 for the base case. The boiling case exhibits wider variation in flow velocities over time. Initially, flow velocities are strongly affected by the non-equilibrium testrelated initial conditions (Figure 4.66 a). Low pressures and unsaturated conditions in the chimney and cavity induce inward and downward flow velocities. High pressure in the compressed zone induces outward flow. High temperatures induce boiling. Generally, initial flow velocities for the boiling case are over two orders of magnitude greater than the base case (Figure $4.51 \mathrm{a}$ ).

By 0.01 y or about $4 \mathrm{~d}$ (Figure $4.66 \mathrm{~b}$ ), initial pressure and boiling conditions have largely dissipated. Downward flow velocities persist in the cavity and chimney primarily as a result of re-saturation of the cavity, chimney, and melt glass zone and cooling of water within the melt glass zone. These downward cavity and chimney flow velocities are higher in magnitude than for the base case (Figure $4.51 \mathrm{~b}$ ). Flow velocities in the lower center of the melt glass zone are up to two orders of magnitude higher in the boiling case compared to the base case.

From 0.04 to $1 \mathrm{y}$, the boiling case produces a thermally-induced recirculation pattern that is similar to but stronger compared to simulation results from the base case (Figure $4.66 \mathrm{c}-\mathrm{f}$ ). The recirculation pattern moves cool water downward along the sides of the cavity and upward from below the melt glass zone, then upward through and above the melt glass zone. Magnitudes of flow velocities in the recirculation pattern are generally between about 0.5 and 1 order of magnitude higher for the boiling case than the base case (Figure $4.51 \mathrm{c}-\mathrm{f}$ ).

By 3.0 to $10 \mathrm{y}$, the flow velocity patterns for the boiling case (Figure $4.67 \mathrm{a}$ and $b$ ) become closer to the base case (Figure $4.52 \mathrm{a}$ and $\mathrm{b}$ ). Heat still affects the flow field for years after the CAMBRIC test, but the upward components of flow velocity, remain below $1 \mathrm{~m} / \mathrm{y}$ in the cavity and chimney, and decay to below $0.1 \mathrm{~m} / \mathrm{y}$ by $10 \mathrm{y}$. Thus, the boiling cases indicate that the impacts of test-related heat, while certainly impacting groundwater flow velocity fields, persist only long enough to cause a few meters of vertical advective transport above the cavity and outer exchange zone at the CAMBRIC site. 


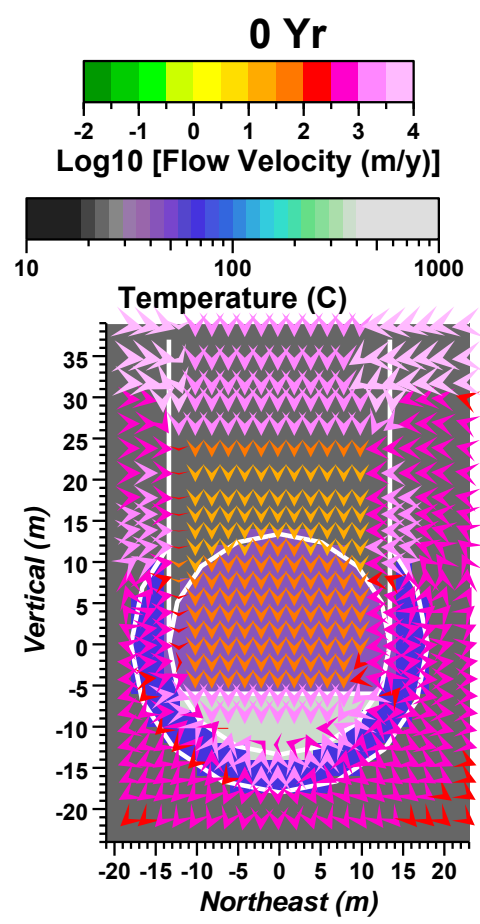

(a)

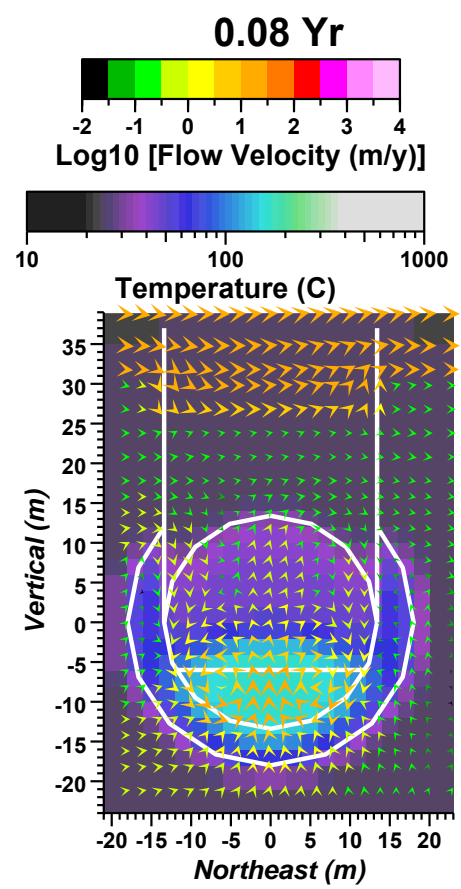

(d)

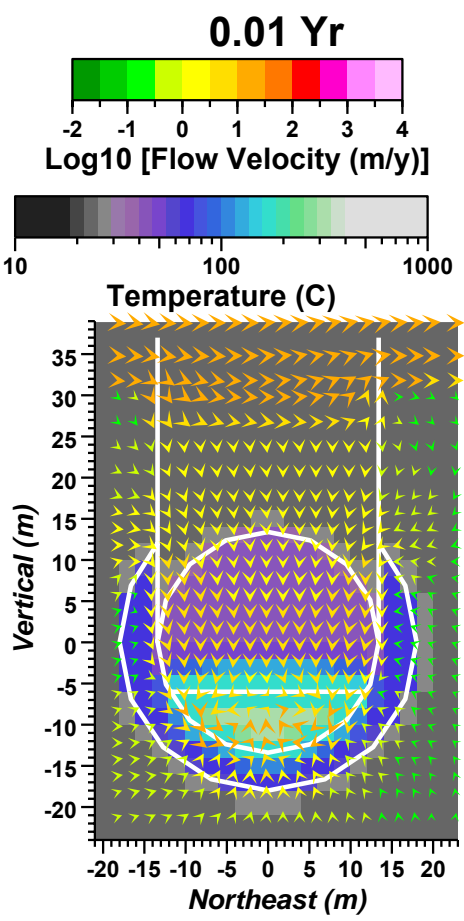

(b)
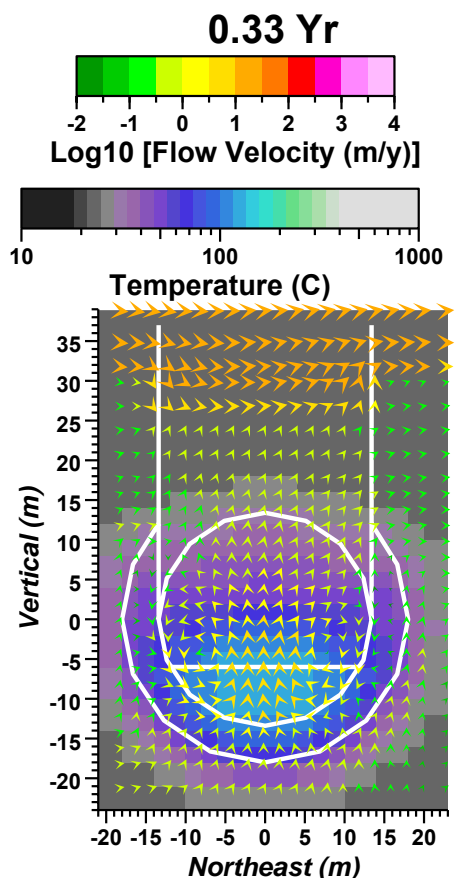

(e)
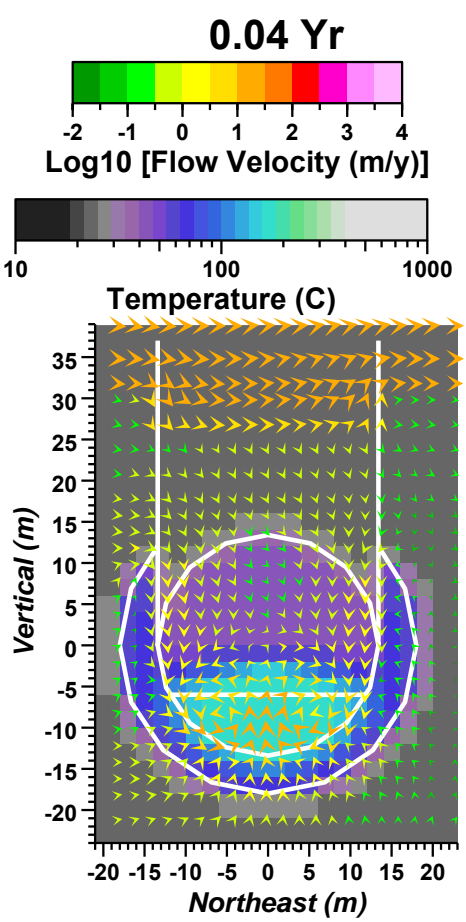

(c)

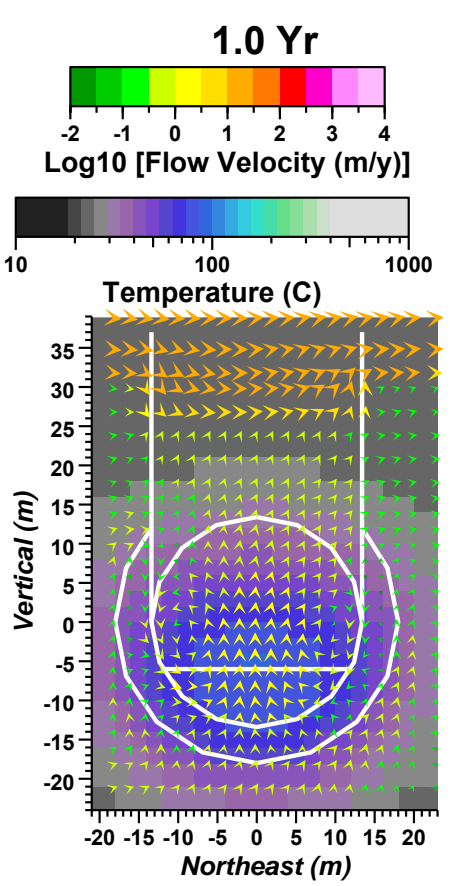

(f)

Figure 4.66 NUFT simulation of flow velocity under boiling conditions superposed on temperature near altered zones at (a) $60 \mathrm{~s}$, (b) $0.01 \mathrm{y}$, (c) $0.04 \mathrm{y}$, (d) $0.08 \mathrm{y}$, (e) $0.33 \mathrm{y}$, and (f) $1.00 \mathrm{y}$. 


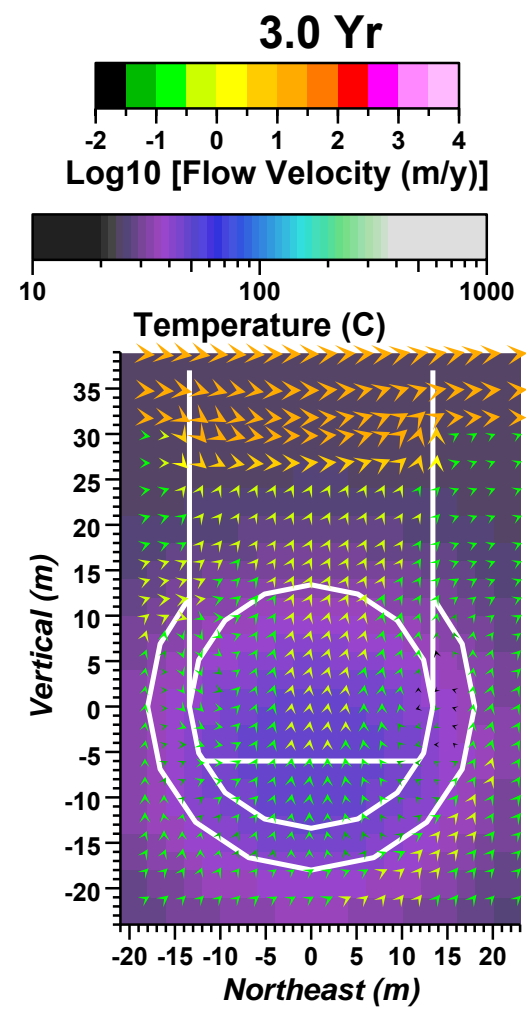

(a)

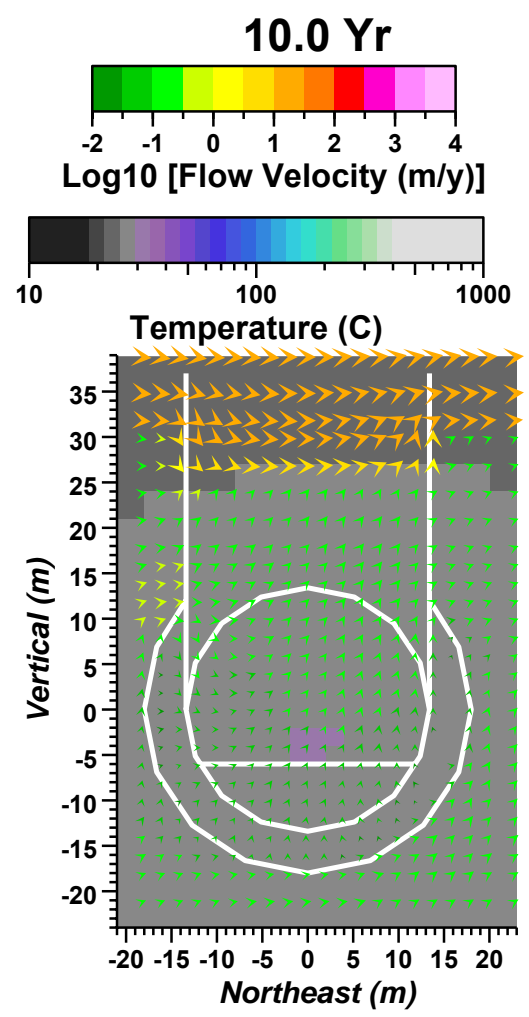

(b)

Figure 4.67 NUFT simulation of flow velocity under boiling conditions superposed on temperature near altered zones at (a) $3 \mathrm{y}$ and (b) $10.0 \mathrm{y}$.

\subsubsection{Tracer Transport}

As discussed at the beginning of Section 4.7.2, simulation of tracer transport provides a means to cumulatively evaluate impacts of test-related phenomenological effects on groundwater flow over a period of years, with ramifications for radionuclide transport behavior. In the NUFT sensitivity cases simulations, tracer with properties of water and concentration of $1.0 \times 10^{-7}$ mole fraction is initially located in spherical volume within an 18-m radius of the CAMBRIC working point, to include the melt glass zone, cavity, compressed zone, and pimento. This volume represents the TracerR volume used to distribute initial ${ }^{3} \mathrm{H}$ in HST calculations discussed in Section 4.8.2.3 and Chapter 5.

Figure 4.68 compares NUFT simulation of tracer concentration at $10 \mathrm{y}$ for the no-heat case, base case, and boiling case with initial melt glass temperature of $350{ }^{\circ} \mathrm{C}$ and 0.99 saturation. The main difference in tracer concentrations at $10 \mathrm{y}$ is seen in Layer $2 \mathrm{~b}$. More tracer migrates to Layer 2 with more initial heat. These sensitivity studies indicate that the main influence of test heat on transport is to increase the upward component of transport, which would facilitate transport into Layer 2.

Figure 4.69 shows NUFT simulation of tracer concentration as liquid and gas phase and water as gas phase. The initial condition (Figure 4.69 a) shows gas phase water concentration at or near 1.0 in the chimney, cavity and melt glass. In the melt glass zone, cavity, pimento, and chimney, water or tracer gas occupies pore space not occupied by 
liquid water or tracer. Gas phase tracer concentration is $1.0 \times 10^{-7}$ mole fraction in the melt glass zone, cavity, and pimento.

Within hours, the chimney returns to full saturation (Figure $4.69 \mathrm{~b}-\mathrm{c}$ ). Boiling persists for a few days, as evidenced by presence of gas in the melt glass zone (Figure $4.69 \mathrm{a}-\mathrm{d})$. By $1 \mathrm{y}$, liquid phase tracer has reached the base of Layer $2 \mathrm{~b}$ and is migrating relatively rapidly downgradient (Figure $4.69 \mathrm{e}$ ). Tracer primarily migrates downgradient from the CAMBRIC source through Layer $2 \mathrm{~b}$ through 10 to $100 \mathrm{y}$ (Figure $4.69 \mathrm{f}-\mathrm{g}$ ). By $900 \mathrm{y}$, most tracer is migrating slowly through Layer 3 because thermal effects have subsided, preventing upward migration to Layer $2 \mathrm{~b}$. 
CHAPTER 4: CALIBRATION AND ASSESSMENT MODELS
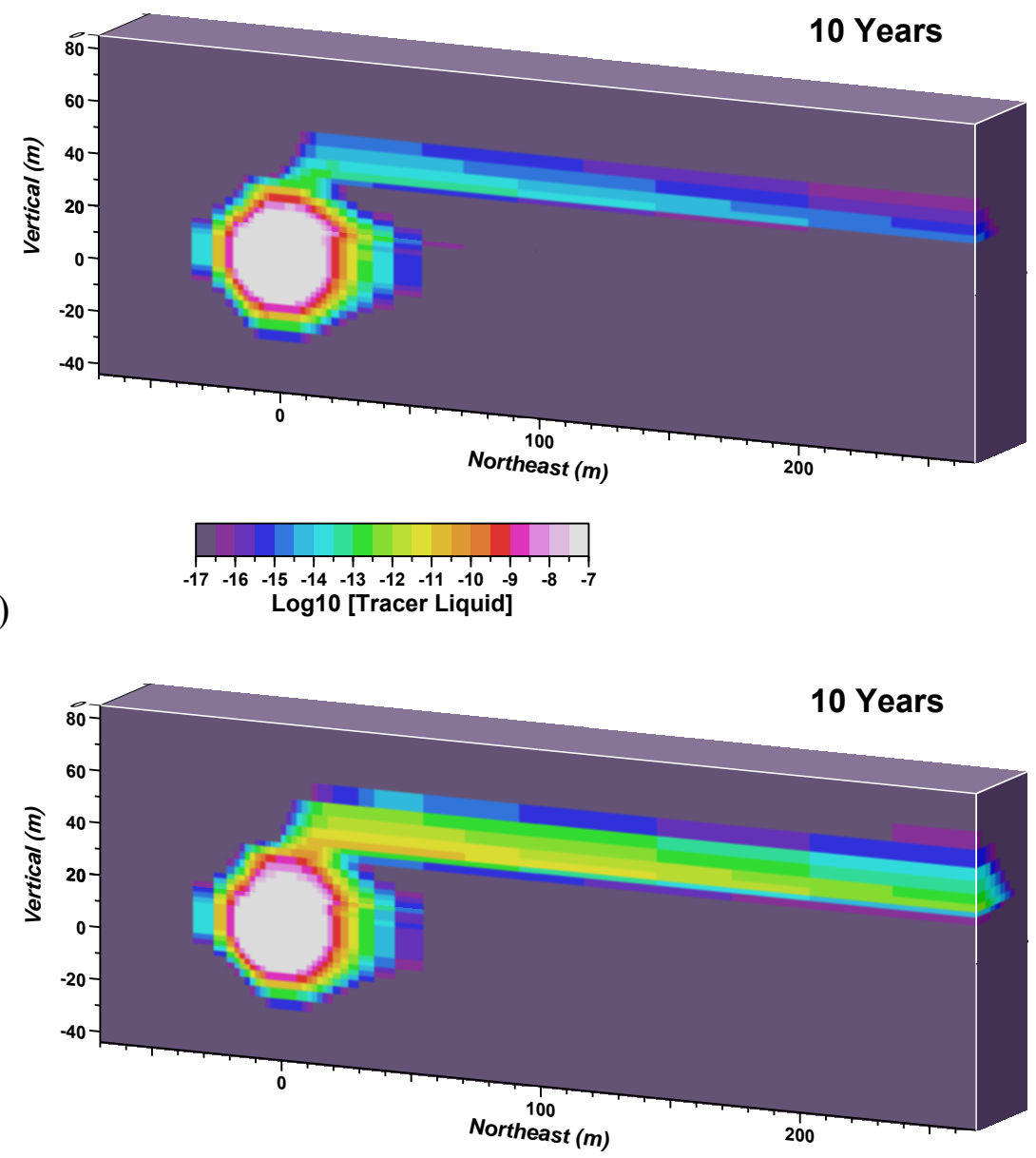

(b)
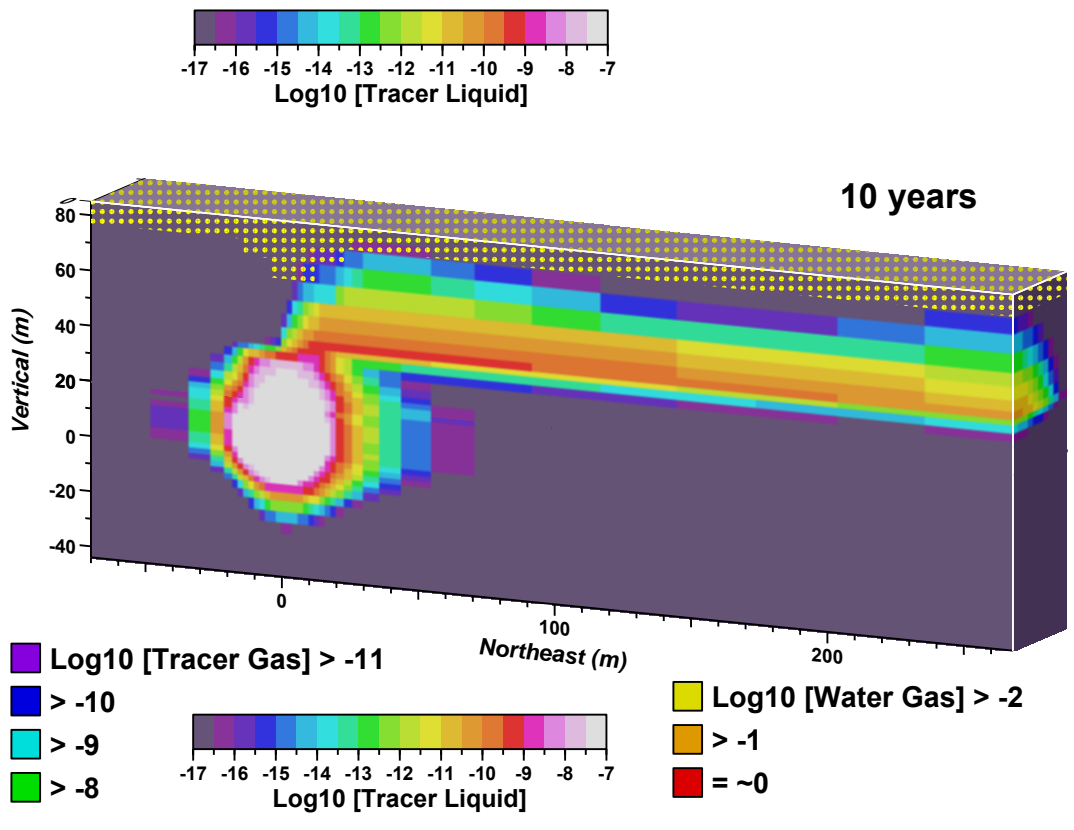

Figure 4.68 NUFT simulation of tracer concentration at $10 \mathrm{y}$ for (a) no-heat, (b) base, and (c) boiling cases at initial melt glass temperature of $350^{\circ} \mathrm{C}$ and 0.99 saturation. 


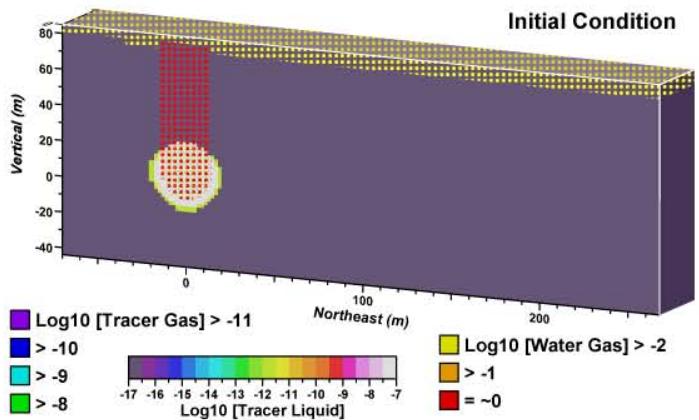

(a)

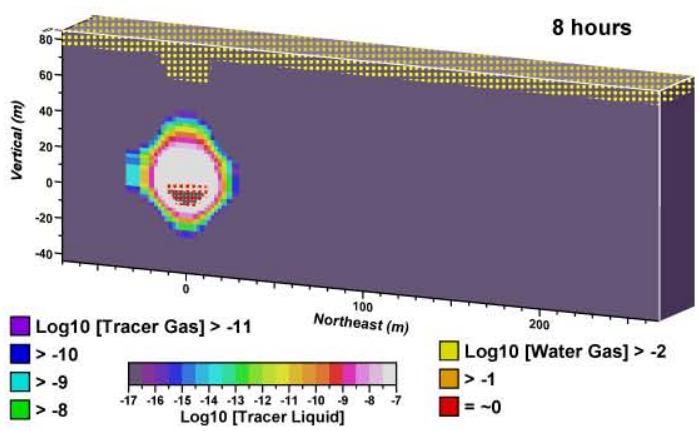

(c)

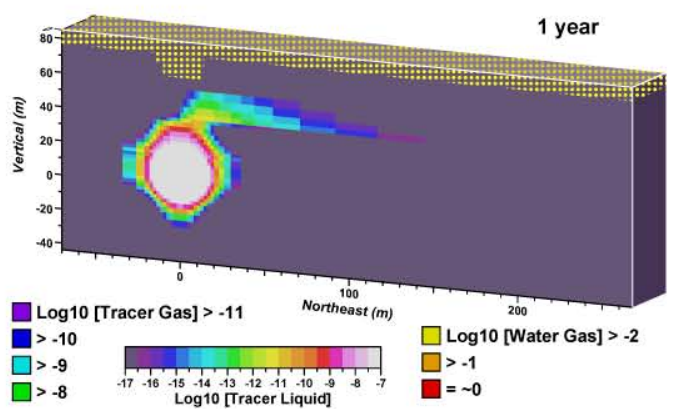

(e)

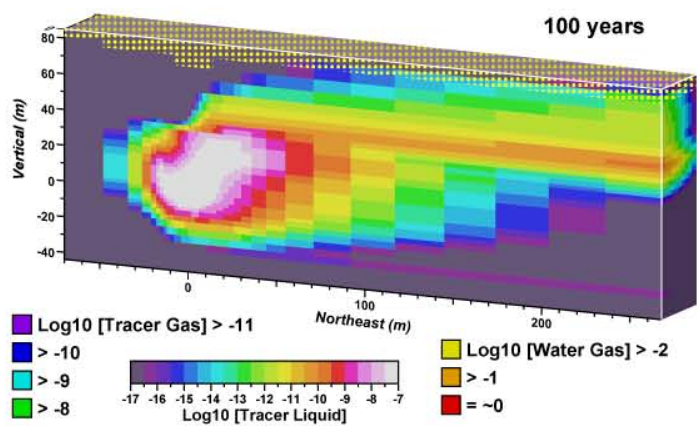

(g)

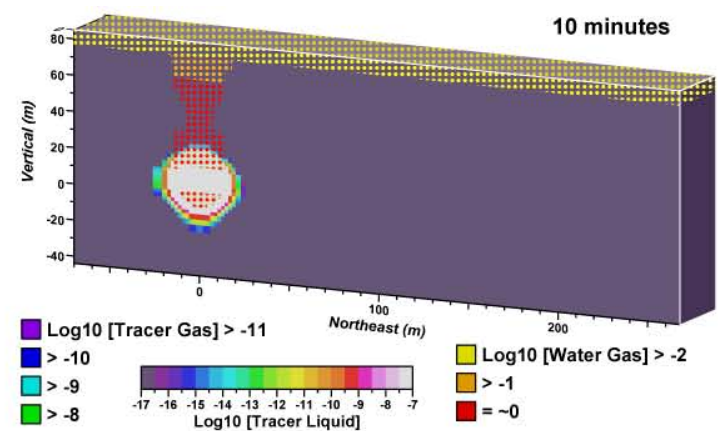

(b)

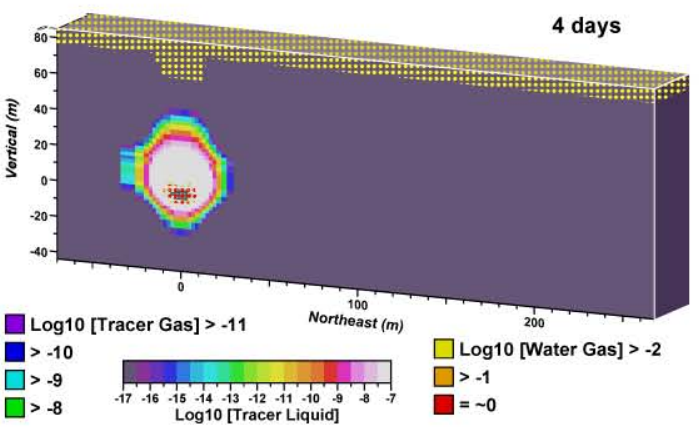

(d)

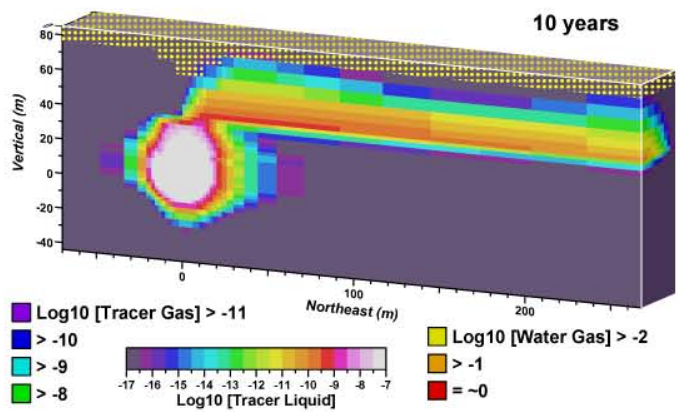

(f)

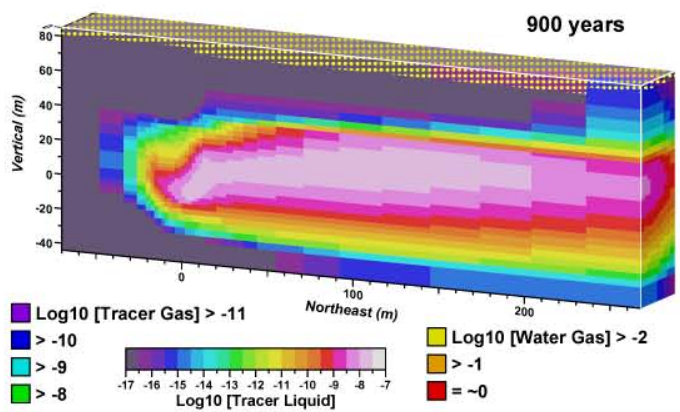

(h)

Figure 4.69 NUFT simulation under boiling case (1) with initial melt glass temperature of $350^{\circ} \mathrm{C}$ and saturation of 0.99 showing simulated liquid-phase tracer concentration and gas-phase tracer and water concentration at (a) initial condition, (b) $10 \mathrm{~min},(\mathrm{c}) 8 \mathrm{~h}$, (d) $4 \mathrm{~d}$, (e) $1 \mathrm{y}$, (f) $10 \mathrm{y},(\mathrm{g})$ $100 \mathrm{y}$, and (h) 900 y.a 
Figure 4.70 compares NUFT simulation of tracer breakthrough at 23, 92, and $268 \mathrm{~m}$ downgradient of the CAMBRIC working point for the sensitivity cases described above, including the base, no-heat, high-pressure, and nine boiling cases. The highpressure case results in very little difference from the base case. The NUFT simulations indicate that initial high test-related pressures would dissipate quickly and cause little cumulative effect on groundwater flow under saturated conditions.

However, different thermal initial conditions did impact tracer breakthrough behavior. Relative to the no-heat and base cases examined previously in Figure 4.62, the boiling cases all produce higher concentrations in the first peak of tracer breakthrough. Maximum concentrations in the first peak are, on average, about one order of magnitude higher for the boiling cases compared to the base case. However, breakthrough behavior for the second peak, visible at the 23- and 92-m breakthrough planes, is nearly identical for all cases. Because the second peak is much longer in duration and higher in concentration, these sensitivity studies indicate that thermal effects at CAMBRIC, with or without heat and including boiling, impact only a very small fraction of the overall tracer transport behavior.

Differences in breakthrough behavior for the boiling cases are related to differences in amount and location of initial heat. Larger and earlier initial breakthrough, particularly at $23 \mathrm{~m}$, is produced with more heat focused in the melt glass zone. Greater initial saturation under the same initial temperature in the melt glass zone produces more initial heat because of the heat capacity of water. The first peak breakthrough behavior after about $10 \mathrm{y}$ for all breakthrough planes is grouped more so by the initial saturation of the melt glass zone than the spatial distribution of heat. The heat-related tracer breakthrough behavior for different boiling cases indicates that the total of the test-related heat is more of a determining factor on thermally enhanced tracer transport after $10 \mathrm{y}$ compared to the spatial distribution of initial heat.

The first peak breakthrough evident in all breakthrough planes is related to tracer transport through Layer $2 b$. Thermal effects would have a larger impact on rapid tracer transport through Layer $2 b$ if the erosional contact between Layer 2 and Layer 3 is lower in elevation than assumed in the NUFT simulations. These simulations suggest that characterization of the alluvial hydrostratigraphy and particularly the shape of the erosional contact between Layer 2 and 3 in central Frenchman Flat near CAMBRIC is important for prediction of nonreactive radionuclide transport. 


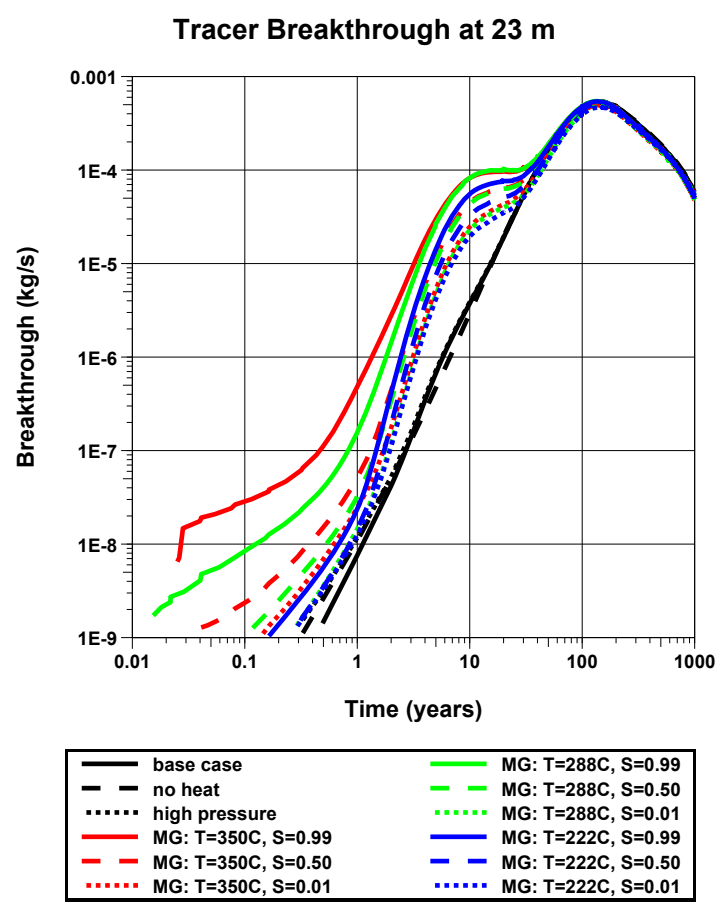

(a)
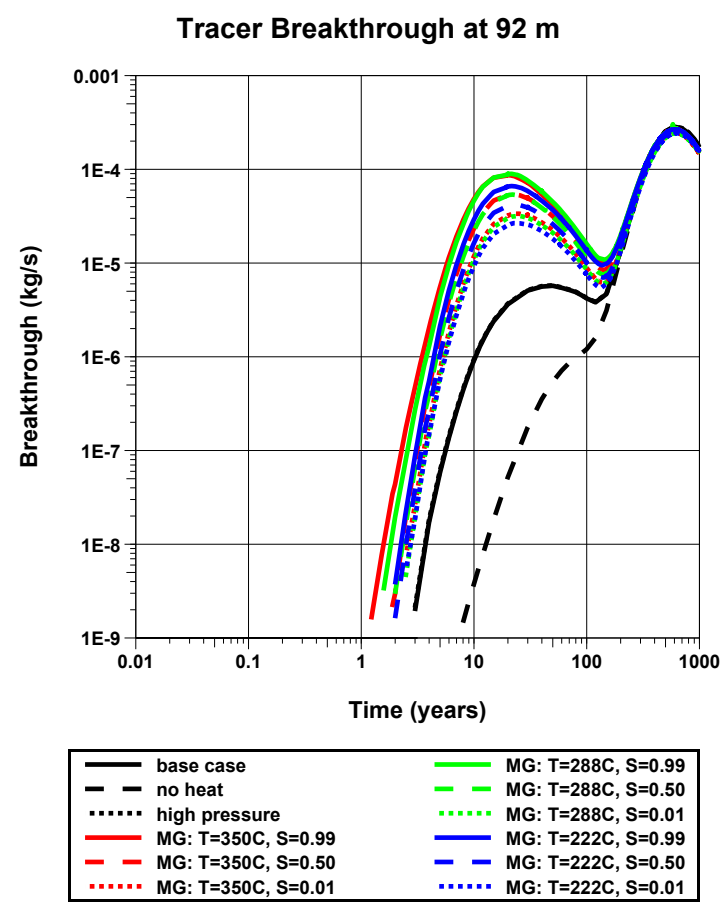

(b)

Tracer Breakthrough at $268 \mathrm{~m}$

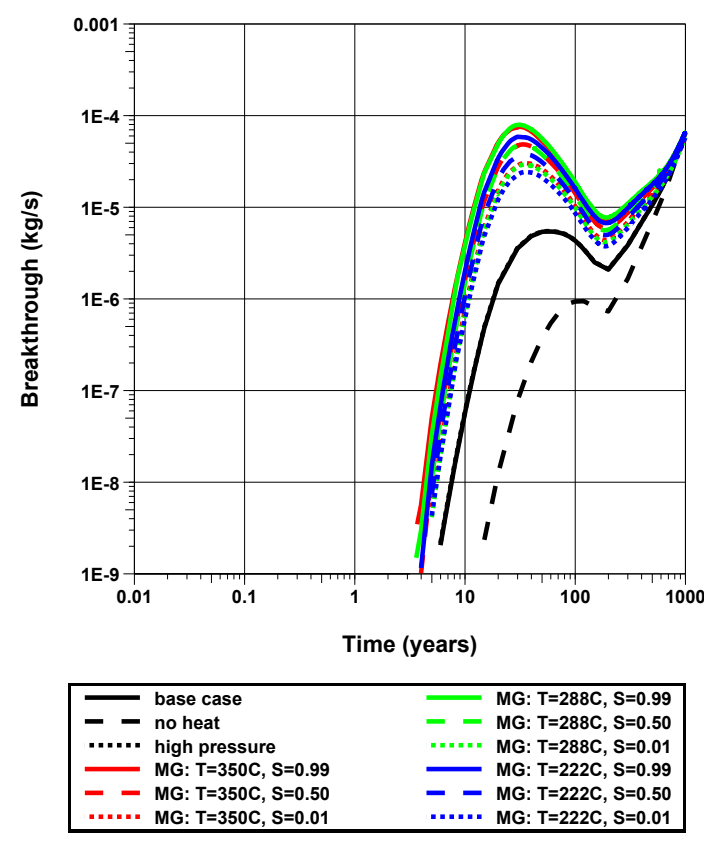

(c)

Figure 4.70 Comparison of NUFT simulation of tracer breakthrough behavior for base, no-heat, high-pressure, and boiling cases at breakthrough planes located (a) $23 \mathrm{~m}$, (b) $92 \mathrm{~m}$, and (c) $268 \mathrm{~m}$ downgradient of the CAMBRIC working point.

\subsubsection{Relative Humidity}

Relative humidity measures the ratio of water vapor density to the saturation vapor density for a given temperature. A relative humidity of 1.0 indicates an equilibrium 
between liquid and gas phase water. In all NUFT simulations, the relative humidity initial condition is 1.0. Figure 4.71 shows NUFT simulations of mean relative humidity in the melt glass zone for the nine boiling cases described in Section 4.7.2.3. The NUFT simulations indicate that relative humidity in the melt glass zone could be below 1.0 for certain cases where the melt glass zone initial temperature is $288^{\circ} \mathrm{C}$ or greater. Also, lower initial saturation favors conditions of lower relative humidity. The lowest simulated relative humidity of about 0.1 for the $350{ }^{\circ} \mathrm{C}$ and 0.01 saturation case is reached within a few hours after the initial condition. Higher initial saturations lead to higher and more delayed minima in relative humidity. Relative humidity returns to 1.0 as boiling conditions cease. However, in the cases of lower-temperature boiling $\left(222^{\circ} \mathrm{C}\right.$ initial condition) and regardless of initial saturation, relative humidity stays at 1.0 during boiling conditions.

\section{Relative Humidity}
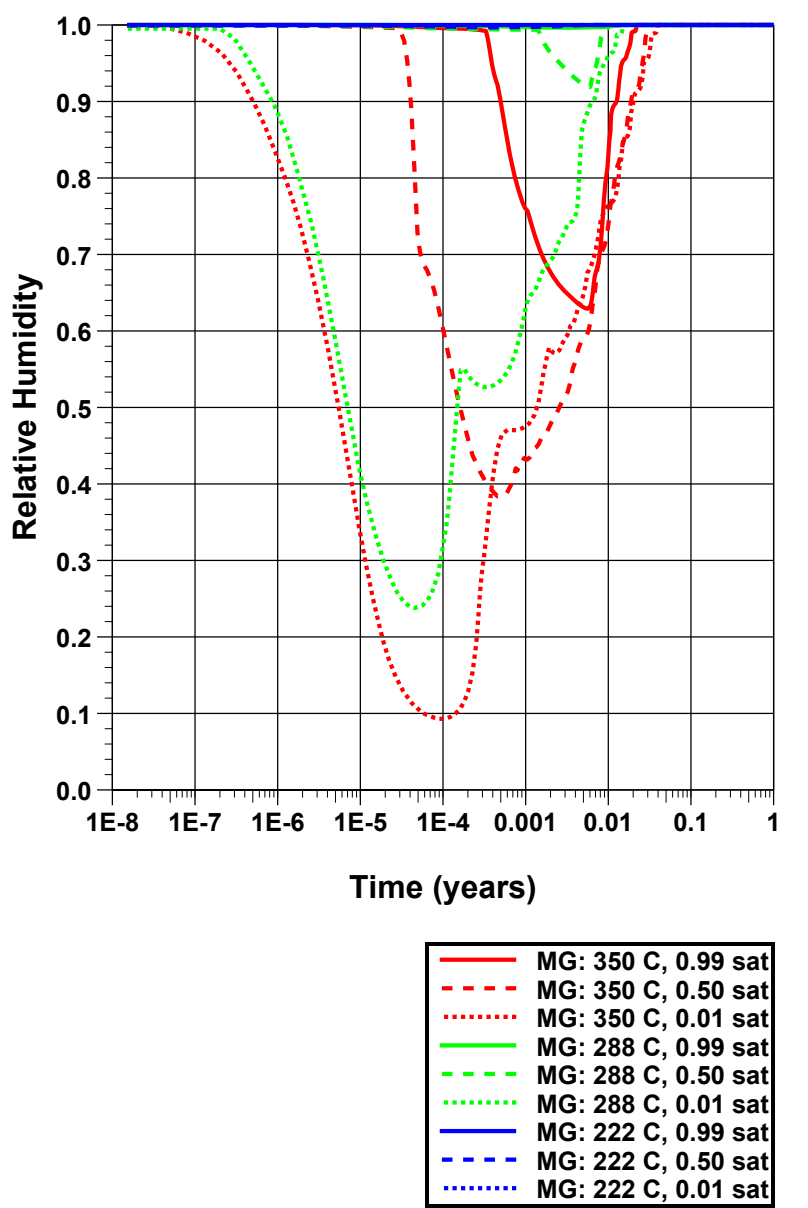

Figure 4.71 NUFT simulations of mean relative humidity in melt glass zone for nine boiling cases. 


\subsubsection{Effects of Diffusion and Numerical Dispersion}

Molecular diffusion and physical dispersion are transport processes that tend to spread and dilute contaminants over time, over and above pure advection in groundwater. In numerical simulations, particularly in grid-based Eulerian algorithms as in NUFT, numerical dispersion errors can also occur and cause similar, yet erroneous, effects.

In the NUFT simulations, physical dispersion (as parameterized by the dispersivity coefficients) was not included. Diffusive transport (alone) was accounted for by setting the free molecular diffusivity in the water phase to $1.0 \times 10^{-9} \mathrm{~m}^{2} / \mathrm{s}$ (Bear and Verruijt, 1987). At low flow velocities, diffusion may play a significant role in transport and cause more transport than advection.

Numerical dispersion occurs if the grid Peclet number, $v L / D$, is sufficiently large, where $v$ is flow velocity, $L$ is grid spacing, and $D$ is a characteristic dispersion. In theNUFT tracer transport simulations, dispersivity is set to zero and, thus, impacts of numerical dispersion are unavoidable. Moreover, the NUFT simulations do not account for macrodispersive effects associated by small-scale heterogeneity. The Lagrangian particle-based simulation results described in Chapter 5 are designed to both account for macrodispersion and eliminate problems associated with numerical dispersion typical of the Eulerian method used in NUFT.

The effects of diffusion and numerical dispersion on the NUFT simulations of transport are important to understand. It is important to assess where diffusion may play a large role in transport, and it is important to assess the relative impact of numerical dispersion on transport predictions based on simulation. The effect of diffusion is relatively easy to assess by running sensitivity cases with the free molecular diffusion coefficient set to zero. This approach enables direct comparison of how molecular diffusion affects transport relative to the base case. Transport behavior not visible in the zero molecular diffusion case can be attributed to molecular diffusion. Assessing effects of numerical dispersion is less straightforward because of the difficulty of evaluating cumulative effects of numerical dispersion in a transient and variably discretized (in time and space) numerical simulation.

The NUFT code offers a method for correcting for numerical dispersion, a flux-correction method suggested by Smolarkiewicz (1984). This method uses upstream weighting with an anti-diffusive term that cancels a portion of the first-order numerical dispersion flux. Efficacy of this correction term, like numerical dispersion itself, is also difficult to evaluate over the course of the NUFT simulations. However, implementing this numerical dispersion correction offers a means to estimate a portion of the cumulative effects of numerical dispersion relative to the base-case results.

Figure 4.72 compares NUFT simulation tracer breakthrough at three breakthrough planes $(23,92$, and $268 \mathrm{~m})$ for four cases: base, dispersion correction only, dispersion correction and no diffusion, and no diffusion. The breakthrough curve color indicates the distance to the breakthrough plane: blue $=23 \mathrm{~m}$, red $=92 \mathrm{~m}$, and green $=$ $268 \mathrm{~m}$. The different cases are coded by line type: thick solid = base case, dashed $=$ dispersion correction (Dis Cor), dotted $=$ dispersion correction and no diffusion (Dis Cor 
$\&$ Dif $=0)$, and thin solid $=$ no diffusion $(\mathrm{Dif}=0)$. Comparsion of the base case to the dispersion-correction case and the no-diffusion case to the dispersion-correction and nodiffusion case for the first tracer breakthrough peak at the 92 and $268 \mathrm{~m}$ breakthrough planes indicates that numerical dispersion causes earlier breakthrough at a given concentration threshold by about 20 to $40 \%$ and higher peak breakthrough by about 50 to $80 \%$. Timing of peak breakthrough is about the same for all cases, with or without dispersion correction or molecular diffusivity. These results indicate that NUFT simulation of tracer transport through Layer $2 b$ before RNM-2S pumping cannot be attributed entirely to numerical dispersion or diffusion.

\section{Effects of Diffusion and Numerical Dispersion}

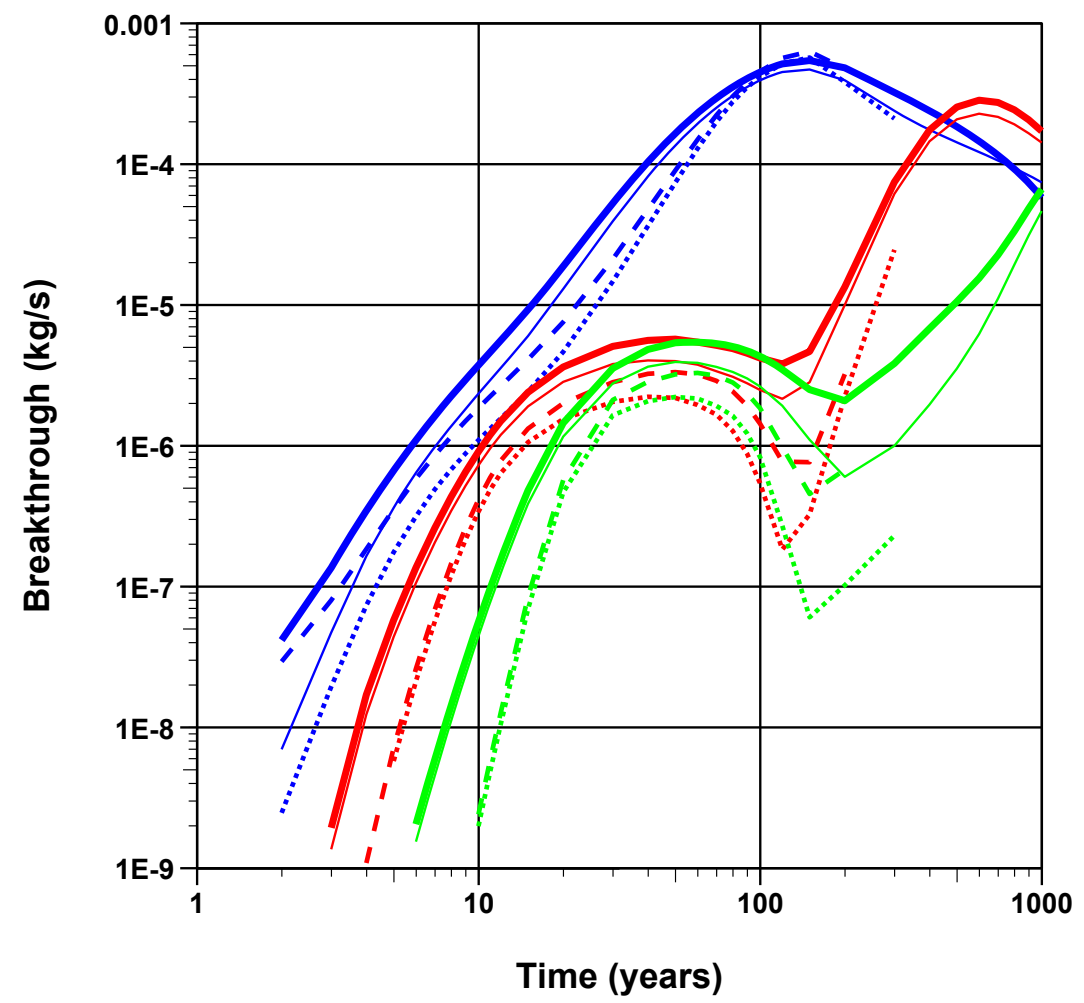

\begin{tabular}{|c|c|c|c|c|c|}
\hline $\begin{array}{l} \\
--- \\
\ldots \ldots \ldots\end{array}$ & $\begin{array}{l}\text { Base Case } 23 \mathrm{~m} \\
\text { Dis Cor } \\
\text { Dis Cor \& Dif=0 } \\
\text { Dif }=0\end{array}$ & $\begin{array}{l}-\ldots- \\
\ldots \ldots \ldots \\
\end{array}$ & $\begin{array}{l}\text { Base Case } 92 \mathrm{~m} \\
\text { Dis Cor } \\
\text { Dis Cor \& Dif=0 } \\
\text { Dif }=0\end{array}$ & 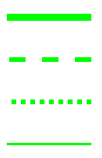 & $\begin{array}{l}\text { Base Case } 268 \text { m } \\
\text { Dis Cor } \\
\text { Dis Cor \& Dif=0 } \\
\text { Dif=0 }\end{array}$ \\
\hline
\end{tabular}

Figure 4.72 NUFT simulation of tracer breakthrough at 23-, 92-, and 268-m downgradient breakthrough planes for base, dispersion correction (Dis Cor), dispersion correction and zero diffusion (Dis Cor \& Dif $=0$ ), and zero diffusion (Dif $=0$ ). 
Figure 4.73 compares NUFT simulations of the tracer concentration field at $10 \mathrm{y}$ for the four cases. Whether or not RNM-2S pumping is considered, these simulations are pertinent to assessing impact of test heat and Layer $2 \mathrm{~b}$ in producing relatively fast-pathway tracer transport within the ambient flow field. As a result of the numerical dispersion correction, tracer concentration in Figure 4.73 (b) shows less dispersion than Figure 4.73 (a), and tracer concentration in Figure 4.73 (c) shows less dispersion than Figure 4.73 (d). Comparing Figure 4.73 (a) and (b) or Figure 4.73 (c) and (d), the dispersion correction has more impact at the leading edge of the tracer plume in Layer $2 b$. This result is consistent with the expectation that numerical dispersion will be greater where flow velocity is higher and discretization is coarse. With diffusivity set to zero, very sharp concentration fronts are maintained near the lower upgradient side of the CAMBRIC source. Such sharp concentration fronts are also maintained by the CRUNCH streamline simulation of tracer transport discussed in Section 4.6.8.2. Considering that the streamline simulation does not account for diffusivity, the NUFT simulations of tracer transport without diffusivity are consistent with the streamline method results. The NUFT simulation results with diffusivity included indicate that diffusion could be a primary mechanism for transport over a scale of a few meters in the downward and upgradient directions relative to the lower portion of the CAMBRIC source region.

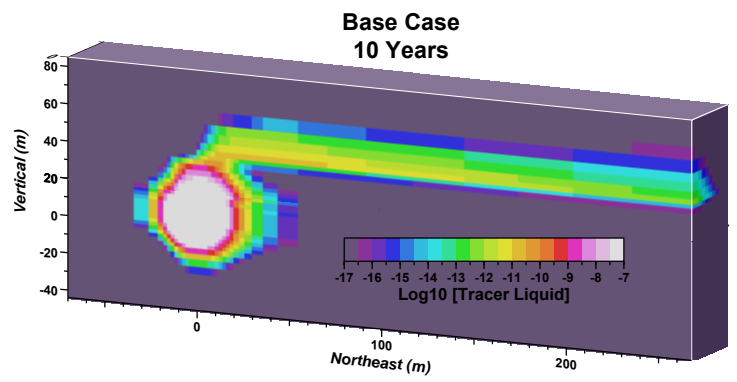

(a)

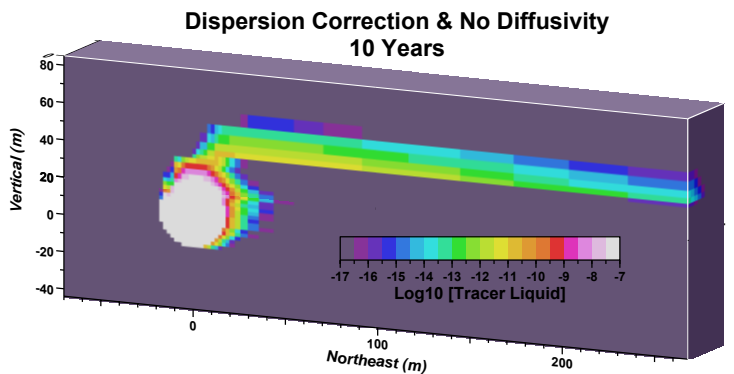

(c)

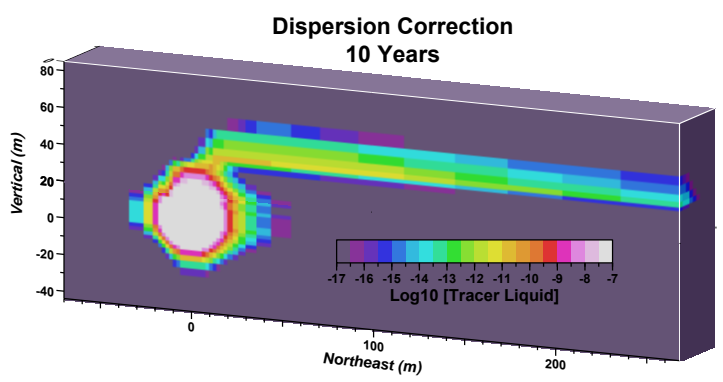

(b)

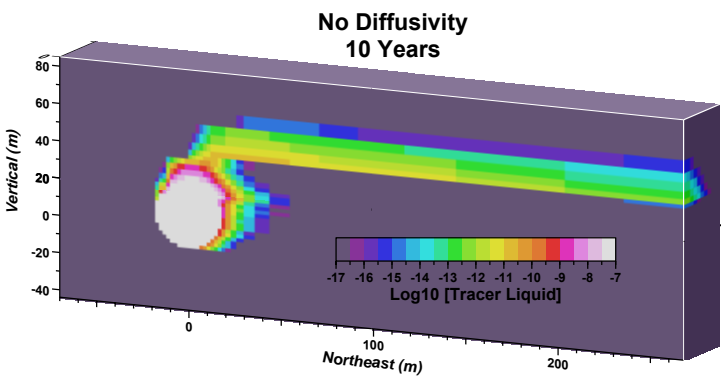

(d)

Figure 4.73 NUFT simulation of tracer concentration field at $10 \mathrm{y}$ for (a) base case, (b) dispersion correction (Dis Cor), (c) dispersion correction and zero diffusion (Dis Cor \& Dif $=0$ ), and (d) zero diffusion (Dif $=0)$. 


\subsection{Effects of Nonlinear Geochemistry}

The CAMBRIC flow model was developed using either the NUFT code or the ParFlow code. The NUFT code simulates variably saturated groundwater multiphase and multicomponent flow, heat flow, and transport using finite-difference-based Eulerian approaches. NUFT simulations focused on early-time flow behavior at CAMBRIC and, in particular, the role of test-derived heat. The ParFlow code efficiently simulates variably saturated groundwater flow for multimillion cell problems on a parallel computing platform using finite-difference algorithms. ParFlow simulations focused on large-scale and long-term flow at CAMBRIC. To evaluate radionuclide transport at CAMBRIC, both the NUFT and ParFlow flow codes were coupled to transport codes. The flow fields simulated in NUFT were imported into streamline-based simulations of radionuclide transport using the reactive transport code $\mathrm{CRUNCH}$. The reactive transport code CRUNCH simulates nonlinear reaction chemistry to evaluate the effects of early-time transient thermal, chemical, and hydrologic effects on radionuclide transport. The flow fields simulated in ParFlow were imported into the SLIM code, which uses Langrangian (particle) tracking methods. The particle tracking code SLIM efficiently simulates the long-term transport behavior of radionuclides using a simplified linear sorption approach. The following sections describe the implementation of the streamline/CRUNCH simulations and, subsequently, the resulting radionuclide transport rates. Chapter 5 describes how the nonlinear geochemistry developed for the streamline/CRUNCH simulations was simplified for use in SLIM transport simulations.

\subsubsection{Streamline Development}

The streamline method introduced in 4.6.8.2 and described in more detail below is modified from past HST modeling to address transient flow. The streamline method for nonlinear reactive transport simulations was chosen for reasons of computational efficiency. The streamline method models $3 \mathrm{D}$ reactive transport processes as a collection of $1 \mathrm{D}$ reactive transport processes occurring along transient flow tubes or "streamlines." The initial volume of chemical species of interest is confined to a small fraction of the entire 3D volume described in the NUFT flow model domain. The streamlines are focused onto this volume to more efficiently simulate radionuclide transport. As a result, the total number of nodes interrogated in the streamline simulation is much smaller than in the $3 \mathrm{D}$ reactive flow simulation. Computational efficiency is critical to these nonlinear reactive transport simulations due to the very large number of chemical reactions included in the model, as will be described below. In the current simulations, there are about 20,000 nodes in a typical streamline simulation. The number of points in the $3 \mathrm{D}$ grid is 308,637 .

There have been a number of improvements in our implementation of the streamline method since the Phase I CAMBRIC HST modeling (Tompson et al., 1999):

- Streamline code modification enables termination of streamlines at a pumping well (Section 4.8.1.1).

- A method for checking off source blocks as streamlines are generated better ensures representation of the initial source region (Section 4.8.1.2). 
- A least-squares method increases accuracy of flux assignment compared to the block-face method previously used (Section 4.8.1.3).

- New algorithms address transient flow, particularly for collecting streamline data to the 3D grid at the end of each time segment (Section 4.8.1.4).

Given a flow field from NUFT, the components of the streamline computation method consist of (1) streamline tracing procedure, (2) computation of the streamline flux, and (3) 1D transport of radionuclides on each streamline using the GIMRT code including their reactions with minerals. After the reactive transport simulation is completed for all the streamlines, the simulation results are either (1) accumulated to a 3D grid for inclusion in the streamline computation using the next flow field; or (2) the breakthrough is accumulated for all the streamlines to determine a global breakthrough at a boundary; or (3) the outflow via a pumping well is accumulated for all the streamlines which exit at a well.

A streamline is defined as a set of points traced out in 3D. Each point contains coordinates in $x, y, z$ and a time of flight, as well as other parameters such as temperature, porosity, and mineral type. The streamline is a collection of piecewise hyperbolic segments. The fundamental computational method used to determine the streamlines, given the 3D flow field, was specified by Pollock (1988). This method assumes a simple linear model for the three components of velocity within each grid block. With this approximation one can analytically compute the trajectory of the streamline through each grid block, which then gives the coordinates of the exit point on a grid-block face and the time of flight to that exit point. This procedure is repeated until some termination criterion is satisfied.

Within the 3D domain, a region exists containing the chemical species of interest; this region is referred to as the "source region." The object of the streamline model is to accurately represent the source region and the subsequent reactive transport of the chemical species along the streamlines and beyond the source region. The resolution of the streamline simulation can be improved by increasing the number of streamlines that pass through each source block. This is controlled by an input parameter, $M_{i n}$ spb , minimum number of streamlines per source block, as defined by Pollock (1998).

A source block is defined as a grid block that contains a chemical species of interest at a concentration above some cutoff value. Current simulations show that requiring at least one streamline per source block is adequate. The selection $\mathrm{Min}_{\mathrm{spb}}$ represents a compromise between accuracy and computation effort.

In order for the streamline to be useful in the modeling of fluid flow, a flux must be assigned to each streamline. In going from a 3D grid representation to a streamline representation, some physical quantities are characterized differently. This is the case for the fluid volume. In the 3D grid model the volume is simply the block volume times the porosity times the saturation. In the streamline representation, the volume of a streamline segment is the fluid flux multiplied by time-of-flight assigned to the segment. If needed, and effective cross-sectional area for the flux can be determined 
for each streamline segment. This cross-sectional area is the segment volume divided by the streamline segment length.

\subsubsection{Streamline Path Computation}

Pollock (1988) describes the computation of the streamline path. It is assumed that the perpendicular component of the fluid velocity is given on all block faces. It is further assumed that within each block, $(i, j, k)$, the velocity varies linearly with its coordinate direction. That is:

$$
\begin{aligned}
& \mathrm{v}_{x}^{i, j, k}(x)=A_{x}^{i, j, k}\left(x-x_{i}\right)+\mathrm{g}_{x}^{i, j, k} \\
& \mathrm{v}_{y}^{i, j, k}(y)=A_{y}^{i, j, k}\left(y-y_{j}\right)+\mathrm{g}_{y}^{i, j, k} \\
& \mathrm{v}_{z}^{i, j, k}(z)=A_{z}^{i, j, k}\left(z-z_{k}\right)+\mathrm{g}_{z}^{i, j, k}
\end{aligned}
$$

where $\mathrm{v}_{x}^{i, j, k}(x), \mathrm{v}_{y}^{i, j, k}(x), \mathrm{v}_{z}^{i, j, k}(x)$ are the flow velocities within the grid block and $\mathrm{g}_{x}^{i, j, k}, \mathrm{~g}_{y}^{i, j, k}$ and $\mathrm{v}_{z}^{i, j, k}(x)$ are the $3 \mathrm{D}$ block face velocity values. The velocity gradients are given by:

$$
\begin{aligned}
& A_{x}^{i, j, k}=\left(\mathrm{g}_{z}^{i+1, j, k}-\mathrm{g}_{z}^{i, j, k}\right) / \Delta x \\
& A_{y}^{i, j, k}=\left(\mathrm{g}_{y}^{i, j+1, k}-\mathrm{g}_{y}^{i, j, k}\right) / \Delta y \\
& A_{z}^{i, j, k}=\left(\mathrm{g}_{z}^{i, j, k+1}-\mathrm{g}_{z}^{i, j, k}\right) / \Delta z
\end{aligned}
$$

The trajectory through each block can be analytically computed using this linear interpolation within each block. The velocity of each particle at the starting position, $\mathrm{v}_{x}^{p}, \mathrm{v}_{y}^{p}$ and $\mathrm{v}_{z}^{p}$, is computed and then the flight time to the six planes containing the six faces of the grid block are computed:

$$
\begin{aligned}
\Delta t_{x, i}^{i, j, k} & =\frac{1}{A_{x}^{i, j, k}} \ln \left(\mathrm{g}_{x}^{i, j, k} / \mathrm{v}_{x}^{p}\right) \\
\Delta t_{x, i+1}^{i, j, k} & =\frac{1}{A_{x}^{i, j, k}} \ln \left(\mathrm{g}_{x}^{i+1, j, k} / \mathrm{v}_{x}^{p}\right) \\
\Delta t_{y, j}^{i, j, k} & =\frac{1}{A_{x y}^{i, j, k}} \ln \left(\mathrm{g}_{y}^{i, j, k} / \mathrm{v}_{y}^{p}\right) \\
\Delta t_{y, j+1}^{i, j, k} & =\frac{1}{A_{y}^{i, j, k}} \ln \left(\mathrm{g}_{y}^{i, j+1, k} / \mathrm{v}_{y}^{p}\right) \\
\Delta t_{z, k}^{i, j, k} & =\frac{1}{A_{z}^{i, j, k}} \ln \left(\mathrm{g}_{z}^{i, j, k} / \mathrm{v}_{z}^{p}\right) \\
\Delta t_{z, k+1}^{i, j, k} & =\frac{1}{A_{z}^{i, j, k}} \ln \left(\mathrm{g}_{z}^{i, j, k+1} / \mathrm{v}_{z}^{p}\right)
\end{aligned}
$$


The minimum positive value of the above six $\Delta t$ is selected as the transit time. The exit face is determined by which $\Delta t$ is the selected minimum. For example, if $\Delta t_{y, j+1}^{i, j, k}$ is the minimum value, then the $y$ face at $j+1$ is the exit face. With the transit time given, the exit position can be computed. The streamline is generated by repeating this process until the streamline satisfies one of the termination citations.

For these simulations the streamlines are mapped from a source block forward in time and backward in time. One of three criteria determines how the forward-in-time half streamline is terminated. These are:

- The streamline is followed until it is at least three times the transport time past the last source block.

- The streamline terminates at a pumping well.

- The streamline intersects a breakthrough plane.

The backward-in-time portion is followed until the end is outside of the source region. This insures that the fluid entering the streamline during the reactive transport simulation is of ambient background composition and temperature. The forward and backward pieces are then combined into one streamline. By doing this, the intersections of the streamline with the source blocks are always interior points in the streamline representation.

\subsubsection{Generating a Set of Streamlines}

To represent the initial chemical species distribution in the streamline model, at least one streamline must pass through each source block. The code generates the streamlines by looping through the list of source blocks, starting a streamline in each block. As each streamline passes through the source blocks, the blocks are checked off the source block list. If the next source block in the list has already been checked off, it is skipped. The resolution of the simulation can be increased by requiring more than one streamline per source block, which is controlled by the input parameter minimum streamlines per block, $\operatorname{Min}_{s p b}$. If $\operatorname{Min}_{s p b}$ is greater than one, the process is repeated until the required minimum is satisfied for all source blocks. Recent simulations show that a $\operatorname{Min}_{\text {spb }}=1$ is adequate.

\subsubsection{Streamline Flux Assignment}

At a minimum, a streamline is defined by a set of positions,

$x_{m, l}(\tau), y_{m, l}(\tau), z_{m, l}(\tau)$, in 3D as a function of time of flight, $\tau_{m, l}$. To use the streamline model to represent a given volume of fluid, a flux must be assigned to each streamline. The accuracy of the streamline transport calculation is crucially dependent on the accuracy of the streamline flux assignment. The flux determines the volume associated with each streamline segment. This, in turn, determines the contribution from each streamline to the total transport out of the domain. 
The flux computation method is based on minimizing grid block volume error, called least squares volume-error-minimization. The volume of a streamline segment, $v_{m, l}^{i, j, k}$, in the $i, j, k$ grid block is given by:

$$
v_{m, l}^{i, j, k}=Q_{m} \Delta \tau_{m, l}^{i, j, k}
$$

where $Q_{m}$ is the flux assigned to the $m^{\text {th }}$ streamline, $\Delta \tau_{m, l}^{i, j, k}$ is the segment's time of flight passing through the $i, j, k$ grid block, and $l$ is the segment index. The block fluid volume in the streamline representation is the sum of all streamline segments encompassed by the $i, j, k$ grid block:

$$
\mathrm{V}_{i, j, k}^{\text {streamline }}=\sum_{m, l} v_{m, l}^{i, j, k}
$$

where the sum over $m, l$ on the right is over all streamlines segments which pass through the grid block $i, j, k$. The fluid volume of the $i, j, k$ grid block in the $3 \mathrm{D}$ grid representation is:

$$
\mathrm{V}_{i, j, k}^{3 D}=\phi_{i, j, k} \Delta V_{i, j, k}
$$

where $\phi_{i, j, k}$ is the porosity and $\Delta V_{i, j, k}$ is the bulk volume of the $i, j, k$ block.

For an ideal case, the streamline segment volume sum would be equal to the total fluid volume in the 3D block:

$$
\mathrm{V}_{i, j, k}^{\text {streamline }}=\mathrm{V}_{i, j, k}^{3 D}
$$

with the possible exception of very simple flows, this relation can only be approximately satisfied for all blocks. The approximate nature of this relation is due to the global nature of the streamline flux because each streamline has the same flux passing through each of its segments. Thus, a single streamline will make the same flux contribution to every grid block it intersects.

This flux computation method strives to minimize the error with respect to all the streamline fluxes. The volume over which this minimization is performed is the volume of the source region. It is important to represent the flow in the source region as accurately as possible. It is not necessary or desirable for the streamlines to represent the fluid volume for a grid block outside of the source region. Attempting to represent the entire 3D volume with streamlines would circumvent the main advantage of the streamline model; that is, its ability to model flow and reactions only in the relevant sub volume of the $3 \mathrm{D}$ grid.

The above set of equations will be approximately solved by a least-squares method. The quantities that are being approximately solved for are the streamline fluxes. The number of unknowns is the number of streamlines and the number of equations is the number of source blocks. For any reasonable streamline simulation, the number of source blocks will be greater than the number of streamlines. The constrained general nonlinear optimization rountine, DBOLS (double precision bounded least squares), from the SLATEC (Sandia, Los Alamos, Air Force Weapons Laboratory Technical Exchange Committee) mathematical library is used to solve the above set of equations. This least- 
squares routine allows one to set a minimum value on each member of the solution, $Q_{\min }$. The minimization must be constrained to give positive values of $Q_{\min }$. It would be inconsistent to allow negative flux values since the direction of flow along the streamline is, by definition, positive. The flow is defined to be in the direction of increasing time of flight.

The success of this method is measured by the error in satisfying the above equation. Another measure of success is the number of streamlines that are set to the minimum flux. This number should be a small fraction of the total number of streamlines. If the minimum flux input parameter is $Q_{\min }$, then streamlines that would otherwise have fluxes less than $Q_{\min }$ are set to $Q_{\min }$. In general, reducing $Q_{\min }$ reduces the number of minimum flux streamlines to a point. However, reducing this quantity below some minimum value does not affect the results.

\subsubsection{Streamline Application in a Transient Flow Field}

The NUFT transient flow model simulations are described by a sequential set of steady-state flow fields. Each of these flow fields describes flow over a short time segment. To model reactive transport in a flow field that is evolving in time (a transient flow field), a number of successive streamline reactive transport simulations is used over a short time segment. Each time segment comprises a steady-state flow field segment of the transient NUFT flow model simulation.

At the end of each time segment, the streamline's output concentrations are collected to a 3D grid. These concentrations are used to define a new source-block region. The next streamline reactive transport simulation is generated based on the next NUFT flow field. However, in general, NUFT produces steady-state flow fields at smaller time intervals than necessary for streamline reactive transport calculations. Thus, the computational effort of the simulations can be reduced by reducing the number of time steps included in streamline calculations. The identification of streamline time segments was based on two criteria. In the first, the error in streamline position due to skipping NUFT time steps was evaluated. This criterion consisted of comparing the end position of two streamlines starting in a source block. One streamline is advanced using only the NUFT flow field at the starting time. The other streamline is advanced using the time-dependent NUFT flow. At each NUFT output time, the end positions of these two streamlines are compared. If this difference is greater than a displacement of $0.5 \mathrm{~m}$, or $1 / 4$ of the minimum grid spacing of $2 \mathrm{~m}$ in the source volume, then the NUFT time step cannot be skipped. This $0.5-\mathrm{m}$ displacement requirement is designed to maintain spatial resolution under transient flow conditions without generating more time segments than needed. The second criterion examined the change in temperature over time. It has been found that the time-integrated temperature can be allowed to change by about $30 \mathrm{~K}$ in a particular grid block before significant changes in overall reactive transport results are noted. Both of these criteria are examined for each source block. The first block that satisfies either of these criteria stops the NUFT time-skipping and determines the streamline time segment. 


\subsubsection{Formulation of Model Geochemical Processes}

The previous section described the development of sets of streamlines that can capture the flow field at locations where radionuclides of interest are present. Each streamline is, in essence, a 1D simulation of flow and transport. The CRUNCH code is used to simulate the transport of radionuclides in each streamline. The CRUNCH code is an updated and combined version of the Global Implicit Multi-component Reactive Transport (GIMRT) and the Operator Splitting 3D (OS3D) codes developed by Steefel and Yabusaki (1996). CRUNCH simulates multicomponent mass transport in porous media under non-isothermal conditions, including consideration of zonal variations in mineralogy and fluid chemistry. Aqueous speciation, surface complexation, ion exchange, mineral dissolution/precipitation, and radionuclide decay are all modeled explicitly. Also, in these streamline calculations, advection, diffusion, and chemical reaction processes occurring over each time step are implicitly coupled.

To simulate the transport of radionuclides in each streamline calculation, a large number of parameters are required for each node along each streamline. Parameters included in CRUNCH simulations are:

- temperature

- flow velocity (or flux)

- porosity

- mineralogy

- major element aqueous concentrations

- radionuclide concentrations

- major element and radionuclide aqueous speciation

- major element and radionuclide surface complexation

- major element and radionuclide ion exchange

- major element and radionuclide mineral solubility

- major element and radionuclide mineral dissolution/precipitation rates

The temperature, flow velocity, and porosity are defined in the NUFT flow model and are imported directly into the streamlines. The remaining parameters are identified in the following several sections of this chapter. 


\subsubsection{Mineralogy}

Table 2.3 lists the mineralogy (mass fractions) for each alluvial layer identified in Warren et al. (2002). These layer mineralogies correspond to hydrofacies included in the NUFT flow model and whose hydraulic conductivities vary (Table 4.5). Background alluvium (AL, ALv) and atmosphere (ATM) hydrofacies mineralogies are not relevant since transport does not occur within them. The RNM-2S gravel pack (GRAV) was identified as 3/8- to 1/4-in. gravel (Stoller-Navarro, 2004a). As such, we expect it to be essentially non-sorbing and its mineralogy is ignored. The slotted interval in RNM-2S is also assumed to be non-sorbing. The remaining hydrofacies can be mapped to the alluvium layers listed in Table 2.3 in the following manner:

- AL1v, AL2v, AL2a, AL2b, AL3, AL4, AL5, AL6, AL7, AL8, AL9, and AL10 hydrofacies are mapped directly to alluvium layers in Table 2.3.

- CZ, CAV, and PIM are located entirely within Layer 3 and have the same mineralogy.

- CHM1, CHM2, and CHM3 hydrofacies have Layer 3, Layer 2, and Layer 2 mineralogies, respectively.

- $\mathrm{MG}$ is the melt glass zone and is located entirely within Layer 3. However, the mineral mass fractions are reduced due to the incorporation of nuclear melt glass in this zone.

- DITCH is located entirely in Layer 1 and has the same mineralogy.

To reduce the number of minerals included in the model, only those minerals that are involved in sorption or are likely to dissolve or precipitate during model simulations are included. Thus, the initial mineralogy of each node in the domain was populated using the abridged mineralogy listed in Table 4.8. The mineral matrix accounts for the mass fraction of all minerals considered to be non-sorbing in this model (e.g., feldspar, opal, and quartz). 
CHAPTER 4: CALIBRATION AND ASSESSMENT MODELS

Table 4.8. Initial mineralogy of hydrofacies distributed within the NUFT flow model domain.

\begin{tabular}{|c|c|c|c|c|c|c|c|c|c|}
\hline Unit $^{1}$ & Hydrofacies $^{2}$ & Calcite & Hematite & Mica & Smectite & Clinoptilolite & Matrix & Glass & Porosity $^{3}$ \\
\hline & & \multicolumn{8}{|c|}{ 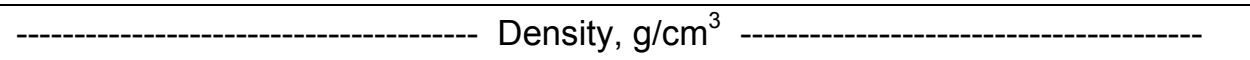 } \\
\hline & & 2.71 & 5.27 & 2.83 & 2.83 & 2.13 & 2.5 & 2.5 & \\
\hline & & \multicolumn{8}{|c|}{ 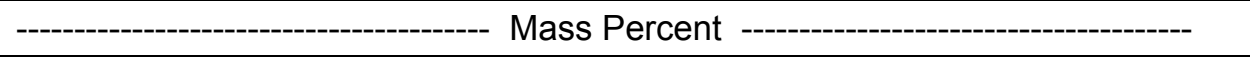 } \\
\hline 1 & $\begin{array}{l}\text { AL1v, } \\
\text { DITCH }\end{array}$ & 4.0 & 1.7 & 5.5 & 5.5 & 2.5 & 80.8 & 0 & 0.36 \\
\hline 2 & $\begin{array}{l}\text { AL2v, } \\
\text { AL2a, } \\
\text { AL2b }\end{array}$ & 3.4 & 0.4 & 2.6 & 11.2 & 3.9 & 78.5 & 0 & 0.36 \\
\hline 3 & AL3 & 0.9 & 0.4 & 4.6 & 10.5 & 21.6 & 62.0 & 0 & 0.32 \\
\hline 4 & AL4 & 1.9 & 0.5 & 6.2 & 12.2 & 17.3 & 62.0 & 0 & 0.32 \\
\hline 5 & AL5 & 2.6 & 0.5 & 6.7 & 10.5 & 12.2 & 67.5 & 0 & 0.32 \\
\hline 6 & AL6 & 0.9 & 0.5 & 4.5 & 13.3 & 2.6 & 78.3 & 0 & 0.32 \\
\hline 7 & AL7 & 3.4 & 0.6 & 4.3 & 13.8 & 2.6 & 75.4 & 0 & 0.32 \\
\hline 8 & AL8 & 2.7 & 0.6 & 3.3 & 22.2 & 1.3 & 70.0 & 0 & 0.32 \\
\hline 9 & AL9 & 14.1 & 0.2 & 2.9 & 30.3 & 3.4 & 49.1 & 0 & 0.3 \\
\hline 10 & AL10 & 3.6 & 0.5 & 3.7 & 16.4 & 0.3 & 75.5 & 0 & 0.3 \\
\hline 11 & AL11 & 3.4 & 0.5 & 4.1 & 11.1 & 11.0 & 70.0 & 0 & 0.3 \\
\hline 12 & AL12 & 1.9 & 0.6 & 2.4 & 14.9 & 0.5 & 79.7 & 0 & 0.3 \\
\hline 2 & $\begin{array}{l}\text { CHM2, } \\
\text { CHM3 }\end{array}$ & 3.4 & 0.4 & 2.6 & 11.2 & 3.9 & 78.5 & 0 & 0.36 \\
\hline 3 & CHM1 & 0.9 & 0.4 & 4.6 & 10.5 & 21.6 & 62.0 & 0 & 0.36 \\
\hline 3 & CAV & 0.9 & 0.4 & 4.6 & 10.5 & 21.6 & 62.0 & 0 & 0.32 \\
\hline 3 & $\mathrm{CZ}$ & 0.9 & 0.4 & 4.6 & 10.5 & 21.6 & 62.0 & 0 & 0.27 \\
\hline 3 & MG & 0.80 & 0.37 & 3.91 & 8.99 & 18.41 & 52.87 & ${ }_{4}^{14.65}$ & 0.29 \\
\hline 3 & PIM & 0.9 & 0.4 & 4.6 & 10.5 & 21.6 & 62.0 & 0 & 0.36 \\
\hline
\end{tabular}

${ }^{1}$ Layer 1 mineralogy is taken from UE-5n (Ramspott and McArthur, 1977, and Beiriger, 1977). All other layer mineralogies are taken from ER-5-4 (Warren et al., 2002).

${ }^{2}$ From Table 4.5 .

${ }^{3}$ Taken directly from NUFT flow model, Table 4.5.

${ }^{4}$ Mass fraction calculated based on 700 -t/kt-yield glass production and glass zone volume described in Section 4.8.2.3. 
In addition to the minerals listed in Table 4.8, a large number of minerals were included that were not initially present. These minerals may form, based on 1D simulations and laboratory glass dissolution experiments, as a result of glass dissolution, particularly at high temperatures. The minerals included:

- Cristobalite( $\beta)$
- Muscovite
- K-Feldspar
- Albite
- Anorthite
- Prehnite
- Boehmite
- Gibbsite

- Cristobalite( $\beta)$

- Muscovite

- Albite

- Anorthite

- Prehnite

- Gibbsite
- Illite

- Beidellite

- Clinochlore

- Montmorillonite

- Nontronite

- Kaolinite

- Goethite

- $\mathrm{AmOHCO}_{3}$

- $\mathrm{EuOHCO}_{3}$
- $\mathrm{Sm}(\mathrm{OH})_{3}(\mathrm{am})$

- $\mathrm{PuO}_{2}(\mathrm{am})$

- $\mathrm{PuO}_{2} \mathrm{OH}(\mathrm{am})$

- Schoepite

- Celestite

- $\mathrm{NpO}_{2} \mathrm{OH}(\mathrm{am})$

- $\mathrm{O}_{2}(\min )$

The mineral $\beta$-cristobalite was chosen as the primary $\mathrm{SiO}_{2}(\mathrm{aq})$ solubility controlling phase. Groundwaters at NTS are typically in equilibrium with this silica phase. Muscovite was used as a proxy for ion exchanging micas reported in Table 4.8. However, it was not allowed to dissolve or precipitate. Potassium feldspar, albite, and anorthite are three minerals in the feldspar group and can all be found at the NTS. Typically, these minerals would form at above ambient temperatures. Boehmite and gibbsite are two aluminum oxide minerals that could provide an $\mathrm{Al}$ sink during glass dissolution. Illite is a micaceous mineral with a chemical composition intermediate between muscovite and montmorillonite. Illite is abundant in NTS alluvium. Beidellite, montmorillonite, and nontronite are all end members in the smectite group of minerals. They represent a variety of clays likely to form at low temperatures as a result of slow glass dissolution. The mineral clinochlore is part of the chlorite group of minerals. These minerals typically form under low-grade metamorphic conditions but may also form under ambient conditions in soils. The precipitation of the chlorite group of minerals provides a sink for $\mathrm{OH}^{-}$species and prevents unrealistic $\mathrm{pH}$ values in the model. Kaolinite is a common aluminosilicate clay that is observed in NTS alluvium. Goethite is a secondary iron oxide mineral likely to form as $\mathrm{Fe}(\mathrm{III})$ concentrations in solution increase. $\mathrm{AmOHCO}_{3}, \mathrm{EuOHCO}_{3}, \mathrm{Sm}(\mathrm{OH})_{3}(\mathrm{am}), \mathrm{PuO}_{2}(\mathrm{am}), \mathrm{PuO}_{2} \mathrm{OH}(\mathrm{am})$, schoepite, celestite, and $\mathrm{NpO}_{2} \mathrm{OH}(\mathrm{am})$ are the relevant secondary minerals that can form as a result of increased radionuclide concentrations in groundwater. $\mathrm{O}_{2}(\mathrm{~min})$ is a proxy mineral used to control the $\mathrm{O}_{2}(\mathrm{~g})$ fugacity in groundwater constant. As described below, the $\mathrm{O}_{2}(\mathrm{~g})$ fugacity was set to $10^{-20}$ bars and held constant in these simulations.

\subsubsection{Major Element Aqueous Concentrations}

The initial concentration of major elements in groundwater was reported in Table 2.2 and was the starting solution composition at all nodes in the model domain. Note that fluoride was not included in the model. While the negatively charged anion could complex with cationic radionuclides and alter their sorption behavior, previous evaluation of the role of fluoride determined it to be relatively minor (Bruton and Nimz, 2005). 
In addition to the elements listed in Table 2.2, several other element concentrations were required for the model. These include:

- $\mathrm{Al}$

- $\mathrm{O}_{2}(\mathrm{aq})$

- $\mathrm{Fe}$

The concentration of $\mathrm{Al}$ was initially set to equilibrium with clinoptilolite. The $\mathrm{O}_{2}(\mathrm{aq})$ concentration was set to equilibrium with an $\mathrm{O}_{2}(\mathrm{~g})$ fugacity of $10^{-20}$ bars. The Fe concentration was set to equilibrium with goethite. Measured Fe concentrations in wells near CAMBRIC range from $0.003 \mathrm{mg} / \mathrm{L}$ for filtered samples to $4.5 \mathrm{mg} / \mathrm{L}$ for unfiltered samples. These concentrations are much higher than expected from iron oxide solubility predictions, suggesting the presence of colloidal Fe in both filtered and unfiltered samples.

While the concentration of Fe and $\mathrm{Al}$ are unlikely to drastically affect these radionuclide transport simulation results, the choice of $\mathrm{O}_{2}(\mathrm{aq})$ has a dramatic effect on the transport behavior of redox-sensitive radionuclides. These radionuclides include Tc, $\mathrm{U}$, $\mathrm{Pu}, \mathrm{Np}$, and a number of others. The choice of $\mathrm{O}_{2}(\mathrm{aq})$ concentration is poorly constrained due to the relatively limited number of in-situ measurements recorded at the NTS. Nevertheless, there is some evidence that cavities of underground nuclear tests may be, at the very least, mildly reducing (Figure 4.74, from Finnegan et al., 2005). The $\mathrm{O}_{2}(\mathrm{~g})$ fugacity used in the model ensured that $\mathrm{Pu}(\mathrm{IV})$ and $\mathrm{Pu}(\mathrm{V})$ species dominated (Figure 4.75). However, it remained relatively oxidizing when compared to redox conditions measured at the NTS and laboratory redox measurements made on heated nuclear melt glass samples. At the initial redox condition used in the simulations, $\mathrm{U}$ and $\mathrm{Np}$ species will remain in the oxidized form. Tc was not allowed to be reduced, which ensures conservative transport behavior of this radionuclide.

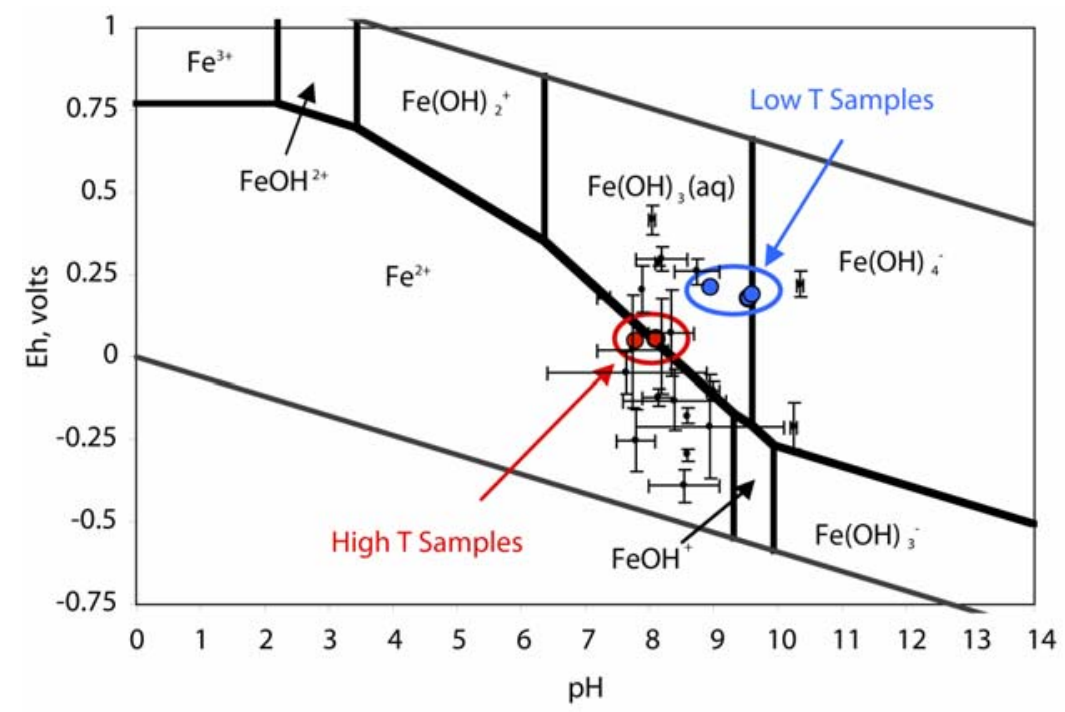

Figure 4.74 Comparison of redox measurements made in the field (Finnegan et al., 2005), redox measurements made on fluid in contact with heated nuclear melt glass (40 to $200{ }^{\circ} \mathrm{C}$, Zavarin et al., 2003), and the stability diagram for Fe species in solution (Fe speciation constants from Johnson and Lundeen, 1997). 


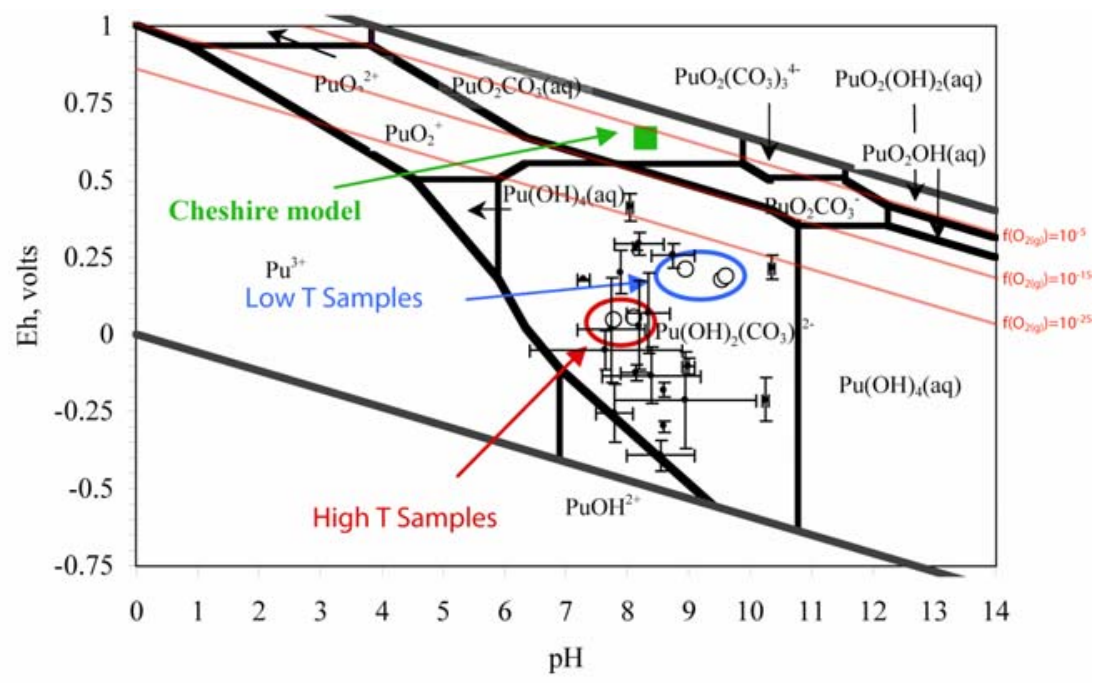

Figure 4.75 Comparison of redox measurements made in the field (Finnegan et al., 2005), redox measurements made on fluid in contact with heated nuclear melt glass (40 to $200{ }^{\circ} \mathrm{C}$, Zavarin et al., 2003), and the stability diagram for $\mathrm{Pu}$ species in solution (Pu speciation constants reported in Table 4.13). Location of $\mathrm{f}\left(\mathrm{O}_{2(\mathrm{~g})}\right)=10^{-5}, 10^{-15}$, and $10^{-25}$ bars, and initial condition used in unclassified CHESHIRE HST simulations is also plotted.

\subsubsection{Radionuclide Concentrations}

Table 3.1 lists the various unclassified RST inventories available for the CAMBRIC test. When calibrating models to the ${ }^{3} \mathrm{H}$ breakthrough at RNM-2S and UE-5n, the CAMBRIC ${ }^{3} \mathrm{H}$ source term from Hoffman et al. (1977) is used. However, during these comprehensive hydrologic source term calculations, the unclassified RST of Bowen et al. (2001) is used. The unclassified RST of Bowen et al. (2001) provides the most comprehensive source term data for unclassified transport modeling calculations. Differences between the various source terms reported in Table 3.1 are discussed in Chapter 3.

Table 3.2 describes the partitioning of RST radionuclides among the glass, rubble, water, and gas fractions, as defined in the IAEA report (1998a). These data provide the framework for initial distribution of radionuclides in the altered zones near CAMBRIC. Conceptually, the glass fraction of the RST is initially incorporated into melt glass and located in the 7-m-thick glass zone at the bottom of the CAMBRIC cavity. The remaining rubble, water, and gas fractions are distributed in the interstitial waters in the 13.4-m-radius cavity and surrounding 18-m-radius compressed zone. As stated in IAEA (1998a), the relationship between rubble, water, and gas fractions primarily is the result of differences in sorptivity and gas solubility of the various radionuclides.

To calculate the initial concentrations of RST radionuclides, the total volume and porosity of each zone is required. These are defined by the observed/estimated dimensions and porosity of the glass, cavity, and compressed zones. Volumes utilize dimensions described in the previous paragraph. Due to the limited model resolution (2-m cubes) within the source region, the total volumes in the model differ slightly from exact geometric volumes. Porosity estimates for alluvium are discussed in Section 4.3.1.1. The glass zone comprises a volume of $2,048 \mathrm{~m}^{3}$. A porosity of 0.29 was 
estimated by combining a glass porosity of 0.1 and alluvium porosity of 0.32 . Volumetrically, the glass zone comprises $11.39 \%$ glass and $88.61 \%$ alluvium. The cavity zone that lies above the glass zone comprises a volume of $8,576 \mathrm{~m}^{3}$. Its porosity is the same as that of the surrounding unaltered alluvium (0.32). The compressed zone comprises a volume of $10,624 \mathrm{~m}^{3}$ and a lower porosity $(0.27)$ resulting from test-induced compression of the alluvium. The section of the compressed zone that lies directly above the cavity is hydrologically distinct because it is coincident with the chimney. Thus, its properties are defined by collapsed chimney rubble properties. This zone has a volume of $3,648 \mathrm{~m}^{3}$ and a porosity identical to that of the overlying chimney zones $(0.36)$. Based on the above values, the total pore volume into which radionuclides are distributed is $7,520 \mathrm{~m}^{3}$. The porosity of all zones (altered and unaltered) is listed in Table 4.5.

Radionuclides are initially distributed the near CAMBRIC based on the IAEA (1998a) partitioning and Bowen et al. (2001) inventory in the following manner:

- Melt glass fraction is incorporated in the glass that is located in the glass zone (700-t/kt-yield melt glass generated produces a volume of $210 \mathrm{~m}^{3}$ ).

- Rubble, water, and gas fractions are homogeneously distributed in the water in the saturated pore space of the compressed zones, cavity zone, and glass zone $\left(7,520 \mathrm{~m}^{3}\right)$.

Importantly, the initial aqueous concentrations of sorbing radionuclides cannot be directly compared to measured radionuclide concentrations reported in Chapter 3 . In the streamline model, partitioning to mineral surfaces or precipitation of radionuclide secondary phases only takes place once simulations begin. Thus, in the initial condition, radionuclides are deposited only in the melt glass or the aqueous phase.

Bowen et al. (2001) include 43 radionuclides in the unclassified RST. For Frenchman Flat, three of those radionuclides $\left({ }^{93 \mathrm{~m}} \mathrm{Nb},{ }^{243} \mathrm{Am}\right.$, and $\left.{ }^{244} \mathrm{Cm}\right)$ have an inventory of $0 \mathrm{~mol}$ and can, thus, be ignored in these calculations. In addition to these three radionuclides, several radionuclides were eliminated because calculations showed they comprised a very small fraction of the total activity or molar quantity at CAMBRIC. This exclusion is identical to the process developed in Pawloski et al. (2001) and was used to reduce the number of radionuclides included in unclassified CHESHIRE HST calculations. The criteria for inclusion in HST calculations are the following:

- The radionuclide must have a reported test-related inventory and this inventory must equal or exceed any corresponding natural inventory in soil or rock.

- For an $\alpha$-decay radionuclide, the ratio of its activity (in $\mathrm{Bq}$ ) or amount (in mol) to the total activity or amount, respectively, of all $\alpha$-decay radionuclides exceeds a value of $10^{-3}(0.1 \%$ of the total $)$ at some time over the next $1,000 \mathrm{y}$.

- For a $\beta$-decay radionuclide, the ratio of its activity (in $\mathrm{Bq}$ ) or amount (in mol) to the total activity or amount, respectively, of all $\beta$-decay radionuclides exceeds a value of $10^{-3}(0.1 \%$ of the total $)$ at some time over the next $1,000 \mathrm{y}$. For the particular cases of ${ }^{121 \mathrm{~m}} \mathrm{Sn}$ and ${ }^{152} \mathrm{Eu}$ that have two principal decay modes, only their respective inventory fractions partaking in a $\beta$-decay process are included in this calculation. 
- For an electron capture/isomeric transition (EC/IT) decay radionuclide, the ratio of its activity (in $\mathrm{Bq}$ ) or amount (in mol) to the total activity or amount, respectively, of all EC/IT decay radionuclides exceeds a value of $10^{-3}(0.1 \%$ of the total) at some time over the next 1,000 y. For the particular cases of ${ }^{121 \mathrm{~m}} \mathrm{Sn}$ and ${ }^{152} \mathrm{Eu}$ that have two principal decay modes, only their respective inventory fractions partaking in an EC/IT decay process are included in this calculation.

- The radionuclide has a reported concentration in groundwater taken from the CAMBRIC cavity, chimney, or near the CAMBRIC event.

Pawloski et al. (2001) used the unclassified average inventory from Smith (2001) which summarizes the total activity (in Bq) and amount (in mol), decay corrected to 1 January 1994, of 48 radionuclides produced by the 76 individual underground nuclear tests detonated below or within $100 \mathrm{~m}$ of the water table in Areas 19 and 20 of the Pahute Mesa at the NTS. In this summary, Smith (2001) specifically distinguishes the natural inventory from soil or rock from the test-derived inventory. Bowen et al. (2001) state that for ${ }^{40} \mathrm{~K},{ }^{232} \mathrm{Th},{ }^{234} \mathrm{U},{ }^{235} \mathrm{U}$, and ${ }^{238} \mathrm{U}$, a significant fraction of the inventory is natural background radioactivity. They calculated the contribution of natural radioactivity to the source term based on a glass production rate of $700-\mathrm{t} / \mathrm{kt}$ yield and $\mathrm{K}$, Th, and $\mathrm{U}$ concentrations of $4 \%, 22 \mathrm{ppm}$, and $3.7 \mathrm{ppm}$ by weight, respectively. However, Bowen et al. (2001) do not identify the total moles of natural versus test-derived radionuclides. Thus, the natural versus test-derived inventories cannot be distinguished. As a result, only radionuclides known to be either wholly or overwhelmingly of a natural background nature can be ignored in these calculations. These radionuclides include ${ }^{40} \mathrm{~K}$ and ${ }^{232} \mathrm{Th}$. All $\mathrm{U}$ isotopes are included because natural versus test-derived inventories cannot be distinguished.

For the $\alpha$-decay radionuclides, ${ }^{232} \mathrm{U},{ }^{233} \mathrm{U},{ }^{234} \mathrm{U},{ }^{236} \mathrm{U},{ }^{237} \mathrm{~Np}$, and ${ }^{242} \mathrm{Pu}$ fall below the $0.1 \%$ criterion. However, all of them were included in our simulations. The $U$ isotopes were all included because many of them have been measured in groundwater. ${ }^{237} \mathrm{~Np}$ was included for the same reason. While ${ }^{242} \mathrm{Pu}$ has not been reported at CAMBRIC, it is not routinely measured. It was deemed important to include all $\mathrm{Pu}$ isotopes in these HST simulations.

For the $\beta$-decay radionuclides, ${ }^{85} \mathrm{Kr}$ and ${ }^{113 \mathrm{~m}} \mathrm{Cd}$ fall below the $0.1 \%$ criterion. However, ${ }^{85} \mathrm{Kr}$ was included because it has been detected in groundwater in and around CAMBRIC. ${ }^{113 \mathrm{~m}} \mathrm{Cd}$ was not included in our simulations.

For the EC/IT-decay radionuclides, ${ }^{26} \mathrm{Al}$ and ${ }^{150} \mathrm{Eu}$ fall below the $0.1 \%$ criterion. However, ${ }^{150} \mathrm{Eu}$ was included because it is one of several Eu isotopes included in our simulations; there was no computational cost associated with including this one additional radionuclide. ${ }^{26} \mathrm{Al}$ was not included in these simulations.

In summary, all 43 radionuclides reported in Bowen et al. (2001) were considered. Three were excluded because they have a 0 -mol source term. Two were excluded because they are overwhelmingly of a natural background source. Two additional radionuclides were excluded based on the $0.1 \%$ criterion. Thus, 36 radionuclides were incorporated in these HST calculations. 
There are a number of radionuclides that were measured in groundwater near CAMBRIC but whose inventory is not reported in Bowen et al. (2001). These are: ${ }^{60} \mathrm{Co}\left(\mathrm{t}_{1 / 2}=5.27 \mathrm{y}\right),{ }^{106} \mathrm{Ru}\left(\mathrm{t}_{1 / 2}=1.02 \mathrm{y}\right),{ }^{125} \mathrm{Sb}\left(\mathrm{t}_{1 / 2}=2.76 \mathrm{y}\right),{ }^{134} \mathrm{Cs}\left(\mathrm{t}_{1 / 2}=2.06 \mathrm{y}\right)$, ${ }^{144} \mathrm{Ce}\left(\mathrm{t}_{1 / 2}=0.78 \mathrm{y}\right),{ }^{147} \mathrm{Pm}\left(\mathrm{t}_{1 / 2}=2.62 \mathrm{y}\right)$, and ${ }^{155} \mathrm{Eu}\left(\mathrm{t}_{1 / 2}=4.76 \mathrm{y}\right)$. The half-life of all these radionuclides is short enough that their long-term contribution to NTS contamination is unlikely to be significant (by $50 \mathrm{y}$, their source term will have decreased to 3 to 20 orders of magnitude less than at $\mathrm{t}_{0}$ ).

Table 4.9 lists the radionuclides, their source term based on Bowen et al. (2001), and their partitioning based on IAEA (1998a). The partitioning of some radionuclides was not reported in IAEA (1998a) but could be estimated by analogy. For example, ${ }^{39} \mathrm{Ar}$ partitioning was not reported in IAEA (1998a) but should be similar to ${ }^{85} \mathrm{Kr}$. The ${ }^{94} \mathrm{Nb}$ partitioning was not reported but is analogous to ${ }^{93} \mathrm{Nb}$. The ${ }^{150} \mathrm{Eu}$ and ${ }^{166}$ Ho partitioning is analogous to ${ }^{152} \mathrm{Eu}$. The ${ }^{232} \mathrm{U},{ }^{234} \mathrm{U},{ }^{235} \mathrm{U}$, and ${ }^{238} \mathrm{U}$ partitioning is analogous to ${ }^{233} \mathrm{U}$ and ${ }^{236} \mathrm{U}$ partitioning.

The partitioning of some radionuclides deviates from that recommended by the IAEA (1998a). The ${ }^{137}$ Cs partitioning to the rubble was set to $80 \%$, significantly higher than the 60 to $75 \%$ reported in IAEA (1998a) because it allowed for both Cs isotopes to have the same partitioning (reduced computational expense), and it more closely resembled the observed partitioning (Chapter 3). Note, however, that the ${ }^{137} \mathrm{Cs}$ partitioning used here is not as high as the partitioning used in Phase I CAMBRIC simulations (Tompson et al., 1999). Similarly, ${ }^{90} \mathrm{Sr}$ partitioning into rubble $(60 \%)$ was set according to IAEA (1998a), which is not as high as the partitioning used in Phase I CAMBRIC simulations (75\%).

The partitioning of 5\% $\mathrm{Pu}$ and $\mathrm{Am}$ isotopes into the rubble fraction is higher than the $2 \%$ recommended by the IAEA (1998a). As stated in Chapter 3, there is significant uncertainty in this value. All previous HST modeling efforts at the NTS have used the $5 \%$ rubble partitioning to provide more conservative radionuclide transport simulation results (Tompson et al., 1999 and Pawloski et al., 2001). 
Table 4.9. Unclassified radiologic source term and radionuclide partitioning between the glass and water at CAMBRIC $\mathrm{t}_{0}$.

\begin{tabular}{|c|c|c|c|c|c|c|c|c|}
\hline Radionuclide & $\begin{array}{l}\text { Half Life } \\
\qquad y r\end{array}$ & $\begin{array}{l}\mathrm{RST}^{\mathrm{a}} \\
\text { moles }\end{array}$ & $\begin{array}{c}\text { Glass }^{b} \\
--P\end{array}$ & $\begin{array}{l}\text { Rubble } \\
\text { Partitioning }\end{array}$ & $\begin{array}{l}\text { Gas } \\
\text { Percen }\end{array}$ & $\begin{array}{l}\text { Water } \\
\text { ht ---- }\end{array}$ & $\begin{array}{l}\text { Glass } \\
\mathrm{mol} / \mathrm{g}\end{array}$ & $\begin{array}{l}\text { Water } \\
\mathrm{mol} / \mathrm{L}\end{array}$ \\
\hline${ }^{3} \mathrm{H}$ & $1.23 \mathrm{E}+01$ & $2.81 \mathrm{E}+00$ & 0 & 0 & 2 & 98 & $0.00 E+00$ & $3.74 \mathrm{E}-07$ \\
\hline${ }^{14} \mathrm{C}$ & $5.73 E+03$ & $1.07 \mathrm{E}-01$ & 0 & 10 & 80 & 10 & $0.00 E+00$ & $1.42 \mathrm{E}-08$ \\
\hline${ }^{36} \mathrm{Cl}$ & $3.01 \mathrm{E}+05$ & $7.50 \mathrm{E}-01$ & 50 & 40 & 0 & 10 & 7.14E-10 & 4.99E-08 \\
\hline${ }^{39} \mathrm{Ar}$ & $2.69 \mathrm{E}+02$ & $4.98 \mathrm{E}-04$ & 0 & 10 & 80 & 10 & $0.00 E+00$ & $6.62 \mathrm{E}-11$ \\
\hline${ }^{41} \mathrm{Ca}$ & $1.03 E+05$ & $1.89 \mathrm{E}+00$ & 70 & 30 & 0 & 0 & $2.51 \mathrm{E}-09$ & $7.52 \mathrm{E}-08$ \\
\hline${ }^{59} \mathrm{Ni}$ & $7.51 \mathrm{E}+04$ & 3.47E-02 & 95 & 5 & 0 & 0 & $6.29 \mathrm{E}-11$ & $2.31 \mathrm{E}-10$ \\
\hline${ }^{63} \mathrm{Ni}$ & $1.00 \mathrm{E}+02$ & $5.68 \mathrm{E}-03$ & 95 & 5 & 0 & 0 & $1.03 E-11$ & 3.77E-11 \\
\hline${ }^{85} \mathrm{Kr}$ & $1.07 \mathrm{E}+01$ & $2.26 \mathrm{E}-03$ & 0 & 10 & 80 & 10 & $0.00 E+00$ & $3.01 \mathrm{E}-10$ \\
\hline${ }^{90} \mathrm{Sr}$ & $2.91 \mathrm{E}+01$ & $2.90 \mathrm{E}-02$ & 40 & 60 & 0 & 0 & $2.21 \mathrm{E}-11$ & $2.32 \mathrm{E}-09$ \\
\hline${ }^{93} \mathrm{Zr}$ & $1.50 \mathrm{E}+06$ & 4.69E-02 & 95 & 5 & 0 & 0 & $8.49 \mathrm{E}-11$ & $3.12 \mathrm{E}-10$ \\
\hline${ }^{94} \mathrm{Nb}$ & $2.03 E+04$ & $3.90 \mathrm{E}-03$ & 95 & 5 & 0 & 0 & 7.06E-12 & $2.59 \mathrm{E}-11$ \\
\hline${ }^{99} \mathrm{Tc}$ & $2.13 E+05$ & $6.96 \mathrm{E}-02$ & 80 & 20 & 0 & 0 & $1.06 \mathrm{E}-10$ & $1.85 \mathrm{E}-09$ \\
\hline${ }^{107} \mathrm{Pd}$ & $6.50 \mathrm{E}+06$ & $3.55 \mathrm{E}-02$ & 70 & 30 & 0 & 0 & $4.73 E-11$ & 1.41E-09 \\
\hline${ }^{121} \mathrm{Sn}$ & $5.50 \mathrm{E}+01$ & $3.58 \mathrm{E}-04$ & 60 & 40 & 0 & 0 & $4.09 \mathrm{E}-13$ & $1.90 \mathrm{E}-11$ \\
\hline${ }^{126} \mathrm{Sn}$ & $1.00 \mathrm{E}+05$ & $5.73 \mathrm{E}-03$ & 70 & 30 & 0 & 0 & 7.64E-12 & $2.29 \mathrm{E}-10$ \\
\hline${ }^{129} \mathrm{I}$ & $1.57 \mathrm{E}+07$ & $1.99 \mathrm{E}-02$ & 50 & 40 & 0 & 10 & $1.90 \mathrm{E}-11$ & 1.33E-09 \\
\hline${ }^{135} \mathrm{Cs}$ & $2.30 \mathrm{E}+06$ & $8.76 \mathrm{E}-02$ & 20 & 80 & 0 & 0 & 3.34E-11 & 9.32E-09 \\
\hline${ }^{137} \mathrm{Cs}$ & $3.02 E+01$ & 7.96E-02 & 20 & 80 & 0 & 0 & $3.03 E-11$ & 8.46E-09 \\
\hline${ }^{151} \mathrm{Sm}$ & $9.00 \mathrm{E}+01$ & $9.17 \mathrm{E}-03$ & 95 & 5 & 0 & 0 & $1.66 \mathrm{E}-11$ & $6.09 E-11$ \\
\hline${ }^{150} \mathrm{Eu}$ & $3.60 \mathrm{E}+01$ & $1.68 \mathrm{E}-07$ & 95 & 5 & 0 & 0 & $3.04 \mathrm{E}-16$ & $1.12 \mathrm{E}-15$ \\
\hline${ }^{152} \mathrm{Eu}$ & $1.35 E+01$ & 1.17E-02 & 95 & 5 & 0 & 0 & $2.12 \mathrm{E}-11$ & $7.78 \mathrm{E}-11$ \\
\hline${ }^{154} \mathrm{Eu}$ & $8.59 E+00$ & $5.73 \mathrm{E}-03$ & 95 & 5 & 0 & 0 & $1.04 \mathrm{E}-11$ & $3.81 \mathrm{E}-11$ \\
\hline${ }^{166} \mathrm{Ho}$ & $1.20 \mathrm{E}+03$ & $6.90 \mathrm{E}-04$ & 95 & 5 & 0 & 0 & $1.25 \mathrm{E}-12$ & $4.59 \mathrm{E}-12$ \\
\hline${ }^{232} U$ & $6.89 \mathrm{E}+01$ & $2.63 \mathrm{E}-07$ & 90 & 10 & 0 & 0 & $4.51 \mathrm{E}-16$ & $3.50 \mathrm{E}-15$ \\
\hline${ }^{233} U$ & $1.59 \mathrm{E}+05$ & $5.94 \mathrm{E}-05$ & 90 & 10 & 0 & 0 & $1.02 \mathrm{E}-13$ & $7.90 \mathrm{E}-13$ \\
\hline${ }^{234} U$ & $2.46 \mathrm{E}+05$ & $2.97 \mathrm{E}-02$ & 90 & 10 & 0 & 0 & $5.09 \mathrm{E}-11$ & $3.95 E-10$ \\
\hline${ }^{235} U$ & $7.04 \mathrm{E}+08$ & $1.69 \mathrm{E}+00$ & 90 & 10 & 0 & 0 & $2.89 \mathrm{E}-09$ & $2.24 \mathrm{E}-08$ \\
\hline
\end{tabular}


Table 4.9. Unclassified radiologic source term and radionuclide partitioning between the glass and water at CAMBRIC $t_{0}$.

\begin{tabular}{|c|c|c|c|c|c|c|c|c|}
\hline Radionuclide & $\begin{array}{c}\text { Half Life } \\
\text { yr }\end{array}$ & $\begin{array}{l}\mathrm{RST}^{\mathrm{a}} \\
\text { moles }\end{array}$ & $\begin{array}{c}\text { Glass }^{b} \\
\text { P }\end{array}$ & $\begin{array}{l}\text { Rubble } \\
\text { Partitioning }\end{array}$ & $\begin{array}{l}\text { Gas } \\
\text { Percen }\end{array}$ & $\begin{array}{l}\text { Water } \\
\text { th ---- }\end{array}$ & $\begin{array}{l}\text { Glass } \\
\mathrm{mol} / \mathrm{g}\end{array}$ & $\begin{array}{l}\text { Water } \\
\text { mol/L }\end{array}$ \\
\hline${ }^{236} \mathrm{U}$ & $2.34 \mathrm{E}+07$ & 1.96E-02 & 90 & 10 & 0 & 0 & 3.36E-11 & $2.61 \mathrm{E}-10$ \\
\hline${ }^{238} \mathrm{U}$ & $4.47 \mathrm{E}+09$ & $1.19 \mathrm{E}+02$ & 90 & 10 & 0 & 0 & $2.04 \mathrm{E}-07$ & $1.58 \mathrm{E}-06$ \\
\hline${ }^{237} \mathrm{~Np}$ & $2.14 \mathrm{E}+06$ & $6.37 \mathrm{E}-03$ & 95 & 5 & 0 & 0 & $1.15 \mathrm{E}-11$ & $4.24 \mathrm{E}-11$ \\
\hline${ }^{238} \mathrm{Pu}$ & 8.77E+01 & $9.84 \mathrm{E}-03$ & 95 & 5 & 0 & 0 & $1.78 \mathrm{E}-11$ & $6.54 \mathrm{E}-11$ \\
\hline${ }^{239} \mathrm{Pu}$ & $2.41 \mathrm{E}+04$ & $9.55 \mathrm{E}+00$ & 95 & 5 & 0 & 0 & $1.73 \mathrm{E}-08$ & $6.35 \mathrm{E}-08$ \\
\hline${ }^{240} \mathrm{Pu}$ & $6.56 \mathrm{E}+03$ & $6.42 \mathrm{E}-01$ & 95 & 5 & 0 & 0 & 1.16E-09 & 4.27E-09 \\
\hline${ }^{241} \mathrm{Pu}$ & $1.44 \mathrm{E}+01$ & $6.63 \mathrm{E}-02$ & 95 & 5 & 0 & 0 & $1.20 \mathrm{E}-10$ & $4.41 \mathrm{E}-10$ \\
\hline${ }^{242} \mathrm{Pu}$ & $3.75 E+05$ & $3.02 \mathrm{E}-03$ & 95 & 5 & 0 & 0 & $5.47 \mathrm{E}-12$ & 2.01E-11 \\
\hline${ }^{241} \mathrm{Am}$ & $4.33 E+02$ & $1.42 \mathrm{E}-02$ & 95 & 5 & 0 & 0 & $2.56 \mathrm{E}-11$ & $9.42 \mathrm{E}-11$ \\
\hline
\end{tabular}

${ }^{a}$ From Bowen et al. (2001), decay-corrected for CAMBRIC to May 14, 1965.

${ }^{b}$ The glass fraction is referred to as the lava fraction in IAEA (1998a).

To minimize the computational effort of simulating the transport of 36 radionuclides, they were categorized into 13 radionuclide classes with distinct partitioning and transport behavior (Table 4.10). The total number of moles in each radionuclide class, in general, equals the sum of all radionuclides that fall within that class. Exceptions to this include:

- Tracer (rubble) is assigned a total mole inventory of 1.0.

- Tracer (glass) is assigned a total mole inventory of 1.0 .

- $\mathrm{Eu}$ is assigned the total mole inventory of ${ }^{150} \mathrm{Eu},{ }^{152} \mathrm{Eu}$, and ${ }^{154} \mathrm{Eu}$.

Two radionuclide classes - Tracer (rubble) and Tracer (glass) — are used to simulate the transport behavior of non-sorbing radionuclides. One tracer is distributed exclusively in the water while the other is placed exclusively in the glass. The transport behavior of all non-sorbing radionuclides can be predicted based on a combination of the transport behavior of these two radionuclide classes. The radionuclide ${ }^{166} \mathrm{Ho}$ is included in the Eu class because sufficient data is not available to simulate its transport behavior directly. Holmium-166 transport behavior is assumed to be similar to the Eu isotopes. The radionuclide ${ }^{241} \mathrm{Pu}$ forms its own radionuclide class because it has a short half-life and ingrowth into ${ }^{241} \mathrm{Am}$ distinguishes it from all other $\mathrm{Pu}$ isotopes. 
Table 4.10. Initial partitioning of radionuclide classes.

\begin{tabular}{|c|c|c|c|c|}
\hline $\begin{array}{l}\text { Radionuclide } \\
\text { Class }\end{array}$ & Radionuclide $^{1}$ & Total & Glass & Water \\
\hline & & mol & $\mathrm{mol} / \mathrm{g}$ & $\mathrm{mol} / \mathrm{L}$ \\
\hline Tracer (rubble) & \multirow{2}{*}{$\begin{array}{l}{ }^{3} \mathrm{H},{ }^{14} \mathrm{C},{ }^{36} \mathrm{Cl},{ }^{39} \mathrm{Ar},{ }^{85} \mathrm{Kr},{ }^{99} \mathrm{Tc},{ }^{129} \mathrm{I}, \\
{ }^{93} \mathrm{Zr},{ }^{94} \mathrm{Nb},{ }^{107} \mathrm{Pd},{ }^{121} \mathrm{Sn},{ }^{126} \mathrm{Sn}\end{array}$} & $1.00 \mathrm{E}+00$ & $0.00 \mathrm{E}+00$ & $1.33 \mathrm{E}-07$ \\
\hline Tracer (glass) & & $1.00 \mathrm{E}+00$ & 1.90E-09 & $0.00 \mathrm{E}+00$ \\
\hline${ }^{41} \mathrm{Ca}$ & ${ }^{41} \mathrm{Ca}$ & $1.89 \mathrm{E}+00$ & $2.51 \mathrm{E}-09$ & $7.52 \mathrm{E}-08$ \\
\hline $\mathrm{Ni}$ & ${ }^{59} \mathrm{Ni},{ }^{63} \mathrm{Ni}$ & 4.04E-02 & $7.31 \mathrm{E}-11$ & $2.69 E-10$ \\
\hline $\mathrm{Sr}$ & ${ }^{90} \mathrm{Sr}$ & $2.90 \mathrm{E}-02$ & $2.21 \mathrm{E}-11$ & $2.32 \mathrm{E}-09$ \\
\hline Cs & ${ }^{137} \mathrm{Cs},{ }^{135} \mathrm{Cs}$ & $1.67 \mathrm{E}-01$ & $6.37 \mathrm{E}-11$ & $1.78 \mathrm{E}-08$ \\
\hline $\mathrm{Sm}$ & ${ }^{151} \mathrm{Sm}$ & 9.17E-03 & $1.66 \mathrm{E}-11$ & $6.09 \mathrm{E}-11$ \\
\hline $\mathrm{Eu}$ & ${ }^{150} \mathrm{Eu},{ }^{152} \mathrm{Eu},{ }^{154} \mathrm{Eu},{ }^{166} \mathrm{Ho}$ & $1.74 \mathrm{E}-02$ & $3.16 \mathrm{E}-11$ & $1.16 \mathrm{E}-10$ \\
\hline$U$ & ${ }^{232} U,{ }^{233} U,{ }^{234} U,{ }^{235} U,{ }^{236} U,{ }^{238} U$ & $1.21 \mathrm{E}+02$ & $2.07 \mathrm{E}-07$ & $1.60 \mathrm{E}-06$ \\
\hline $\mathrm{Np}$ & ${ }^{237} \mathrm{~Np}$ & 6.37E-03 & $1.15 \mathrm{E}-11$ & $4.24 \mathrm{E}-11$ \\
\hline $\mathrm{Pu}$ & ${ }^{238} \mathrm{Pu},{ }^{239} \mathrm{Pu},{ }^{240} \mathrm{Pu},{ }^{242} \mathrm{Pu}$ & $1.02 \mathrm{E}+01$ & $1.85 \mathrm{E}-08$ & $6.78 \mathrm{E}-08$ \\
\hline${ }^{241} \mathrm{Pu}$ & ${ }^{241} \mathrm{Pu}$ & $6.63 \mathrm{E}-02$ & $1.20 \mathrm{E}-10$ & $4.41 \mathrm{E}-10$ \\
\hline $\mathrm{Am}$ & ${ }^{241} \mathrm{Am}$ & 1.42E-02 & $2.56 \mathrm{E}-11$ & $9.42 \mathrm{E}-11$ \\
\hline
\end{tabular}

${ }^{1}$ Radionuclides listed in italics are treated as tracers in simulations but are known to sorb. They are treated as non-sorbing tracers only due to insufficient sorption information.

\subsubsection{Major Element and Radionuclide Aqueous Speciation}

Thermodynamic data for aqueous species were taken from

DATACOM.V8.R6 of the GEMBOCHS thermodynamic database (Johnson and Lundeen, 1997) with revised and updated thermodynamic data as presented in Tompson et al. (1999), Pawloski et al., (2000), and Pawloski et al. (2001) and noted below. The primary species included in the simulations are reported in Table 4.11. The choice of secondary aqueous species used in the simulations is based on recent simulations of Pahute Mesa and Frenchman Flat groundwaters (Pawloski et al., 2000; Pawloski et al., 2001; and Tompson et al., 1999). Additional aqueous species were added based on simulation of groundwater speciation over a range of $\mathrm{pH}$ and carbonate alkalinity centered on the initial groundwater composition listed in Table 2.2. Speciation calculations were conducted using the Geochemist's Workbench family of codes (Bethke, 1998).

The extended Debye-Hückel formulation (also known as the B-DOT model) was used for activity coefficients of aqueous species (Bethke, 1998 and Helgeson, 1969). This formulation is well-suited to describe groundwater at NTS, which possesses ionic strengths significantly less than 0.1. Values of the ion size parameter (Bethke, 1998 and Helgeson, 1969) for aqueous species added to the database were estimated by analogy to aqueous species of similar valence and ligand. Parameters used in the Debye-Hückel activity coefficient model are listed in Tables 4.11 and 4.12.

The major element and radionuclide speciation reactions included in the streamline model are listed in Table 4.13. The effect of temperature on major element speciation reaction constants was included in the model. The effect of temperature on radionuclide speciations constants was not included. Burton et al. (2005) conducted a 
detailed analysis of radionuclide speciation as a function of temperature. Established estimation techniques such as the Criss-Cobble method and other correlation algorithms were tested to calculate thermodynamic parameters needed to extrapolate aqueous complexation data to higher temperatures. The conclusion that using $25^{\circ}-\mathrm{C}$ data for all temperatures may be the best modeling approach currently available is applied in these simulations.

Table 4.11 Basis species used in thermodynamic database.

\begin{tabular}{|c|c|c|}
\hline & $\begin{array}{c}\text { Ion size } \\
\AA \dagger\end{array}$ & $\begin{array}{c}\text { Mol. Wt. } \\
\text { g/mol }\end{array}$ \\
\hline $\mathrm{H}_{2} \mathrm{O}$ & 3 & 18.0 \\
\hline $\mathrm{Al}^{3+}$ & 9 & 27.0 \\
\hline $\mathrm{Am}^{3+}$ & 5 & 243.0 \\
\hline $\mathrm{Ca}^{2+}$ & 6 & 40.1 \\
\hline${ }^{41} \mathrm{Ca}^{2+}$ & 6 & 40.1 \\
\hline $\mathrm{Cl}$ & 3 & 35.5 \\
\hline $\mathrm{Cs}^{+}$ & 2.5 & 132.9 \\
\hline $\mathrm{Eu}^{3+}$ & 5 & 152.0 \\
\hline $\mathrm{Fe}^{3+}$ & 9 & 55.8 \\
\hline $\mathrm{H}^{+}$ & 9 & 1.0 \\
\hline $\mathrm{HCO}_{3}$ & 4 & 61.0 \\
\hline $\mathrm{K}^{+}$ & 3 & 39.1 \\
\hline $\mathrm{Mg}^{2+}$ & 8 & 24.3 \\
\hline $\mathrm{Na}^{+}$ & 4 & 23.0 \\
\hline $\mathrm{Ni}^{2+}$ & 6 & 58.69 \\
\hline $\mathrm{NpO}_{2}^{+}$ & 4 & 269.0 \\
\hline $\mathrm{Pu}^{4+}$ & 5.5 & 244.0 \\
\hline${ }^{241} \mathrm{Pu}^{4+}$ & 5.5 & 244.0 \\
\hline $\mathrm{SO}_{4}{ }^{\tilde{2}}$ & 4 & 96.1 \\
\hline $\mathrm{SiO}_{2}(\mathrm{aq})$ & 3 & 60.1 \\
\hline $\mathrm{Sm}^{3+}$ & 9 & 150.4 \\
\hline $\mathrm{Sr}^{2+}$ & 5 & 87.6 \\
\hline $\mathrm{UO}_{2}{ }^{2+}$ & 4.5 & 270.0 \\
\hline $\mathrm{O}_{2}(\mathrm{aq})$ & 3 & 32.0 \\
\hline TracerR & 1 & 1.0 \\
\hline TracerL & 1 & 1.0 \\
\hline
\end{tabular}

$\dagger$ Ion size parameter used in Debye-Huckel activity coefficient model. 
CHAPTER 4: CALIBRATION AND ASSESSMENT MODELS

Table 4.12. Parameters in extended Debye-Huckel activity coefficient model as a function of temperature $\left({ }^{\circ} \mathrm{C}\right)$.

\begin{tabular}{|l|l|l|l|l|l|}
\hline Constants & \multicolumn{1}{|c|}{$\mathbf{2 5}^{\circ} \mathbf{C}$} & $\mathbf{6 0}^{\circ} \mathbf{C}$ & $\mathbf{1 0 0}^{\circ} \mathbf{C}$ & \multicolumn{1}{|c|}{$\mathbf{5 0}^{\circ} \mathbf{C}$} & $\mathbf{2 0 0}^{\circ} \mathbf{C}$ \\
\hline$A$ & 0.5114 & 0.5465 & 0.5995 & 0.6855 & 0.7994 \\
\hline$B$ & 0.3288 & 0.3346 & 0.3421 & 0.3525 & 0.3639 \\
\hline$B^{\circ}$ & 0.041 & 0.044 & 0.046 & 0.047 & 0.047 \\
\hline
\end{tabular}

Table 4.13. Logarithm of equilibrium constants $(K)$ of aqueous reactions used in streamline simulations.

\begin{tabular}{|c|c|c|c|c|c|c|}
\hline \multirow[t]{2}{*}{ Reaction } & \multicolumn{5}{|c|}{$\log K$} & \multirow{2}{*}{$\begin{array}{c}\text { Ion size } \dagger \\
\AA\end{array}$} \\
\hline & $25^{\circ} \mathrm{C}$ & $60^{\circ} \mathrm{C}$ & $100^{\circ} \mathrm{C}$ & $150^{\circ} \mathrm{C}$ & $200^{\circ} \mathrm{C}$ & \\
\hline $\mathrm{H}_{2} \mathrm{O}=\mathrm{OH}^{-}+\mathrm{H}^{+}$ & & -13.03 & -12.26 & -11.63 & -11.28 & 3.5 \\
\hline $\mathrm{Al}^{3+}+2 \mathrm{H}_{2} \mathrm{O}=\mathrm{AlO}_{2}^{-}+4 \mathrm{H}^{+}$ & -22.20 & -19.04 & -16.21 & -13.46 & -11.34 & 4 \\
\hline $\mathrm{Al}^{3+}+2 \mathrm{H}_{2} \mathrm{O}=\mathrm{HAlO}_{2}{ }^{0}+3 \mathrm{H}^{+}$ & -15.60 & -12.90 & -10.55 & -8.34 & -6.64 & 3 \\
\hline $\mathrm{HCO}_{3}^{-}=\mathrm{CO}_{3}^{2-}+\mathrm{H}^{+}$ & -10.33 & -10.13 & -10.08 & -10.20 & -10.46 & 4.5 \\
\hline $\mathrm{HCO}_{3}^{-}+\mathrm{H}^{+}=\mathrm{CO}_{2}(\mathrm{aq})+\mathrm{H}_{2} \mathrm{O}$ & 6.34 & 6.27 & 6.39 & 6.72 & 7.20 & 3 \\
\hline $\mathrm{Fe}^{3+}+2 \mathrm{H}_{2} \mathrm{O}=\mathrm{FeO}_{2}^{-}+4 \mathrm{H}^{+}$ & -21.62 & -18.44 & -15.71 & -13.19 & -11.34 & 4 \\
\hline $\mathrm{Fe}^{3+}+2 \mathrm{H}_{2} \mathrm{O}=\mathrm{HFeO}_{2}{ }^{0}+3 \mathrm{H}^{+}$ & -12.02 & -9.60 & -7.59 & -5.81 & -4.52 & 3 \\
\hline $\mathrm{Fe}^{3+}+1 \mathrm{H}_{2} \mathrm{O}=\mathrm{FeO}^{+}+2 \mathrm{H}^{+}$ & -5.65 & -4.23 & -3.03 & -1.94 & -1.13 & 4 \\
\hline $\mathrm{SiO}_{2}(\mathrm{aq})+\mathrm{H}_{2} \mathrm{O}=\mathrm{HSiO}_{3}^{-}+\mathrm{H}^{+}$ & -9.59 & -9.24 & -8.96 & -8.80 & -8.83 & 4 \\
\hline $\mathrm{Ca}^{2+}+\mathrm{HCO}_{3}^{-}=\mathrm{CaCO}_{3}^{0}+\mathrm{H}^{+}$ & -7.00 & -6.45 & -5.97 & -5.49 & -5.06 & 3 \\
\hline${ }^{41} \mathrm{Ca}^{2+}+\mathrm{HCO}_{3}^{-}={ }^{41} \mathrm{CaCO}_{3}{ }^{0}+\mathrm{H}^{+}$ & -7.00 & -6.45 & -5.97 & -5.49 & -5.06 & 3 \\
\hline $\mathrm{Mg}^{2+}+\mathrm{HCO}_{3}^{-}=\mathrm{MgCO}_{3}{ }^{0}+\mathrm{H}^{+}$ & -7.35 & -6.93 & -6.57 & -6.23 & -5.91 & 3 \\
\hline $\mathrm{O}_{2}(\mathrm{aq})=\mathrm{O}_{2}(\mathrm{~g})$ & -2.90 & -3.06 & -3.11 & -3.04 & -2.87 & \\
\hline $\mathrm{Sr}^{2+}+\mathrm{HCO}_{3}^{-}=\mathrm{SrCO}_{3}^{0}+\mathrm{H}^{+}$ & & & -7.46 & & & 3 \\
\hline $\mathrm{Sr}^{2+}+\mathrm{HCO}_{3}^{-}=\mathrm{SrHCO}_{3}{ }^{+}$ & & & 1.18 & & & 4 \\
\hline $\mathrm{Ni}^{2+}+\mathrm{HCO}_{3}^{-}=\mathrm{NiCO}_{3}^{0}+\mathrm{H}^{+}$ & & & -6.13 & & & 3 \\
\hline $\mathrm{Ni}^{2+}+\mathrm{HCO}_{3}^{-}=\mathrm{NiHCO}_{3}^{+}$ & & & 2.19 & & & 4 \\
\hline $\mathrm{NpO}_{2}^{+}+\mathrm{HCO}_{3}^{-}=\mathrm{NpO}_{2} \mathrm{CO}_{3}^{-}+\mathrm{H}^{+}$ & & & -5.73 & & & 4 \\
\hline $\mathrm{NpO}_{2}^{+}+2 \mathrm{HCO}_{3}^{-}=\mathrm{NpO}_{2}\left(\mathrm{CO}_{3}\right)_{2}^{3-}+2 \mathrm{H}^{+}$ & & & -13.66 & & & 4 \\
\hline $\mathrm{NpO}_{2}^{+}+3 \mathrm{HCO}_{3}^{-}=\mathrm{NpO}_{2}\left(\mathrm{CO}_{3}\right)_{2}{ }^{5-}+3 \mathrm{H}^{+}$ & & & -22.49 & & & 4 \\
\hline $\mathrm{NpO}_{2}^{+}+\mathrm{H}_{2} \mathrm{O}=\mathrm{NpO}_{2} \mathrm{OH}^{0}+\mathrm{H}^{+}$ & & & -8.90 & & & 3 \\
\hline $\mathrm{Am}^{3+}+\mathrm{HCO}_{3}^{-}=\mathrm{AmCO}_{3}^{+}+\mathrm{H}^{+}$ & & & -2.54 & & & 4 \\
\hline $\mathrm{Am}^{3+}+2 \mathrm{HCO}_{3}^{-}=\mathrm{Am}\left(\mathrm{CO}_{3}\right)_{2}^{-}+2 \mathrm{H}^{+}$ & & & -8.39 & & & 4 \\
\hline $\mathrm{Am}^{3+}+3 \mathrm{HCO}_{3}^{-}=\mathrm{Am}\left(\mathrm{CO}_{3}\right)_{3}{ }^{3-}+3 \mathrm{H}^{+}$ & & & -15.83 & & & 4 \\
\hline $\mathrm{Am}^{3+}+\mathrm{H}_{2} \mathrm{O}=\mathrm{AmOH}^{2+}+\mathrm{H}^{+}$ & & & -6.41 & & & 4.5 \\
\hline $\mathrm{Am}^{3+}+2 \mathrm{H}_{2} \mathrm{O}=\mathrm{Am}(\mathrm{OH})_{2}^{+}+2 \mathrm{H}^{+}$ & & & -14.11 & & & 4 \\
\hline $\mathrm{Eu}^{3+}+\mathrm{HCO}_{3}^{-}=\mathrm{EuCO}_{3}^{+}+\mathrm{H}^{+}$ & & & -2.37 & & & 4 \\
\hline $\mathrm{Eu}^{3+}+2 \mathrm{HCO}_{3}^{-}=\mathrm{Eu}\left(\mathrm{CO}_{3}\right)_{2}^{-}+2 \mathrm{H}^{+}$ & & & -7.67 & & & 4 \\
\hline
\end{tabular}


Table 4.13. Logarithm of equilibrium constants $(K)$ of aqueous reactions used in streamline simulations.

\begin{tabular}{|c|c|c|c|c|c|c|}
\hline \multirow[t]{2}{*}{ Reaction } & \multicolumn{5}{|c|}{$\log K$} & \multirow{2}{*}{$\frac{\text { Ion size } \dagger}{\AA}$} \\
\hline & $25^{\circ} \mathrm{C}$ & $60^{\circ} \mathrm{C}$ & $100{ }^{\circ} \mathrm{C}$ & $150^{\circ} \mathrm{C}$ & $200^{\circ} \mathrm{C}$ & \\
\hline $\mathrm{Eu}^{3+}+2 \mathrm{H}_{2} \mathrm{O}=\mathrm{Eu}(\mathrm{OH})_{2}^{+}+2 \mathrm{H}^{+}$ & \multicolumn{5}{|c|}{-14.86} & 4 \\
\hline $\mathrm{Eu}^{3+}+3 \mathrm{H}_{2} \mathrm{O}=\mathrm{Eu}(\mathrm{OH})_{3}{ }^{0}+3 \mathrm{H}^{+}$ & \multicolumn{5}{|c|}{-24.13} & 3 \\
\hline $\mathrm{Sm}^{3+}+\mathrm{HCO}_{3}^{-}=\mathrm{SmCO}_{3}^{+}+\mathrm{H}^{+}$ & \multicolumn{5}{|c|}{-2.48} & 4 \\
\hline $\mathrm{Sm}^{3+}+2 \mathrm{HCO}_{3}^{-}=\mathrm{Sm}\left(\mathrm{CO}_{3}\right)_{2}^{-}+2 \mathrm{H}^{+}$ & \multicolumn{5}{|c|}{-7.86} & 4 \\
\hline $\mathrm{UO}_{2}^{2+}+\mathrm{HCO}_{3}^{-}=\mathrm{UO}_{2} \mathrm{CO}_{3}^{0}+\mathrm{H}^{+}$ & \multicolumn{5}{|c|}{-0.67} & 3 \\
\hline $\mathrm{UO}_{2}^{2+}+2 \mathrm{HCO}_{3}^{-}=\mathrm{UO}_{2}\left(\mathrm{CO}_{3}\right)_{2}^{2-}+2 \mathrm{H}^{+}$ & \multicolumn{5}{|c|}{-3.76} & 4 \\
\hline $\mathrm{UO}_{2}{ }^{2+}+3 \mathrm{HCO}_{3}^{-}=\mathrm{UO}_{2}\left(\mathrm{CO}_{3}\right)_{3}^{4-}+3 \mathrm{H}^{+}$ & \multicolumn{5}{|c|}{-9.44} & 4 \\
\hline $\mathrm{UO}_{2}^{2+}+\mathrm{H}_{2} \mathrm{O}=\mathrm{UO}_{2} \mathrm{OH}^{+}+\mathrm{H}^{+}$ & \multicolumn{5}{|c|}{-5.22} & 4 \\
\hline $\mathrm{UO}_{2}^{2+}+\mathrm{H}_{2} \mathrm{O}=\mathrm{UO}_{3}{ }^{0}+2 \mathrm{H}^{+}$ & \multicolumn{5}{|c|}{-10.31} & 3 \\
\hline $\mathrm{UO}_{2}^{2+}+2 \mathrm{H}_{2} \mathrm{O}=\mathrm{HUO}_{4}^{-}+3 \mathrm{H}^{+}$ & \multicolumn{5}{|c|}{-19.25} & 4 \\
\hline $\mathrm{Pu}^{4+}+3 \mathrm{H}_{2} \mathrm{O}=\mathrm{Pu}(\mathrm{OH})_{3}^{+}+3 \mathrm{H}^{+}$ & \multicolumn{5}{|c|}{-4.62} & 4 \\
\hline $\mathrm{Pu}^{4+}+4 \mathrm{H}_{2} \mathrm{O}=\mathrm{Pu}(\mathrm{OH})_{4}{ }^{0}+4 \mathrm{H}^{+}$ & \multicolumn{5}{|c|}{-8.85} & 3 \\
\hline $\begin{array}{l}\mathrm{Pu}^{4+}+2 \mathrm{HCO}_{3}^{-}+2 \mathrm{H}_{2} \mathrm{O}= \\
\mathrm{Pu}(\mathrm{OH})_{2}\left(\mathrm{CO}_{3}\right)_{2}^{2-}+4 \mathrm{H}^{+}\end{array}$ & \multicolumn{5}{|c|}{-2.76} & 3 \\
\hline $\begin{array}{l}\mathrm{Pu}^{4+}+0.25 \mathrm{O}_{2}(\mathrm{aq})+1.5 \mathrm{H}_{2} \mathrm{O}=\mathrm{PuO}_{2}^{+}+ \\
3 \mathrm{H}^{+}\end{array}$ & \multicolumn{5}{|c|}{3.29} & 4 \\
\hline $\mathrm{PuO}_{2}^{+}+\mathrm{H}_{2} \mathrm{O}=\mathrm{PuO}_{2} \mathrm{OH}^{0}+\mathrm{H}^{+}$ & \multicolumn{5}{|c|}{-5.50} & 4 \\
\hline $\mathrm{PuO}_{2}^{+}+\mathrm{HCO}_{3}^{-}=\mathrm{PuO}_{2} \mathrm{CO}_{3}^{-}+\mathrm{H}^{+}$ & \multicolumn{5}{|c|}{1.26} & 4 \\
\hline${ }^{241} \mathrm{Pu}^{4+}+3 \mathrm{H}_{2} \mathrm{O}={ }^{241} \mathrm{Pu}(\mathrm{OH}){ }_{3}^{+}+3 \mathrm{H}^{+}$ & \multicolumn{5}{|c|}{-4.62} & 4 \\
\hline${ }^{241} \mathrm{Pu}^{4+}+4 \mathrm{H}_{2} \mathrm{O}={ }^{241} \mathrm{Pu}(\mathrm{OH})_{4}{ }^{0}+4 \mathrm{H}^{+}$ & \multicolumn{5}{|c|}{-8.85} & 3 \\
\hline $\begin{array}{l}{ }^{241} \mathrm{Pu}^{4+}+2 \mathrm{HCO}_{3}{ }^{-}+2 \mathrm{H}_{2} \mathrm{O}= \\
{ }^{241} \mathrm{Pu}(\mathrm{OH})_{2}\left(\mathrm{CO}_{3}\right)_{2}{ }^{2-}+4 \mathrm{H}^{+}\end{array}$ & \multicolumn{5}{|c|}{-2.76} & 3 \\
\hline $\begin{array}{l}{ }^{241} \mathrm{Pu}^{4+}+0.25 \mathrm{O}_{2}(\mathrm{aq})+1.5 \mathrm{H}_{2} \mathrm{O}= \\
{ }^{241} \mathrm{PuO}_{2}^{+}+3 \mathrm{H}^{+}\end{array}$ & \multicolumn{5}{|c|}{3.29} & 4 \\
\hline${ }^{241} \mathrm{PuO}_{2}{ }^{+}+\mathrm{H}_{2} \mathrm{O}={ }^{241} \mathrm{PuO}_{2} \mathrm{OH}^{0}+\mathrm{H}^{+}$ & \multicolumn{5}{|c|}{-5.50} & 4 \\
\hline${ }^{241} \mathrm{PuO}_{2}{ }^{+}+\mathrm{HCO}_{3}^{-}={ }^{241} \mathrm{PuO}_{2} \mathrm{CO}_{3}^{-}+\mathrm{H}^{+}$ & \multicolumn{5}{|c|}{1.26} & 4 \\
\hline
\end{tabular}

$\dagger$ Ion size parameter, used in Debye-Huckel activity coefficient model, for the aqueous complex formed by the basis species. 


\subsubsection{Major Element and Radionuclide Surface Complexation}

Surface complexation (SC) reactions involve mineral surface functional groups and aqueous species. A surface complexation reaction and associated equilibrium constant can be written in the following manner:

$$
\begin{aligned}
& >\mathrm{SiOH}+\mathrm{Pu}^{4+} \Leftrightarrow>\mathrm{SiOPu}^{3+}+\mathrm{H}^{+} \\
& K=\frac{\left(>\mathrm{SiOPu}^{3+}\right)\left(\mathrm{H}^{+}\right)}{(>\mathrm{SiOH})\left(\mathrm{Pu}^{4+}\right)}
\end{aligned}
$$

where $>\mathrm{SiOH}$ is a surface functional group (on a silicate mineral), $\mathrm{Pu}^{4+}$ is an aqueous $\mathrm{Pu}$ species that reacts with the surface (to form $>\mathrm{SiOPu}^{3+}$ ), and $\mathrm{H}^{+}$is released as a result of the reaction. Just as for simple aqueous complexation reactions, the above surface complexation reaction has an equilibrium reaction constant, $K$, that describes the relative activity of all species at equilibrium.

Factors that influence surface complexation on a particular mineral include:

- Surface area

- $\mathrm{pH}$

- Aqueous complexation

- Ionic strength

- Surface charge

Since sorption reactions occur at the mineral-water interface, sorption will be dependent on the mineral surface area available for reaction. The $\mathrm{pH}$ can significantly affect sorption as well. For example, in Equation (4.16), as the concentration of $\mathrm{H}^{+}$ increases, a larger fraction of $\mathrm{Pu}^{4+}$ will remain in solution. Surface functional groups (e.g. $>\mathrm{SiOH}$ ) may also become protonated/deprotonated as a function of $\mathrm{pH}$ and affect sorption. Aqueous complexation will influence the concentration of aqueous species in solution; this may increase or decrease sorption depending on the species involved in the reactions. For example, $U$ sorption decreases as a function of carbonate concentration in solution due to the formation of uranyl carbonate complexes (Duff and Amrhein, 1996). Ionic strength may influence sorption by reducing the effective concentration (i.e. activity) of aqueous species and affect the charging behavior of the surface. Surface complexes as well as surface protonation and deprotonation can also affect the charging of the surface which will, in turn, influence sorption. Unlike $K_{d} \mathrm{~S}$, surface complexation reactions can, ideally, account for all factors that influence the ratio of sorbed to aqueous radionuclide concentrations. Because surface complexation reactions account for changes in environmental conditions, they provide a much more robust basis for simulating radionuclide sorption.

The nonelectrostatic surface complexation model (NEM) is used to define major elements and radionuclide surface complexation. The NEM (Kurbatov et al., 1951) assumes that surface electrical charge does not affect equilibrium surface complexation reactions. Although the NEM oversimplifies the factors affecting surface complexation, several investigators have used this model approach to describe sorption reactions (Bradbury and Baeyens, 1997; Davis et al., 1998; Zachara et al., 1994). Davis et al. 
(1998) argued that the NEM approach may be the most appropriate for complex environmental applications since the surface charging behavior of non-ideal natural mineral phases is not well known. For additional information regarding the nonelectrostatic model and data, see Zavarin and Bruton (2004a and 2004b). The model validation effort for reactive transport in alluvium is reported in Zavarin et al. (2002).

Minerals addressed in the surface complexation model include iron oxide, smectite, and calcite. Radionuclides addressed in the model include $\mathrm{Ni}, \mathrm{Sr}, \mathrm{Sm}, \mathrm{Eu}, \mathrm{U}$, $\mathrm{Np}, \mathrm{Pu}$, and $\mathrm{Am}$. The surface complexation of Ni was added only recently to the database of sorption reactions; surface complexation model calibration to Ni sorption data are reported in Appendix A. Mineral characteristics (surface area, cation exchange capacity, etc.) were taken directly from Zavarin et al. (2002) and are reproduced in Table 4.14. Surface complexation reaction constants for iron oxide, smectite, and calcite are reported in Tables 4.15 to 4.17 , respectively.

All reaction constants are reported at $25^{\circ} \mathrm{C}$. Sorption is likely to change as a function of temperature. However, as in the case of aqueous complexation, insufficient data and/or extrapolation algorithms are available to adequately predict the effect of temperature on sorption. Burton et al. (2005) concluded that using $25{ }^{\circ} \mathrm{C}$ data for all temperatures may be the best modeling approach currently available.

Table 4.14. Mineral characteristics used to define reactions on mineral surfaces.

\begin{tabular}{|c|c|c|c|c|c|}
\hline Mineral & $\begin{array}{l}\text { Iron Oxide } \\
\text { (Hematite) }\end{array}$ & Calcite & $\begin{array}{c}\text { Smectite } \\
\text { (Montmorillonite) }\end{array}$ & $\begin{array}{c}\text { Zeolite } \\
\text { (Clinoptilolite) }\end{array}$ & $\begin{array}{l}\text { Illite/Mica } \\
\text { (Illite) }\end{array}$ \\
\hline $\begin{array}{l}\text { Density, } \\
\text { g/cm }\end{array}$ & 5.27 & 2.71 & 2.83 & 2.13 & 2.83 \\
\hline $\begin{array}{l}\text { Surface Area, } \\
\mathrm{m}^{2} / \mathrm{g}\end{array}$ & 0.25 & 0.1 & 30.0 & - & - \\
\hline $\begin{array}{l}\text { Site Density, } \\
\mathrm{nm}^{-2}\end{array}$ & 2.31 & 5.0 & 0.231 & - & - \\
\hline Site Type & $>\mathrm{FeOH}$ & $>\mathrm{Ca}^{2+}$ & $\begin{array}{c}>\mathrm{SiOH}(0.5) \\
>\mathrm{AlOH}(0.5) \\
\text { (ion exchange) }\end{array}$ & (ion exchange) & $\begin{array}{c}\text { I }(0.005) \\
\text { II }(0.03) \\
\text { III }(0.965)\end{array}$ \\
\hline $\begin{array}{l}\text { CEC, } \\
\text { meq/g }\end{array}$ & - & - & 0.425 & 2.12 & 0.2 \\
\hline
\end{tabular}


Table 4.15. Surface complexation reaction for iron oxides using the NEM.

\begin{tabular}{|c|c|}
\hline Reaction & $\log K$ \\
\hline$>\mathrm{FeOH} \Leftrightarrow>\mathrm{FeO}^{-}+\mathrm{H}^{+}$ & -8.93 \\
\hline$>\mathrm{FeOH}+\mathrm{H}^{+} \Leftrightarrow>\mathrm{FeOH}_{2}^{+}$ & 7.29 \\
\hline$>\mathrm{FeOH}+\mathrm{Am}^{3+} \Leftrightarrow>\mathrm{FeOAm}^{2+}+\mathrm{H}^{+}$ & $1.24 \pm 0.43$ \\
\hline$>\mathrm{FeOH}+\mathrm{Am}^{3+}+2 \mathrm{H}_{2} \mathrm{O} \Leftrightarrow>\mathrm{FeOAm}(\mathrm{OH})_{2}+3 \mathrm{H}^{+}$ & $-15.29 \pm 0.37$ \\
\hline$>\mathrm{FeOH}+\mathrm{Eu}^{3+} \Leftrightarrow>\mathrm{FeOEu}^{2+}+\mathrm{H}^{+}$ & $1.85 \pm 0.58$ \\
\hline$>\mathrm{FeOH}+\mathrm{Ni}^{2+} \Leftrightarrow>\mathrm{FeOHNi}^{2+}$ & $4.8 \pm 0.6$ \\
\hline$>\mathrm{FeOH}+\mathrm{Ni}^{2+}+\mathrm{H}_{2} \mathrm{O} \Leftrightarrow>\mathrm{FeONiOH}+2 \mathrm{H}^{+}$ & $-13.3 \pm 0.3$ \\
\hline$>\mathrm{FeOH}+\mathrm{NpO}_{2}^{+} \Leftrightarrow>\mathrm{FeOHNpO}_{2}^{+}$ & $4.32 \pm 0.11$ \\
\hline$>\mathrm{FeOH}+\mathrm{NpO}_{2}^{+}+\mathrm{H}_{2} \mathrm{O} \Leftrightarrow>\mathrm{FeOHNpO}_{3}^{-}+2 \mathrm{H}^{+}$ & -11.26 \\
\hline$>\mathrm{FeOH}+\mathrm{Pu}^{4+}+\mathrm{H}_{2} \mathrm{O} \Leftrightarrow>\mathrm{FeOHPuO}^{2+}+2 \mathrm{H}^{+}$ & 6.93 \\
\hline$>\mathrm{FeOH}+\mathrm{Pu}^{4+}+2 \mathrm{H}_{2} \mathrm{O} \Leftrightarrow>\mathrm{FeOHPuO}_{2}+4 \mathrm{H}^{+}$ & -1.29 \\
\hline$>\mathrm{FeOH}+\mathrm{PuO}_{2}^{+} \Leftrightarrow>\mathrm{FeOHPuO}_{2}{ }^{+}$ & 4.79 \\
\hline$>\mathrm{FeOH}+\mathrm{PuO}_{2}^{+}+\mathrm{H}_{2} \mathrm{O} \Leftrightarrow>\mathrm{FeOHPuO}_{3}^{-}+2 \mathrm{H}^{+}$ & -10.66 \\
\hline$>\mathrm{FeOH}+\mathrm{Sm}^{3+} \Leftrightarrow>\mathrm{FeOSm}^{2+}+\mathrm{H}^{+}$ & $1.85 \pm 0.58^{\mathrm{a}}$ \\
\hline$>\mathrm{FeOH}+\mathrm{Sr}^{2+} \Leftrightarrow>\mathrm{FeOHSr}^{2+}$ & $2.22 \pm 0.13$ \\
\hline$>\mathrm{FeOH}+\mathrm{Sr}^{2+} \Leftrightarrow>\mathrm{FeOSr}^{+}+\mathrm{H}^{+}$ & $-5.30 \pm 0.31$ \\
\hline$>\mathrm{FeOH}+\mathrm{Sr}^{2+}+\mathrm{H}_{2} \mathrm{O} \Leftrightarrow>\mathrm{FeOSrOH}+2 \mathrm{H}^{+}$ & $-14.14 \pm 0.40$ \\
\hline$>\mathrm{FeOH}+\mathrm{UO}_{2}^{2+}+\mathrm{H}_{2} \mathrm{O} \Leftrightarrow>\mathrm{FeOHUO}_{3}+2 \mathrm{H}^{+}$ & $-3.05 \pm 0.43$ \\
\hline$>\mathrm{FeOH}+\mathrm{UO}_{2}{ }^{2+} \Leftrightarrow>\mathrm{FeOHUO}_{2}{ }^{2+}$ & $6.63 \pm 0.54$ \\
\hline
\end{tabular}

${ }^{\mathrm{a}} \mathrm{Sm}$ data were not available; reaction constants were set equal to Eu. 
Table 4.16. Surface complexation reactions for aluminosilicates using the NEM.

\begin{tabular}{|c|c|}
\hline Reaction & $\log K$ \\
\hline$>\mathrm{SiOH} \Leftrightarrow>\mathrm{SiO}^{-}+\mathrm{H}^{+}$ & -7.2 \\
\hline$>\mathrm{AlOH} \Leftrightarrow>\mathrm{AlO}^{-}+\mathrm{H}^{+}$ & -9.73 \\
\hline$>\mathrm{AIOH}+\mathrm{H}^{+} \Leftrightarrow>\mathrm{AlOH}_{2}^{+}$ & 8.33 \\
\hline$>\mathrm{AlOH}+\mathrm{Am}^{3+} \Leftrightarrow>\mathrm{AlOAm}^{2+}+\mathrm{H}^{+}$ & $2.49 \pm 0.26$ \\
\hline$>\mathrm{SiOH}+\mathrm{Am}^{3+} \Leftrightarrow>\mathrm{SiOAm}^{2+}+\mathrm{H}^{+}$ & $0.7 \pm 0.1$ \\
\hline$>\mathrm{SiOH}+\mathrm{Am}^{3+}+\mathrm{H}_{2} \mathrm{O} \Leftrightarrow>\mathrm{SiOAmO}+3 \mathrm{H}^{+}$ & $-14.2 \pm 0.8$ \\
\hline$>\mathrm{AlOH}+\mathrm{Eu}^{3+} \Leftrightarrow>\mathrm{AlOEu}^{2+}+\mathrm{H}^{+}$ & $2.21 \pm 0.54$ \\
\hline$>\mathrm{SiOH}+\mathrm{Eu}^{3+} \Leftrightarrow>\mathrm{SiOEu}^{2+}+\mathrm{H}^{+}$ & -0.62 \\
\hline$>\mathrm{SiOH}+\mathrm{Eu}^{3+}+\mathrm{H}_{2} \mathrm{O} \Leftrightarrow>\mathrm{SiOEuO}+3 \mathrm{H}^{+}$ & -15.30 \\
\hline$>\mathrm{AIOH}+\mathrm{Ni}^{2+} \Leftrightarrow>\mathrm{AlOHNi}^{2+}$ & 5.56 \\
\hline$>\mathrm{SiOH}+\mathrm{Ni}^{2+} \Leftrightarrow>\mathrm{SiONi}^{+}+\mathrm{H}^{+}$ & -0.59 \\
\hline$>\mathrm{AIOH}+\mathrm{NpO}_{2}^{+} \Leftrightarrow>\mathrm{AlONpO}_{2}+\mathrm{H}^{+}$ & $-4.67 \pm 0.27$ \\
\hline$>\mathrm{AlOH}+\mathrm{NpO}_{2}^{+}+\mathrm{H}_{2} \mathrm{O} \Leftrightarrow>\mathrm{AlONpO}_{3} \mathrm{H}^{-}+2 \mathrm{H}^{+}$ & $-14.26 \pm 0.04$ \\
\hline$>\mathrm{SiOH}+\mathrm{NpO}_{2}^{+} \Leftrightarrow>\mathrm{SiONpO}_{2}+\mathrm{H}^{+}$ & $-3.72 \pm 0.15$ \\
\hline$>\mathrm{SiOH}+\mathrm{NpO}_{2}^{+}+\mathrm{H}_{2} \mathrm{O} \Leftrightarrow>\mathrm{SiONpO}_{3} \mathrm{H}^{-}+2 \mathrm{H}^{+}$ & -12.16 \\
\hline$>\mathrm{AIOH}+\mathrm{Pu}^{4+}+\mathrm{H}_{2} \mathrm{O} \Leftrightarrow>\mathrm{AlOPuO}^{+}+3 \mathrm{H}^{+}$ & $5.95 \pm 0.47$ \\
\hline$>\mathrm{AlOH}+\mathrm{Pu}^{4+}+2 \mathrm{H}_{2} \mathrm{O} \Leftrightarrow>\mathrm{AlOPuO}_{2}^{-}+5 \mathrm{H}^{+}$ & -11.93 \\
\hline$>\mathrm{SiOH}+\mathrm{Pu}^{4+}+\mathrm{H}_{2} \mathrm{O} \Leftrightarrow>\mathrm{SiOPuO}^{+}+\mathrm{H}^{+}$ & $2.32 \pm 0.89$ \\
\hline$>\mathrm{AlOH}+\mathrm{PuO}_{2}^{+} \Leftrightarrow>\mathrm{AlOPuO}_{2}+\mathrm{H}+$ & -3.09 \\
\hline$>\mathrm{SiOH}+\mathrm{PuO}_{2}^{+} \Leftrightarrow>\mathrm{SiOPuO}_{2}+\mathrm{H}+$ & -6.43 \\
\hline$>\mathrm{SiOH}+\mathrm{PuO}_{2}^{+}+\mathrm{H}_{2} \mathrm{O} \Leftrightarrow>\mathrm{SiOPuO}_{3} \mathrm{H}^{-}+2 \mathrm{H}^{+}$ & -14.80 \\
\hline$>\mathrm{AlOH}+{ }^{241} \mathrm{Pu}^{4+}+\mathrm{H}_{2} \mathrm{O} \Leftrightarrow>\mathrm{AlO}^{241} \mathrm{PuO}^{+}+3 \mathrm{H}^{+}$ & $5.95 \pm 0.47$ \\
\hline$>\mathrm{AlOH}+{ }^{241} \mathrm{Pu}^{4+}+2 \mathrm{H}_{2} \mathrm{O} \Leftrightarrow>\mathrm{AlO}^{241} \mathrm{PuO}_{2}^{-}+5 \mathrm{H}^{+}$ & -11.93 \\
\hline$>\mathrm{SiOH}+{ }^{241} \mathrm{Pu}^{4+}+\mathrm{H}_{2} \mathrm{O} \Leftrightarrow>\mathrm{SiO}^{241} \mathrm{PuO}^{+}+\mathrm{H}^{+}$ & $2.32 \pm 0.89$ \\
\hline$>\mathrm{AIOH}+{ }^{241} \mathrm{PuO}_{2}{ }^{+} \Leftrightarrow>\mathrm{AlO}^{241} \mathrm{PuO}_{2}+\mathrm{H}+$ & -3.09 \\
\hline$>\mathrm{SiOH}+{ }^{241} \mathrm{PuO}_{2}{ }^{+} \Leftrightarrow>\mathrm{SiO}^{241} \mathrm{PuO}_{2}+\mathrm{H}+$ & -6.43 \\
\hline$>\mathrm{SiOH}+{ }^{241} \mathrm{PuO}_{2}{ }^{+}+\mathrm{H}_{2} \mathrm{O} \Leftrightarrow>\mathrm{SiO}^{241} \mathrm{PuO}_{3} \mathrm{H}^{-}+2 \mathrm{H}^{+}$ & -14.80 \\
\hline$>\mathrm{AlOH}+\mathrm{Sm}^{3+} \Leftrightarrow>\mathrm{AlOSm}^{2+}+\mathrm{H}^{+}$ & $2.21 \pm 0.54^{a}$ \\
\hline$>\mathrm{SiOH}+\mathrm{Sm}^{3+} \Leftrightarrow>\mathrm{SiOSm}^{2+}+\mathrm{H}^{+}$ & $-0.62^{\mathrm{a}}$ \\
\hline$>\mathrm{SiOH}+\mathrm{Sm}^{3+}+\mathrm{H}_{2} \mathrm{O} \Leftrightarrow>\mathrm{SiOSmO}+3 \mathrm{H}^{+}$ & $-15.30^{a}$ \\
\hline$>\mathrm{AlOH}+\mathrm{UO}_{2}^{2+} \Leftrightarrow>\mathrm{AlOUO}_{2}^{+}+\mathrm{H}^{+}$ & $3.13 \pm 0.15$ \\
\hline$>\mathrm{SiOH}+\mathrm{UO}_{2}^{2+}+\mathrm{H}_{2} \mathrm{O} \Leftrightarrow>\mathrm{SiOUO}_{3} \mathrm{H}+2 \mathrm{H}^{+}$ & $-5.18 \pm 0.31$ \\
\hline$>\mathrm{SiOH}+\mathrm{UO}_{2}^{2+}+\mathrm{H}_{2} \mathrm{O} \Leftrightarrow>\mathrm{SiOUO}_{3}^{-}+3 \mathrm{H}^{+}$ & -12.35 \\
\hline
\end{tabular}

${ }^{\mathrm{a}} \mathrm{Sm}$ data were not available; reaction constants were set equal to $\mathrm{Eu}$. 
Table 4.17. Surface complexation reactions for calcite using the NEM.

\begin{tabular}{|c|c|}
\hline Reaction & $\log K$ \\
\hline$>\mathrm{Ca}^{2+}+\mathrm{AmCO}_{3}{ }^{+} \Leftrightarrow>\mathrm{AmCO}_{3}{ }^{+}+\mathrm{Ca}^{2+}$ & $4.13 \pm 0.06$ \\
\hline$>\mathrm{Ca}^{2+}+{ }^{41} \mathrm{Ca}^{2+} \Leftrightarrow>^{41} \mathrm{Ca}^{2+}+\mathrm{Ca}^{2+}$ & 0 \\
\hline$>\mathrm{Ca}^{2+}+\mathrm{EuCO}_{3}^{+} \Leftrightarrow>\mathrm{EuCO}_{3}^{+}+\mathrm{Ca}^{2+}$ & 4.14 \\
\hline$>\mathrm{Ca}^{2+}+\mathrm{Ni}^{2+} \Leftrightarrow>\mathrm{Ni}^{2+}+\mathrm{Ca}^{2+}$ & 0.16 \\
\hline$>\mathrm{Ca}^{2+}+\mathrm{NpO}_{2}^{+} \Leftrightarrow>\mathrm{NpO}_{2}^{+}+\mathrm{Ca}^{2+}$ & 1.46 \\
\hline$>\mathrm{Ca}^{2+}+\mathrm{PuO}_{2}^{+} \Leftrightarrow>\mathrm{PuO}_{2}^{+}+\mathrm{Ca}^{2+}$ & 1.63 \\
\hline$>\mathrm{Ca}^{2+}+\mathrm{Pu}(\mathrm{OH})_{3}^{+} \Leftrightarrow>\mathrm{Pu}(\mathrm{OH})_{3}{ }^{+}+\mathrm{Ca}^{2+}$ & 7.23 \\
\hline$>\mathrm{Ca}^{2+}+{ }^{241} \mathrm{PuO}_{2}{ }^{+} \Leftrightarrow>{ }^{241} \mathrm{PuO}_{2}{ }^{+}+\mathrm{Ca}^{2+}$ & 1.63 \\
\hline$>\mathrm{Ca}^{2+}+{ }^{241} \mathrm{Pu}(\mathrm{OH})_{3}{ }^{+} \Leftrightarrow>{ }^{241} \mathrm{Pu}(\mathrm{OH})_{3}{ }^{+}+\mathrm{Ca}^{2+}$ & 7.23 \\
\hline$>\mathrm{Ca}^{2+}+\mathrm{SmCO}_{3}^{+} \Leftrightarrow>\mathrm{SmCO}_{3}^{+}+\mathrm{Ca}^{2+}$ & 4.62 \\
\hline$>\mathrm{Ca}^{2+}+\mathrm{Sr}^{2+} \Leftrightarrow>\mathrm{Sr}^{2+}+\mathrm{Ca}^{2+}$ & -1.92 \\
\hline$>\mathrm{Ca}^{2+}+\mathrm{UO}_{2}{ }^{2+} \Leftrightarrow>\mathrm{UO}_{2}{ }^{2+}+\mathrm{Ca}^{2+}$ & 5.12 \\
\hline
\end{tabular}

${ }^{\mathrm{a}}$ Single point data.

\subsubsection{Major Element and Radionuclide lon Exchange}

The permanent charge on some clay minerals is the result of non-chargebalanced ion substitution. For example, the substitution of $\mathrm{Si}^{4+}$ for $\mathrm{Al}^{3+}$ in a clay will result in a permanent negative charge. A permanent negative charge is typically balanced by cations in solution that are attracted to the mineral surface. For example, the aluminosilicate montmorillonite will typically have a permanent negative charge equal to $\sim 800 \mathrm{meq} / \mathrm{kg}$. In soils, the majority of this charge is balanced by the major cations in the waters $\left(\mathrm{Na}^{+}, \mathrm{K}^{+}, \mathrm{Ca}^{2+}\right.$, and $\left.\mathrm{Mg}^{2+}\right)$. When other cations such as $\mathrm{Cs}^{+}$are present, they may also become associated with the negatively charged surface via ion exchange. The distribution of cations on surfaces as a result of permanent charge can be described by ion exchange reactions of the following form:

$$
\mathrm{Na}-\mathrm{X}+\mathrm{Cs}^{+}<==>\mathrm{Cs}-\mathrm{X}+\mathrm{Na}^{+}
$$

with an associated equilibrium constant :

$$
K=\frac{(\mathrm{Cs}-\mathrm{X})\left(\mathrm{Na}^{+}\right)}{(\mathrm{Na}-\mathrm{X})\left(\mathrm{Cs}^{+}\right)}
$$

where "X" designates a surface association and the four terms in parentheses are the activities of the respective species. For homovalent exchange such as the reaction shown here, the activity of surface-associated species is often assumed to be defined by the relative concentration of each species $\left(\frac{[\mathrm{Cs}-\mathrm{X}]}{[\mathrm{Cs}-\mathrm{X}]+[\mathrm{Na}-\mathrm{X}]}\right.$ and $\left.\frac{[\mathrm{Na}-\mathrm{X}]}{[\mathrm{Cs}-\mathrm{X}]+[\mathrm{Na}-\mathrm{X}]}\right)$.

Because the denominators for $\mathrm{Cs}-\mathrm{X}$ and $\mathrm{Na}-\mathrm{X}$ activity are identical, the activity ratio of surface species can be simplified to the total mol ratio of $\mathrm{Cs}$ and $\mathrm{Na}$ associated with the mineral surface. The activity of species in solution is determined from speciation and 
ionic strength activity corrections. The constant, $K$, describes the relative activity of the various species at equilibrium.

For heterovalent ion exchange, the equilibrium reactions are complicated by the fact that the two exchanging ions balance different amounts of charge on the surface. Heterovalent ion exchange reactions can be written in several forms. By the Vanselow convention, a heterovalent exchange reaction is written in a form that relates to the relative mol concentration of surface species:

$$
\mathrm{Na}-\mathrm{X}+0.5 \mathrm{Ca}^{2+}<==>0.5 \mathrm{Ca}-\mathrm{X}_{2}+\mathrm{Na}^{+}
$$

with an associated equilibrium constant of the form:

$$
K=\frac{\left(\mathrm{Ca}-\mathrm{X}_{2}\right)^{0.5}\left(\mathrm{Na}^{+}\right)}{(\mathrm{Na}-\mathrm{X})\left(\mathrm{Ca}^{2+}\right)^{0.5}}
$$

The two terms in the above equation that relate to surface species activity are determined by:

$$
\left(\frac{\left[\mathrm{Ca}-\mathrm{X}_{2}\right]}{\left(\left[\mathrm{Ca}-\mathrm{X}_{2}\right]+[\mathrm{Na}-\mathrm{X}]\right)}\right)^{0.5} \text { and }\left(\frac{[\mathrm{Na}-\mathrm{X}]}{\left(\left[\mathrm{Ca}-\mathrm{X}_{2}\right]+[\mathrm{Na}-\mathrm{X}]\right)}\right)
$$

where the terms in the brackets relate to $\mathrm{mol} / \mathrm{L}$ concentrations. For more information regarding the Vanselow and other ion exchange conventions, see Zavarin and Bruton (2004a and 2004b).

Radionuclide and major element ion exchange was simulated for three minerals: smectite, illite/mica, and clinoptilolite. The characteristics of these minerals are reported in Table 4.14. Reaction constants are reported in Table 4.18. 
Table 4.18. Vanselow ion exchange reaction constants for smectite, illite/mica, and clinoptilolite.

\begin{tabular}{|c|c|c|}
\hline Exchange Reaction & $\log K$ & Site Type ${ }^{a}$ \\
\hline \multicolumn{3}{|c|}{ 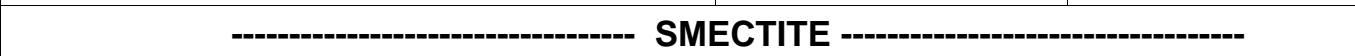 } \\
\hline $\mathrm{Na}^{+}+0.5^{41} \mathrm{Ca}-\mathrm{X}_{2} \Leftrightarrow 0.5^{41} \mathrm{Ca}^{2+}+\mathrm{Na}-\mathrm{X}$ & 0.0 & \\
\hline $\mathrm{Na}^{+}+0.5 \mathrm{Ca}-\mathrm{X}_{2} \Leftrightarrow 0.5 \mathrm{Ca}^{2+}+\mathrm{Na}-\mathrm{X}$ & 0.0 & \\
\hline $\mathrm{Na}^{+}+0.5 \mathrm{Mg}-\mathrm{X}_{2} \Leftrightarrow 0.5 \mathrm{Mg}^{2+}+\mathrm{Na}-\mathrm{X}$ & 0.0 & \\
\hline $\mathrm{Na}^{+}+0.5 \mathrm{Sr}-\mathrm{X}_{2} \Leftrightarrow 0.5 \mathrm{Sr}^{2+}+\mathrm{Na}-\mathrm{X}$ & -0.2 & \\
\hline $\mathrm{Na}^{+}+\mathrm{K}-\mathrm{X} \Leftrightarrow \mathrm{K}^{+}+\mathrm{Na}-\mathrm{X}$ & 0.255 & \\
\hline $\mathrm{Na}^{+}+\mathrm{Cs}-\mathrm{X} \Leftrightarrow \mathrm{Cs}^{+}+\mathrm{Na}-\mathrm{X}$ & 1.75 & \\
\hline $\mathrm{Na}^{+}+0.5 \mathrm{UO}_{2}-\mathrm{X} \Leftrightarrow 0.5 \mathrm{UO}_{2}^{2+}+\mathrm{Na}-\mathrm{X}$ & -0.040 & \\
\hline \multicolumn{3}{|c|}{ 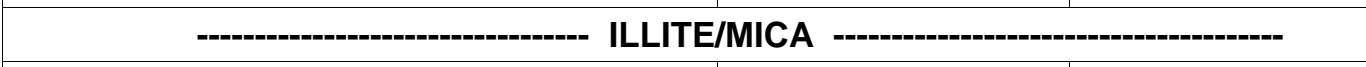 } \\
\hline \multirow[t]{3}{*}{$\mathrm{Na}^{+}+0.5^{41} \mathrm{Ca}-\mathrm{X}_{2} \Leftrightarrow 0.5^{41} \mathrm{Ca}^{2+}+\mathrm{Na}-\mathrm{X}$} & -0.375 & I \\
\hline & -0.147 & II \\
\hline & 0.000 & III \\
\hline \multirow[t]{3}{*}{$\mathrm{Na}^{+} 0.5 \mathrm{Ca}-\mathrm{X}_{2} \Leftrightarrow 0.5 \mathrm{Ca}^{2+}+\mathrm{Na}-\mathrm{X}$} & -0.375 & I \\
\hline & -0.147 & II \\
\hline & 0.000 & III \\
\hline \multirow[t]{3}{*}{$\mathrm{Na}^{+}+0.5 \mathrm{Mg}-\mathrm{X}_{2} \Leftrightarrow 0.5 \mathrm{Mg}^{2+}+\mathrm{Na}-\mathrm{X}$} & -0.375 & 1 \\
\hline & -0.147 & II \\
\hline & 0.000 & III \\
\hline \multirow[t]{3}{*}{$\mathrm{Na}^{+}+0.5 \mathrm{Sr}-\mathrm{X}_{2} \Leftrightarrow 0.5 \mathrm{Sr}^{2+}+\mathrm{Na}-\mathrm{X}$} & -0.375 & I \\
\hline & -0.147 & II \\
\hline & 0.000 & III \\
\hline \multirow[t]{3}{*}{$\mathrm{Na}^{+}+\mathrm{K}-\mathrm{X} \Leftrightarrow \mathrm{K}^{+}+\mathrm{Na}-\mathrm{X}$} & 1.613 & I \\
\hline & 1.686 & II \\
\hline & 0.894 & III \\
\hline \multirow[t]{3}{*}{$\mathrm{Na}^{+}+\mathrm{Cs}-\mathrm{X} \Leftrightarrow \mathrm{Cs}^{+}+\mathrm{Na}-\mathrm{X}$} & 6.718 & 1 \\
\hline & 3.079 & II \\
\hline & 1.539 & III \\
\hline \multicolumn{3}{|c|}{ 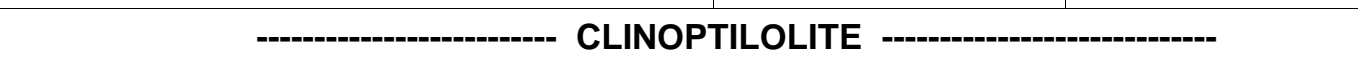 } \\
\hline $\mathrm{Na}^{+}+\mathrm{K}-\mathrm{X} \Leftrightarrow \mathrm{K}^{+}+\mathrm{Na}-\mathrm{X}$ & 1.40 & \\
\hline $\mathrm{Na}^{+}+\mathrm{Cs}-\mathrm{X} \Leftrightarrow \mathrm{Cs}^{+}+\mathrm{Na}-\mathrm{X}$ & 2.01 & \\
\hline $\mathrm{Na}^{+}+0.5^{41} \mathrm{Ca}-\mathrm{X}_{2} \Leftrightarrow 0.5^{41} \mathrm{Ca}^{2+}+\mathrm{Na}-\mathrm{X}$ & 0.36 & \\
\hline $\mathrm{Na}^{+}+0.5 \mathrm{Ca}-\mathrm{X}_{2} \Leftrightarrow 0.5 \mathrm{Ca}^{2+}+\mathrm{Na}-\mathrm{X}$ & 0.36 & \\
\hline $\mathrm{Na}^{+}+0.5 \mathrm{Sr}-\mathrm{X}_{2} \Leftrightarrow 0.5 \mathrm{Sr}^{2+}+\mathrm{Na}-\mathrm{X}$ & 0.25 & \\
\hline
\end{tabular}

${ }^{a}$ Site types I to III on illite refer to the three ion exchange sites with distinct cation affinities, particularly for Cs. 


\subsubsection{Major Element and Radionuclide Mineral Solubility}

Thermodynamic data for mineral solubility were taken from

DATACOM.V8.R6 of the GEMBOCHS thermodynamic database (Johnson and Lundeen, 1997). Table 4.19 lists the reaction constants for radionuclide-containing secondary mineral phases. Similar to the sorption and aqueous speciation reaction constants, these are only reported at $25^{\circ} \mathrm{C}$.

Table 4.20 lists the reaction constants for secondary minerals that do not include radionuclides. For these minerals, temperature-dependent reaction constants were used in the model. The mineral " $\mathrm{O}_{2}(\mathrm{~min})$ " was used to force the model to remain at an $\mathrm{O}_{2}(\mathrm{~g})$ fugacity of $10^{-20}$ bars during simulations. One mineral included in the simulations but not reported here is "matrix". "Matrix" was used as a substitute for all minerals not explicitly identified in the simulations; it was not allowed to dissolve or precipitate. Hematite and muscovite were involved in surface complexation and ion exchange reactions, respectively, but also not allowed to dissolve or precipitate. The mineral " $\mathrm{SiO}_{2}(\mathrm{am})$ " was used in conjunction with the cross affinity term to control the saturation state of the nuclear melt glass. The glass dissolution rate model is described in the following section. It should be noted that the solubilities of clays and zeolites were controlled by the solubility of their homovalent end-members. The CRUNCH model does not include any mechanism for defining the solubility of a heterovalent clay mineral.

Table 4.21 lists the solubility of the nuclear melt glass. As stated above, the solubility of the nuclear melt glass was, in fact, controlled by the solubility product of $\mathrm{SiO}_{2}(\mathrm{am})$ by employing the cross affinity term. Thus, the Log K constant of 50 reported in Table 4.21 was not used in the simulations. However, it is important to note that the stoichiometry of the melt glass changes with time. This results from our explicit modeling of the decay of ${ }^{90} \mathrm{Sr},{ }^{151} \mathrm{Sm},{ }^{241} \mathrm{Pu},{ }^{241} \mathrm{Am}$ and ingrowth of ${ }^{241} \mathrm{Am}$ and ${ }^{237} \mathrm{~Np}$. While the CRUNCH code can account for the decay of radionuclides in the solid phase during each simulation, it cannot account for this process in a transient flow system where new sets of streamlines are generated. Thus, a unique glass stoichiometry is needed for each set of streamlines associated with a particular flow field time step. The last flow field time step begins at $12.3 \mathrm{y}$ and ends at $25.6 \mathrm{y}$ (the end of continuous RNM-2S pumping). 
CHAPTER 4: CALIBRATION AND ASSESSMENT MODELS

Table 4.19. Solubility of radionuclide-containing secondary mineral phases.

\begin{tabular}{|c|c|c|c|}
\hline Reaction & $\log K$ & $\begin{array}{l}\text { Molar } \\
\text { Mass }\end{array}$ & $\begin{array}{c}\text { Molar } \\
\text { Volume }\end{array}$ \\
\hline & $25^{\circ} \mathrm{C}$ & $\mathbf{g}$ & $\mathrm{cm}^{3}$ \\
\hline $\mathrm{PuO}_{2}(\mathrm{am})+4 \mathrm{H}^{+}=\mathrm{Pu}^{4+}+2 \mathrm{H}_{2} \mathrm{O}$ & -0.22 & 275.9988 & $1.00 \mathrm{E}+01$ \\
\hline $\mathrm{PuO}_{2} \mathrm{OH}(\mathrm{am})+\mathrm{H}^{+}=\mathrm{H}_{2} \mathrm{O}+\mathrm{PuO}_{2}^{+}$ & 5.01 & 293 & $1.00 \mathrm{E}+02$ \\
\hline${ }^{241} \mathrm{PuO}_{2}(\mathrm{am})+4 \mathrm{H}^{+}={ }^{241} \mathrm{Pu}^{4+}+2 \mathrm{H}_{2} \mathrm{O}$ & -0.22 & 275.9988 & $1.00 \mathrm{E}+01$ \\
\hline${ }^{241} \mathrm{PuO}_{2} \mathrm{OH}(\mathrm{am})+\mathrm{H}^{+}=\mathrm{H}_{2} \mathrm{O}+{ }^{241} \mathrm{PuO}_{2}{ }^{+}$ & 5.01 & 293 & $1.00 \mathrm{E}+02$ \\
\hline $\mathrm{EuOHCO}{ }_{3}+2 \mathrm{H}^{+}=\mathrm{Eu}^{3+}+\mathrm{H}_{2} \mathrm{O}+\mathrm{HCO}_{3}^{-}$ & 2.9839 & 228.9815 & $1.00 \mathrm{E}+02$ \\
\hline $\mathrm{AmOHCO}_{3}+2 \mathrm{H}^{+}=\mathrm{Am}^{3+}+\mathrm{H}_{2} \mathrm{O}+\mathrm{HCO}_{3}^{-}$ & 3.1519 & 320.0165 & $1.00 \mathrm{E}+02$ \\
\hline $\mathrm{Sm}(\mathrm{OH})_{3}(\mathrm{am})+3 \mathrm{H}^{+}=\mathrm{Sm}^{3+}+3 \mathrm{H}_{2} \mathrm{O}$ & 18.5852 & 201.382 & $1.00 \mathrm{E}+02$ \\
\hline $\mathrm{NpO}_{2} \mathrm{OH}(\mathrm{am})+\mathrm{H}^{+}=\mathrm{H}_{2} \mathrm{O}+\mathrm{NpO}_{2}^{+}$ & 4.71 & 286.0541 & $1.00 \mathrm{E}+02$ \\
\hline Schoepite $+2 \mathrm{H}^{+}=\mathrm{UO}_{2}{ }^{2+}+3 \mathrm{H}_{2} \mathrm{O}$ & 4.8442 & 322.0577 & $6.61 \mathrm{E}+01$ \\
\hline Celestite $=\mathrm{SO}_{4}^{2-}+\mathrm{Sr}^{2+}$ & -6.613 & 183.6836 & $4.63 E+01$ \\
\hline
\end{tabular}


Table 4.20. Solubility of secondary mineral phases.

\begin{tabular}{|c|c|c|c|c|c|c|c|}
\hline \multirow[t]{2}{*}{ Reaction } & \multicolumn{5}{|c|}{$\log K$} & \multirow{2}{*}{$\begin{array}{c}\text { Molar } \\
\text { Mass }\end{array}$} & \multirow{2}{*}{$\begin{array}{c}\begin{array}{c}\text { Molar } \\
\text { Volume }\end{array} \\
\mathrm{cm}^{\mathbf{3}}\end{array}$} \\
\hline & $25^{\circ} \mathrm{C}$ & $60^{\circ} \mathrm{C}$ & $100^{\circ} \mathrm{C}$ & $150^{\circ} \mathrm{C}$ & $200^{\circ} \mathrm{C}$ & & \\
\hline Illite $+8 \mathrm{H}^{+}=0.25 \mathrm{Mg}^{2+}+0.6 \mathrm{~K}^{+}+2.3 \mathrm{Al}^{3+}+3.5 \mathrm{SiO}_{2}(\mathrm{aq})+5 \mathrm{H}_{2} \mathrm{O}$ & 7.4514 & 4.3128 & 1.1164 & -2.2251 & -5.0395 & $3.84 \mathrm{E}+02$ & $1.36 \mathrm{E}+02$ \\
\hline Kaolinite $+6 \mathrm{H}^{+}=2 \mathrm{Al}^{3+}+2 \mathrm{SiO}_{2}(\mathrm{aq})+5 \mathrm{H}_{2} \mathrm{O}$ & 5.4408 & 2.7666 & 0.1448 & -2.5511 & -4.8041 & $2.58 \mathrm{E}+02$ & $9.95 \mathrm{E}+01$ \\
\hline Hematite $+6 \mathrm{H}^{+}=2 \mathrm{Fe}^{3+}+3 \mathrm{H}_{2} \mathrm{O}$ & 0.1086 & -2.2815 & -4.4731 & -6.6792 & -8.5315 & $1.60 \mathrm{E}+02$ & $3.03 E+01$ \\
\hline Goethite $+3 \mathrm{H}^{+}=\mathrm{Fe}^{3+}+2 \mathrm{H}_{2} \mathrm{O}$ & 0.5345 & -0.5818 & -1.5472 & -2.4508 & -3.1544 & $8.89 \mathrm{E}+01$ & $2.08 \mathrm{E}+01$ \\
\hline $\begin{array}{l}\text { Beidellite-Ca }+7.32 \mathrm{H}^{+}=0.165 \mathrm{Ca}^{2+}+2.33 \mathrm{Al}^{3+}+3.67 \mathrm{SiO}_{2}(\mathrm{aq})+ \\
4.66 \mathrm{H}_{2} \mathrm{O}\end{array}$ & 3.9962 & 1.0169 & -2.0576 & -5.2881 & -8.0113 & $3.67 E+02$ & $1.30 \mathrm{E}+02$ \\
\hline $\begin{array}{l}\text { Beidellite- } \mathrm{Na}+7.32 \mathrm{H}^{+}=0.33 \mathrm{Na}^{+}+2.33 \mathrm{Al}^{3+}+3.67 \mathrm{SiO}_{2}(\mathrm{aq})+ \\
4.66 \mathrm{H}_{2} \mathrm{O}\end{array}$ & 4.0521 & 1.198 & -1.7518 & -4.846 & -7.4481 & $3.68 \mathrm{E}+02$ & $1.31 \mathrm{E}+02$ \\
\hline $\begin{array}{l}\text { Beidellite- } \mathrm{K}+7.32 \mathrm{H}^{+}=0.33 \mathrm{~K}^{+}+2.33 \mathrm{Al}^{3+}+3.67 \mathrm{SiO}_{2}(\mathrm{aq})+4.66 \\
\mathrm{H}_{2} \mathrm{O}\end{array}$ & 5.3088 & 2.2062 & -0.9869 & -4.3427 & -7.1735 & $3.73 E+02$ & $1.34 \mathrm{E}+02$ \\
\hline $\begin{array}{l}\text { Beidellite-Mg }+7.32 \mathrm{H}^{+}=0.165 \mathrm{Mg}^{2+}+2.33 \mathrm{Al}^{3+}+3.67 \mathrm{SiO}_{2}(\mathrm{aq})+ \\
4.66 \mathrm{H}_{2} \mathrm{O}\end{array}$ & 3.9585 & 0.9241 & -2.1978 & -5.4717 & -8.2268 & $3.64 \mathrm{E}+02$ & $1.23 \mathrm{E}+02$ \\
\hline $\begin{array}{l}\text { Montmor-Ca }+6 \mathrm{H}^{+}=0.165 \mathrm{Ca}^{2+}+0.33 \mathrm{Mg}^{2+}+1.67 \mathrm{Al}^{3+}+4 \mathrm{H}_{2} \mathrm{O}+ \\
4 \mathrm{SiO}_{2}(\mathrm{aq})\end{array}$ & 1.3519 & -0.5906 & -2.7222 & -4.9795 & -6.8565 & $3.66 \mathrm{E}+02$ & $1.33 \mathrm{E}+02$ \\
\hline $\begin{array}{l}\text { Montmor-Na }+6 \mathrm{H}^{+}=+0.33 \mathrm{Mg}^{2+}+0.33 \mathrm{Na}^{+}+1.67 \mathrm{Al}^{3+}+4 \mathrm{H}_{2} \mathrm{O}+4 \\
\mathrm{SiO}_{2}(\mathrm{aq})\end{array}$ & 1.3411 & -0.4691 & -2.4697 & -4.5845 & -6.3355 & $3.67 \mathrm{E}+02$ & $1.34 \mathrm{E}+02$ \\
\hline $\begin{array}{l}\text { Montmor-K }+6 \mathrm{H}^{+}=0.33 \mathrm{~K}^{+}+0.33 \mathrm{Mg}^{2+}+1.67 \mathrm{Al}^{3+}+4 \mathrm{H}_{2} \mathrm{O}+4 \\
\mathrm{SiO}_{2}(\mathrm{aq})\end{array}$ & 0.9989 & -0.7265 & -2.6661 & -4.7403 & -6.476 & $3.72 \mathrm{E}+02$ & 1.37E+02 \\
\hline Montmor-Mg $+6 \mathrm{H}^{+}=0.495 \mathrm{Mg}^{2+}+1.67 \mathrm{Al}^{3+}+4 \mathrm{H} 2 \mathrm{O}+4 \mathrm{SiO}_{2}(\mathrm{aq})$ & 1.2445 & -0.7421 & -2.9112 & -5.2248 & -7.1822 & $3.63 \mathrm{E}+02$ & $1.32 \mathrm{E}+02$ \\
\hline $\begin{array}{l}\text { Nontronite- } \mathrm{Ca}+7.32 \mathrm{H}^{+}=0.165 \mathrm{Ca}^{2+} 0.33 \mathrm{Al}^{3+} 2 \mathrm{Fe}^{3+} 3.67 \mathrm{SiO}_{2}(\mathrm{aq}) \\
4.66 \mathrm{H}_{2} \mathrm{O}\end{array}$ & -11.8082 & -12.7653 & -13.9481 & -15.2637 & -16.4276 & $4.24 \mathrm{E}+02$ & $1.31 \mathrm{E}+02$ \\
\hline $\begin{array}{l}\text { Nontronite-Na }+7.32 \mathrm{H}^{+}=0.33 \mathrm{Al}^{3+} 0.33 \mathrm{Na}+2 \mathrm{Fe}^{3+} 3.67 \mathrm{SiO}_{2}(\mathrm{aq}) \\
4.66 \mathrm{H}_{2} \mathrm{O}\end{array}$ & -11.7523 & -12.5839 & -13.6419 & -14.8209 & -15.8636 & $4.25 E+02$ & $1.32 \mathrm{E}+02$ \\
\hline $\begin{array}{l}\text { Nontronite- } \mathrm{K}+7.32 \mathrm{H}^{+}=0.33 \mathrm{Al}^{3+}+0.33 \mathrm{~K}^{+}+2 \mathrm{Fe}^{3+} 3.67 \mathrm{SiO}_{2}(\mathrm{aq}) \\
4.66 \mathrm{H}_{2} \mathrm{O}\end{array}$ & -12.0907 & -12.8345 & -13.8207 & -14.9392 & -15.9423 & $4.31 \mathrm{E}+02$ & $1.35 \mathrm{E}+02$ \\
\hline Nontronite-Mg $+7.32 \mathrm{H}^{+}=0.165 \mathrm{Mg}^{2+}+0.33 \mathrm{Al}^{3+}+2 \mathrm{Fe}^{3+}+3.67$ & -11.8459 & -12.8579 & -14.0879 & -15.4465 & -16.6414 & $4.22 \mathrm{E}+02$ & $1.30 \mathrm{E}+02$ \\
\hline
\end{tabular}




\section{CHAPTER 4: CALIBRATION AND ASSESSMENT MODELS}

Table 4.20. Solubility of secondary mineral phases.

\begin{tabular}{|c|c|c|c|c|c|c|c|}
\hline \multirow[t]{2}{*}{ Reaction } & \multicolumn{5}{|c|}{$\log K$} & \multirow{2}{*}{$\begin{array}{c}\text { Molar } \\
\text { Mass } \\
\mathbf{g}\end{array}$} & \multirow{2}{*}{$\begin{array}{c}\begin{array}{c}\text { Molar } \\
\text { Volume }\end{array} \\
\mathbf{c m}^{3}\end{array}$} \\
\hline & $25^{\circ} \mathrm{C}$ & $60^{\circ} \mathrm{C}$ & $100{ }^{\circ} \mathrm{C}$ & $150{ }^{\circ} \mathrm{C}$ & $200{ }^{\circ} \mathrm{C}$ & & \\
\hline \multicolumn{8}{|l|}{$\mathrm{SiO}_{2}(\mathrm{aq})+4.66 \mathrm{H}_{2} \mathrm{O}$} \\
\hline Muscovite $+10 \mathrm{H}^{+}=\mathrm{K}++3 \mathrm{Al}^{3+}+3 \mathrm{SiO}_{2}(\mathrm{aq})+6 \mathrm{H}_{2} \mathrm{O}$ & 11.5319 & 7.2185 & 2.9778 & -1.4004 & -5.0698 & $3.98 \mathrm{E}+02$ & $1.41 \mathrm{E}+02$ \\
\hline $\mathrm{SiO} 2(\mathrm{am})=\mathrm{SiO}_{2}(\mathrm{aq})$ & -2.7136 & -2.4067 & -2.1843 & -1.9796 & -1.819 & $6.01 \mathrm{E}+01$ & $2.90 \mathrm{E}+01$ \\
\hline Cristobalite $($ beta $)=\mathrm{SiO}_{2}(\mathrm{aq})$ & -3.0053 & -2.6268 & -2.3583 & -2.1179 & -1.9264 & $6.01 \mathrm{E}+01$ & $2.74 \mathrm{E}+01$ \\
\hline $\begin{array}{l}\text { Clinoptilolite- } \mathrm{Ca}+13.868 \mathrm{H}^{+}=1.7335 \mathrm{Ca}^{2+}+3.467 \mathrm{Al}^{3+}+14.533 \\
\mathrm{SiO}_{2}(\mathrm{aq})+17.856 \mathrm{H}_{2} \mathrm{O}\end{array}$ & -9.2283 & -11.32 & -14.4836 & -18.2046 & -21.527 & $1.34 \mathrm{E}+03$ & $6.32 \mathrm{E}+02$ \\
\hline $\begin{array}{l}\text { Clinoptilolite- } \mathrm{Na}+13.868 \mathrm{H}^{+}=3.467 \mathrm{Al}^{3+}+3.467 \mathrm{Na}^{+}+14.533 \\
\mathrm{SiO}_{2}(\mathrm{aq})+17.856 \mathrm{H}_{2} \mathrm{O}\end{array}$ & -9.3552 & -9.9812 & -11.6984 & -13.8529 & -15.7986 & $1.35 \mathrm{E}+03$ & $6.32 \mathrm{E}+02$ \\
\hline $\begin{array}{l}\text { Clinoptilolite-K + } 13.868 \mathrm{H}^{+}=3.467 \mathrm{Al}^{3+} 3.467 \mathrm{~K}^{+}+14.533 \mathrm{SiO}_{2}(\mathrm{aq}) \\
+17.856 \mathrm{H}_{2} \mathrm{O}\end{array}$ & -13.1674 & -12.6358 & -13.3852 & -14.6935 & -16.0609 & $1.41 \mathrm{E}+03$ & $6.32 \mathrm{E}+02$ \\
\hline Calcite $+\mathrm{H}^{+}=\mathrm{Ca}^{2+}+\mathrm{HCO}_{3}^{-}$ & 1.8487 & 1.333 & 0.7743 & 0.0999 & -0.5838 & $1.00 \mathrm{E}+02$ & $3.69 E+01$ \\
\hline Boehmite $+3 \mathrm{H}^{+}=\mathrm{Al}^{3+}+2 \mathrm{H}_{2} \mathrm{O}$ & 7.5642 & 5.465 & 3.5242 & 1.5677 & -0.0516 & $6.00 \mathrm{E}+01$ & $1.95 \mathrm{E}+01$ \\
\hline Gibbsite $+3 \mathrm{H}^{+}=\mathrm{Al}^{3+}+3 \mathrm{H}_{2} \mathrm{O}$ & 7.0714 & 5.3246 & 3.7378 & 2.1623 & 0.8686 & $7.80 \mathrm{E}+01$ & $3.20 \mathrm{E}+01$ \\
\hline $\mathrm{K}-$ Feldspar $+4 \mathrm{H}^{+}=\mathrm{Al}^{3+} \mathrm{K}+2 \mathrm{H}_{2} \mathrm{O}+3 \mathrm{SiO}_{2}(\mathrm{aq})$ & -0.9599 & -1.5011 & -2.2602 & -3.1343 & -3.9038 & $2.78 \mathrm{E}+02$ & $1.09 \mathrm{E}+02$ \\
\hline Albite $+4 \mathrm{H}^{+}=\mathrm{Al}^{3+}+\mathrm{Na}^{+}+2 \mathrm{H}_{2} \mathrm{O}+3 \mathrm{SiO}_{2}(\mathrm{aq})$ & 2.0799 & 1.0277 & -0.1811 & -1.4704 & -2.5398 & $2.62 \mathrm{E}+02$ & $1.00 \mathrm{E}+02$ \\
\hline Anorthite $+8 \mathrm{H}^{+}=\mathrm{Ca}^{2+}+2 \mathrm{Al}^{3+}+2 \mathrm{SiO}_{2}(\mathrm{aq})+4 \mathrm{H}_{2} \mathrm{O}$ & 25.2087 & 19.7289 & 14.5027 & 9.1904 & 4.8135 & $2.78 \mathrm{E}+02$ & $1.01 \mathrm{E}+02$ \\
\hline Prehnite $+10 \mathrm{H}^{+}=2 \mathrm{Al}^{3+}+2 \mathrm{Ca}^{2+}+3 \mathrm{SiO}_{2}(\mathrm{aq})+6 \mathrm{H}_{2} \mathrm{O}$ & 31.5613 & 25.8511 & 20.3518 & 14.7549 & 10.1453 & $4.12 \mathrm{E}+02$ & $1.40 \mathrm{E}+02$ \\
\hline Clinochlore-7A + $16 \mathrm{H}^{+}=2 \mathrm{Al}^{3+}+3 \mathrm{SiO}_{2}(\mathrm{aq})+5 \mathrm{Mg}^{2+}+12 \mathrm{H}_{2} \mathrm{O}$ & 69.2432 & 57.8251 & 47.2661 & 36.8365 & 28.4769 & $5.56 \mathrm{E}+02$ & $2.12 \mathrm{E}+02$ \\
\hline $\mathrm{O}_{2}(\min )=\mathrm{O}_{2}(\mathrm{~g})$ & -20 & -20 & -20 & -20 & -20 & $3.20 \mathrm{E}+01$ & $1.00 \mathrm{E}+00$ \\
\hline
\end{tabular}


Table 4.21. Solubility of nuclear melt glass.

\begin{tabular}{|c|c|c|c|}
\hline Reaction $^{\text {b }}$ & $\log K$ & $\begin{array}{l}\text { Molar } \\
\text { Mass }\end{array}$ & $\begin{array}{c}\text { Molar } \\
\text { Volume }\end{array}$ \\
\hline & $25-200^{\circ} \mathrm{C}$ & g & $\mathrm{cm}^{3}$ \\
\hline $\begin{array}{l}\text { Cglass } 0 \mathrm{y}+1.58 \mathrm{H}^{+}=0.79 \mathrm{H}_{2} \mathrm{O}+1.08 \mathrm{SiO}_{2}(\mathrm{aq})+0.30 \mathrm{Al}^{3+}+0.055 \mathrm{Fe}^{3+}+0.090 \mathrm{Na}^{+}+0.071 \mathrm{~K}^{+}+0.125 \\
\mathrm{Ca}^{2+}+0.057 \mathrm{Mg}^{2+}+2.51 \mathrm{E}-07{ }^{41} \mathrm{Ca}^{2+}+2.07 \mathrm{E}-05 \mathrm{UO}^{2+}+6.37 \mathrm{E}-09 \mathrm{Cs}^{+}+2.21 \mathrm{E}-09 \mathrm{Sr}^{2+}+1.66 \mathrm{E}-09 \mathrm{Sm} \\
3^{+}+3.16 \mathrm{E}-09 \mathrm{Eu}^{3+}+1.15 \mathrm{E}-09 \mathrm{NpO}_{2}^{+}+1.85 \mathrm{E}-06 \mathrm{Pu}^{4+}+1.20 \mathrm{E}-08{ }^{241} \mathrm{Pu}^{4+}+ \\
2.56 \mathrm{E}-09 \mathrm{Am}^{3+}+1.90 \mathrm{E}-07 \text { tracerL }+7.32 \mathrm{E}-09 \mathrm{Ni}^{2+}\end{array}$ & $50^{a}$ & 100 & $4.00 \mathrm{E}+01$ \\
\hline $\begin{array}{l}\text { Cglass } 0.006 \mathrm{y}+1.58 \mathrm{H}^{+}=0.79 \mathrm{H}_{2} \mathrm{O}+1.08 \mathrm{SiO}_{2}(\mathrm{aq})+0.30 \mathrm{Al}^{3+}+0.055 \mathrm{Fe}^{3+}+0.090 \mathrm{Na}^{+}+0.071 \mathrm{~K}^{+}+ \\
0.125 \mathrm{Ca}^{2+}+0.057 \mathrm{Mg}^{2+}+2.51 \mathrm{E}-07^{41} \mathrm{Ca}^{2+}+2.07 \mathrm{E}-05 \mathrm{UO}^{2+}+6.37 \mathrm{E}-09 \mathrm{Cs}^{+}+2.21 \mathrm{E}-09 \mathrm{Sr}^{2+}+1.66 \mathrm{E}- \\
09 \mathrm{Sm}^{3+}+3.16 \mathrm{E}-09 \mathrm{Eu}^{3+}+1.15 \mathrm{E}-09 \mathrm{NpO}_{2}^{+}+1.85 \mathrm{E}-06 \mathrm{Pu}^{4+}+1.20 \mathrm{E}-08{ }^{241} \mathrm{Pu}^{4+}+ \\
2.57 \mathrm{E}-09 \mathrm{Am}^{3+}+1.90 \mathrm{E}-07 \text { tracerL }+7.32 \mathrm{E}-09 \mathrm{Ni}^{2+}\end{array}$ & $50^{a}$ & 100 & $4.00 \mathrm{E}+01$ \\
\hline $\begin{array}{l}\text { Cglass } 0.014 \mathrm{y}+1.58 \mathrm{H}^{+}=0.79 \mathrm{H}_{2} \mathrm{O}+1.08 \mathrm{SiO}_{2}(\mathrm{aq})+0.30 \mathrm{Al}^{3+}+0.055 \mathrm{Fe}^{3+}+0.090 \mathrm{Na}^{+}+0.071 \mathrm{~K}^{+}+ \\
0.125 \mathrm{Ca}^{2+}+0.057 \mathrm{Mg}^{2+}+2.51 \mathrm{E}-07^{41} \mathrm{Ca}^{2+}+2.07 \mathrm{E}-05 \mathrm{UO}^{2+}+6.37 \mathrm{E}-09 \mathrm{Cs}^{+}+2.21 \mathrm{E}-09 \mathrm{Sr}^{2+}+1.66 \mathrm{E}- \\
09 \mathrm{Sm}^{3+}+3.16 \mathrm{E}-09 \mathrm{Eu}^{3+}+1.15 \mathrm{E}-09 \mathrm{NpO}_{2}^{+}+1.85 \mathrm{E}-06 \mathrm{Pu}^{4+}+1.20 \mathrm{E}-08{ }^{241} \mathrm{Pu}^{4+}+ \\
2.57 \mathrm{E}-09 \mathrm{Am}^{3+}+1.90 \mathrm{E}-07 \text { tracerL }+7.32 \mathrm{E}-09 \mathrm{Ni}^{2+}\end{array}$ & $50^{a}$ & 100 & $4.00 \mathrm{E}+01$ \\
\hline $\begin{array}{l}\text { Cglass } 0.019 \mathrm{y}+1.58 \mathrm{H}^{+}=0.79 \mathrm{H}_{2} \mathrm{O}+1.08 \mathrm{SiO}_{2}(\mathrm{aq})+0.30 \mathrm{Al}^{3+}+0.055 \mathrm{Fe}^{3+}+0.090 \mathrm{Na}^{+}+0.071 \mathrm{~K}^{+}+ \\
0.125 \mathrm{Ca}^{2+}+0.057 \mathrm{Mg}^{2+}+2.51 \mathrm{E}-07^{41} \mathrm{Ca}^{2+}+2.07 \mathrm{E}-05 \mathrm{UO}^{2+}+6.37 \mathrm{E}-09 \mathrm{Cs}^{+}+2.21 \mathrm{E}-09 \mathrm{Sr}^{2+}+1.66 \mathrm{E}- \\
09 \mathrm{Sm}^{3+}+3.16 \mathrm{E}-09 \mathrm{Eu}^{3+}+1.15 \mathrm{E}-09 \mathrm{NpO}_{2}^{+}+1.85 \mathrm{E}-06 \mathrm{Pu}^{4+}+1.20 \mathrm{E}-08{ }^{241} \mathrm{Pu}^{4+}+ \\
\text { 2.57E-09 } \mathrm{Am}^{3+}+1.90 \mathrm{E}-07 \text { tracerL }+7.32 \mathrm{E}-09 \mathrm{Ni}^{2+}\end{array}$ & $50^{a}$ & 100 & $4.00 \mathrm{E}+01$ \\
\hline $\begin{array}{l}\text { Cglass } 0.027 \mathrm{y}+1.58 \mathrm{H}^{+}=0.79 \mathrm{H}_{2} \mathrm{O}+1.08 \mathrm{SiO}_{2}(\mathrm{aq})+0.30 \mathrm{Al}^{3+}+0.055 \mathrm{Fe}^{3+}+0.090 \mathrm{Na}^{+}+0.071 \mathrm{~K}^{+}+ \\
0.125 \mathrm{Ca}^{2+}+0.057 \mathrm{Mg}^{2+}+2.51 \mathrm{E}-07^{41} \mathrm{Ca}^{2+}+2.07 \mathrm{E}-05 \mathrm{UO}^{2+}+6.37 \mathrm{E}-09 \mathrm{Cs}^{+}+2.21 \mathrm{E}-09 \mathrm{Sr}^{2+}+1.66 \mathrm{E}- \\
09 \mathrm{Sm}^{3+}+3.16 \mathrm{E}-09 \mathrm{Eu}^{3+}+1.15 \mathrm{E}-09 \mathrm{NpO}_{2}^{+}+1.85 \mathrm{E}-06 \mathrm{Pu}^{4+}+1.20 \mathrm{E}-08{ }^{241241} \mathrm{Pu}^{4+}+ \\
2.58 \mathrm{E}-09 \mathrm{Am}^{3+}+1.90 \mathrm{E}-07 \text { tracerL }+7.32 \mathrm{E}-09 \mathrm{Ni}^{2+}\end{array}$ & $50^{a}$ & 100 & $4.00 \mathrm{E}+01$ \\
\hline $\begin{array}{l}\text { Cglass0.036y }+1.58 \mathrm{H}^{+}=0.79 \mathrm{H}_{2} \mathrm{O}+1.08 \mathrm{SiO}_{2}(\mathrm{aq})+0.30 \mathrm{Al}^{3+}+0.055 \mathrm{Fe}^{3+}+0.090 \mathrm{Na}^{+}+0.071 \mathrm{~K}^{+}+ \\
0.125 \mathrm{Ca}^{2+}+0.057 \mathrm{Mg}^{2+}+2.51 \mathrm{E}-07^{41} \mathrm{Ca}^{2+}+2.07 \mathrm{E}-05 \mathrm{UO}^{2+}+6.37 \mathrm{E}-09 \mathrm{Cs}^{+}+2.21 \mathrm{E}-09 \mathrm{Sr}^{2+}+1.66 \mathrm{E}- \\
09 \mathrm{Sm}^{3+}+3.16 \mathrm{E}-09 \mathrm{Eu}^{3+}+1.15 \mathrm{E}-09 \mathrm{NpO}_{2}^{+}+1.85 \mathrm{E}-06 \mathrm{Pu}^{4+}+1.20 \mathrm{E}-08{ }^{241} \mathrm{Pu}^{4+}+ \\
2.58 \mathrm{E}-09 \mathrm{Am}^{3+}+1.90 \mathrm{E}-07 \text { tracerL }+7.32 \mathrm{E}-09 \mathrm{Ni}^{2+}\end{array}$ & $50^{a}$ & 100 & $4.00 \mathrm{E}+01$ \\
\hline
\end{tabular}


Table 4.21. Solubility of nuclear melt glass.

\begin{tabular}{|c|c|c|c|}
\hline Reaction $^{\mathrm{b}}$ & $\log K$ & $\begin{array}{l}\text { Molar } \\
\text { Mass }\end{array}$ & $\begin{array}{c}\text { Molar } \\
\text { Volume }\end{array}$ \\
\hline & $25-200^{\circ} \mathrm{C}$ & g & $\mathrm{cm}^{3}$ \\
\hline $\begin{array}{l}\text { Cglass } 0.047 \mathrm{y}+1.58 \mathrm{H}^{+}=0.79 \mathrm{H}_{2} \mathrm{O}+1.08 \mathrm{SiO}_{2}(\mathrm{aq})+0.30 \mathrm{Al}^{3+}+0.055 \mathrm{Fe}^{3+}+0.090 \mathrm{Na}^{+}+0.071 \mathrm{~K}^{+}+ \\
0.125 \mathrm{Ca}^{2+}+0.057 \mathrm{Mg}^{2+}+2.51 \mathrm{E}-07^{41} \mathrm{Ca}^{2+}+2.07 \mathrm{E}-05 \mathrm{UO}^{2+}+6.37 \mathrm{E}-09 \mathrm{Cs}^{+}+2.21 \mathrm{E}-09 \mathrm{Sr}^{2+}+1.66 \mathrm{E}- \\
09 \mathrm{Sm}^{3+}+3.16 \mathrm{E}-09 \mathrm{Eu}^{3+}+1.15 \mathrm{E}-09 \mathrm{NpO}_{2}^{+}+1.85 \mathrm{E}-06 \mathrm{Pu}^{4+}+1.20 \mathrm{E}-08{ }^{241} \mathrm{Pu}^{4+}+ \\
2.59 \mathrm{E}-09 \mathrm{Am}^{3+}+1.90 \mathrm{E}-07 \text { tracerL }+7.32 \mathrm{E}-09 \mathrm{Ni}^{2+}\end{array}$ & $50^{a}$ & 100 & $4.00 E+01$ \\
\hline $\begin{array}{l}\text { Cglass } 0.11 \mathrm{y}+1.58 \mathrm{H}^{+}=0.79 \mathrm{H}_{2} \mathrm{O}+1.08 \mathrm{SiO}_{2}(\mathrm{aq})+0.30 \mathrm{Al}^{3+}+0.055 \mathrm{Fe}^{3+}+0.090 \mathrm{Na}^{+}+0.071 \mathrm{~K}^{+}+ \\
0.125 \mathrm{Ca}^{2+}+0.057 \mathrm{Mg}^{2+}+2.51 \mathrm{E}-07^{41} \mathrm{Ca}^{2+}+2.07 \mathrm{E}-05 \mathrm{UO}^{2+}+6.37 \mathrm{E}-09 \mathrm{Cs}^{+}+2.21 \mathrm{E}-09 \mathrm{Sr}^{2+}+1.66 \mathrm{E}- \\
09 \mathrm{Sm}^{3+}+3.16 \mathrm{E}-09 \mathrm{Eu}^{3+}+1.15 \mathrm{E}-09 \mathrm{NpO}_{2}^{+}+1.85 \mathrm{E}-06 \mathrm{Pu}^{4+}+1.19 \mathrm{E}-08{ }^{241} \mathrm{Pu}^{4+}+ \\
2.62 \mathrm{E}-09 \mathrm{Am}^{3+}+1.90 \mathrm{E}-07 \text { tracerL }+7.32 \mathrm{E}-09 \mathrm{Ni}^{2+}\end{array}$ & $50^{a}$ & 100 & $4.00 E+01$ \\
\hline $\begin{array}{l}\text { Cglass } 0.14 \mathrm{y}+1.58 \mathrm{H}^{+}=0.79 \mathrm{H}_{2} \mathrm{O}+1.08 \mathrm{SiO}_{2}(\mathrm{aq})+0.30 \mathrm{Al}^{3+}+0.055 \mathrm{Fe}^{3+}+0.090 \mathrm{Na}^{+}+0.071 \mathrm{~K}^{+}+ \\
0.125 \mathrm{Ca}^{2+}+0.057 \mathrm{Mg}^{2+}+2.51 \mathrm{E}-07^{41} \mathrm{Ca}^{2+}+2.07 \mathrm{E}-05 \mathrm{UO}^{2+}+6.37 \mathrm{E}-09 \mathrm{Cs}^{+}+2.20 \mathrm{E}-09 \mathrm{Sr}^{2+}+1.66 \mathrm{E}- \\
09 \mathrm{Sm}^{3+}+3.16 \mathrm{E}-09 \mathrm{Eu}^{3+}+1.15 \mathrm{E}-09 \mathrm{NpO}_{2}^{+}+1.85 \mathrm{E}-06 \mathrm{Pu}^{4+}+1.19 \mathrm{E}-08^{241} \mathrm{Pu}^{4+}+ \\
2.64 \mathrm{E}-09 \mathrm{Am}^{3+}+1.90 \mathrm{E}-07 \text { tracerL }+7.32 \mathrm{E}-09 \mathrm{Ni}^{2+}\end{array}$ & $50^{a}$ & 100 & $4.00 E+01$ \\
\hline $\begin{array}{l}\text { Cglass } 0.18 \mathrm{y}+1.58 \mathrm{H}^{+}=0.79 \mathrm{H}_{2} \mathrm{O}+1.08 \mathrm{SiO}_{2}(\mathrm{aq})+0.30 \mathrm{Al}^{3+}+0.055 \mathrm{Fe}^{3+}+0.090 \mathrm{Na}^{+}+0.071 \mathrm{~K}^{+}+ \\
0.125 \mathrm{Ca}^{2+}+0.057 \mathrm{Mg}^{2+}+2.51 \mathrm{E}-07^{41} \mathrm{Ca}^{2+}+2.07 \mathrm{E}-05 \mathrm{UO}^{2+}+6.37 \mathrm{E}-09 \mathrm{Cs}^{+}+2.20 \mathrm{E}-09 \mathrm{Sr}^{2+}+1.66 \mathrm{E}- \\
09 \mathrm{Sm}^{3+}+3.16 \mathrm{E}-09 \mathrm{Eu}^{3+}+1.15 \mathrm{E}-09 \mathrm{NpO}_{2}^{+}+1.85 \mathrm{E}-06 \mathrm{Pu}^{4+}+1.19 \mathrm{E}-08^{241} \mathrm{Pu}^{4+}+ \\
2.66 \mathrm{E}-09 \mathrm{Am}^{3+}+1.90 \mathrm{E}-07 \text { tracerL }+7.32 \mathrm{E}-09 \mathrm{Ni}^{2+}\end{array}$ & $50^{a}$ & 100 & $4.00 \mathrm{E}+01$ \\
\hline $\begin{array}{l}\text { Cglass } 0.23 \mathrm{y}+1.58 \mathrm{H}^{+}=0.79 \mathrm{H}_{2} \mathrm{O}+1.08 \mathrm{SiO}_{2}(\mathrm{aq})+0.30 \mathrm{Al}^{3+}+0.055 \mathrm{Fe}^{3+}+0.090 \mathrm{Na}^{+}+0.071 \mathrm{~K}^{+}+ \\
0.125 \mathrm{Ca}^{2+}+0.057 \mathrm{Mg}^{2+}+2.51 \mathrm{E}-07^{41} \mathrm{Ca}^{2+}+2.07 \mathrm{E}-05 \mathrm{UO}^{2+}+6.37 \mathrm{E}-09 \mathrm{Cs}^{+}+2.20 \mathrm{E}-09 \mathrm{Sr}^{2+}+1.66 \mathrm{E}- \\
09 \mathrm{Sm}^{3+}+3.16 \mathrm{E}-09 \mathrm{Eu}^{3+}+1.15 \mathrm{E}-09 \mathrm{NpO}_{2}^{+}+1.85 \mathrm{E}-06 \mathrm{Pu}^{4+}+1.19 \mathrm{E}-08{ }^{241} \mathrm{Pu}^{4+}+ \\
2.69 \mathrm{E}-09 \mathrm{Am}^{3+}+1.90 \mathrm{E}-07 \text { tracerL }+7.32 \mathrm{E}-09 \mathrm{Ni}^{2+}\end{array}$ & $50^{a}$ & 100 & $4.00 E+01$ \\
\hline $\begin{array}{l}\text { Cglass } 0.28 \mathrm{y}+1.58 \mathrm{H}^{+}=0.79 \mathrm{H}_{2} \mathrm{O}+1.08 \mathrm{SiO}_{2}(\mathrm{aq})+0.30 \mathrm{Al}^{3+}+0.055 \mathrm{Fe}^{3+}+0.090 \mathrm{Na}^{+}+0.071 \mathrm{~K}^{+}+ \\
0.125 \mathrm{Ca}^{2+}+0.057 \mathrm{Mg}^{2+}+2.51 \mathrm{E}-07^{41} \mathrm{Ca}^{2+}+2.07 \mathrm{E}-05 \mathrm{UO}^{2+}+6.37 \mathrm{E}-09 \mathrm{Cs}^{+}+2.20 \mathrm{E}-09 \mathrm{Sr}^{2+}+1.65 \mathrm{E}- \\
09 \mathrm{Sm}^{3+}+3.16 \mathrm{E}-09 \mathrm{Eu}^{3+}+1.15 \mathrm{E}-09 \mathrm{NpO}_{2}^{+}+1.85 \mathrm{E}-06 \mathrm{Pu}^{4+}+1.18 \mathrm{E}-08{ }^{241} \mathrm{Pu}^{4+}+ \\
2.72 \mathrm{E}-09 \mathrm{Am}^{3+}+1.90 \mathrm{E}-07 \text { tracerL }+7.32 \mathrm{E}-09 \mathrm{Ni}^{2+}\end{array}$ & $50^{a}$ & 100 & $4.00 \mathrm{E}+01$ \\
\hline $\begin{array}{l}\text { Cglass } 0.45 \mathrm{y}+1.58 \mathrm{H}^{+}=0.79 \mathrm{H}_{2} \mathrm{O}+1.08 \mathrm{SiO}_{2}(\mathrm{aq})+0.30 \mathrm{Al}^{3+}+0.055 \mathrm{Fe}^{3+}+0.090 \mathrm{Na}^{+}+0.071 \mathrm{~K}^{+}+ \\
0.125 \mathrm{Ca}^{2+}+0.057 \mathrm{Mg}^{2+}+2.51 \mathrm{E}-07^{41} \mathrm{Ca}^{2+}+2.07 \mathrm{E}-05 \mathrm{UO}^{2+}+6.37 \mathrm{E}-09 \mathrm{Cs}^{+}+2.19 \mathrm{E}-09 \mathrm{Sr}^{2+}+1.65 \mathrm{E}- \\
09 \mathrm{Sm}^{3+}+3.16 \mathrm{E}-09 \mathrm{Eu}^{3+}+1.15 \mathrm{E}-09 \mathrm{NpO}_{2}^{+}+1.85 \mathrm{E}-06 \mathrm{Pu}^{4+}+1.17 \mathrm{E}-08{ }^{241} \mathrm{Pu}^{4+}+\end{array}$ & $50^{a}$ & 100 & $4.00 \mathrm{E}+01$ \\
\hline
\end{tabular}


Table 4.21. Solubility of nuclear melt glass.

\begin{tabular}{|c|c|c|c|}
\hline Reaction $^{\mathbf{b}}$ & $\log K$ & $\begin{array}{l}\text { Molar } \\
\text { Mass }\end{array}$ & $\begin{array}{c}\text { Molar } \\
\text { Volume }\end{array}$ \\
\hline & $25-200{ }^{\circ} \mathrm{C}$ & g & $\mathrm{cm}^{3}$ \\
\hline \multicolumn{4}{|l|}{$2.82 \mathrm{E}-09 \mathrm{Am}^{3+}+1.90 \mathrm{E}-07$ tracerL $+7.32 \mathrm{E}-09 \mathrm{Ni}^{2+}$} \\
\hline $\begin{array}{l}\text { Cglass } 0.72 \mathrm{y}+1.58 \mathrm{H}^{+}=0.79 \mathrm{H}_{2} \mathrm{O}+1.08 \mathrm{SiO}_{2}(\mathrm{aq})+0.30 \mathrm{Al}^{3+}+0.055 \mathrm{Fe}^{3+}+0.090 \mathrm{Na}^{+}+0.071 \mathrm{~K}^{+}+ \\
0.125 \mathrm{Ca}^{2+}+0.057 \mathrm{Mg}^{2+}+2.51 \mathrm{E}-07^{41} \mathrm{Ca}^{2+}+2.07 \mathrm{E}-05 \mathrm{UO}^{2+}+6.37 \mathrm{E}-09 \mathrm{Cs}^{+}+2.17 \mathrm{E}-09 \mathrm{Sr}^{2+}+1.65 \mathrm{E}- \\
09 \mathrm{Sm}^{3+}+3.16 \mathrm{E}-09 \mathrm{Eu}^{3+}+1.15 \mathrm{E}-09 \mathrm{NpO}_{2}^{+}+1.85 \mathrm{E}-06 \mathrm{Pu}^{4+}+1.16 \mathrm{E}-08{ }^{241} \mathrm{Pu}^{4+}+\end{array}$ & & & \\
\hline $2.97 \mathrm{E}-09 \mathrm{Am}^{3+}+1.90 \mathrm{E}-07$ tracerL $+7.32 \mathrm{E}-09 \mathrm{Ni}^{2+}$ & $50^{a}$ & 100 & $4.00 E+01$ \\
\hline $\begin{array}{l}\text { Cglass } 1.0 \mathrm{y}+1.58 \mathrm{H}^{+}=0.79 \mathrm{H}_{2} \mathrm{O}+1.08 \mathrm{SiO}_{2}(\mathrm{aq})+0.30 \mathrm{Al}^{3+}+0.055 \mathrm{Fe}^{3+}+0.090 \mathrm{Na}^{+}+0.071 \mathrm{~K}^{+}+0.125 \\
\mathrm{Ca}^{2+}+0.057 \mathrm{Mg}^{2+}+2.51 \mathrm{E}-07^{41} \mathrm{Ca}^{2+}+2.07 \mathrm{E}-05 \mathrm{UO} 2^{2+}+6.37 \mathrm{E}-09 \mathrm{Cs}^{+}+2.16 \mathrm{E}-09 \mathrm{Sr}^{2+}+1.65 \mathrm{E}-09 \mathrm{Sm} \\
+3.16 \mathrm{E}-09 \mathrm{Eu}^{3+}+1.15 \mathrm{E}-09 \mathrm{NpO}_{2}^{+}+1.85 \mathrm{E}-06 \mathrm{Pu}^{4+}+1.14 \mathrm{E}-08 \mathrm{Pl}^{241} \mathrm{Pu}^{4+}+ \\
\text { 3.12E-09 } \mathrm{Am}^{3+}+1.90 \mathrm{E}-07 \text { tracerL }+7.32 \mathrm{E}-09 \mathrm{Ni}^{2+}\end{array}$ & $50^{a}$ & 100 & $4.00 E+01$ \\
\hline $\begin{array}{l}\text { Cglass } 1.3 \mathrm{y}+1.58 \mathrm{H}^{+}=0.79 \mathrm{H}_{2} \mathrm{O}+1.08 \mathrm{SiO}_{2}(\mathrm{aq})+0.30 \mathrm{Al}^{3+}+0.055 \mathrm{Fe}^{3+}+0.090 \mathrm{Na}^{+}+0.071 \mathrm{~K}^{+}+0.125 \\
\mathrm{Ca}^{2+}+0.057 \mathrm{Mg}^{2+}+2.51 \mathrm{E}-07^{41} \mathrm{Ca}^{2+}+2.07 \mathrm{E}-05 \mathrm{UO}^{2+}+6.37 \mathrm{E}-09 \mathrm{Cs}^{+}+2.14 \mathrm{E}-09 \mathrm{Sr}^{2+}+1.64 \mathrm{E}-09 \mathrm{Sm} \\
{ }^{3+}+3.16 \mathrm{E}-09 \mathrm{Eu}^{3+}+1.15 \mathrm{E}-09 \mathrm{NpO}_{2}^{+}+1.85 \mathrm{E}-06 \mathrm{Pu}^{4+}+1.13 \mathrm{E}-08 \mathrm{Pl}^{241} \mathrm{Pu}^{4+}+3.28 \mathrm{E}-09 \mathrm{Am}^{3+}+1.90 \mathrm{E}-07 \\
\text { tracerL }+7.32 \mathrm{E}-09 \mathrm{Ni}^{2+}\end{array}$ & $50^{a}$ & 100 & $4.00 E+01$ \\
\hline $\begin{array}{l}\text { Cglass } 2.4 \mathrm{y}+1.58 \mathrm{H}^{+}=0.79 \mathrm{H}_{2} \mathrm{O}+1.08 \mathrm{SiO}_{2}(\mathrm{aq})+0.30 \mathrm{Al}^{3+}+0.055 \mathrm{Fe}^{3+}+0.090 \mathrm{Na}^{+}+0.071 \mathrm{~K}^{+}+0.125 \\
\mathrm{Ca}^{2+}+0.057 \mathrm{Mg}^{2+}+2.51 \mathrm{E}-07^{41} \mathrm{Ca}^{2+}+2.07 \mathrm{E}-05 \mathrm{UO}^{2+}+6.37 \mathrm{E}-09 \mathrm{Cs}^{+}+2.09 \mathrm{E}-09 \mathrm{Sr}^{2+}+1.63 \mathrm{E}-09 \mathrm{Sm} \\
3^{++}+3.16 \mathrm{E}-09 \mathrm{Eu}^{3+}+1.15 \mathrm{E}-09 \mathrm{NpO}_{2}^{+}+1.85 \mathrm{E}-06 \mathrm{Pu}^{4+}+1.07 \mathrm{E}-08{ }^{241} \mathrm{Pu}^{4+}+\end{array}$ & & & \\
\hline 3.84E-09 $\mathrm{Am}^{3+}+1.90 \mathrm{E}-07$ tracerL $+7.32 \mathrm{E}-09 \mathrm{Ni}^{2+}$ & $50^{a}$ & 100 & $4.00 E+01$ \\
\hline $\begin{array}{l}\text { Cglass } 3.4 \mathrm{y}+1.58 \mathrm{H}^{+}=0.79 \mathrm{H}_{2} \mathrm{O}+1.08 \mathrm{SiO}_{2}(\mathrm{aq})+0.30 \mathrm{Al}^{3+}+0.055 \mathrm{Fe}^{3+}+0.090 \mathrm{Na}^{+}+0.071 \mathrm{~K}^{+}+0.125 \\
\mathrm{Ca}^{2+}+0.057 \mathrm{Mg}^{2+}+2.51 \mathrm{E}-07^{41} \mathrm{Ca}^{2+}+2.07 \mathrm{E}-05 \mathrm{UO} 2^{2+}+6.37 \mathrm{E}-09 \mathrm{Cs}^{+}+2.04 \mathrm{E}-09 \mathrm{Sr}^{2+}+1.62 \mathrm{E}-09 \mathrm{Sm} \\
{ }^{3+}+3.16 \mathrm{E}-09 \mathrm{Eu}^{3+}+1.15 \mathrm{E}-09 \mathrm{NpO}_{2}^{+}+1.85 \mathrm{E}-06 \mathrm{Pu}^{4+}+1.02 \mathrm{E}-08{ }^{241} \mathrm{Pu}^{4+}+ \\
4 . \mathrm{F}-09 \mathrm{Am}^{3+}+1.00 \mathrm{~F}-07 \mathrm{tracerl}+732 \mathrm{~F}-09 \mathrm{Ni}^{2+}\end{array}$ & $50^{a}$ & & \\
\hline & 50 & 100 & $4.00 E+01$ \\
\hline $\begin{array}{l}\text { Cglass5.0y }+1.58 \mathrm{H}^{+}=0.79 \mathrm{H}_{2} \mathrm{O}+1.08 \mathrm{SiO}_{2}(\mathrm{aq})+0.30 \mathrm{Al}^{3+}+0.055 \mathrm{Fe}^{3+}+0.090 \mathrm{Na}^{+}+0.071 \mathrm{~K}^{+}+0.125 \\
\mathrm{Ca}^{2+}+0.057 \mathrm{Mg}^{2+}+2.51 \mathrm{E}-07^{41} \mathrm{Ca}^{2+}+2.07 \mathrm{E}-05 \mathrm{UO}^{2+}+6.37 \mathrm{E}-09 \mathrm{Cs}^{+}+1.96 \mathrm{E}-09 \mathrm{Sr}^{2+}+1.60 \mathrm{E}-09 \mathrm{Sm} \\
{ }^{++}+3.16 \mathrm{E}-09 \mathrm{Eu}^{3+}+1.15 \mathrm{E}-09 \mathrm{NpO}_{2}^{+}+1.85 \mathrm{E}-06 \mathrm{Pu}^{4+}+9.44 \mathrm{E}-09 \mathrm{Pu}^{24} \mathrm{Pu}^{4+}+\end{array}$ & & & \\
\hline $5.08 \mathrm{E}-09 \mathrm{Am}^{3+}+1.90 \mathrm{E}-07$ tracerL $+7.32 \mathrm{E}-09 \mathrm{Ni}^{2+}$ & $50^{a}$ & 100 & $4.00 \mathrm{E}+01$ \\
\hline $\begin{array}{l}\text { Cglass } 5.7 \mathrm{y}+1.58 \mathrm{H}^{+}=0.79 \mathrm{H}_{2} \mathrm{O}+1.08 \mathrm{SiO}_{2}(\mathrm{aq})+0.30 \mathrm{Al}^{3+}+0.055 \mathrm{Fe}^{3+}+0.090 \mathrm{Na}^{+}+0.071 \mathrm{~K} \\
\mathrm{Ca}^{2+}+0.057 \mathrm{Mg}^{2+}+2.51 \mathrm{E}-07^{41} \mathrm{Ca}^{2+}+2.07 \mathrm{E}-05 \mathrm{UO}^{2+}+6.37 \mathrm{E}-09 \mathrm{Cs}^{+}+1.93 \mathrm{E}-09 \mathrm{Sr}^{2+}+1.59 \mathrm{E}\end{array}$ & $50^{a}$ & 100 & $4.00 \mathrm{E}+01$ \\
\hline
\end{tabular}


Table 4.21. Solubility of nuclear melt glass.

\begin{tabular}{|c|c|c|c|}
\hline Reaction $^{\text {b }}$ & $\log K$ & $\begin{array}{l}\text { Molar } \\
\text { Mass }\end{array}$ & $\begin{array}{c}\text { Molar } \\
\text { Volume }\end{array}$ \\
\hline & $25-200{ }^{\circ} \mathrm{C}$ & g & $\mathrm{cm}^{3}$ \\
\hline \multicolumn{4}{|l|}{$\begin{array}{l}{ }^{3+}+3.16 \mathrm{E}-09 \mathrm{Eu}^{3+}+1.15 \mathrm{E}-09 \mathrm{NpO}_{2}^{+}+1.85 \mathrm{E}-06 \mathrm{Pu}^{4+}+9.13 \mathrm{E}-09^{241} \mathrm{Pu}^{4+}+ \\
5.38 \mathrm{E}-09 \mathrm{Am}^{3+}+1.90 \mathrm{E}-07 \text { tracerL }+7.32 \mathrm{E}-09 \mathrm{Ni}^{2+}\end{array}$} \\
\hline $\begin{array}{l}\text { Cglass6.3y }+1.58 \mathrm{H}^{+}=0.79 \mathrm{H}_{2} \mathrm{O}+1.08 \mathrm{SiO}_{2}(\mathrm{aq})+0.30 \mathrm{Al}^{3+}+0.055 \mathrm{Fe}^{3+}+0.090 \mathrm{Na}^{+}+0.071 \mathrm{~K}^{+}+0.125 \\
\mathrm{Ca}^{2+}+0.057 \mathrm{Mg}^{2+}+2.51 \mathrm{E}-07^{41} \mathrm{Ca}^{2+}+2.07 \mathrm{E}-05 \mathrm{UO} 2^{2+}+6.37 \mathrm{E}-09 \mathrm{Cs}^{+}+1.90 \mathrm{E}-09 \mathrm{Sr}^{2+}+1.58 \mathrm{E}-09 \mathrm{Sm} \\
{ }^{3+}+3.16 \mathrm{E}-09 \mathrm{Eu}^{3+}+1.15 \mathrm{E}-09 \mathrm{NpO}_{2}^{+}+1.85 \mathrm{E}-06 \mathrm{Pu}^{4+}+8.84 \mathrm{E}-0{ }^{241} \mathrm{Pu}^{4+}+ \\
5.67 \mathrm{E}-09 \mathrm{Am}^{3+}+1.90 \mathrm{E}-07 \text { tracerL }+7.32 \mathrm{E}-09 \mathrm{Ni}^{2+}\end{array}$ & $50^{a}$ & 100 & $4.00 \mathrm{E}+01$ \\
\hline $\begin{array}{l}\text { Cglass7.8y }+1.58 \mathrm{H}^{+}=0.79 \mathrm{H}_{2} \mathrm{O}+1.08 \mathrm{SiO}_{2}(\mathrm{aq})+0.30 \mathrm{Al}^{3+}+0.055 \mathrm{Fe}^{3+}+0.090 \mathrm{Na}^{+}+0.071 \mathrm{~K}^{+}+0.125 \\
\mathrm{Ca}^{2+}+0.057 \mathrm{Mg}^{2+}+2.51 \mathrm{E}-07^{41} \mathrm{Ca}^{2+}+2.07 \mathrm{E}-05 \mathrm{UO}^{2+}+6.37 \mathrm{E}-09 \mathrm{Cs}^{+}+1.84 \mathrm{E}-09 \mathrm{Sr}^{2+}+1.56 \mathrm{E}-09 \mathrm{Sm} \\
{ }^{3+}+3.16 \mathrm{E}-09 \mathrm{Eu}^{3+}+1.15 \mathrm{E}-09 \mathrm{NpO}_{2}^{+}+1.85 \mathrm{E}-06 \mathrm{Pu}^{4+}+8.25 \mathrm{E}-0{ }^{241} \mathrm{Pu}^{4+}+ \\
6.25 \mathrm{E}-09 \mathrm{Am}^{3+}+1.90 \mathrm{E}-07 \text { tracerL }+7.32 \mathrm{E}-09 \mathrm{Ni}^{2+}\end{array}$ & $50^{a}$ & 100 & $4.00 E+01$ \\
\hline $\begin{array}{l}\text { Cglass8.4y }+1.58 \mathrm{H}^{+}=0.79 \mathrm{H}_{2} \mathrm{O}+1.08 \mathrm{SiO}_{2}(\mathrm{aq})+0.30 \mathrm{Al}^{3+}+0.055 \mathrm{Fe}^{3+}+0.090 \mathrm{Na}^{+}+0.071 \mathrm{~K}^{+}+0.125 \\
\mathrm{Ca}^{2+}+0.057 \mathrm{Mg}^{2+}+2.51 \mathrm{E}-07^{41} \mathrm{Ca}^{2+}+2.07 \mathrm{E}-05 \mathrm{UO} 2^{2+}+6.37 \mathrm{E}-09 \mathrm{Cs}^{+}+1.81 \mathrm{E}-09 \mathrm{Sr}^{2+}+1.55 \mathrm{E}-09 \mathrm{Sm}^{2+} \mathrm{m}^{3+}+3.16 \mathrm{E}-09 \mathrm{Eu}^{3+}+1.15 \mathrm{E}-09 \mathrm{NpO}_{2}^{+}+1.85 \mathrm{E}-06 \mathrm{Pu}^{4+}+8.01 \mathrm{E}-0{ }^{241} \mathrm{Pu}^{4+}+ \\
6.48 \mathrm{E}-09 \mathrm{Am}^{3+}+1.90 \mathrm{E}-07 \text { tracerL }+7.32 \mathrm{E}-09 \mathrm{Ni}^{2+}\end{array}$ & $50^{a}$ & 100 & $4.00 E+01$ \\
\hline $\begin{array}{l}\text { Cglass9.0y+1.58 } \mathrm{H}^{+}=0.79 \mathrm{H}_{2} \mathrm{O}+1.08 \mathrm{SiO}_{2}(\mathrm{aq})+0.30 \mathrm{Al}^{3+}+0.055 \mathrm{Fe}^{3+}+0.090 \mathrm{Na}^{+}+0.071 \mathrm{~K}^{+}+0.125 \\
\mathrm{Ca}^{2+}+0.057 \mathrm{Mg}^{2+}+2.51 \mathrm{E}-07^{41} \mathrm{Ca}^{2+}+2.07 \mathrm{E}-05 \mathrm{UO}^{2+}+6.37 \mathrm{E}-09 \mathrm{Cs}^{+}+1.78 \mathrm{E}-09 \mathrm{Sr}^{2+}+1.55 \mathrm{E}-09 \mathrm{Sm} \\
{ }^{3+}+3.16 \mathrm{E}-09 \mathrm{Eu}^{3+}+1.15 \mathrm{E}-09 \mathrm{NpO}_{2}^{+}+1.85 \mathrm{E}-06 \mathrm{Pu}^{4+}+7.77 \mathrm{E}-0{ }^{241} \mathrm{Pu}^{4+}+ \\
6.71 \mathrm{E}-09 \mathrm{Am}^{3+}+1.90 \mathrm{E}-07 \text { tracerL }+7.32 \mathrm{E}-09 \mathrm{Ni}^{2+}\end{array}$ & $50^{a}$ & 100 & $4.00 \mathrm{E}+01$ \\
\hline $\begin{array}{l}\text { Cglass10.0y }+1.58 \mathrm{H}^{+}=0.79 \mathrm{H}_{2} \mathrm{O}+1.08 \mathrm{SiO}_{2}(\mathrm{aq})+0.30 \mathrm{Al}^{3+}+0.055 \mathrm{Fe}^{3+}+0.090 \mathrm{Na}^{+}+0.071 \mathrm{~K}^{+}+ \\
0.125 \mathrm{Ca}^{2+}+0.057 \mathrm{Mg}^{2+}+2.51 \mathrm{E}-07^{41} \mathrm{Ca}^{2+}+2.07 \mathrm{E}-05 \mathrm{UO}^{2+}+6.37 \mathrm{E}-09 \mathrm{Cs}^{+}+1.74 \mathrm{E}-09 \mathrm{Sr}^{2+}+1.54 \mathrm{E}- \\
09 \mathrm{Sm}^{3+}+3.16 \mathrm{E}-09 \mathrm{Eu}^{3+}+1.15 \mathrm{E}-09 \mathrm{NpO}_{2}^{+}+1.85 \mathrm{E}-06 \mathrm{Pu}^{4+}+7.41 \mathrm{E}-0 \mathrm{P}^{241} \mathrm{Pu}^{4+}+ \\
7.06 \mathrm{E}-09 \mathrm{Am}^{3+}+1.90 \mathrm{E}-07 \text { tracerL }+7.32 \mathrm{E}-09 \mathrm{Ni}^{2+}\end{array}$ & $50^{a}$ & 100 & $4.00 E+01$ \\
\hline $\begin{array}{l}\text { Cglass10.4y }+1.58 \mathrm{H}^{+}=0.79 \mathrm{H}_{2} \mathrm{O}+1.08 \mathrm{SiO}_{2}(\mathrm{aq})+0.30 \mathrm{Al}^{3+}+0.055 \mathrm{Fe}^{3+}+0.090 \mathrm{Na}^{+}+0.071 \mathrm{~K}^{+}+ \\
0.125 \mathrm{Ca}^{2+}+0.057 \mathrm{Mg}^{2+}+2.51 \mathrm{E}-07{ }^{41} \mathrm{Ca}^{2+}+2.07 \mathrm{E}-05 \mathrm{UO}^{2+}+6.37 \mathrm{E}-09 \mathrm{Cs}^{+}+1.73 \mathrm{E}-09 \mathrm{Sr}^{2+}+1.53 \mathrm{E}- \\
09 \mathrm{Sm}^{3+}+3.16 \mathrm{E}-09 \mathrm{Eu}^{3+}+1.15 \mathrm{E}-09 \mathrm{NpO}_{2}^{+}+1.85 \mathrm{E}-06 \mathrm{Pu}^{4+}+7.27 \mathrm{E}-0 \mathrm{P}^{241} \mathrm{Pu}^{4+}+ \\
7.20 \mathrm{E}-09 \mathrm{Am}^{3+}+1.90 \mathrm{E}-07 \text { tracerL }+7.32 \mathrm{E}-09 \mathrm{Ni}^{2+}\end{array}$ & $50^{a}$ & 100 & $4.00 \mathrm{E}+01$ \\
\hline Cglass12.3y $+1.58 \mathrm{H}^{+}=0.79 \mathrm{H}_{2} \mathrm{O}+1.08 \mathrm{SiO}_{2}(\mathrm{aq})+0.30 \mathrm{Al}^{3+}+0.055 \mathrm{Fe}^{3+}+0.090 \mathrm{Na}^{+}+0.071 \mathrm{~K}^{+}+$ & $50^{a}$ & 100 & $4.00 E+01$ \\
\hline
\end{tabular}


CHAPTER 4: CALIBRATION AND ASSESSMENT MODELS

Table 4.21. Solubility of nuclear melt glass.

\begin{tabular}{|c|c|c|c|}
\hline Reaction $^{\text {b }}$ & $\log K$ & $\begin{array}{l}\text { Molar } \\
\text { Mass }\end{array}$ & $\begin{array}{c}\text { Molar } \\
\text { Volume }\end{array}$ \\
\hline & $25-200^{\circ} \mathrm{C}$ & $\mathbf{g}$ & $\mathrm{cm}^{3}$ \\
\hline $\begin{array}{l}0.125 \mathrm{Ca}^{2+}+0.057 \mathrm{Mg}^{2+}+2.51 \mathrm{E}-07^{41} \mathrm{Ca}^{2+}+2.07 \mathrm{E}-05 \mathrm{UO}^{2+}+6.37 \mathrm{E}-09 \mathrm{Cs}^{+}+1.65 \mathrm{E}-09 \mathrm{Sr}^{2+}+1.51 \mathrm{E}- \\
09 \mathrm{Sm}^{3+}+3.16 \mathrm{E}-09 \mathrm{Eu}^{3+}+1.15 \mathrm{E}-09 \mathrm{NpO}_{2}^{+}+1.85 \mathrm{E}-06 \mathrm{Pu}^{4+}+6.63 \mathrm{E}-09{ }^{241} \mathrm{Pu}^{4+}+ \\
7.82 \mathrm{E}-09 \mathrm{Am}^{3+}+1.90 \mathrm{E}-07 \text { tracerL }+7.32 \mathrm{E}-09 \mathrm{Ni}^{2+}\end{array}$ & & & \\
\hline
\end{tabular}

${ }^{\text {a }}$ Note that solubility constants reported in this table are not used in simulations. Instead, the solubility of the glass is controlled by the solubility of SiO ${ }_{2}$ (am).

${ }^{\mathrm{b}}$ The name of the glass indicates the starting point of the time step for which it is used. 


\subsubsection{Major Element and Radionuclide Mineral Dissolution/Precipitation Rates}

\subsection{Minerals}

Minerals are allowed to precipitate and dissolve during the CRUNCH simulations according to the kinetic rate equation

$$
r=\operatorname{sgn}\left(\log \left(\frac{Q}{K}\right)\right) \times k_{0} \times e^{\frac{E_{a}}{R}\left(\frac{T-T_{0}}{T_{0} T}\right)} \times A_{s} \times \prod_{i} a_{i}^{n_{i}} \times\left(1-\left(\frac{Q}{K}\right)^{1 / \sigma}\right)^{v}
$$

where $r$ is the rate of dissolution of a particular mineral $(\mathrm{mol} / \mathrm{s}), Q$ and $K$ are the ion activity product and equilibrium constant of the mineral (Aagaard and Helgeson, 1982), respectively, $k_{0}$ is the rate constant $\left(\mathrm{mol} / \mathrm{m}^{2}-\mathrm{s}\right), E_{a}$ is the activation energy (cal $\left./ \mathrm{mol}\right), R$ is the gas constant $(1.99 \mathrm{cal} / \mathrm{mol}-\mathrm{K}) T$ and $T_{0}$ are the temperature of the system and a reference temperature (typically $298 \mathrm{~K}$ ), respectively, $A_{s}$ is the surface area $\left(\mathrm{m}^{2}\right), a_{i}$ is the activity of a dissolution/precipitation inhibiting/enhancing species $i$ to the $n^{\text {th }}$ power, and $\sigma$ and $v$ are empirically fitted parameters (Steefel and Yabusaki, 1996). In these simulations, the only dissolution inhibiting/enhancing species included are $\mathrm{H}^{+}$and $\mathrm{OH}^{-}$. The values $\sigma$ and $v$ are determined experimentally but are assumed to equal one in this work. Dissolution and precipitation can be expressed as the sum of $\mathrm{pH}$-dependent, $\mathrm{pH}$ independent and pOH-dependent reactions by specifying multiple parallel reactions with different dependencies on the $a_{i}$ term. The multiple parallel reactions are summed to obtain the total rate, as follows:

$$
r=\operatorname{sgn}\left(\log \left(\frac{Q}{K}\right)\right) \times e^{\frac{E_{a}}{R}\left(\frac{T-T_{0}}{T_{0} T}\right)} \times A_{s} \times\left(1-\left(\frac{Q}{K}\right)^{1 / \sigma}\right)^{v} \times \sum_{i} k_{i} \times a_{i}^{n_{i}} .
$$

Thus, in our model, $a_{i}$ is equal to 1 ( $\mathrm{pH}$-independent rate), $a_{i}$ is equal to the activity of $\mathrm{H}^{+}$, or $a_{i}$ is equal to the activity of $\mathrm{OH}^{-}$. The equation is the same for both precipitation and dissolution except that the sign $\left(\operatorname{sgn}\left(\log \left[\mathrm{Q}_{\mathrm{m}} / \mathrm{K}_{\mathrm{m}}\right]\right)\right)$ of the equation changes.

Tables 4.22 and 4.23 list kinetic parameters for the minerals considered in CRUNCH. Kinetic parameters for glass dissolution are discussed separately in the following section. The rate parameters for clays, zeolites, and the feldspars were based on published data and those for calcite, goethite, and the radionuclide-bearing solids were chosen to limit kinetic inhibitions to their precipitation and dissolution. Calcite and goethite are known to precipitate relatively quickly from solution. Little is known about the reaction kinetics of radionuclide-bearing solids, so relatively fast reaction kinetics were imposed. Activation energies are also unknown for minerals such as the radionuclide-bearing precipitates. In these cases, the activation energy is assumed equal to that of glass. Note that the coprecipitation of radionuclides with secondary mineral phases was not included in our model. This process may be important in trapping radionuclides released from the dissolving glass. However, the process has not been sufficiently studied (and parameterized) to allow for its incorporation into the model. Exclusion of the coprecipitation effects leads to more conservative radionuclide release predictions. 
The reactive surface area of most mineral phases was set to $2,000 \mathrm{~m}^{2} / \mathrm{m}^{3}$ alluvium. This value was based on the reactive surface area of a zone with $20 \%$ porosity and $80 \%$ glass, in which the glass possessed a reactive surface area of $0.001 \mathrm{~m}^{2} / \mathrm{g}$ and a density of $2.5 \mathrm{~g} / \mathrm{cm}^{3}$. The glass is assumed to act as the substrate for secondary mineral precipitation. The reactive surface areas for all minerals in the native alluvium were also assumed to equal $2,000 \mathrm{~m}^{2} / \mathrm{m}^{3}$-medium. Mineral reactions, other than calcite reactions, were extremely limited and inconsequential outside the vicinity of the melt glass zone. Thus, the reactive surface areas of minerals outside the melt glass zone do not affect the reactive transport simulations.

The reactive surface areas $\left(A_{s}\right)$ of secondary minerals (minerals whose initial volume fraction equalled zero) were updated according to the following expressions from Steefel and Yabusaki (1996):

$$
\begin{aligned}
& A_{s}=A_{s}^{0}\left[\left(\frac{\phi}{\phi^{0}}\right) \phi_{m}\right]^{\frac{2}{3}} \text { for dissolution } \\
& A_{s}=A_{s}^{0}\left(\frac{\phi}{\phi_{0}}\right)^{\frac{2}{3}} \text { for precipitation }
\end{aligned}
$$

where $A_{s}^{0}$ denotes the initial surface area of the mth mineral, $\phi^{\circ}$ stands for the initial porosity of the medium, and $\phi_{\mathrm{m}}$ represents the volume fraction of the mth mineral. Montmorillonite-Ca and calcite were the only exceptions. For these two minerals, reactive surface area was correlated directly to mineral mass, as listed in Table 4.23. These minerals were treated in this fashion to allow them to be linked to surface complexation algorithms in the code.

In the course of simulations with $\mathrm{CRUNCH}$, it was discovered that for secondary minerals, the affinity term tended to compensate for the value of the reactive surface area. If the surface area was decreased, the rate of precipitation decreased, and the mineral's degree of saturation increased. The increase in the saturation term effectively negated the decrease in the surface area to maintain a nearly constant dissolution rate.

Note that nucleation kinetics - the energetic barrier to precipitation that must be overcome before precipitation can begin-were not accounted for in the simulations. Data on nucleation kinetics for the minerals considered in this study, and for most rockforming minerals, are generally not available. 
Table 4.22. Kinetic parameters for radionuclide-bearing mineral dissolution/precipitation.

\begin{tabular}{|c|c|c|c|c|}
\hline Phase & $\log k_{i}{ }^{a}$ & $E_{a}$ & $A_{s}$ & $\log \left(k_{i}\right), a_{i}, n_{i}$ \\
\hline & $\log \left(\mathrm{mol} / \mathrm{m}^{2} / \mathrm{s}\right)$ & kcal & $\mathrm{m}^{2} / \mathrm{m}^{3}$ & \\
\hline $\mathrm{PuO}_{2}(\mathrm{am})$ & -10 & 15 & 2,000 & - \\
\hline $\mathrm{PuO}_{2} \mathrm{OH}(\mathrm{am})$ & -10 & 15 & 2,000 & - \\
\hline${ }^{241} \mathrm{PuO}_{2}(\mathrm{am})$ & -10 & 15 & 2,000 & - \\
\hline${ }^{241} \mathrm{PuO}_{2} \mathrm{OH}(\mathrm{am})$ & -10 & 15 & 2,000 & - \\
\hline $\mathrm{EuOHCO}_{3}$ & -10 & 15 & 2,000 & - \\
\hline $\mathrm{AmOHCO}_{3}$ & -10 & 15 & 2,000 & - \\
\hline $\mathrm{Sm}(\mathrm{OH})_{3}(\mathrm{am})$ & -10 & 15 & 2,000 & - \\
\hline $\mathrm{NpO}_{2} \mathrm{OH}(\mathrm{am})$ & -10 & 15 & 2,000 & 一 \\
\hline Schoepite & -10 & 15 & 2,000 & - \\
\hline Celestite & -10 & 15 & 2,000 & - \\
\hline
\end{tabular}

${ }^{\mathrm{a}}$ The $\mathrm{pH}$ independent rate constant.

Table 4.23. Kinetic parameters for secondary mineral dissolution/precipitation.

\begin{tabular}{|c|c|c|c|c|}
\hline Phase & $\log k_{i}^{a}$ & $E_{a}$ & $A_{s}$ & $\log \left(k_{i}\right), a_{i}, n_{i}$ \\
\hline & $\log \left(\mathrm{mol} / \mathrm{m}^{2} / \mathrm{s}\right)$ & kcal & $\mathrm{m}^{2} / \mathrm{m}^{3}$ & - \\
\hline Illite & -13 & 6.39 & 2,000 & $-11.25, \mathrm{OH}^{-}, 0.25$ \\
\hline Kaolinite & -13 & 6.39 & 2,000 & $-11.25, \mathrm{OH}^{-}, 0.25$ \\
\hline Goethite & -10 & 15 & 2,000 & - \\
\hline Beidellite-Ca & -13 & 6.39 & 2,000 & $-11.25, \mathrm{OH}^{-}, 0.25$ \\
\hline Beidellite-Na & -13 & 6.39 & 2,000 & $-11.25, \mathrm{OH}^{-}, 0.25$ \\
\hline Beidellite-K & -13 & 6.39 & 2,000 & $-11.25, \mathrm{OH}^{-}, 0.25$ \\
\hline Beidellite-Mg & -13 & 6.39 & 2,000 & $-11.25, \mathrm{OH}^{-}, 0.25$ \\
\hline Montmorillonite-Ca & -13 & 6.39 & $3.0 \mathrm{~m}^{2} / \mathrm{g}$ & $-11.25, \mathrm{OH}^{-}, 0.25$ \\
\hline Montmorillonite- $\mathrm{Na}$ & -13 & 6.39 & 2,000 & $-11.25, \mathrm{OH}^{-}, 0.25$ \\
\hline Montmorillonite-K & -13 & 6.39 & 2,000 & $-11.25, \mathrm{OH}^{-}, 0.25$ \\
\hline Montmorillonite-Mg & -13 & 6.39 & 2,000 & $-11.25, \mathrm{OH}^{-}, 0.25$ \\
\hline Nontronite-Ca & -13 & 6.39 & 2,000 & $-11.25, \mathrm{OH}^{-}, 0.25$ \\
\hline Nontronite- $\mathrm{Na}$ & -13 & 6.39 & 2,000 & $-11.25, \mathrm{OH}^{-}, 0.25$ \\
\hline Nontronite-K & -13 & 6.39 & 2,000 & $-11.25, \mathrm{OH}^{-}, 0.25$ \\
\hline Nontronite-Mg & -13 & 6.39 & 2,000 & $-11.25, \mathrm{OH}^{-}, 0.25$ \\
\hline Cristobalite(beta) & -10 & 15 & 2,000 & - \\
\hline Clinoptilolite-Ca & -12 & 13.86 & 2,000 & $-9.2, \mathrm{OH}^{-}, 0.4$ \\
\hline Clinoptilolite-Na & -12 & 13.86 & 2,000 & $-9.2, \mathrm{OH}^{-}, 0.4$ \\
\hline Clinoptilolite-K & -12 & 13.86 & 2,000 & $-9.2, \mathrm{OH}^{-}, 0.4$ \\
\hline
\end{tabular}


Table 4.23. Kinetic parameters for secondary mineral dissolution/precipitation.

\begin{tabular}{|l|c|c|c|c|}
\hline \multicolumn{1}{|c|}{ Phase } & $\log _{\boldsymbol{i}}{ }^{\mathbf{a}}$ & $\boldsymbol{E}_{\boldsymbol{a}}$ & $\boldsymbol{A}_{\mathbf{s}}$ & $\boldsymbol{L o g}\left(\boldsymbol{k}_{\boldsymbol{i}}\right), \boldsymbol{a}_{\boldsymbol{i}}, \boldsymbol{n}_{\boldsymbol{i}}$ \\
\hline Calcite & $\log \left(\mathbf{m o l} / \mathbf{m}^{\mathbf{2}} \mathbf{l s}\right)$ & $\mathbf{k c a l}$ & $\mathbf{m}^{2} / \mathbf{m}^{\mathbf{3}}$ & - \\
\hline Boehmite & -10 & 15 & $0.1 \mathrm{~m}^{2} / \mathrm{g}$ & - \\
\hline Gibbsite & -10 & 15 & 2,000 & - \\
\hline K-Feldspar & -10 & 15 & 2,000 & - \\
\hline Albite & -12.15 & 13.82 & 2,000 & $-9.75, \mathrm{OH}^{-}, 0.67$ \\
\hline Anorthite & -12.15 & 13.82 & 2,000 & $-9.75, \mathrm{OH}^{-}, 0.67$ \\
\hline Prehnite & -12.15 & 13.82 & 2,000 & $-9.75, \mathrm{OH}^{-}, 0.67$ \\
\hline Clinochlore-7A & -12 & 13.86 & 2,000 & $-9.2, \mathrm{OH}^{-}, 0.4$ \\
\hline $\mathrm{O}_{2}$ (min) & -13 & 6.39 & 2,000 & $-11.25, \mathrm{OH}^{-}, 0.25$ \\
\hline
\end{tabular}

${ }^{\mathrm{a}}$ The $\mathrm{pH}$ independent rate constant.

\subsection{Glass}

Glasses are amorphous, thermodynamically unstable materials that tend to transform with time into more stable crystalline phases. The rate of this transformation provides a limit to the release rates of radioactive elements contained in the melt glass.

When water first contacts an alkali aluminosilicate glass such as a rhyolitic melt glass, an ion exchange process takes place that quickly depletes alkalis from the outermost few nanometers of glass surface. With time, this outer alkali-depleted hydrous surface layer thickens. For high-silica glasses such as rhyolites, the hydration layer can continue to thicken over time further slowing the release rates of species from the glass. This process also restricts further water contact along narrow fractures where the hydration swelling reduces fracture permeability.

Some of the elements released from the melt glass may be incorporated into alteration phases, and some may remain in solution and may be carried away in the fluid. For a silicate glass such as that generated from tuffs at the NTS, reaction with groundwater will cause the formation of mainly clay and zeolite minerals. Zeolite precipitation is generally restricted to temperatures above ambient. Alteration minerals can affect the release rates of radionuclides from the melt glass through ion exchange, sorption, and precipitation reactions involving both major elements and radionuclides.

Alkali aluminosilicate glasses, such as rhyolitic glass, typically show a Vshaped $\mathrm{pH}$ dependence to their dissolution rates that has a minimum at near-neutral $\mathrm{pH}$. Figure 4.76 presents far-from-saturation dissolution rate data where the dissolution rates are not reduced by saturation effects (Mazer, 1987). These rates are, therefore, the maximum values at which the glass will dissolve at the given $\mathrm{pH}$ (excepting any catalytic effects such as might occur in the presence of strong complexing agents). The rate data show a progressive increase in durability (decrease in dissolution rate) as the silica content of the glass increases. For example, rhyolitic glass dissolves more slowly than basaltic glass. 


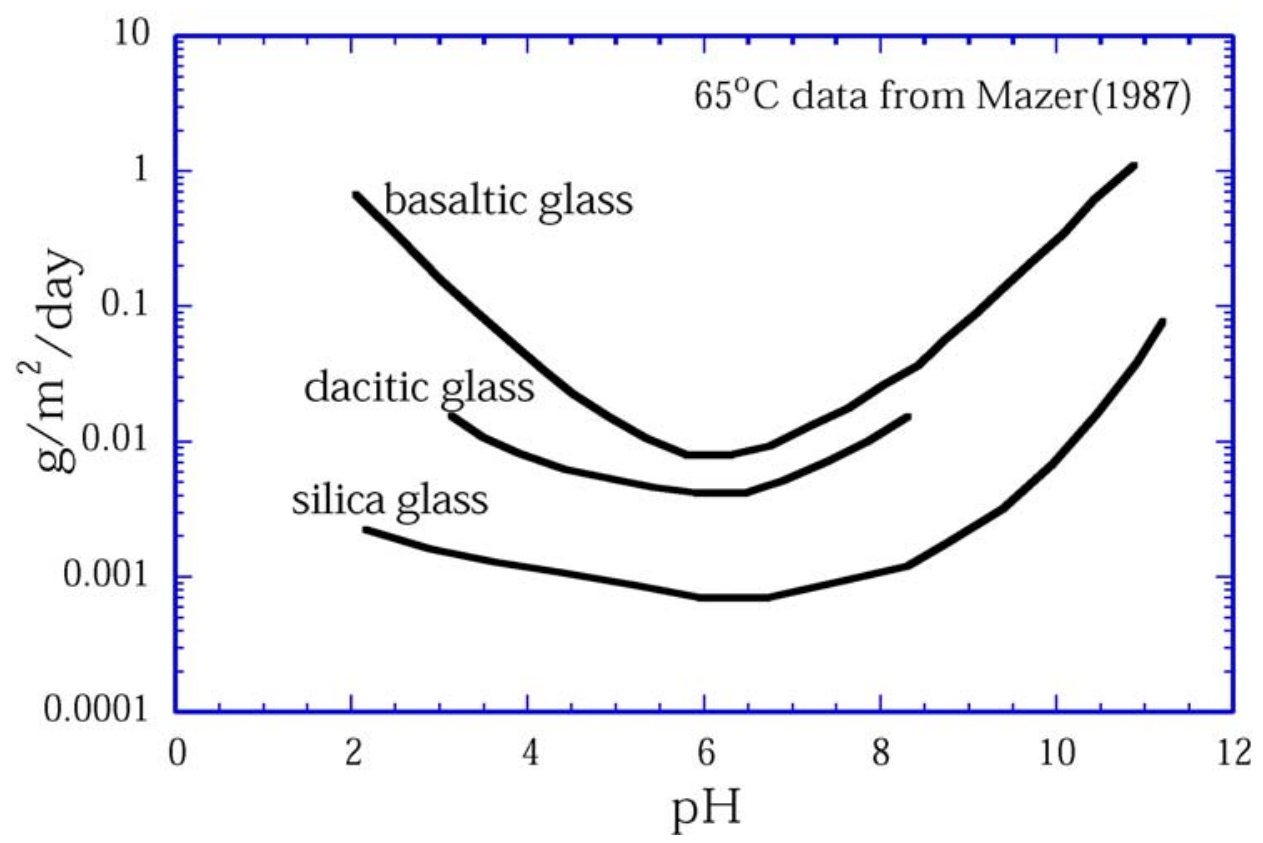

Figure 4.76 Dissolution rates for synthetic volcanic glasses measured at $65^{\circ} \mathrm{C}$ by Mazer (1987). These rates are for experimental conditions far from saturation with respect to the glass.

Glasses exhibit a saturation effect similar to that of crystalline solids. In closed system experiments, the dissolution rate slows as species build up in solution. The dissolution rate under near-saturation conditions can be several orders of magnitude slower than the rate measured far from saturation. For silicate glasses, the saturation effect is due mainly to dissolved silica. Most other aqueous species have less effect, particularly in neutral to alkaline $\mathrm{pH}$ solutions. The saturation effect, which slows the reaction rate, is likely to be important for slowly flowing groundwater interacting with the melt glass. Slow groundwater flow rates relative to glass-water reaction rates favor a buildup of silica concentrations in solution. Furthermore, since the ambient groundwater at NTS has relatively high silica concentrations due to the dissolution of native volcanic rocks containing glass and cristobalite, initial glass dissolution rates in contact with native waters will also be affected by saturation effects.

\subsection{The Glass Dissolution Rate Equation}

The processes controlling the rate of glass dissolution described above are accounted for in a rate equation as follows:

$$
r=k_{0} \times e^{\frac{E_{a}}{R}\left(\frac{T-T_{0}}{T_{0} T}\right)} \times A_{s} \times \prod_{i} a_{i}^{n_{i}} \times\left(1-\left(\frac{Q}{K}\right)^{1 / \sigma}\right)^{v}+A_{s} k_{f}
$$

where $r$ is the rate of glass dissolution (mol-glass/g-glass/s), $k_{f}$ is a term sometimes used to account for the relatively slow rate of glass dissolution close to saturation where the saturation term $(1-Q / K)$ alone is inadequate, and all other terms are defined in Section 4.8.2.8.1. This rate equation is identical to the one used for secondary minerals in the previous section except for the addition of an additional near-saturation rate term. The values used for each of these parameters are reported in the following sections. 


\subsection{Glass Surface Area, $\mathrm{A}_{\mathrm{s}}$}

One of the most critical parameters necessary for predicting radionuclide release rates from melt glass is the reactive surface area of the melt glass. This term is important because the reaction rate of the glass is proportional to the reactive surface area. ${ }^{1}$ Estimating the reactive surface area for melt glass is complicated by the high degree of heterogeneity of the melt glass zone. Photos taken of exploratory post-test drifts show that the melt glass zone is a breccia of blocks (introduced during cavity collapse) that are incorporated into melt glass that is variably cracked and vesiculated. The relative proportions of massive glass to fractured and vesicular glass are unknown, and their distributions in space are probably chaotic.

The reactive surface area of glass is initially formed from several processes. Groundwater and other volatiles present in the subsurface at the time of the test and incorporated in the melt will tend to exsolve as the melt solidifies. This will result in vesicular zones of high porosity and comparatively high effective surface areas. However, it is not known whether these vesicular zones also have high permeability and allow flowing groundwater to contact most of its surface area, which is a measure of reactive surface area. When glasses cool from the outside, thermal gradients normal to the cooling surface produce differential thermal contraction that causes cracking. Even slowly cooled meter-sized glass masses end up as composites of fist-sized glass pieces along with finer material in a 3D mosaic of cracks (Baxter, 1983). A similar cracking process probably affects massive melt glass as it cools.

In the long term, reactions between the melt glass and water will give rise to hydrous alteration products. These reactions generally have a positive molar volume change and will therefore have a tendency to decrease the permeability in the zones that contain the hydrous phases. This results in an overall decrease in the fluid-accessible reactive surface area of glass. This effect has been observed in leaching studies of glasses from in-situ vitrification sites (Timmons and Thompson, 1996). The above issues are difficult to address without detailed field examination and laboratory studies of melt glasses.

To provide a better estimate for reactive surface area, measurements of reactive surface areas of intact natural analog rhyolite glass cores were made (Bourcier et al., 2000). Analog samples of pumice, breccias, massive glass, and mixtures of all three textures were collected. These samples were then cored and the cores used in flowthrough dissolution tests. The reactive surface area was determined by measuring the amounts of species dissolved by the fluid during passage through, and reaction with, the glass. Because surface-area-normalized glass dissolution rate constants are known from previous work under these conditions, the integrated reactive surface area for the sample was computed from the amounts of dissolved glass constituents in the outlet fluid. The

\footnotetext{
${ }^{1}$ Note that the reactive surface area of glass refers to the surface area of glass alone, and not the surface areas of secondary precipitates on the glass (e.g., clays). Surface areas of crushed glass measured using BET may include the contributions of these alteration minerals that have much higher surface areas than glass. Only the surface area of glass is included in the rate. It is the dissolution of glass that releases radionuclides. Each alteration mineral is represented by its own rate equation and sorption characteristics, when appropriate.
} 
values for reactive surface area of these rhyolite samples ranged from about 0.001 to $0.01 \mathrm{~m}^{2} / \mathrm{g}$.

Based on observations of melt glass samples, it is believed that the natural analog samples represent the high porosity vesiculated zones of the nuclear melt glasses. However, nuclear melt glasses are heterogeneous and also contain zones of massive glass. The reactive surface area of the massive glass is likely to be very low; it could not be measured in laboratory experiments because flow could not be established (massive glass was not permeable). Water will contact only the fractured surfaces of the massive glass. The reactive surface areas of fractured man-made glass cylinders reported by Baxter (1983) are on the order of $0.00005 \mathrm{~m}^{2} / \mathrm{g}$, which is much lower than our measured reactive surface areas for vesicular and brecciated natural glass samples. Baxter's measurements were made on glass logs that were $2 \mathrm{ft}$ wide and $10 \mathrm{ft}$ long. The logs fracture during cooling due to thermal gradients and dissolution along these fractures dominated the reactive surface area test.

A bulk value for reactive surface area of $0.001 \mathrm{~m}^{2} / \mathrm{g}$ was chosen for the CAMBRIC model to account for the contribution of massive glass zones to reactive surface area, and to provide for the likelihood that hydrous phases will precipitate and reduce permeability. This value is identical to that used in the unclassified CHESHIRE HST simulations. The $0.001 \mathrm{~m}^{2} / \mathrm{g}$ value lies on the low end of the range of reported data for the analog samples. However, given the vessiculated nature of the analog glasses, this value is considered a fairly conservative estimate of the reactive surface area of the entire melt glass zone (that is, it does not underestimate surface area). In the model, the surface area of glass was allowed to decrease linearly with the amount of glass dissolved.

\subsection{Rate Coefficient $\mathrm{k}$ and Product Terms $\mathrm{a}_{\mathrm{i}}{ }_{\mathrm{i}}{ }$, and Activation Energy, $\mathrm{E}_{\mathrm{a}}$}

Because the melt glass composition is similar to that for natural rhyolitic glasses, results of previous dissolution studies of natural silicate glasses (i.e., Mazer, 1987) were used to estimate the glass dissolution rate of the CAMBRIC melt glass. The effects of small amounts of contaminants, including radioactive ones with their associated radiation fields, have been shown to have negligible effects on glass dissolution rates (Bibler and Jantzen, 1987).

For the CAMBRIC melt glass, the dacite $\left(63.24 \% \mathrm{SiO}_{2}\right)$ dissolution data in Figure 4.76 were used to regress the value of the rate coefficient for glass dissolution (dacite $\mathrm{SiO}_{2}$ concentration is similar to that of the CAMBRIC alluvium). First, the $65^{\circ} \mathrm{C}$ data for dacite glass were fit to a polynomial. Three rate constants, in combination with the product function (where $\mathrm{a}_{\mathrm{i}}$ is the activity of $\mathrm{H}^{+}$or $\mathrm{OH}^{-}$and $n_{i}$ is the fitted exponent), were fit to this polynomial (Figure 4.77). Specifically, the V-shaped polynomial fit to the glass dissolution rate was modeled by using the sum of three linear rates: a $\mathrm{pOH}-$ dependent rate at low $\mathrm{pH}$, a $\mathrm{pH}$-independent rate at intermediate $\mathrm{pH}$, and a $\mathrm{pH}$-dependent rate at high $\mathrm{pH}$. The combination of these log-linear rates accounts for the $\mathrm{pH}$ effect on the dissolution rate. 


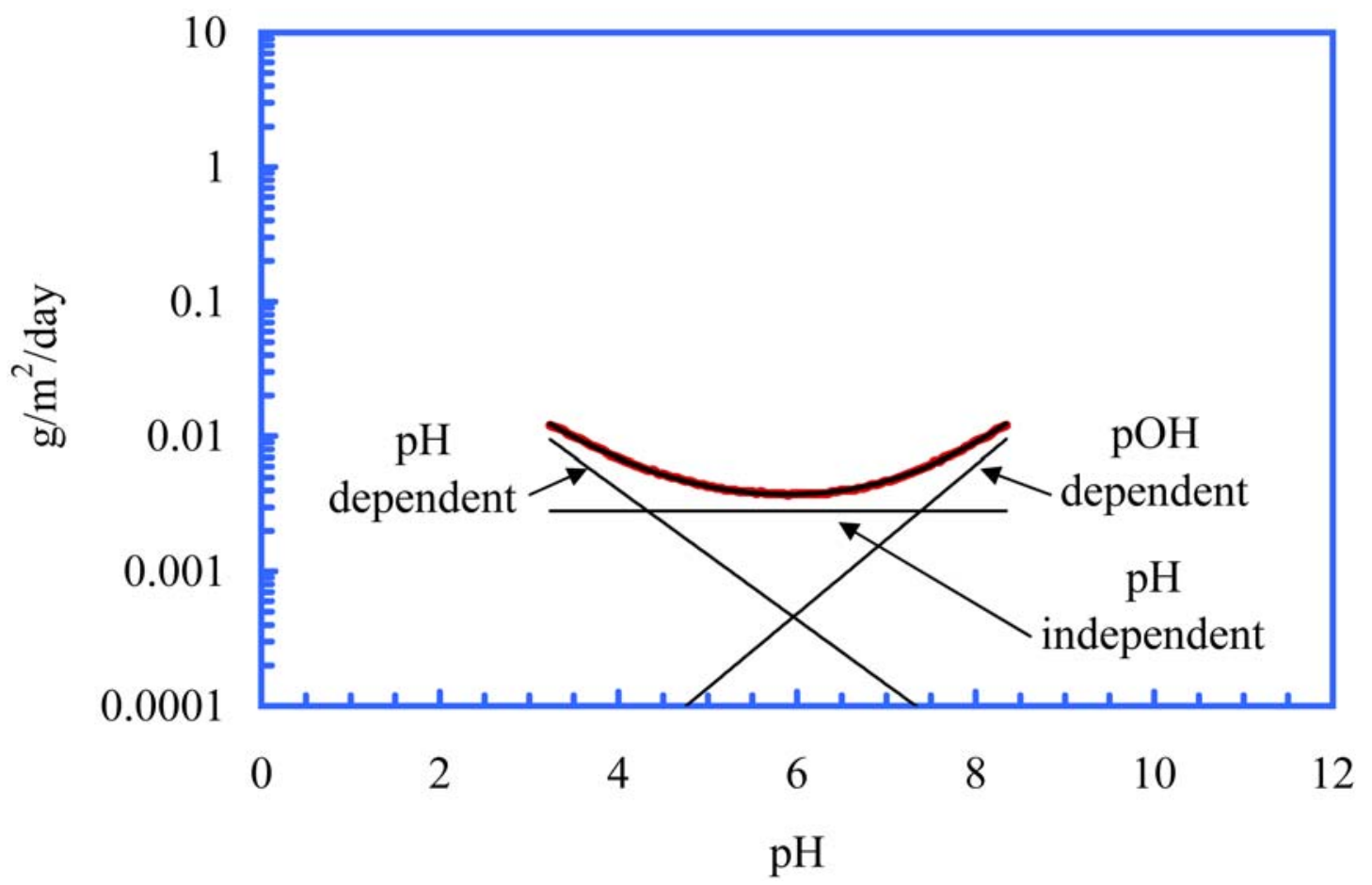

Figure 4.77 Fit (thick black line) to $65^{\circ} \mathrm{C}$ dacite dissolution data of Mazer (1987) (thick red line). The $\mathrm{pH}$-dependent rate is fit using a sum of three rates: a $\mathrm{pOH}$-dependent rate, a $\mathrm{pH}$ independent rate, and a $\mathrm{pH}$-dependent rate (thin black lines). One mol of glass is defined as $100 \mathrm{~g}$.

As suggested earlier, the rate that glass will dissolve is greatly affected by its silica content (Figure 4.76). Based on a regression analysis of the data shown in that figure, the dissolution rate (in $\mathrm{mol} \mathrm{Si} / \mathrm{m}^{2} / \mathrm{s}$ ) was found to decrease by 0.03 log units for each $1 \%$ increase in $\mathrm{SiO}_{2}$ content. Thus, to arrive at dissolution rate constants and $\mathrm{pH}$ dependence for rhyolite glass with $65.1 \% \mathrm{SiO}_{2}$, the rate constants for dacite $(63.24 \%$ $\mathrm{SiO}_{2}$ ), as shown in Figure 4.77, were adjusted by $-0.056 \log$ units. The rate of glass dissolution is strongly dependent on temperature (Pawloski et al., 2001). The temperature dependence is controlled by the activation energy $E_{a}$. In the CHESHIRE HST model, it was conservatively assumed that the activation energy for glass (and several secondary minerals) was $20 \mathrm{kcal} / \mathrm{mol}$. Recent glass dissolution experiments suggest that the activation energy is closer to 12 to $15 \mathrm{kcal} / \mathrm{mol}$ This reduction in activation energy dramatically reduces the glass dissolution rate at high temperatures $(\mathrm{a}>2$-order-ofmagnitude decrease in dissolution rate at $150{ }^{\circ} \mathrm{C}$ ). The range of plausible activation energy is from 10 to $20 \mathrm{kcal} / \mathrm{mol}$.

In general, the standard state in the thermodynamic database is reported at $25^{\circ} \mathrm{C}$. Thus, rate constants need to be determined at $25^{\circ} \mathrm{C}$. To determine the melt glass dissolution rate constants in their standard state, the rate constants determined at $65^{\circ} \mathrm{C}$ must be adjusted by the temperature-dependent term. The melt glass dissolution standard state $\left(25^{\circ} \mathrm{C}\right)$ rate constants used in the CAMBRIC model are listed in Table 4.24. The values used for this work differ from the unclassified CHESHIRE HST model. This difference is affected by three factors: adjustment of parameters from 60 to $25{ }^{\circ} \mathrm{C}$ was accomplished here (1) using an activation energy of $15 \mathrm{kcal} / \mathrm{mol},(2)$ accounting for the 
changing water dissociation constant $(\mathrm{Kw})$ as a function of temperature, and (3) using a $\mathrm{SiO}_{2}$ concentration consistent with XRF measurements of Frenchman Flat alluvium. The uncertainty associated with the parameters in Table 4.24 is difficult to assess. However, uncertainties in these parameters are likely to be lower than the range of uncertainty reported for the reactive surface area of the glass. Thus, the uncertainty associated with these parameters can likely be neglected.

Table 4.24. CAMBRIC melt glass dissolution rate constants at standard state $\left(25^{\circ} \mathrm{C}\right)$. $\left[\mathrm{H}^{+}\right]$and $\left[\mathrm{OH}^{-}\right]$refer to the activity of these species. In low ionic strength solutions, the activity is similar to the concentration of these species in solution.

\begin{tabular}{|l|l|}
\hline \multicolumn{1}{|c|}{ Species } & \multicolumn{1}{c|}{ Rate (mol-glass $\left./ m^{2}-\mathrm{s}\right)^{*}$} \\
\hline $\mathrm{H}^{+}(\mathrm{pH}$ dependent $)$ & $1.75 \mathrm{E}-9 \times\left[\mathrm{H}^{+}\right]^{0.48}$ \\
\hline $\mathrm{OH}^{-}(\mathrm{pOH}$ dependent $)$ & $1.60 \mathrm{E}-8 \times\left[\mathrm{OH}^{-0.55}\right.$ \\
\hline $\mathrm{pH}$ independent & $1.44 \mathrm{E}-11$ \\
\hline
\end{tabular}

* One mol of glass is defined as $100 \mathrm{~g}$ of glass.

Figure 4.78 illustrates the effect of both $\mathrm{pH}$ and temperature on the far-fromsaturation dissolution rates of the CAMBRIC melt glass. The rates are calculated using an activation energy of $15 \mathrm{kcal} / \mathrm{mol}$. Note that the $\mathrm{V}$-shaped curves shift to the left with increasing temperature. This shift results from the change in the water dissociation as a function of temperature. For example, at $25^{\circ} \mathrm{C}$, the $\mathrm{Kw}$ of water is known to be $10^{-14}$. However, it is $\sim 10^{-15}$ at $0^{\circ} \mathrm{C}$ and $\sim 10^{-13}$ at $60^{\circ} \mathrm{C}$. This forces the curve to shift to the left. This was observed in borosilicate glass dissolution experiments of Knauss et al. (1990) and is likely to occur in the case of nuclear melt glass dissolution as well. 


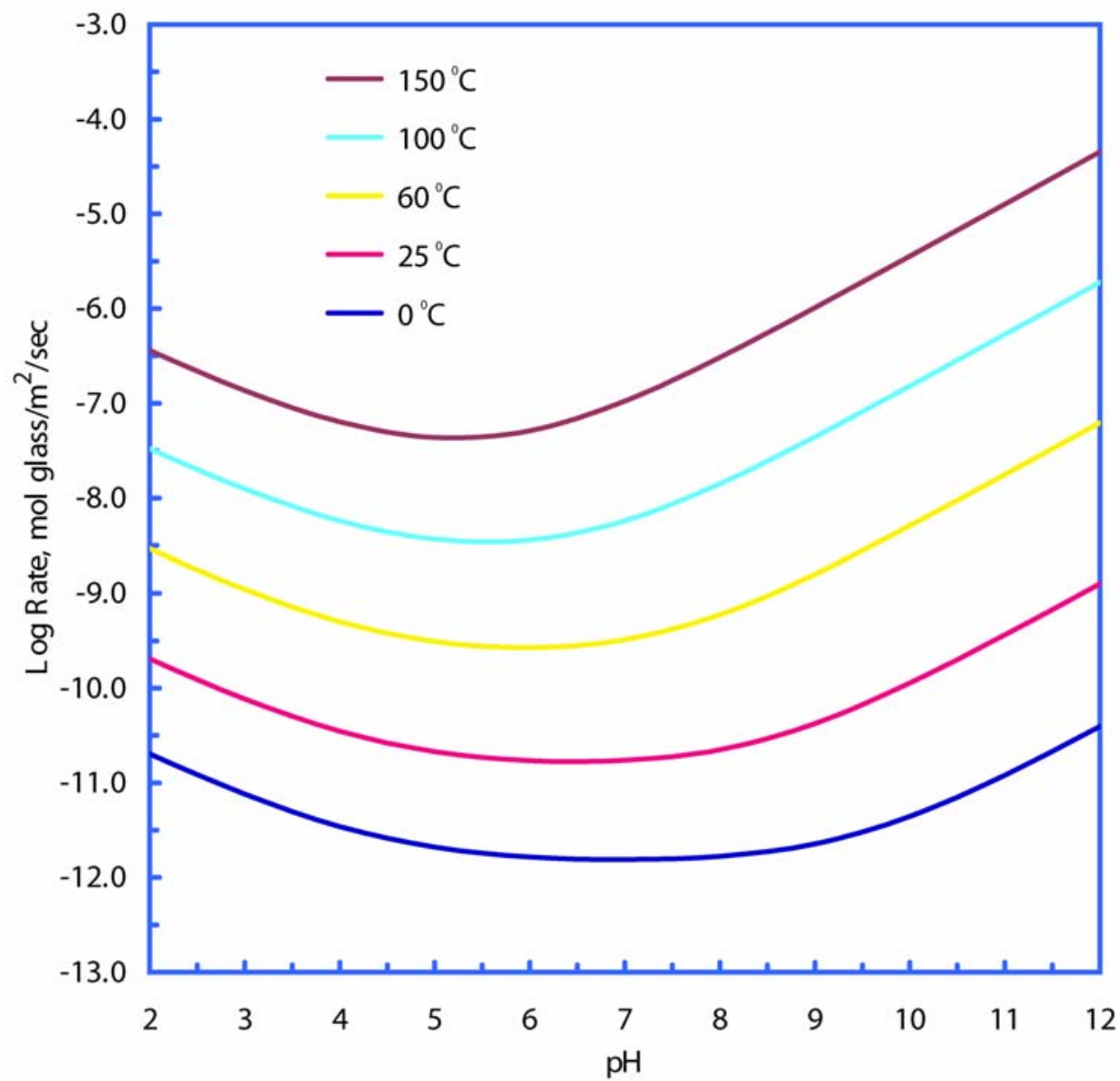

Figure 4.78 Far-from-saturation surface-area-normalized dissolution rates for CAMBRIC glass as a function of temperature and $\mathrm{pH}$.

\subsection{The Saturation Term $\left(1-(\mathrm{Q} / \mathrm{K})^{1 / \sigma}\right)^{v}$}

As mentioned earlier, the rate of glass dissolution slows as the solution approaches saturation with respect to the glass. Previous studies have shown that the primary cause of the rate decrease is the increasing concentration of dissolved silica (Grambow, 1987). Although other species may have some effect, the glass dissolution model is limited to the effect of silica because of the lack of more detailed information. This implies that for the saturation term $(1-Q / K)$ in the rate equation, the value of $Q$ is simply the concentration of dissolved $\mathrm{SiO}_{2}(\mathrm{aq})$ and $K$ is the silica concentration in solution at glass saturation for a particular glass composition.

The equilibrium constant $(K)$ for glasses is usually determined experimentally by measuring the silica concentration in solution under conditions when the dissolution rate of the glass slows to near zero in static (closed system) glass dissolution experiments. For silica-rich glasses such as rhyolites, values of $K$ usually lie between the values of $K$ for the silica polymorphs cristobalite and amorphous silica (Grambow, 1987). Because of the lack of available experimental data on saturation effects for melt glasses, the conservative assumption is made that $K$ is defined by amorphous silica. The larger the 
value of $K$, the larger the value of the saturation term becomes, which increases the calculated dissolution rate.

Recent glass dissolution experiments close to saturation (see Zavarin et al., $2004 a, b)$ suggest that the $\sigma$ coefficient may be as high as 100 , which leads to greatly reduced glass dissolution rates even under relatively unsaturated conditions. Values as high as 10 were previously reported (Bourcier et al., 1994). However, sufficient evidence was not available to confidently apply an exponent to the saturation term in the steady state model, particularly since this might significantly reduce the overall rate of glass dissolution. The results of Zavarin et al. (2004a, b) were used only to adjust the activation energy of reaction, as described in the previous section. However, from the standpoint of parameter uncertainty and based on these experimental data, it is reasonable to suggest a range of $\sigma$ from 1 to 100 .

\subsection{The Close-to-Saturation Rate $\mathrm{k}_{\mathrm{f}}$}

Glasses exhibit a saturation effect similar to that of crystalline solids where the dissolution rate slows as species build up in solution. However, due to the unstable nature of glass, dissolution is expected to continue even when solutions approach saturation. The close-to-saturation rate is intended to account for this glass instability. Typically, the close-to-saturation rate is several orders of magnitude slower than the farfrom-saturation rate.

In the CAMBRIC model, silica concentrations in solution were not allowed to build up to levels high enough to make the close-to-saturation rate significant. The simulations were prevented from reaching high aqueous silica concentrations for two reasons: (1) silica aqueous concentrations in Frenchman Flat are typically found close to equilibrium with $\beta$-cristobalite (below saturation with respect to amorphous silica), and (2) melt glass dissolution was estimated more conservatively due to the lack of field observations suggesting high silica buildup in solution. Thus, the close-to-saturation rate of glass dissolution could be ignored in the model. The close-to-saturation rate may become more important in future simulations when understanding of the precipitation rates of secondary minerals and evolution of groundwater composition in contact with melt glasses improves. 


\subsubsection{Streamline Simulations}

As described in Section 4.8.1, a streamline method was employed in conjunction with a multicomponent reactive transport model to simulate $3 \mathrm{D}$ reactive transport of radionuclides originating from the CAMBRIC test. The streamline method is designed to reduce computational burden in two ways: (1) by focusing calculations on the regions where concentrations of chemical species of interest are significant and (2) by approximating 3D reactive transport processes as a collection of $1 \mathrm{D}$ reactive transport processes occurring along transient flow paths or "streamlines." Compared to the total of 308,637 grid cells in the flow simulation, the maximum number of points of computation traced by streamlines reaches only about 20,000 .

Flow velocities, porosities, and saturations from the NUFT non-isothermal flow simulations are used to prescribe streamline traces (Figure 4.79) and fluxes. The fundamental computational method used to determine streamlines given the 3D flow field are described in Section 4.8.1. The integration of the product of time-of-flight across grid cells and streamline flux determines the volumetric discretization along which the 1D reactive transport processes are simulated. The flux also determines the contribution from each streamline to the total 3D transport.

At time zero, streamlines for the CAMBRIC simulations originate from the spherical shaped source volume where radionuclides are assumed to be initially deposited by the test, including the melt glass, cavity, compressed, and lower chimney zones. Under transient flow and transport conditions, the streamline paths evolve with time.

As described in Section 4.8.2, the 1D reactive transport processes are simulated on streamlines using the CRUNCH code (Steefel and Yabusaki, 1996). CRUNCH simulates multicomponent mass transport in porous media under nonisothermal conditions, including consideration of zonal variations in mineralogy and fluid chemistry. Aqueous speciation, surface complexation, ion exchange, mineral dissolution/precipitation, and radionuclide decay are all modeled explicitly. The parameters used in the CRUNCH simulations are all listed in Section 4.8.2. CRUNCH implicitly couples advection, diffusion, and chemical reaction processes occurring over each time step. The temperature along each streamline is imported from the NUFT nonisothermal flow simulation. 


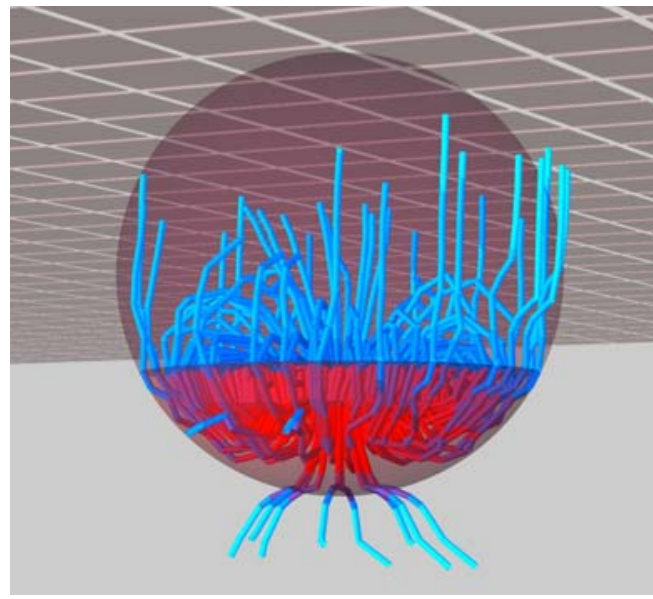

(a)

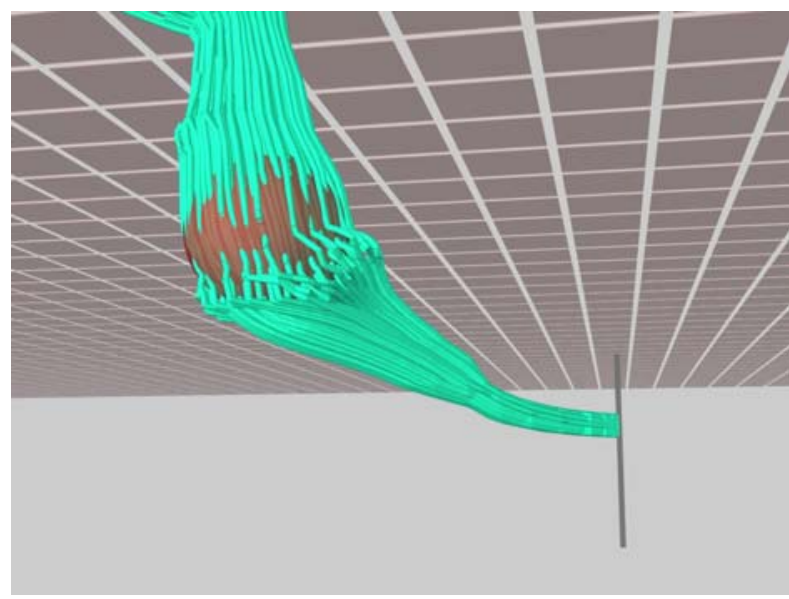

(b)

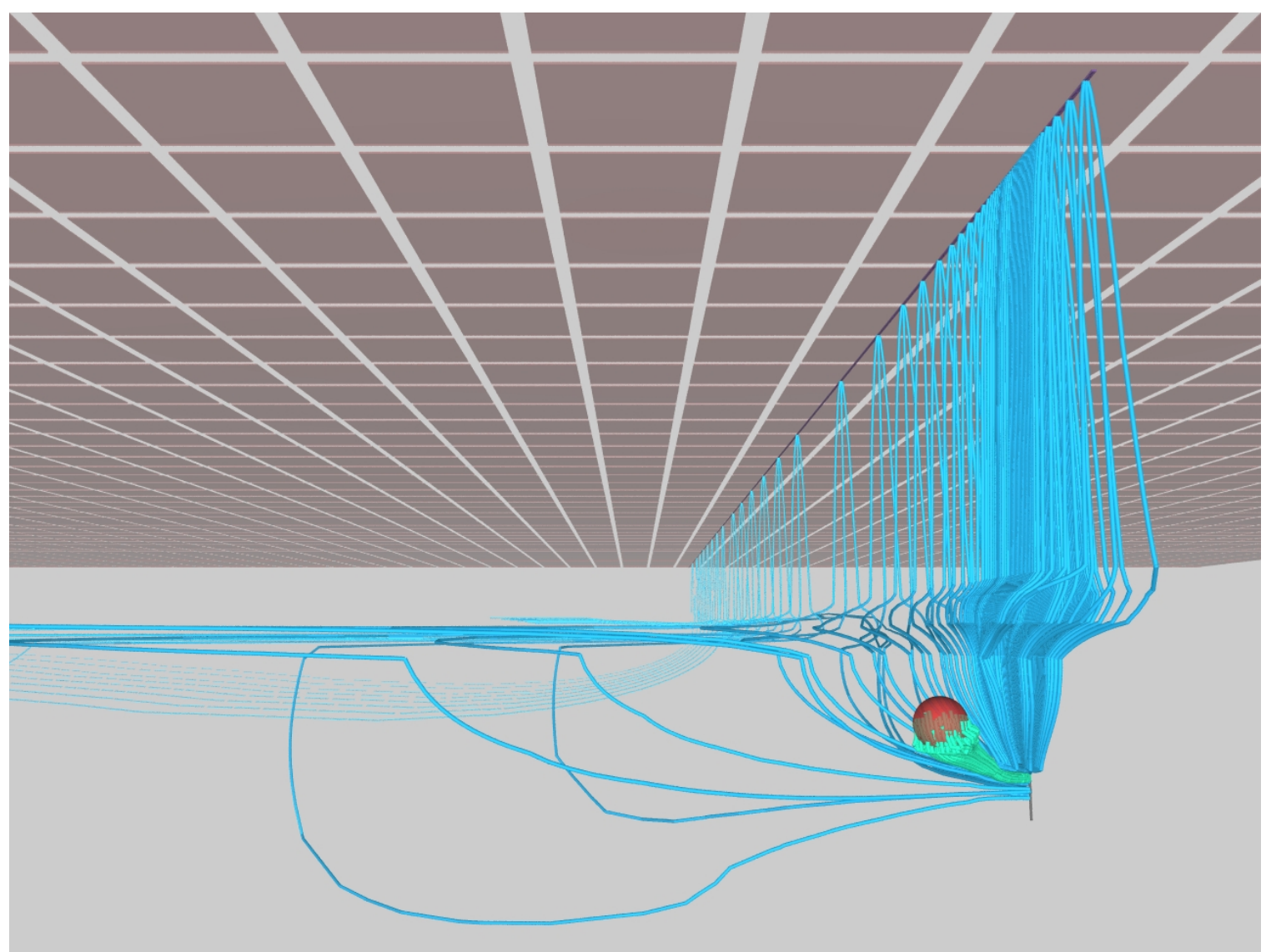

(c)

Figure 4.79 Streamlines originating from melt glass zone at (a) $0.1 \mathrm{y}$, and subsequently evolved through the pumping stage between 10.4 and $25.6 \mathrm{y}$ for locations between the CAMBRIC source and (b) the pumping well and (c) overall flow system. 


\subsubsection{Thermal Effects on Glass Dissolution}

Temperature affects radionuclide transport primarily by accelerating groundwater flow velocities, melt glass dissolution rates, and secondary mineral precipitation rates. Most long-lived radionuclides associated with an underground nuclear test are initially incorporated in melt glass. Silicate melt glass dissolution rate is strongly temperature-dependent (Figure 4.80). Glass dissolution and secondary mineral precipitation reactions may also alter the water chemistry which will, in turn, alter the aqueous speciation, surface complexation, and ion exchange processes that retard radionuclide transport and affect glass dissolution rates.

Secondary mineral precipitation depends on a range of conditions including the composition of silicate glass, temperature, $\mathrm{pH}$, and groundwater composition. In general, zeolites form over a temperature range of 100 to $250{ }^{\circ} \mathrm{C}$. At lower temperatures, a variety of clays are more likely to form. At higher temperatures, feldspars and other aluminosilicates are likely to form. Geochemical modeling suggests that when clay precipitation dominates, the $\mathrm{pH}$ tends to rise. This rise in $\mathrm{pH}$ affects both the sorption behavior of radionuclides and the overall rate of glass dissolution, as described below.

The glass dissolution activation energy, $\mathrm{E}_{\mathrm{a}}$, typically ranges from 10 to $20 \mathrm{kcal}$ $\mathrm{mol}^{-1}$ and has a dramatic effect on glass dissolution rates (Figure 4.80). For example, between 25 and $150{ }^{\circ} \mathrm{C}$, glass dissolution rates may increase by factors of $10^{2}$ to $10^{4}$ depending on the choice of activation energy. The streamline simulations used an activation energy of $15 \mathrm{kcal}$ which results in a thousand-fold increase in glass dissolution rates at $150{ }^{\circ} \mathrm{C}$ compared to $25^{\circ} \mathrm{C}$. It should not be surprising that a significant proportion of glass dissolution occurs at early time when the temperatures are elevated.

It should be noted that $\mathrm{H}^{+}$and $\mathrm{OH}^{-}$, which are the principal dissolutionpromoting aqueous species, are also affected by temperature and, in turn, affect glass dissolution rates. A model of glass dissolution rates as a function of temperature and $\mathrm{pH}$ is shown in Figure 4.81. The evolution of $\mathrm{pH}$ and glass dissolution rates in the reactive transport simulations is shown in Figure 4.81 as well.

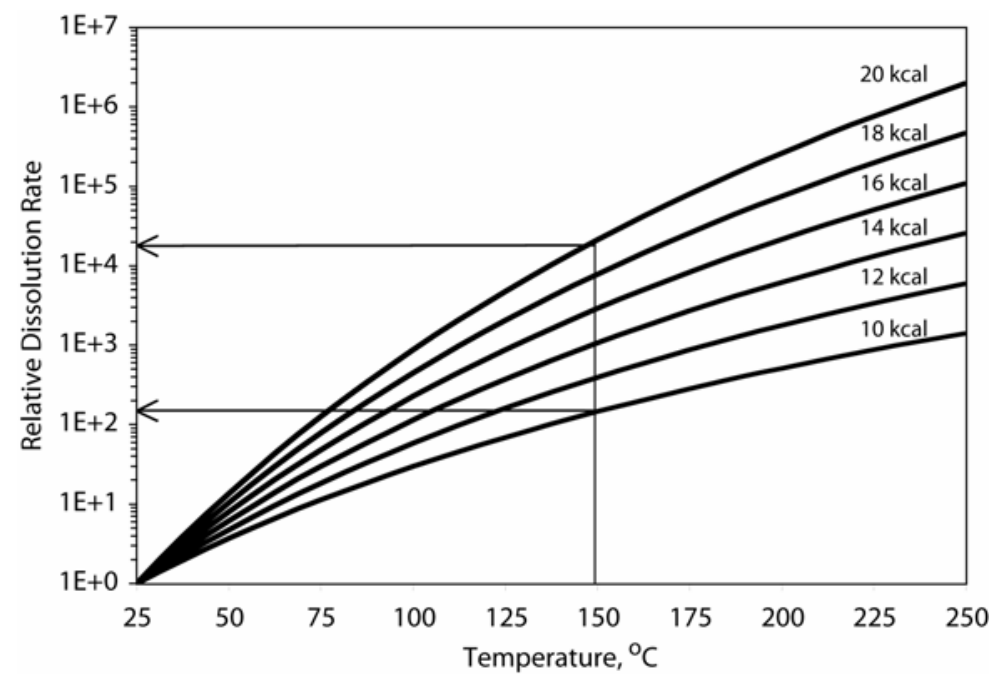

Figure 4.80 The effect of activation energy and temperature on dissolution rates as a function of temperature. 


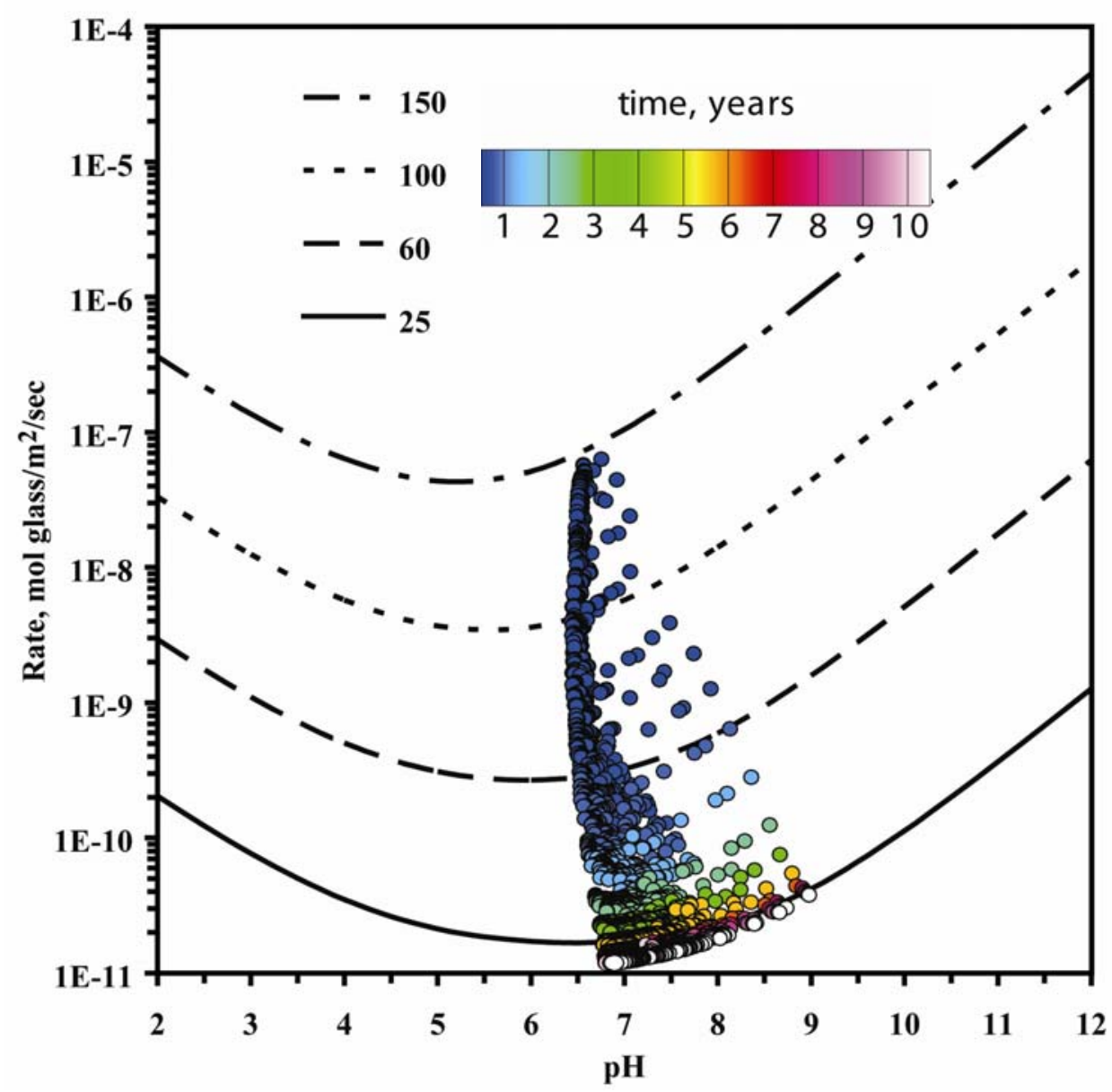

Figure 4.81 Glass dissolution rates from streamline simulations superimposed on model glass dissolution rates as a function of $\mathrm{pH}$ and temperature for activation energy of $15 \mathrm{kcal} / \mathrm{mol}$ and ignoring saturation effects.

The saturation term in the glass dissolution rate equation, which is controlled by the activity of $\mathrm{SiO}_{2}(\mathrm{aq})$ and solubility of $\mathrm{SiO}_{2}(\mathrm{am})$, will be affected by rate of glass dissolution (which releases $\mathrm{SiO}_{2}(\mathrm{aq})$ ), rate of secondary silicate mineral precipitation (which sequesters $\mathrm{SiO}_{2}(\mathrm{aq})$ ), and fluid velocity in the glass zone (which affects build-up of $\mathrm{SiO}_{2}(\mathrm{aq})$ in the glass zone). Figure 4.82 permits comparison of streamline simulation of glass dissolution rate to temperature, $\mathrm{pH}$, and $\mathrm{SiO}_{2}(\mathrm{aq})$ concentration at $0.0266,0.72$, and $9.0 \mathrm{y}$ after the CAMBRIC test. Between 0.0266 and $9.0 \mathrm{y}$, simulated melt glass dissolution rates decrease from about $5 \times 10^{-8}$ to $1 \times 10^{-11} \mathrm{~mol} / \mathrm{m}^{2} / \mathrm{s}$, affected primarily by temperature. While the melt glass is relatively hot, the $\mathrm{pH}$ remains near 6.5 in the melt glass zone (compared to 8.5 under ambient conditions). With time, the $\mathrm{pH}$ tends to increase to a range of 7 to 9 . The evolution of $\mathrm{pH}$ is primarily affected by temperature and the precipitation of clay secondary phases. The evolution of $\mathrm{SiO}_{2}(\mathrm{aq})$ concentrations in the glass zone is primarily driven by changes in the solubility of cristobalite $\left(\alpha / \beta-\mathrm{SiO}_{2}\right)$ secondary phases which are temperature dependent. Fluid velocity and $\mathrm{pH}$ play a secondary role in $\mathrm{SiO}_{2}(\mathrm{aq})$ concentration. 

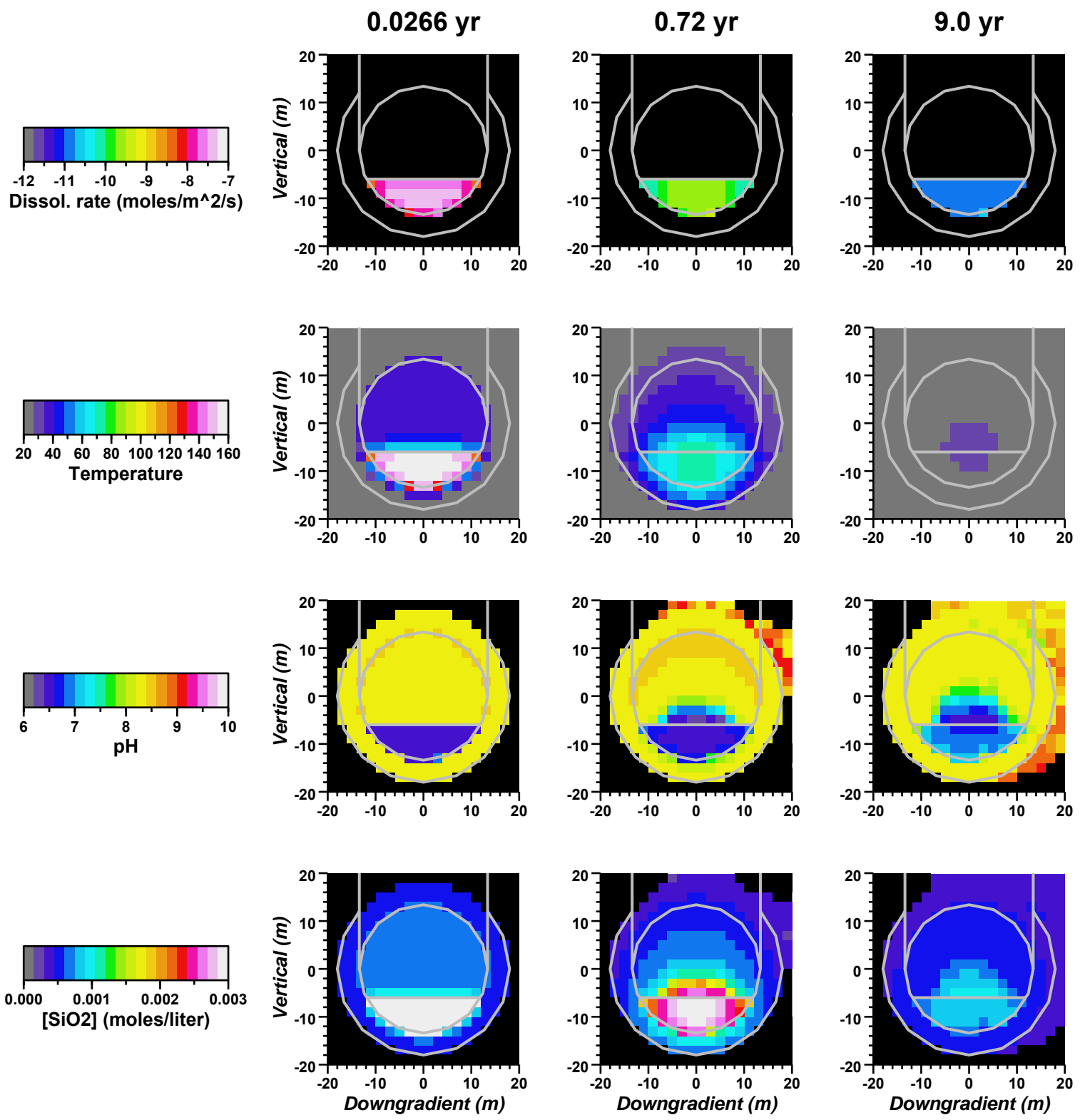

Figure 4.82 Streamline simulation of melt glass dissolution rate, temperature, $\mathrm{pH}$, and $\mathrm{SiO}_{2}$ concentration at $0.0266,0.72$, and 9.0 y since the CAMBRIC test. Areas shaded in black indicate zones where reactive transport was not simulated.

\subsubsection{Thermal Effects on Radionuclide Transport}

The transient streamline reactive transport simulations distinguished between 11 sorbing and two non-sorbing radionuclide classes that combined multiple isotopes of the same element and/or radionuclides expected to have similar reactive transport properties. From the 13 radionuclide classes, the transport behavior of all 36 radionuclides of interest can be de-convolved. Interestingly, only four sorbing classes and two non-sorbing radionuclide classes were predicted to migrate an appreciable distance away from the CAMBRIC cavity (Figure 4.83). The four sorbing radionuclide classes include $\mathrm{U}, \mathrm{Np}$, and, to a lesser degree, ${ }^{241} \mathrm{Pu}$ and $\mathrm{Pu}$. 


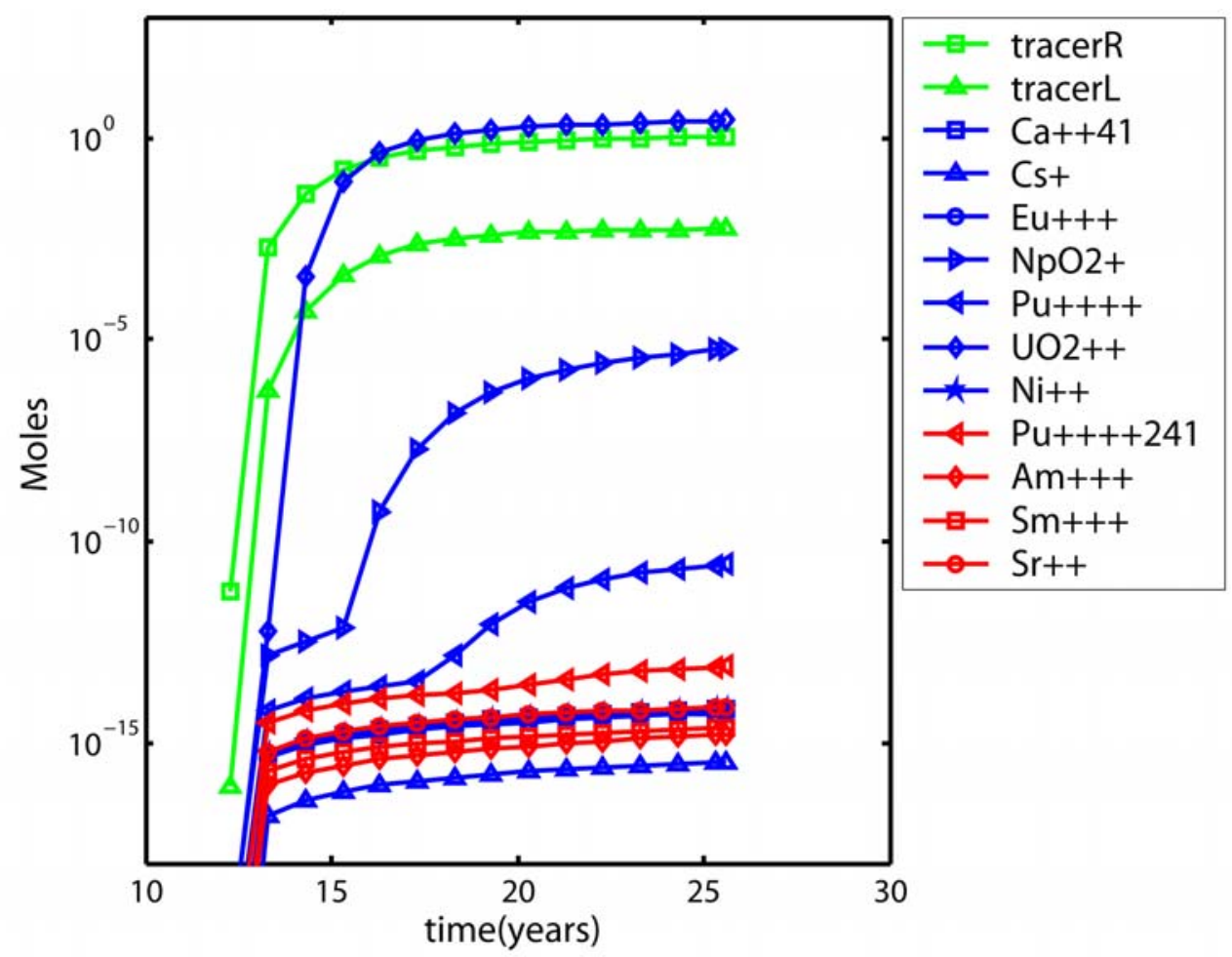

Figure 4.83 Simulated radionuclide class cumulative moles that reached the RNM-2S pumping well in the first $25 \mathrm{y}$ after the CAMBRIC test.

The early-time thermal effects on radionuclide transport can be subdivided into three processes:

- Increased mobilization of refractory radionuclides from the nuclear melt glass

- Thermally induced hydraulic gradients that increase fluid velocities

- Thermally induced changes in the sorptive behavior of radionuclides

The mobilization of refractory radionuclides as a result of glass dissolution was described in the previous section. To provide additional context to the role of heat on radionuclide release, it is interesting to examine the percent glass dissolved as a function of time. Figure 4.84 shows that between 1 and $2 \%$ of the nuclear melt glass is predicted to dissolve in the first $10 \mathrm{y}$ after the CAMBRIC test. Since, for the most refractory radionuclides ( $\mathrm{Pu}, \mathrm{Am}$, etc.), 5\% of the initial inventory is initially distributed in the rubble, it is apparent that glass dissolution will contribute a relatively small additional source of radiologic inventory to the groundwater at early time. ${ }^{2}$ Between 10 and 1,000 y, an additional $4 \%$ of the melt glass is predicted to dissolve. It appears from these simulations that the assumptions governing the initial partitioning of radionuclides into the rubble fraction will have a more significant impact on radionuclide transport rates (and contaminant boundary calculations) than the release of radionuclides as a result of glass dissolution.

\footnotetext{
${ }^{2}$ The additional 1 to $2 \%$ glass dissolved will bring the fractional inventory of the refractory radionuclides in the rubble zone from $5 \%$ to $6-7 \%$.
} 


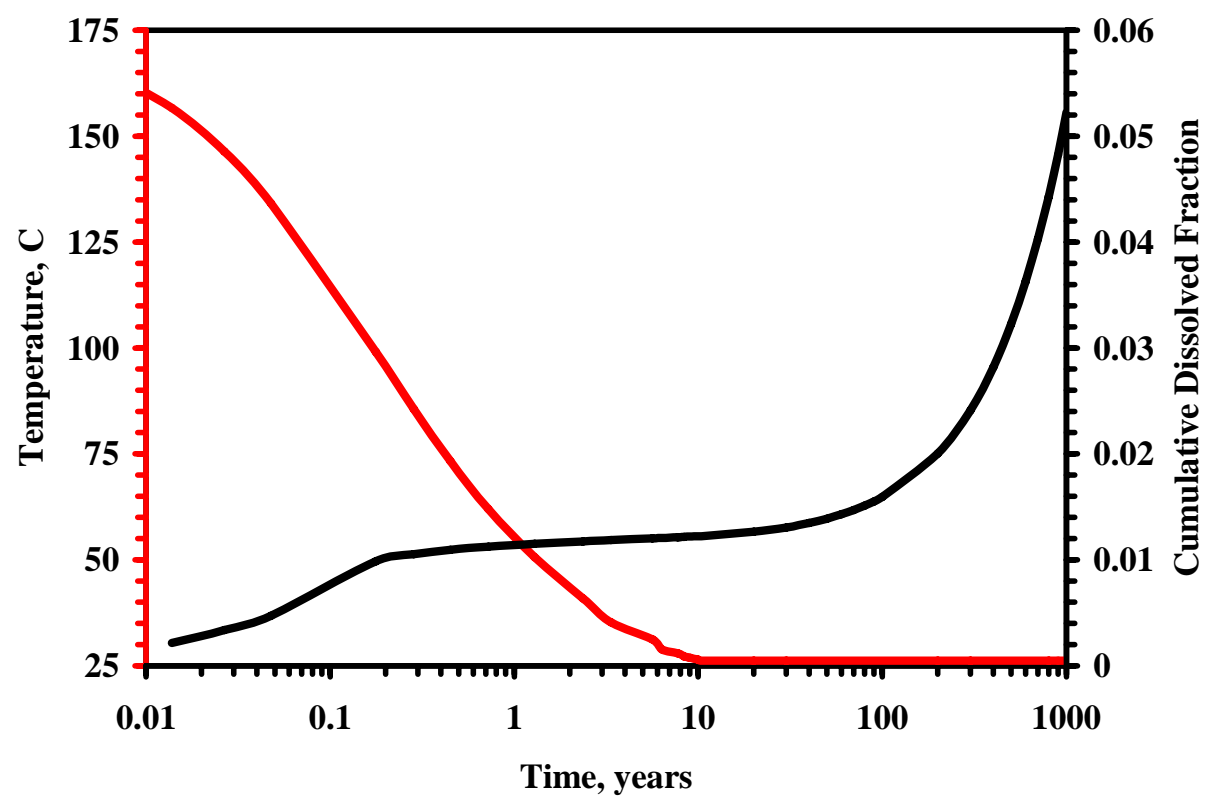

Figure 4.84 Temperature history and cumulative glass dissolution as a function of time.

While the total radiologic source term associated with glass dissolution may be relatively small when compared to the source term initially distributed in the cavity and compressed zones, it is still important to identify the role of glass dissolution in downgradient radionuclide migration. Transient streamline reactive transport simulations tracked fluid containing dissolved melt glass by including $1 \mathrm{~mol}$ of non-sorbing tracer in the melt glass (radionuclide class TracerL). The first column of images in Figure 4.85 shows simulated concentration fields for a tracer released from dissolving melt glass. The evolution of the melt glass zone tracer concentration field before $10 \mathrm{y}$ shows two main impacts of test-related heat: (1) rapid increase in concentrations in the melt glass zone before $1 \mathrm{y}$, and (2) upward advection from the melt glass zone caused by thermallyinduced groundwater flow in the upward direction. By $25.6 \mathrm{y}$, tracer concentrations in the melt glass zone drop about two orders of magnitude as a result of decreased melt glass dissolution rates and pumping from RNM-2S.

The second and third columns in Figure 4.85 show simulated concentration fields for the radionuclides ${ }^{237} \mathrm{~Np}$ and ${ }^{241} \mathrm{Pu}$. The initial ${ }^{237} \mathrm{~Np}$ and ${ }^{241} \mathrm{Pu}$ aqueous concentrations are uniform in a spherical source zone including the melt glass zone, cavity, compressed zone, and lower chimney. However, the majority $(95 \%)$ of the ${ }^{237} \mathrm{~Np}$ and ${ }^{241} \mathrm{Pu}$ is incorporated initially in the melt glass. Neptunium-237 is very mobile while ${ }^{241} \mathrm{Pu}$ is relatively immobile. Increases of ${ }^{237} \mathrm{~Np}$ and ${ }^{241} \mathrm{Pu}$ concentration in the melt glass zone evident before $10 \mathrm{y}$ are attributed to melt glass dissolution. Thermal effects before $1.0 \mathrm{y}$ dominate change in concentration of ${ }^{237} \mathrm{~Np}$ in the melt glass zone before $10 \mathrm{y}$. Temporal change in ${ }^{241} \mathrm{Pu}$ concentration is visibly affected due to the $14.4-\mathrm{y}{ }^{241} \mathrm{Pu}$ halflife. The pumping-induced transport of ${ }^{237} \mathrm{~Np}$ and ${ }^{241} \mathrm{Pu}$ evident at $25.6 \mathrm{y}$ highlights differences in radionuclide mobility. The ${ }^{237} \mathrm{~Np}$ plume reaching $\mathrm{RNM}-2 \mathrm{~S}$ is derived from a combination of ${ }^{237} \mathrm{~Np}$ distributed initially in the aqueous phase and that resulting from glass dissolution. The ${ }^{241} \mathrm{Pu}$ plume, however, is highly retarded and shows only a few meters of motion toward RNM-2S along flow paths originating from the melt glass zone. 
While it does not appear that thermally induced hydraulic gradients at CAMBRIC were present over a long enough time period to result in significant radionuclide transport, there is evidence for early-time vertical migration (Figure 4.86). It appears that some downgradient migration of non-sorbing radionuclides may have occurred as a result of upward and then lateral migration in a high permeability zone. This was previously mentioned as a possible explanation for low levels of ${ }^{3} \mathrm{H}$ observed during drilling of ER-5-4.
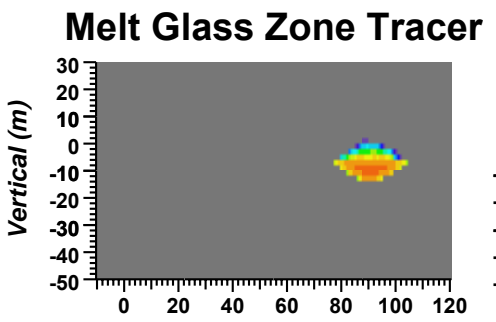

$0.7 \mathrm{yr}$

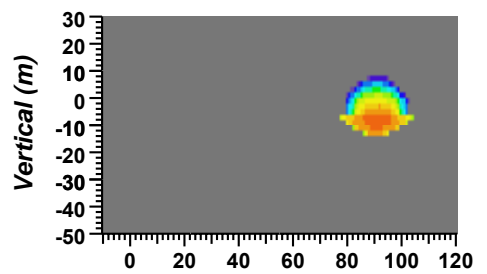

$9.0 \mathrm{yr}$
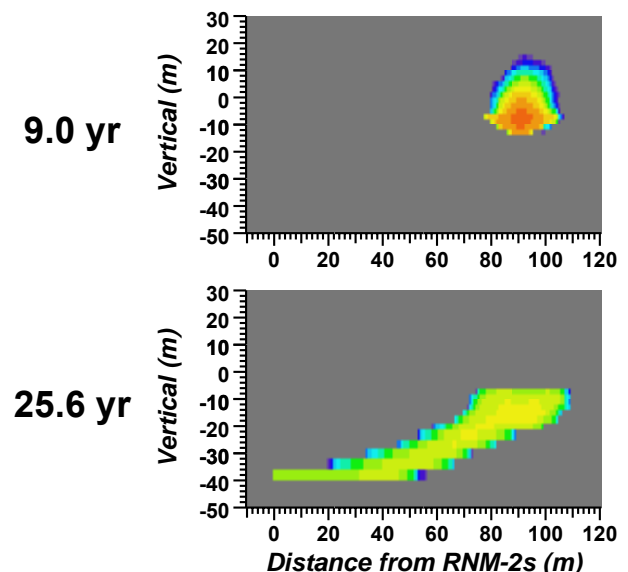
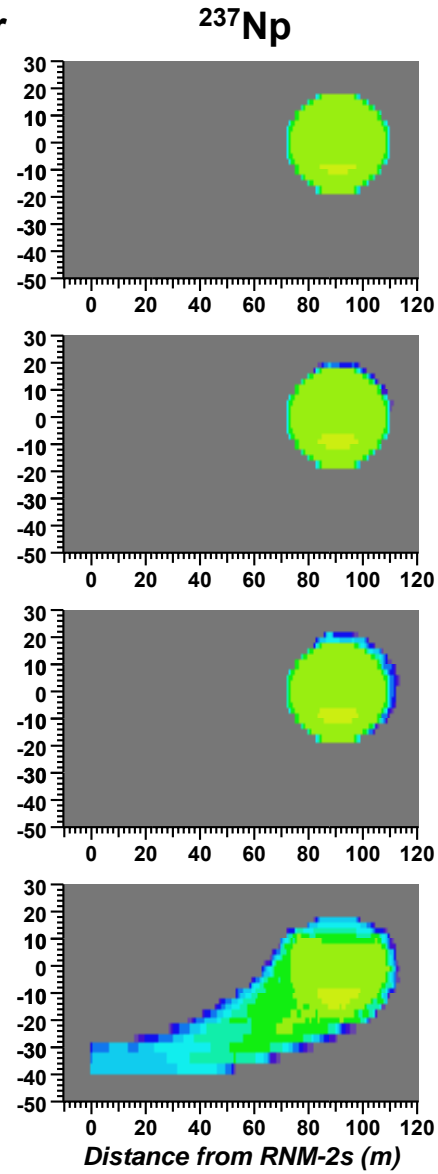
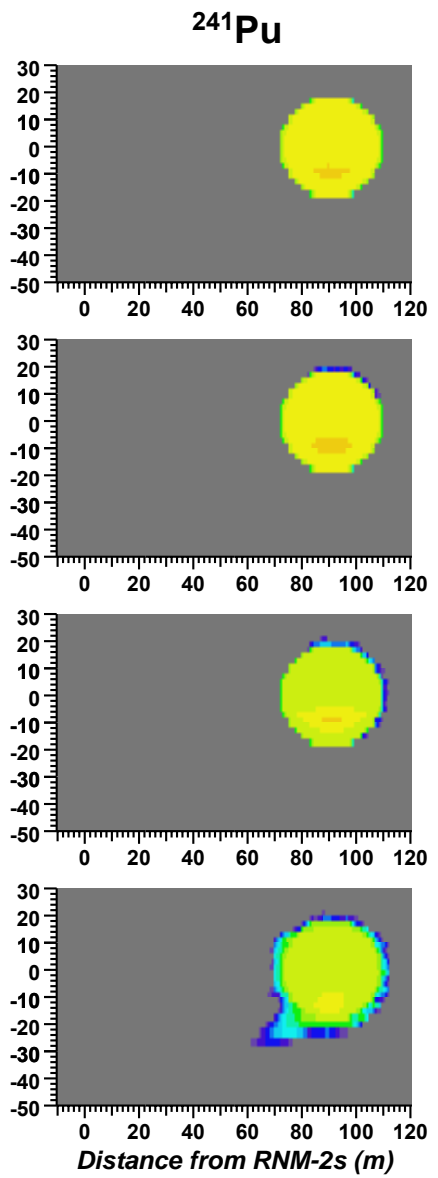

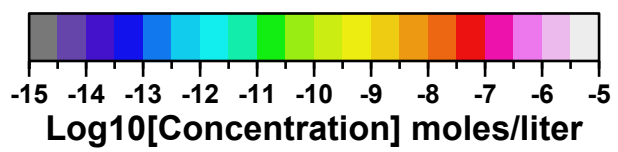

Figure 4.85 Oblique cross sections through pumping well RNM-2S and the center of CAMBRIC test-altered zones showing concentration fields for melt glass zone tracer, ${ }^{237} \mathrm{~Np}$, and ${ }^{241} \mathrm{Pu}$ at 0.1 , $0.7,9.0$, and 25.6 y after the CAMBRIC test. 

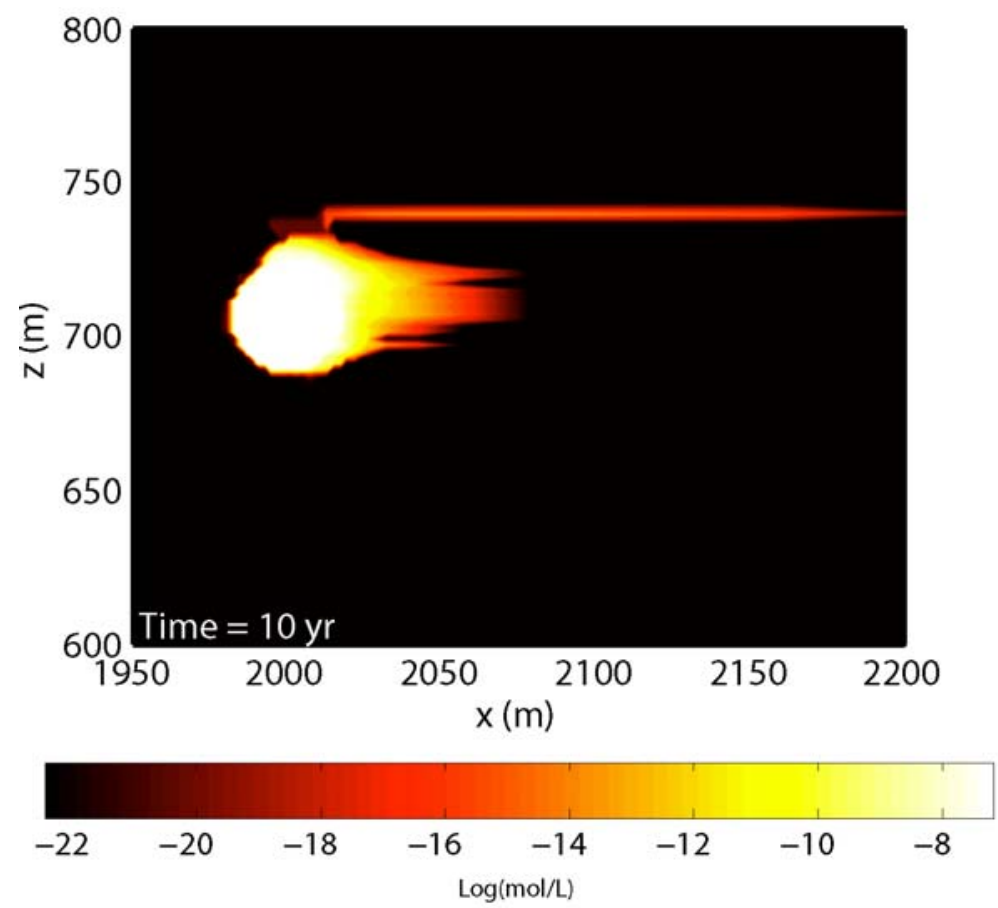

Figure 4.86 Downgradient migration of TracerR radionuclide class at $10 \mathrm{y}$.

The role of early-time test heat in controlling the retardation behavior of radionuclides can be evaluated by examining the transient nature of retardation factors near CAMBRIC. These are plotted in Figure 4.87 to 4.89 for all radionuclide classes. Retardation factors are plotted only at streamline locations and where radionuclide class total concentrations ${ }^{3}$ are above a set cutoff concentration. The cutoff concentrations during transient streamline calculations for ${ }^{41} \mathrm{Ca}, \mathrm{Ni}, \mathrm{Cs}, \mathrm{Sr}, \mathrm{Am}, \mathrm{Eu}, \mathrm{Sm}, \mathrm{Np}, \mathrm{Pu},{ }^{241} \mathrm{Pu}$, U, TracerR, and TracerL were $10^{-15}, 10^{-18}, 10^{-16}, 10^{-17}, 10^{-18}, 10^{-18}, 10^{-18}, 10^{-18}, 10^{-15}$, $10^{-17}, 10^{-14}, 10^{-15}$, and $10^{-16}$, respectively (Section 4.8.1). These cutoff values were multiplied by $10^{-4}$ to produce cutoff values for the retardation plots.

The retardation factor for Am at zero time $(0.006 \mathrm{y})$ in the cavity and glass zone is above $10^{4}$, consistent with simulated retardation factors under ambient conditions for the cavity and glass zones $\left(10^{4.5}\right.$ and $10^{4.1}$, respectively). The high temperatures and resulting high rates of glass dissolution in the first year reduce the retardation factor in the glass zone. However, this reduction in retardation factor does not appear to propagate downstream. Changes in water chemistry and, thus, retardation in the glass zone are buffered as the water migrates. The behavior observed for $\mathrm{Am}$ is also true for ${ }^{41} \mathrm{Ca}, \mathrm{Cs}$, $\mathrm{Eu}, \mathrm{Ni}, \mathrm{Sm}$, and $\mathrm{Sr}$.

The spatial and temporal variation in $\mathrm{Np}$ retardation is distinctly different from that of Am and other radionuclide classes listed above. For Np, initial retardation in the glass zone $\left(10^{1.5}\right)$ is higher than predicted under ambient conditions. However, it tends to decrease with time. Temporal variation in retardation factors in the glass zone propagate downstream, resulting in a distinctly heterogeneous spatial retardation. The

\footnotetext{
${ }^{3}$ Total concentration refers to the concentration, in $\mathrm{mol} / \mathrm{L}$, of the aqueous, sorbed, and ion exchangeable fractions.
} 
sensitivity of $\mathrm{Np}$ retardation factors to both $\mathrm{pH}$ and carbonate complexation is likely the reason for the observed retardation heterogeneity. Similar behavior is observed for ${ }^{241} \mathrm{Pu}$ and $\mathrm{Pu}$ radionuclide classes.

It should be noted that the retardation factors for ${ }^{241} \mathrm{Pu}$ and $\mathrm{Pu}$ radionuclide classes should be identical but appear slightly different in the plots in Figures 4.87, 4.88, and 4.89. As stated earlier, retardation factors are plotted only at streamline locations and above a set cutoff value. The cutoff value for ${ }^{241} \mathrm{Pu}$ is two orders of magnitude lower. Thus, the range over which it is plotted is somewhat greater. However, where both $\mathrm{Pu}$ and ${ }^{241} \mathrm{Pu}$ retardation factors are plotted, the values are essentially the same.

The spatial and temporal variation in $\mathrm{U}$ retardation is similar to that of $\mathrm{Np}$, ${ }^{241} \mathrm{Pu}$, and $\mathrm{Pu}$. However, initially U retardation in the glass zone is very low. At the initial condition, the temperature has decreased but the effects of glass dissolution are not manifest. The reduction in $\mathrm{pH}$ at early time drastically reduces the $\mathrm{U}$ retardation factor in the glass zone. As the glass dissolution and secondary mineral precipitation reactions occur, the retardation factor is further reduced. Downstream retardation factors are significantly reduced (ambient retardation factors in the surrounding alluvium is $10^{0.9}$ ). However, it should be noted that the observed changes are on the scale of $50 \mathrm{~m}$ from the cavity; it is likely that these changes will be buffered at larger scales.

The spatial and temporal variation in retardation factors of radionuclide classes shown in Figures 4.87, 4.88, and 4.89 are indications of possible effects on radionuclide retardation. However, because of the limitations in the thermodynamic data, these results should be interpreted with caution. The temperature-dependent thermodynamic data for the major elements was included in this model but that of the radionuclide classes was not. Thus, the response of major elements to the transient hydrothermal conditions is simulated, the effect of this major element response on radionuclide retardation is simulated, but the response of the radionuclide speciation directly to the transient hydrothermal conditions is ignored. In effect, the simulations produce accurate radionuclide retardation values at high temperatures only if it is assumed that radionuclide speciation, surface protonation/deprotonation, surface complexation, ion exchange, and radionuclide solubility are not strongly temperature dependent between 25 and $170{ }^{\circ} \mathrm{C}$. This is clearly not the case (Burton et al., 2005). Nevertheless, by $1.3 \mathrm{y}$, glass zone temperatures have decreased to $<50{ }^{\circ} \mathrm{C}$ and, thus, radionuclide retardation factors calculated at $\geq 1.3$ y should not have increased uncertainty resulting from limitations in the temperature-dependent thermodynamic data. In effect, simulated retardation factors at $\geq 1.3 \mathrm{y}$ are the result of historical high temperatures in the glass zone but not the result of immediate thermal conditions. 
CHAPTER 4: CALIBRATION AND ASSESSMENT MODELS
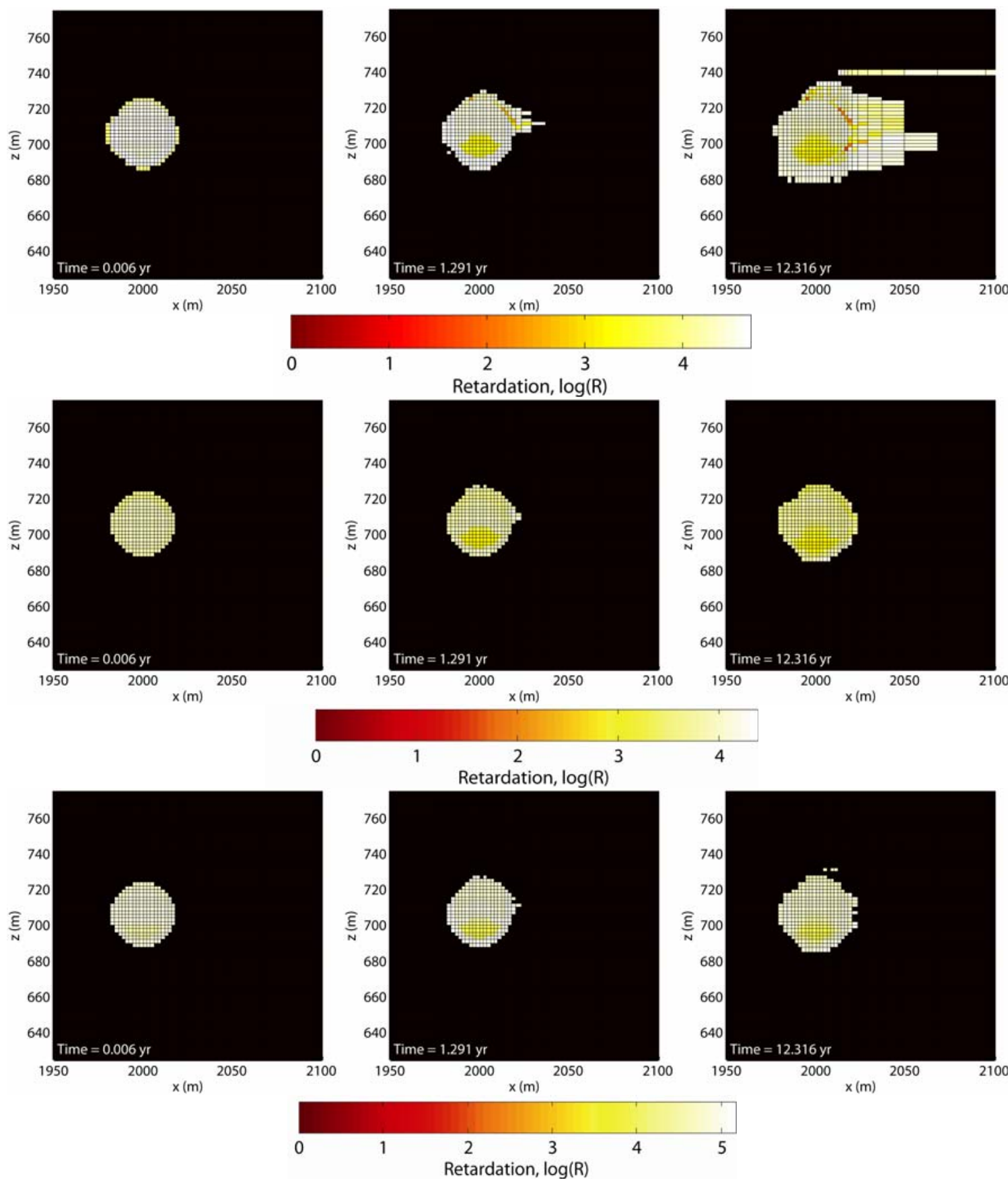

Figure 4.87 Evolution of radionuclide retardation $(\log (R))$ with time for $\mathrm{Am},{ }^{41} \mathrm{Ca}$, and $\mathrm{Cs}$ radionuclide classes. 
CHAPTER 4: CALIBRATION AND ASSESSMENT MODELS
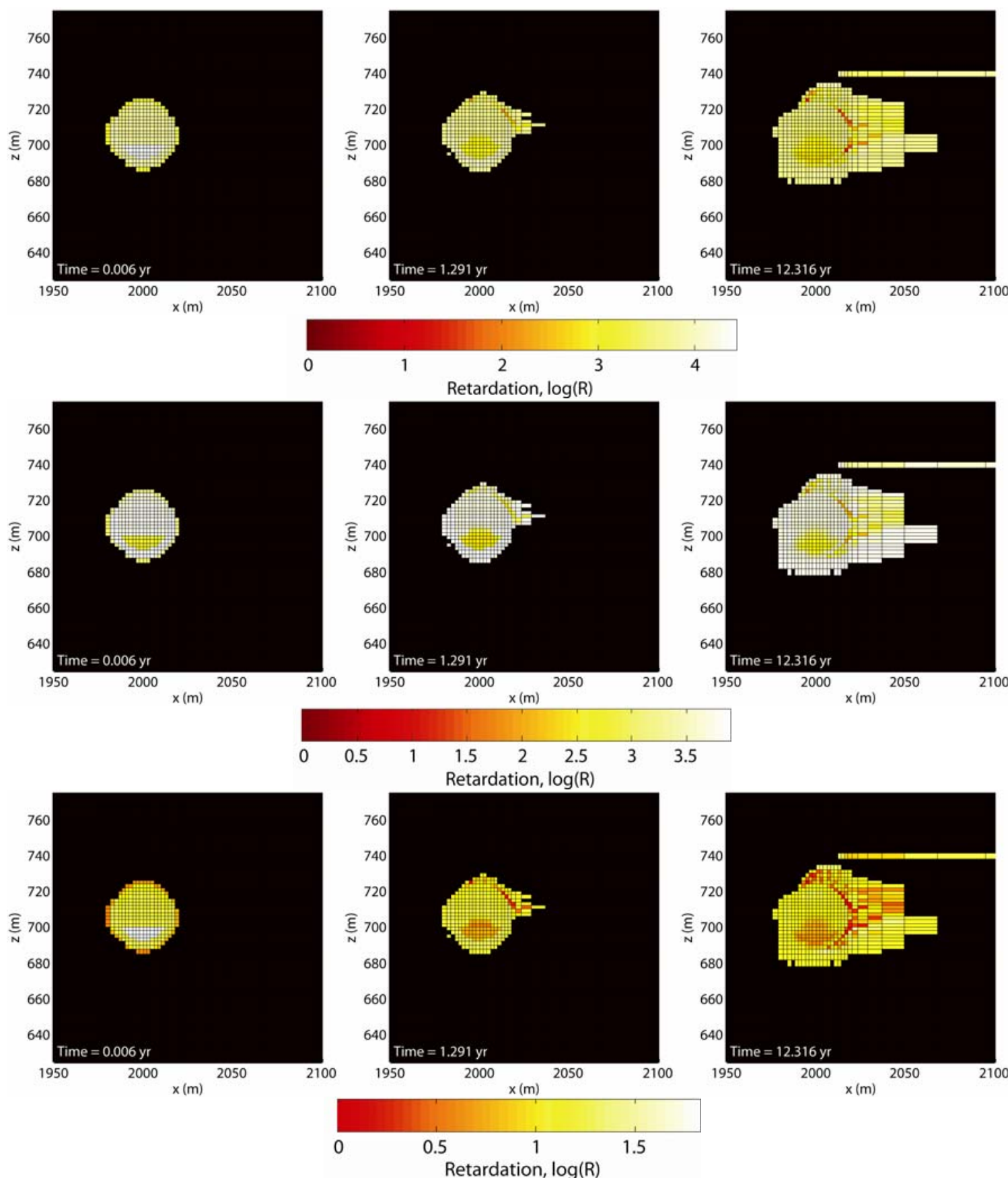

Figure 4.88 Evolution of radionuclide retardation $(\log (R))$ with time for $\mathrm{Eu}, \mathrm{Ni}$, and $\mathrm{Np}$ radionuclide classes. 
CHAPTER 4: CALIBRATION AND ASSESSMENT MODELS
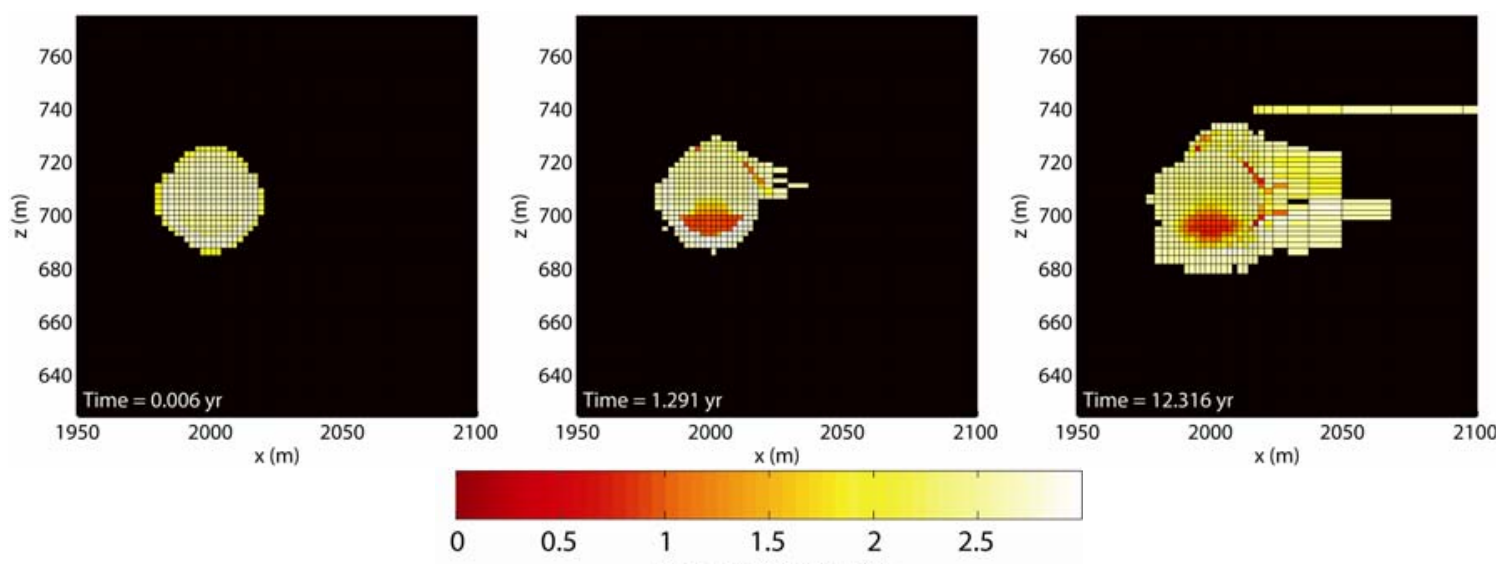

Retardation, $\log (\mathrm{R})$
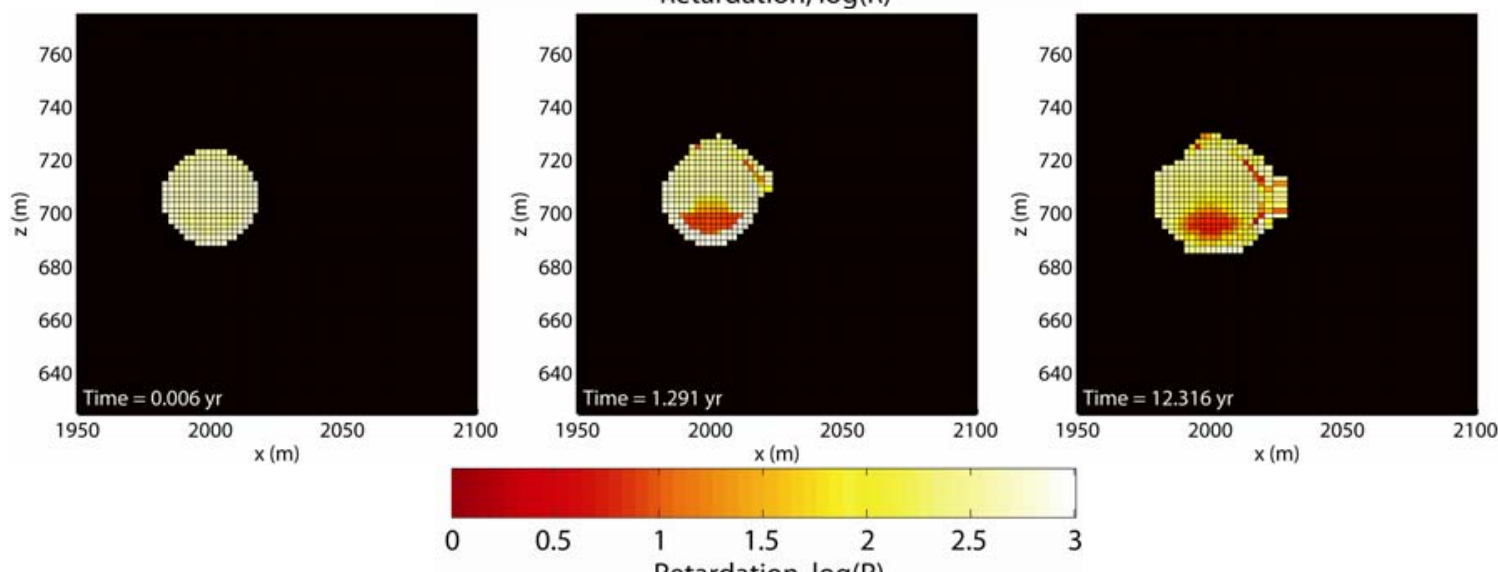

Retardation, $\log (\mathrm{R})$
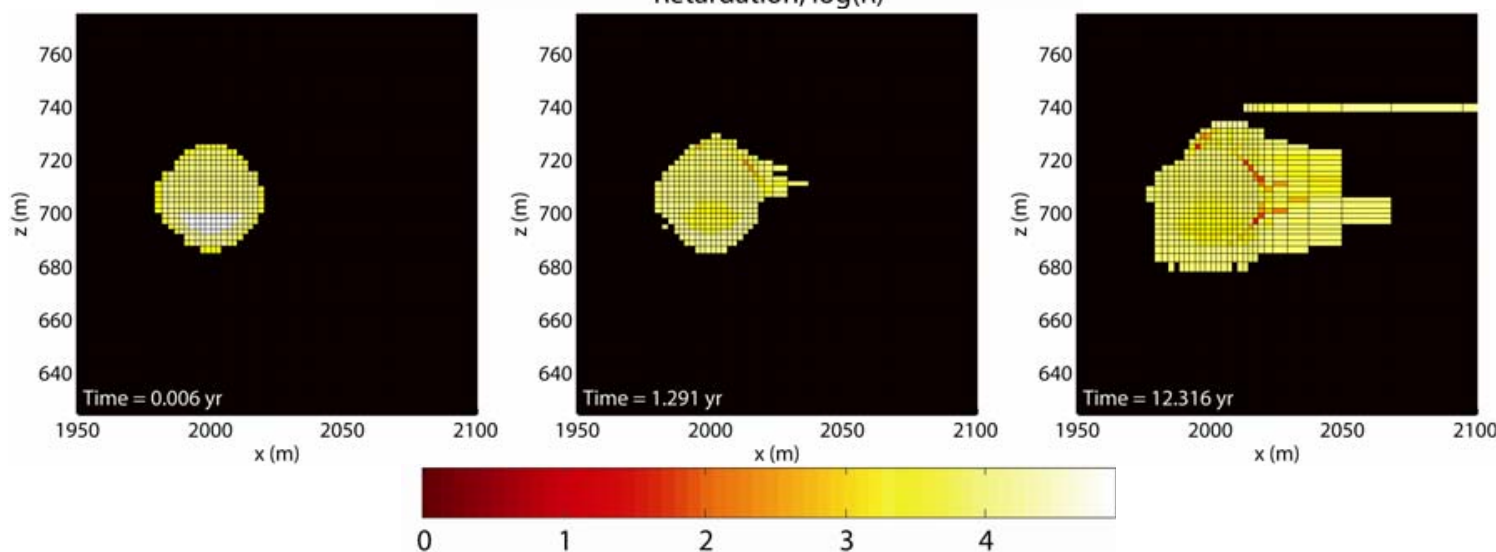

Retardation, $\log (\mathrm{R})$

Figure 4.89 Evolution of radionuclide retardation $(\log (R))$ with time for ${ }^{241} \mathrm{Pu}, \mathrm{Pu}$, and $\mathrm{Sm}$ radionuclide classes. 
CHAPTER 4: CALIBRATION AND ASSESSMENT MODELS
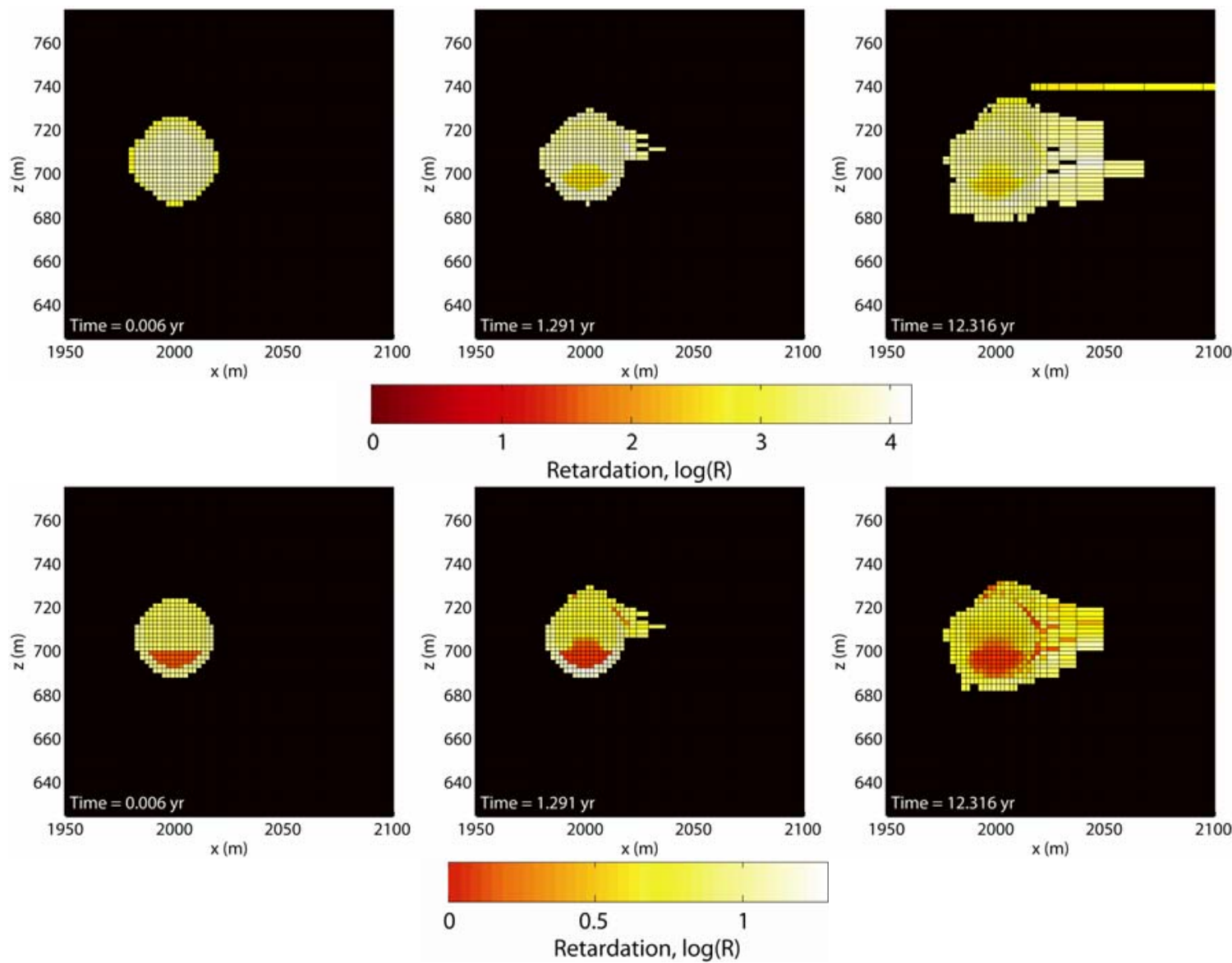

Figure 4.90 Evolution of radionuclide retardation $(\log (R))$ with time for $\mathrm{Sr}$ and $\mathrm{U}$ radionuclide classes. 


\section{$5 \quad$ Hydrologic Source Term Models}

\section{$5.1 \quad$ Overview}

This chapter reviews the development and application of the ParFlow/SLIM model for determining the long-term (1,000-y) HST for the CAMBRIC test under pumping and recharge conditions associated with the RNM experiment. The simulations presented here are both supported by and meant to be consistent with the calibration and assessment models presented in Chapter 4. The ParFlow/SLIM models are preferred for use in order to exploit computational efficiencies necessary for examining long-term transport behavior in large, heterogeneous porous flow systems and associated sensitivity analyses. The efficiencies are derived from the use of simplified geochemical models, efficient mass transport algorithms, and parallel computing techniques for simulating variably saturated flow in large flow systems. ParFlow (Kollet and Maxwell, 2006; Jones and Woodward, 2002; and Ashby and Falgout, 1996) is a parallel subsurface flow simulator designed to efficiently solve saturated and variably saturated problems with complex heterogeneity. It is described further in Tompson, et al. (1999) and Tompson et al. (2006). SLIM (Maxwell and Kastenberg, 1999) is a particle tracking code designed to efficiently and accurately solve contaminant transport in heterogeneous subsurface systems. It has many features related to radionuclide transport, sorption, decay, glass dissolution, and particle implementations to improve accuracy that are described in detail in Appendix C of Pawloski, et al. (2001).

Section 5.2 presents several updates to the conceptualizations upon which the model analyses are based. New information includes key geochemical simplifications associated with glass dissolution and radionuclide retardation processes that are motivated and substantiated by the work in Chapter 4, as well as an examination of the impacts of physical and chemical heterogeneity on the nature and evolution of radionuclide transport processes.

Sections 5.3, 5.4, and 5.5 present additional analyses focused on radionuclide transport and the evolution of the HST:

- In the saturated zone away from the cavity system, under both pumping and longerterm ambient conditions

- In the unsaturated zone between the ditch and Frenchman Lake and the water table

- In the upper saturated zone underlying the ditch and Frenchman Lake following infiltration

\subsection{Updated Conceptual Models for Flow and Transport}

\subsubsection{Formulation of Simplified Model Geochemical Processes}

As identified in Section 4.6, two geochemical processes are relevant to predicting the hydrologic source term. These are:

- Glass dissolution

- Radionuclide retardation

The mechanistic modeling approach in Section 4.8 described in detail the geochemical reactions considered in calculating the HST for CAMBRIC. The approach included 
feedback between temperature, solution speciation, glass dissolution, secondary mineral dissolution/precipitation, surface complexation, ion exchange, and radionuclide decay, and variations of these processes that occurred between various layers. Details of mechanistic processes were simplified to reduce the computational burden of HST calculations. A glass dissolution rate algorithm (with temperature as its only variable) was calculated by applying simplifying assumptions to the transition state theory model developed in Section 4.8.2.8.2.1. Radionuclide retardation is simplified to a linear $\mathrm{K}_{\mathrm{d}}$ approach by simulating surface complexation and ion exchange processes under ambient groundwater and mineralogic conditions, leading to retardation factors that are dependent only on mineralogic abundance. Details regarding the simplifying assumptions are described below.

\subsubsection{Simplified Glass Dissolution Model}

The glass dissolution model described in Section 4.8.2.8.2 was used for both the NUFT/CRUNCH and ParFlow/SLIM models. In CRUNCH, glass dissolution can be implemented directly, using the glass dissolution rate equation and parameters described in the previous chapter. SLIM, however, does not explicitly provide for the complex chemical interactions such as $\mathrm{pH}$ and secondary mineral precipitation that control glass dissolution rates. Thus, the effects of chemistry have to be anticipated and pre-programmed into this glass model. The major differences between the glass model used in CRUNCH and the glass model in the SLIM code are that:

- $\quad$ The $\mathrm{pH}$ and glass activity product $Q$ are allowed to vary in CRUNCH.

- CRUNCH allows alteration minerals to precipitate and sequester elements released from glass. The precipitation of alteration minerals changes the fluid chemistry, including $\mathrm{pH}$ and $Q$, which affects the glass dissolution rate.

Implementation of the glass dissolution model in the CRUNCH model was described in Chapter 4. The implementation of the glass dissolution model in the ParFlow/SLIM model simulations is described below.

A simplified temperature-dependent glass dissolution model is required for the ParFlow/SLIM code simulations. The model must bound the expected limits of glass dissolution rates given potential variability in chemical and physical conditions. Based on the results of preliminary CRUNCH simulations and published glass dissolution data, a moderate rate was defined at $25^{\circ} \mathrm{C}$ that represents a conservative estimate of the glass dissolution under nearambient chemical conditions. Assumptions for this rate included:

- $\quad \mathrm{The} \mathrm{SiO}_{2}(\mathrm{aq})$ activity in solution is controlled by the solubility of $\beta$-cristobalite at all temperatures. This controls the saturation state of the solution with respect to glass.

- The $\mathrm{pH}$ of the solution is not affected by secondary mineral precipitation but is affected by temperature.

- The $\mathrm{pH}$-dependent glass dissolution rate constants are identical to those developed for the CRUNCH code.

- An activation energy of $15 \mathrm{kcal} / \mathrm{mol}$ controls the temperature dependence of the glass dissolution rate.

This simplified glass model is significantly different from the model used in the unclassified CHESHIRE HST calculations (Pawloski et al., 2001). In those simulations, the glass dissolution rate was based on a rate constant calculated at $\mathrm{pH} 8.3$ and at $25^{\circ} \mathrm{C}(\mathrm{pH} 8.4$ is used 
here to reflect ambient solution conditions). In the CAMBRIC model, the glass dissolution rate was based on a $\mathrm{SiO}_{2}$ content of $65.1 \%$ instead of $78.6 \%$ to reflect the silica content of the surrounding alluvium. Also, in the unclassified CHESHIRE HST, the saturation state of the solution with respect to the glass $(1-Q / K)$ was constant and based on equilibrium with $\alpha$ cristobalite at $25^{\circ} \mathrm{C}(Q)$ and the solubility of amorphous silica at $25^{\circ} \mathrm{C}(K)$, resulting in a constant $1-Q / K$ of 0.48 . In the CAMBRIC model, the saturation state was defined by $\beta$-cristobalite and amorphous silica solubilities as a function of temperature. Finally, the temperature dependence of glass dissolution was a function of an activation energy of $20 \mathrm{kcal} / \mathrm{mol}$ in the CHESHIRE model while $15 \mathrm{kcal} / \mathrm{mol}$ is used in the CAMBRIC model. In addition, the CAMBRIC model allows the $\mathrm{pH}$ to vary as a function of temperature as a result of water dissociation. The improvements made to the ParFlow/SLIM glass dissolution model result in a glass model that more closely resembles the full complexity of the mechanistic NUFT/CRUNCH model.

To determine the glass dissolution rate for the ParFlow/SLIM model, the following procedure was taken. First, the rate coefficient $k$ and product terms $a_{j}^{i}$ were based on the parameters in Table 4.21. The $\mathrm{pH}$ and $\mathrm{pOH}$ terms were determined by assuming that the initial solution $\mathrm{pH}$ at $25^{\circ} \mathrm{C}$ is 8.4 and that deviations from $\mathrm{pH} 8.4$ as a function of temperature are constrained by the $\mathrm{K}_{\mathrm{w}}$ of water and charge balance. The $\log \left(\mathrm{K}_{\mathrm{w}}\right)$ of water as a function of temperature was fit to the following polynomial based on $K_{w}$ data from the EQ3/6 database (Johnson and Lundeen, 1997):

$$
\log \left(\mathrm{K}_{\mathrm{w}}\right)=6.1485 \times 10^{-10} \mathrm{~T}^{4}-4.9425 \times 10^{-7} \mathrm{~T}^{3}+1.9154 \times 10^{-4} \mathrm{~T}^{2}-4.1691 \times 10^{-2} \mathrm{~T}+14.935
$$

where $\mathrm{T}$ is in degrees Celsius.

Using this function for $\mathrm{K}_{\mathrm{w}}$ and knowing that the charge imbalance between $\mathrm{H}^{+}$and $\mathrm{OH}^{-}$at $25^{\circ} \mathrm{C}$ and $\mathrm{pH} 8.4$ is $2.48 \times 10^{-6} \mathrm{~mol} / \mathrm{L}$, the $\mathrm{pH}$ and $\mathrm{pOH}$ change as a function of temperature were predicted by the following equations:

$$
p H(T)=-\log \left(\frac{-2.48 \times 10^{-6}+\left(\left(2.48 \times 10^{-6}\right)^{2}+\left(4 K_{w}(T)\right)\right)^{1 / 2}}{2}\right)
$$

and

$$
p O H(T)=-\log \left(K_{w}(T)\right)-p H(T)
$$

These values were combined with the information of Table 4.21 to determine the glass dissolution rate far from saturation at a particular temperature. To determine the saturation term as a function of temperature, the solubility of $\beta$-cristobalite and amorphous silica as a function of temperature were incorporated into the $1-Q / K$ term. By fitting the solubility of these two minerals to a polynomial, the saturation term as a function of temperature is predicted by the following:

$$
1-\frac{Q(T)}{K(T)}=4.1559 \times 10^{-11} T^{4}-5.8913 \times 10^{-8} T^{3}+2.1665 \times 10^{-5} T^{2}-4.1143 \times 10^{-3} T+0.58456
$$


Finally, an activation energy of $15 \mathrm{kcal} / \mathrm{mol}$ is included in the temperature-dependent term. The above equations and the rate constant data in Table 4.21 produce the equation that controls glass dissolution rates in the ParFlow/SLIM code. ${ }^{1}$ The resulting rate of glass dissolution as a function of temperature is compared with the far-from-saturation rates in Figure 5.1. In the ParFlow/SLIM code, the effects of temperature on $\mathrm{pH}$ and their influence on dissolution are directly incorporated into the dissolution rate curves used. In the CRUNCH code, $\mathrm{pH}$ is allowed to vary as a result of secondary mineral precipitation or other geochemical reactions. Similarly, the $\mathrm{SiO}_{2}(\mathrm{aq})$ activity in solution may also vary depending on solution conditions and affect glass dissolution rates. Simply put, while the glass dissolution model in the ParFlow/SLIM model is obliged to follow the path that connects the data points in Figure 5.1, the CRUNCH code allows the glass dissolution rate to vary, in principle, over the entire 2-D space of Figure 5.1. The range of glass dissolution rates as a function of time in the mechanistic NUFT/CRUNCH calculations is included in Figure 5.1 for comparison.

The temperature history of the glass zone and the resulting glass dissolution as a function of time (Figure 5.2) indicates that the high temperatures at early time result in glass dissolution rates significantly faster than under ambient conditions. The NUFT/CRUNCH model predicts greater glass dissolution at early time that the simplified ParFlow/SLIM model, as a result of its inclusion of feedback between water chemistry evolution and glass dissolution. However, the total amount of glass dissolved in the two models over 1,000 years differs by less than $20 \%$. Thus, the simplifying assumptions made for the ParFlow/SLIM model do not drastically alter glass dissolution behavior.

\footnotetext{
${ }^{1}$ The reactive surface area of glass is $0.001 \mathrm{~m}^{2} / \mathrm{g}$ in both CRUNCH and SLIM.
} 


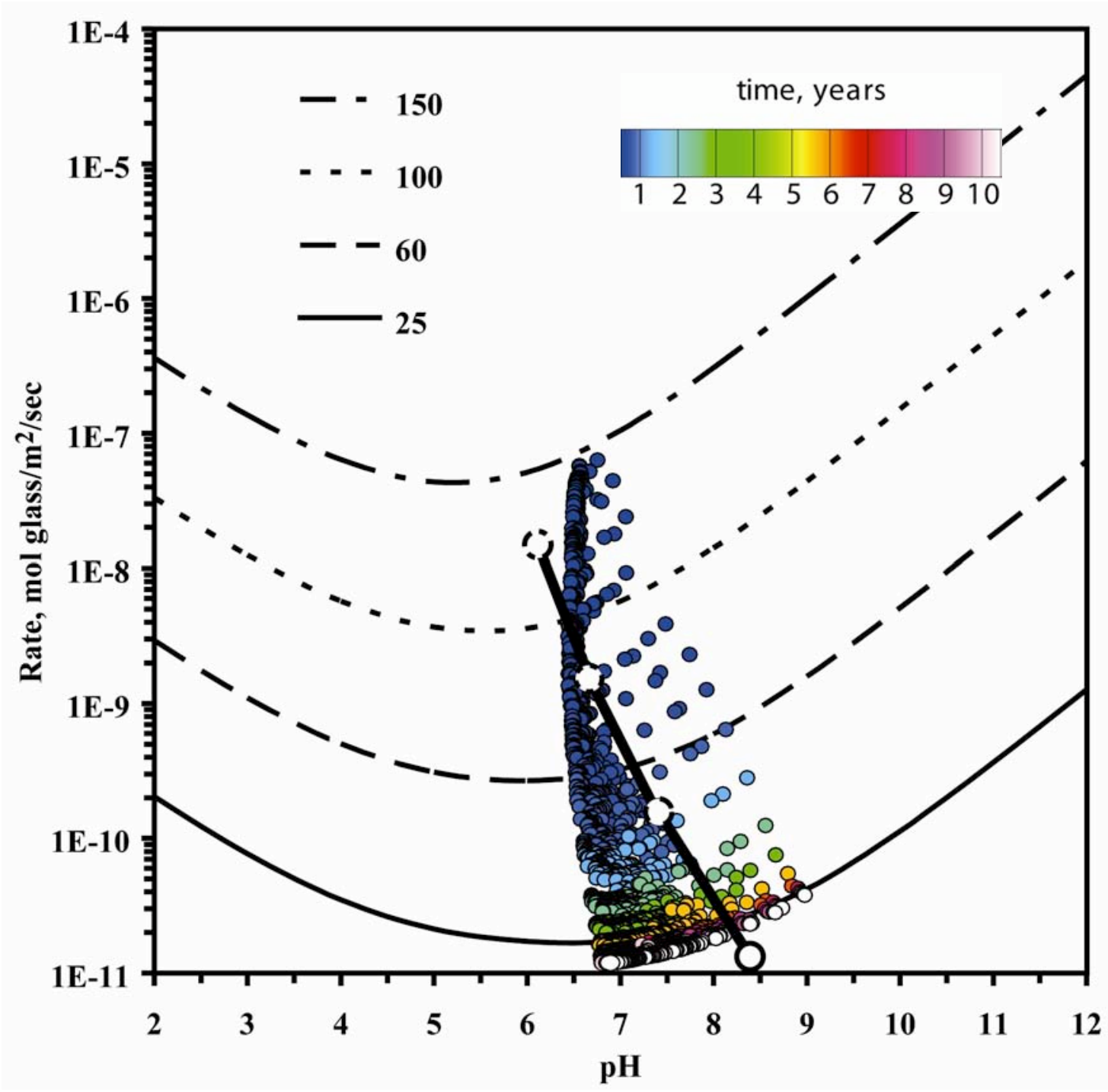

Figure 5.1 Glass dissolution rates from NUFT/CRUNCH simulations (colored circles identify glass dissolution rate and $\mathrm{pH}$ for each node in the glass zone) superimposed on model (far-from-saturation) glass dissolution rates as a function of $\mathrm{pH}$ at four different temperatures $\left(150,100,60\right.$, and $\left.25^{\circ} \mathrm{C}\right)$. Large circles simulate the change in $\mathrm{pH}$ and glass dissolution rate at the four temperatures based on the ParFlow/SLIM glass dissolution rate algorithm. 


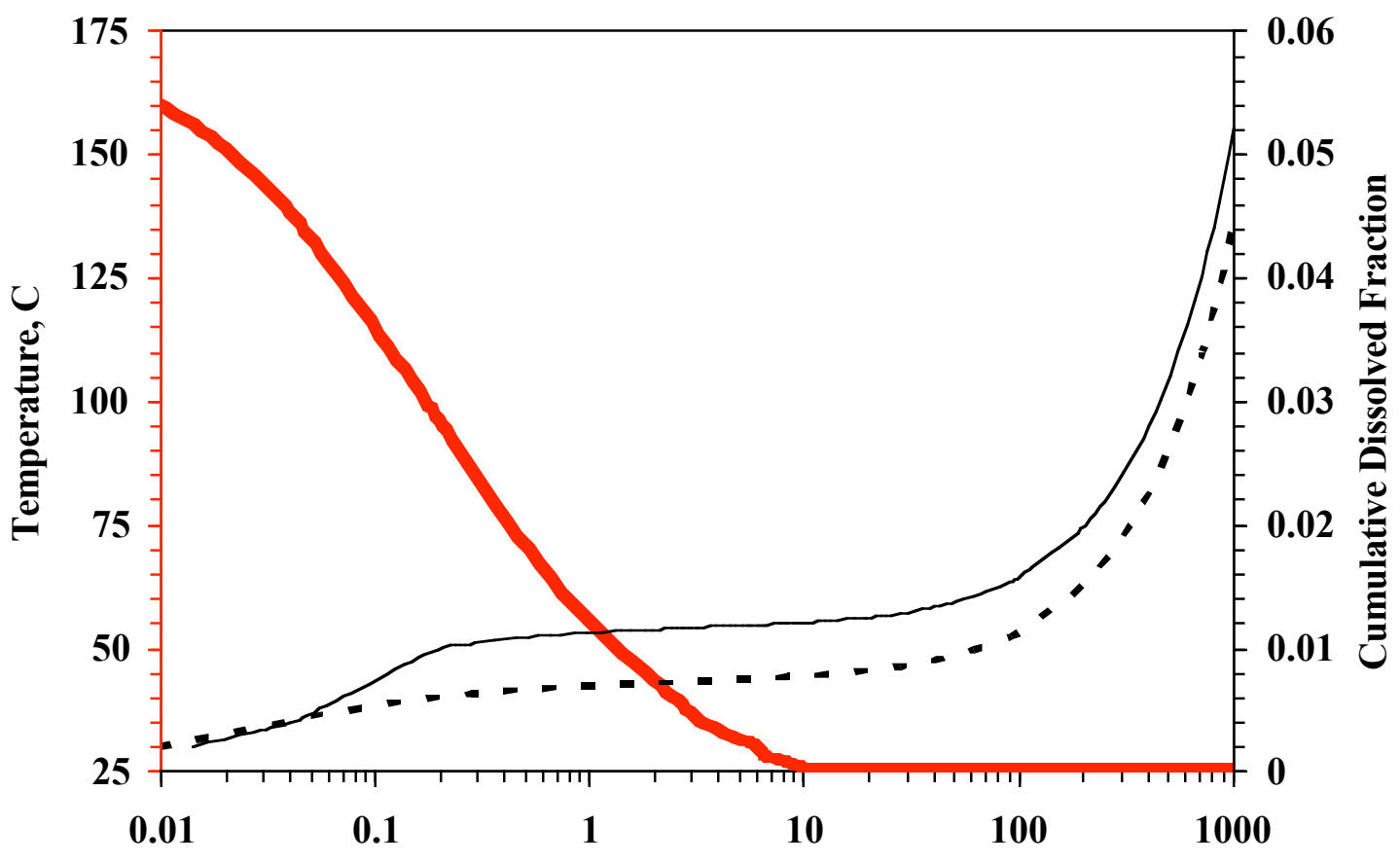

Time, years

Figure 5.2 Mean glass zone temperature and cumulative dissolved glass fraction as a function of time for the NUFT/CRUNCH calculations (solid line) and ParFlow/SLIM model glass dissolution algorithm (dashed line).

\subsubsection{Simplified Radionuclide Retardation Model}

The radionuclide retardation model was based on the mechanistic modeling approach identified in Section 4.8. For the modeling approach used to calculate the transient HST, the thermodynamic data for each radionuclide class were reduced to produce a simple linear $\mathrm{K}_{\mathrm{d}}$ model for each radionuclide-mineral pair. This was accomplished to ease the computational burden of the HST calculations. It also allowed the importance of non-linear reaction chemistry on overall near-field radionuclide transport to be evaluated.

The $K_{d}$ values for each alluvial layer included in the steady-state model were calculated based on the water chemistry near the CAMBRIC test and the detailed mineralogic analyses of the alluvium layers in ER-5-4 reported by Warren et al. (2002). The arithmetic average and standard deviation of $\log _{10} \mathrm{~K}_{\mathrm{d}}$ (e.g., $<\mathrm{Z}>$ and $\mathrm{s}_{\mathrm{z}}$ where $\mathrm{Z}=\log _{10} \mathrm{~K}_{\mathrm{d}}$ ) for each radionuclide class and each alluvial layer were determined from the geometric mean of $K_{d}$ values calculated from all of the alluvium XRD measurements reported by Warren et al. (2002) for ER-5-4. Because XRD data were not available for Layer 1 from ER-5-4, mineralogy measurements from UE-5n were used. The water chemistry used to derive radionuclide-mineral $\mathrm{K}_{\mathrm{d}}$ values, or more specifically their corresponding retardation parameters $\left(\mathrm{R}=1+\rho_{\mathrm{b}} \mathrm{K}_{\mathrm{d}} / \phi\right)$ is listed in Table 2.2. This water chemistry was based on an average water chemistry measured in RNM-1, RNM-2S, and UE-5n. For the purpose of calculating $\mathrm{K}_{d} \mathrm{~S}$, the $\mathrm{O}_{2}(\mathrm{~g})$ fugacity was set to $10^{-20}$ bars; this ensured that the $\mathrm{Pu}$ oxidation states that dominate in the aqueous phase are $\mathrm{Pu}(\mathrm{IV})$ and $\mathrm{Pu}(\mathrm{V})$. All other radionuclides remain in their oxidized form under these conditions. Radionuclide $\mathrm{K}_{\mathrm{d}} \mathrm{S}$ are reported in Table 5.1. 
Table 5.1. Values for mean and standard deviation of $Z=\log _{10} R=\log _{10}\left(1+\rho_{b} K_{d} / \phi\right)$ used to populate the spatially variable retardation values for the sorbing radionuclide classes.

\begin{tabular}{|c|c|c|c|c|c|c|c|c|c|c|c|}
\hline Unit & & $\mathrm{Ca}$ & Cs & $\mathrm{Sr}$ & $\mathrm{Ni}$ & $\mathrm{Am}$ & Eu & Sm & $\mathrm{Np}$ & U & $\mathrm{Pu}$ \\
\hline \multirow[t]{2}{*}{ AL2a } & $<Z>$ & 2.838 & 4.446 & 2.582 & 3.718 & 4.517 & 3.821 & 4.103 & 1.226 & 0.877 & 2.644 \\
\hline & $\sigma_{Z}$ & 0.130 & 0.183 & 0.133 & 0.080 & 0.098 & 0.131 & 0.173 & 0.138 & 0.051 & 0.097 \\
\hline \multirow[t]{2}{*}{ AL2b } & $<Z>$ & 2.838 & 4.446 & 2.582 & 3.718 & 4.517 & 3.821 & 4.103 & 1.226 & 0.877 & 2.644 \\
\hline & $\sigma_{Z}$ & 0.130 & 0.183 & 0.133 & 0.080 & 0.098 & 0.131 & 0.173 & 0.138 & 0.051 & 0.097 \\
\hline \multirow[t]{2}{*}{ AL3 } & $<Z>$ & 3.502 & 4.797 & 3.273 & 3.752 & 4.530 & 3.791 & 4.003 & 1.169 & 0.908 & 2.656 \\
\hline & $\sigma_{Z}$ & 0.219 & 0.115 & 0.221 & 0.148 & 0.138 & 0.132 & 0.157 & 0.107 & 0.155 & 0.113 \\
\hline \multirow[t]{2}{*}{ AL4 } & $<Z>$ & 3.450 & 4.864 & 3.220 & 3.804 & 4.583 & 3.847 & 4.066 & 1.228 & 0.966 & 2.707 \\
\hline & $\sigma_{\mathrm{Z}}$ & 0.139 & 0.264 & 0.140 & 0.203 & 0.217 & 0.248 & 0.303 & 0.236 & 0.134 & 0.203 \\
\hline \multirow[t]{2}{*}{ AL5 } & $<Z>$ & 3.306 & 4.951 & 3.077 & 3.703 & 4.498 & 3.789 & 4.043 & 1.223 & 0.924 & 2.651 \\
\hline & $\sigma_{\mathrm{Z}}$ & 0.148 & 0.105 & 0.150 & 0.266 & 0.270 & 0.288 & 0.330 & 0.226 & 0.160 & 0.227 \\
\hline \multirow[t]{2}{*}{ AL6 } & $<Z>$ & 2.841 & 4.772 & 2.574 & 3.865 & 4.637 & 3.888 & 4.092 & 1.247 & 1.006 & 2.753 \\
\hline & $\sigma_{Z}$ & 0.103 & 0.080 & 0.109 & 0.105 & 0.108 & 0.118 & 0.142 & 0.108 & 0.065 & 0.098 \\
\hline \multirow[t]{2}{*}{ AL7 } & $<Z>$ & 2.835 & 4.745 & 2.566 & 3.875 & 4.669 & 3.960 & 4.220 & 1.351 & 1.028 & 2.797 \\
\hline & $\sigma_{Z}$ & 0.136 & 0.133 & 0.140 & 0.118 & 0.121 & 0.138 & 0.174 & 0.139 & 0.077 & 0.111 \\
\hline \multirow[t]{2}{*}{ AL8 } & $<Z>$ & 2.838 & 4.617 & 2.521 & 4.087 & 4.867 & 4.136 & 4.371 & 1.482 & 1.175 & 2.973 \\
\hline & $\sigma_{Z}$ & 0.060 & 0.181 & 0.046 & 0.112 & 0.105 & 0.092 & 0.074 & 0.068 & 0.080 & 0.094 \\
\hline \multirow[t]{2}{*}{ AL9 } & $<Z>$ & 3.021 & 4.619 & 2.698 & 4.246 & 5.064 & 4.394 & 4.702 & 1.760 & 1.252 & 3.164 \\
\hline & $\sigma_{Z}$ & 0.297 & 0.159 & 0.329 & 0.170 & 0.182 & 0.215 & 0.268 & 0.246 & 0.157 & 0.188 \\
\hline \multirow[t]{2}{*}{ PIM } & $<Z>$ & 3.425 & 4.720 & 3.196 & 3.674 & 4.452 & 3.713 & 3.925 & 1.098 & 0.842 & 2.579 \\
\hline & $\sigma_{Z}$ & 0.218 & 0.115 & 0.220 & 0.148 & 0.138 & 0.132 & 0.157 & 0.106 & 0.152 & 0.113 \\
\hline \multirow[t]{2}{*}{ CHIM1 } & $<Z>$ & 3.425 & 4.720 & 3.196 & 3.674 & 4.452 & 3.713 & 3.925 & 1.098 & 0.842 & 2.579 \\
\hline & $\sigma_{Z}$ & 0.218 & 0.115 & 0.220 & 0.148 & 0.138 & 0.132 & 0.157 & 0.106 & 0.152 & 0.113 \\
\hline \multirow[t]{2}{*}{ CHIM2 } & $<Z>$ & 3.425 & 4.720 & 3.196 & 3.674 & 4.452 & 3.713 & 3.925 & 1.098 & 0.842 & 2.579 \\
\hline & $\sigma_{\mathrm{Z}}$ & 0.218 & 0.115 & 0.220 & 0.148 & 0.138 & 0.132 & 0.157 & 0.106 & 0.152 & 0.113 \\
\hline \multirow[t]{2}{*}{ CZ } & $<Z>$ & 3.607 & 4.902 & 3.378 & 3.857 & 4.635 & 3.895 & 4.107 & 1.267 & 1.001 & 2.760 \\
\hline & $\sigma_{Z}$ & 0.219 & 0.115 & 0.221 & 0.148 & 0.138 & 0.133 & 0.157 & 0.109 & 0.160 & 0.113 \\
\hline \multirow[t]{2}{*}{ MG } & $<Z>$ & 3.212 & 4.343 & 3.012 & 3.430 & 4.110 & 3.464 & 3.649 & 1.178 & 0.948 & 2.474 \\
\hline & $\sigma_{\mathrm{Z}}$ & 0.191 & 0.100 & 0.193 & 0.129 & 0.120 & 0.116 & 0.137 & 0.094 & 0.138 & 0.098 \\
\hline \multirow[t]{2}{*}{ CHIM3 } & $<Z>$ & 2.838 & 4.446 & 2.582 & 3.718 & 4.517 & 3.821 & 4.103 & 1.226 & 0.877 & 2.644 \\
\hline & $\sigma_{Z}$ & 0.130 & 0.183 & 0.133 & 0.080 & 0.098 & 0.131 & 0.173 & 0.138 & 0.051 & 0.097 \\
\hline \multirow[t]{2}{*}{ CAV } & $<Z>$ & 3.502 & 4.797 & 3.273 & 3.752 & 4.530 & 3.791 & 4.003 & 1.169 & 0.908 & 2.656 \\
\hline & $\sigma_{Z}$ & 0.219 & 0.115 & 0.221 & 0.148 & 0.138 & 0.132 & 0.157 & 0.107 & 0.155 & 0.113 \\
\hline
\end{tabular}




\subsubsection{Model Domain and Grid Structure}

Three levels of detail have been used to describe the geologic structure employed in the ParFlow model. The outermost is the most recent hydrostratigraphic (HSU) framework model, exactly as is being used to develop the Frenchman Flat CAU flow model. In the central portion of the domain, notably the AA units, a layered alluvium configuration is used as derived and calibrated in Chapter 4. Within the alluvial layers themselves, as well as most of the altered zones near the working point, a finer level of detail is used to represent small-scale heterogeneity in the geologic material properties. Here, a stochastic model of local heterogeneity in the hydraulic conductivity distribution is modeled using a Gaussian random field representation. This is similar to the approach used in the previous CAMBRIC HST calculations (Tompson et al., 1999). The parametric characteristics of the stochastic conductivity distribution specified in the extended, unaltered alluvial layers were chosen to be consistent with available information on alluvial heterogeneity (as in Tompson et al., 1999), and also ensure that the effective (scaled-up) conductivities associated with each distribution in each layer match their homogeneous counterparts. The alluvial layers developed and discussed in Sections 4.2.1-4.2.3 are assumed to extend to the boundary of the AA unit. Clearly lateral changes in stratigraphy could be expected, though a lack of data exists regarding the areal distribution of these units in much of the Frenchman Flat alluvium.

As described in Section 4.2.6, the ParFlow model domain is similar to the NUFT model domain in its size and orientation. Early model scoping runs determined that the influence of pumping from RNM-2S during the RNM experiment extended several kilometers and that there was a need to isolate the simplified, regional boundary conditions used in the ParFlow model from the area of interest, the vicinity of the test and the ditch. This led to the adoption of a nested model grid approach, where the outer area of the ParFlow model domain was represented by a coarse grid $(200 \times 300 \times 50 \mathrm{~m}$ in $x, y$, and $z)$ and the inner region surrounding the ditch, playa, and test was represented by a fine grid $(4 \times 4 \times 2 \mathrm{~m}$ in $x, y$, and $z)$ in order to resolve local heterogeneity in the alluvium flow and transport properties. The CAU-scale HFM (Bechtel Nevada, 2005b) was combined with the calibrated NUFT model to generate a series of HSUs and layers for the assignment of hydraulic conductivity values (Nicole Denovio, 2005, personal communication) in the ParFlow model. The region defining the CAU HFM subset is shown in Figure 5.3 along with the rotated ParFlow model domain $(7,600 \times 6,400 \times 1,000 \mathrm{~m}$ in size). Figure 5.4 shows a plan view of the ParFlow model domain, in local $x-y$ coordinates, with the fine-mesh region indicated $(2,200 \times 600 \times 500 \mathrm{~m}$ in size $)$. The total number of computational cells in the ParFlow model is $24,197,936$.

The ParFlow model domain is shown in perspective in Figure 5.5 with the corresponding units and indices shown in Table 5.2. This figure shows the hydrostratigraphic units (HSUs), by unit number assigned within the model, for the coarse grid regions. These units are labeled according to their overall unit type (AA represents the alluvial units; PCU, the playa confining units; TMWTA, the Timber Mountain units; LTCU, the lower tuff confining units; and LCA, the lower carbonate aquifer). The (effective) hydraulic conductivity values assigned to these units in the ParFlow model are listed in Table 4.5. 
CHAPTER 5: HYDROLOGIC SOURCE TERM MODELS

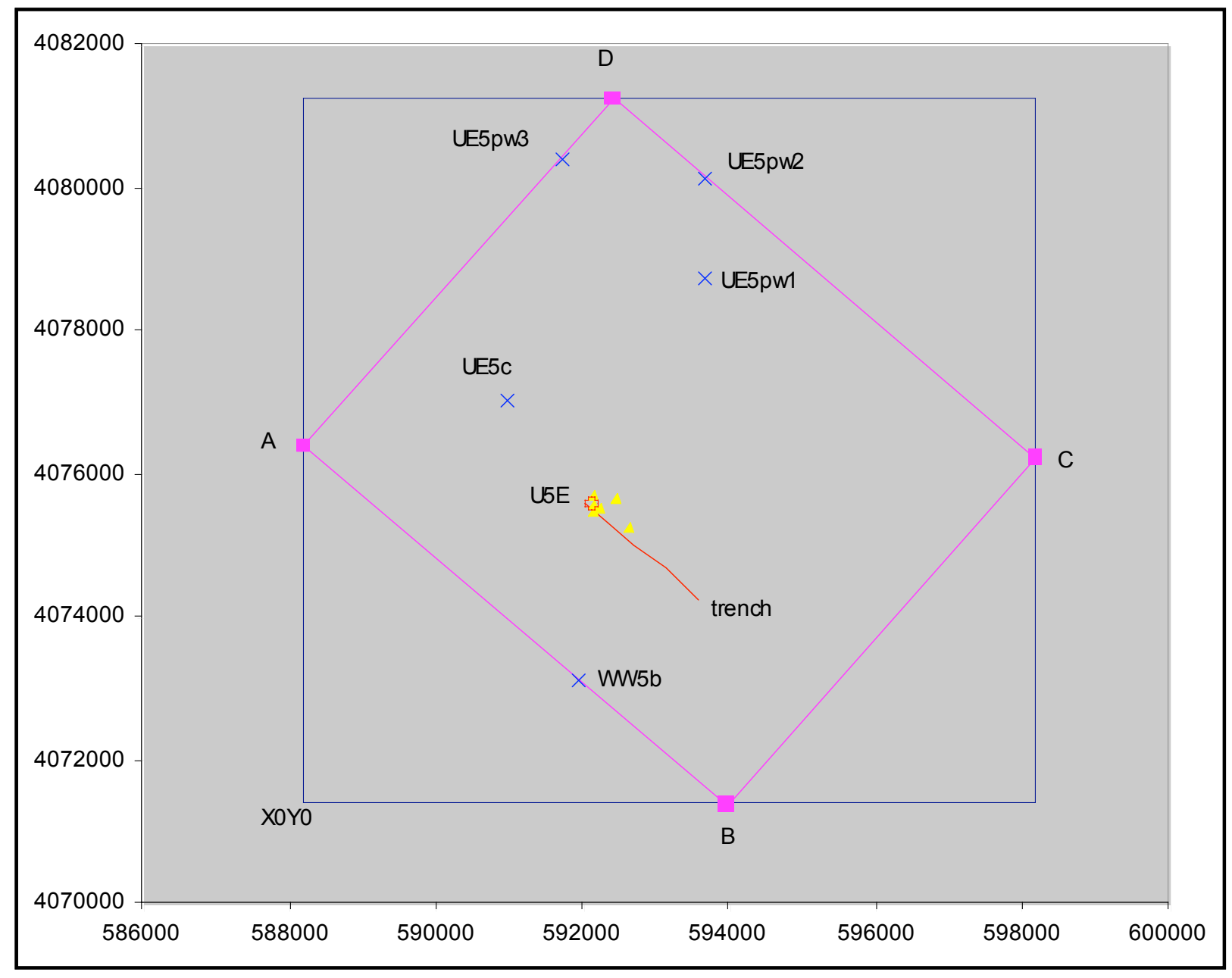

Figure 5.3 Plan view of the rotated ParFlow model domain (box ABCD) and surrounding wells in NAD27 coordinates. The larger box shows the extent of the HSU features obtained as a subset of the CAU-scale geologic model (Bechtel Nevada, 2005b). 
CHAPTER 5: HYDROLOGIC SOURCE TERM MODELS

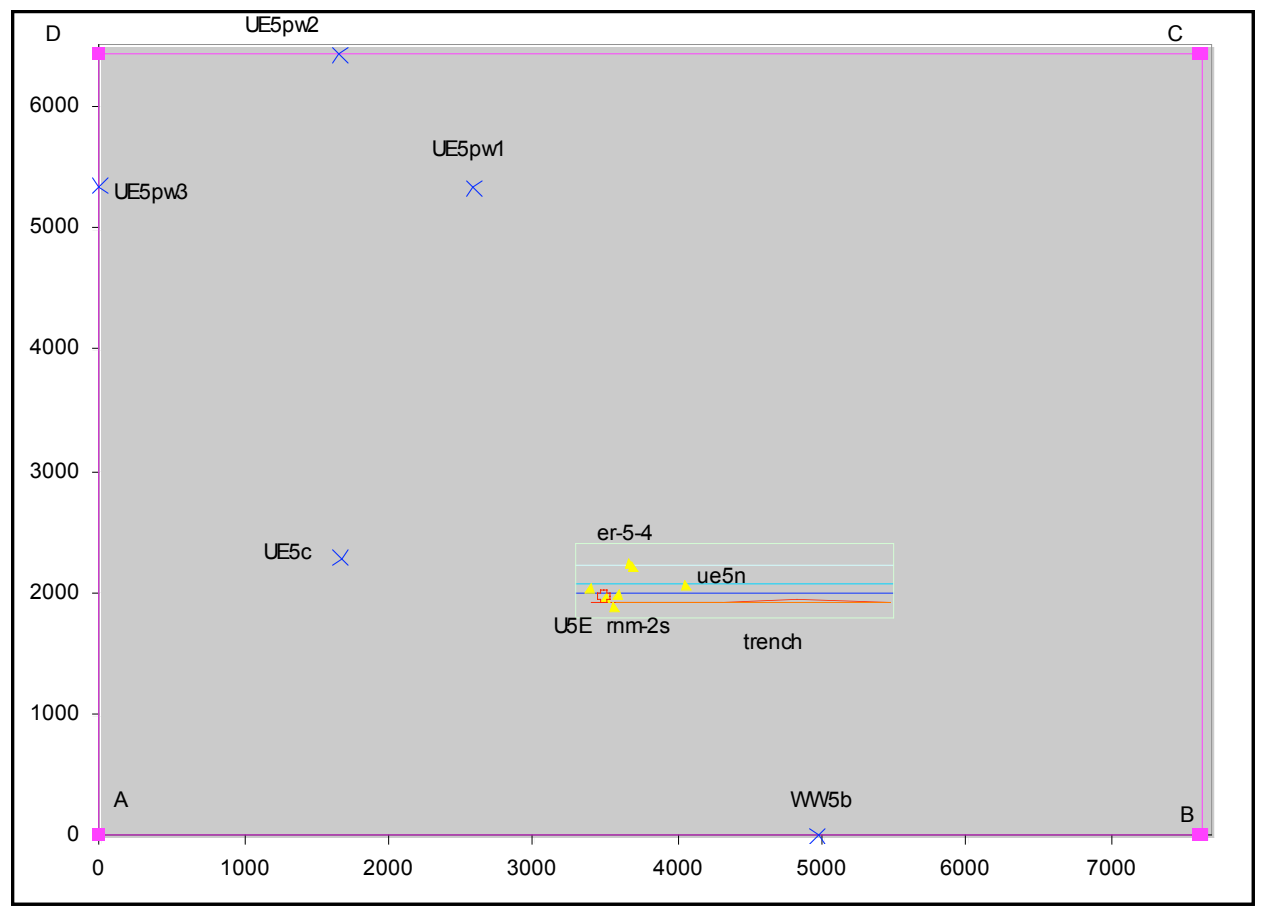

Figure 5.4 Plan view of ParFlow model domain (box $A B C D)$ and surrounding wells in local $x(A B)$ and $y$ $(A D)$ coordinates $(m)$. The fine-mesh region is located within the green box. The red, blue, and blue-green lines correspond to vertical breakthrough planes 1-3 used in Tompson et al. (2005) and discussed in Section 5.4.5.
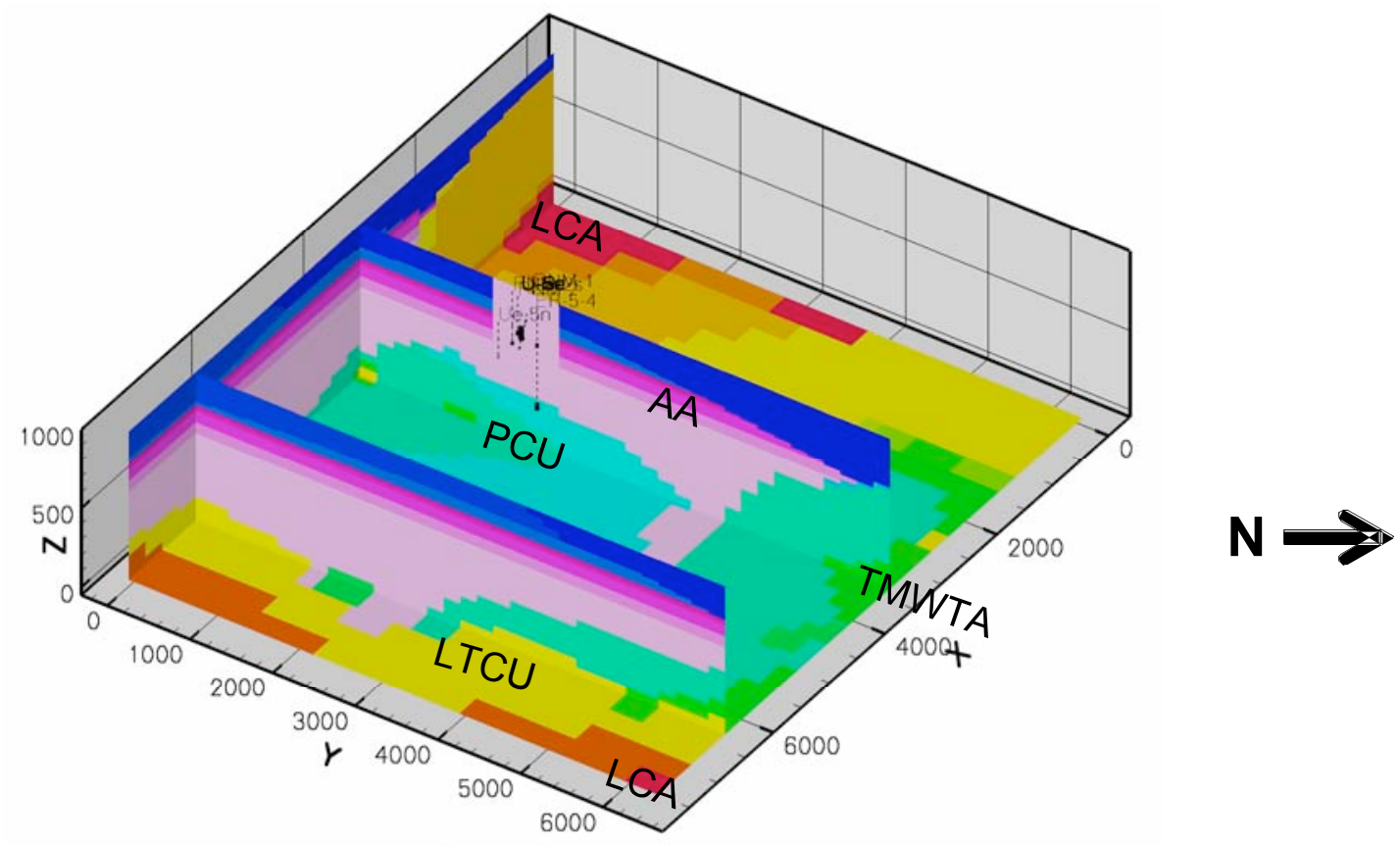

12345678910111213141516171819202122313233343680

Figure 5.5: Major hydrostratographic units used in the ParFlow model domain. 
CHAPTER 5: HYDROLOGIC SOURCE TERM MODELS

Table 5.2. Hydrostratigraphic units used in the ParFlow domain and corresponding index.

\begin{tabular}{cccccc}
\hline Unit & Index & Unit & Index & Unit & Index \\
\hline AA3 & 1 & VCU & 18 & AL7 & 37 \\
PCU2t & 2 & LCA3 & 19 & AL8 & 38 \\
AA2 & 3 & UCCU & 20 & AL9/PCU1L & 39 \\
OAA & 4 & LCA & 21 & PIM & 40 \\
BLFA & 5 & LCCU & 22 & PLAYA & 41 \\
PCU1u & 6 & CAV & 23 & AL2Ah & 51 \\
AA1 & 7 & CHM1 & 24 & AL2Bh & 52 \\
OAA1 & 8 & MG & 25 & AL3h & 53 \\
PCU1I & 9 & TRENCH & 28 & AL4h & 54 \\
TMWTA & 10 & CHM2 & 29 & AL5h & 55 \\
TMLVTA & 11 & CHM3 & 30 & AL6h & 56 \\
UTCu & 12 & AL2A & 31 & AA3h & 61 \\
TSA & 13 & AL2B & 32 & PCU2th & 62 \\
LVTA & 14 & AL3 & 33 & AA2h & 63 \\
LTCU & 15 & AL4 & 34 & DZ4 & 72 \\
WCU & 16 & AL5 & 35 & DZ5 & 73 \\
LTCU1 & 17 & AL6 & 36 & & \\
\hline
\end{tabular}




\subsubsection{Alluvial Heterogeneity}

The existence of heterogeneity in alluvium and its impact on the HST evolution was discussed in Chapter 2 and the previous CAMBRIC HST model report (Tompson et al., 1999). In the ParFlow model, the fine-mesh region was used to assign stochastic flow and transport properties based upon the calibration performed in the NUFT model (Chapter 4). As described in Chapter 4 and Tompson et al. (2005), a stochastic model of local heterogeneity in the hydraulic conductivity distribution is modeled using a Gaussian random field representation. This is similar to the approach used in the previous CAMBRIC HST calculations (Tompson et al., 1999). The parametric characteristics of the stochastic conductivity distribution specified in the extended, unaltered alluvial layers were chosen to be consistent with available information on alluvial heterogeneity (as in Tompson et al., 1999), and also ensure that the effective (scaled-up) conductivities associated with each distribution in each layer match their homogeneous counterparts developed in the NUFT MWAT calibration. The homogeneous layer conductivities developed in the NUFT calibration essentially represent effective scale properties for each alluvial layer.

The statistics used to generate the hydraulic conductivity values for the finemesh units are given in Table 4.5. These were based, in large part, upon the same observations, judgments, and procedures outlined in Section 4.3 and in Tompson et al. $(1999,2005)$. It should be noted that the layers, zones, and HSUs in the fine-mesh region were all treated as being heterogeneous, including the unsaturated alluvium. In the finemesh region, physical anisotropy was treated statistically using anisotropy in the spatial correlation parameters (See Appendix B of Tompson et al., 2005), and only scalar-valued hydraulic conductivities were used. Conversely, units in the coarse mesh region were treated as tensor-valued, effective (upscaled) properties with anisotropy values listed in Table 4.5. In the unsaturated alluvium, flow was modeled with a Richards' equation formulation based upon the VanGenuchten parametric models described in Section 4.6.1. The specific VanGenuchten parameter values used in ParFlow $\left(\alpha=1.0 \mathrm{~m}^{-1}, \mathrm{~m}=0.5\right.$, and $\mathrm{S}_{\mathrm{r}}=0.5$ ) were held constant in all unsaturated alluvium, even if the medium was considered heterogeneous.

Figure 5.6 is a perspective view of the entire ParFlow model domain showing the hydraulic conductivity values used for the different HSUs. Figure 5.7 zooms in closer and shows conductivities in the fine-mesh area. Figure 5.8 zooms in closer yet and shows conductivities in the vicinity of the CAMBRIC test, RNM-2S, and altered zones. 
CHAPTER 5: HYDROLOGIC SOURCE TERM MODELS

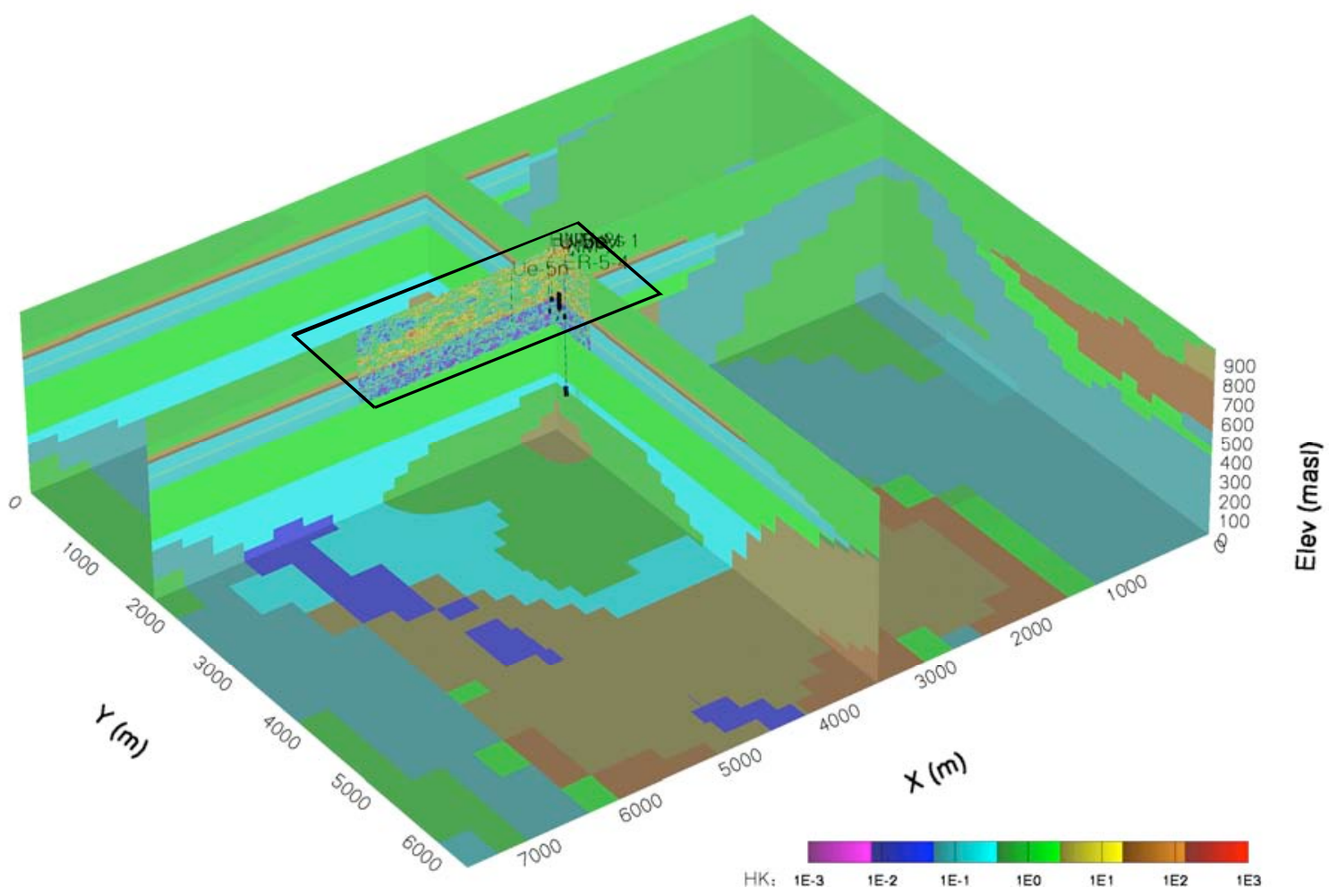

Figure 5.6 Hydraulic conductivity field used in the ParFlow model with a box denoting the surface projection of the fine resolution mesh region. 


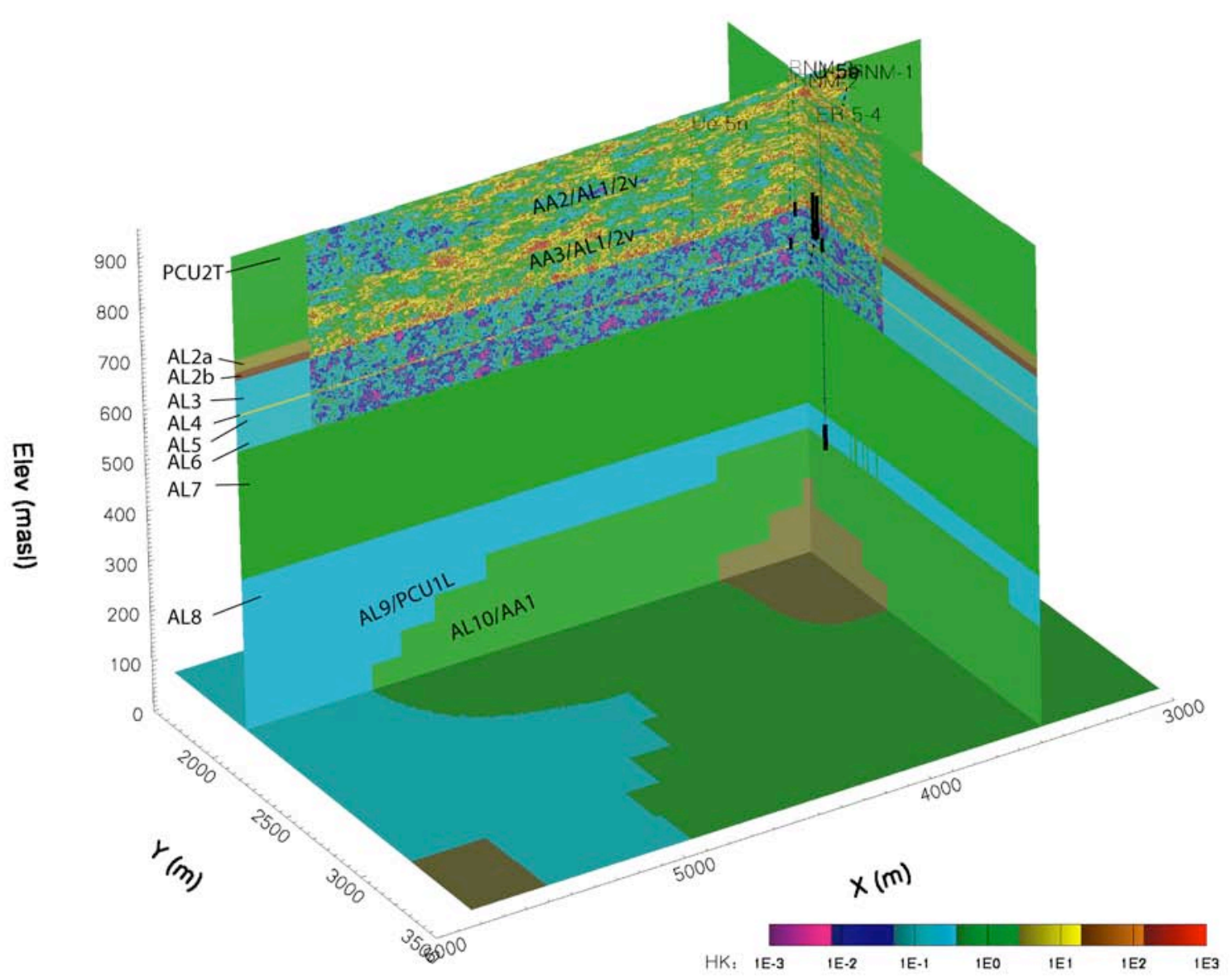

Figure 5.7 Close-in view of the ParFlow model hydraulic conductivity field showing units within the fine-mesh region indicated in Figure 5.6. Note that because the hydraulic conductivity values for AL8 and PCU1L are similar they appear as the same color in this figure. 


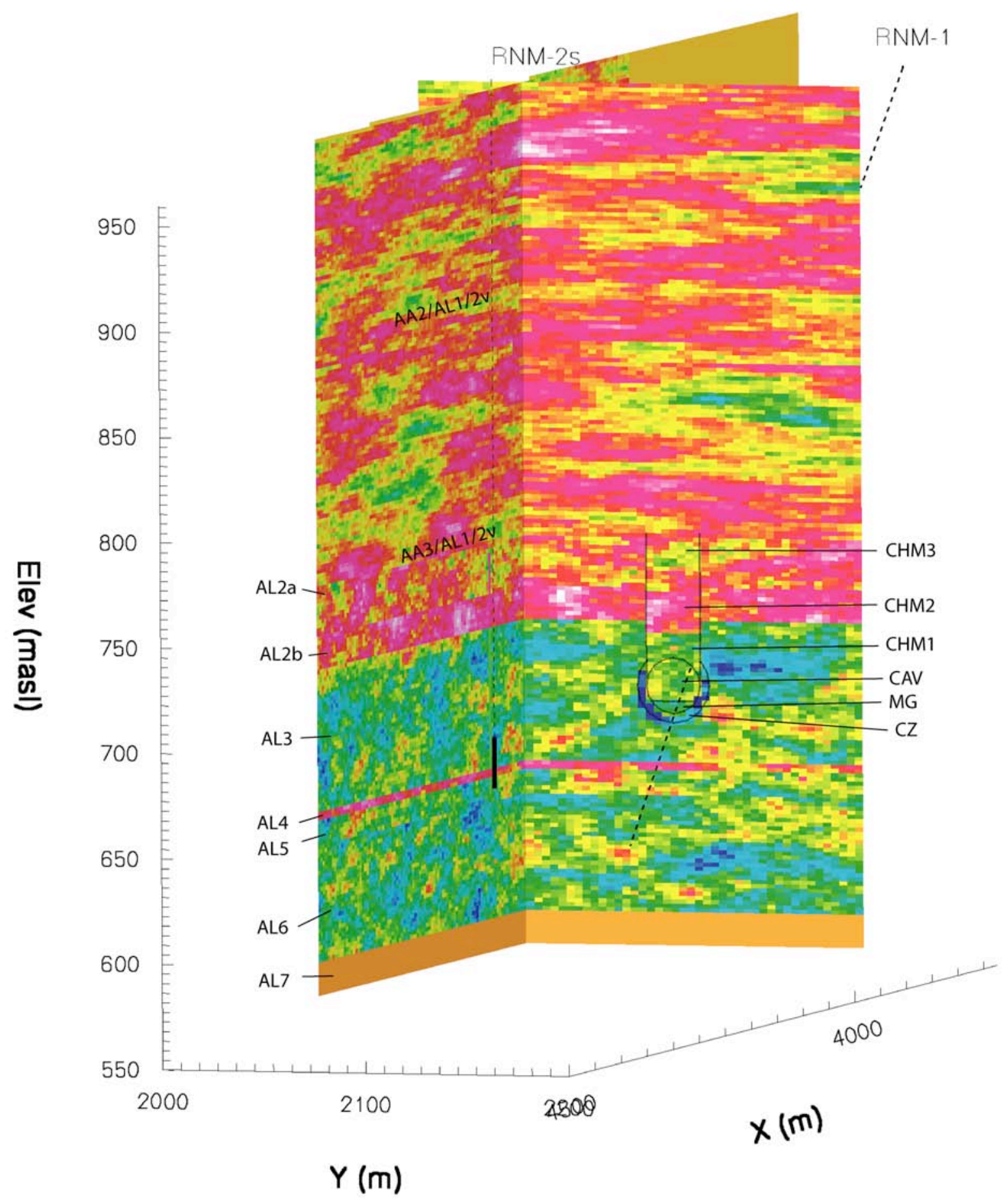

Figure 5.8 Detail of hydraulic conductivity distributions in the ParFlow model close to the CAMBRIC test area showing altered zones and heterogeneous layers. 


\subsubsection{Boundary Conditions, Model Initialization, and Realization Selection}

The transient ParFlow simulations were initialized from the steady-state flow solution documented in Tompson et al. (2005). In the steady-state model, water level data at WW-5b and UE-5 PW2 were used as a starting point to specify constant head conditions along the SW and NE sides of the model domain. These head conditions were then varied to calibrate a simulation of the steady-state flow field using water level observations in RNM-2S, RNM-2, UE-5n, ER-5-4, and ER-5-4 piezometer. The calibration was stopped when the RMS error between observations and model predictions was less than $0.3 \mathrm{~m}$. Final results of the calibrated head values for all 50 realizations are shown in Figure 5.9. Historical water levels are plotted for each well with uncertainty and error bounds associated with them (Nicole Denovio, 2005, personal communication). The 50 ParFlow steady-state realizations and the single transient realization are shown as gray tics. The differences between realizations of hydraulic conductivity on the simulated head values for each of these locations are demonstrated by scatter among the tics. All of the ParFlow simulated heads fall within the error bars of each static water level. Frenchman Flat CAU model simulations are also shown on this plot, including base case and alternate case simulations. In general, the ParFlow model simulations fall within the measured water levels as well as or better than the CAU simulations, indicating that the local gradient in the vicinity of CAMBRIC is captured by the flow model.

The final, calibrated heads assigned to the southwest and northeast sides were $734.85 \mathrm{~m}$ asl and $732.0 \mathrm{~m}$ asl, respectively. No-flow conditions were used along the northwest and southeast sides and along the bottom of the domain. Although approximate, these perimeter specifications were used to develop a more accurate representation of the water levels in the central part of the modeling domain in the immediate vicinity of CAMBRIC. 


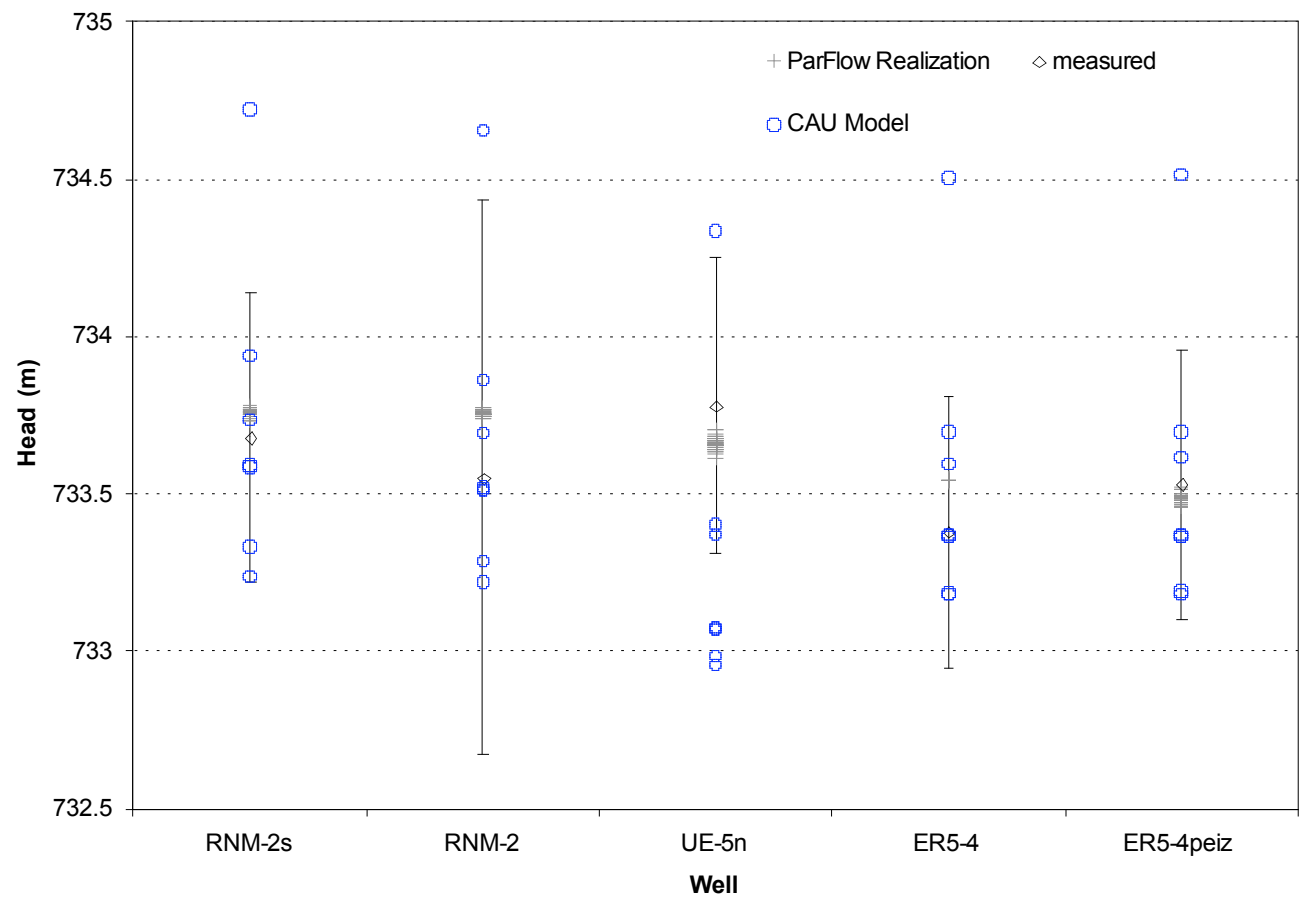

Figure 5.9 Comparison of simulated steady-state ParFlow water levels, simulated base case and alternative CAU flow model water levels, and measured levels and their uncertainties.

The transient ParFlow simulations incorporated continuous pumping from RNM-2S over a 16-y period using two specified pumping rates. The first pumping period involves a $300-\mathrm{gpm}\left(1635.3 \mathrm{~m}^{3} / \mathrm{d}\right)$ pumping rate instituted for the first $700 \mathrm{~d}$, while the second involves a 600 -gpm rate $\left(3270.6 \mathrm{~m}^{3} / \mathrm{d}\right)$ applied for the duration of the $16-\mathrm{y}$ experiment (short-term, minor shutdowns were not included in the model). During each pumping period, a portion of the pumping effluent discharged into the ditch was allowed to infiltrate over its $1.6-\mathrm{km}$ length, while the remaining portion was allowed to accumulate in a closed surface impoundment or discharge area in Frenchman Lake. The approximate locations and dimensions of the ditch and lake discharge area were assigned based on visual inspection of an aerial photograph of the CAMBRIC test area, shown in Figure 5.10.

As reported in Tompson et al. (2005), flume-based flow measurements in the ditch indicated that approximately one third of the ditch flow (i.e., discharge from the well) was lost to infiltration and evapotranspiration over the first $1,000 \mathrm{~m}$ of the ditch length (Ross and Wheatcraft, 1994). As a conservative approximation, the effects of evapotranspiration were ignored. This observation was used to specify upper bound infiltration rates in the model, over the entire length of the ditch, and over both pumping periods. Flow into the Frenchman Lake discharge area was then estimated. As noted in Tompson et al. (2006), evidence for transpiration by phreatophyte vegetation surrounding the ditch was suggested in ditch flow observations and analyzed by Love et al. (2002), but is not considered here to be a significant fraction of the ditch flow. This estimate was used to specify upper bound infiltration rates in the model over the entire length of the ditch, as well as to estimate the flows into the lake discharge area. For the first pumping period ( 0 to $700 \mathrm{~d}$ at $300 \mathrm{gpm}=1635.3 \mathrm{~m}^{3} / \mathrm{d}$ ), this implied a mean infiltration rate of 
$910.3 \mathrm{~m}^{3} / \mathrm{d}$ over the length of the ditch (ignoring evapotranspiration) and a loss of 725.0 $\mathrm{m}^{3} / \mathrm{d}$ into the lake discharge area. For the second pumping period $(700 \mathrm{~d}$ to $16 \mathrm{y}$ at 600 gpm $=3270.6 \mathrm{~m}^{3} / \mathrm{d}$ ), this implied a mean infiltration rate of $1,820.6 \mathrm{~m}^{3} / \mathrm{d}$ over the length of the ditch (ignoring evapotranspiration) and a loss of $1,450.0 \mathrm{~m}^{3} / \mathrm{d}$ into the lake discharge area. These rates can be normalized to yield (a) flux per unit length of ditch $\left(\mathrm{m}^{2} / \mathrm{d}\right)$, (b) flux per unit length and width (planar area) of ditch $(\mathrm{m} / \mathrm{d}$, using an approximate ditch width of $4 \mathrm{~m}$ ), or (c) flux per unit length, width, and thickness of the upper infiltration layer (1/d). The latter specification was used in ParFlow, where the thickness of the upper infiltration layer corresponds to the vertical grid length $(\Delta \mathrm{z}=2 \mathrm{~m})$ at the top boundary in the model. For estimated ditch and playa areas of $6,680 \mathrm{~m}^{2}$ and $92,000 \mathrm{~m}^{2}$ respectively, flux inputs (b, above) of 0.136 and $0.273 \mathrm{~m} / \mathrm{d}$ for the ditch and $0.0079 \mathrm{~m} / \mathrm{d}$ and $0.0158 \mathrm{~m} / \mathrm{d}$ for the playa were calculated. This resulted in normalized infiltration rates (c, above) of $0.0681 \mathrm{~d}^{-1}$ and $0.1363 \mathrm{~d}^{-1}$ for the ditch and $0.00394 \mathrm{~d}^{-1}$ and $0.00788 \mathrm{~d}^{-1}$ for the lake, which were input into the ParFlow model.

As a conservative assumption, flows into the lake discharge area were assumed to completely infiltrate without any surface accumulation or evaporative losses. This is clearly an exaggeration, as the potential for evaporation and low infiltration rates seem quite plausible in the lake, as based upon observations of the retention of precipitation in Frenchman Lake. But in the absence of any data, the assumption was regarded as providing an end-member case in the range of potential infiltration scenarios.

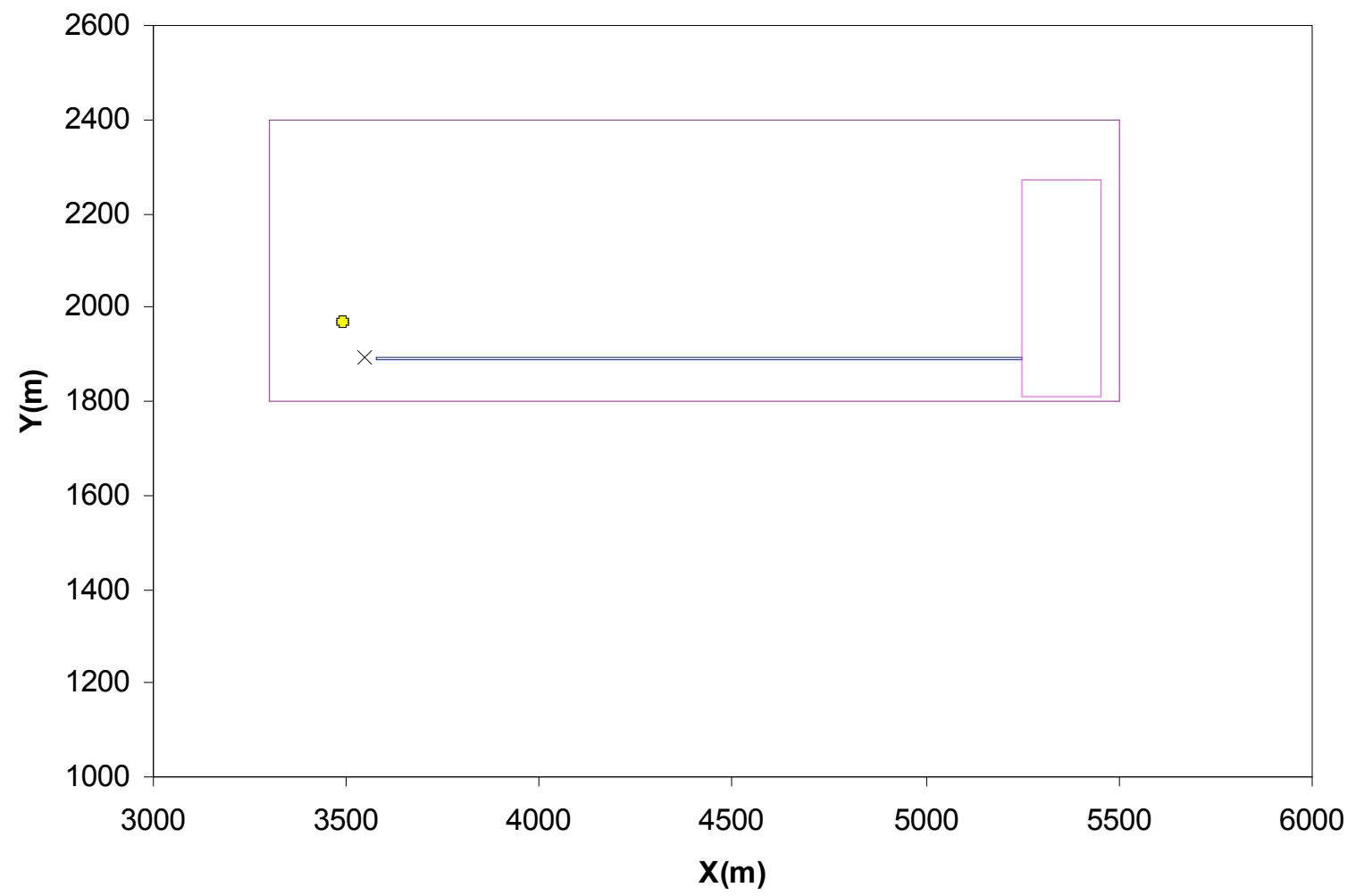

Figure 5.10 Location of the ditch and playa influx boundaries in the ParFlow model. The location of $\mathrm{U}-5 \mathrm{e}$ (filled circle), RNM-2S (x), and the fine-mesh region (inside the rectangular area) are also shown. Coordinates are in meters and are local to the model domain. 
Initially, an abbreviated transient model taking into account only the wellpumping scenario was developed. This model was pursued to rapidly examine the sensitivity of the simulations to heterogeneity and its influence in controlling tracer breakthrough at RNM-2S. The model used the same domain size as the steady-state model and excluded, for computational efficiency, infiltration and recharge under the ditch and lake. For model calibration purposes, the CAMBRIC-specific ${ }^{3} \mathrm{H}$ inventory estimated in Hoffman et al. (1977) was used. Fifteen realizations of the conductivity on the high-resolution area of the model were generated and used to develop a flow and transport model to yield the breakthrough of ${ }^{3} \mathrm{H}$ at RNM-2S for comparison with the observations. Figure 5.11 shows these breakthrough curves. Two realizations provided equally good fits to the observations but only one (R6) provided an equally good fit to the observed drawdown and was chosen as a "base case realization" (Figure 5.12). This realization (R6) was then used to develop the complete transient flow model and forecast the HST during the $1,000 \mathrm{y}$ following the test.

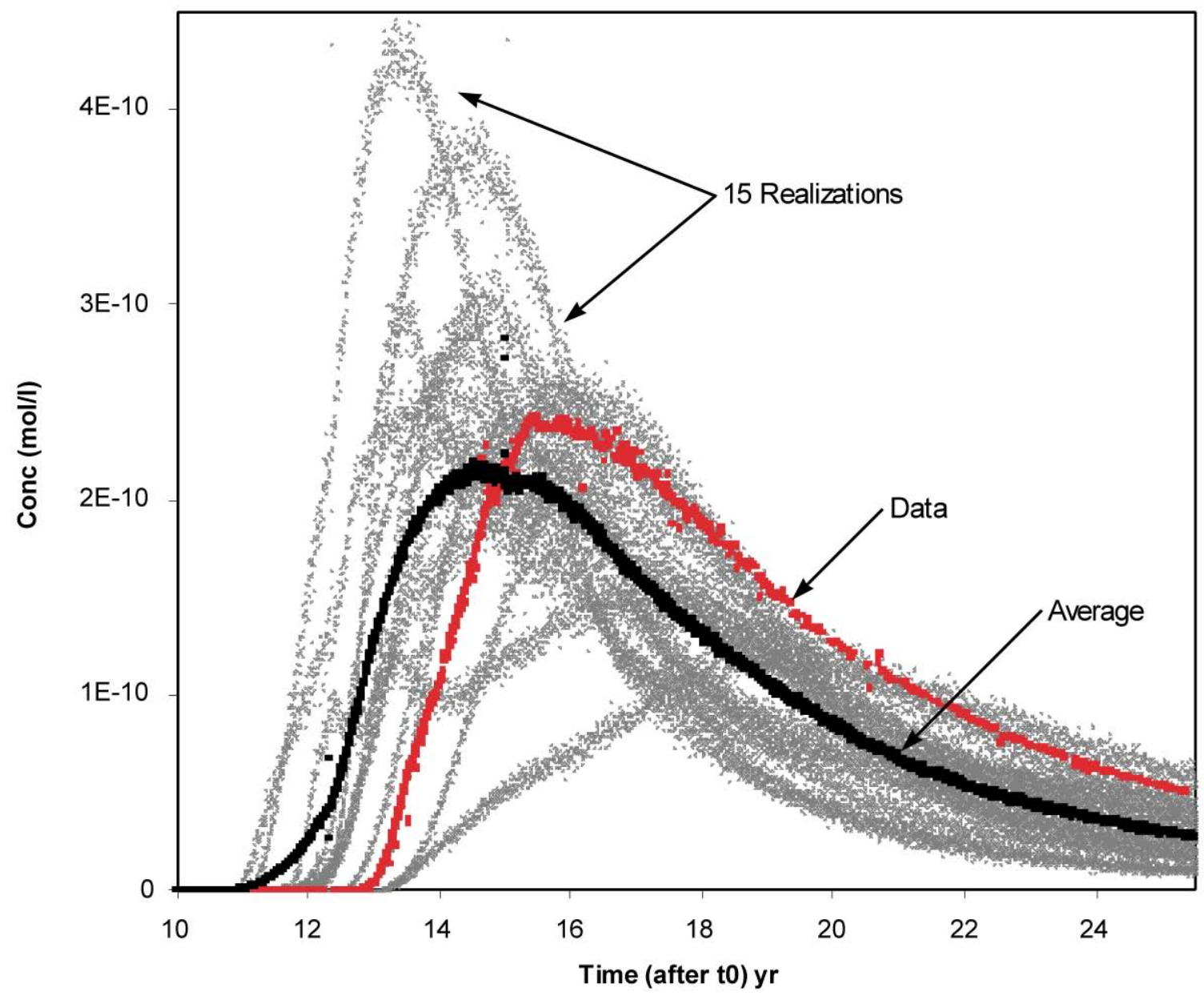

Figure 5.11 Observed (red) and simulated (gray) breakthrough of ${ }^{3} \mathrm{H}$ at RNM-2S based upon 15 realizations of hydraulic conductivity in the fine resolution area of the ParFlow model. The black curve represents the average of the 15 simulated curves. "Recirculation" effects, as discussed in Section 5.3.3 of this report, were not included in the simulations. 


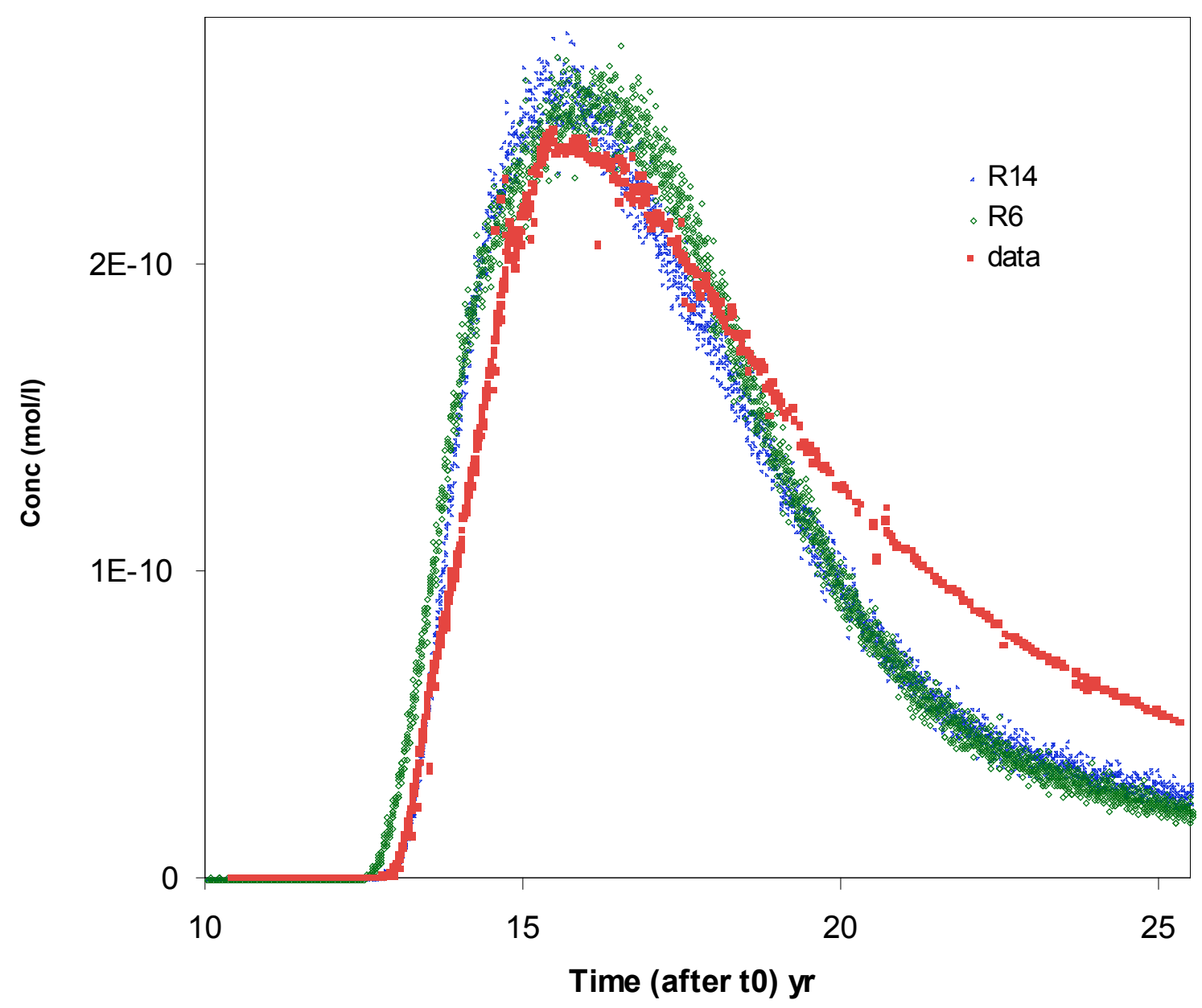

Figure 5.12 Observed (red) and simulated breakthrough of ${ }^{3} \mathrm{H}$ at RNM-2S for the two best-fit realizations, R14 (blue) and R6 (green), of hydraulic conductivity in the fine resolution area of the ParFlow model. "Recirculation" effects, as discussed in Section 5.3.3, were not included in the simulations. 


\subsection{Flow and Transport Model Simulation of the RNM Experiment}

\subsubsection{Basic Hydraulic Results}

The combined transient ParFlow/SLIM model was run to simulate flow and radionuclide transport behavior for 1,000 y after the CAMBRIC test. This was done in five distinct steps, with the flow conditions and radionuclide distributions at the end of each step serving as initial conditions for the next step:

(1) In the first step, the steady-state flow model (with no pumping or infiltration boundary conditions) was used to simulate radionuclide migration away from the initial RST configuration in the cavity and exchange volume system (described in Section 4.8.2.3) for the first $10.4 \mathrm{y}$ after the test.

(2) In the second step, the pumping well was operated at the 300-gpm rate for $700 \mathrm{~d}$. The pumping well effluent and dissolved radionuclides entrained within it were discharged to the ditch and lake impoundment areas and allowed to infiltrate as described in Section 5.2.3.

(3) In the third step, the pumping rate was increased to the final 600 -gpm rate and was run for an additional 4,853 d (completing over $15 \mathrm{y}$ of steady pumping). ${ }^{2}$ The pumping effluent and entrained radionuclides were discharged to the ditch and lake impoundment areas, infiltrating as described in Section 5.2.3. Figure 5.13 shows a saturation solution during this step.

(4) In the fourth step, following the cessation of pumping, a 40-y recession period was simulated in which residual saturation in the unsaturated zone underlying the ditch and lake discharge areas was allowed to drain, and the accumulated or "mounded" water on the water table was allowed to dissipate. Over this period, the flow system effectively relaxed to its ambient, steady-state condition (as in step 1).

(5) In the last step of the simulation, the steady-state flow model was used to further simulate radionuclide migration behavior for the remaining $935 \mathrm{y}$ of the timeframe.

\footnotetext{
${ }^{2}$ Minor (approximately $1 \mathrm{~d}$ ) interruptions in the pumping schedule during the experiment were not simulated.
} 


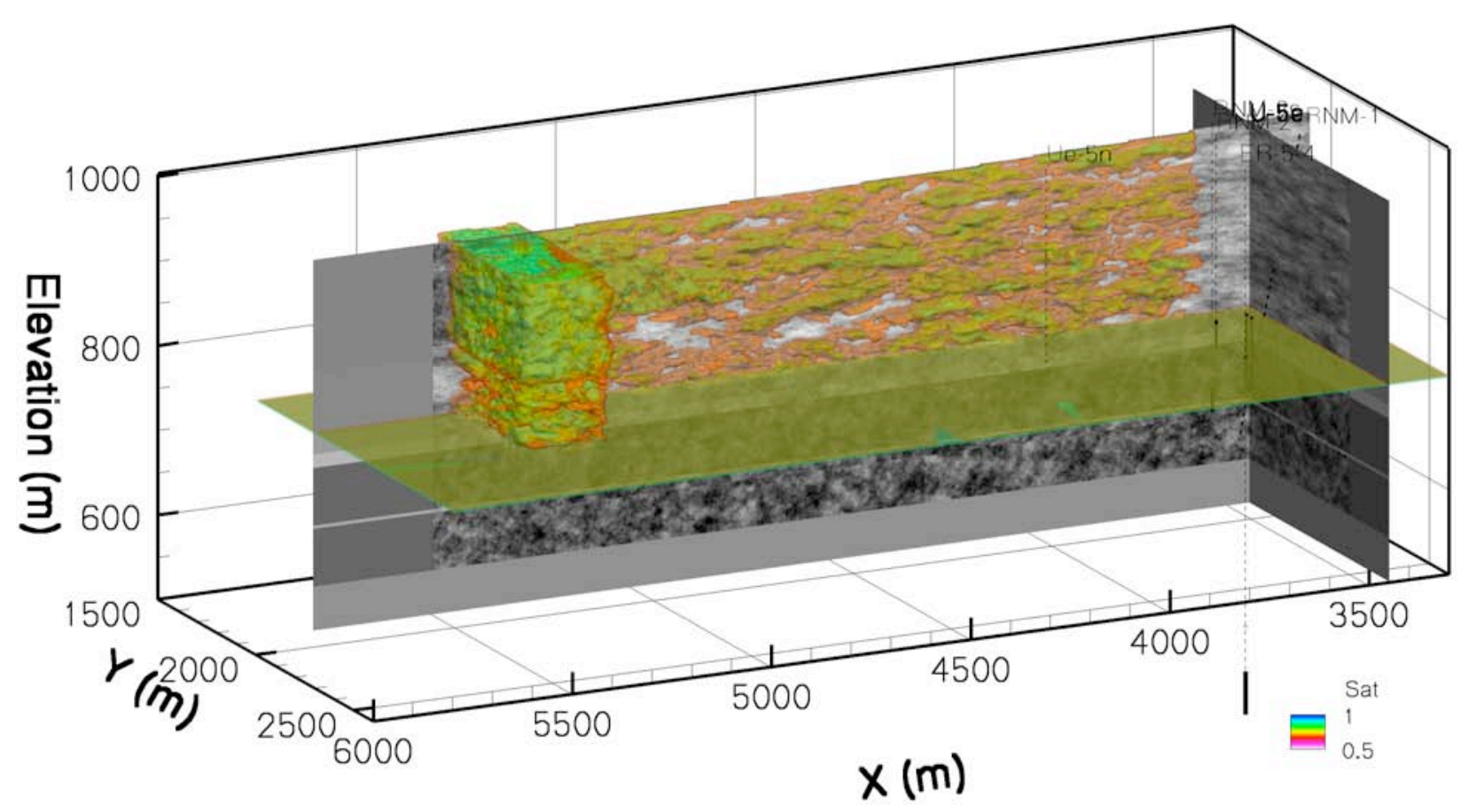

Figure 5.13 Simulated saturation profile after 8 y of pumping and ditch infiltration (1983).

The water levels in the pumping well RNM-2S and surrounding wells were tracked over the course of the simulation. A plot of water level over time for the main wells in the vicinity of the CAMBRIC test may be found in Figure 5.14. The effect of drawdown in ER-5-4, ER-5-4 piezometer, and UE-5n may be seen in three distinct stages in this figure. The first stage corresponds to the 300-gpm pumping stage with each well exhibiting a different response related to distance and local heterogeneity. The second stage corresponds to the 600 -gpm pumping period and is similar in character to the first pumping stage but with a larger drawdown. Around 1980, the infiltration front from the ditch reaches the water table and all the wells exhibit a clear but differing response to an accumulating groundwater mound under the ditch, with UE-5n almost returning to its original ambient water level. After pumping ceases, all wells exhibit continued mounding as the vadose zone below the ditch continues to drain, with UE-5n again exhibiting the largest response. Figure 5.15 compares the observed water levels in UE-5n with the ParFlow simulation. The data before 1985 were deemed unreliable, due to measurement and surveying issues and a number of short-term stops and starts of the pumping well. Though the static water levels differ slightly, the response simulated by ParFlow is quite similar to the observed response during the recession and drainage phase after 1985. 
CHAPTER 5: HYDROLOGIC SOURCE TERM MODELS

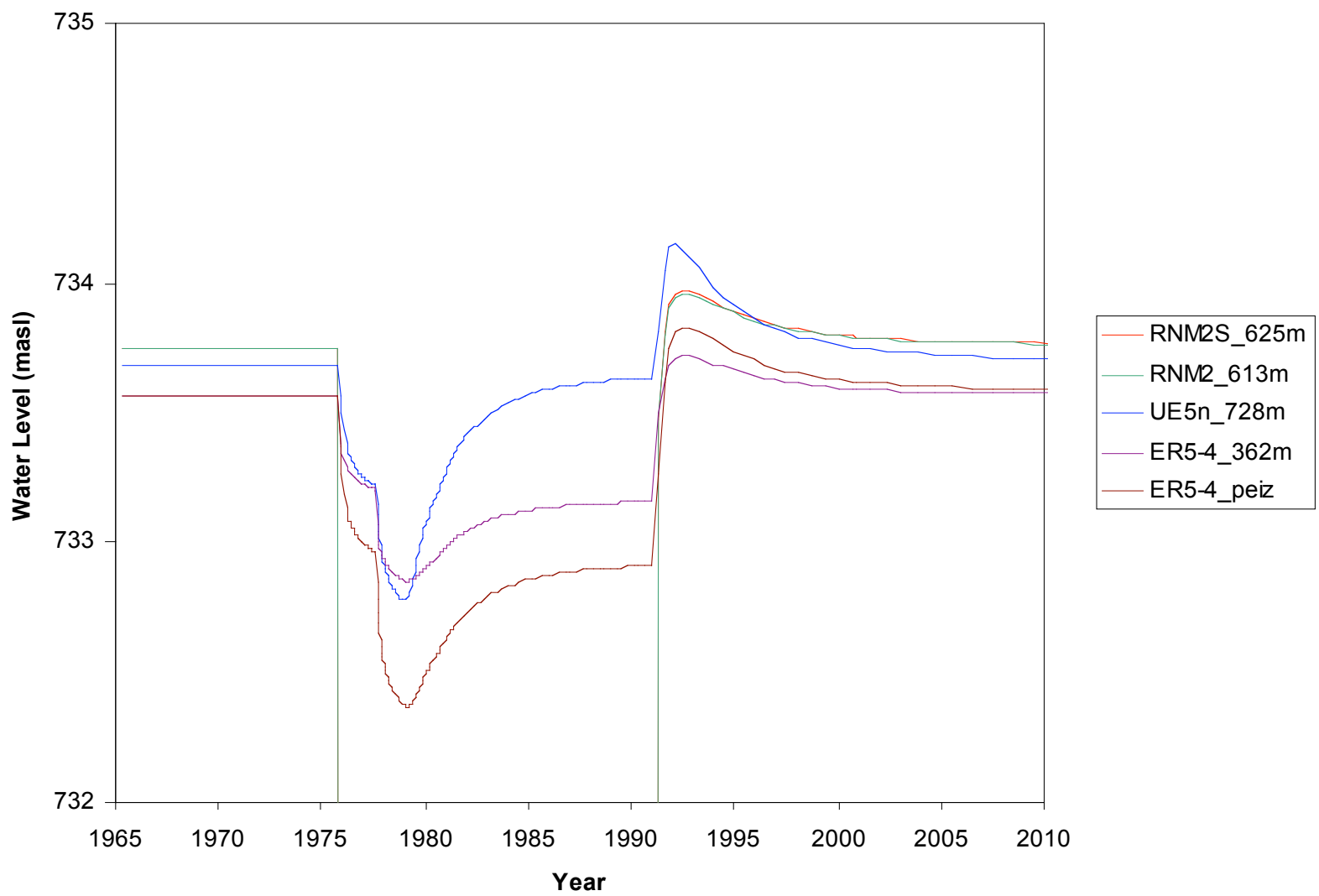

Figure 5.14 Simulated water levels at various depths in UE-5n, RNM-2S, and ER-5-4. 


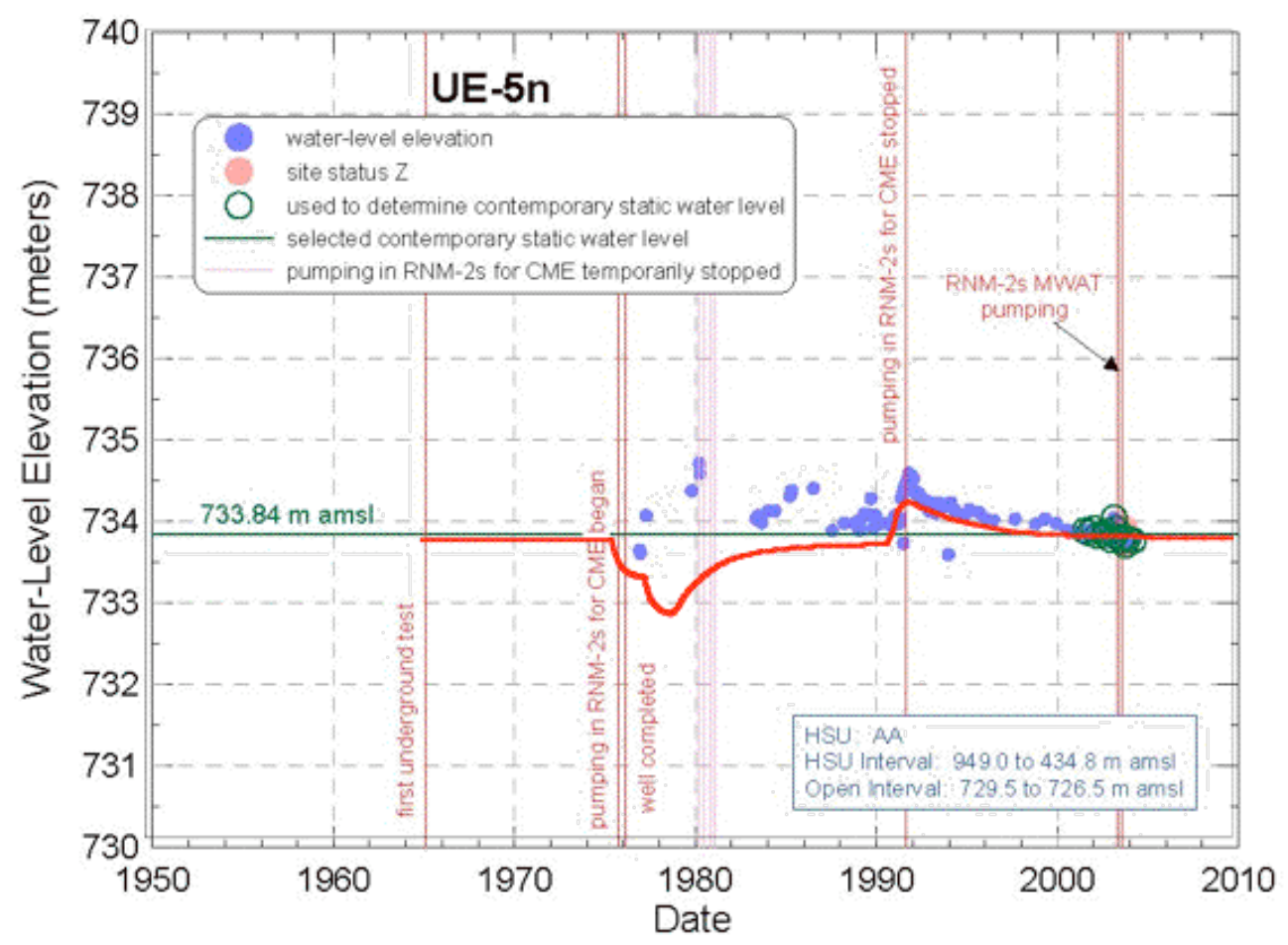

Figure 5.15 Observed and simulated water levels at UE-5n, located $106 \mathrm{~m}$ from the ditch. Observed values are plotted as symbols and the solid red line is the ParFlow simulation. Figure modified from Stoller-Navarro (2004a).

The ParFlow model was interrogated to generate velocity information for Layers AL2a and AL2b. Steady-state velocities in the in the $y$ direction in Layer 2b center around a median of $22 \mathrm{~m} / \mathrm{y}$ and range from 1 to $70 \mathrm{~m} / \mathrm{y}$. The $y$ velocities in Layer $2 \mathrm{a}$ are lower and range from 0.5 to $20 \mathrm{~m} / \mathrm{y}$. Velocities increased due to pumping and ditch infiltration and were as much as a factor of 5 larger during pumping and a factor of 3 larger during recession than steady-state values.

Figure 5.16 shows the velocity in the $x, y$, and $z$ directions at two points (730-m elevation, denoted at the water table, and 70-m elevation, denoted at $2 \mathrm{~b}$ ) along the middle of the ditch and $10 \mathrm{~m}$ downgradient. Because the velocities are point values and the points are essentially chosen at random, the steady-state velocity for the point in Layer $2 \mathrm{~b}$ is actually slower than the point near the water table. This figure illustrates trends in the velocity over time for an entire alluvial layer. Note the large $z$ velocity near the water table during pumping and recession, the increase in $y$ velocities with pumping and recession, and that the $x$ and $z$ velocities return to near zero values after the influence of pumping is over. 


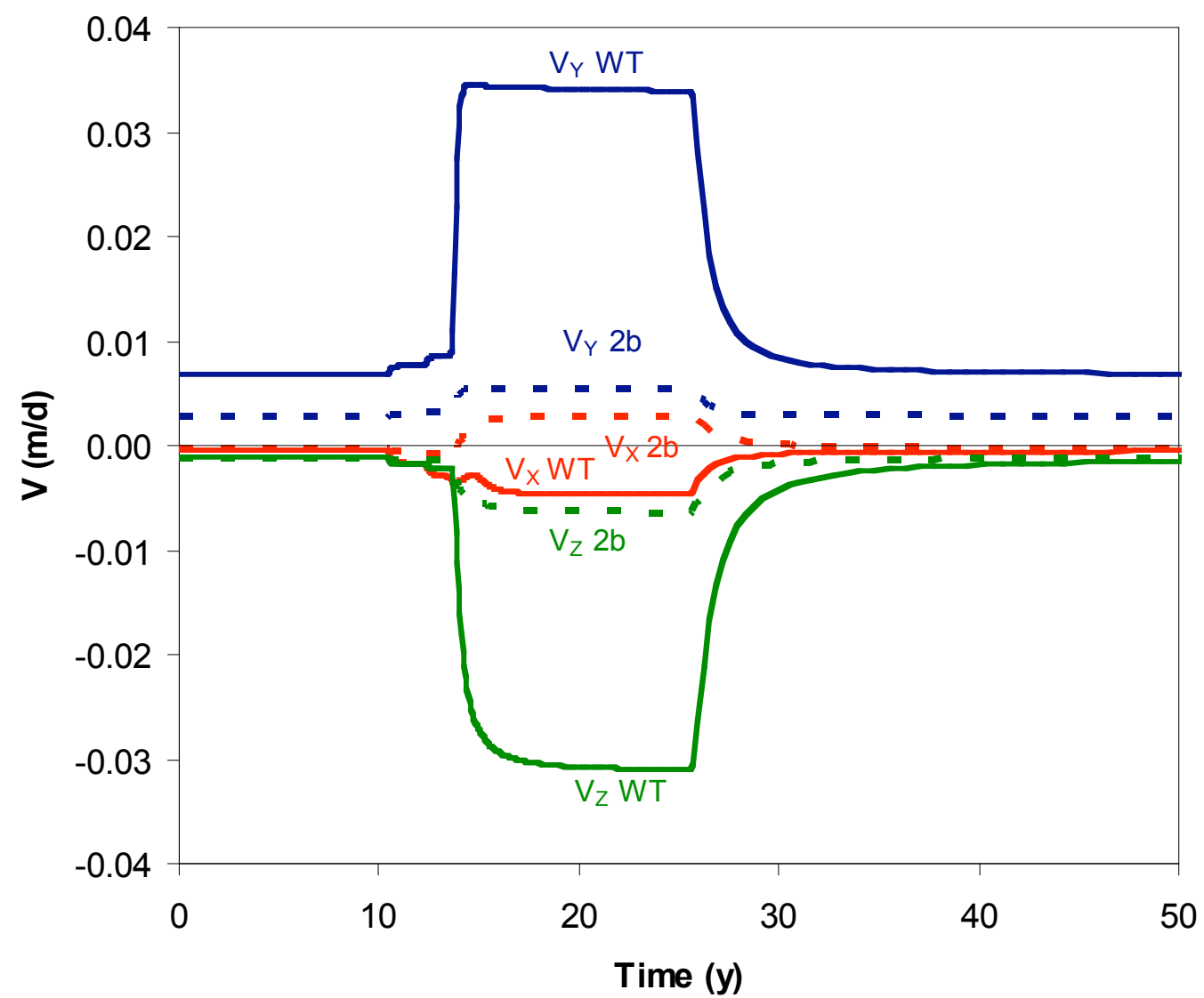

Figure 5.16 Plot of $x, y$, and $z$ velocities with time for two locations at the water table (WT) and in layer AL2b (2b).

Figure 5.17 shows the change in $x$ and $y$ velocities for three wells-UE-5n, ER-5-4, and ER-5-4 piezometer. This figure plots point values at the $x-y$ locations for those wells at the elevation listed, not over the entire screen (these locations correspond to the locations shown in Figure 5.14). It should be noted that the location for ER-5-4 is in the coarse mesh portion of the domain, so those velocities do not vary with depth and are not influenced by the heterogeneity introduced in the fine-mesh region of the domain. This figure clearly shows the large transient variations in velocities experienced at those locations due to pumping and drainage of the vadose zone. 


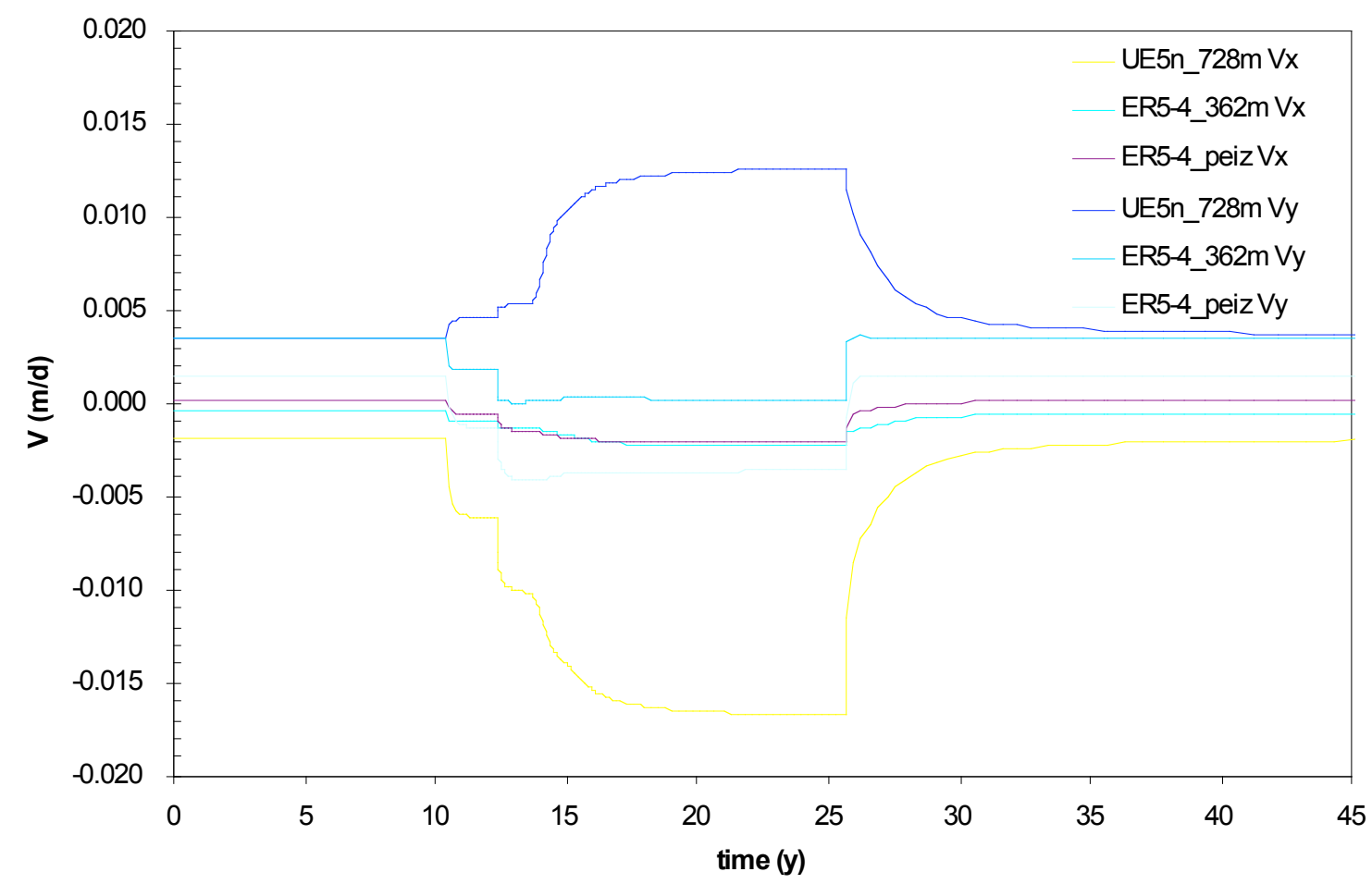

Figure 5.17 Plot of $x$ - and $y$-direction velocities in three wells surrounding the CAMBRIC test.

\subsubsection{Simulation of Radionuclide Transport to RNM-2S}

A suite of radionuclide classes, that is radionuclide isotopes that are grouped by similar transport parameters (discussed in Section 4.8.2.3), were used to simulate transport from CAMBRIC to RNM-2S, into the ditch, and back into groundwater. Radionuclide classes (e.g., U) were assigned using aggregates of radionuclides derived from the Bowen et al. (2001) source term, which is averaged over all the tests in the Frenchman Flat CAU. As mentioned in Section 5.2.4, ${ }^{3} \mathrm{H}$ transport was also simulated to compare to ${ }^{3} \mathrm{H}$ observations at RNM-2S during the RNM experiment. This simulation used a CAMBRIC-specific ${ }^{3} \mathrm{H}$ estimated inventory from Hoffman et al. (1977). For all transient transport simulations the ParFlow/SLIM model was used to simulate and track transport away from CAMBRIC; breakthrough at RNM-2S, re-introduction of mass into either the ditch or lake discharge zone (using the flow rates detailed in Section 5.2.3 to distribute radionuclide mass); transport in the vadose zone; and transport in the saturated zones underlying the ditch and playa with potential for subsequent recapture (or recycling) of mass at RNM-2S. Breakthrough curves at RNM-2S and all other wells were generated, along with accounting for mass crossing several breakthrough planes.

The ${ }^{3} \mathrm{H}$ breakthrough results at RNM-2S (using the Hoffman et al., 1977, estimated CAMBRIC-specific inventory) are shown in Figure 5.18. Here, the simulated ${ }^{3} \mathrm{H}$ breakthrough is compared to the breakthrough with no ditch or recycling of mass (the same result shown in Figure 5.17), a ditch-only simulation using the observed breakthrough as a ditch source, and the observations of ${ }^{3} \mathrm{H}$ in RNM-2S during the 
migration experiment. The transient vadose-zone breakthrough curve clearly shows the influence of the ditch-playa infiltration and recapture in RNM-2S on the breakthrough curve. Enhanced tailing begins around $18 \mathrm{y}$ and reaches a maximum around $20 \mathrm{y}$ after the test. The ditch-only curve confirms this effect.

\subsubsection{Analysis of Radionuclide Recirculation}

Because the SLIM model is based upon a Lagrangian, particle-based transport algorithm (Pawloski et al., 2001, Appendix D), an incremental "particle counter" attribute was implemented. This attribute's purpose was to determine if (and how often) particles associated with any radionuclide class are captured in RNM-2S, discharged into the ditch, and eventually recaptured in RNM-2S, establishing a pattern of recirculation. This process has been suggested in recent isotopic measurements (Tompson et al., 2006).

The results of the ${ }^{3} \mathrm{H}$ "counter" are shown in Figure 5.19. Here, it is clear that a majority of the initial mass is simulated to have broken through in RNM-2S (corresponding to a value of 1 on the $x$-axis) and a smaller fraction made multiple passes between the pumping well and ditch-lake system (corresponding to values greater than 1 on the $x$-axis). The simulation results shown in this figure also indicate that a small fraction of ${ }^{3} \mathrm{H}$ mass has been captured by RNM-2S as many as five times (thus recirculating as many as four times).

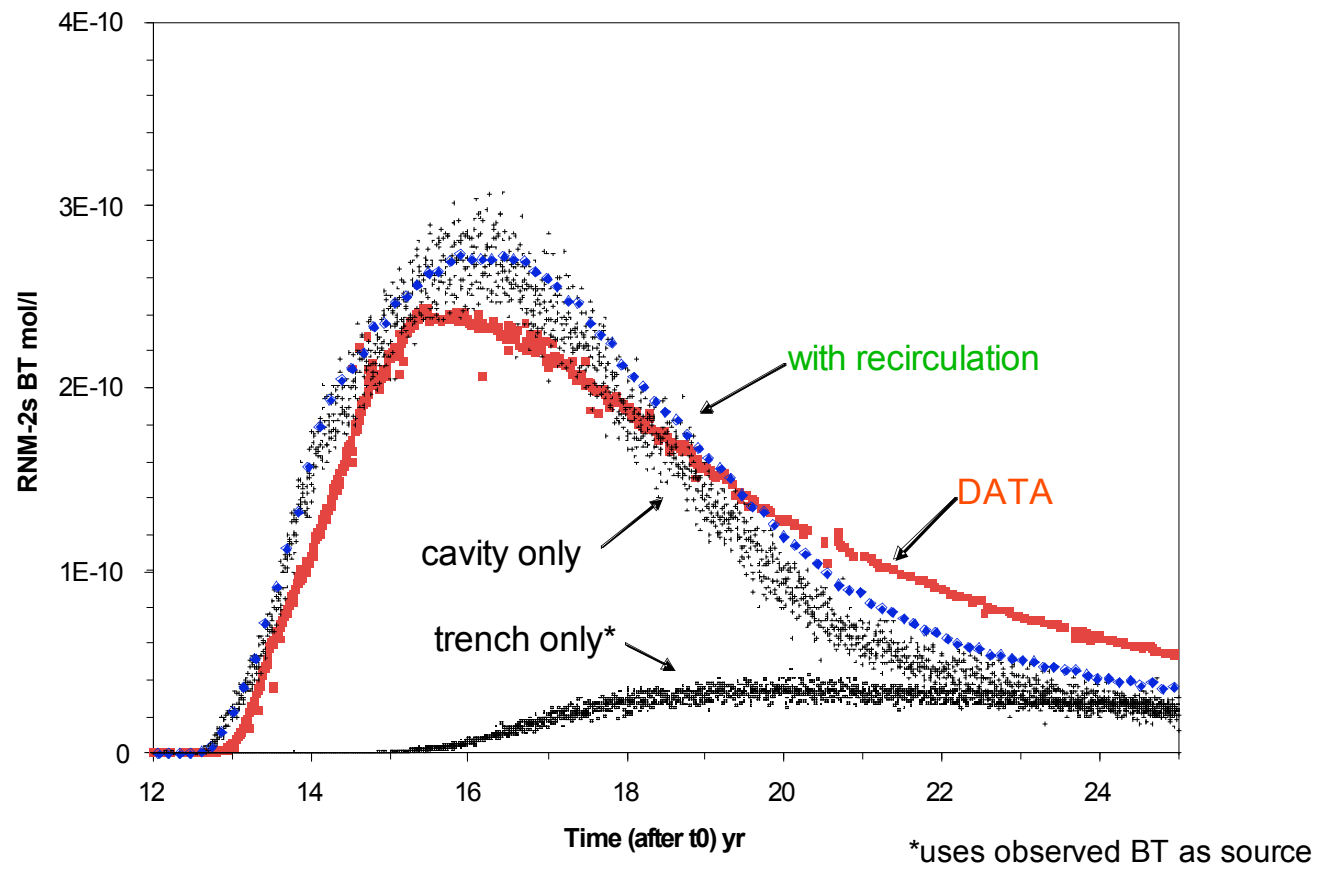

Figure 5.18 Simulated and observed ${ }^{3} \mathrm{H}$ breakthrough at RNM-2S. Simulated breakthrough sources include the cavity, the ditch only, and mass that has recycled through the well-ditch system. Note the ditch-only source uses the observations as a ditch initial concentration. 


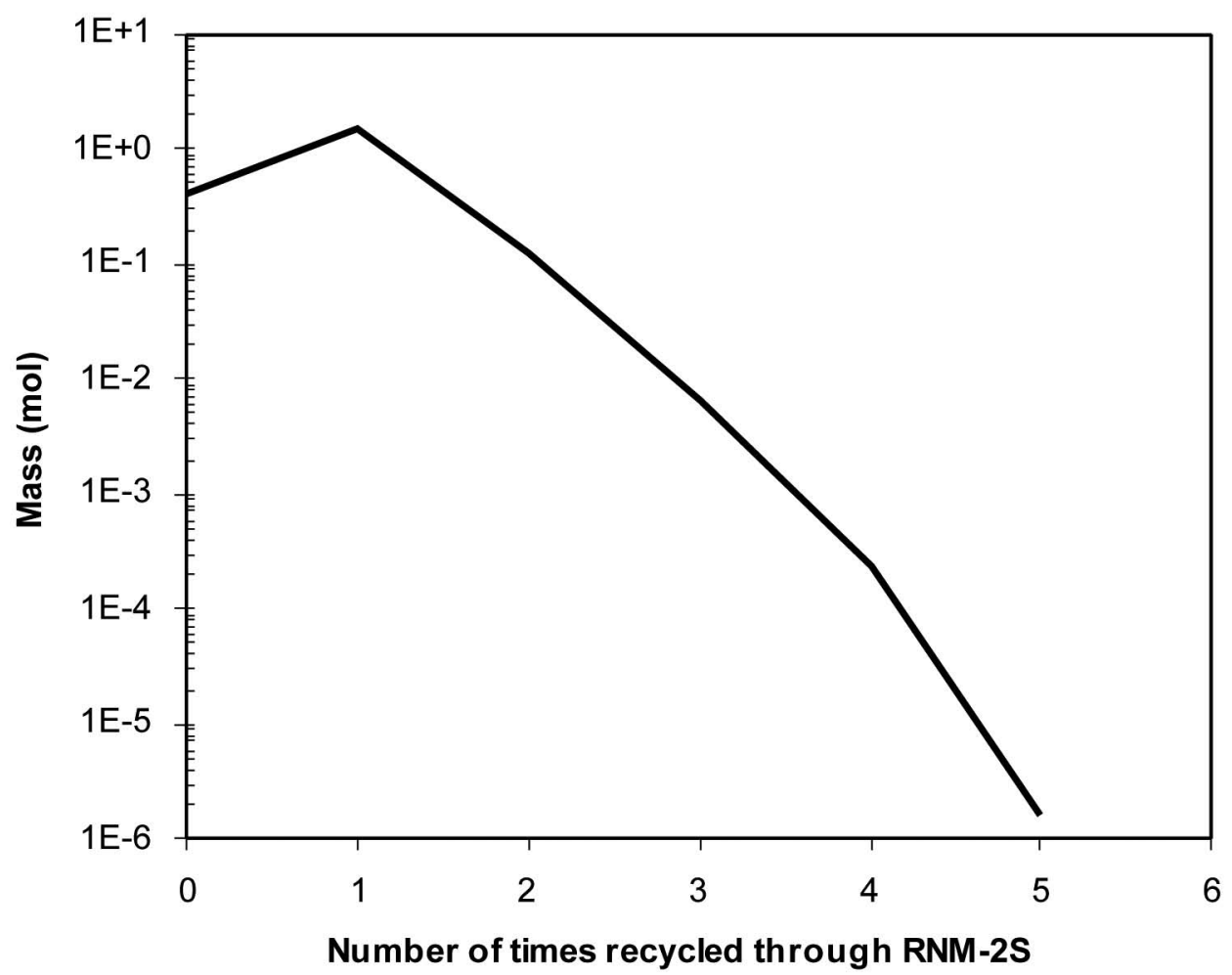

Figure 5.19 Mass (in moles) of ${ }^{3} \mathrm{H}$ simulated to have been entrained in pumping well RNM-2S. Mass is the fraction of the total source term used from Bowen et al. (2001). A zero value indicates mass of ${ }^{3} \mathrm{H}$ that did not breakthrough in RNM-2S. (Note the log scale.)

Thirteen radionuclide classes (identified in Table 4.10) composed of two tracer classes (TracerL and TracerR), eight sorbing radionuclides not decayed during the simulation ( $\mathrm{Ca}, \mathrm{Cs}, \mathrm{Eu}, \mathrm{Ni}, \mathrm{Pu}, \mathrm{Sm}, \mathrm{Sr}$, and $\mathrm{U})$, and three sorbing members of a decay chain that required real-time calculation of ingrowth and decay $\left(\mathrm{Am}, \mathrm{Np}\right.$, and $\left.{ }^{241} \mathrm{Pu}\right)$ were included in simulations. Of these radionuclide classes, most did not break through at RNM-2S at all during the pumping phases of the calculation. The tracers (TracerR and TracerL) were the most mobile and exhibited both the largest breakthrough and the greatest overall extent of migration. Figure 5.20 plots the simulated breakthrough in RNM-2S for the four radionuclide classes that were captured (TracerR, TracerL, Np, and $\mathrm{U})$. All other radionuclides were not captured by RNM-2S in the transport simulation. 


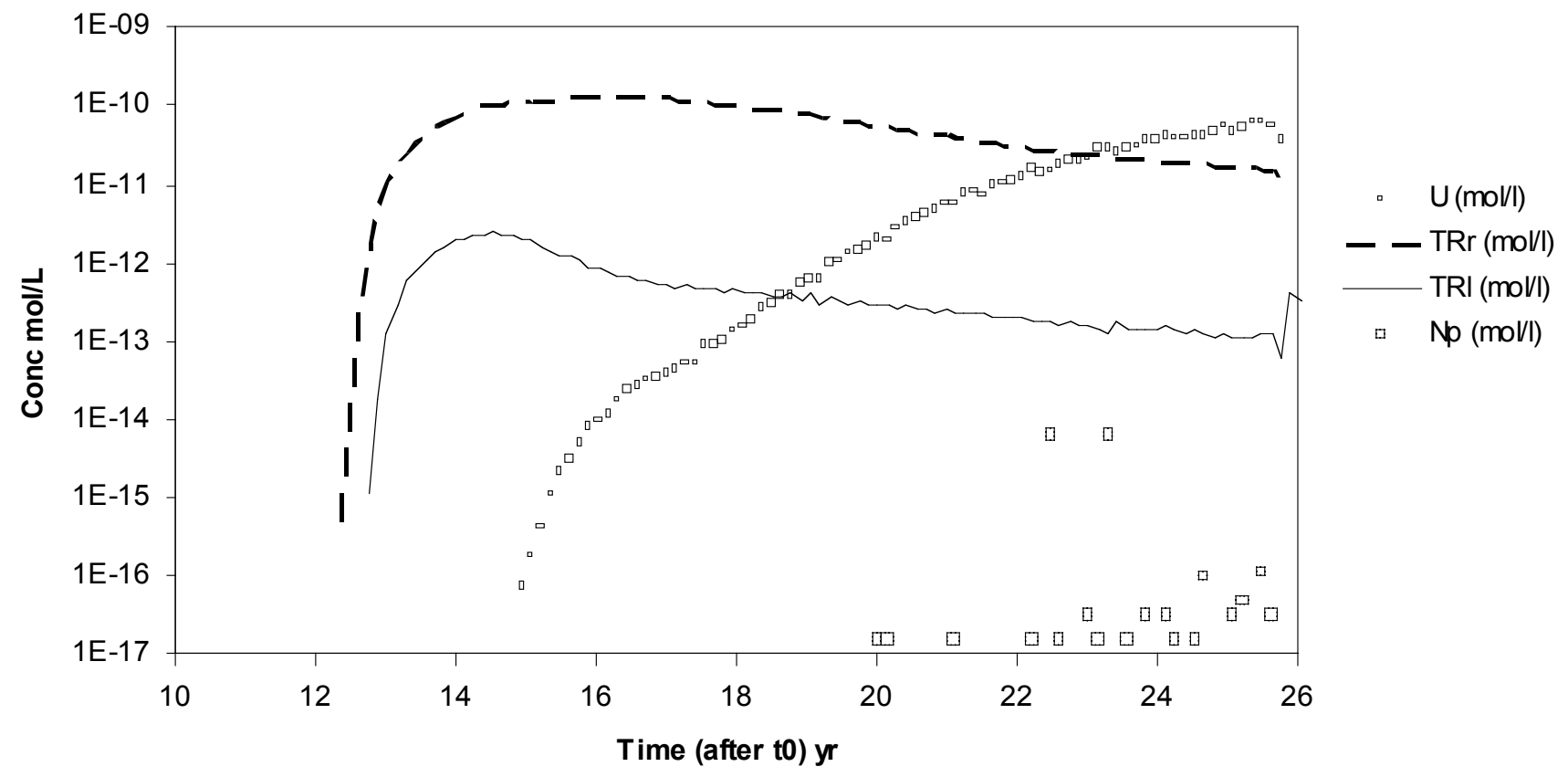

Figure 5.20 Plot of radionuclide concentration over time for four radionuclide classes (TracerR, TracerL, Np, and U) in pumping well RNM-2S.

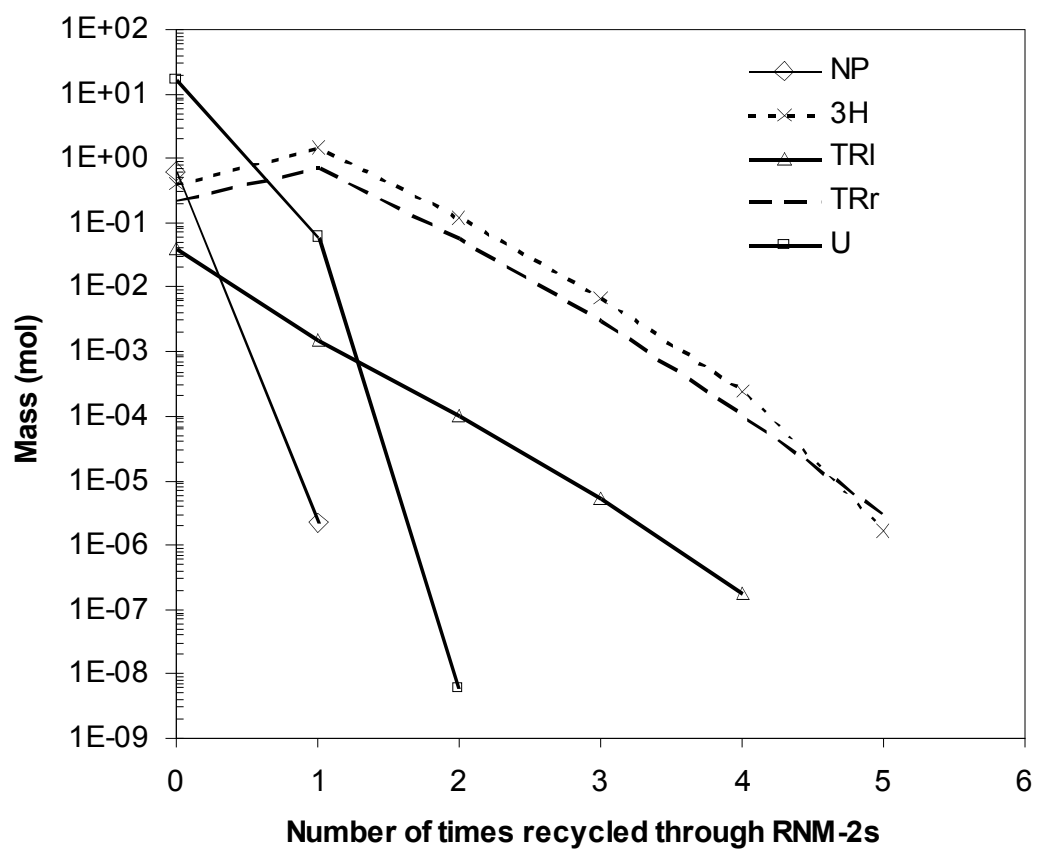

Figure 5.21 Plot of total radionuclide mass as a function of number of times it arrived at RNM-2S. Mass totals to the initial condition in cavity, altered zone, and melt glass. Mass corresponding to a zero on the $x$-axis never reaches the well, and mass plotted two or greater on the $x$-axis recycles between the well and ditch. 
Recirculation was analyzed for those four radionuclide classes exhibiting breakthrough at RNM-2S, and the results are plotted in Figure 5.21. This figure is very similar to 5.19 and shows similar results. Both tracers, TracerR and TracerL, are recaptured by RNM-2S a large number of times ( 4 and 3, respectively) and similar to ${ }^{3} \mathrm{H}$ in Figure 5.19, recycling (or recapture) of mass would have a significant effect on the breakthrough in RNM-2S. Two sorbing radionuclide classes, $\mathrm{U}$ and $\mathrm{Np}$, also show effects of capture in RNM-2S, although only $\mathrm{U}$ is recaptured after migrating back through the ditch and vadose zone, and only a very small quantity of mass is recaptured.

\subsubsection{Simulated Radionuclide Breakthrough at RNM-2S}

Figure 5.22 presents the simulated breakthrough of all 36 radionuclides included in both NUFT/CRUNCH and ParFlow/SLIM simulations, using the average Frenchman Flat RST from Bowen et al. (2001). Decay is included for all radionuclides in these results. Of the 36 radionuclides, 12 radionuclides never reached RNM-2S during the $15 \mathrm{y}$ of pumping. Furthermore, only trace amounts of the various $\mathrm{Pu}$ isotopes were predicted to reach RNM-2S, and only in the NUFT/CRUNCH model. In effect, $\mathrm{Pu}$ breakthrough is negligible.

It should be noted that several radionuclides were predicted to migrate to RNM-2S due to the conservative nature of some assumptions. For example, ${ }^{14} \mathrm{C}$ is likely to be at least weakly retarded. However, sufficient sorption data were not available to quantitatively include retardation effects in the simulations. Radionuclides ${ }^{93} \mathrm{Zr},{ }^{94} \mathrm{Nb}$, ${ }^{107} \mathrm{Pd},{ }^{121} \mathrm{Sn}$, and ${ }^{126} \mathrm{Sn}$ were also treated as non-sorbing tracers though their retardation is likely to be quite high. Like the ${ }^{14} \mathrm{C}$ case, sufficient data were not available to quantify their retardation behavior in the simulations. These radionuclides were treated as nonsorbing tracers to avoid possible underprediction of transport (i.e., these are conservative transport estimates).

Based on the simulated breakthrough at RNM-2S, and realizing the simplifying assumption made regarding retardation of certain radionuclides, a list of radionuclides relevant to the more than 15-y RNM experiment can be made. Of the 24 radionuclides predicted to reach $\mathrm{RNM}-2 \mathrm{~S}$, the breakthrough of all $5 \mathrm{Pu}$ isotopes can be considered negligible. Furthermore, ${ }^{93} \mathrm{Zr},{ }^{94} \mathrm{Nb},{ }^{107} \mathrm{Pd},{ }^{121} \mathrm{Sn}$, and ${ }^{126} \mathrm{Sn}$ are, in reality, significantly retarded and not likely to have reached RNM-2S. Thus, the total number of radionuclides likely to have reached $\mathrm{RNM}-2 \mathrm{~S}$ is 14 . They include ${ }^{3} \mathrm{H},{ }^{14} \mathrm{C},{ }^{36} \mathrm{Cl},{ }^{39} \mathrm{Ar}$, ${ }^{85} \mathrm{Kr},{ }^{99} \mathrm{Tc},{ }^{129} \mathrm{I},{ }^{232} \mathrm{U},{ }^{233} \mathrm{U},{ }^{234} \mathrm{U},{ }^{235} \mathrm{U},{ }^{236} \mathrm{U},{ }^{238} \mathrm{U}$, and ${ }^{237} \mathrm{~Np}$. 

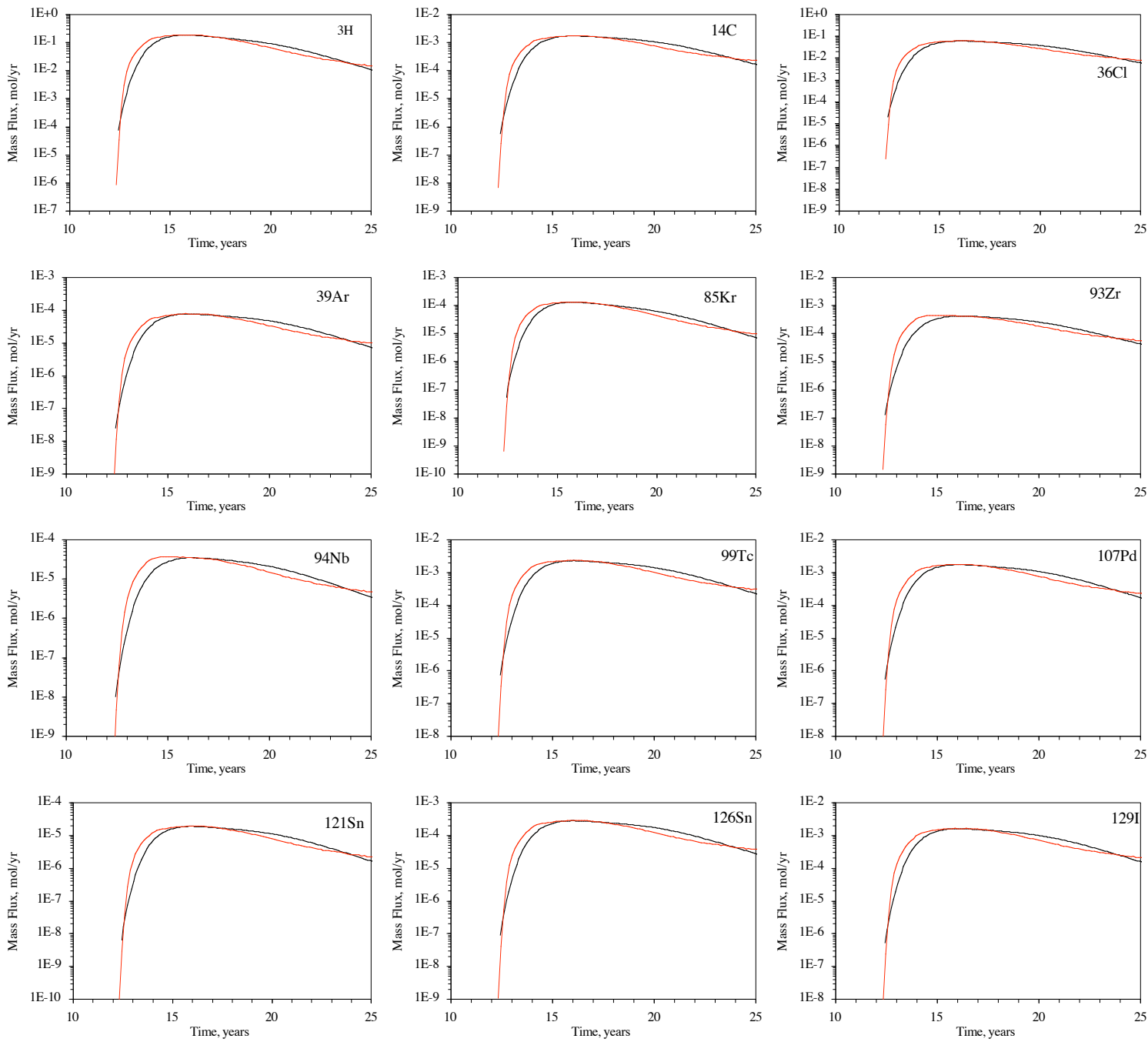

Figure 5.22a Breakthrough of radionuclides at RNM-2S from the NUFT/CRUNCH model (black) and ParFlow/SLIM model (red). Calcium-41, ${ }^{59} \mathrm{Ni},{ }^{63} \mathrm{Ni},{ }^{90} \mathrm{Sr},{ }^{135} \mathrm{Cs},{ }^{137} \mathrm{Cs},{ }^{151} \mathrm{Sm},{ }^{150} \mathrm{Eu},{ }^{152} \mathrm{Eu},{ }^{154} \mathrm{Eu}$, ${ }^{166} \mathrm{Ho}$, and ${ }^{241} \mathrm{Am}$ radionuclides had no breakthrough in either model. All calculations used the RST from Bowen et al. (2001). 

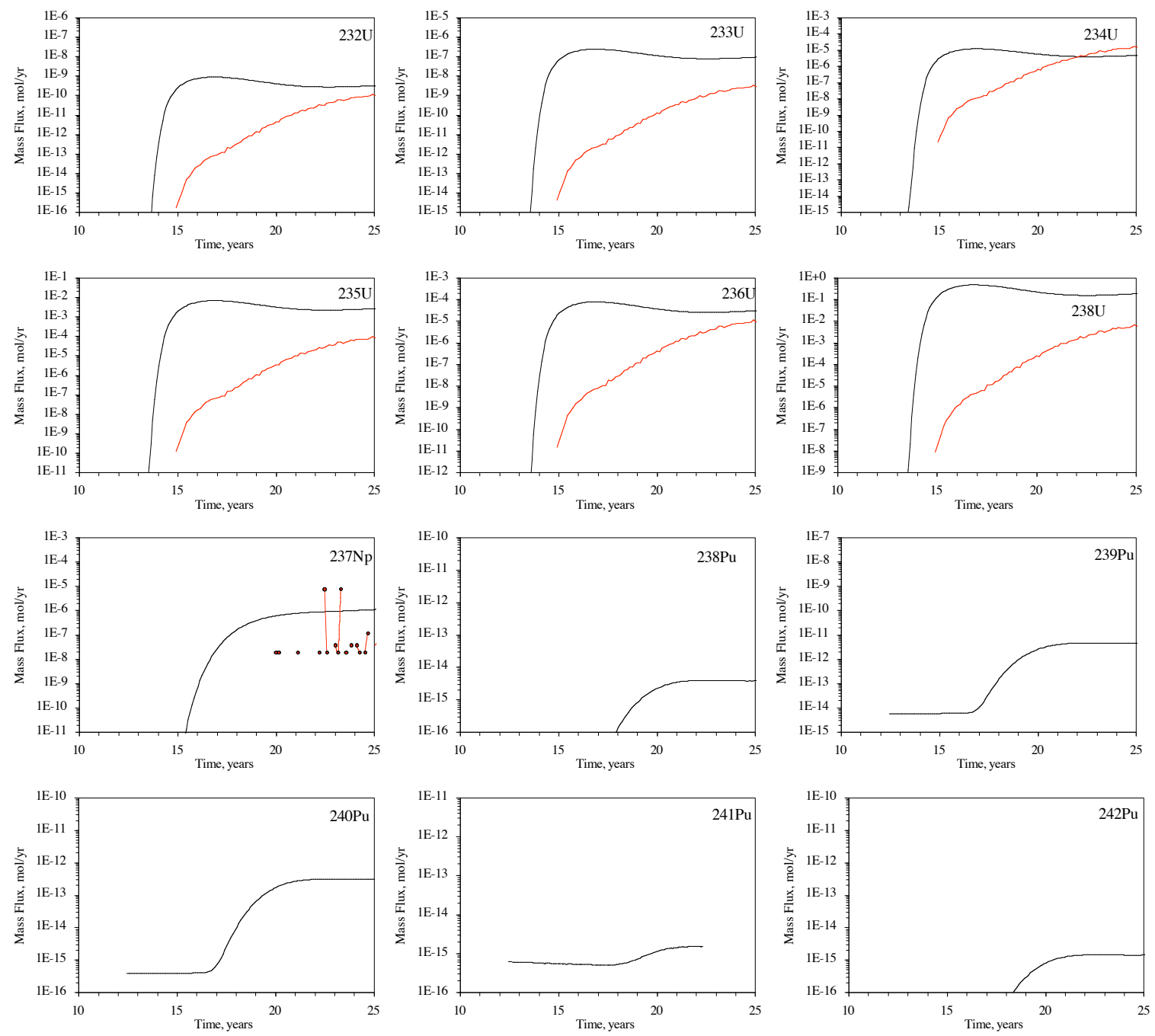

Figure 5.22b Breakthrough of radionuclides at RNM-2S from the NUFT/CRUNCH model (black) and ParFlow/SLIM model (red). Calcium-41, ${ }^{59} \mathrm{Ni},{ }^{63} \mathrm{Ni},{ }^{90} \mathrm{Sr},{ }^{135} \mathrm{Cs},{ }^{137} \mathrm{Cs},{ }^{151} \mathrm{Sm},{ }^{150} \mathrm{Eu},{ }^{152} \mathrm{Eu},{ }^{154} \mathrm{Eu}$, ${ }^{166} \mathrm{Ho}$, and ${ }^{241} \mathrm{Am}$ radionuclides had no breakthrough in either model. All calculations used the RST from Bowen et al. (2001).

It is useful to plot the breakthrough results in terms of a curie flux at RNM-2S. These breakthroughs are shown in Figures 5.23a through 5.23c. As in past HST models (e.g., Pawloski et al., 2001), curie flux is subdivided into alpha-decaying radionuclides, beta-decaying radionuclides, and radionuclides that undergo electron capture or isomeric transition (EC/IT). It is relevant to group the RST radionuclide by their mode of decay to identify the dominant source of activity. It is also relevant for identifying the radionuclides of greatest significance as source terms deposited in the CAMBRIC ditch.

For alpha-decaying radionuclides, the $\mathrm{U}$ isotopes provide the largest activity at RNM-2S during pumping. However, groundwater near the CAMBRIC test has an average natural $\mathrm{U}$ concentration of $4 \mu \mathrm{g} / \mathrm{L}$. Based on natural $\mathrm{U}$ isotope ratios, this 
produces an activity of $1.33,0.06$, and $1.32 \mathrm{pCi} / \mathrm{L}$ of ${ }^{234} \mathrm{U},{ }^{235} \mathrm{U}$, and ${ }^{238} \mathrm{U}$, respectively. At $600 \mathrm{gpm}$ this would produce a curie flux of $1.6 \times 10^{-3}, 7.1 \times 10^{-5}$, and $1.5 \times 10^{-3} \mathrm{Ci} / \mathrm{y}$ at RNM-2S for ${ }^{234} U,{ }^{235} \mathrm{U}$, and ${ }^{238} \mathrm{U}$, respectively. For each of these radionuclides and for the total alpha decay activity, this natural background is higher than the predicted activity using the Bowen et al. (2001) RST. It appears that, from an alpha activity standpoint, the activity that reaches RNM-2S is below background.

For beta-decaying radionuclides, ${ }^{3} \mathrm{H}$ provided the majority of the activity at RNM-2S during pumping. However, as ${ }^{3} \mathrm{H}$ decays, the importance of other radionuclides will increase. Interestingly, all beta-decaying radionuclides that reach RNM-2S were treated as non-sorbing tracers in the simulations (except for the negligible quantity of ${ }^{241} \mathrm{Pu}$ ). However, several of these radionuclides, namely ${ }^{93} \mathrm{Zr},{ }^{94} \mathrm{Nb},{ }^{107} \mathrm{Pd},{ }^{121} \mathrm{Sn}$, and ${ }^{126} \mathrm{Sn}$, were treated as non-sorbing tracers only because sufficient data were not available in the literature to provide retardation parameters. These radionuclides are, in fact, likely to be greatly retarded and, thus, not reach RNM-2S. As a result, beta-decaying radionuclides that reach $\mathrm{RNM}-2 \mathrm{~S}$ are likely to be ${ }^{3} \mathrm{H},{ }^{14} \mathrm{C},{ }^{36} \mathrm{Cl},{ }^{39} \mathrm{Ar},{ }^{85} \mathrm{Kr},{ }^{99} \mathrm{Tc}$, and ${ }^{129} \mathrm{I}$. In terms of a CAMBRIC ditch source, ${ }^{39} \mathrm{Ar}$ and ${ }^{85} \mathrm{Kr}$ will be lost from the RNM-2S pumped water when it is released into the CAMBRIC ditch. As a result, the beta-decaying radionuclides most relevant in terms of a CAMBRIC ditch source term are ${ }^{3} \mathrm{H},{ }^{14} \mathrm{C},{ }^{36} \mathrm{Cl}$, ${ }^{99} \mathrm{Tc}$, and ${ }^{129} \mathrm{I}$ (Guell and Hunt, 2003).

For EC/IT-decaying radionuclides, only ${ }^{121} \mathrm{Sn}$ reaches RNM-2S. It was treated as a non-sorbing tracer only because data were not sufficiently available in the literature to provide a retardation parameter. In fact, this radionuclide is likely to be significantly retarded in Frenchman Flat alluvium. As a result, it should be expected that no significant EC/IT-decaying radiologic source is likely to reach RNM-2S.

In summary, from both an activity and molar breakthrough standpoint, it appears that the most relevant radionuclides to have reached the RNM-2S pumping well are ${ }^{3} \mathrm{H},{ }^{14} \mathrm{C},{ }^{36} \mathrm{Cl},{ }^{39} \mathrm{Ar},{ }^{85} \mathrm{Kr},{ }^{99} \mathrm{Tc}$, and ${ }^{129} \mathrm{I}$. All seven radionuclides except ${ }^{39}$ Ar were found in the RNM-2S pumped groundwater $\left({ }^{39} \mathrm{Ar}\right.$ was not measured), as described in Chapter 3. At UE-5n, all but ${ }^{39} \mathrm{Ar}$ and ${ }^{85} \mathrm{Kr}$ were found $\left({ }^{39} \mathrm{Ar}\right.$ was not measured). Interestingly, the ${ }^{14} \mathrm{C}$ concentration in $\mathrm{UE}-5 \mathrm{n}$ is quite low, suggesting significant retardation of this radionuclide. If ${ }^{39} \mathrm{Ar}$ and ${ }^{85} \mathrm{Kr}$ are effectively removed from the pumped groundwater and escape to the atmosphere during CAMBRIC ditch infiltration, the relevant CAMBRIC ditch source term radionuclides are reduced to five radionuclides: ${ }^{3} \mathrm{H}$, ${ }^{14} \mathrm{C},{ }^{36} \mathrm{Cl},{ }^{99} \mathrm{Tc}$, and ${ }^{129} \mathrm{I}$. 
CHAPTER 5: HYDROLOGIC SOURCE TERM MODELS
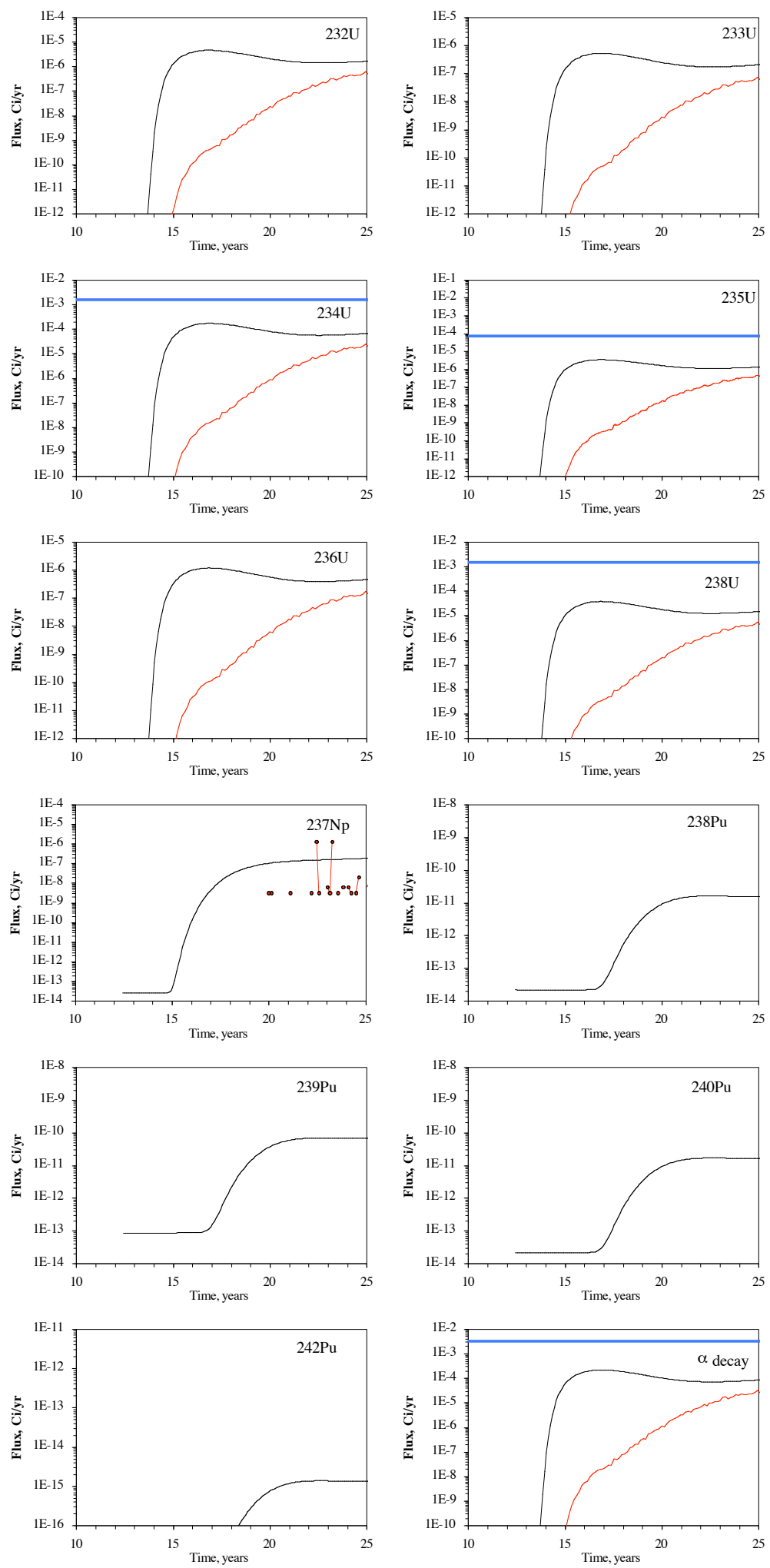

Figure 5.23a Alpha-decaying radionuclide breakthrough at RNM-2S from the NUFT/CRUNCH model (black) and ParFlow/SLIM model (red). Americium-241 had no breakthrough in either model. All calculations used the RST from Bowen et al. (2001). The blue line represents background activity from natural $U$ isotopes. 
CHAPTER 5: HYDROLOGIC SOURCE TERM MODELS
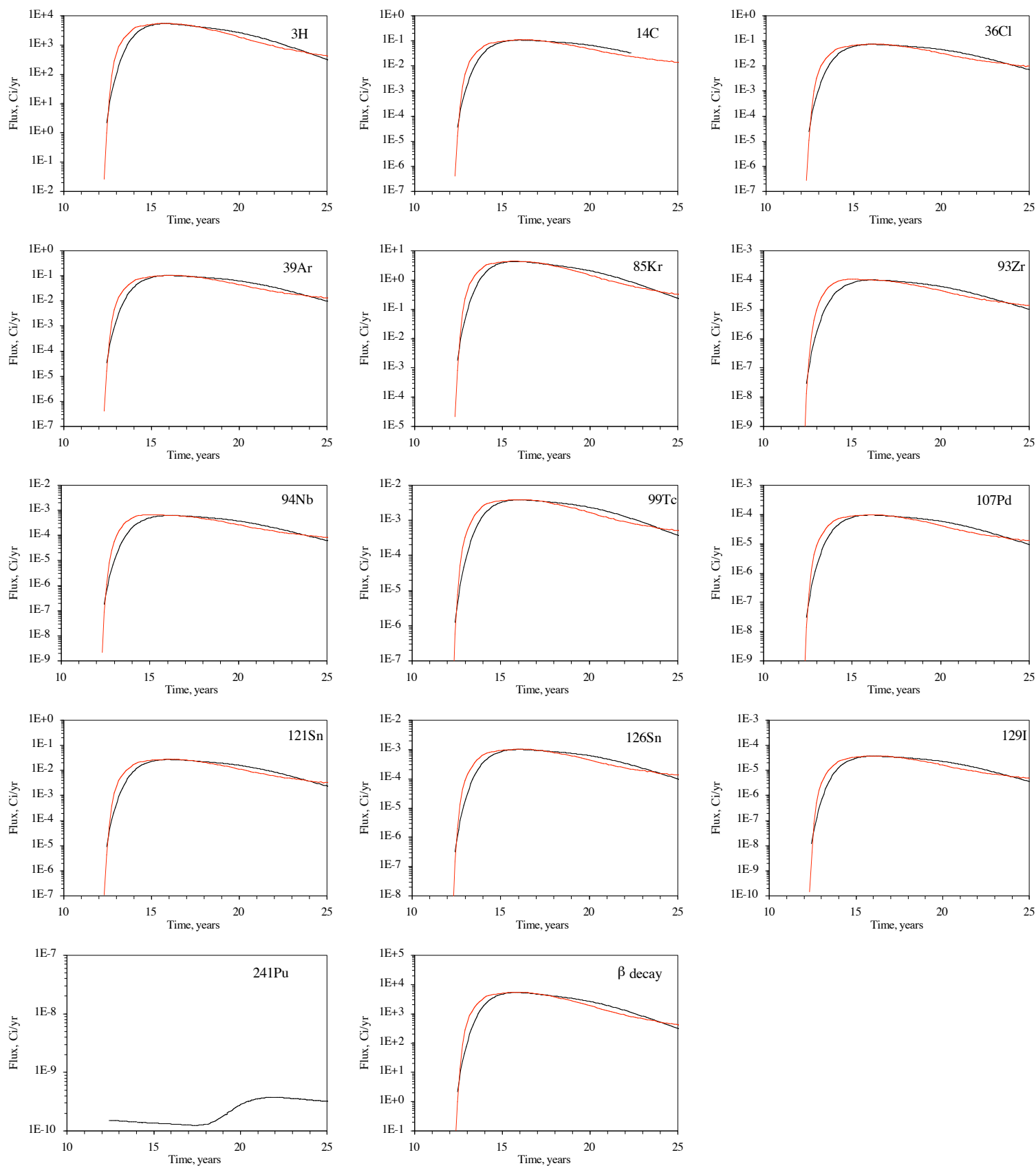

Figure 5.23b Beta-decaying radionuclide breakthrough at RNM-2S from the NUFT/CRUNCH model (black) and ParFlow/SLIM model (red). Nickel-63, ${ }^{90} \mathrm{Sr},{ }^{135} \mathrm{Cs},{ }^{137} \mathrm{Cs},{ }^{151} \mathrm{Sm},{ }^{152} \mathrm{Eu},{ }^{154} \mathrm{Eu}$, and ${ }^{166} \mathrm{Ho}$ radionuclides had no breakthrough in either model. All calculations used the RST from Bowen et al. (2001). 

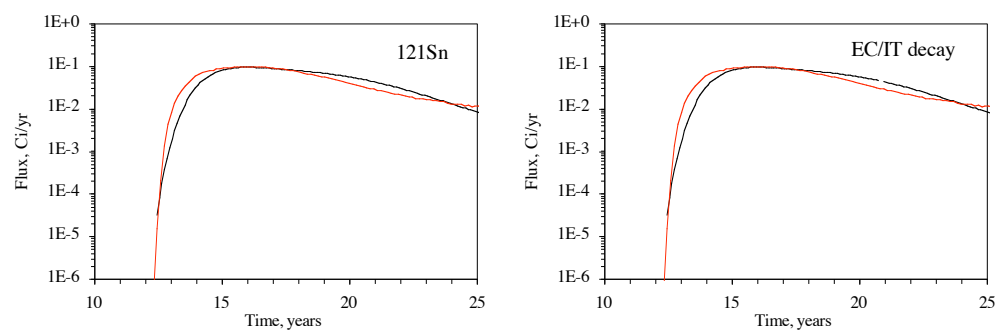

Figure 5.23c EC/IT-decaying radionuclide breakthrough at RNM-2S from the NUFT/CRUNCH model (black) and ParFlow/SLIM model (red). Calcium-41, ${ }^{59} \mathrm{Ni},{ }^{150} \mathrm{Eu}$, and ${ }^{152} \mathrm{Eu}$ radionuclides had no breakthrough in either model. All calculations used the RST from Bowen et al. (2001).

\subsubsection{Comparison of ParFlow/SLIM and NUFT/CRUNCH Transport Simulation Results}

Section 5.3.4 shows breakthrough results at RNM-2S from the ParFlow/SLIM and NUFT/CRUNCH models. Six radionuclide classes were observed to break through in the NUFT/CRUNCH simulations: TracerR, TracerL, U, Np, and, to a small degree, ${ }^{241} \mathrm{Pu}$ and $\mathrm{Pu}$. Only TracerR, TracerL, U, and Np breakthrough was observed in ParFlow/SLIM simulations. Plutonium and ${ }^{241} \mathrm{Pu}$ concentrations in NUFT/CRUNCH simulations were very low and certainly below the detection limit of the ParFlow/SLIM simulations. Comparison plots are shown in Figure 5.24.

Simulated TracerR breakthrough in NUFT/CRUNCH and ParFlow/SLIM models are nearly the same. Because TracerR is non-sorbing, its transport is only affected by the hydraulic properties of the medium. The similar behavior of this tracer in the two models suggests:

- Tracer transport as a result of early test-derived hydrothermal processes (included in NUFT/CRUNCH model) does not drastically affect transport rates to $\mathrm{RNM}-2 \mathrm{~S}$.

- Gaussian random field hydrologic heterogeneity (included in the ParFlow/SLIM model) does not drastically affect transport rates to RNM-2S.

- Tracer recirculation effects from the CAMBRIC ditch (included in the ParFlow/SLIM model) does not drastically affect transport rates to RNM-2S.

While drastic changes are not observed, some subtle difference can be attributed to these processes. For example, the greater breakthrough of TracerR at early time in the ParFlow/SLIM model is likely to be the result of greater dispersion due to the permeability heterogeneity included in that model. Also, upward transport due to early time hydrothermal effects may have slowed tracer migration to RNM-2S in the NUFT/CRUNCH model. The slightly higher concentration at RNM-2S at $25 \mathrm{y}$ in the ParFlow/SLIM model is likely due to the role of tracer recirculation that was not included in the NUFT/CRUNCH model. 


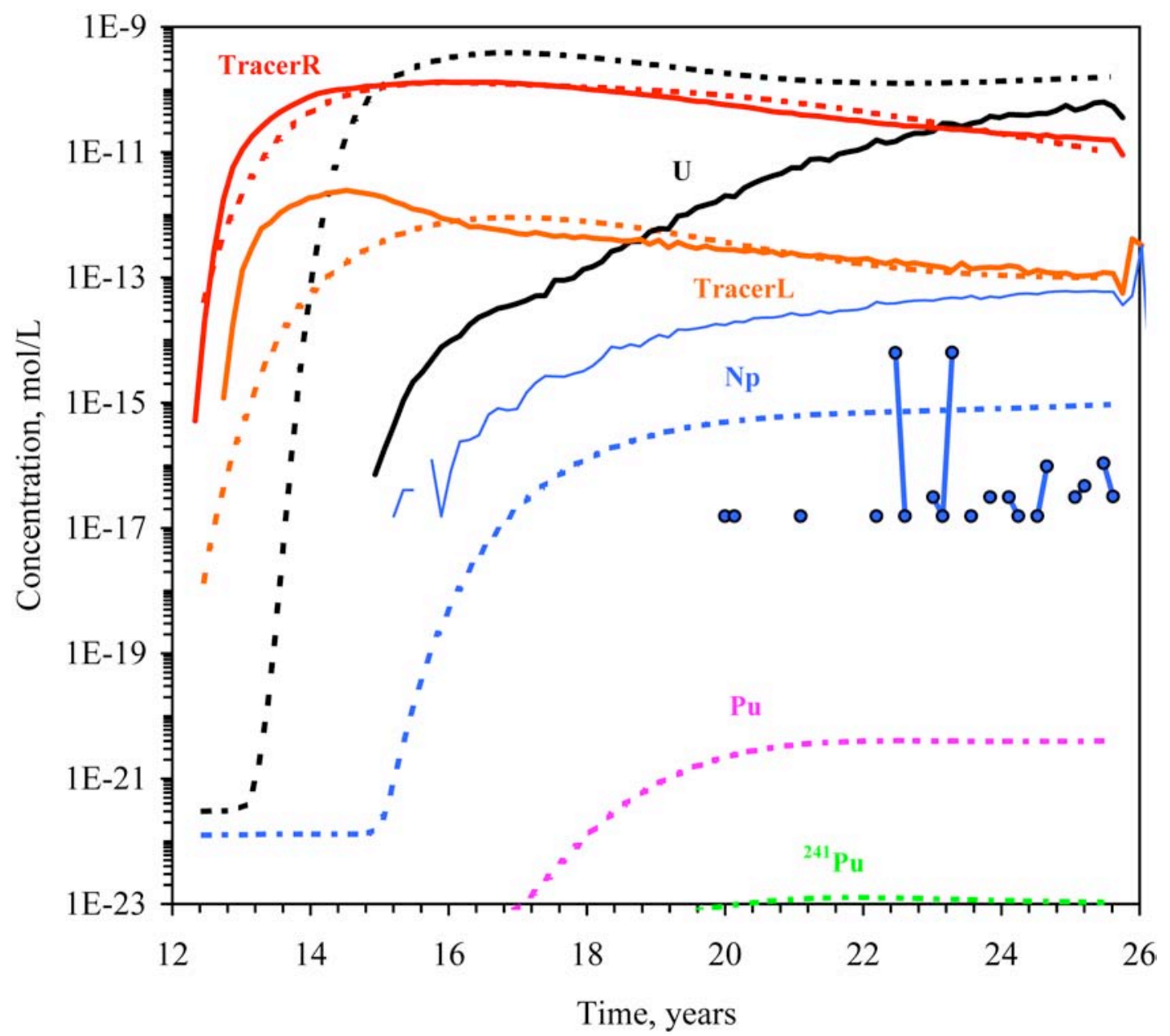

Figure 5.24 Comparison of breakthrough between NUFT/CRUNCH (dashed lines) and ParFlow/SLIM (solid lines) in RNM-2S. The thin solid line shows Np breakthrough with a $\mathrm{K}_{d}$ reduced by $10^{0.5}$.

The breakthrough of TracerL in the two models is distinctly different at $<15 \mathrm{y}$. By 25.5 y, 60\% more TracerL reaches RNM-2S in the ParFlow/SLIM model compared to the NUFT/CRUNCH model. Much of this difference can be attributed to breakthrough at $<15 \mathrm{y}$. The higher TracerL concentrations at RNM-2S in the ParFlow/SLIM model correlate with the higher concentrations of TracerR, suggesting the hydraulic factors play an important role in these differences. Comparison of glass dissolution rates for the two models (Figure 5.2) suggests that greater TracerL breakthrough should be observed in the NUFT/CRUNCH model. Because the reverse is observed, hydraulic factors may overwhelm any geochemical factors and affect TracerL breakthrough at early time.

The breakthrough of $\mathrm{Np}$ in the ParFlow/SLIM model appears to be lower than in the NUFT/CRUNCH model. However, the ParFlow/SLIM model is not able to accurately simulate the breakthrough of trace $\mathrm{Np}$ concentrations due to the computational limitations of the particle tracking method. A greater number of particles and/or increased particle splitting would be necessary to better define $\mathrm{Np}$ breakthrough at these low concentrations. The apparently faster breakthrough of $\mathrm{Np}$ in the NUFT/CRUNCH model 
can be explained by the reduced $\mathrm{Np}$ retardation resulting from glass dissolution and secondary mineral precipitation processes. As shown in Figure 4.88, Np retardation factors drop below the ambient $10^{1.2}$ due to the changes in groundwater chemistry. Apparently, these changes are significant enough to affect migration to RNM-2S. Interestingly, if $\mathrm{Np} \log \left(\mathrm{K}_{\mathrm{d}}\right)$ values used in the ParFlow/SLIM model are reduced by 0.5 , breakthrough is significantly faster than in the NUFT/CRUNCH model. Thus, it is apparent that changes in groundwater chemistry near the test reduced $\mathrm{Np}$ retardation by less than a factor of 3 .

The difference in $U$ breakthrough in the two models is large and even more significant than in the case of $\mathrm{Np}$. In this case, the ParFlow/SLIM model simulates significantly less breakthrough than the NUFT/CRUNCH model. This behavior is opposite to that observed for the non-sorbing tracers. The total U source term is 121 moles, $10 \%$ of which is initially distributed in the rubble. Because the fraction of glass dissolved in the first $10 \mathrm{y}$ is $<2 \%$, $\mathrm{U}$ release as a result of glass dissolution contributes only a minor amount to the mobile source term. Differences in $U$ transport must be the result of hydrologic and/or retardation differences between the two models. Hydrologic differences appear to favor greater breakthrough in the ParFlow/SLIM simulations (based on tracer results). Thus, $\mathrm{U}$ retardation is the source of $\mathrm{U}$ breakthrough differences. By 25 $\mathrm{y}$, a total of 2.7 moles $\mathrm{U}$ is transported to RNM-2S in the NUFT/CRUNCH model compared to 0.16 moles in the ParFlow/SLIM model. In both cases, this represents only a fraction of the $\mathrm{U}$ initially distributed in the cavity rubble ( $22 \%$ and $1.4 \%$, respectively).

NUFT/CRUNCH simulations predict that the retardation factor for $\mathrm{U}$ in the glass zone will be reduced to nearly 1.0 (Figure 4.89). Thus, a fraction of the U may migrate unretarded near the cavity. This fast transport is observed in cross sections between the CAMBRIC cavity and RNM-2S (Figure 5.25). At $13 \mathrm{y}$, a high concentration of $\mathrm{U}$ builds up in the glass zone. Once pumping begins, this zone of high $\mathrm{U}$ concentration and low retardation quickly migrates to RNM-2S while the remaining $U$ is held back. Because the ParFlow/SLIM model uses a linear retardation model, this fast path is not present. The fast migration rates of $U$ in the NUFT/CRUNCH model are a manifestation of the non-linear reaction chemistry included in this model. 
(A) NUFT/CRUNCH retardation factors
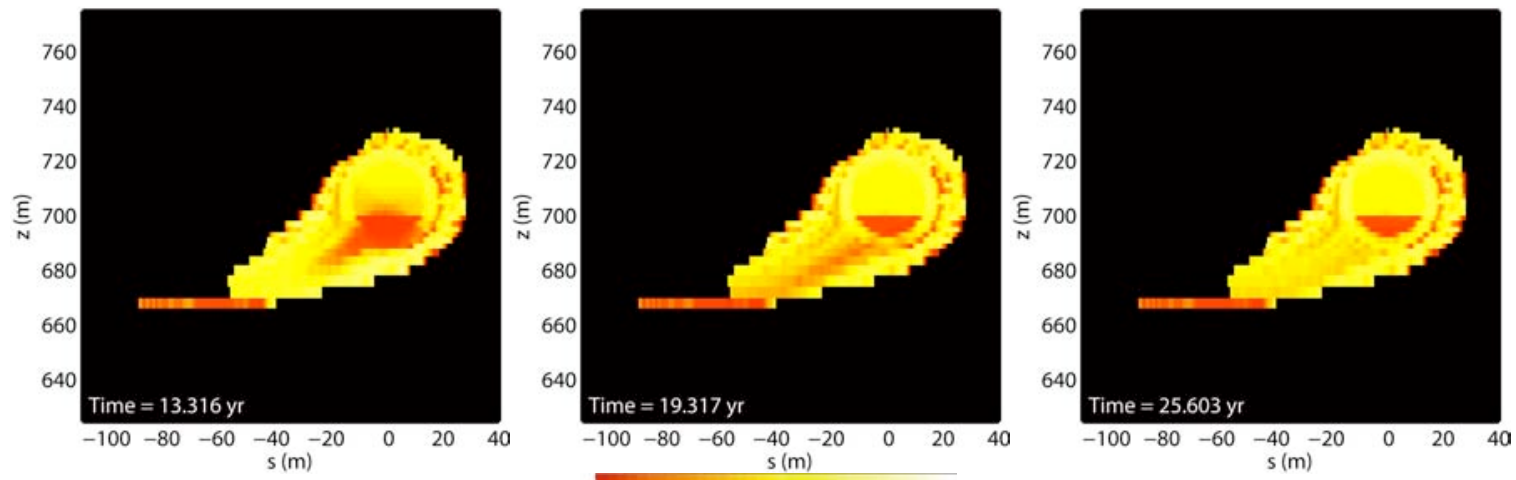

(B) NUFT/CRUNCH U concentration

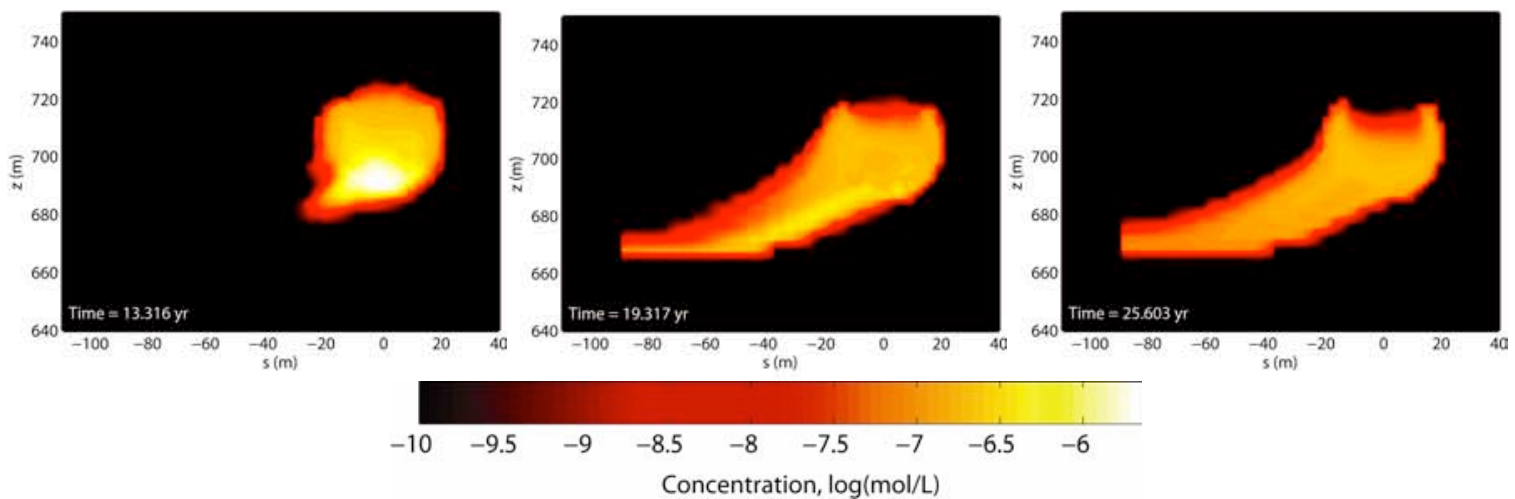

(C) ParFlow/SLIM U concentration

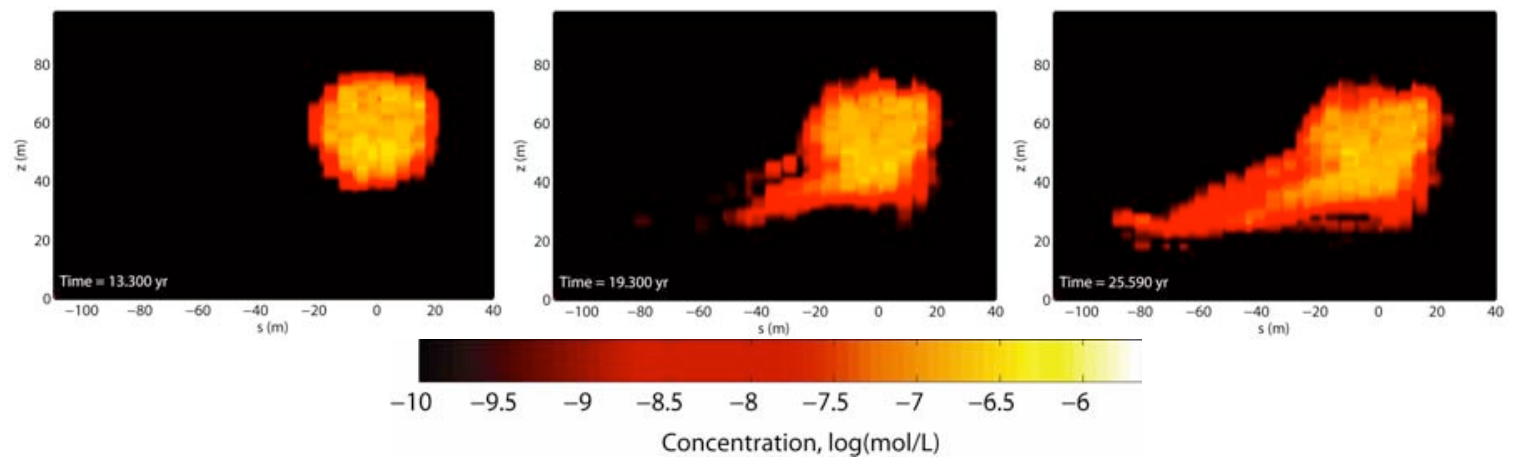

Figure 5.25 Uranium retardation factors and concentration cross sections between the CAMBRIC cavity and the RNM-2S pumping well in the NUFT/CRUNCH (A, B) and ParFlow/SLIM (C) models. 


\subsubsection{Comparison of ParFlow/SLIM and NUFT/CRUNCH Simulation Results to Data}

\subsubsection{RNM-1 Radionuclide Initial Concentrations}

Section 3.6.2 describes the data reported in Hoffman et al. (1977) and elsewhere regarding the distribution of radionuclides in the CAMBRIC cavity prior to the RNM experiment. These data can be compared to simulated radionuclide partitioning. The two relevant datasets from Hoffman et al. (1977) are the calculated $\mathrm{K}_{\mathrm{d}}$ data (Table 3.5) and initial radionuclide concentrations in pumped groundwater (Table 3.6). In addition, observed major element groundwater chemistry (Table 3.7) can be compared to the evolving water chemistry produced in the NUFT/CRUNCH model. A comparison of measured data and simulated values for each of these datasets is described below.

The data in Hoffman et al. (1977) could be used to establish $\mathrm{K}_{\mathrm{d}} \mathrm{s}$ for four radionuclides: ${ }^{90} \mathrm{Sr},{ }^{125} \mathrm{Sb},{ }^{137} \mathrm{Cs}$, and ${ }^{239} \mathrm{Pu}$. Because the CAMBRIC cavity is located entirely within Layer 3 alluvium, as defined in Warren et al. (2002), measured values are best compared to those listed for that alluvium layer (Table 5.3). The simulated ${ }^{90} \mathrm{Sr} \mathrm{K} \mathrm{d}_{\mathrm{d}}$ of $10^{2.5 \pm 0.2} \mathrm{~mL} / \mathrm{g}$ compares very well with the measured value of $10^{2.5 \pm 0.6}$. The uncertainties in the simulated and measured values are not equivalent. For the simulated $K_{d} s$, the uncertainty is related to the mineralogic variability in Layer 3 alluvium. Additional uncertainty related to the mechanistic model itself is not accounted for but may be significantly larger. For the measured $\mathrm{K}_{\mathrm{d}} \mathrm{s}$, the uncertainty is simply the standard deviation for the small number of measured $\mathrm{K}_{\mathrm{d}}$ values.

The measured ${ }^{125} \mathrm{Sb} \mathrm{K}$ is $10^{2.2 \pm 0.5} \mathrm{~mL} / \mathrm{g}$. The retardation of ${ }^{125} \mathrm{Sb}$ was not simulated because the Bowen et al. (2001) inventory does not include this radionuclide (due to its short half-life, $\mathrm{t}_{1 / 2}=2.76$ years).

The simulated ${ }^{137} \mathrm{Cs} \mathrm{K}_{\mathrm{d}}$ of $10^{4.1 \pm 0.1} \mathrm{~mL} / \mathrm{g}$ compares well with the measured value of $10^{3.8 \pm 0.3}$. The simulated $\mathrm{K}_{\mathrm{d}}$ reported here is calculated at ambient groundwater and mineralogic conditions. Some changes in $\mathrm{K}_{\mathrm{d}}$ are expected as a result of test-related heat and glass dissolution/secondary mineral precipitation (see Figure 4.87). However, these changes are rather small for $\mathrm{Cs}$ (as well as $\mathrm{Sr}$ ).

The simulated ${ }^{239} \mathrm{Pu} \mathrm{K}_{\mathrm{d}}$ of $10^{1.9 \pm 0.1} \mathrm{~mL} / \mathrm{g}$ is significantly lower than the measured value $\left(10^{6.2 \pm 1.4}\right)$ even when the large uncertainty in the measured value is taken into account. The measured $\mathrm{K}_{\mathrm{d}} \mathrm{S}$ were based on Pu concentrations in "native" and "fine" fractions reported at 297.9-m and 298.5-m depths in Table 3.4. These values are much higher than predicted ${ }^{239} \mathrm{Pu}$ concentrations in the rubble and suggest that nuclear melt glass may be present in these samples. The $\mathrm{Pu} \mathrm{K}_{\mathrm{d}}$ calculated using the predicted $\mathrm{Pu}$ concentration in rubble $\left(6 \times 10^{-12} \mathrm{~mol} / \mathrm{g}\right.$, Table 3.2) and the pumped groundwater $\mathrm{Pu}$ concentration from zone II $\left(2.3 \times 10^{-13} \mathrm{~mol} / \mathrm{L}\right.$, Table 3.6$)$ is $10^{4.4} \mathrm{~mL} / \mathrm{g}$. This value is likely to be more accurate. Nevertheless, the simulated $\mathrm{K}_{\mathrm{d}}$ is still significantly lower than this measured value. The mechanistic model has been found to underpredict $\mathrm{Pu} \mathrm{K}_{\mathrm{d}} \mathrm{s}$ (and overpredict initial concentrations in the cavity) both at CHESHIRE (Pawloski et al., 2001) and in previous CAMBRIC simulations (Tompson et al., 1999). Limitations in the mechanistic model, particularly for Pu sorption to aluminosilicate minerals, may account for some of the discrepancy. The assumption that $\mathrm{Pu}$ partitioning between the rubble and 
groundwater is governed by an equilibrium sorption process also leads to underestimated retardation. The disequilibrium between sorption and desorption processes is commonly observed for strongly sorbing species and could account for the discrepancy between simulated and measured $\mathrm{Pu} \mathrm{K}_{\mathrm{d}} \mathrm{s}$.

The measured initial radionuclide concentrations in the CAMBRIC cavity (Hoffman et al., 1977) are reported in Table 3.6. The values of greatest interest are those reported for Zone II, which intersects the cavity. Values are reported for ${ }^{3} \mathrm{H},{ }^{85} \mathrm{Kr},{ }^{106} \mathrm{Ru}$, ${ }^{125} \mathrm{Sb},{ }^{137} \mathrm{Cs},{ }^{90} \mathrm{Sr},{ }^{144} \mathrm{Ce},{ }^{147} \mathrm{Pm}$, and ${ }^{239} \mathrm{Pu}$. Of these, ${ }^{106} \mathrm{Ru},{ }^{125} \mathrm{Sb},{ }^{144} \mathrm{Ce}$, and ${ }^{147} \mathrm{Pm}$ were not included in the model due to their absence from the Bowen et al. (2001) inventory. For the remaining radionuclides $\left({ }^{3} \mathrm{H},{ }^{85} \mathrm{Kr},{ }^{137} \mathrm{Cs},{ }^{90} \mathrm{Sr}\right.$, and $\left.{ }^{239} \mathrm{Pu}\right)$, simulation results can be compared to measured values once the radionuclide class concentrations (Table 4.10) are adjusted to CAMBRIC-specific isotopic inventories. CAMBRIC-specific isotopic inventories are estimated in Hoffman et al. (1977), Hoffman (1979), and Schroeder et al. (1993, Table 3.1). 
Table 5.3. Radionuclide class $\mathrm{K}_{d} \mathrm{~s}$ distributed within the ParFlow/SLIM model domain.

\begin{tabular}{|c|c|c|c|c|c|c|c|c|c|c|c|}
\hline \multirow[b]{2}{*}{ Unit $^{1}$} & \multirow[b]{2}{*}{ Layer or unit ${ }^{2}$} & \multicolumn{10}{|c|}{$\log \left({ }_{\mathrm{d}}{ }\right), \mathrm{mL} g \mathrm{~g}$} \\
\hline & & $\mathrm{Ca}$ & Cs & $\mathrm{Sr}$ & $\mathrm{Ni}$ & Am & Eu & Sm & $\mathrm{Np}$ & $\mathbf{U}$ & $\mathbf{P u}^{3}$ \\
\hline \multirow[t]{2}{*}{1} & AL1v, DITCH & 2.0 & 4.1 & 1.8 & 2.7 & 3.6 & 3.0 & 3.4 & 0.6 & 0.3 & 1.9 \\
\hline & & \pm 0.1 & \pm 0.3 & \pm 0.1 & \pm 0.3 & \pm 0.1 & \pm 0.0 & \pm 0.1 & \pm 0.2 & \pm 0.4 & \pm 0.1 \\
\hline \multirow[t]{2}{*}{2} & AL2v, AL2a, AL2b & 2.2 & 3.8 & 1.9 & 3.1 & 3.9 & 3.2 & 3.5 & 0.6 & 0.2 & 2.0 \\
\hline & & \pm 0.1 & \pm 0.2 & \pm 0.1 & \pm 0.1 & \pm 0.1 & \pm 0.1 & \pm 0.2 & \pm 0.1 & \pm 0.1 & \pm 0.1 \\
\hline \multirow[t]{2}{*}{3} & AL3 & 2.8 & 4.1 & 2.5 & 3.0 & 3.8 & 3.1 & 3.3 & 0.4 & 0.1 & 1.9 \\
\hline & & \pm 0.2 & \pm 0.1 & \pm 0.2 & \pm 0.1 & \pm 0.1 & \pm 0.1 & \pm 0.2 & \pm 0.1 & \pm 0.2 & \pm 0.1 \\
\hline \multirow[t]{2}{*}{4} & AL4 & 2.7 & 4.1 & 2.5 & 3.1 & 3.9 & 3.1 & 3.3 & 0.5 & 0.2 & 2.0 \\
\hline & & \pm 0.1 & \pm 0.3 & \pm 0.1 & \pm 0.2 & \pm 0.2 & \pm 0.2 & \pm 0.3 & \pm 0.3 & \pm 0.2 & \pm 0.2 \\
\hline \multirow[t]{2}{*}{5} & AL5 & 2.6 & 4.2 & 2.4 & 3.0 & 3.8 & 3.1 & 3.3 & 0.5 & 0.1 & 1.9 \\
\hline & & \pm 0.1 & \pm 0.1 & \pm 0.2 & \pm 0.3 & \pm 0.3 & \pm 0.3 & \pm 0.3 & \pm 0.2 & \pm 0.2 & \pm 0.2 \\
\hline \multirow[t]{2}{*}{6} & AL6 & 2.1 & 4.0 & 1.8 & 3.1 & 3.9 & 3.2 & 3.4 & 0.5 & 0.2 & 2.0 \\
\hline & & \pm 0.1 & \pm 0.1 & \pm 0.1 & \pm 0.1 & \pm 0.1 & \pm 0.1 & \pm 0.1 & \pm 0.1 & \pm 0.1 & \pm 0.1 \\
\hline \multirow[t]{2}{*}{7} & AL7 & 2.1 & 4.0 & 1.8 & 3.1 & 3.9 & 3.2 & 3.5 & 0.6 & 0.3 & 2.1 \\
\hline & & \pm 0.1 & \pm 0.1 & \pm 0.1 & \pm 0.1 & \pm 0.1 & \pm 0.1 & \pm 0.2 & \pm 0.1 & \pm 0.1 & \pm 0.1 \\
\hline \multirow[t]{2}{*}{8} & AL8 & 2.1 & 3.9 & 1.8 & 3.4 & 4.1 & 3.4 & 3.6 & 0.7 & 0.4 & 2.2 \\
\hline & & \pm 0.1 & \pm 0.2 & \pm 0.0 & \pm 0.1 & \pm 0.1 & \pm 0.1 & \pm 0.1 & \pm 0.1 & \pm 0.1 & \pm 0.1 \\
\hline \multirow[t]{2}{*}{9} & AL9 & 2.3 & 3.9 & 1.9 & 3.5 & 4.3 & 3.6 & 3.9 & 1.0 & 0.5 & 2.4 \\
\hline & & \pm 0.3 & \pm 0.2 & \pm 0.3 & \pm 0.2 & \pm 0.2 & \pm 0.2 & \pm 0.3 & \pm 0.3 & \pm 0.2 & \pm 0.2 \\
\hline \multirow[t]{2}{*}{10} & AL10 & 1.9 & 4.0 & 1.5 & 3.2 & 4.0 & 3.3 & 3.6 & 0.7 & 0.3 & 2.1 \\
\hline & & \pm 0.2 & \pm 0.1 & \pm 0.1 & \pm 0.2 & \pm 0.2 & \pm 0.1 & \pm 0.1 & \pm 0.1 & \pm 0.1 & \pm 0.1 \\
\hline \multirow[t]{2}{*}{11} & AL11 & 2.6 & 4.0 & 2.3 & 3.1 & 3.9 & 3.2 & 3.5 & 0.6 & 0.2 & 2.0 \\
\hline & & - & - & - & - & - & - & - & - & - & - \\
\hline \multirow[t]{2}{*}{12} & AL12 & 1.9 & 3.7 & 1.5 & 3.2 & 4.0 & 3.2 & 3.5 & 0.6 & 0.3 & 2.1 \\
\hline & & \pm 0.1 & \pm 0.3 & \pm 0.1 & \pm 0.1 & \pm 0.1 & \pm 0.1 & \pm 0.1 & \pm 0.1 & \pm 0.1 & \pm 0.1 \\
\hline \multirow[t]{2}{*}{13} & MG & 2.7 & 4.0 & 2.5 & 3.0 & 3.7 & 3.0 & 3.2 & 0.4 & 0.1 & 1.9 \\
\hline & & \pm 0.2 & \pm 0.1 & \pm 0.2 & \pm 0.1 & \pm 0.1 & \pm 0.1 & \pm 0.2 & \pm 0.1 & \pm 0.2 & \pm 0.1 \\
\hline
\end{tabular}

For ${ }^{3} \mathrm{H}$, Hoffman et al. (1977) estimates that a total of 2.08 moles are initially distributed in the cavity and compressed zones. In the simulations, 1.0 mole of TracerR was distributed in the same fashion. Thus, an initial TracerR concentration of $1.33 \times 10^{-7}$ $\mathrm{mol} / \mathrm{L}$ is equivalent to an initial simulated ${ }^{3} \mathrm{H}$ concentration of $2.8 \times 10^{-7} \mathrm{~mol} / \mathrm{L}$. This value matches the measured ${ }^{3} \mathrm{H}$ concentration in Zone II $\left(3.1( \pm 0.7) \times 10^{-7} \mathrm{~mol} / \mathrm{L}\right)$. This match should not be surprising, as the Tritium Exchange Ratio (TER) used in the model was based upon a fit to this initial ${ }^{3} \mathrm{H}$ concentration.

For ${ }^{85} \mathrm{Kr}$, Hoffman et al. (1977) estimates the initial inventory to be $2.53 \times 10^{-}$ ${ }^{4}$ moles. Krypton- 85 is initially distributed in the same fashion as the 1.0 mole of TracerR. Thus, an initial TracerR concentration of $1.33 \times 10^{-7} \mathrm{~mol} / \mathrm{L}$ is equivalent to an initial simulated ${ }^{85} \mathrm{Kr}$ concentration of $3.4 \times 10^{-11} \mathrm{~mol} / \mathrm{L}$. This value most closely resembles the maximum concentration observed in water extracted from RNM-1 core samples $\left(2.12 \times 10^{-11} \mathrm{~mol} / \mathrm{L}\right.$, Figure 3.8). Pumped groundwater samples from RNM-1 showed some evidence of ${ }^{85} \mathrm{Kr}$ redistribution in the $10 \mathrm{y}$ between the CAMBRIC test 
detonation and cavity sampling at RNM-1. It was also suggested that sample degassing might have produced lower than expected measured values $\left(9.0 \times 10^{-12} \mathrm{~mol} / \mathrm{L}\right.$ in Zone II and $1.3 \times 10^{-11}$ in Zone III).

Ruthenium-106 was not included in the simulations because it was not part of the Bowen et al. (2001) source term. However, estimates of its $\mathrm{K}_{\mathrm{d}}$ can be made if information on its source term, initial partitioning, exchange volume, and aqueous concentration are available. Using the source term from Hoffman et al. (1977) $\left(7.74 \times 10^{-}\right.$ ${ }^{3}$ moles), a $30 \%$ partitioning to the rubble fraction (from IAEA, 1998a), the aqueous concentration in Zone II pumped water $\left(8.7 \times 10^{-12} \mathrm{~mol} / \mathrm{L}\right)$, and distributing it in the 4.29 $\times 10^{7}$ kilograms of rubble associated with the cavity and compressed zones and $7.52 \times$ $10^{6}$ liters pore fluid results in an estimated $\mathrm{K}_{\mathrm{d}}$ of $6 \mathrm{~mL} / \mathrm{g}$. This very low $\mathrm{K}_{\mathrm{d}}$ is consistent with its observed migration to RNM-2S during the pumping experiment (Figure 3.19).

Antimony-125 also was not included in the simulation because it was not part of the Bowen et al. (2001) source term. However, a source term is reported in Hoffman et al. (1977) and a $K_{d}$ can be calculated using the method described above. The estimated $\mathrm{K}_{\mathrm{d}}$ is also $\sim 6 \mathrm{~mL} / \mathrm{g}$. The low $\mathrm{K}_{\mathrm{d}}$ is consistent with its observed migration to RNM-2S. When compared to ${ }^{106} \mathrm{Ru}$ breakthrough, the $\mathrm{K}_{\mathrm{d}}$ is expected to be somewhat higher. However, given the assumptions and uncertainties in these $\mathrm{K}_{\mathrm{d}}$ estimates, the only conclusion that can be made is that both ${ }^{106} \mathrm{Ru}$ and ${ }^{125} \mathrm{Sb}$ are only weakly retarded.

The simulated ${ }^{137} \mathrm{Cs}$ concentrations should compare well with measured concentrations given that the simulated and measured $\mathrm{K}_{\mathrm{d}} \mathrm{S}$ match very well (Figure 5.26). At $12.3 \mathrm{y}$, the Cs radionuclide class aqueous concentration in the cavity is approximately $3 \times 10^{-13} \mathrm{~mol} / \mathrm{L}$ while the concentration in the glass zone is higher (approximately $2 \times 10^{-}$ $12 \mathrm{~mol} / \mathrm{L}$ ) as a result of glass dissolution. The total inventory of the Cs radionuclide class is 0.167 moles. The CAMBRIC-specific ${ }^{137}$ Cs inventory estimated in Hoffman (1977) is 0.0104 moles. Correcting for the CAMBRIC-specific ${ }^{137} \mathrm{Cs}$ inventory, the predicted concentrations in the cavity and glass zones at $12.3 \mathrm{y}$ are $2 \times 10^{-14}$ and $1 \times 10^{-13} \mathrm{~mol} / \mathrm{L}$, respectively. These concentrations bracket the observed ${ }^{137} \mathrm{Cs}$ concentrations in pumped groundwater samples from Zones II, III, and IV $\left(7.0 \times 10^{-14}, 6.5 \times 10^{-14}\right.$, and $3.4 \times 10^{-14}$ mol/L, respectively).

The simulated ${ }^{90} \mathrm{Sr}$ concentrations should also compare well with measured concentrations given that the simulated and measured $\mathrm{K}_{\mathrm{d}} \mathrm{s}$ match very well (Figure 5.26). The total Sr radionuclide class inventory is $2.9 \times 10^{-2}$ moles. The CAMBRIC-specific ${ }^{90} \mathrm{Sr}$ inventory estimated in Hoffman (1977) is $3.45 \times 10^{-3}$ moles. Correcting for the CAMBRIC-specific ${ }^{90} \mathrm{Sr}$ inventory (and decay-correcting to $\mathrm{t}_{0}$ ), the predicted ${ }^{90} \mathrm{Sr}$ concentrations in the cavity and glass zones are approximately $8 \times 10^{-14}$ and $8 \times 10^{-13}$ $\mathrm{mol} / \mathrm{L}$, respectively. As in the ${ }^{137} \mathrm{Cs}$ case, these concentrations bracket the observed ${ }^{90} \mathrm{Sr}$ concentrations in pumped groundwater samples from Zones II, III, and IV $\left(3.0 \times 10^{-13}\right.$, $2.5 \times 10^{-13}$, and $2.1 \times 10^{-13} \mathrm{~mol} / \mathrm{L}$, respectively).

As in the case of ${ }^{106} \mathrm{Ru}$ and ${ }^{125} \mathrm{Sb}$, the transport of ${ }^{144} \mathrm{Ce}$ and ${ }^{147} \mathrm{Pm}$ were not included in the simulations because they were not reported in the Bowen et al. (2001) source term. Nevertheless, their estimated retardation based on groundwater concentrations and source terms reported in Hoffman et al. (1977) can be calculated. 
Furthermore, retardation behavior of these two radionuclides is expected to be similar to that of other trivalent radionuclides ( $\mathrm{Sm}, \mathrm{Eu}$, and $\mathrm{Am})$. Thus, it is relevant to compare the estimated retardation of ${ }^{144} \mathrm{Ce}$ and ${ }^{147} \mathrm{Pm}$ to other trivalent radionuclides that are included in the simulations. The IAEA (1998a) estimates that $5 \%$ of ${ }^{147} \mathrm{Pm}$ partitions into rubble. Using the source term from Hoffman et al. (1977) and the partitioning from IAEA (1998a), the ${ }^{147} \mathrm{Pm} \mathrm{K} \mathrm{d}_{\mathrm{d}}$ is estimated to be $10^{3.8} \mathrm{~mL} / \mathrm{g}$. This value agrees well with the simulated $\mathrm{K}_{\mathrm{d}} \mathrm{S}$ for other trivalent radionuclides $\left(10^{3.8}, 10^{3.1}\right.$, and $10^{3.3} \mathrm{~mL} / \mathrm{g}$ for $\mathrm{Am}, \mathrm{Eu}$, and $\mathrm{Sm}$, respectively). Assuming that $5 \%$ of ${ }^{144} \mathrm{Ce}$ partitions into rubble (partitioning was not reported in IAEA, 1998a), the estimated $\mathrm{K}_{\mathrm{d}}$ is $10^{0.9} \mathrm{~mL} / \mathrm{g}$. The unrealistically low $\mathrm{K}_{\mathrm{d}}$ for the trivalent radionuclide indicates either that the partitioning of ${ }^{144} \mathrm{Ce}$ into the rubble is much greater than $5 \%$ or that the measured water concentration is in error.

Based on earlier comparison of estimated and simulated $\mathrm{Pu} \mathrm{K}_{\mathrm{d}} \mathrm{S}$, simulated aqueous ${ }^{239} \mathrm{Pu}$ concentrations should be significantly higher than measured concentrations. In effect, this is the case. The total inventory of the Pu radionuclide class is 10.2 moles. The CAMBRIC-specific ${ }^{239} \mathrm{Pu}$ inventory estimated in Hoffman (1977) is 13.0 moles. Correcting for the CAMBRIC-specific ${ }^{239} \mathrm{Pu}$ inventory, the predicted ${ }^{239} \mathrm{Pu}$ concentrations in the cavity and glass zones are $10^{-10}$ and $4 \times 10^{-8} \mathrm{~mol} / \mathrm{L}$, respectively. These values are radically higher than the measured concentrations of ${ }^{239} \mathrm{Pu}$ in pumped samples from Zone II in RNM-1 $\left(2.3 \times 10^{-13} \mathrm{~mol} / \mathrm{L}\right)$ and reflect an underestimation of $\mathrm{Pu}$ $\mathrm{K}_{\mathrm{d}} \mathrm{S}$ in the simulations, as described earlier. 


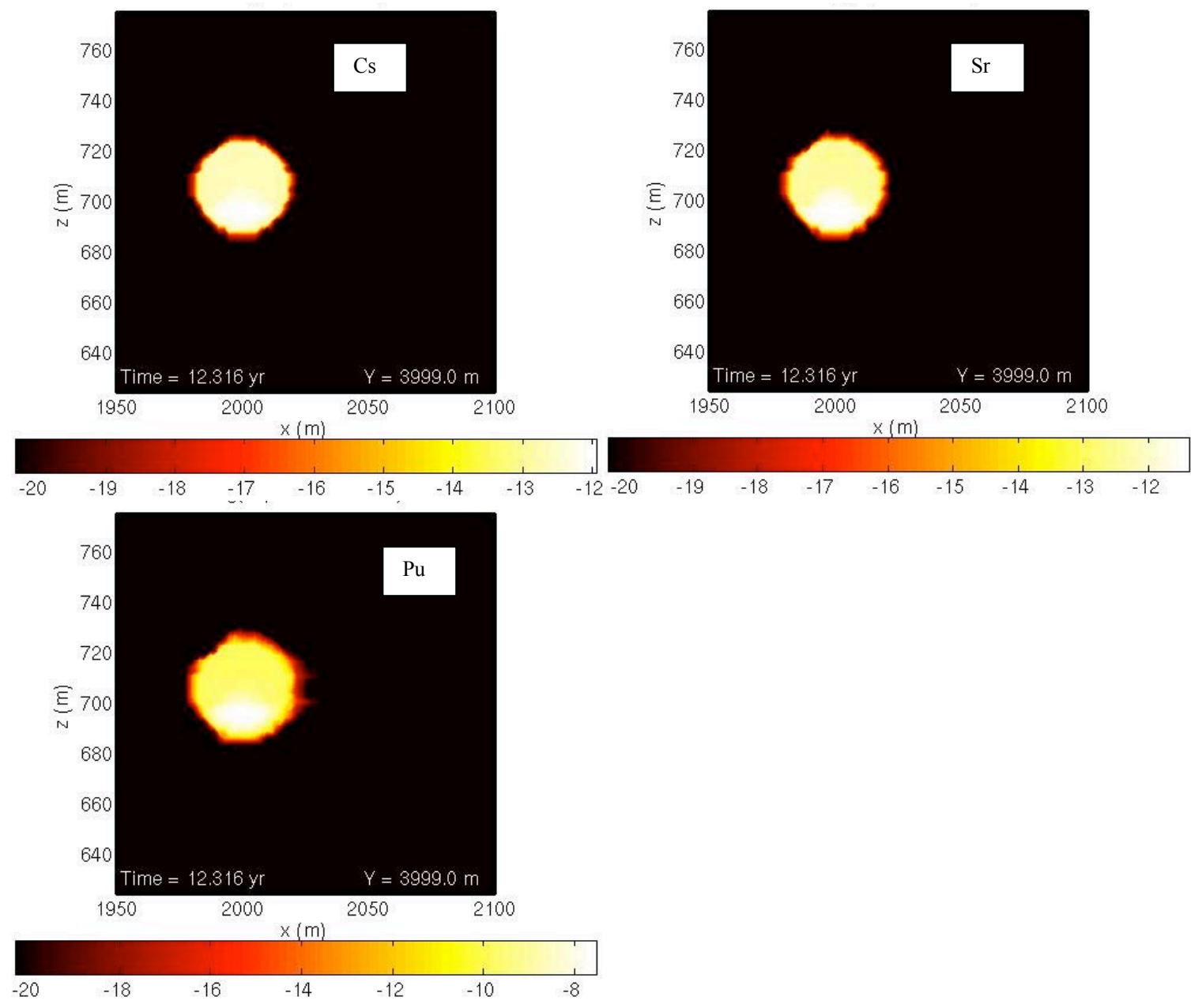

Figure 5.26 Simulated aqueous $\mathrm{Cs}$, $\mathrm{Sr}$, and Pu radionuclide class concentrations in the CAMBRIC cavity (log scale) at 12 y (NUFT/CRUNCH model). 


\subsubsection{RNM-1, RNM-2S, and UE-5n Radionuclide Concentrations During and After the RNM Experiment}

In Section 3.7, measured radionuclide concentrations at RNM-2S and other nearby wells over a 40-y time interval were reported. When the simulated concentrations are based on a CAMBRIC-specific source term (e.g., Table 3.1, Hoffman, 1977, data), they can be directly compared to measured radionuclide concentration data at these wells as a function of time. Converting simulated radionuclide class concentrations to CAMBRICspecific radionuclide concentrations was described in the previous section. This same method is used below to compare simulated and measured radionuclide concentrations as a function of time.

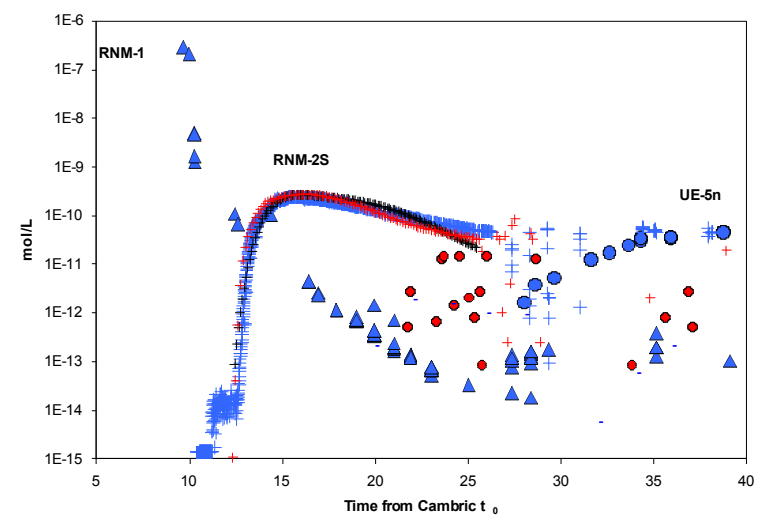

Figure 5.27 Measured (blue), NUFT/CRUNCH (black), and ParFlow/SLIM (red) ${ }^{3} \mathrm{H}$ concentrations in three wells near the CAMBRIC test: RNM-1 (triangle), RNM-2S (plus sign), and UE-5n (circle). Simulated concentrations are adjusted to the CAMBRIC-specific ${ }^{3} \mathrm{H}$ inventory estimate of Hoffman et al. (1977).
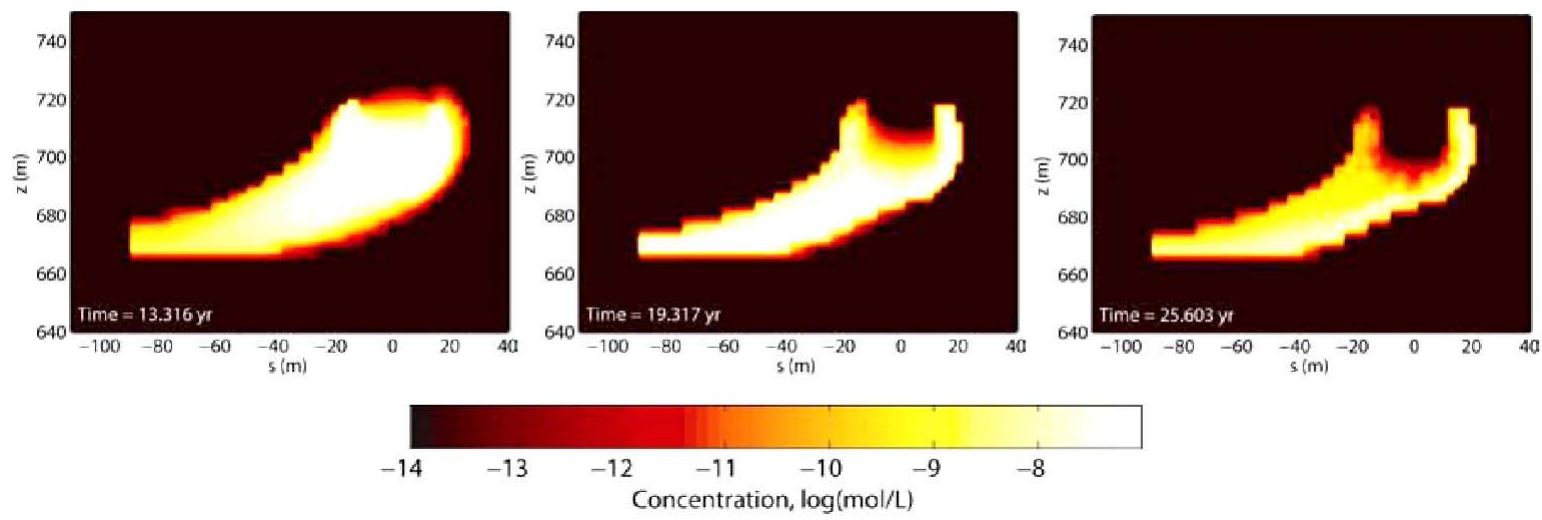

Figure 5.28 TracerR concentration as a function of time in the NUFT/CRUNCH simulations. 
The match between measured and simulated ${ }^{3} \mathrm{H}$ concentrations at RNM-2S was discussed as part of the model calibration effort (Section 4.6.8.1). However, ${ }^{3} \mathrm{H}$ concentrations at RNM- 1 and UE-5 $\mathrm{n}$ as a function of time were not evaluated in detail. A comparison between measured and simulated concentration in all three nearby wells is plotted in Figures 5.27 and 5.28. Measured ${ }^{3} \mathrm{H}$ concentration in RNM-1 started above $1 \times$ $10^{-7} \mathrm{~mol} / \mathrm{L}$ and dropped by over six orders of magnitude as a result of the RNM experiment. After pumping stopped, ${ }^{3} \mathrm{H}$ concentrations at UE-5n increased. The trend observed in RNM-1 is replicated in both the ParFlow/SLIM and the NUFT/CRUNCH models. However, only the ParFlow/SLIM model incorporated groundwater infiltration in the CAMBRIC ditch and the resulting appearance of ${ }^{3} \mathrm{H}$ in UE-5n. Unfortunately, particle resolution and heterogeneity effects in the model create significant noise in the simulated UE-5n concentrations. Simply put, the range of concentrations simulated at UE- $5 n$ is consistent with observations. However, additional effort would be required to better resolve ${ }^{3} \mathrm{H}$ breakthrough at UE-5n.

Figure 5.29 provides a comparison of ${ }^{85} \mathrm{Kr}$ simulated and measured concentrations at three wells near CAMBRIC. The simulations match the observed data nearly as well as in the ${ }^{3} \mathrm{H}$ case. The simulations overpredict the peak concentration in RNM-2S, most likely because the models do not account for any ${ }^{85} \mathrm{Kr}$ losses as a result of volatilization (Guell and Hunt, 2003). Furthermore, the ParFlow/SLIM simulation predicts ${ }^{85} \mathrm{Kr}$ transport to UE-5n. Krypton-85 has not been observed at UE-5n. It is expected that most of the ${ }^{85} \mathrm{Kr}$ would degas from the pumped fluid at RNM-2S as it is deposited into the ditch and infiltrates the vadose zone. However, the ParFlow/SLIM model does not allow ${ }^{85} \mathrm{Kr}$ to escape into a gas phase. In the simulations, ${ }^{85} \mathrm{Kr}$ in the pumped fluid at $\mathrm{RNM}-2 \mathrm{~S}$ is conserved as it migrates through the vadose zone.

Trace quantities of ${ }^{137} \mathrm{Cs}$ and ${ }^{239,240} \mathrm{Pu}$ were reported at RNM-2S during pumping (Figure 3.18). Reported breakthrough for both these radionuclides was coincident with ${ }^{3} \mathrm{H}$ breakthrough, and could only have occurred as a result of colloidfacilitated radionuclide transport. However, Buddemeier and Isherwood (1985) critically evaluated these measurements and concluded that they cannot be positively distinguished from blanks. Colloid-facilitated transport was not included in our model and ${ }^{137} \mathrm{Cs}$ and ${ }^{239,240} \mathrm{Pu}$ breakthrough at RNM-2S was not predicted. Based on the measured ${ }^{137} \mathrm{Cs}$ and ${ }^{239,240} \mathrm{Pu}$ concentrations at RNM-2S and the data evaluations by Buddemeier and Isherwood (1985), colloid-facilitated radionuclide transport is not significant in Frenchman Flat alluvium.

Observed concentrations of ${ }^{137} \mathrm{Cs}$ and ${ }^{239,240} \mathrm{Pu}$ at RNM-1 are extremely low. Adjusting for the difference between the Cs radionuclide class inventory ( 0.167 moles) and the CAMBRIC-specific ${ }^{137} \mathrm{Cs}$ inventory (0.0104) estimated in Hoffman et al. (1977), simulated concentrations in RNM-1 start at $2 \times 10^{-14}$ to $1 \times 10^{-13} \mathrm{~mol} / \mathrm{L}$ and trend slightly lower, if they change at all, during pumping (Figure 5.30). This is consistent with observed trends in Figure 3.18. Interestingly, ${ }^{239,240} \mathrm{Pu}$ concentrations apparently decreased with time at RNM-1 (three data points only). This trend was not reproduced in simulations (Figure 5.31). A kinetically slow ${ }^{239,}{ }^{240} \mathrm{Pu}$ sorption process could account for the observed loss of $\mathrm{Pu}$ from solution. However, these types of processes are not well defined and were not included in the models. 
CHAPTER 5: HYDROLOGIC SOURCE TERM MODELS

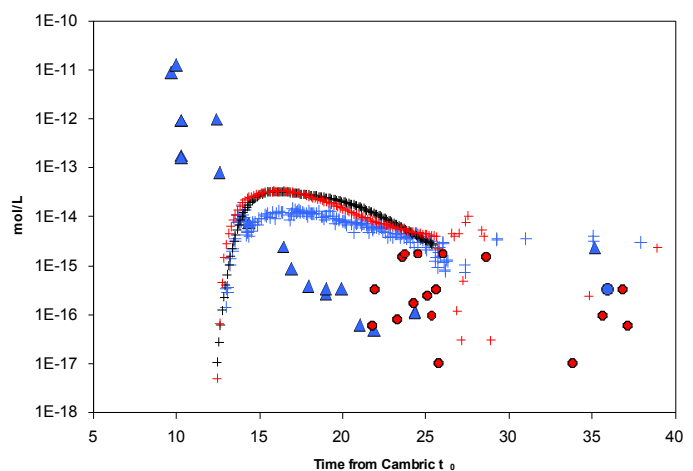

Figure 5.29 Measured (blue), NUFT/CRUNCH (black), and ParFlow/SLIM (red) ${ }^{85} \mathrm{Kr}$ concentrations in three wells near the CAMBRIC test: RNM-1 (triangle), RNM-2S (plus sign), and UE-5n (circle). Simulated concentrations are adjusted to the CAMBRIC-specific ${ }^{85} \mathrm{Kr}$ inventory estimate of Hoffman et al. (1977).
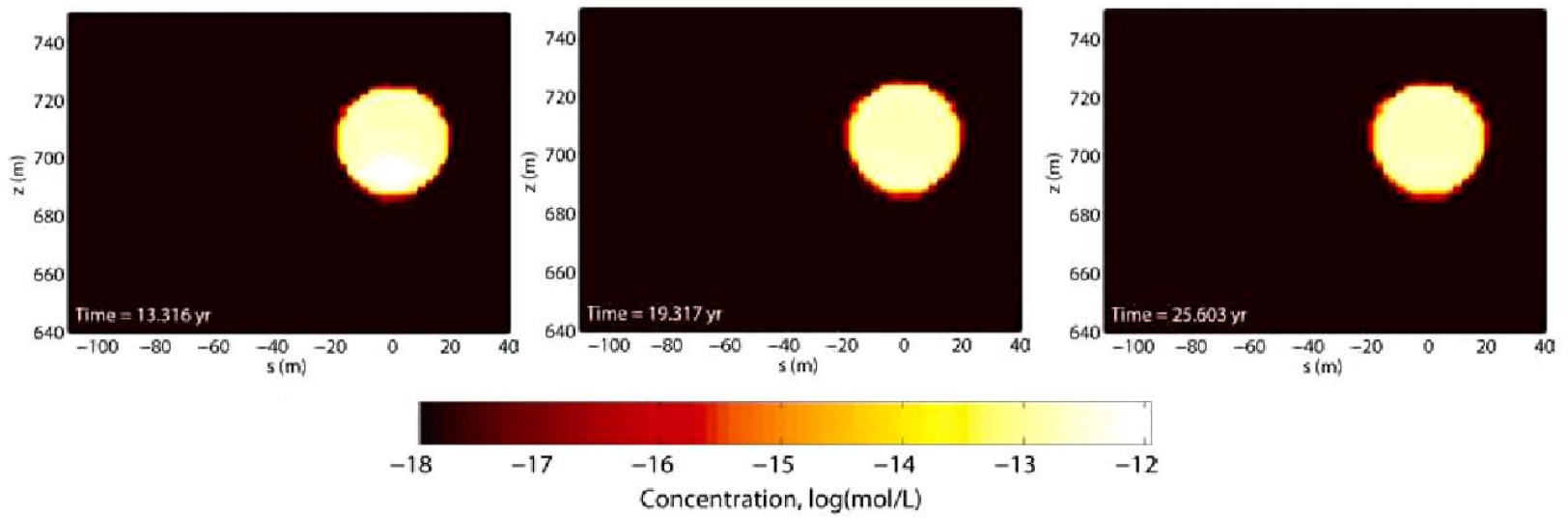

Figure 5.30 Cs radionuclide class concentrations in the CAMBRIC cavity during the RNM experiment. 


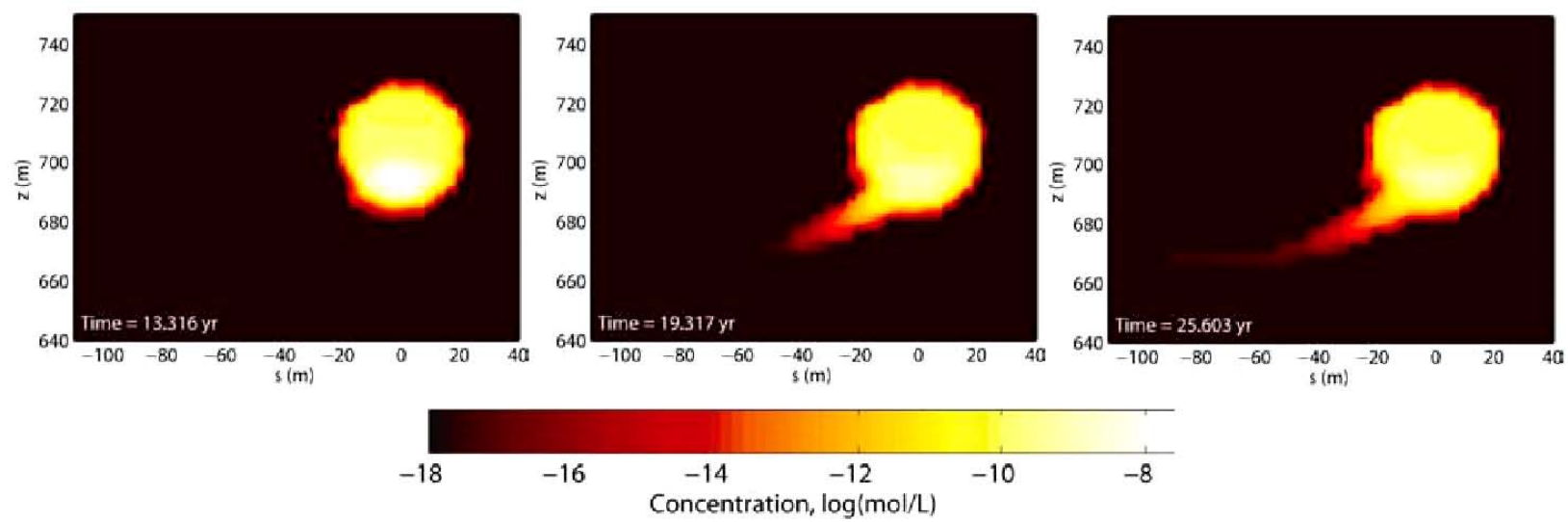

Figure 5.31 Pu radionuclide class concentrations in the CAMBRIC cavity during the RNM experiment.
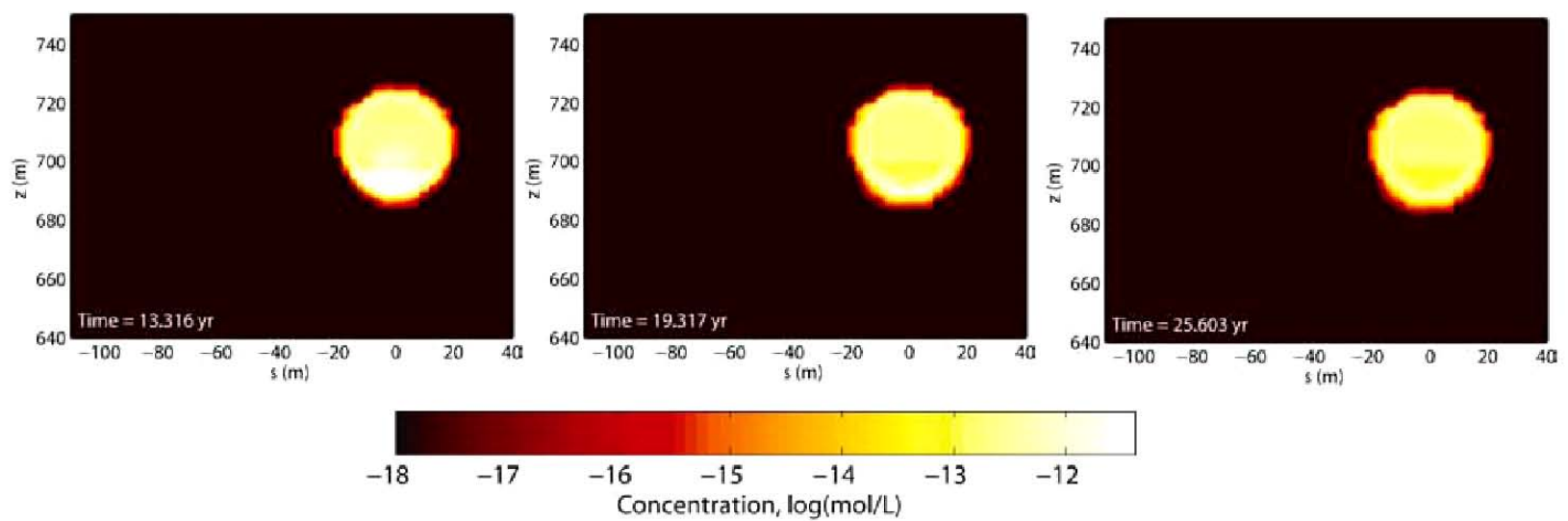

Figure 5.32 Sr radionuclide class concentrations in the CAMBRIC cavity during the RNM experiment. 
The trends in ${ }^{90} \mathrm{Sr}$ breakthrough at UE-5n and concentrations at RNM-1 are similar to those found for Cs (Figure 5.32). However, the decrease in cavity ${ }^{90} \mathrm{Sr}$ during pumping by one to two orders of magnitude is greater than predicted. As in the Pu case, a kinetically slow sorption process could account for this reduction. However, kinetically controlled sorption processes were not included in the models.

Measured and predicted ${ }^{99} \mathrm{Tc}$ concentrations are shown in Figure 5.33. The simulated CAMBRIC-specific ${ }^{99}$ Tc concentration can be calculated by combining the results from TracerR and TracerL radionuclide classes, using the IAEA (1998a) ${ }^{99} \mathrm{Tc}$ partitioning (20\% in rubble, $80 \%$ in glass), and adjusting to the CAMBRIC-specific ${ }^{99} \mathrm{Tc}$ inventory estimated in Schroeder et al. (1993). Based on these calculations, the CAMBRICspecific initial ${ }^{99} \mathrm{Tc}$ concentration is predicted to be $3 \times 10^{-10} \mathrm{~mol} / \mathrm{L}$. This value is three to four orders of magnitude higher than the measured concentration. This is consistent with the interpretation by Schroeder et al. (1993) that only a small fraction of the ${ }^{99} \mathrm{Tc}$ RST is available for transport. They suggest that only $0.01 \%$ of the ${ }^{99} \mathrm{Tc}$ escaped from the vitrified nuclear melt glass and into groundwater (as opposed to $20 \%$ suggested by IAEA, 1998a). However, other processes such as reduction and sorption of Tc and/or losses of Tc due to volatilization may also affect the measured ${ }^{99} \mathrm{Tc}$ concentrations. Furthermore, the fact that ${ }^{99} \mathrm{Tc}$ concentrations at RNM-2S and UE-5n at $40 \mathrm{y}$ are higher than those at 15 y (time of peak RNM-2S ${ }^{3} \mathrm{H}$ concentration) suggests that the historical samples analyzed by Schroeder et al. (1993) may have lost significant ${ }^{99} \mathrm{Tc}$ during storage. Taking a ratio of the most recent measured ${ }^{3} \mathrm{H} /{ }^{\rho 9} \mathrm{Tc}$ in groundwater and comparing it to the predicted ${ }^{3} \mathrm{H} /{ }^{99} \mathrm{Tc}$ (using the IAEA, 1998a, radionuclide partitioning into rubble; the Hoffman et al., 1977, ${ }^{3} \mathrm{H}$ inventory; and the Schroeder et al., 1993, ${ }^{99} \mathrm{Tc}$ inventory), the ${ }^{99} \mathrm{Tc}$ concentration is found to be $1-6 \%$ of the expected value (assuming unretarded transport). This calculation suggests that the simulations may overpredict ${ }^{99} \mathrm{Tc}$ concentrations by one to two orders of magnitude.

Comparison of measured and simulated ${ }^{36} \mathrm{Cl}$ and ${ }^{129} \mathrm{I}$ breakthrough is presented in Figures 5.34 and 5.35, respectively. Importantly, the comparisons are qualitative because the simulated ${ }^{36} \mathrm{Cl}$ and ${ }^{129} \mathrm{I}$ breakthrough was adjusted to the average Frenchman Flat (Bowen et al., 2001) inventory. A CAMBRIC-specific inventory is not available. It is not known how the Bowen et al. $(2001){ }^{36} \mathrm{Cl}$ and ${ }^{129} \mathrm{I}$ inventories compare to the CAMBRIC-specific ${ }^{36} \mathrm{Cl}$ and ${ }^{129} \mathrm{I}$ inventories. However, Figure 3.6 suggests that the Bowen et al. (2001) inventory may be one order of magnitude or more greater than the CAMBRIC-specific inventory for low $\mathrm{Z}$ radionuclides. The observed difference between measured and simulated (using Bowen et al., 2001) ${ }^{36} \mathrm{Cl}$ and ${ }^{129} \mathrm{I}$ breakthrough is consistent with this apparent difference. 


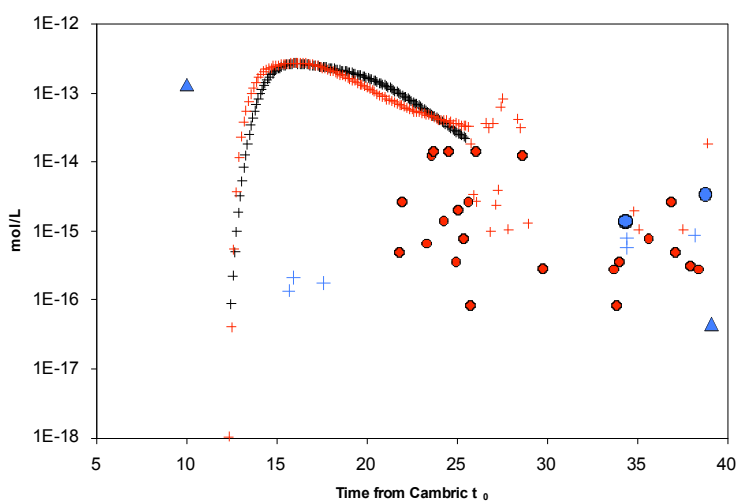

Figure 5.33 Measured (blue), NUFT/CRUNCH (black), and ParFlow/SLIM (red) ${ }^{99} \mathrm{Tc}$ concentrations in three wells near the CAMBRIC test: RNM-1 (triangle), RNM-2S (plus sign), and UE-5n (circle). Simulated concentrations are adjusted to the CAMBRIC-specific ${ }^{99} \mathrm{Tc}$ inventory estimate of Schroeder et al. (1993).

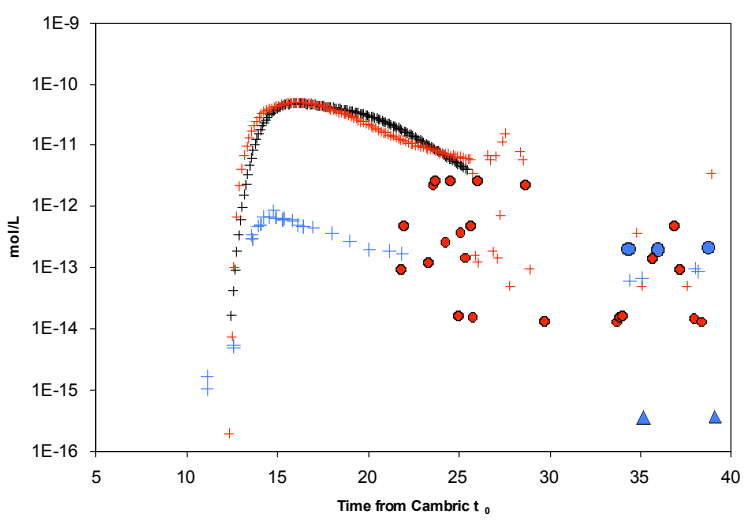

Figure 5.34 Measured (blue), NUFT/CRUNCH (black), and ParFlow/SLIM (red) ${ }^{36} \mathrm{CI}$ concentrations in three wells near the CAMBRIC test: RNM-1 (triangle), RNM-2S (plus sign), and UE-5n (circle). Simulation results are based on the average Frenchman Flat source term reported by Bowen et al. (2001).

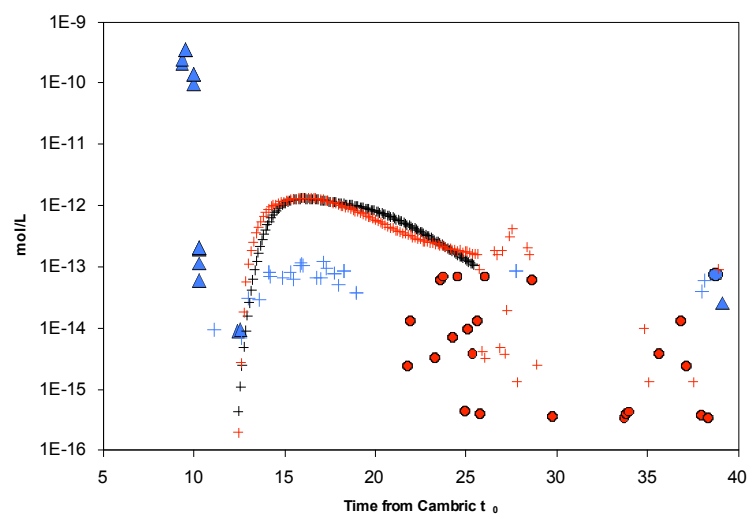

Figure 5.35 Measured (blue), NUFT/CRUNCH (black), and ParFlow/SLIM (red) ${ }^{129}$ concentrations in three wells near the CAMBRIC test: RNM-1 (triangle), RNM-2S (plus sign), and UE-5n (circle). Simulation results are based on the average Frenchman Flat source term reported by Bowen et al. (2001). 


\subsection{Ditch Hydrologic Source Term}

\subsubsection{Simulation of Radionuclide Breakthrough Across the Water Table}

The unique interactions of the pumping well and the re-infiltration of radionuclides from the ditch were a key component of the ParFlow/SLIM flow and transport model. Both the flow and transport models take into account the capture of water and radionuclides in RNM-2S and reintroduction into the ditch and playa, and migration through the vadose zone and possible re-capture of that water and radionuclide mass. This creates many more migration pathways for water and radionuclides than any other test in Frenchman Flat. Some of these dynamics are illustrated in Figure 5.36, including the dramatic effect of pumping and infiltration on tracer migration over the first $27 \mathrm{y}$ after the test. In the first panel, after $10.4 \mathrm{y}$ of ambient migration, the tracer (TracerR) has moved an almost imperceptible amount. In the second panel, after $700 \mathrm{~d}$ of pumping at $300 \mathrm{gpm}$ and just over $2 \mathrm{y}$ of pumping at $600 \mathrm{gpm}$, a significant quantity of tracer mass has been captured by the pumping well RNM-2S, has been reinfiltrated into the vadose zone, and is just reaching the water table. The effect of subsurface heterogeneity can also be seen in the variability of migration pathways and spatial distribution of concentration. At $17 \mathrm{y}$ after the test (or about $6.6 \mathrm{y}$ of pumping) some tracer has migrated back to RNM-2S and is about to be recaptured. Tracer is being recaptured by RNM-2S by 18 y after the test. These two panels show that highconductivity fast pathways play a role in creating migration pathways back to RNM-2S, including the effects of physical heterogeneity and the RNM-2S gravel pack. The fifth panel in Figure 5.36, at 26 y after the test, is about a year after the cessation of pumping. The pumping well has pulled a large amount of tracer mass downward. Connected high conductivity pathways in Layer AL3 and Layer AL4 act as conduits for tracer migration. A large quantity of tracer mass has drained from the vadose zone underlying the ditch, but some tracer is still held in lower-conductivity units. In the last panel of Figure 5.36, at $27 \mathrm{y}$, much of the tracer has drained from the vadose zone. Some areas still remain as the lower conductivity units may take tens of years to drain. Vadose zone drainage has pushed a significant quantity of tracer laterally through Layer AL2b. This is due mainly to the hydrologic mounding and the very permeable nature of this alluvial layer. 

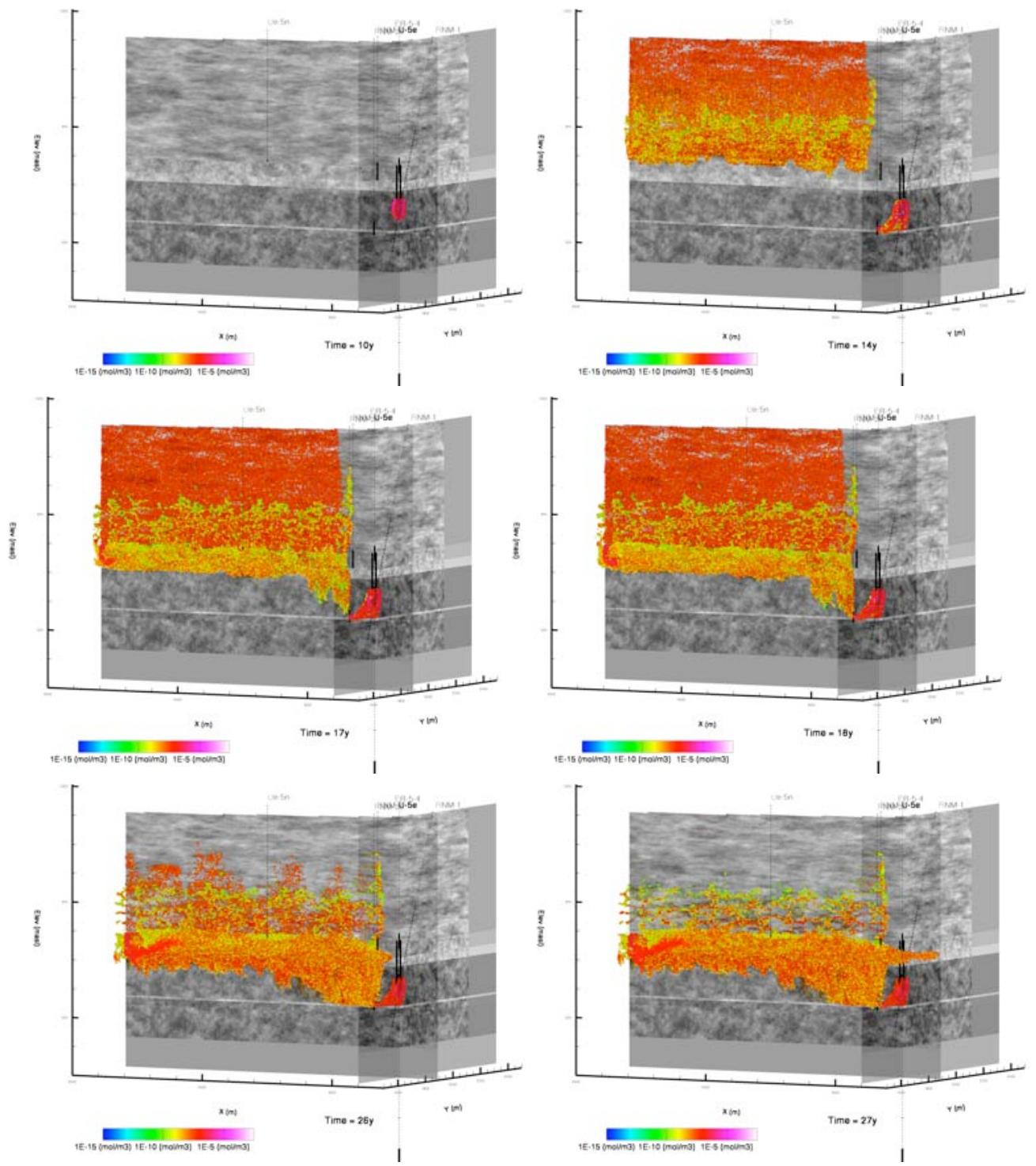

Figure 5.36 Results for tracer transport at different points in time during the simulation $(10.4,14$, $17,18,26$, and $27 \mathrm{y}$, from top left) focused on the region near the cavity. The upper left panel represents tracer transport after $10.4 \mathrm{y}$ of ambient migration, just before the onset of pumping. The last panel represents tracer transport at $27 \mathrm{y}, 2 \mathrm{y}$ after the cessation of pumping. Note the pathway from cavity to well and from ditch to water table. 


\subsubsection{Ditch Hydrologic Source Term Results for 1,000 Years}

The fluxes of the 13 radionuclide classes were tracked using four breakthrough planes. Three of these (1-3) are vertical planes positioned 16, 93, and $269 \mathrm{~m}$ downgradient from CAMBRIC and the ditch (as in Tompson et al., 2005, and shown in Figure 5.4), and the last plane (4) is a horizontal plane located just above the water table. For most radionuclide classes (e.g., Ca, Cs, Eu, Sm, and Sr) transport was very limited and, over the 1,000-y period, was observed to occur only across plane 1 . In these cases, the dominant transport mechanism was diffusive (as modified by the local retardation for each radionuclide class). These results are shown in Figure 5.37 where a small amount of advective transport is seen for some radionuclides in early times $(\mathrm{t}<100 \mathrm{y})$ but transport across the first breakthrough plane is mostly diffusion driven and near the limit of resolution for the ParFlow/SLIM model. Figures 5.38, 5.39, and 5.40 plot breakthrough for $\mathrm{Pu}+,{ }^{241} \mathrm{Pu}$, and ${ }^{241} \mathrm{Am}$, which also demonstrate very limited transport distances. These radionuclides show slightly more advective transport at early times but are still limited to transport past plane 1 and not the other planes. Note that ${ }^{241} \mathrm{Pu}$ and ${ }^{241} \mathrm{Am}$ have real-time decay and ingrowth. None of the aforementioned radionuclide classes were captured by pumping well RNM-2S or infiltrated into the ditch and lake discharge area.

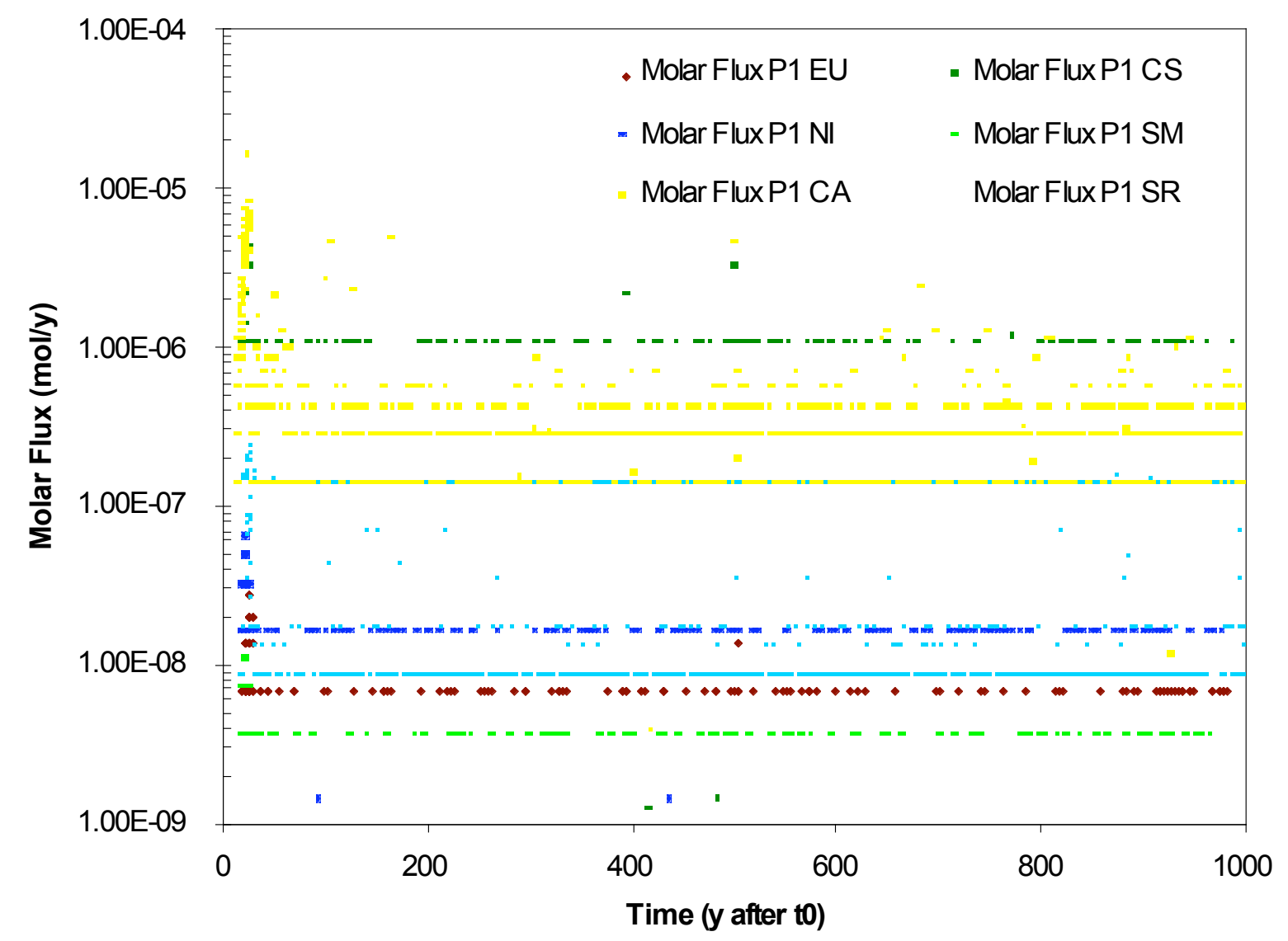

Figure 5.37 Plot of molar fluxes at plane 1 for radionuclide classes $\mathrm{Ca}, \mathrm{Cs}, \mathrm{Eu}, \mathrm{Ni}, \mathrm{Sm}$, and $\mathrm{Sr}$. 


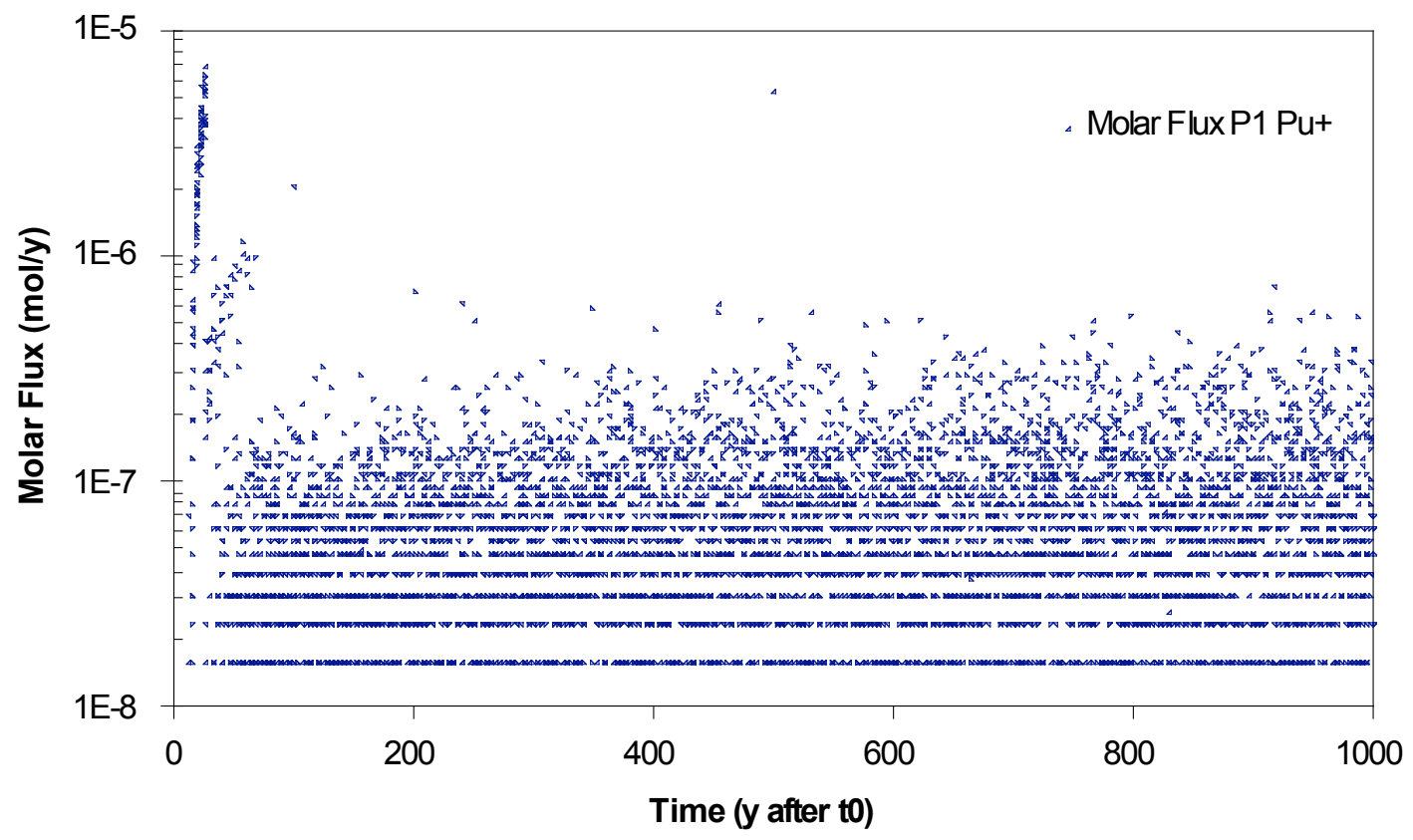

Figure 5.38 Plot of molar flux at plane 1 for radionuclide class Pu+.

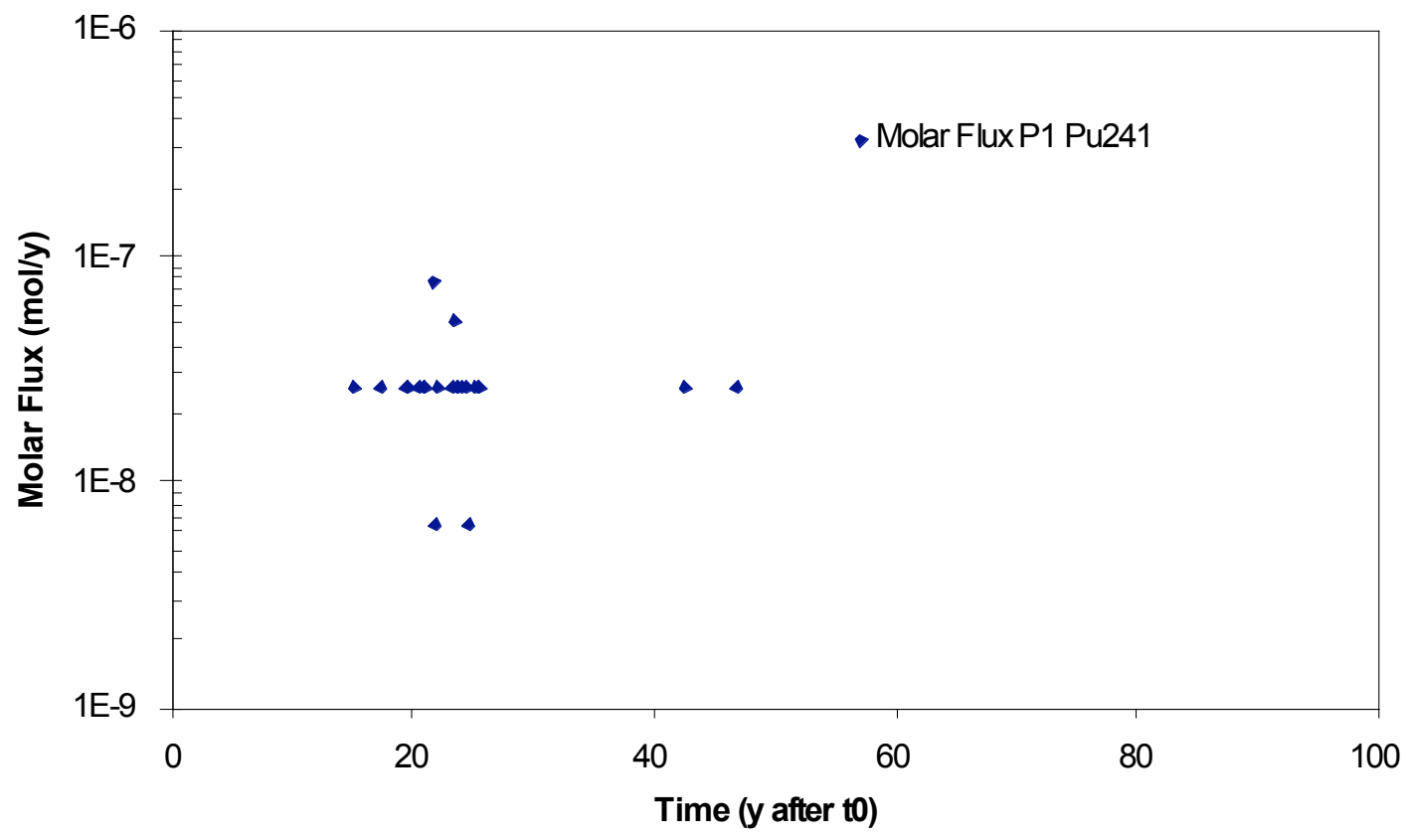

Figure 5.39 Plot of molar flux at plane 1 for radionuclide class ${ }^{241} \mathrm{Pu}$. 


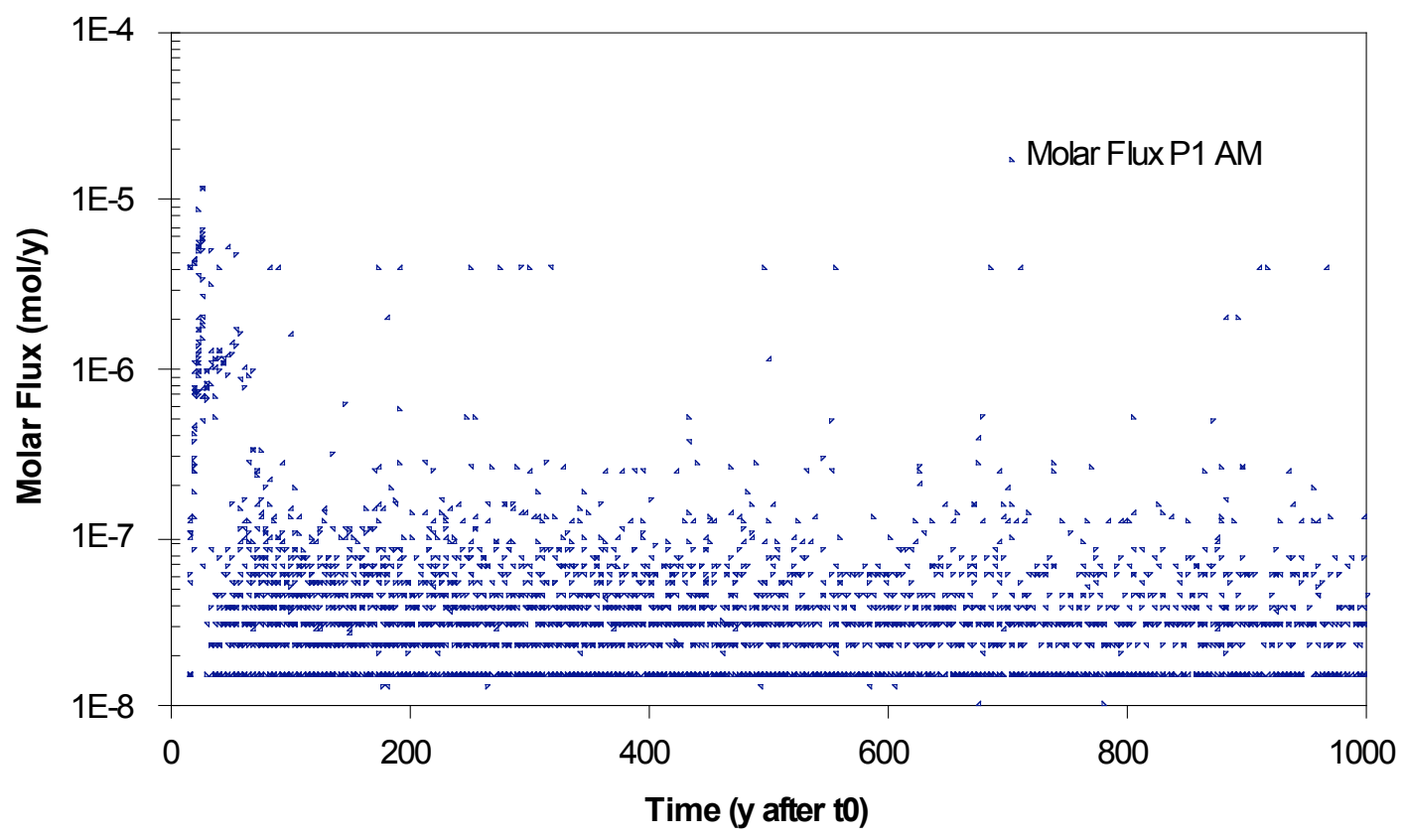

Figure 5.40 Plot of molar fluxes at plane 1 for radionuclide class Am.

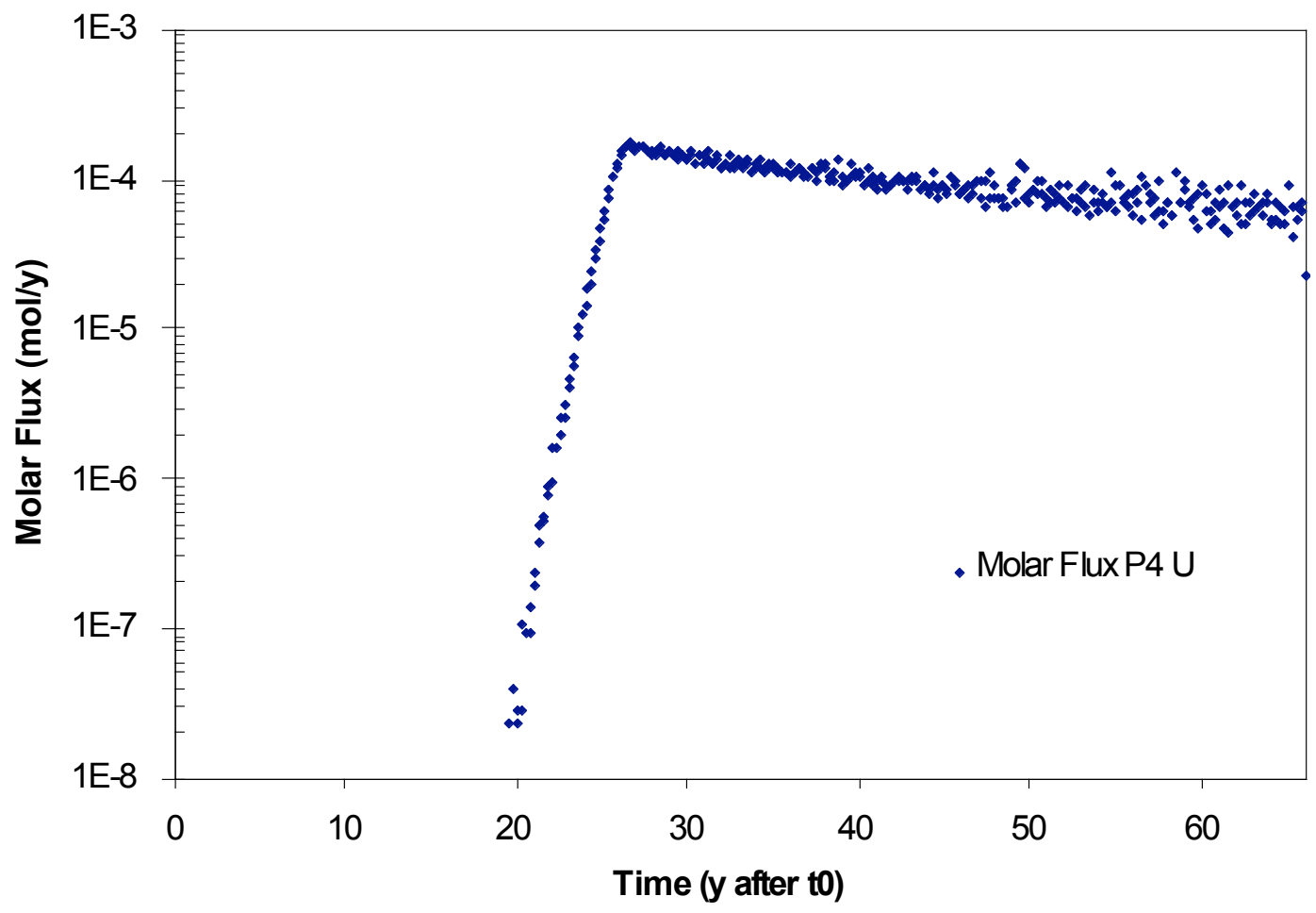

Figure 5.41 Plot of molar flux at plane 4 for radionuclide class $\mathrm{U}$. 
The two tracer classes and $\mathrm{U}$ and $\mathrm{Np}$ behave very differently from the other nine radionuclide classes discussed above and require special treatment for the hydrologic source term. As discussed earlier, these radionuclide classes break through at RNM-2S and are then redistributed along the ditch and lake discharge area, thus being reintroduced as source into the domain. The footprint of the lake discharge area extends beyond the breakthrough planes 1-3 making them useless to track mass or molar fluxes while pumping and vadose zone migration is occurring. For this reason, breakthrough plane 4 was used to track mass that crosses the water table from the ditch and lake discharge area via the vadose zone. Figure 5.41 plots the molar flux that crosses plane 4 for the radionuclide class $\mathrm{U}$. This figure shows that the molar flux for $\mathrm{U}$ grows after about $20 \mathrm{y}$ and reaches a maximum just after RNM-2S pumping has ceased, with continued migration for the majority of the recession and vadose zone drainage period, up to about $65 \mathrm{y}$. Figure 5.42 plots $\mathrm{U}$ breakthrough across the breakthrough planes 1-3 from 60 to $1,000 \mathrm{y}$. This figure shows that that much of the $\mathrm{U}$ remains in the CAMBRIC alteredzone system (including the melt glass) after RNM-2S is turned off, and that the ditch and lake discharge area creates a large distributed source that spans the breakthrough planes. These points (the second in particular) tend to negate the concept of breakthrough planes reflecting the behavior of a discrete source that migrates in favor of a much more ergodic plume that covers a very large area. It should also be noted that due to sorption some mass of $\mathrm{U}$ remains in the vadose zone for the entire 1,000-y simulation period.

Figures 5.43 and 5.44 plot the molar fluxes for the tracer class TracerR. These plots show similar behavior to the U breakthrough plots, though the pumping well and ditch are more dominant for TracerR. As discussed earlier and shown in Figure 5.36, $77 \%$ of the TracerR mass is pumped into RNM-2S and distributed along the ditch and lake discharge area. This creates a much larger vadose-zone source, as seen in Figure 5.44, and creates such a large distributed source (see Figure 5.36) that the three breakthrough planes show almost identical behavior, as seen in Figure 5.43. 


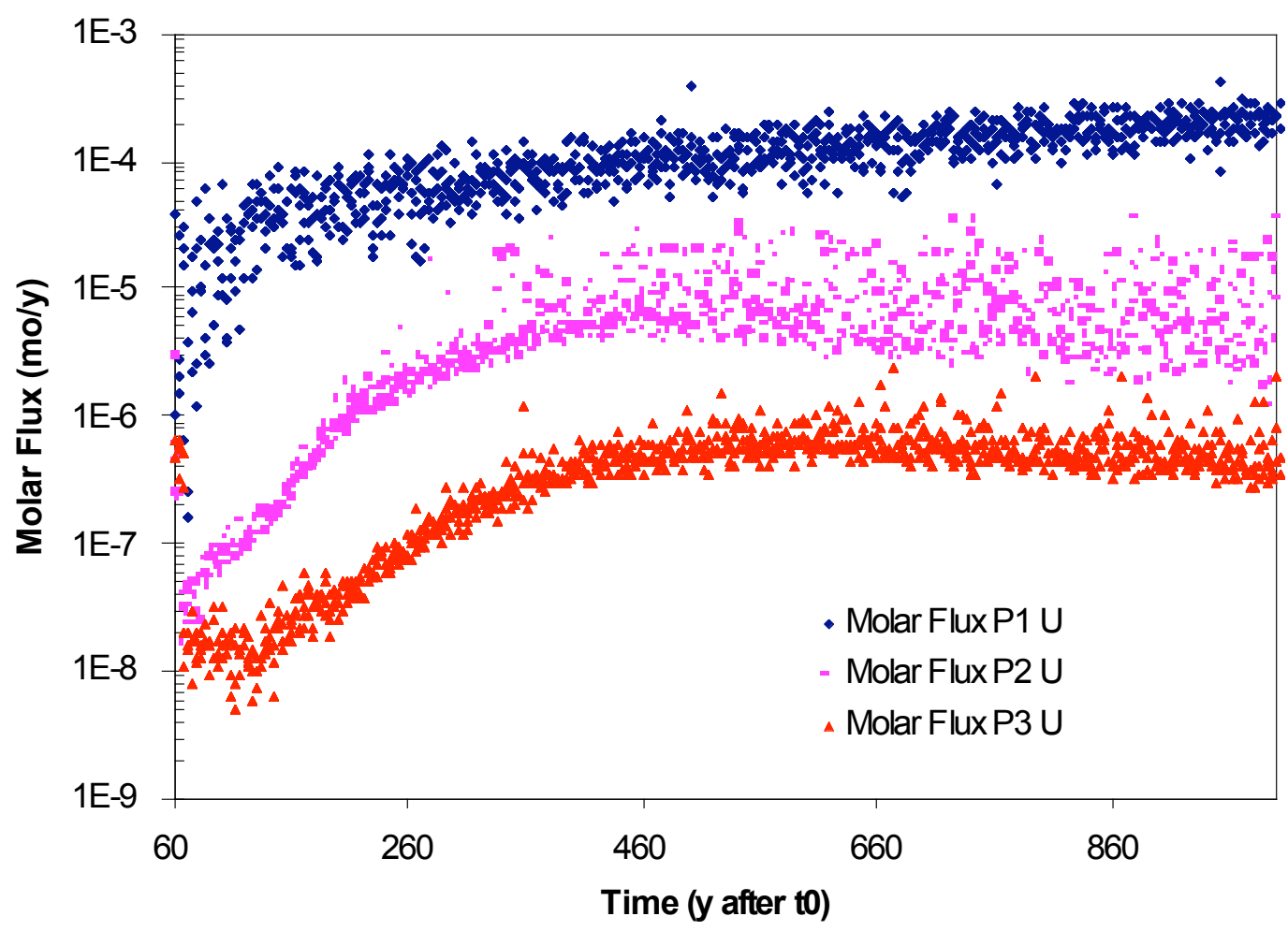

Figure 5.42 Plot of molar fluxes at planes $1-3$ for radionuclide class $\mathrm{U}$.

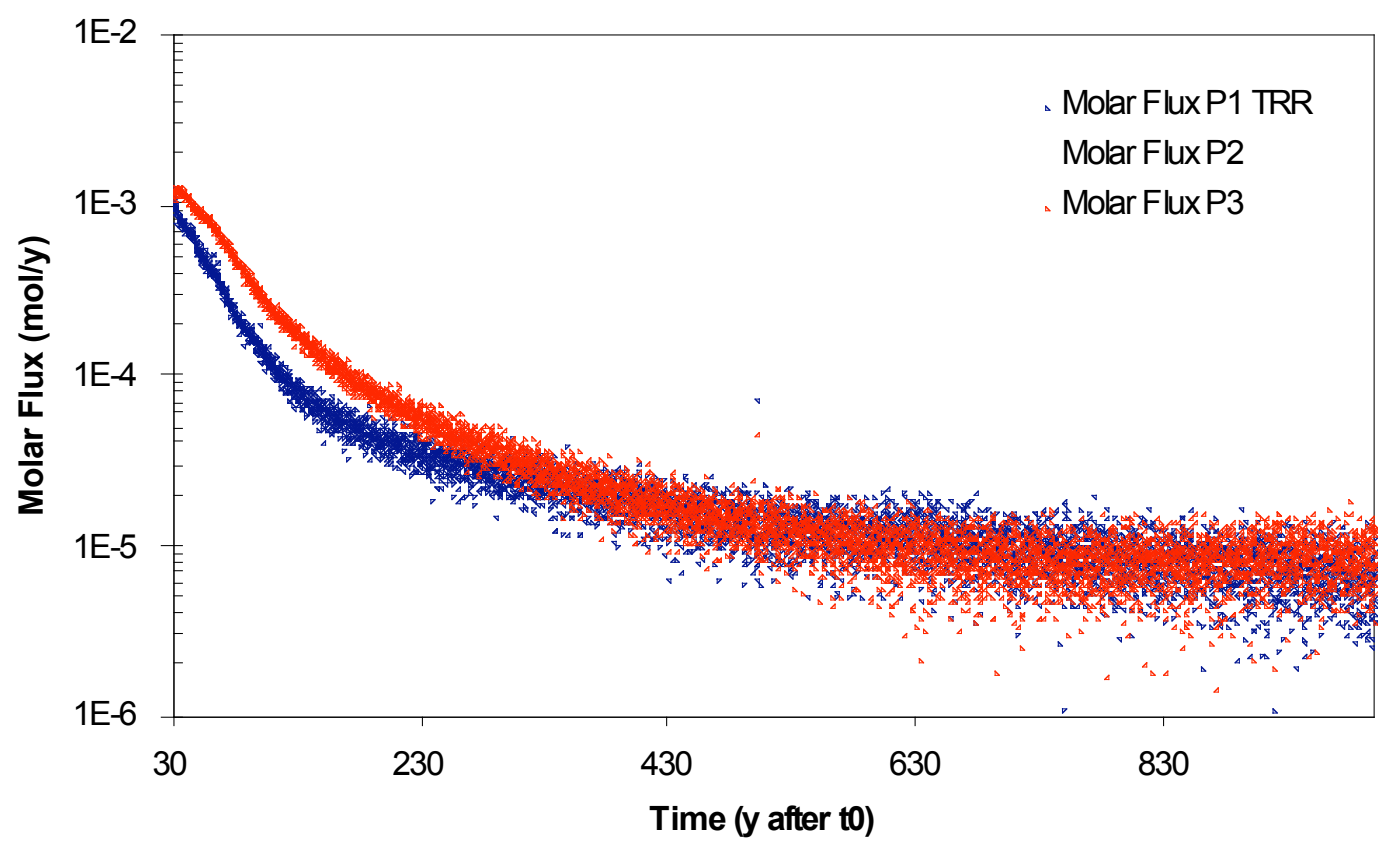

Figure 5.43 Plot of molar fluxes at planes 1-3 for radionuclide class TracerR. 


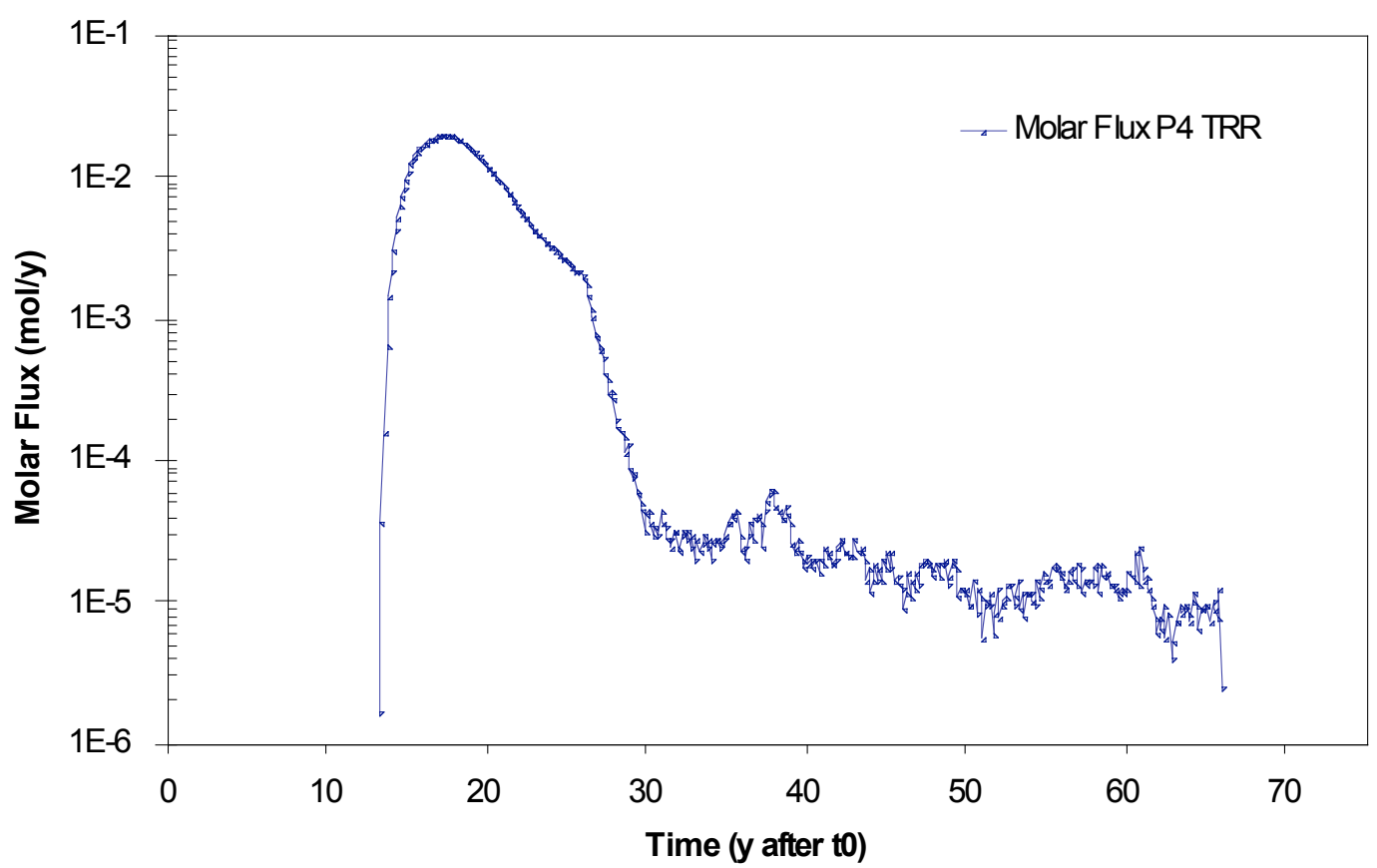

Figure 5.44 Plot of molar flux at plane 4 for radionuclide class TracerR.

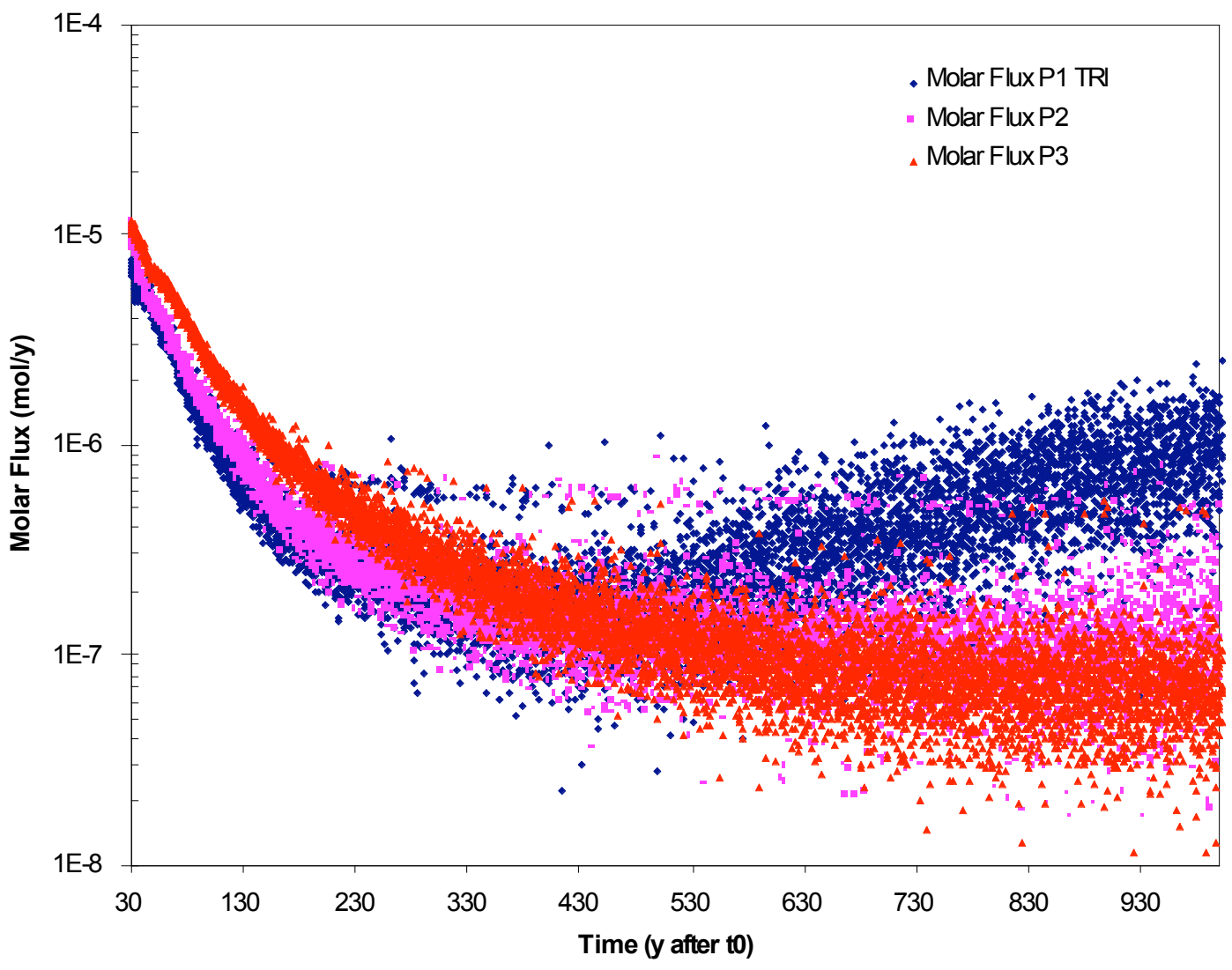

Figure 5.45 Plot of molar fluxes at planes 1-3 for radionuclide class TracerL. 


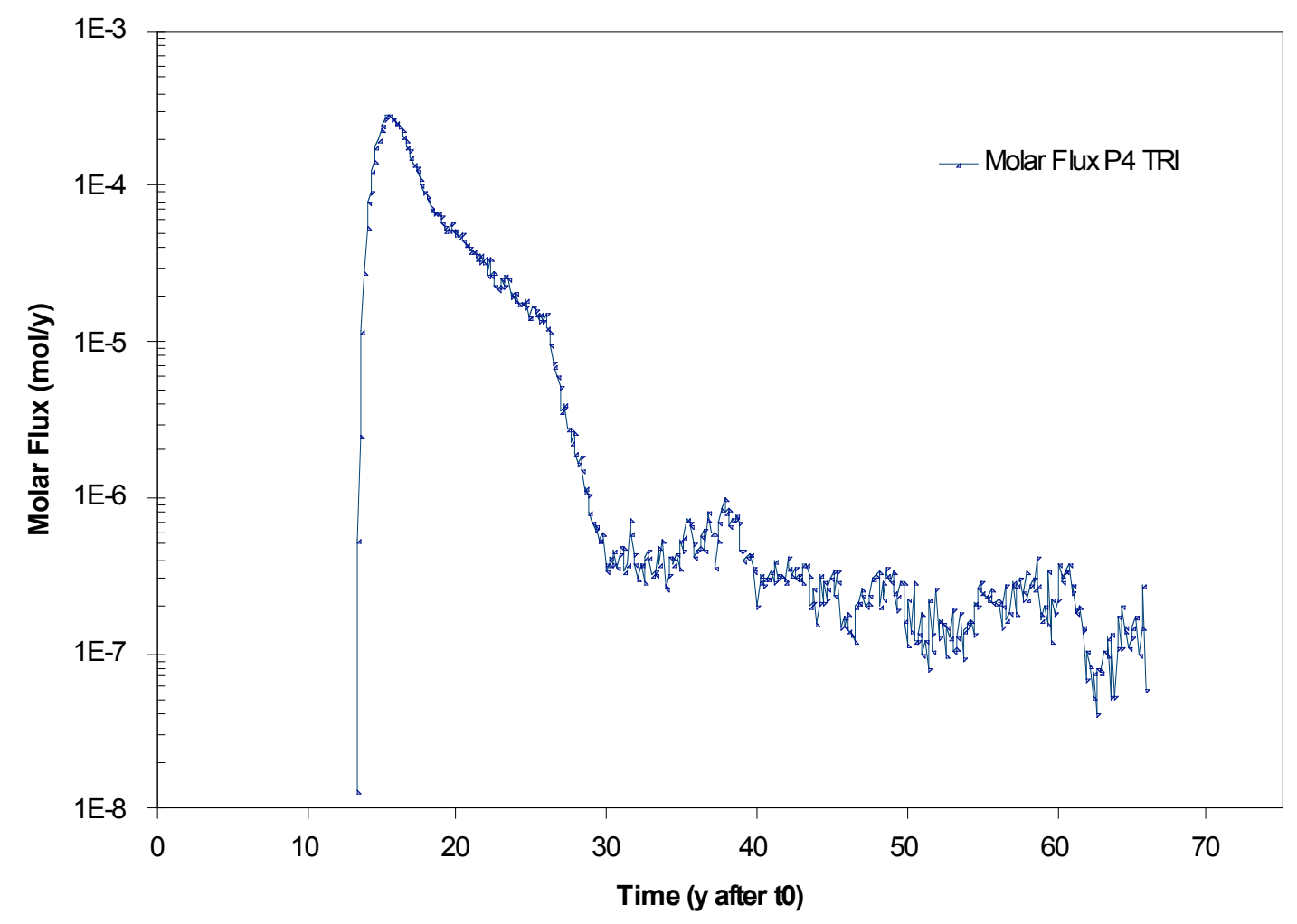

Figure 5.46 Plot of molar flux at plane 4 for radionuclide class TracerL.

Figures 5.45 and 5.46 plot molar fluxes for the TracerL radionuclide class. These plots show similar behavior to TracerR in Figures 5.43 and 5.44, though the magnitudes are different. One notable exception is growth in molar flux over time for plane 1 , likely due to migration of TracerL from the vadose zone.

Figures 5.47 and 5.48 plot molar fluxes for the radionuclide class $\mathrm{Np}$. Though a small amount of Np broke through at RNM-2S (see Figure 5.20) this was not enough mass to represent a significant number of particles, and the ditch and lake discharge area sources were below the particle resolution of the original simulation. A second simulation was run using the Np breakthrough at RNM-2S in Figure 5.20 as a source only for the ditch and lake discharge area (i.e., the cavity was not simulated) with increased particle resolution. This resulted in the molar fluxes shown in Figure 5.48. In Figure 5.47 it should be noted that no $\mathrm{Np}$ arrived at breakthrough planes 2 or 3 during the simulation. 


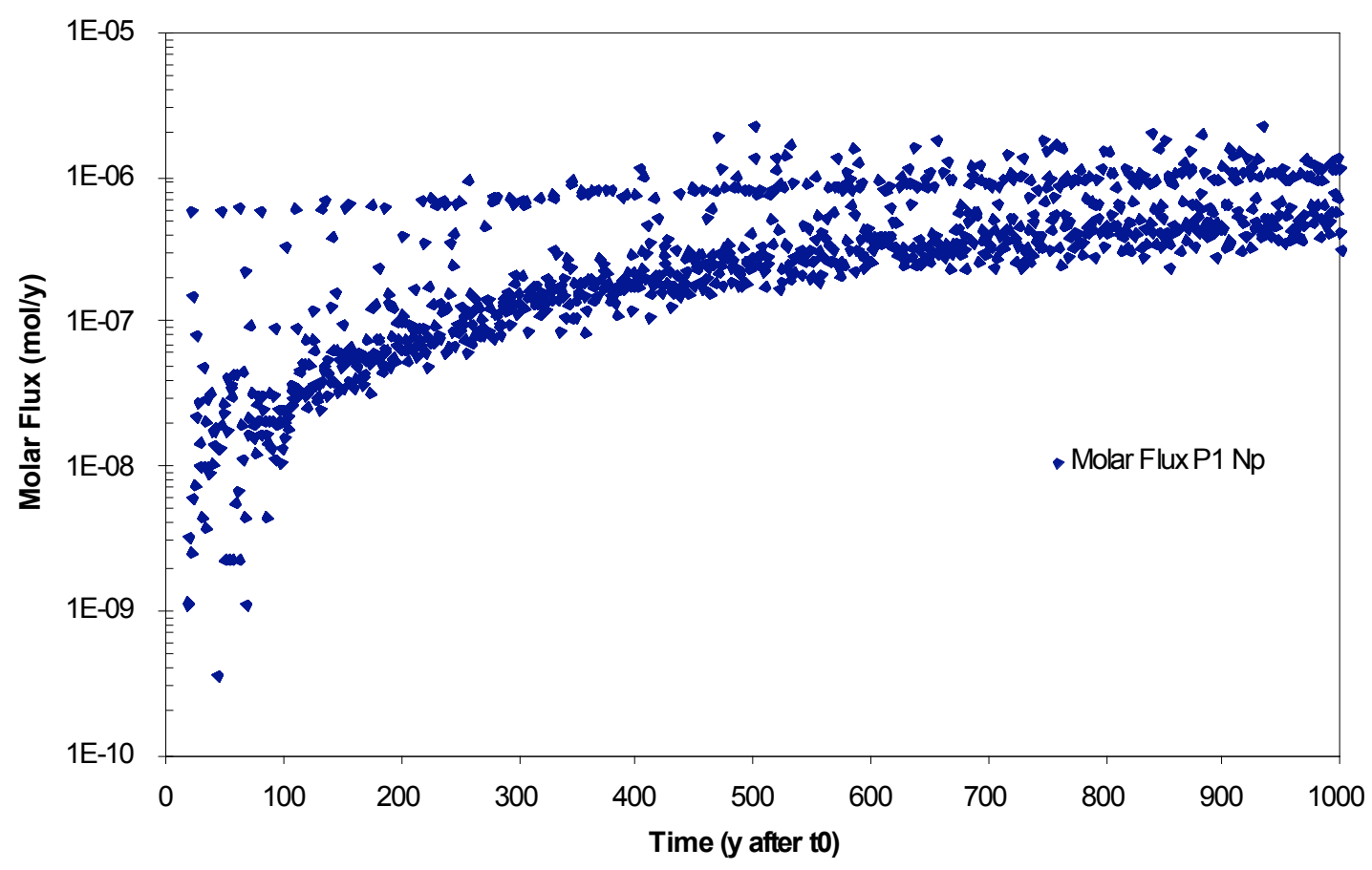

Figure 5.47 Plot of molar flux at plane 1 for radionuclide class $\mathrm{Np}$.

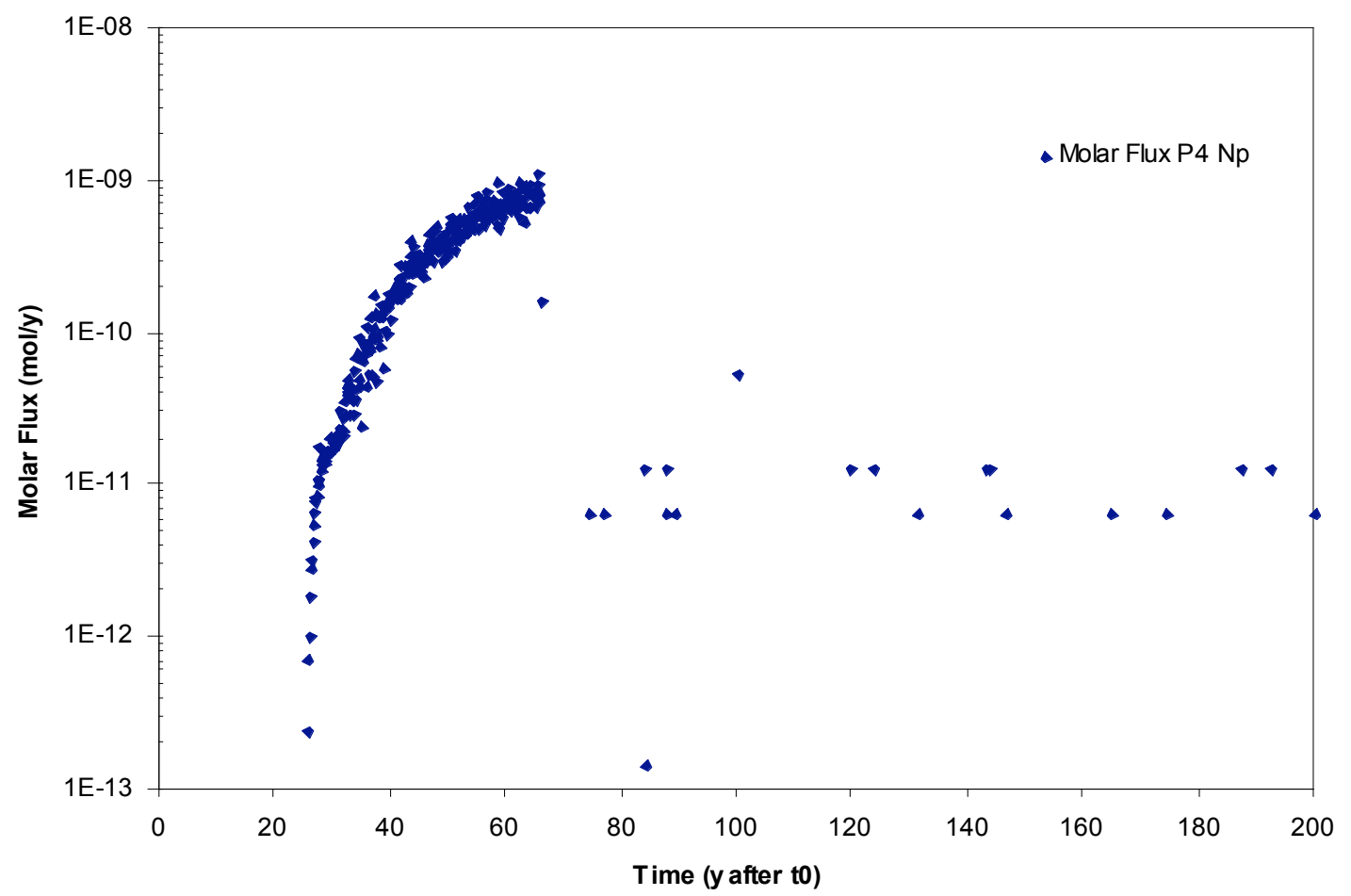

Figure 5.48 Plot of molar flux at plane 4 for radionuclide class Np. 
Due to the large spatial extent of the migration of these four radionuclide classes, snapshots of concentration were generated at $65.75 \mathrm{y}$ (when the vadose zone below the ditch and lake discharge area drained). These concentration snapshots are shown in Figures 5.49 through 5.53 for TracerR, TracerL, U, Np (the cavity Np simulation described above), and $\mathrm{Np} 2$ (the ditch $\mathrm{Np}$ simulation described above). These figures clearly indicate that RNM-2S, in conjunction with reintroduction in the ditch and lake discharge area, has a significant effect on the hydrologic source term. This is most pronounced in Figures 5.49 and 5.50, which show TracerR and TracerL migration over an area of several square kilometers (or a distance of several kilometers). U and Np2 also migrate a significant distance due to pumping and reinfiltration, though to a much less pronounced degree than the two tracers.

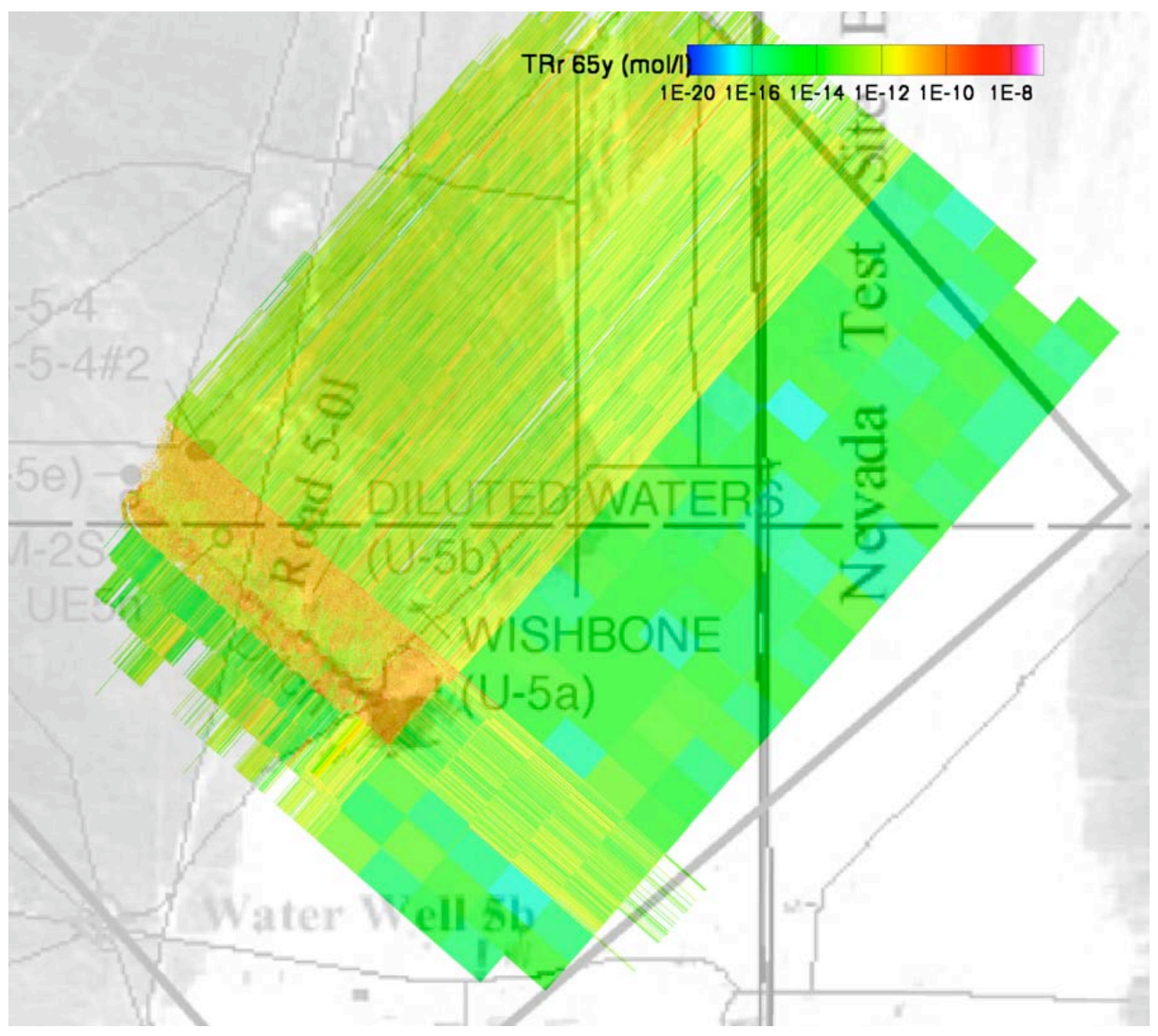

Figure 5.49 Plot of simulated TracerR migration 65.75 y after the CAMBRIC test, after drainage of the vadose zone is mostly complete. An aerial photograph of the NTS is included for reference. 
CHAPTER 5: HYDROLOGIC SOURCE TERM MODELS

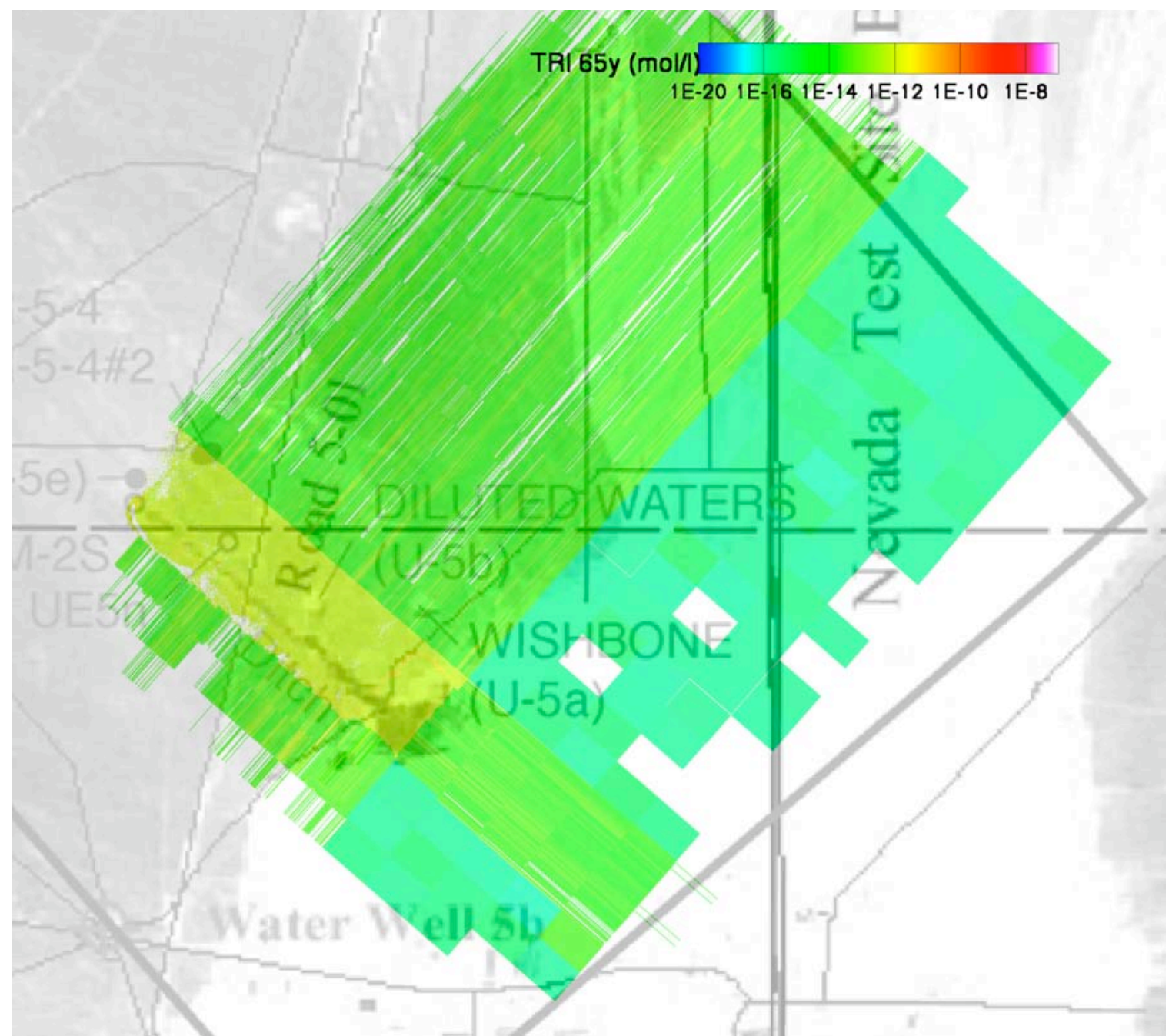

Figure 5.50 Plot of simulated TracerL migration 65.75 y after the CAMBRIC test, after drainage of the vadose zone is mostly complete. An aerial photograph of the NTS is included for reference. 
CHAPTER 5: HYDROLOGIC SOURCE TERM MODELS

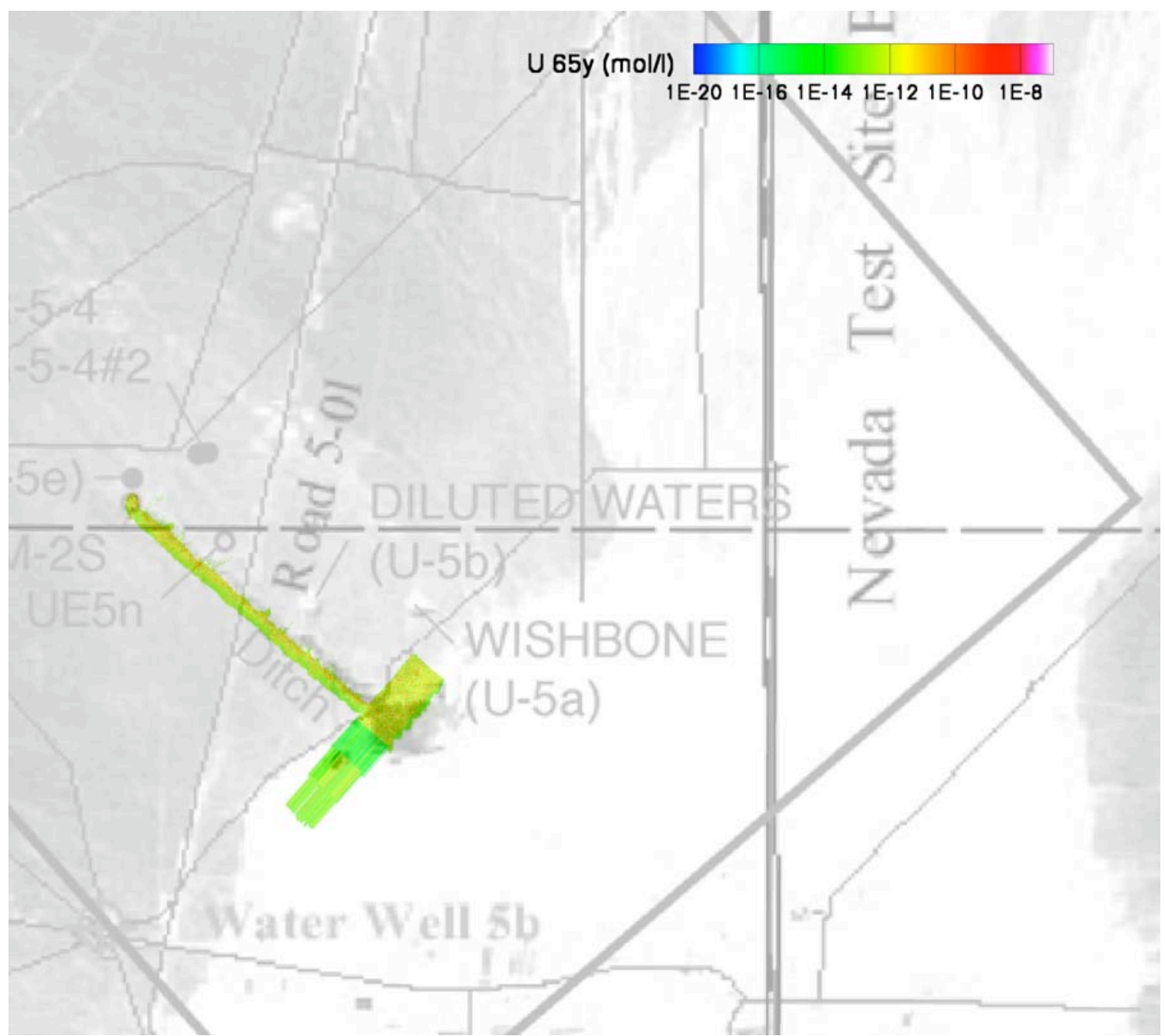

Figure 5.51 Plot of simulated U migration $65.75 \mathrm{y}$ after the CAMBRIC test, after drainage of the vadose zone is mostly complete. An aerial photograph of the NTS is included for reference. 
CHAPTER 5: HYDROLOGIC SOURCE TERM MODELS

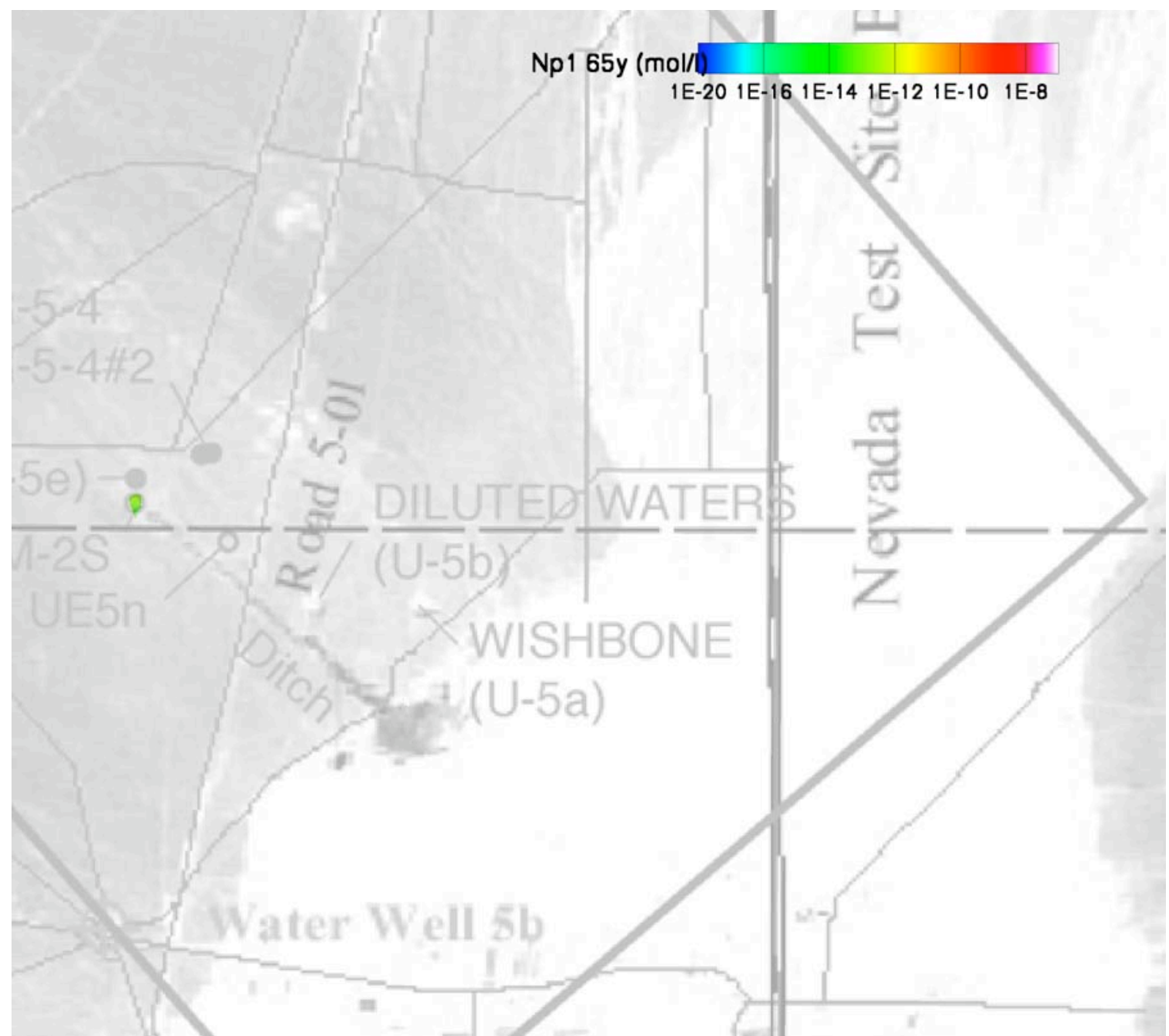

Figure 5.52 Plot of simulated Np1 migration $65.75 \mathrm{y}$ after the CAMBRIC test, after drainage of the vadose zone is mostly complete. An aerial photograph of the NTS is included for reference. 
CHAPTER 5: HYDROLOGIC SOURCE TERM MODELS

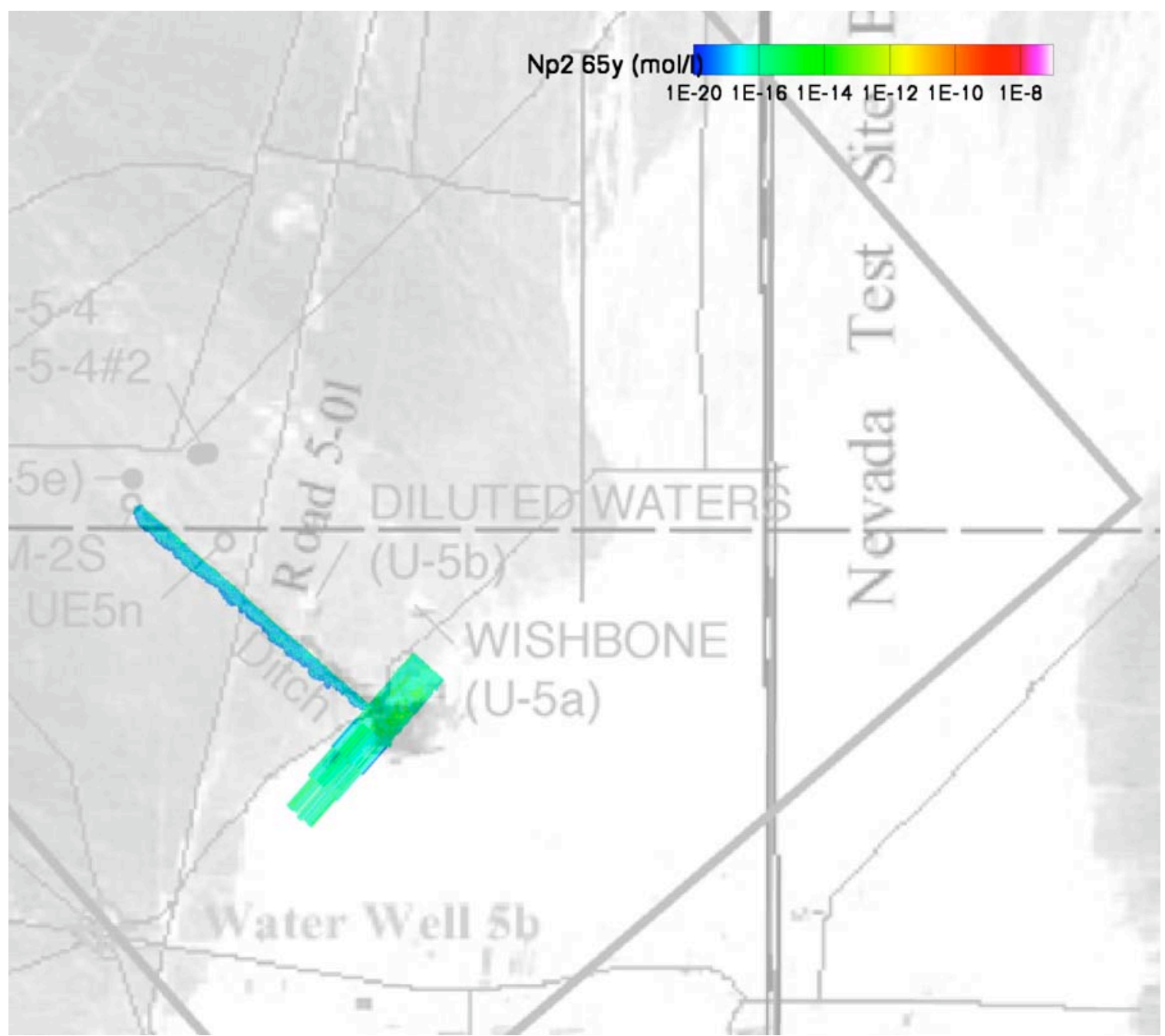

Figure 5.53 Plot of simulated Np2 migration $65.75 \mathrm{y}$ after the CAMBRIC test, after drainage of the vadose zone is mostly complete. An aerial photograph of the NTS is included for reference. 


\subsection{Additional Interpretations and Discussion}

The ParFlow/SLIM transport model can be used to predict migration of radionuclides over the entire domain. Though the model was originally designed to investigate transport over the fine-mesh region only, upon analysis of results over the entire domain for both coarse and fine-mesh regions (e.g., Figure 5.54), the fact that the model predicted transport beyond the fine-mesh region in a short period of time $(<20 \mathrm{y})$ was realized. Figure 5.55 demonstrates the extent of tracer migration after $50 \mathrm{y}$. This figure shows that migration of TracerR extends outward from the cavity/chimney region, into RNM-2S, through the ditch and playa, back down to the water table, and eventually filling the upper alluvial layers of the AA CAU-scale units. Though the coarse mesh region of the ParFlow model does not incorporate some aspects of the fine-mesh region designed to more accurately represent the velocities that eventually are used to simulate transport, it does point to some mechanisms that may lead to more extensive transport predictions. A number of factors lead to these comprehensive transport predictions:

- Most of the tracer is captured by the pumping well RNM-2S.

- This tracer is then distributed over a very large area (the ditch and playa) at the ground surface where it reinfiltrates.

- While most of the area under the ditch is within the capture zone of RNM-2S, most of the playa and some of the ditch are not. This is seen in Figure 5.54, which shows tracer migration after $20 \mathrm{y}$ (or over $9 \mathrm{y}$ of pumping and infiltration) where the tracer underneath the ditch is migrating toward the pumping well (in the right of the figure) and the tracer under the playa is migrating away from the playa and is in the coarse mesh region of the model (evident by the obvious change in resolution).

- Reinfiltration of pumped effluent creates significant mounding at the water table, which is shown in Figures 5.14 and 5.15. This effect creates a large hydraulic potential resulting in large velocities, shown in Figures 5.16 and 5.17 .

- These large velocities push the tracer down first into Layer AL2b, which is more permeable than Layer AL3, and then laterally along this unit.

- The simplified geologic model used to construct the ParFlow grid assumes that the alluvial layers are laterally extensive across the entire AA HSU unit at the CAU scale.

Tracer is thus predicted to migrate laterally a significant distance. To examine how significant these concentrations may be, a simulation that incorporated the Hoffman et al. (1977) ${ }^{3} \mathrm{H}$ source term with decay was carried out. The results of this simulation are shown in Figure 5.56, which also includes an aerial photograph and map of Frenchman Flat. It should be noted that the concentrations modeled are actually lower than detectable $\left(1 \times 10^{-16} \mathrm{~mol} / \mathrm{L}\right.$, light and dark-blue in the figure) and that the EPA limit for ${ }^{3} \mathrm{H}$ in groundwater is $1 \times 10^{-12} \mathrm{~mol} / \mathrm{L}$, or yellow in this figure. The model predicts significant migration after $20 \mathrm{y}$ (1985), including transport eastward, though the concentrations are below both detection and background. By 40 y after the test (2005), the model predicts transport over much of the AA HSU and predicts detectable concentrations to the east. At 
$100 \mathrm{y}$ after the test (2065), ${ }^{3} \mathrm{H}$ has filled the local basin and has extended to two edges of the model boundary, though with radioactive decay, these concentrations are all at or below detection and background levels.

While these results suggest more radionuclide migration than was anticipated, these simulations are subject to much uncertainty in:

- The magnitude and direction of the hydraulic gradients. Although there are some data regarding direction and magnitude of the background and ditchinfluenced hydraulic gradients, there is still much uncertainty in large portions of the east side of Frenchman Flat.

- The true permeability structure, which is unknown and could inhibit transport.

- The predicted concentrations, which are small.

Nevertheless, these results suggest significant influence from RNM-2S pumping and ditch-playa infiltration on large-scale migration. CAU transport modeling will investigate issues related to radionuclide migration over a large scale and those results will be used to develop the contaminant boundary.

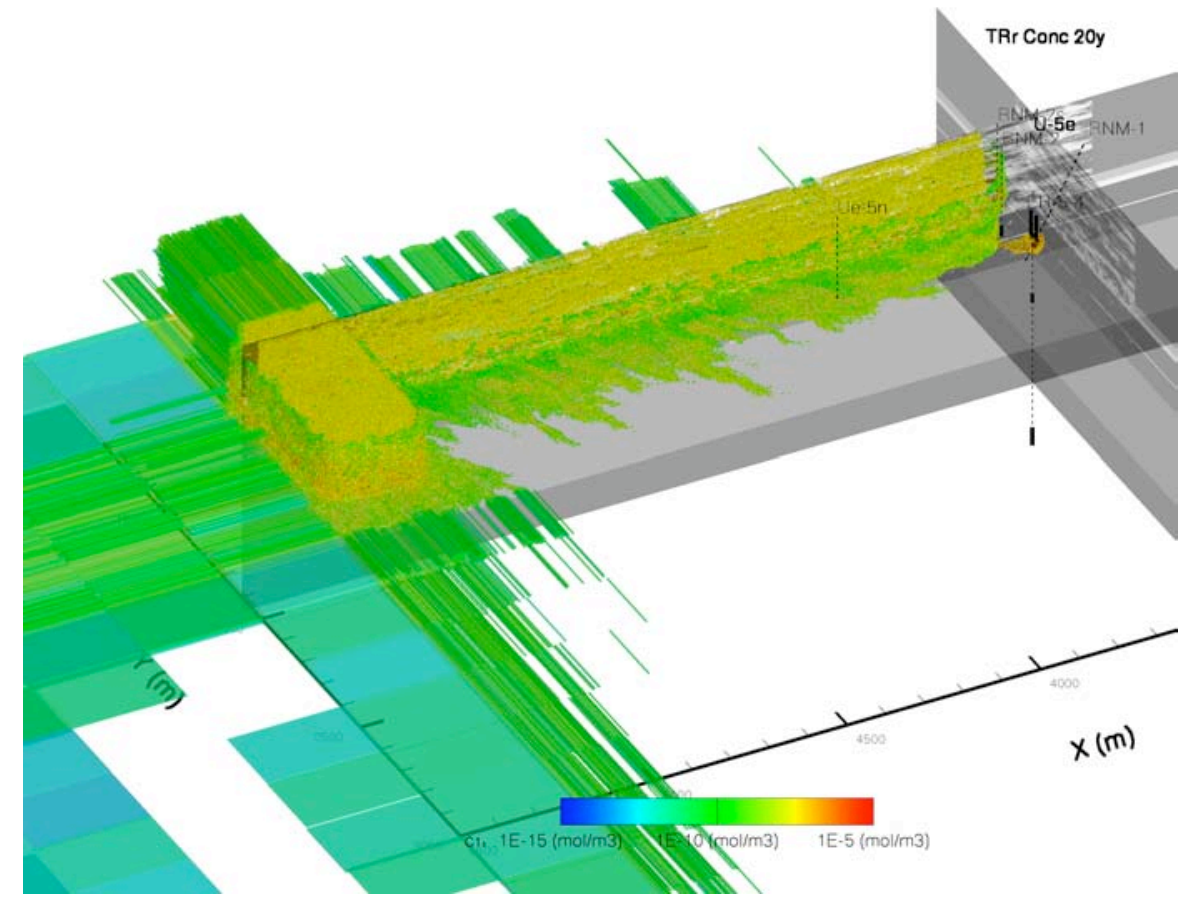

Figure 5.54 Plot of simulated tracer (TracerR) migration at $20 \mathrm{y}$ after the CAMBRIC test. The test location and vicinity wells are shown, as are two cross sections of hydraulic conductivity in grayscale. Note that this simulation does not include decay. 


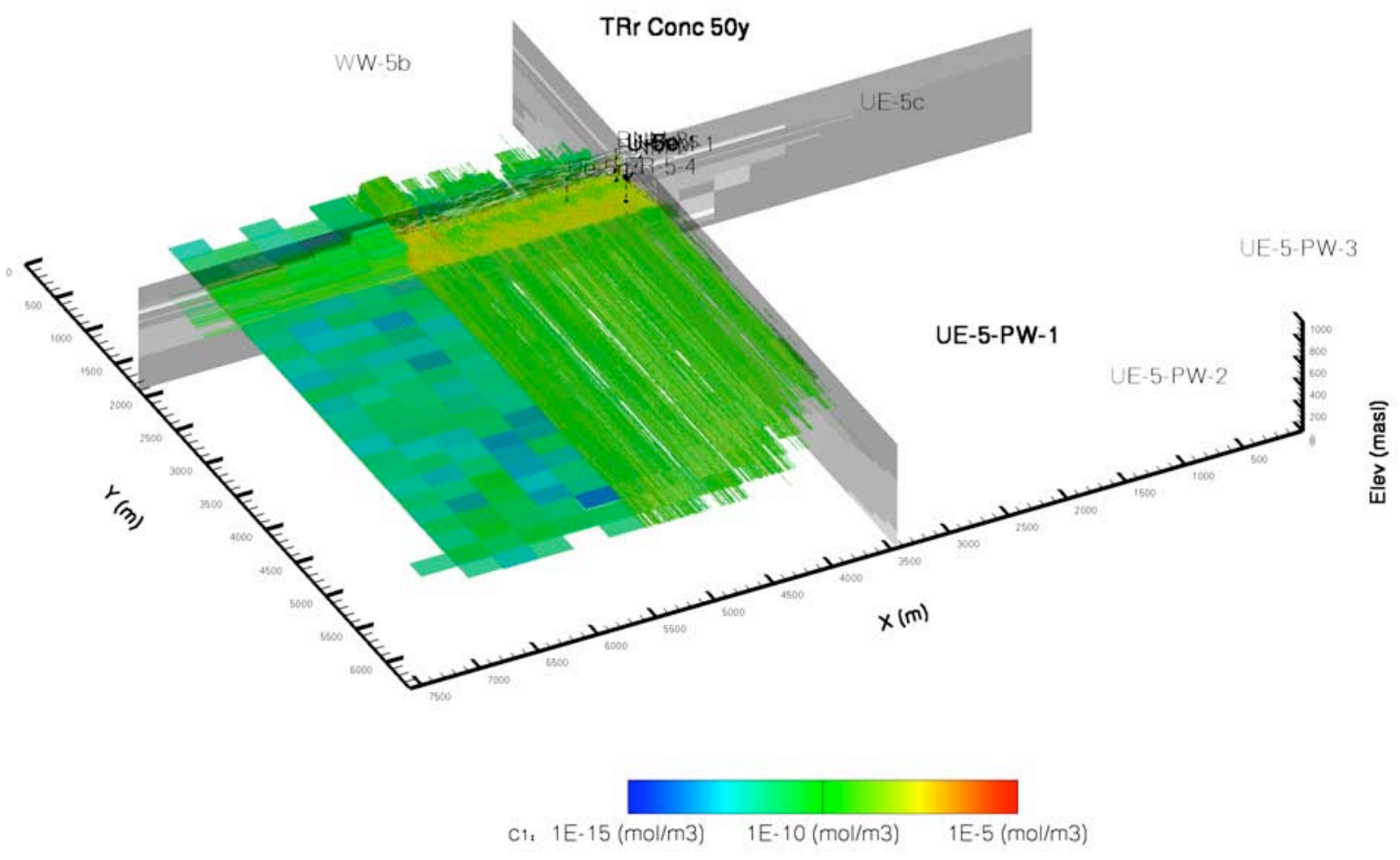

Figure 5.55 Plot of simulated tracer (TracerR) migration at $50 \mathrm{y}$ after the CAMBRIC test. The test location and a number of Frenchman Flat wells are shown for reference, as are two cross sections of hydraulic conductivity in grayscale. Note that this simulation does not include decay. 
CHAPTER 5: HYDROLOGIC SOURCE TERM MODELS

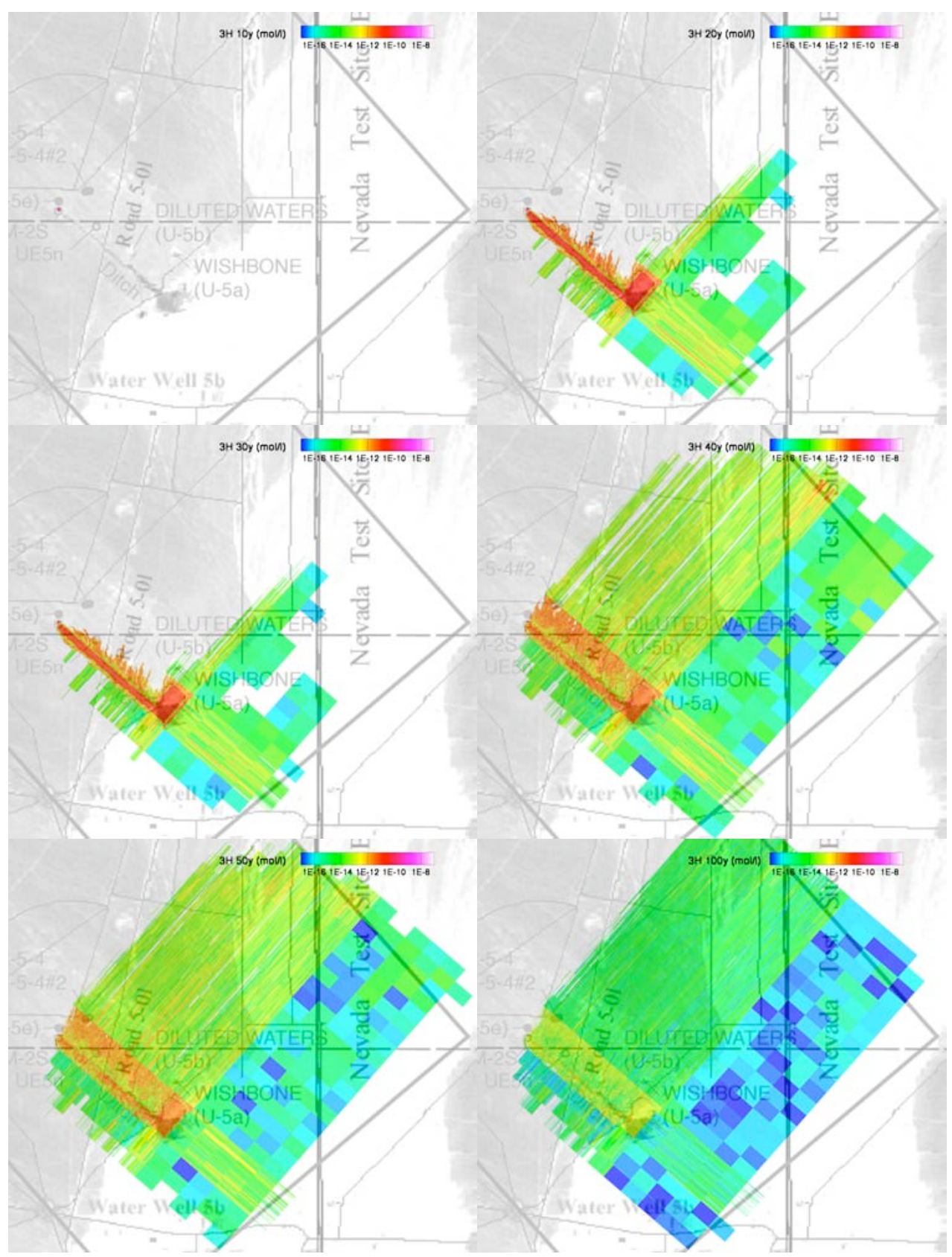

Figure 5.56 Plot of simulated ${ }^{3} \mathrm{H}$ migration at 10, 20, 30, 40, 50, and $100 \mathrm{y}$ after the CAMBRIC test. An aerial photograph of the NTS is included for reference. All concentrations include radioactive decay. 


\section{Considerations for Applying HST Results in the CAU Model}

\subsection{Background}

The HST model results presented in Chapter 5 were developed under detailed, site-specific conditions associated with CAMBRIC. These conditions include:

- A small-scale, high-resolution, and complex reactive transport modeling framework in the immediate vicinity of the test

- Specific hydraulic, physical, and mineralogical characteristics of the site, including the structure and composition of the alluvium, saturation conditions, water levels and hydraulic gradients, and groundwater chemistry, as well as altered aspects of the site associated with the test, such as the cavity, chimney, and melt-glass zones

- The effects of transient flow associated with residual test heat and groundwater pumping, ditch recharge, and infiltration to the saturated zone

The results provide detailed insight into the groundwater flow and radionuclide transport that occurred in and around the cavity and melt glass zones at CAMBRIC, as well as the ditch and lake impoundment infiltration areas. However, their direct applicability in the Frenchman Flat CAU-scale model, either at the CAMBRIC site itself or at other testing locations, is limited in several ways.

First, in all cases, the CAU model has a coarser grid resolution and is unable to fully represent or reproduce all of the processes included in the HST model. This discrepancy between the models will require some distillation of the results, either for inclusion as an external type of source input across idealized flux planes or for the development of simplified numerical or analytical models that can be calibrated to reproduce the current results and predict new results under different scenarios, or both, as has been discussed and advanced in previous HST model reports (Tompson et al., 1999 and Pawloski et al., 2001) and simplified source term model analyses (Tompson et al., 2004 and Stoller-Navarro, 2005b).

Second, other test locations in Frenchman Flat have different physical, chemical, and test-related features that will affect the nature of the HST evolution differently than they do at CAMBRIC.

Third, other test locations do not have the same kind of transient flow due to test-related heat and pumping and infiltration that has modified radionuclide distribution at CAMBRIC. A separate set of HST results was therefore generated at CAMBRIC based upon a steady-state groundwater flow field (Tompson et al., 2005). This steady-state scenario can be used to aid in the development of simpler release models at the other nine underground test sites in the Frenchman Flat CAU. 
Below, several considerations are reviewed as they pertain to using these HST results in a CAU model. Additional details may be found in the reports of Pawloski et al. (2001), Tompson et al. (2004), and Stoller-Navarro (2005b).

\subsection{Considerations for Applying the Steady-State HST Elsewhere in Frenchman Flat}

The steady-state source term simulations at the CAMBRIC site are described and summarized in a separate report (Tompson et al., 2005). They are based upon a steady-state groundwater flow field at CAMBRIC, unaffected by any transient flow effects from test-related heat, pumping, or ditch recharge. This flow field is essentially equivalent to the transient flow field at later times, between years 100 and 1,000 , in the transient flow simulation.

As such, the steady-state source term model is based upon similar physical and mineralogical characteristics of the site, both natural and altered, and similar background hydraulic conditions as in the current transient source term simulations. The radionuclide inventory used in the steady-state source term simulations was the mean unclassified RST for Frenchman Flat (Bowen et al., 2001), averaged for the 10 underground tests. Although the steady-state simulations were based upon an isothermal flow model, the melt glass temperature history presented in Chapter 4 was still used to determine melt glass radionuclide release functions.

The steady-state source term results were reported in terms of radionuclide fluxes determined over a 1,000-y period across three vertical flux planes described in Chapter 5 (shown again in Figure 6.2). The orientation of the planes was selected to be perpendicular to the simulated flow directions developed in the model.

Use of the steady-state source term results at generic, assumed saturated zone test locations in Frenchman Flat will require consideration of the computed groundwater flux at these locations relative to the flux inherent in the steady-state results, as well as corresponding differences in the mineralogic and reactive nature of the geologic media at each location:

- Scaling of the existing results may be considered as a means to adjust for differences in local fluxes or reactive properties, in the manner of Chapter 8 in Pawloski et al. (2001).

- Alternatively, simplified analytic flow models calibrated to reproduce the steady-state results can be developed, as in Tompson et al. (2004) or StollerNavarro (2005b), and applied at other locations in Frenchman Flat.

Unfortunately, neither of these approaches is able to reflect any buoyancy effect of residual test-related heat or other transient flow process. 


\subsection{Additional Considerations for Applying the Transient HST at the CAMBric Site}

As discussed in Chapter 5, the transient CAMBRIC HST results can be generally organized into three broad mobility classes that may influence how they are treated in a CAU model.

\section{Non-reactive tracer radionuclides ( $\operatorname{such}$ as ${ }^{3} \mathrm{H}, \mathrm{Cl}$, and $\mathrm{Kr}$ ) were strongly affected by transient flow processes at the site such as thermally induced buoyant flow, pumping, infiltration, mounding, and recirculation.}

Most ( $>70 \%$ ) of the non-sorbing radionuclides in the RST (that portion initially available in the exchange volume) were flushed from the cavity and chimney system and captured by RNM-2S during the pumping experiment. The remaining fraction $(<30 \%)$ is retained in the melt glass. Radionuclides captured in the pumping well were discharged into the ditch and allowed to infiltrate to the water table and potentially be recaptured by the well or be driven away from the ditch by the accumulated groundwater mound or the background groundwater flow. This creates a widely dispersed source in the near-field saturated zone system by the time the transient effects dissipate, approximately $65 \mathrm{y}$ after CAMBRIC was detonated.

The movement of radionuclides in groundwater underlying the ditch is affected by interacting hydraulic flow gradients induced by pumping, the accumulated groundwater mound, and the local background flow gradient. The first two of these effects are short lived but well represented in the HST model as a result of calibration and available observations.

Reproduction of the dispersed tracer radionuclide plume in the CAU model may be achieved either through direct specification of the distributed plume as an initial source at some delayed time (say, at the 65-y mark) in the model, or recreation of the pumping, infiltration, recapture, and radionuclide flux mechanisms in the CAU model from the beginning of the simulation.

The first approach is conceptually simple but may generate inconsistencies arising from differences in the local gradients and flow fields simulated by the HST and CAU models. One inconsistency will arise if the HST model-generated tracer plumewhose evolution was controlled by the HST background gradient - is inserted at the same location into the CAU model where the gradient differs. Another inconsistency will arise if the HST model-generated tracer plume has moved into perimeter areas of the HST model domain model where confidence in the results is lower than in the center of the domain. Additional discussion of the CAU and HST model flow gradients is given in section 6.4 .

The second approach requires formal inclusion of transient behavior in the CAU flow model and depends on how well the pumping, infiltration, and recapture mechanisms are represented and interfaced with the local background flow, in an equivalent balance as in the HST model. Although local background gradients in the 
CAU model may differ, the plume evolution that results will be internally more consistent.

2. Most strongly sorbing radionuclides (e.g., Sr, Cs, and Pu) were unaffected by pumping and infiltration.

The movement of these radionuclides in the groundwater flow system under the transient flow period was minimal. The principal mode of transport in the hydrologic regime will occur under ambient flow conditions for $935 \mathrm{y}$ after the initial transient period.

Reproduction of these HST radionuclides in the CAU model can be achieved in a manner similar to what has been used in previous steady flow scenarios (see above, Tompson et al., 2004, and Stoller-Navarro, 2005b). In the CAU model, where the background flow gradient may differ from that in the HST model, the simulated radionuclide fluxes crossing the planes in Figure 6.1 can be construed as crossing three "rotated" planes perpendicular to the simulated gradient yet equidistant to U-5e.

3. Most glass-bound radionuclides (including those tracers not in the exchange volume) were completely unaffected by pumping and infiltration because of the slow rate of dissolution of the glass

The movement of these radionuclides in the groundwater flow system under the transient flow period was also minimal. The principal mode of transport in the hydrologic regime will occur under ambient flow conditions for $935 \mathrm{y}$ after the initial transient period. Glass dissolution provides a small but long-term source for both sorbing and non-sorbing radionuclides.

4. Uranium and $\mathrm{Np}$, the only sorbing radionuclides observed in the simulations to break through at the pumping well, are among the most weakly sorbing considered.

Neptunium concentrations are very small and potentially insignificant to the overall HST. Uranium concentrations are significant to the HST but still a small percentage of the total source term.

\subsection{Differences between the HST and CAU Model-Generated Flow Gradients at CAMBRIC}

The discussion in Section 6.3 refers to potential differences in the background flow gradients simulated by the HST and CAU models and the possibility for inconsistencies to arise when concentration results from the HST model are imported into the CAU model. This discussion refers inherently to local gradients in the immediate vicinity of the CAMBRIC test as opposed to larger-scale gradients that exist or extend over the CAU model domain. The local gradient governs the rate and direction of radionuclide movements away from the test. Larger-scale gradients are more coarsely defined and are indicative of the general groundwater flow rates and directions over much of Frenchman 
Flat. These kinds of gradients are not necessarily the same and should be distinguished from one another.

\subsubsection{Flow Gradients over the CAU Area}

A relatively simple post-HST-modeling exercise evaluated the north-to-south hydraulic gradient over the larger-scale CAU model area. The gradient was determined from measured water levels and associated uncertainties and motivated by an observation in Stoller-Navarro (2006b) that

"...the [water-level] data [in Frenchman Flat] show an overall north-to-south gradient between the northernmost wells and the wells along the southern edge of the playa, but ...there is almost no difference in heads in the northern and central portions of the basin...."

The current determination is based upon updated water-level data in the Frenchman Flat CAU model domain provided in Stoller-Navarro (2006b) and repeated in Table 6.1. (These data differ slightly from those in Table 2.1, as they include recent corrections to well coordinates and elevations provided by Stoller-Navarro, 2006a.) These water-level elevations, obtained from wells screened only in alluvium, show differences of about $1 \mathrm{~m}$ or less, generally comparable to the total uncertainty of the estimated steady-state water level elevations. A small north-to-south gradient within the Frenchman Flat CAU model domain could be attributed to relatively high permeability alluvium combined with lack of flow barriers such as faults. Stoller-Navarro (2006b) does not provide a quantitative analysis of the magnitude and direction of the horizontal hydraulic gradient within the CAU.

If the general north-to-south gradient through Frenchman Flat suggested by Stoller-Navarro (2006b) persists within the CAU model domain, then the CAU-scale horizontal gradient in alluvium over a distance of about $6 \mathrm{~km}$ can be analyzed by plotting the water level elevation data given in Table 6.1 as a function of northing, as shown in Figure 6.2. For simplicity in Figure 6.2, data for the three ER-5-3 wells is represented solely by the "ER-5-3 sh" (shallow) data because mean water-level elevations and uncertainties are nearly identical for all three ER-5-3 measuring points. RNM-1 was not included in this exercise because of the relatively large uncertainty in water level (about $4 \mathrm{~m}$ ), which is unresolvable due to poorly known coordinates and depth for this slant hole.

Estimates of minimum and maximum horizontal gradients are fit through the data in Figure 6.1 by honoring the range of uncertainty for all wells. Thus, if a northsouth alignment is assumed for the CAU-scale horizontal hydraulic gradient, the data indicate a possible gradient range of 0.00023 south to 0.000043 north. Notably, a zero north-to-south CAU-scale gradient would fall within the range of uncertainty. A median estimate, taken by averaging the range, is 0.000094 south. Therefore, if an average northto-south hydraulic gradient were expected to persist through the entire CAU, a realistic estimate of its magnitude would be on the order of 0.0001 south. 
Table 6.1. Coordinates and steady-state water level elevations and uncertainties for wells screened in alluvium within the Frenchman Flat CAU (modified from StollerNavarro, 2006a and Stoller-Navarro, 2006b). These data are updated from those shown in Table 2.1.

\begin{tabular}{|l|l|l|l|l|}
\hline \multicolumn{1}{|c|}{ Well } & Easting $\mathbf{( k m )}$ & Northing $\mathbf{( k m )}$ & $\begin{array}{c}\text { Water-Level } \\
\text { Elevation }(\mathbf{m})\end{array}$ & $\begin{array}{c}\text { Total } \\
\text { Uncertainty }(\mathbf{m})\end{array}$ \\
\hline ER-5-3 \#3 & 594.655 & $4,081.116$ & 733.9 & $+/-1.05$ \\
\hline ER-5-3 m/c* & 594.655 & $4,081.116$ & 733.88 & $+/-1.07$ \\
\hline ER-5-3 sh* & 594.655 & $4,081.116$ & 733.9 & $+/-1.06$ \\
\hline UE-5f & 593.975 & $4,080.785$ & 734.9 & $+/-1.43$ \\
\hline UE-5 PW-2 & 593.670 & $4,080.144$ & 733.74 & $+/-0.75$ \\
\hline UE-5 PW-1 & 593.656 & $4,078.714$ & 733.79 & $+/-0.71$ \\
\hline ER-5-4 pz* & 592.444 & $4,075.676$ & 733.53 & $+/-0.43$ \\
\hline ER-5-4 m/c ${ }^{*}$ & 592.444 & $4,075.676$ & 733.38 & $+/-0.38$ \\
\hline RNM-2 & 592.221 & $4,075.527$ & 733.55 & $+/-0.88$ \\
\hline RNM-2S & 592.137 & $4,075.483$ & 733.68 & $+/-0.68$ \\
\hline UE-5n & 597.627 & $4,075.284$ & 733.80 & $+/-0.47$ \\
\hline
\end{tabular}

* Abbreviations m/c, sh, and pz stand for main/composite, shallow, and piezometer, respectively.

In Figure 6.1, it is interesting to note the conspicuously larger gradient evident in the mean water-level data closest to CAMBRIC (specifically from ER-5-4 piezometer, ER-5-4 main/composite, RNM-2, RNM-2S, and UE-5n). Collectively, these indicate a northerly horizontal gradient on the order of 0.001 north local to CAMBRIC. This is over an order of magnitude greater, and in a nearly opposite direction, than the gross CAUscale gradient of 0.0001 south estimated from the data in Figure 6.1. These differences may be caused, all or in part, by local variations in the hydraulic gradient attributable to heterogeneity, vertical or transient flow events, uncertainty in the data, or a specific focus on local data as compared to CAU-scale data. In truth, local variations in the hydraulic gradient are not unexpected, and it is, therefore, not unreasonable to expect that the local gradient in the vicinity of CAMBRIC may be different than a gradient at the CAU or regional scale. 


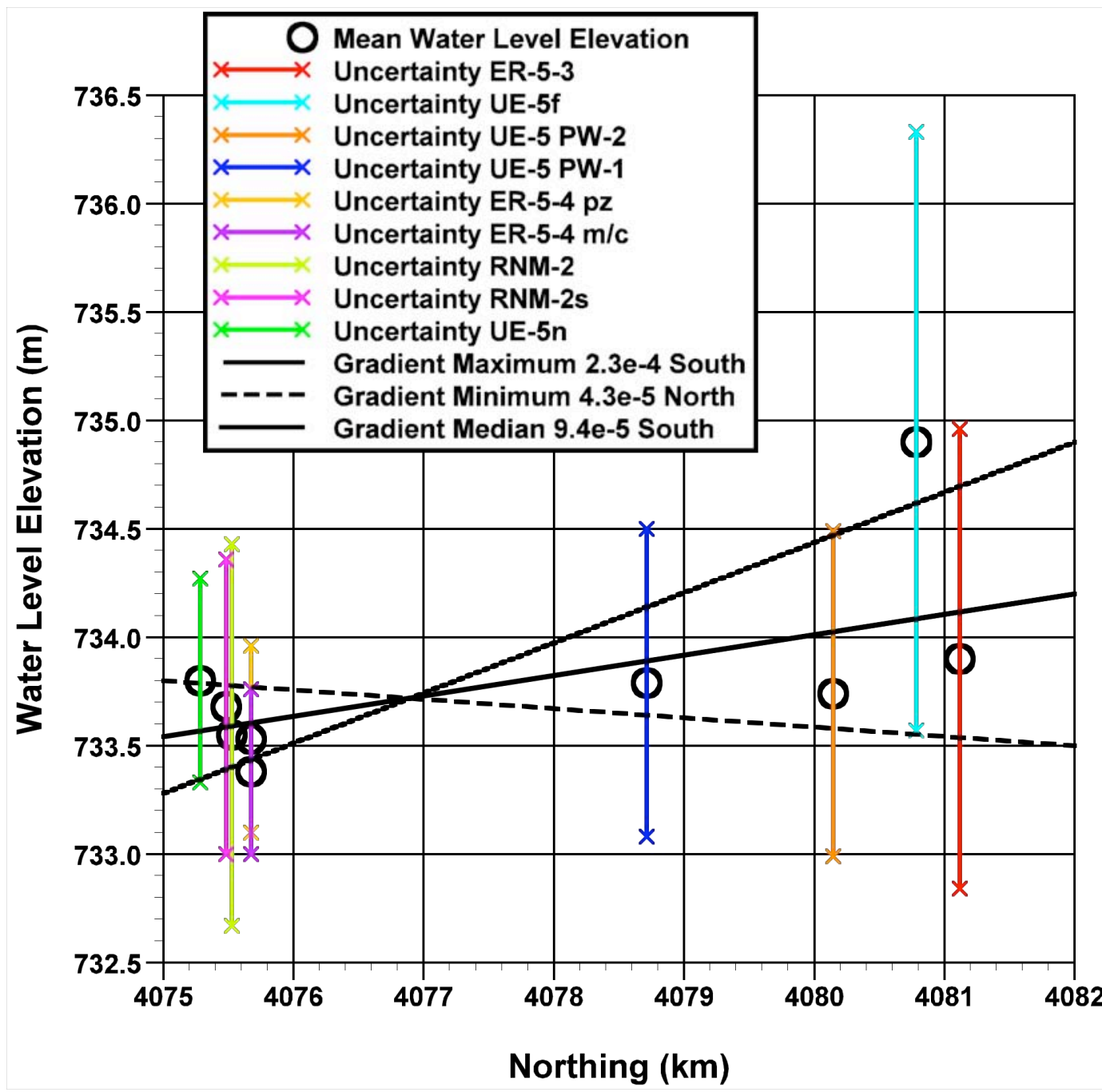

Figure 6.1 Mean water-level elevations and uncertainty range for wells screened in alluvium in Frenchman Flat. Estimates of maximum and minimum north-to-south CAU-scale horizontal hydraulic gradients fit within the uncertainty range of all of the data. The median estimate averages the maximum and minimum gradients.

\subsubsection{Flow Gradients in the Vicinity of CAMBRIC}

The approximate local horizontal gradient evident in the water-level data closest to CAMBRIC, discussed above in relation to Figure 6.1, is consistent with an earlier estimate presented in Section 2.2.2. That estimate was determined from measured water levels in ER-5-4 (main), RNM-2S, and UE-5n. The earlier estimate indicates a mean local, horizontal gradient slightly to the east of north with a magnitude of 0.0013 , as shown in Figure 2.6. If uncertainty in the water-level measurements is taken into account, it could trend in a variety of other directions with different magnitudes, also indicated in Figure 2.6, as calculated from uniformly random head measurements sampled from the measured water-level ranges in each of the three wells. These results are presented again in Figure 6.2. 
The mean measured water levels in these and two other nearby wells were used as a primary calibration target for the HST groundwater flow model. Good matches to the water levels help to provide accurate forecasts of the local rate and direction of radionuclide movements away from the CAMBRIC test. Estimates of the local flow gradient produced by the steady-state HST flow model, as determined from simulated water levels in ER-5-4 (main), RNM-2S, and UE-5n in 50 separate flow model realizations, are also shown in Figure 6.2. These results are more closely clustered and indicate a smaller horizontal gradient in a more northeasterly direction. The relative degree of model calibration is also evident in Figure 5.9 and the related discussion in Section 5.2.4. The variability in these results is due to different realizations of spatially variable hydraulic conductivity specified in the fine grid area of the model.

As a means of comparison, estimates of the local flow gradient produced by the CAU flow model, as determined from simulated water levels in ER-5-4 (main), RNM-2S, and UE-5n in 8 base case and alternative model realizations, are also shown in Figure 6.2 (Nicole DeNovio, Stoller-Navarro, personal communication, 2005). These results are less clustered than the HST results and indicate a horizontal gradient of comparable magnitude to the HST results, but in a more easterly, slightly southerly direction. The variability among these results is due to alternative recharge and various hydrostratigraphic framework models employed in the CAU flow model.

Differences between the CAU and HST model estimates of the local flow gradient are mainly due to differences in the scale and grid resolution and the associated calibration strategies used in their development. HST simulations were conducted over a small area using a highly resolved grid. The flow model was calibrated primarily to observed water levels in five nearby local wells using locally specified boundary conditions. The CAU-scale simulations, on the other hand, were conducted over a much larger model domain with lower grid resolution. The CAU model was driven by more remote boundary conditions and a calibration strategy designed to match many more water levels (than just the three) dispersed over a much larger modeling area. 
CHAPTER 6: CONSIDERATIONS FORAPPLYING HST RESULTS IN THE CAU MODEL

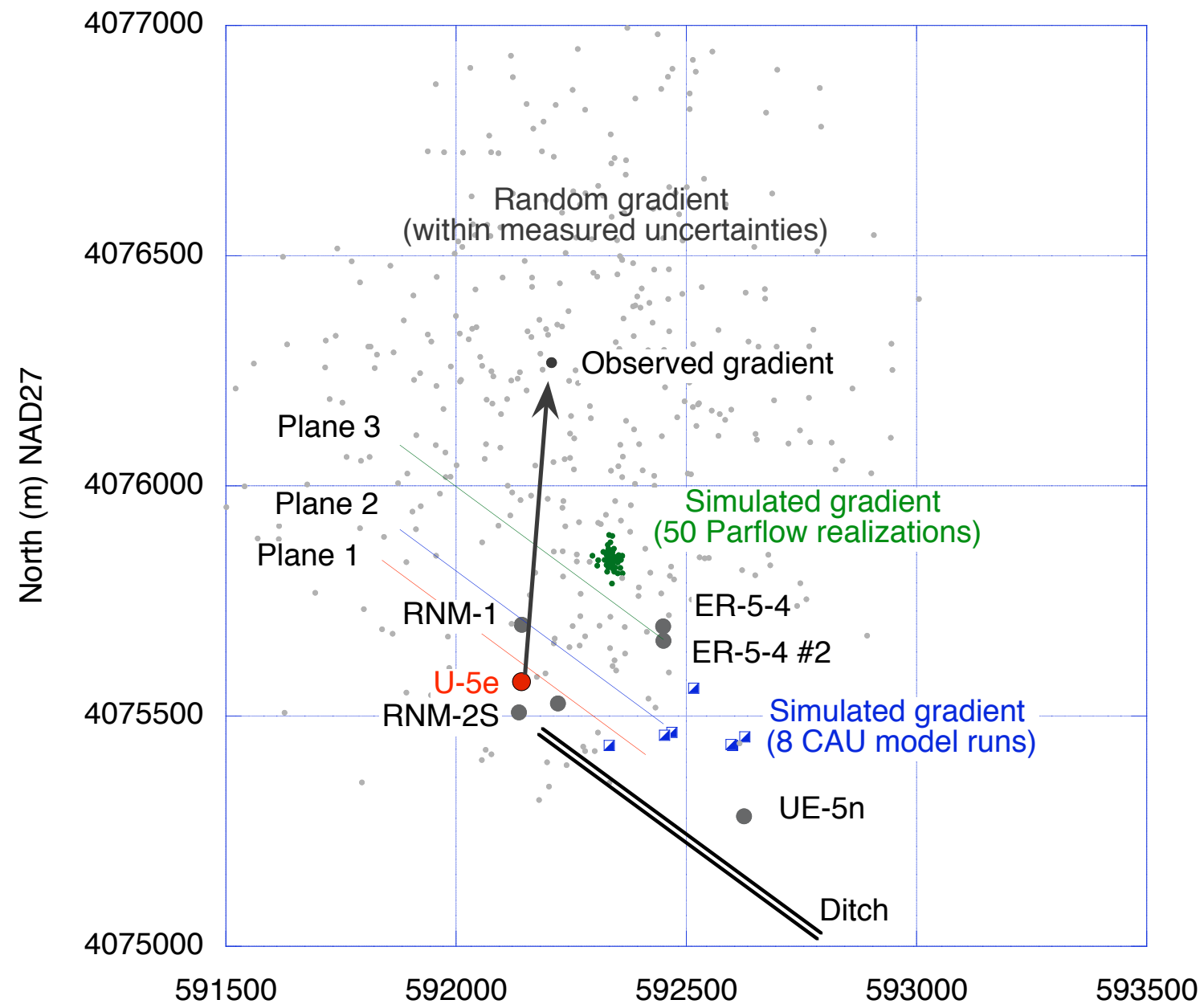

East (m) NAD27

Figure 6.2 Close-up view of the CAMBRIC site shows the ditch, nearby wells, and locations of three vertical breakthrough planes. Approximate flow directions away from $\mathrm{U}-5 \mathrm{e}$ are from water levels in UE-5n, RNM-2S, and ER-5-4 (upper) (1) computed from the observation (black arrow) in Table 2.1 and a series of 400 random head observations falling within the measured uncertainties indicated in Table 2.1 (gray dots without arrows); (2) simulated by 50 steady-state ParFlow realizations (green) reported in Tompson et al., (2005); and (3) simulated by 8 CAU model runs (blue squares) reported by Nicole DeNovio (Stoller-Navarro, personal communication, 2005). The distance between U-5e and each "point" is proportional to the magnitude of the head gradient. The observed gradient magnitude (black arrow) is 0.0013 . 


\section{$7 \quad$ Summary}

This study uses numerical models to estimate a hydrologic source term (HST) resulting from groundwater flow, heat flow, and radionuclide transport associated with the CAMBRIC underground nuclear test. The objective of this work is to improve the 1,000-y HST model for the CAMBRIC underground nuclear test relative to previous HST work (Tompson et al., 1999 and Pawloski et al., 2001). The improvements result from the incorporation of new data, consideration of additional processes relevant to radionuclide transport in Frenchman Flat, and development and improvement of methods used for simulation of flow and reactive transport. This work provides a better understanding of activities as they actually occurred, and provides a basis to use the CAMBRIC site for model validation and monitoring activities as required by the UGTA Project. CAMBRIC was the only test in Frenchman Flat detonated under the water table and best represents a fully saturated environment.

\subsection{HST Modeling Approach}

The HST modeling approach involved a calibration and assessment phase (Chapter 4) and a source term simulation phase (Chapter 5). "Calibration" refers to establishing the appropriate conceptual and parametric models of the environmental system consistent with available data. "Assessment" refers to evaluating the importance of various processes included in the models that may lead to simplifications so more efficient HST calculations can be made.

Different numerical models are used in each of these phases to systematically address the combined effects of test heat, hydraulic and mineralogic heterogeneity, transient unconfined groundwater flow, recirculation of groundwater through the vadose zone, groundwater composition, melt glass dissolution, and nonlinear geochemistry on radionuclide transport. Neither the combined NUFT/CRUNCH nor the combined ParFlow/SLIM models by themselves addresses all of the flow and transport phenomena considered in calibration and assessment or HST simulation phases. This is why both the NUFT/CRUNCH and ParFlow/SLIM simulation methods were used to address unique issues in each phase of the modeling approach.

\subsubsection{Calibration and Assessment: NUFT/CRUNCH}

The calibration and assessment simulations were conducted to test and refine the conceptual hydrogeologic model and were calibrated to the MWAT and ${ }^{3} \mathrm{H}$ recovery at RNM-2S. They were designed to focus on the relatively short-term (within $50 \mathrm{y}$ ) and near-field (less than 300-m) combined effects of test heat, pumping from RNM-2S, and CAMBRIC ditch discharge on the groundwater flow field near CAMBRIC. The simulations were used for sensitivity studies on test heat, boiling conditions and initial pressure, and to assess the viability of simpler geochemical reaction process models, including melt glass dissolution.

The NUFT/CRUNCH simulation method couples 3D transient non-isothermal and variably saturated flow with nonlinear reactive geochemistry processes (Sections 4.1 and 4.8). The NUFT model simulates variably saturated groundwater multi-phase and 
multi-component flow, heat flow, and transport using finite-difference-based Eulerian approaches (Sections 4.6 and 4.7). Transient groundwater flow fields from NUFT are used for streamline-based simulation of nonlinear geochemistry and radionuclide transport using the multi-component reactive transport code CRUNCH (Section 4.8). The streamline framework ensures feedback between transient flow velocity, temperature, and reactive transport processes (Section 4.8.1). This is particularly important for underground nuclear test scenarios involving test-related heat, which induces thermal conditions near boiling temperatures in the melt glass zone. If thermal effects are not accounted for, the fraction of radionuclides released into solution from melt glass dissolution can be underestimated, particularly at early time. Thermal effects can also play an important role in promoting transient vertical flow at early time.

The NUFT/CRUNCH method is computationally intensive and limited in its ability to address small-scale physical and chemical heterogeneity, prediction uncertainty (e.g., through multiple realizations), and larger-scale transient effects (e.g., ditch infiltration and recirculation), and long-term transport (e.g., to 1,000 y).

Since the Phase I HST modeling was completed (Tompson et al., 1999), major improvements have been implemented into the streamline simulation method (Section 4.8.1). A more accurate flux assignment procedure was developed, based on the need to model transient temperature and flow conditions, resulting in an improved representation of the source volume in the streamline calculation. A systematic procedure based on flow velocity and temperature changes over time was devised to determine the time interval of each streamline segment. At the end of each time segment the geochemical parameters from the streamlines are collected to the 3D grid. Using updated 3D grid values and updated temperature and groundwater flow fields, a new set of streamlines is generated for a subsequent time segment.

\subsubsection{HST Simulations: ParFlow/SLIM}

The HST simulations were designed to address high-resolution variably saturated flow and transport, under isothermal conditions, with emphasis on longer-term (greater than $50 \mathrm{y}$ ) and larger-scale (greater than $300 \mathrm{~m}$ ) HST behavior, and under uncertainties generated by physical and chemical heterogeneity. The ParFlow/SLIM models were specifically configured to forecast radionuclide flux between the test and several control planes in the saturated zone, as well as evaluate infiltration and recirculation from the RNM-2S experiment. The HST simulations were based on the same conceptual model developed in the calibration and assessment phase, and incorporated several simplifications to process models justified from that phase.

ParFlow is an isothermal, massively parallel saturated-unsaturated groundwater flow model designed to directly and efficiently resolve geologic heterogeneities in multi-million cell flow simulations to assess the influence of groundwater flow, solute dispersion, and contaminant migration behavior. The ParFlow simulations address effects on groundwater flow including hydraulic gradient, pumping from RNM-2S, and ditch discharge and subsequent infiltration (Section 5.3.1). The highresolution capabilities of ParFlow also enable consideration of macrodispersive effects caused by alluvial heterogeneity and merging of the HST-scale model with CAU-scale hydrostratigraphic units in central Frenchman Flat (Section 5.2.3). 
SLIM uses a Lagrangian, particle-based numerical method to simulate nonreactive transport and reactive transport assuming linear sorption processes with retardation coefficients given flow fields generated externally by ParFlow (Section 5.1.2.1). After the calibration and assessment stage was completed, ParFlow/SLIM were used to simulate radionuclide transport for the transient CAMBRIC HST (Sections 5.3.5.4 and 5.5).

Because ParFlow does not address heat flow, the ParFlow/SLIM method does not directly reflect the impact of residual test heat. Thermal effects on glass dissolution rates are considered indirectly by implementation of algorithms fitted to the glass dissolution model developed for the CRUNCH multi-component reactive transport code, as well as importation of the glass zone thermal histories from the NUFT code (Section 5.2.1.1).

\subsection{HST Simulation Objectives}

\subsubsection{Incorporation of New Data}

\subsubsection{Geology, Mineralogy, and Hydrostratigraphy}

New geologic, mineralogic, and hydrostratigraphic data has improved the understanding of the physical and chemical setting near CAMBRIC. In particular, data obtained from ER-5-4 has helped refine interpretation of alluvial stratigraphy and mineralogic variability and zonation (Sections 1.3.5 and 4.2). Alluvial layers identified in ER-5-4 provide a template for consideration of zonal variations in both hydraulic and mineralogic properties within alluvium (Sections 4.3.3 and 4.8.2.1).

HST simulations using NUFT/CRUNCH consider zonal variations in mineralogy directly through explicit modeling of aqueous speciation, surface complexation, ion exchange, and mineral dissolution/precipitation processes (Section 4.8.2). HST simulations using ParFlow/SLIM consider mineralogic variability through estimation of retardation coefficients based on both zonal and local spatial variability of mineralogy (Section 5.2.1.2).

The hydrostratigraphic framework model (HFM) developed by Bechtel Nevada (2005b) provides a larger-scale hydrologic framework for the Frenchman Flat basin. The geometry of the HFM is incorporated directly into the ParFlow/SLIM flow simulations (Sections 4.2 and 5.2.2). The HFM is not incorporated into the NUFT/CRUNCH streamline-based HST calculations, wherein flow and transport simulations are assumed local to alluvium near CAMBRIC.

\subsubsection{RNM-2S Multiple Well Aquifer Test (MWAT)}

A multiple well aquifer test (MWAT) was conducted by pumping RNM-2S at a constant rate of approximately $600 \mathrm{gpm}$ for $75 \mathrm{~d}$ beginning on April 26, 2003 (Sections 1.3.5 and 4.5.1). Water level responses were monitored at RNM-2S, RNM-1, RNM-2, and ER-5-4 (piezometer and upper screened interval). The MWAT provides a means to calibrate hydraulic properties including permeability, specific yield, and storage coefficient within alluvium near CAMBRIC. The depth ranges of alluvial layers identified in ER-5-4 provide a framework interpreting the MWAT drawdown data (Section 4.5.1). 
Flow models for both the streamline- and particle-tracking-based HST simulations incorporate layers with different effective hydraulic properties as calibrated to the MWAT. These zonations of hydraulic properties are also consistent with lithologic textures described in ER-5-4 and UE-5n and the ranges of permeability inferred from other pumping tests in Frenchman Flat (Sections 2.2.4, 4.2, and 4.3).

\subsubsection{Water Levels and Hydraulic Gradients}

Hydraulic gradients in the vicinity of CAMBRIC are low, and water levels have fluctuated historically. Recent water level measurements have improved the quality of the values and associated uncertainty. Mapping of the local flow direction based on nearby wells indicates flow directions between NW and NE and gradients ranging from 0 to 0.0025 (Sections 2.2.2 and 5.2.4). The local gradient was developed to evaluate migration of radionuclides from the CAMBRIC site. Differences between the local and CAU gradients are discussed in Chapter 6. ER-5-4 water samples indicate similar chemistry in nearby wells. Thus, average water chemistry used during these simulations (Section 2.2.3) does not differ significantly from previous HST work (Tompson et al., 1999).

\subsubsection{Glass Dissolution Rates}

Laboratory work on glass surface area, secondary minerals, and temperature and saturation effects (Section 4.8.2.8.2) has greatly improved understanding of glass dissolution processes since the Phase I HST modeling (Tompson et al., 1999). Parameter input into the glass dissolution rate equation is better constrained compared to previous Frenchman Flat HST calculations (Section 4.8.2.8.2.1). These thermal effects on glass dissolution are incorporated into the NUFT/CRUNCH streamline-based simulations of reactive transport (Section 4.8.3). Interestingly, the improved glass dissolution model drastically reduces the importance of radionuclide release from the melt glass. Thermal effects on glass dissolution are significant in the first few years after detonation, when only about $2 \%$ of the glass is predicted to dissolve. After $1,000 \mathrm{y}$, the total amount of glass predicted to dissolve is less than $5 \%$. Detailed modeling of glass dissolution and the role of test-derived heat has permitted simplification of the glass dissolution process for incorporation into the ParFlow/SLIM transport simulations (Section 5.2.1.1).

\subsubsection{Retardation}

Acquisition of new mineralogic and water composition data and laboratory experimental batch sorption flow-through results are used to improve the mechanistic model used in NUFT/CRUNCH simulations that predict radionuclide transport (Section 4.8.2). In Phase I HST calculations, a small number of radionuclides and a subset of relevant sorption and dissolution/precipitation reactions were addressed. The mechanistic model is now more comprehensive and has been validated by a number of laboratory experiments. This permits a more complete prediction of radionuclide/rock/water interactions than previously obtained. A simplified linear $\mathrm{K}_{\mathrm{d}}$ model was also developed for each radionuclide-mineral pair and applied in the ParFlow/SLIM simulations (Section5.2.1.2). This permits the mechanistic approach to be upscaled for use in $\mathrm{K}_{\mathrm{d}}$-type transport codes. 


\subsubsection{Inventory}

Limited unclassified radionuclide inventory information existed for the previous radionuclide migration simulations at CAMBRIC (Tompson et al., 1999). Data for 12 radionuclides were derived from unclassified CAMBRIC-specific calculations with assumptions on the performance of the CAMBRIC test (Section 3.5). In Phase I HST calculations only six radionuclides were actually considered to represent a cross section of geochemical behavior. The number of measured, CAMBRIC-specific radionuclide inventories has not changed. However, an unclassified source term for all Frenchman Flat tests has been published, and includes 43 radionuclides. The total number of radionuclides included now in CAMBRIC HST simulations was reduced to 36 based on the relative importance of each radionuclide to the molar concentrations and total activity of the inventory. The 36 radionuclides were further reduced to 13 radionuclide classes based on chemical similarities (Section 4.8.2.3).

\subsubsection{Improving Models of Important Processes}

\subsubsection{Heterogeneity}

Spatial variation, or heterogeneity, in the physical and chemical properties of the geologic medium occurs within both in situ and test-altered rocks. In the HST models, physical properties conceptualized as heterogeneous include the permeability, hydraulic conductivity, or porosity of the medium, while chemical properties conceptualized as heterogeneous include mineralogy, retardation coefficients, and radiologic source term (RST). Zonal hydraulic heterogeneity in in-situ rocks is largely associated with alluvial layers and test-altered zones for both the NUFT/CRUNCH and ParFlow/SLIM simulations (Sections 4.2 and 4.3). Mineralogic heterogeneity is associated with different mass fractions of minerals in different alluvial layers (Section 4.8.2.1). The ParFlow/SLIM simulations also consider the physical and chemical heterogeneity within the alluvial layers using Gaussian random field conceptualizations (Sections 4.3.5.2.1.2 and 5.2.3). Thus, the ParFlow/SLIM simulations assess the combined zonal and local effects of physical and chemical heterogeneity. The physical and chemical distribution of the RST is heterogeneous and a function of the device design, geologic media, radionuclide properties, and cavity growth and collapse history (Sections 3.6 and 4.8.2.3).

\subsubsection{Test Heat}

A large proportion of the energy of an underground nuclear test is released as heat (Section 3.1). The NUFT/CRUNCH simulations include consideration of residual test heat and the geothermal gradient (Section 4.6). Thermal effects from residual test heat include thermal conduction, non-isothermal groundwater flow behavior (e.g., thermal convection, fluid density change, and viscosity change), increased dissolution rates of melt glass containing refractory radionuclides, changes in water chemistry, and, in turn, changes in radionuclide sorption behavior (Section 4.8.3). The melt glass zone incorporates most of the residual test heat. An initial melt glass zone temperature of $170^{\circ} \mathrm{C}$, slightly below the boiling temperature of water at hydrostatic conditions $74 \mathrm{~m}$ below the water table, is assumed as an initial condition for the base-case NUFT/CRUNCH flow simulations (Section 4.4.5.1). Initial conditions for the base case NUFT/CRUNCH flow simulation produce a temperature anomaly of 2 to $3^{\circ} \mathrm{C}$ consistent 
with a RNM-1 drill back temperature log obtained 9 y after the CAMBRIC test (Sections 3.4 and 4.4.3). Boiling conditions are examined in additional sensitivity studies on groundwater flow (Section 4.7).

\subsubsection{Transient Flow}

Processes contributing to transient groundwater flow considered in the models include residual test heat and groundwater pumping, discharge, and infiltration from the RNM experiment. Both the NUFT/CRUNCH and ParFlow/SLIM HST simulations include transient flow processes related to the RNM experiment (Sections 4.6 and 5.3). Only the NUFT/CRUNCH simulations include thermal processes incorporating testrelated heat and the geothermal gradient (Sections 4.6 and 4.7). NUFT flow simulations indicate residual test-related heat induces increased groundwater flow velocities and decreased fluid density and viscosity in test-altered zones primarily within $1 \mathrm{y}$ after the CAMBRIC test. The NUFT and ParFlow flow simulations indicate that pumping at RNM-2S for about 16 y produced a large cone of depression centered at RNM-2S (Sections 4.6.2 and 5.3.1). Test-related ${ }^{3} \mathrm{H}$ breakthrough measured at RNM-2S provided additional flow model calibration, particularly estimation of the permeability of the compressed zone and the depth interval of the permeable zone within the slotted interval of RNM-2S (Sections 4.5.2.1 and 5.2.4).

The NUFT and ParFlow flow simulations consider infiltration of pumping effluent discharged into the CAMBRIC ditch and Frenchman Lake impoundment areas and subsequent unsaturated flow from the ground surface downward approximately $220 \mathrm{~m}$ to the water table (Sections 1.3, 4.5, 4.6, and 5.3.3). The accumulation of ditch discharge reaching the saturated zone causes mounding of the water table (Sections 4.5.2.4, 4.6.2, and 5.3.1). This became an important factor influencing the movement of infiltrated radionuclides to the northeast, away from the vertical projection of the ditch and lake discharge areas. The combined effect of RNM-2S pumping and ditch infiltration leads to repeated recirculation of RNM-2S discharge back to RNM-2S pumping intake (Sections 4.5.2.2 and 5.3.3).

\subsubsection{Reactive Transport}

Non-linear geochemical effects on reactive transport arise from interaction of multiple processes including transient groundwater and heat flow, aqueous speciation, surface complexation, ion exchange, mineral dissolution/precipitation, radionuclide decay, and diffusion and dispersion (Section 4.8.2). These processes are explicitly considered in the NUFT/CRUNCH simulation method. Another objective of using the CRUNCH multi-component reactive transport model is to estimate linear retardation coefficients used in the ParFlow/SLIM method as an approximation to the effects of nonlinear geochemical processes (Section 5.2.1.2).

Thermal effects resulting from the CAMBRIC test affect reactive transport primarily by changing the flow field velocities (Sections 4.6.6 and 4.7.3.4), increasing melt glass dissolution and secondary mineral precipitation rates, and altering the groundwater chemistry (Section 4.8.3) that, in turn, affects radionuclide retardation (Section 5.2.1.2). Thermal effects on groundwater flow can increase flow velocities by orders of magnitude over ambient conditions, cause convection cells and recirculation, and induce a significant upward flow velocity component relative to the ambient flow 
field. Rates of melt glass dissolution can increase by orders of magnitude. Changes in $\mathrm{pH}$ and carbonate alkalinity can drastically increase or decrease radionuclide sorption.

\subsection{Results and Conclusions}

The radionuclide transport simulation results presented here are consistent with a diverse collection of field experimental and characterization data acquired subsequent to the CAMBRIC test.

\subsubsection{Cambric Hydrologic Source Term}

The CAMBRIC HST is derived from the test itself, the RNM experiment, and ditch infiltration and recirculation. Flow and transport simulations included:

- Ambient groundwater flow and the short-lived effects of test-related heat, beginning just after the test in 1965

- Two stages of pumping for the RNM experiment, conducted between 1976 and 1991, which drew many mobile radionuclides away from the CAMBRIC cavity toward pumping well RNM-2S

- Infiltration of the discharge in the ditch and Frenchman Lake impoundment areas during the pumping experiment and the generation of subsequent groundwater mounding effects

- Draining of the unsaturated zone underlying the ditch and lake impoundment areas and the eventual dissipation of the groundwater mounding effects over a recession period lasting over $40 \mathrm{y}$

- The ultimate return to the ambient system for another $935 \mathrm{y}$ of continued radionuclide evolution and transport from the cavity

Results show that most $(>70 \%)$ of the non-sorbing radionuclides were flushed out of the cavity and chimney area and captured by RNM-2S during the more than 16-y pumping experiment (Sections 5.3.2, 5.3.3, and 5.3.4). These were discharged into the ditch and lake impoundment areas and infiltrated into the unsaturated zone, creating a dispersed source.

A majority of the sorbing radionuclide classes $\left({ }^{241} \mathrm{Am},{ }^{41} \mathrm{Ca}, \mathrm{Cs}, \mathrm{Eu}, \mathrm{Pu},{ }^{241} \mathrm{Pu}\right.$, $\mathrm{Sm}, \mathrm{Np}$, and $\mathrm{Sr}$ ) are not significantly affected by the RNM experiment (Sections 5.3.2, 5.3.3, and 5.3.4). Small amounts of U and Np were captured by RNM-2S during pumping. Plutonium exhibits some transport away from the CAMBRIC cavity. This occurs primarily during the $16 \mathrm{y}$ of pumping at RNM-2S. Only four radionuclide classes - two tracers (TracerR and TracerL) and two sorbing classes ( $\mathrm{Np}$ and $\mathrm{U}$ ) — are affected by the RNM experiment. Once pumping has ceased, gradients in the vicinity of CAMBRIC are low and transport distances are very low over the 1,000 y simulation time period $(<100 \mathrm{~m})$. Only $\mathrm{Np}$ and $\mathrm{U}$ exhibit transport over the 1,000 y timeframe.

Importantly, the movement of radionuclides not captured by the RNM experiment occurs primarily under ambient flow conditions over the $935 \mathrm{y}$ following the heat- and pumping-induced transients at early time. Because ambient groundwater flow rates are small and the effects of heat were not significant, much of the observed 
radionuclide transport in groundwater away from the cavity is diffusively dominated. Glass dissolution provides a small yet long-term radiologic source for both sorbing and non-sorbing radionuclides at the CAMBRIC cavity.

\subsubsection{Ditch Hydrologic Source Term}

Because the pumping effluent from the RNM experiment was discharged into an unlined ditch and an impoundment area in Frenchman Lake, and because rising levels of tritium in a groundwater well adjacent to the ditch have been observed since 1991, it was possible to further investigate the ditch and impoundment areas as additional sources of radionuclides in the Frenchman Flat CAU. Based on RNM experiment data, approximately half of the pumped effluent infiltrated into the subsurface along the ditch. Model simulations are consistent with field observations and suggest that only weakly sorbing radionuclides form the ditch source term.

- Well discharge introduced to the ditch system infiltrated to groundwater beneath the ditch creating a groundwater mound. Radionuclides in the infiltrating water moved away from the ditch shadow due to the mounding.

- Radionuclides infiltrating to the groundwater were recaptured by the pumping well and recirculated through the system up to four times over the experiment duration.

- Radionuclide movement in groundwater between the cavity, pumping well, and ditch during this period is consistent with ${ }^{3} \mathrm{H}$ observations during the construction of well ER-5-4.

Model simulations suggest a 40-y (or more) infiltration and drainage period from the ditch through the alluvium and to the groundwater, after which the underlying groundwater mound eventually dissipated. The groundwater mound appears to be an important factor influencing the movement of infiltrated radionuclides to the northeast. It affects areas not influenced by the RNM-2S capture zone, even after pumping ceases. The mounding effects are consistent with observations near CAMBRIC, and because of the low flow gradient, confidence in the direction and magnitude of the groundwater mounding in the immediate area of the ditch is high. The impacts seen in the model, especially in terms of distance of radionuclide transport away from the shadow area of the ditch, are significant. Radionuclide migration extends to areas where mesh resolution is coarse, data points are few, and fidelity in the flow solution may be low, which provide undetermined uncertainty.

Based on simulation results, relevant radionuclides that form the ditch source include ${ }^{3} \mathrm{H},{ }^{14} \mathrm{C},{ }^{36} \mathrm{Cl},{ }^{129} \mathrm{I}$, and ${ }^{99} \mathrm{Tc}$. Two noble gases $\left({ }^{39} \mathrm{Ar}\right.$ and $\left.{ }^{85} \mathrm{Kr}\right)$ are predicted to be present, but subsequent degassing to the atmosphere is likely to minimize their impact during ditch infiltration. Simulation results are in good agreement with observed breakthrough of these non-sorbing radionuclides at RNM-2S (Sections 4.5.2.1 and 5.2.4). 


\subsubsection{Effects of Physical and Chemical Heterogeneity}

model to:

Physical and chemical heterogeneity were included in the ParFlow/SLIM

- Directly represent the effects of small scale spreading and mixing processes (as opposed to the use of gross dispersion models), which can dilute radionuclide concentrations or more widely scatter radionuclide mass along the frontal areas of radionuclide plumes, and

- Account for reduced overall retardation effects arising from non-uniform distributions of reactive minerals.

In many respects, heterogeneity may only have a secondary effect on transport. This is based on the favorable comparisons between the ParFlow/SLIM and NUFT/CRUNCH model results. The NUFT/CRUNCH model does not include heterogeneity, except in terms of a layered alluvium stratigraphy or what may result from the effects of nonlinear geochemistry. The most significant difference between these models is the apparent migration rates of $U$ isotopes, which suggests that geochemical nonlinearities affect transport more significantly than the spatial heterogeneities included in the ParFlow/SLIM model. Nevertheless, significant variations in the RNM-2S ${ }^{3} \mathrm{H}$ breakthrough curves were seen in multiple system realizations using ParFlow/SLIM (Figure 5.11), illustrating the impact of heterogeneity and uncertainty of small-scale spreading and mixing processes, especially when realized over short distances.

Although variability in alluvium mineralogy within alluvial layers appears to be small, downstream radionuclide migration is affected by a reduction in the effective level of retardation. Because the presence of reactive minerals was not correlated with areas of high or low permeability, the more stark effects seen in earlier simulations of lava heterogeneity at CHESHIRE or in the Phase I simulations at CAMBRIC were not present. It appears that depositional characteristics of the alluvium layers, as currently conceptualized, result in an apparently relatively homogeneous distribution of radionuclide-sorbing minerals for CAMBRIC.

Heterogeneity in the permeability distributions affects flow rates in the unsaturated alluvium and imparts spatially variable degrees of saturation. These, in turn, affect the overall drainage (and radionuclide transport) rates to groundwater, which impact the source term derived from the ditch.

\subsubsection{Thermal Effects}

Early-time thermal effects on radionuclide transport include increased mobilization of refractory radionuclides from the melt glass, thermally induced hydraulic gradients that increase fluid velocity, and thermally induced changed in the sorptive behavior of radionuclides (Sections 4.6, 4.7.3, and 4.8.3). While the effects of nonisothermal flow and radionuclide transport are observed in these CAMBRIC streamline simulations, it does not appear that these effects drastically alter larger-scale and longerterm transport behavior of radionuclides (Section 5.3.5). There are several reasons why thermal effects appear to play a secondary role in radionuclide migration. These are: 
- The CAMBRIC test has a small yield and the total amount of heat in the system is relatively small.

- The heat dissipates quickly so large hydrothermally driven fluid velocities are not sustained.

- High temperatures in the melt glass zone are not sustained long enough to dissolve sufficient glass to drastically affect the early-time release of radionuclides in the rubble.

- The potential changes in water chemistry induced by heat, glass dissolution, and secondary mineral precipitation are sufficiently buffered by both the mineralogy and water chemistry such that drastic changes in radionuclide sorption are not observed. This is particularly true when radionuclide retardation is averaged over the model domain.

The role of heat at the CAMBRIC site is in stark contrast to earlier modeling results of the role of heat on radionuclide transport behavior (Pawloski et al., 2001 and Carle et al., 2003). Earlier examinations of the role of test heat focused on large tests conducted in fractured rock, and hydrothermal effects were significantly more pronounced because of more residual test heat and thermally-induced groundwater convection. In the case of CAMBRIC, less residual test heat and conduction-dominated heat flow diminishes thermal effects on radionuclide transport. The results from these CAMBRIC simulations clearly indicate that the role and importance of heat in the migration of radionuclides from the test will be dependent on both the characteristics of tests and its hydrologic environment.

\subsubsection{Considerations for Applying HST Results in the CAU Model}

The current flow and transport modeling results were developed utilizing detailed, site-specific conditions associated with the CAMBRIC test. They are not directly applicable to other tests in Frenchman Flat because of differing physical, chemical, and test-related features, and because the transient conditions at CAMBRIC (test-related heat, pumping, and infiltration) did not exist or may be different in magnitude and duration.

\subsubsection{Considerations for Applying the Steady-State HST Elsewhere in Frenchman Flat}

A steady-state groundwater flow model was generated to evaluate the development of a source term for other tests in Frenchman Flat. The flow field is essentially the same as the transient flow field at later times, between 100 and 1,000 y, in the transient flow simulations. This steady state scenario can be used to produce a generic release model to develop simpler release models at the other test locations. Some of the simplification methods described in Tompson et al. (2005) are relatively generic and can be applied or scaled for use at other locations, as described in Pawloski et al. (2001) and Tompson et al. (2004).

Use of the steady-state HST results at other locations requires careful considerations of the computed groundwater flux at these locations relative to the flux inherent in the steady-state model, as well as consideration of reactive properties at each location. Scaling of the existing results may be considered as a means to adjust for 
differences in local fluxes or reactive properties, in the manner of Chapter 8 in Pawloski et al. (2001). Alternately, simplified analytic flow models calibrated to reproduce the steady-state results can be developed, as in Tompson et al. (2004) or Stoller-Navarro (2005b), and applied at other locations in Frenchman Flat.

\subsubsection{Additional Considerations for Applying the Transient HST at CAMBRIC}

The transient CAMBRIC HST results can be generally organized into broad mobility classes that may influence how they are treated in a CAU model.

- Non-reactive tracer radionuclides ( such as ${ }^{3} \mathrm{H}, \mathrm{Cl}$, and $\mathrm{Kr}$ ) were strongly affected by transient flow processes at the site such as thermally induced buoyant flow, pumping, infiltration, mounding, and recirculation. Reproduction of the dispersed plumes associated with these radionuclides in the CAU model may be achieved by a direct specification of the distributed plume as an initial source at a delay time in the model, or recreation of the pumping, infiltration, recapture, and radionuclide flux mechanisms in the CAU model from the beginning of the simulation.

- Most strongly sorbing radionuclides (e.g., $\mathrm{Sr}, \mathrm{Cs}$, and $\mathrm{Pu}$ ) were unaffected by pumping and infiltration. As a result, their movement in the groundwater flow system under the transient flow period was minimal. The principal mode of transport in the hydrologic regime will occur under ambient flow conditions for $935 \mathrm{y}$ after the initial transient period. Thus, reproduction of these radionuclides in the CAU model can be achieved in a manner similar to that used in previous steady flow scenarios.

- Most glass-bound radionuclides (including those tracers not in the exchange volume) were completely unaffected by pumping and infiltration because of the slow rate of dissolution of the glass. Thus, their movement in the groundwater flow system under the transient flow period was also minimal. Their principal mode of transport in the hydrologic regime will occur under ambient flow conditions for $935 \mathrm{y}$ after the initial transient period. Thus, reproduction of these radionuclides in the CAU model can be achieved in a manner similar to that used in previous steady flow scenarios. Glass dissolution provides a small but longterm source for both sorbing and non-sorbing radionuclides.

- The only sorbing radionuclides observed in the simulations to break through at the pumping well, $\mathrm{U}$ and $\mathrm{Np}$, are among the most weakly sorbing radionuclides considered. Neptunium concentrations are very small and potentially insignificant to the overall HST. Uranium concentrations are significant to the HST but still a small percentage of the total source term.

Outside of the transient flow effects occurring at CAMBRIC, there are differences in the local horizontal flow gradients simulated by the HST and CAU models that may potentially lead to conceptual inconsistencies when results from the HST model are imported into the CAU model. These differences are related to the scale and grid resolution of each model and the associated calibration strategies used in model development. Recognition of these flow gradient differences and their causes will be important when incorporating the CAMBRIC HST into the CAU model. 


\section{$8 \quad$ References}

Aagaard, P. and H. C. Helgeson (1982), Thermodynamic and kinetic constraints on reaction rates among minerals and aqueous solutions, I. Theoretical considerations, American Journal of Science 282, 237-285.

Ashby S. F. and Falgout R. D. (1996) A parallel multigrid preconditioned conjugate gradient algorithm for groundwater flow simulations, Nucl Sci Eng 124(1):145-59.

Baxter, R. G. (1983), Description of Defense Waste Processing Facility Reference Form and Canister, Savannah River Plant, Savannah River, GA, Report no. DP-1606, rev. 1.

Bear, J., C.-F. Tsang, and G. de Marsily, Eds. (1993), Flow and Contaminant Transport in Fractured Rock, Academic Press, San Diego, CA.

Bechtel Nevada (2005), A Hydrostratigraphic Framework Model and Alternatives for the Groundwater Flow and Contaminant Transport Model of Corrective Action Unit 98: Frenchman Flat, Clark, Lincoln and Nye Counties, Nevada, prepared for U.S. Department of Energy, DOE/NV/11718-1064.

Bethke, C. M. (1998), The Geochemist's Workbench: Release 3.0, U. Illinois Press.

Beiriger W. (1977), X-ray Analysis of 36 Samples from Ue5n, personal communication to L. D. Ramspott, April 21.

Boardman, C. R. (1966), Some Characteristics of the Hardhat Chimney and Surrounding Wall Rock, Lawrence Livermore National Laboratory, Livermore, CA, UCRL-50177.

Borg, I., R. Stone, H. B. Levy, and L. D. Ramspott (1976), Information Pertinent to the Migration of Radionuclides in Ground Water at the Nevada Test Site, Part 1: Review and analysis of existing information, Lawrence Livermore National Laboratory, Livermore, CA, UCRL-52078.

Bourcier, W. L. (1994), Waste glass corrosion modeling: comparison with experimental results, Materials Research Society Symposium Proceedings 333, 69-82.

Bowen, S., D. L. Finnegan, J. L. Thompson, C. M. Miller, P. L. Baca, L. F. Olivas, C. G. Geoffrion, D. K. Smith, W. Goishi, B. K. Esser, J. W. Meadows, N. Namboodiri, J. F. Wild (2001), Nevada Test Site Radionuclide Inventory 1951-1992, Los Alamos National Laboratory, Los Alamos, NM, LA-13859-MS.

Bright, D. J., S. A. Watkins, and B. A. Lisle (2001), Analysis of Water Levels in the Frenchman Flat Area, Nevada Test Site, USGS Water Resources Investigations, Report 00-4272, U. S. Geological Survey, Denver, CO.

Bryant, E. A. (1992), The CAMBRIC migration experiment: A summary report, Los Alamos National Laboratory, Los Alamos, NM, LA-12335-MS. 
Buddemeier, R. W. and D. Isherwood (1985), Radionuclide Migration Program, 1984 Progress Report, Lawrence Livermore National Laboratory, Livermore, CA, UCRL-53628.

Buddemeier, R.W., R. C. Finkel, K. V. Marsh, M. R. Ruggieri, J. H. Rego, and R. J. Silva (1991), Hydrology and radionuclide migration at the Nevada Test Site, Radiochimica Acta, $\mathbf{5 2 / 5 3}, 275-282$.

Burbey, T. J. and S. W. Wheatcraft (1986), Tritium and chlorine-36 migration from a nuclear explosion cavity, Desert Research Institute, University of Nevada System, Reno, NV, Publication 4505.

Burkhard, N. R. and J. T. Rambo (1991), One Plausible Explanation for Groundwater Mounding, Proc. Of the $6^{\text {th }}$ Containment of Underground Nuclear Explosions, Lawrence Livermore National Laboratory, Livermore, CA, CONF-9109114, Vol. 2.

Burton E. A., C. A. Bruton, M. R. Johnson, J. Rard, and M. Zavarin (2005), Radionuclide Reaction Chemistry as a Function of Temperature at the Cheshire Site, Lawrence Livermore National Laboratory, Livermore, CA, UCRL-216745.

Carle. S. F., M. Zavarin, and G. A. Pawloski (2002), Geostatistical Analysis of Spatial Variability of Mineral Abundance and Kd in Frenchman Flat, NTS, Alluvium, Lawrence Livermore National Laboratory, Livermore, CA, UCRL-ID-150200.

Carle. S. F., R. M. Maxwell, and G. A. Pawloski (2003), Impact of Test Heat on Groundwater Flow at Pahute Mesa, Nevada Test Site. Lawrence Livermore National Laboratory, Livermore, CA, UCRL-ID-152599.

Daniels, W. R., ed. (1982), Laboratory and field studies related to the radionuclide migration project, October 1, 1981-September 30, 1982, Los Alamos National Laboratory, Los Alamos, NM, LA-9691-PR.

Daniels, W. R. and J. L. Thompson, eds. (1984), Laboratory and field studies related to the radionuclide migration project, October 1, 1982-September 30, 1983, Los Alamos National Laboratory, Los Alamos, NM, LA-10121-PR.

Davisson, M . L., J. M. Kenneally, D. K. Smith, G. B. Hudson, G. J. Nimz, and J. H. Rego (1994), Preliminary report on the isotope hydrology investigations at the Nevada Test Site: hydrologic resources management program FY 1992-1993, Lawrence Livermore National Laboratory, Livermore, CA, UCRL-ID-116122.

Germain, L. S. and J. S. Kahn (1968), Phenomenology and Containment of Underground Nuclear Explosions, Lawrence Livermore National Laboratory, Livermore, CA, UCRL50482.

Gillespie, D. (2005), Temperature Profiles and Hydrologic Implications from the Nevada Test Site Area, Publication No. 45211, Desert Research Institute, U. S. Department of Energy, DOE/NV/13609-40. 
Grambow, B. (1987), Nuclear Waste Glass Dissolution: Mechanism, Model and Application, JSS Project, Swedish Nuclear Fuel and Waste Management Co., Report Number 87-02.

Guell, M. A., and J. R. Hunt (2003) Groundwater transport of tritium and krypton 85 from a nuclear detonation cavity, Water Resources Research 39 (7), doi:10.1029/2001WR001249.

Hanson, R. J. (1982) Linear Least Squares with Bounds and Linear Constraints, Sandia Laboratories, Albuquerque, NM, SAND82-1517.

Helgeson, H. C. (1969), Thermodynamics of hydrothermal systems at elevated temperatures and pressures, American Journal of Science 267, 729-804.

Hoffman, D. C., R. Stone, and W. W. Dudley, Jr. (1977), Radioactivity in the Underground Environment of the CAMBRIC Nuclear Explosion at the Nevada Test Site, Los Alamos National Laboratory, Los Alamos, NM, LA-6877-MS.

Hoffman, D. C. (1979), A field study of radionuclide migration, in Radioactive Waste in Geologic Storage, S. Fried, ed., American Chemical Society Symposium Series, 100, 149166.

IAEA (International Atomic Energy Agency) (1998a), The Radiological Situation at the Atolls of Mururoa and Fangataufa, Technical Report, Volume 3: Inventory of radionuclides underground at the atolls, Vienna, Austria, IAEA-MFTR-3.

IAEA (International Atomic Energy Agency) (1998b), The Radiological Situation at the Atolls of Mururoa and Fangataufa, Technical report, Volume 4: Releases to the biosphere of radionuclides from underground nuclear weapons tests at the atolls, Vienna, Austria, IAEA-MFTR-4.

IAEA (International Atomic Energy Agency) (1998c), The Radiological Situation at the Atolls of Mururoa and Fangataufa. Technical report, Volume 6: Doses due to radioactive materials present in the environment or released from the atolls, Vienna, Austria, IAEA-MFTR-6.

Istok, J. D., D. O. Blout, L. Barker, K. R. Johnejack and D. P. Hammermeister (1994), Spatial variability in alluvium properties at a low level nuclear waste site, Soil Science Society of America Journal 58,1040-1051.

IT Corporation (1998c), Groundwater Flow and Contaminant Transport Model Development Package, unpublished report, Vol. III of Underground Test Area Project Correction Action Unit 98: Frenchman Flat Data Analysis Task, International Technology Corporation, North Las Vegas, NV.

IT Corporation (1999), Underground Test Area Project, Corrective Action Unit 98: Frenchman Flat. Volume 2: Groundwater Data Documentation Package, International Technology Corporation, Las Vegas, NV.

IT Corporation (2001), Frenchman Flat ER-5-4 Well Data Report (Preliminary), International Technology Corporation, Las Vegas, NV, Revision Number 0. 
IT Corporation (2003), Frenchman Flat ER-5-4 \#2 Well Data Report (Preliminary), International Technology Corporation, Las Vegas, NV, Revision Number 0.

Johnson, J. W., and S. R. Lundeen (1997), GEMBOCHS thermodynamic data files for use with EQ3/6 modeling package, Lawrence Livermore National Laboratory, Livermore, CA, internal report.

Jones J. E. and C. S. Woodward (2001), Newton-Krylov-multigrid solvers for large-scale, highly heterogeneous, variably saturated flow problems, Advances in Water Resources 24, 76374.

Kersting, A. B. (1996), The state of the hydrologic source term, Lawrence Livermore National Laboratory, Livermore, CA, UCRL-ID-126557.

Knox, J. B., D. E. Rawson, and J. A. Korve (1965), Analysis of a groundwater anomaly created by an underground nuclear explosion, Journal of Geophysical Research 70(4), 823-835.

Kollet, S. J. and R. M. Maxwell (2006), Integrated surface-groundwater flow modeling: A freesurface overland flow boundary condition in a parallel groundwater flow model, Advances in Water Resources, 29(7), 945-958.

Kurbatov, M. H., G. B. Wood, and J. D. Kurbatov (1951), Isothermal adsorption of cobalt from dilute solutions, Journal of Physical Chemistry 55, 1170-1182.

LATA (1982), Selection of a simulation model for analysis of radionuclide migration at the RNM experiment site Nevada Test Site, Nevada, Los Alamos Technical Associates, Inc., Los Alamos, NM, LATA-LSL-29-01.

Laczniak, R. J., J. Cole, D. A. Sawyer, and D. A. Trudeau (1996), Summary of Hydrogeologic Controls and Ground-Water Flow at the Nevada Test Site, Nye County, Nevada, U.S. Geological Survey Water-Resources Investigations Report 96-4109.

Love, A. H., J. R. Hunt, M. L. Roberts, J. R. Southon, M. L. Chiarappa-Zucca, and K. H. Dingley (2002), Use of tritium accelerator mass spectrometry for tree ring analysis, Environ Sci Technol 36(13), 2848-2852.

Lu, N., S. R. Cotter, H. D. Kitten, J. Bentley, and I. R. Triay (1998), Reversibility of sorption of Plutonium-239 onto hematite and goethite colloids, Radiochimica Acta 83(4),167-173.

Mathews, M., K. Hahn, J. Thompson, L. Gadeken, and W. Madigan (1994), Subsurface radionuclide investigation of a nuclear test, Applied Geophysics 32, 279-291.

Maxwell, R. M. (1998), The Effects of Uncertainty and Variability in Groundwater-driven Health Risk Assessment, Ph.D. dissertation, University of California, Berkeley, 157 p.

Maxwell, R. M. and W. E. Kastenberg (1999), Stochastic Environmental Risk Analysis: An integrated methodology for predicting cancer risk from contaminated groundwater, Stochastic Environmental Research and Risk Assessment 13(1-2), 27-47. 
Maxwell, R. M., A. F. B. Tompson, J. T. Rambo, S. F. Carle, and G. A. Pawloski (2000), Thermally induced groundwater flow resulting from an underground nuclear test, in Computational Methods in Water Resources XIII, Volume 1, L. Bentley, J. Sykes, C. Brebbia, W. Gray, and G. Pinder, Eds. (A. A. Balkema Publishers, Rotterdam, Netherlands), pp. 45-50.

Maxwell, R. M., C. W. Welty, and A. F. B. Tompson (2003), Streamline-Based Simulation of Virus Transport Resulting from Long Term Artificial Recharge in a Heterogeneous Aquifer, Advances in Water Resources 26(10), 1075-1096.

Mazer, J. J. (1987), Kinetics of Glass Dissolution as a Function of Temperature, Glass Composition, and Solution $\mathrm{pHs}$, Ph.D. thesis, Northwestern University.

Nimz, G. J. and J. L. Thompson (1992), Underground Radionuclide Migration at the Nevada Test Site, U. S. Department of Energy, Nevada Field Office, DOE/NV-246, UC-703.

Office of Technology Assessment (1989), The Containment of Underground Explosions, United States Congress, Office of Technology Assessment, OTA-ISC-414.

Ogard, A. E., J. L. Thompson, R. S. Rundberg, K. Wolfsberg, P. W. Kubic, D. Elmore, and H. W. Bentley (1988), Migration of chlorine-36 and tritium from an underground nuclear test, Radiochimica Acta, 44/45, 213-217.

Painter, S., V. Cvetkovic, and D. R. Turner (2001), Effects of Heterogeneity on Radionuclide Retardation in the Alluvial Aquifer Near Yucca Mountain, Nevada, Ground Water 39(3), $326-338$.

Pawloski, G. A. (1999), Development of Phenomenological Models of Underground Nuclear Tests on Pahute Mesa, Nevada Test Site-BENHAM and TYBO, Lawrence Livermore National Laboratory, Livermore, CA, UCRL-ID-136003.

Pawloski, G. A., A. F. B. Tompson, C. J. Bruton, and M. Zavarin, Eds. (2000), Evaluation of the Hydrologic Source Term from Underground Nuclear Tests in Frenchman Flat at the Nevada Test Site (U), Lawrence Livermore National Laboratory, Livermore, CA, UCRLID-138007-DR.

Pawloski, G. A., A. F. B. Tompson, and S. F. Carle, Eds. (2001), Evaluation of the hydrologic source term from underground nuclear tests on Pahute Mesa at the Nevada Test Site: The CHESHIRE test, Lawrence Livermore National Laboratory, Livermore, CA, UCRL-ID147023.

Pohll, G., J. Chapman, A. Hassan, L. Papelis, R. Andricevic, and C. Shirley (1998), Evaluation of groundwater flow and transport at the SHOAL underground nuclear test: An interim report, Desert Research Institute, University of Nevada System, Reno, NV, Water Resources Center Publication 45162, DOE/NV/11508-35. 
Pohll, G., A. Hassan, J. Chapman, C. Papelis, and R. Andricevic (1999), Modeling Ground Water Flow and Radioactive Transport in a Fractured Aquifer, Ground Water 37(5), 770 784.

Pollock, D. W. (1988), Semianalytical Computation of Path Lines for Finite-Difference Models, Groundwater 26(6), 743-750.

Ramspott, L. D. and R. D. McArthur (1977), Results of the Exploratory Drill Hole Ue5n, Frenchman Flat, Nevada Test Site, Lawrence Livermore National Laboratory, Livermore, California, UCID-17392.

REECO (Reynolds Electrical \& Engineering Co., Inc.) (1994), Site Characterization and Monitoring Data from Area 5 Pilot Wells, Nevada Test Site, Nye County, Nevada, U.S. Department of Energy, DOE/NV/11432-74.

Rose, T. P., R. I. Yamamoto, and G. F. Eaton, Eds. (2002), Hydrologic Resources Management Program and Underground Test Area Project FY 2000 Progress Report, Lawrence Livermore National Laboratory, Livermore CA, UCRL-ID-145167.

Ross, W. C. and S. W. Wheatcraft (1994), A two-dimensional simulation of tritium transport in the vadose zone at the Nevada Test Site, Desert Research Institute, Reno, NV, Publication No. 45098.

Schoonen, M. A. A. (1994), Calculation of the point of zero charge of metal oxides between 0 and 350C, Geochimica et Cosmochimica Acta 58(13), 2845-4851.

Schroeder, N. C., D. Morgan, D. J. Rokop, and J. Fabryka-Martin (1993), Migration of Technetium-99 in the alluvial aquifer at the Nevada Test Site, Nevada, Radiochimica Acta, 60, 203-209.

Schwartz L., A. Piwinski , F. Ryerson, H. Tewes, and W. Beiringer (1984), Glass produced by underground nuclear explosions, Natural Glasses (L. D. Pye, J. A. O'Keefe, and V. D. Frechette, Eds.), North Holland, 559-598.

Smith, D. K. (1995a), Characterization of Nuclear Explosive Melt Debris, Radiochimica Acta 69, $157-167$.

Smith, D. K. (1995b), 1994 CAMBRIC Source Term, personal communication to J. Hunt (U.C. Berkeley), Lawrence Livermore National Laboratory, Livermore, CA.

Smith, D. K., R. J. Nagle, and J. M. Kenneally (1996), Transport of gaseous fission products adjacent to an underground nuclear test cavity, Radiochimica Acta, 73, 177-183.

Smith, D. K. (1997), Radionuclides Recommended by the Underground Test Area-Source and Transport (UGTA-S\&T) Subcommittee of Significance for Remedial Investigations at the Nevada Test Site, memorandum to Janet Wille (IT Corp.), April 2, Lawrence Livermore National Laboratory, Livermore, CA. 
Smolarkiewicz, P. K. (1984), A fully multidimensional positive definite advection transport algorithm with small implicit diffusion, J. Computational Physics, 54, 325-362.

Steefel, C. I. and S. B. Yabusaki (1996), OS3D/GIMRT, Software for Modeling Multicomponent and Multidimensional Reactive Transport, User manual and programmer's guide, Version 1.0, Pacific Northwest National Laboratory, Richland, WA, PNL-11166.

Stoller-Navarro (2003), Frenchman Flat Well ER-5-4\#2 Data Report for Development and Hydraulic Testing, Nevada Test Site, Nevada, Revision No.: 0, September 2003.

Stoller-Navarro (2004a), Integrated Analysis Report for Single- and Multiple-Well Aquifer Testing at Frenchman Flat Well Cluster RNM-2S, Nevada Test Site, Nevada, Revision No.: 0, September 2004.

Stoller-Navarro (2004b), Phase II Hydrologic Data for the Groundwater Flow and Contaminant Transport Model of Corrective Action Unit 98: Frenchman Flat, Nye County, Nevada, Revision No.: 0, December, 2004.

Stoller-Navarro (2005a), Phase II Contaminant Transport Parameters for the Groundwater Flow and Contaminant Transport Model of Corrective Action Unit 98: Frenchman Flat, Nye County, Nevada, S-N/99205-043.

Stoller-Navarro, (2005b), Unclassified Source Term and Radionulcide Data for Corrective Action Unit 98: Frenchman Flat, Nevada Test Site, Nevada, S-N/99205-058.

Stoller-Navarro (2005c), Geochem05.mdb and A User's Guide to the Comprehensive Water Quality Database for Groundwater in the Vicinity of the Nevada Test Site, S-N/99205-059, September, 2005 Revision No.: 0.

Stoller-Navarro (2006a), Analysis of New Water-Level and Ground-Surface Elevation Measurements for Frenchman Flat Relative to the Frenchman Flat Hydrologic Data Report, Unpublished Report, $18 \mathrm{p}$.

Stoller-Navarro (2006b), Phase II Groundwater Flow Model of Correction Action Unit 98 : Frenchman Flat, Nevada Test Site, Nye County, Nevada, S-N/99205-074.

Stone, R. (1975), Lithologic description and particle size distribution of sidewall samples of valley fill material from RNM\#1, K-division internal memorandum UOPKB 75-46, April 1, Lawrence Livermore National Laboratory, Livermore, CA.

Thompson, J. L. (1996), Radionuclide Distribution in a Nuclear Test Cavity: The BASEBALL event, Radiochimica Acta 72, 157-162.

Timmons, D. M., and L. E. Thompson (1996), Geochemical and petrographic studies and the relationships to durability and leach resistance of vitrified products from the in situ vitrification process, International Topical Meeting on Nuclear and Hazardous Waste Management. 
Tompson, A. F. B., C. J. Bruton, and G. A. Pawloski, Eds. (1999), Evaluation of the hydrologic source term from the underground nuclear tests in Frenchman Flat and the Nevada Test Site: The CAMBRIC test, Lawrence Livermore National Laboratory, Livermore, CA, UCRLID-132300.

Tompson, A. F. B., C. J. Bruton, G. A. Pawloski, D. K. Smith, W. L. Bourcier, D. E. Shumaker, A. B. Kersting, S. F. Carle, and R. M. Maxwell (2002), On the Evaluation of Groundwater Contamination from Underground Nuclear Tests, Environmental Geology, 42, 235-247.

Tompson, A. F. B., M. Zavarin, C. J. Bruton, and G. A. Pawloski (2004), Methods for Calculating a Simplified Hydrologic Source Term for Frenchman Flat Sensitivity Studies of Radionuclide Transport Away from Underground Nuclear Tests, Lawrence Livermore National Laboratory, Livermore, CA, UCRL-TR-201817.

Tompson, A. F. B., D. K. Smith, G. B. Hudson, and J. R. Hunt (2006), Analysis of radionuclide migration through a $200-\mathrm{m}$ vadose zone following a 16-year infiltration event, Advances in Water Resources, 29, 281-292.

Tompson, A. F. B., R. M. Maxwell, S. F. Carle, M. Zavarin, G. A. Pawloski, and D. E. Shumaker (2005), Evaluation of the Non-Transient Hydrologic Source Term from the CAMBRIC Underground Nuclear Test in Frenchman Flat, Nevada Test Site, Lawrence Livermore National Laboratory, Livermore, CA, UCRL-TR-217191.

USDOE (U.S. Department of Energy) (1997a), Regional groundwater flow and tritium transport modeling and risk assessment of the underground test area, Nevada Test Site, Nevada, USDOE, Nevada Operations Office, Las Vegas, NV, DOE/NV-477.

USDOE (U.S. Department of Energy) (1997b), Shaft and tunnel nuclear detonations at the Nevada Test Site: Development of a primary database for the estimation of potential interactions with the regional groundwater system, U.S. Department of Energy, Nevada Operations Office, Las Vegas, NV, DOE/NV-464.

USDOE (U.S. Department of Energy) (2000), United States Nuclear Tests, July 1945-September 1992, U.S. Department of Energy, Nevada Operations Office, Las Vegas, NV, DOE/NV209, Rev 15.

USGS (1973), Geologic and Hydrolgic Effects Prediction and Effects Program, Alemendro (U19v) event, Pahute Mesa, Nevada Test Site, USGS-474-163 Special Studies-92.

USGS (2004), Aquifer Test-Analysis of multiple-well aquifer test RNM-2S, Frenchman Flat, Nevada, memorandum from M. T. Pavelko and K. J. Halford, June 6, U. S. Geological Survey.

Warren R. G., F. C. Benedict, Jr., T. P. Rose, D. K. Smith, S. J. Chipera, E. C. Kluk, and K. M. Raven (2002), Alluvial Layering and Distribution of Reactive Phases within Drill Holes ER5/4 and UE5n of Frenchman Flat, Los Alamos National Laboratory, Los Alamos, NM, LA-UR-02-6206. 
Winograd, I. J. (1970), Noninstrumental factors affecting measurements of static water levels in deeply buried aquifers and aquitards, Nevada Test Site, Ground Water 8(2), 19-28.

Wolfsberg, A., L. Glascoe, G. Lu, A. Olson, P. Lichtner, M. McGraw, and T. Cherry (2001), TYBO/BENHAM Model Analysis of Groundwater Flow and Radionuclide Migration from an Underground Nuclear Test in Southwestern Pahute Mesa, NTS, Los Alamos National Laboratory, Los Alamos, NM, LA-UR-012924.

Zavarin, M. and C. J. Bruton (2004a), A Non-Electrostatic Surface Complexation Approach to Modeling Radionuclide Migration at the Nevada Test Site: Aluminosilicates, Lawrence Livermore National Laboratory, Livermore, CA, UCRL-ID-141840.

Zavarin, M. and C. J. Bruton (2004b), A Non-Electrostatic Surface Complexation Approach to Modeling Radionuclide Migration at the Nevada Test Site: Iron Oxides and Calcite, Lawrence Livermore National Laboratory, Livermore, CA, UCRL-ID-141841.

Zavarin, M., S. K. Robers, T. P. Rose, and D. L. Phinney (2002), Validating Mechanistic Sorption Model Parameters and Processes for Reactive Transport in Alluvium, Lawrence Livermore National Laboratory, Livermore, CA, UCRL-ID-149728.

Zavarin, M., S. K. Roberts, P. Zhao, R. W. Williams, T. P. Rose, A. Rainer, and G. A. Pawloski (2004b), High Temperature Studies of Glass Dissolution Rates Close to Saturation, Lawrence Livermore National Laboratory, Livermore, CA, UCRL-TR-204874.

Zavarin, M., S. F. Carle, and R.M. Maxwell (2004c), Upscaling Radionuclide RetardationLinking the Surface Complexation and Ion Exchange Mechanistic Approach to a Linear Kd Approach, Lawrence Livermore National Laboratory, Livermore, CA, UCRL-TR-204713. 


\section{$9 \quad$ Distribution List}

Bruce Crowe

Environmental Restoration Project

U.S. Department of Energy

National Nuclear Security Administration

Nevada Site Office

P.O. Box 98518, MS 505

Las Vegas, NV 89193-8518

Bill Wilborn

Environmental Restoration Project

U.S. Department of Energy

National Nuclear Security Administration

Nevada Site Office

P.O. Box 98518, MS 505

Las Vegas, NV 89193-8518

U.S. Department of Energy

National Nuclear Security Administration

Nevada Site Office

Technical Library

P.O. Box 98518, MS 505

Las Vegas, NV 89193-8518

U.S. Department of Energy

Office of Scientific and Technical Information

P.O. Box 62

Oak Ridge, TN 37831-0062

U.S. Department of Energy

Southern Nevada Public Reading Room

c/o Nuclear Testing Archive

P.O. Box 98521, MS 400

Las Vegas, NV 89193-8521

Steven Carle

Lawrence Livermore National Laboratory

P.O. Box 808, L-208

Livermore, CA 94550

Jeff Daniels

Lawrence Livermore National Laboratory

P.O. Box 808, L-072

Livermore, CA 94550 
CHAPTER 9: DISTRIBUTION LIST

$\mathrm{Max} \mathrm{Hu}$

Lawrence Livermore National Laboratory

P.O. Box 808, L-231

Livermore, CA 94550

Annie Kersting

Lawrence Livermore National Laboratory

P.O. Box 808, L-231

Livermore, CA 94550

Reed Maxwell

Lawrence Livermore National Laboratory

P.O. Box 808, L-208

Livermore, CA 94550

Walt McNab

Lawrence Livermore National Laboratory

P.O. Box 808, L-530

Livermore, CA 94550

Gayle Pawloski

Lawrence Livermore National Laboratory

P.O. Box 808, L-221

Livermore, CA 94550

Dan Shumaker

Lawrence Livermore National Laboratory

P.O. Box 808, L-561

Livermore, CA 94550

Yunwei Sun

Lawrence Livermore National Laboratory

P.O. Box 808, L-631

Livermore, CA 94550

Andrew Tompson

Lawrence Livermore National Laboratory

P.O. Box 808, L-208

Livermore, CA 94550

Mavrik Zavarin

Lawrence Livermore National Laboratory

P.O. Box 808, L-231

Livermore, CA 94550 
Sig Drellack

NSTec

P.O. Box 98521, MS NLV

Las Vegas, NV 89193

Ken Ortego

NSTec

P.O. Box 98521, MS NLV

Las Vegas, NV 89193

Lance Prothro

NSTec

P.O. Box 98521, MS NLV

Las Vegas, NV 89193

Maggie Townsend

NSTec

P.O. Box 98521, MS NLV

Las Vegas, NV 89193

Vefa Yucel

NSTec

P.O. Box 98521, MS NLV

Las Vegas, NV 89193

Jenny Chapman

Desert Research Institute

755 East Flamingo

Las Vegas, NV 89119

Ron Hershey

Desert Research Institute

2215 Raggio Parkway

Reno, NV 89512

Roger Jacobson

Desert Research Institute

2215 Raggio Parkway

Reno, NV 89512

Greg Pohll

Desert Research Institute

2215 Raggio Parkway

Reno, NV 89512 
CHAPTER 9: DISTRIBUTION LIST

Chuck Russell

Desert Research Institute

755 East Flamingo

Las Vegas, NV 89119

Irene Farnham

Stoller Navarro Joint Venture

7710 West Cheyenne Ave

Las Vegas, NV 89129

John McCord

Stoller Navarro Joint Venture

7710 West Cheyenne Ave

Las Vegas, NV 89129

Greg Ruskauff

Stoller Navarro Joint Venture

7710 West Cheyenne Ave

Las Vegas, NV 89129

Jeffrey Wurtz

Stoller Navarro Joint Venture

7710 West Cheyenne Ave

Las Vegas, NV 89129

Naomi Becker

Los Alamos National Laboratory

P.O. Box 1663, MS T003

Los Alamos, NM 87545

Dave Finnegan

Los Alamos National Laboratory

P.O. Box 1663, MS J514

Los Alamos, NM 87545

Ed Kwicklis

Los Alamos National Laboratory

P.O. Box 1663, MS T003

Los Alamos, NM 87545

Andy Wolfsberg

Los Alamos National Laboratory

P.O. Box 1663, MS F649

Los Alamos, NM 87545 
Robert Graves

U.S. Geological Survey

160 North Stephanie Street

Henderson, NV 89074

Keith Halford

U.S. Geological Survey

2730 North Deer Run Road

Carson City, NV 89701

Randy Laczniak

U.S. Geological Survey

160 North Stephanie Street

Henderson, NV 89074

Geoff Phelps

U.S. Geological Survey

345 Middlefield Road, MS0989

Menlo Park, CA 94025

Bonnie Thompson

U.S. Geological Survey

160 North Stephanie Street

Henderson, NV 89074

Rick Waddell

HIS GeoTrans

363 Centennial Parkway

Suite 210

Louisville, CO 80030 